\title{
MEASURING INDOOR ENVIRONMENTAL QUALITY (IEQ) IN A NATIONAL SCHOOL PROPERTY PORTFOLIO
}

(An Empirical Inquiry in Three Case Studies from Wellington)

By

\section{ANIEBIETABASI UFOT ACKLEY}

\begin{abstract}
A thesis
submitted to the Victoria University of Wellington

in fulfilment of the requirements for the degree of

Doctor of Philosophy
\end{abstract}

The School of Architecture and Design

Victoria University of Wellington, New Zealand 


\section{Declaration}

I declare that this thesis entitled: "Measuring Indoor Environmental Quality (IEQ) in a National School Property Portfolio" is a research work I carried out and that all the sources that I have quoted have been indicated by means of complete references. 


\section{Dedication}

This thesis is dedicated to God Almighty for His infinite grace and to my parents, Professor Ackley Akpan-Idiok and Dr (Mrs) Paulina Ackley for their love and sacrifice in sponsoring all my education. 


\section{Acknowledgements}

I would like to give thanks first and foremost to God Almighty for giving me life and good health throughout this research journey. My sincere gratitude goes to my supervisors, Professor Michael Donn and Dr Geoff Thomas for painstakingly reading through the manuscript and conceptual analysis of this research work and whose scholarly criticisms and contributions has brought it to the standard as it appears here.

My gratitude also goes to the Ministry of Education, New Zealand (the School Design and the Research and Development teams in the Strategy Investment and Policy Group) for their support in providing the data loggers used for monitoring the case study classrooms and the Building Research Association of New Zealand (BRANZ) for providing the device calibration insights. I would like to acknowledge the case study schools (I am unable to mention the name due to confidentiality reasons) and Associate Professor Louise Starkey, Leader of the Learning Environment team at the School of Education, Victoria University of Wellington.

I cannot end this acknowledgement without expressing my heartfelt and special gratitude to my beloved parents, Professor Ackley Akpan-Idiok and Dr (Mrs) Paulina Ackley for their care, advise, unwavering financial support and prayers. 


\section{Confidentiality Statement}

No material within this thesis may be used without permission of the copyright owner. 


\section{Abstract}

This thesis introduces a methodological approach for assessing Indoor Environmental Quality (IEQ) at an unprecedented scale in a large property portfolio to identify good and poor IEQ in buildings to inform design, asset management, maintenance, and evidence-based policy decisions. There is clear evidence that with deteriorating IEQ conditions, there is a decrease in human performance and their acceptability of the indoor environment. This thesis initially sought to find precedents for the influence of combined IEQ (lighting, temperature, relative humidity, acoustics, and indoor air quality) measurements on learning performance in schools and found none. No standards for measuring or characterizing this all inclusive IEQ in classrooms was found. In previous IEQ studies, there is no coherent guidance on representative placement of sensors (data loggers) and height to place a multi-variable sensor within a space.

The primary purpose of this thesis was to ascertain whether a one-point sensor measurement could be representative of the environmental condition across a space and where might be the best location to measure IEQ in many classrooms. Using the New Zealand Ministry of Education portfolio as a case study, physical measurements and observations were carried out in three typical case study classrooms, in three selected schools in Wellington. An array of sensors that simultaneously measures all five IEQ variables in a single device were deployed on the vertical walls and on the horizontal measuring plane in the case study classrooms during non-school days and school days in summer, autumn, and spring. One external sensor was positioned outside the classroom in a shaded walkway to monitor external environmental data and external weather data was also retrieved from the closet weather station.

The main conclusion is that for all five environmental variables, the relationship between the horizontal plane and vertical wall sensors was consistent for approximately $80 \%$ of the time. This indicated that a vertical wall sensor can reliably predict IEQ levels at the centre of a classroom. This study concludes that a one-point sensor located on an unglazed vertical wall, where the sun is unlikely to shine and away from any sources of heat can strongly predict IEQ at the most frequently occupied parts of a space (the centre). A one-point measurement provides an indication of what is happening in a room, but not necessarily all the variations 
(differences) across the room. The use of a one-point sensor gives a general indication of IEQ trends and patterns. It can suggest that IEQ highs are way too high or the lows way too low, or the range of extremes are too broad. It cannot pinpoint problem causes, or specific local issues, but is useful to triage good and poor IEQ in classrooms for early discrimination from hundreds or more classrooms of how to direct the maintenance or refurbishment programmes for large groups of school buildings. An additional level of information could be picked up better by using multiple sensors, building modelling or in combination with other qualitative methods such as survey of occupants. These findings can be used by researchers, architects, building scientist and policymakers to diagnose building performance in a national school property portfolio. The same process could be used in any large property portfolio to prioritize remediation works. 


\section{Table of Contents}

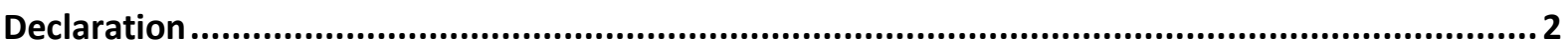

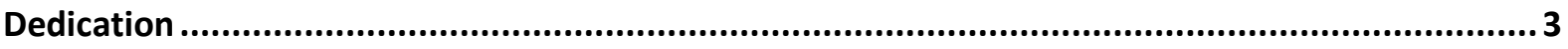

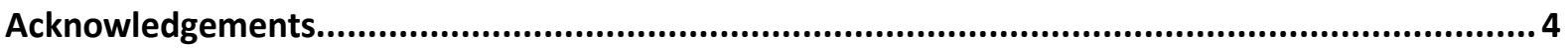

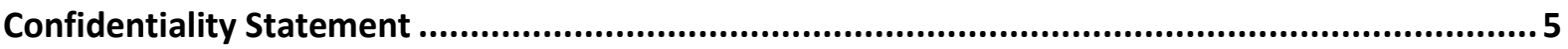

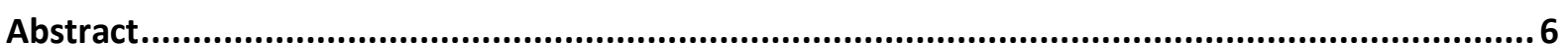

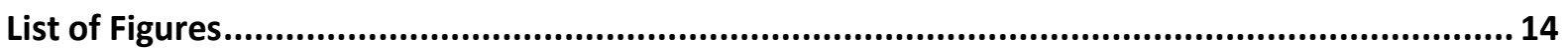

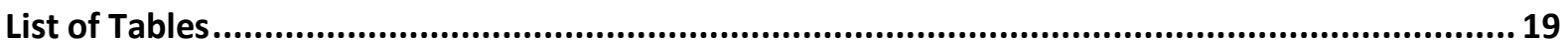

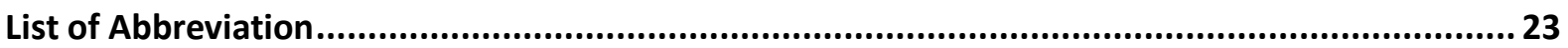

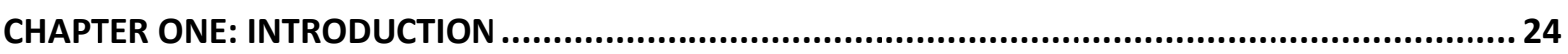

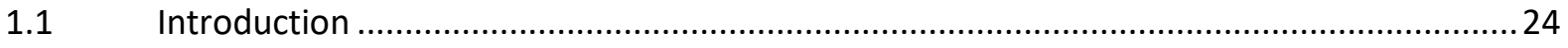

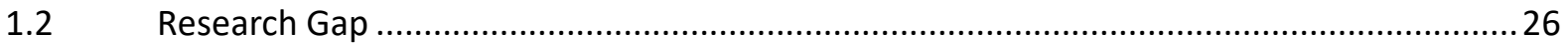

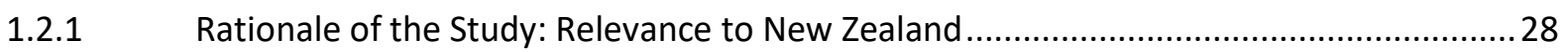

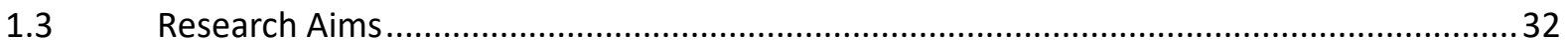

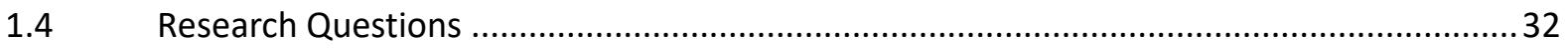

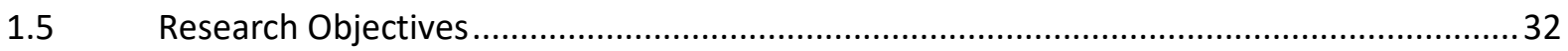

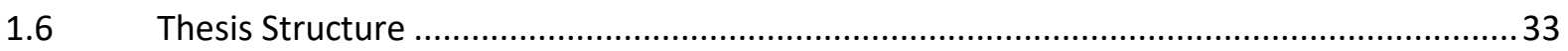

CHAPTER TWO: LITERATURE REVIEW - THE INFLUENCE OF IEQ ON STUDENTS' LEARNING

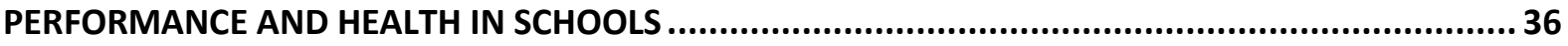

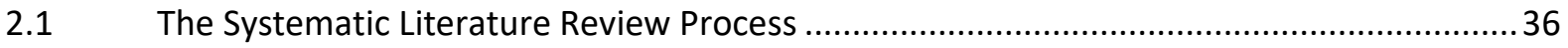

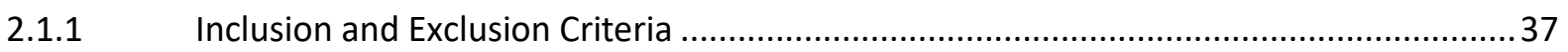

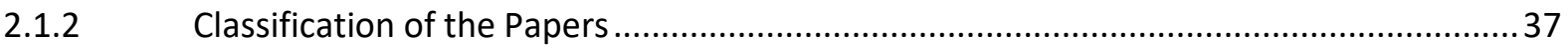

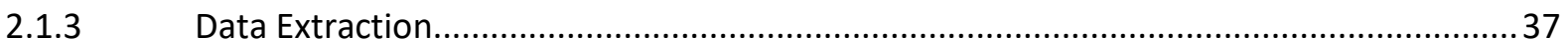

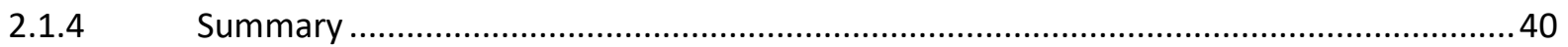

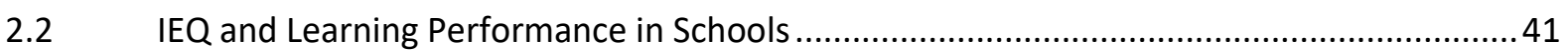


2.2.1 Daylight and Learning Performance

2.2.2 Thermal Comfort and Learning Performance ................................................................ 43

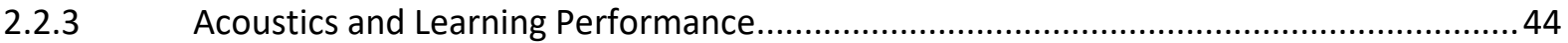

2.2.4 Indoor Air Quality (IAQ) and Learning Performance................................................... 45

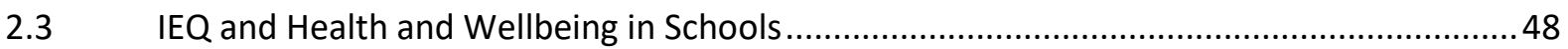

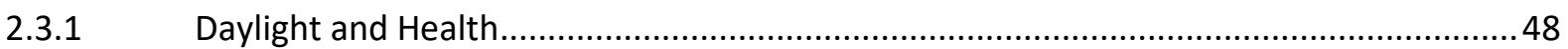

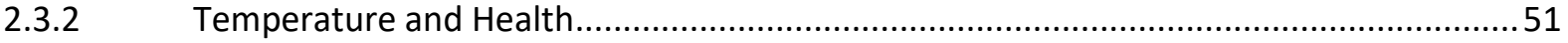

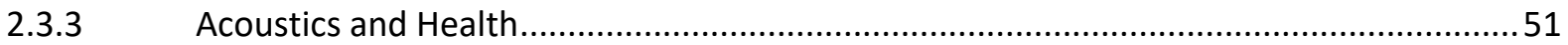

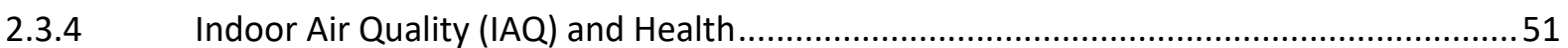

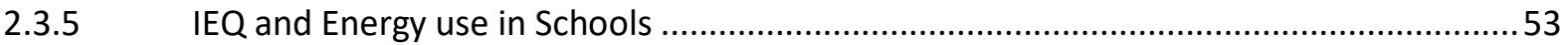

2.4 Summary of IEQ and Learning Performance and Health in Schools ...................................55

2.5 Determination of IEQ and Learning Performance Target Range .......................................56

2.5.1 Determination of Lighting and Learning Performance Target Range ...............................56

2.5.2 Determination of Temperature and Learning Performance Target Range ......................62

2.5.3 Determination of Sound Level and Learning Performance Target Range ....................... 71

2.5.4 Determination of Carbon Dioxide and Learning Performance Target Range ................... 78

2.5.5 Summary of IEQ and Learning Performance Target Range …....................................... 84

CHAPTER THREE: IEQ PHYSICAL MEASUREMENT IN SCHOOLS................................................. 85

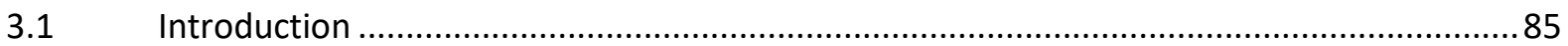

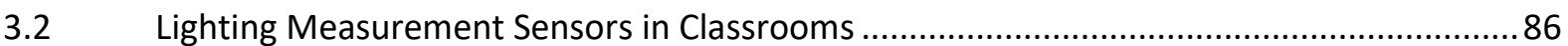

3.2.1 Metrics for Assessing Daylight Quality within a Classroom ...........................................8 88

3.3 Thermal Measurement Sensors in Classrooms............................................................... 90

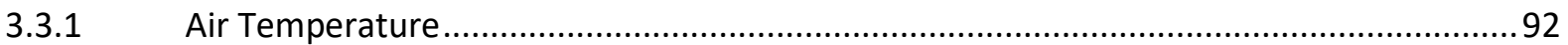

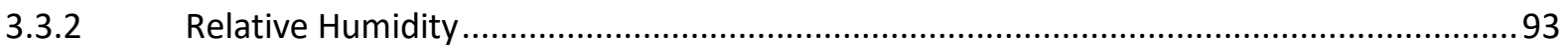

3.4 Acoustic Measurement Sensors in Classrooms …........................................................... 96 
3.5.1 Determination of IAQ through Measuring $\mathrm{CO}_{2}$ Concentrations ..................................105

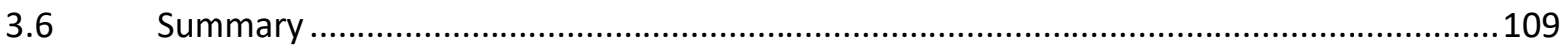

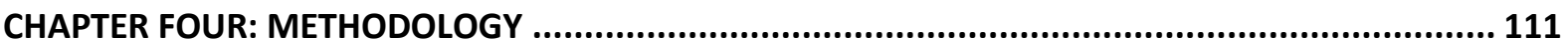

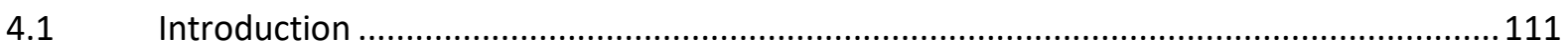

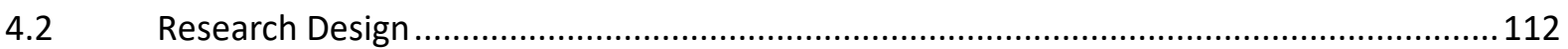

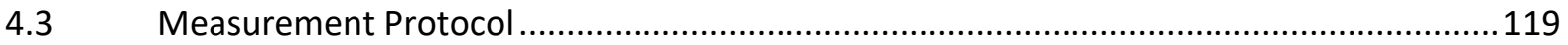

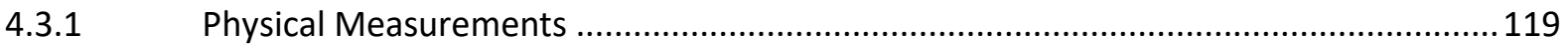

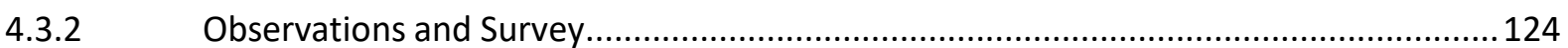

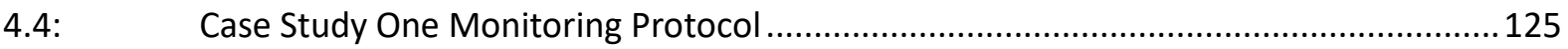

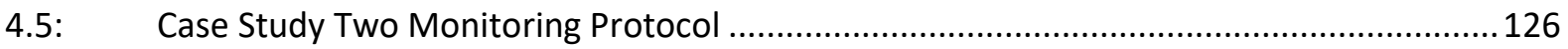

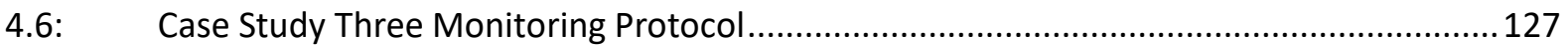

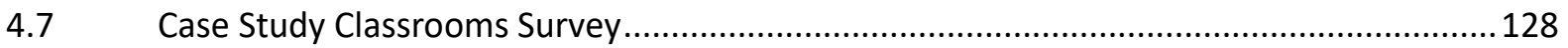

4.7.1 Building Characteristics of Case Study One Classroom .............................................128

4.7.2 Building Characteristics of Case Study Two Classroom.............................................131

4.7.3 Building Characteristics of Case Study Three Classroom ….......................................... 132

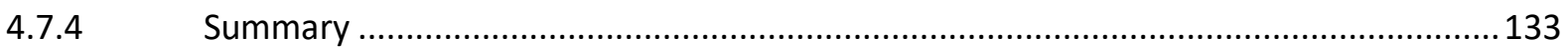

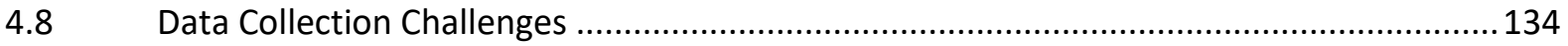

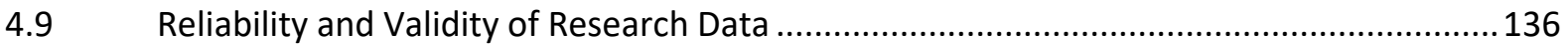

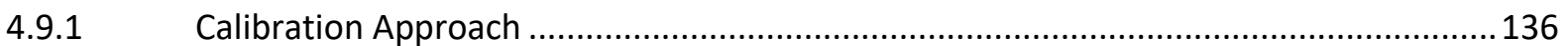

4.9.2 Spot Measurement Calibration Methodology ….....................................................137

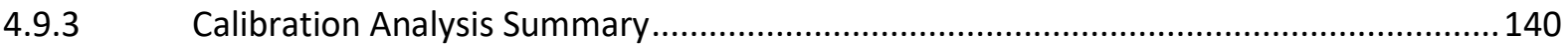

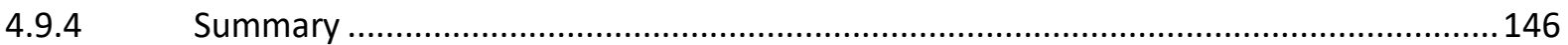

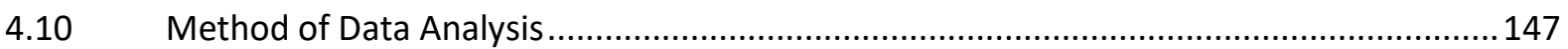

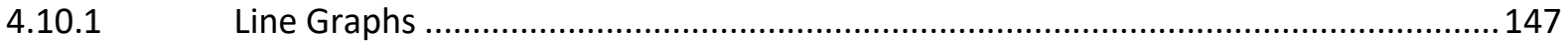




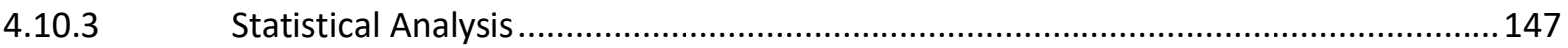

4.11 Pilot Study Experiment - IEQ Measurement Sensors Comparison ................................149

CHAPTER FIVE: CAN A ONE-POINT SENSOR PREDICT THE LIGHTING LEVELS IN A CLASSROOM?... 154

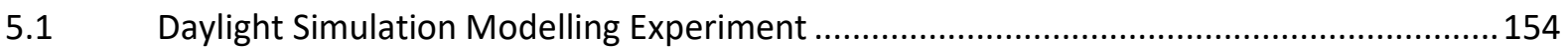

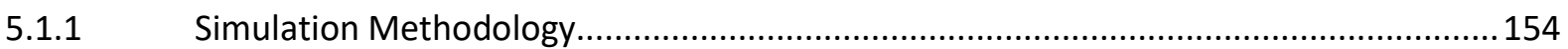

5.1.2. Results on the Daylight Distribution in Classroom A and B .....................................157

5.1.3 Discussion on Using a One-Point Sensor to Measure the Daylight Performance of Classrooms

5.2 Physical Measurement Experiment Methodology ......................................................170

5.3 Physical Measurement of Lighting Distribution in the Case Study Classrooms..................173

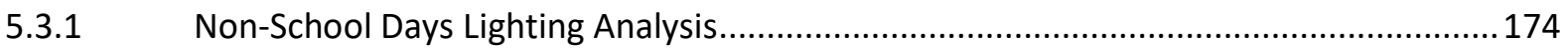

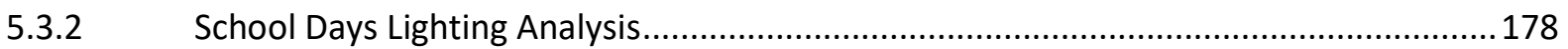

5.3.3 Correlation between Horizontal and Vertical Sensors Lighting Levels ........................183

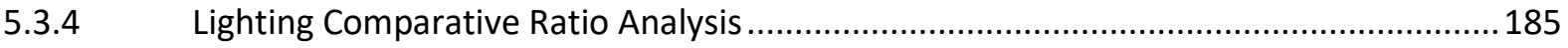

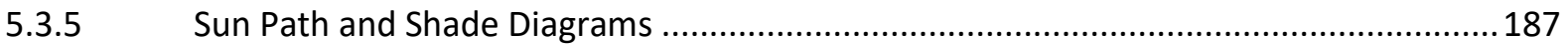

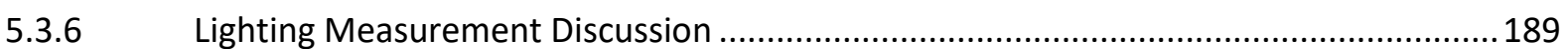

5.3.7 How to use a One-Point Sensor for Lighting Prediction.............................................. 192

CHAPTER SIX: CAN A ONE-POINT SENSOR PREDICT THE THERMAL CONDITION IN A CLASSROOM?

6.1 Physical Measurement of Temperature and Relative Humidity Distribution in the Case Study Classrooms

6.1.1 Non-School Days Temperature and Relative Humidity Analysis................................... 194

6.1.2 School Days Temperature and Relative Humidity Analysis..........................................201

6.1.3 Temperature and Relative Humidity Comparative Ratio Analysis 207 
6.1.4 Comparison between Horizontal and Vertical Sensors Average Temperature and

Relative Humidity Levels

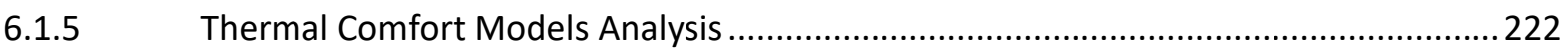

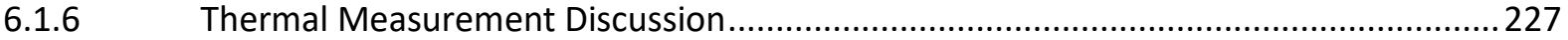

6.1.7 How to use a One-Point Sensor for Thermal Performance Prediction ..........................231

CHAPTER SEVEN: CAN A ONE-POINT SENSOR PREDICT THE SOUND LEVELS IN A CLASSROOM?... 234

7.1 Physical Measurement of Sound Level Distribution in the Case Study Classrooms ...........234

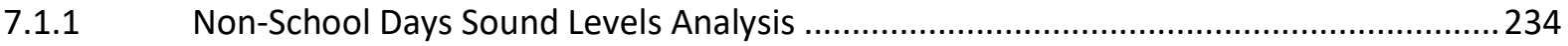

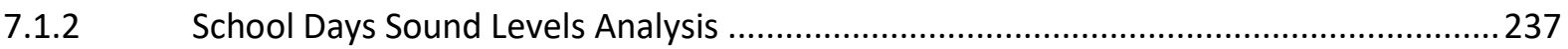

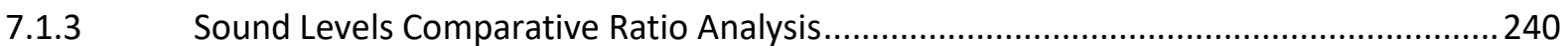

7.1.4 Comparison between Horizontal and Vertical Sensors Average Sound Levels ..............244

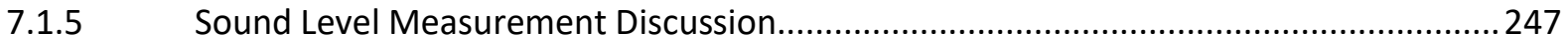

7.1.6 How to use a One-Point Sensor for Sound Levels Prediction .......................................248

CHAPTER EIGHT: CAN A ONE-POINT SENSOR PREDICT THE INDOOR AIR QUALITY IN A CLASSROOM?

8.1 Physical Measurement of $\mathrm{CO}_{2}$ levels in the Case Study Classrooms ...............................2252

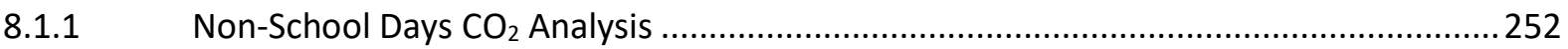

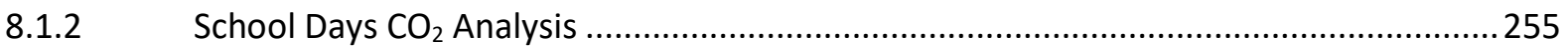

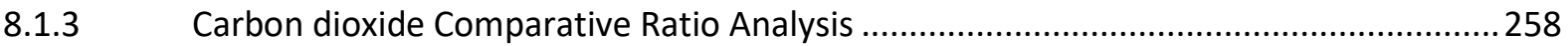

8.1.4 Comparison between Horizontal and Vertical Sensors Average $\mathrm{CO}_{2}$ Levels..................262

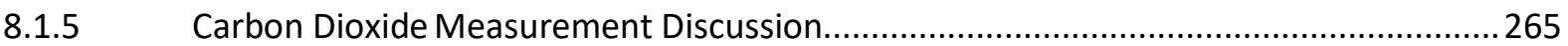

8.1.6 How to use a One-Point Sensor for IAQ Prediction ......................................................270

8.2 Summary of Overall IEQ Measurements Findings......................................................272

CHAPTER NINE: DETERMINATION OF IEQ FRAMEWORK FOR ANALYSING AND REPORTING IEQ AT

SCALE

9.1 IEQ Variables Weighting Factor in Buildings 274 
9.2 Determination and Distribution of IEQ Code and Index ..............................................282

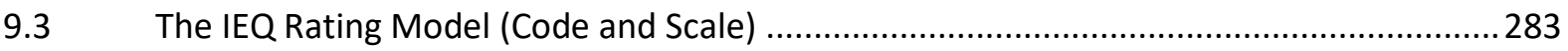

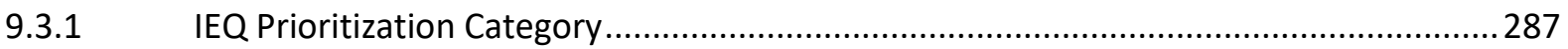

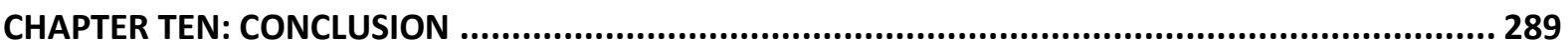

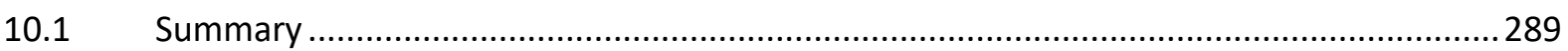

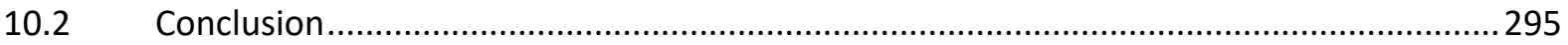

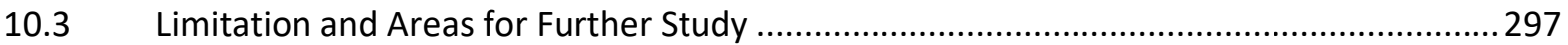

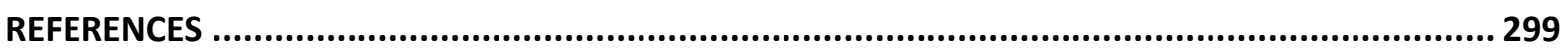

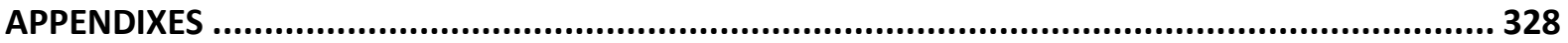

Appendix 1: The Systematic Appraisal of 150 Articles that met the Inclusion Criteria of the Study . 328

Appendix 2: Building Survey Templates 339

Appendix 3: IEQ On-Site Measurement Information Collation Templates.......................................341

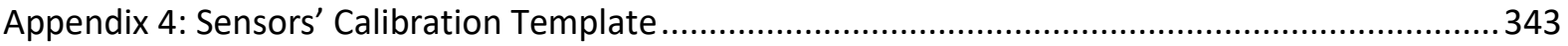

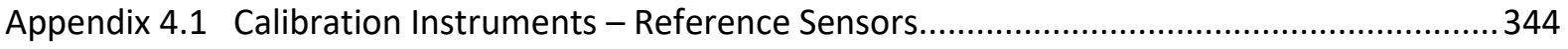

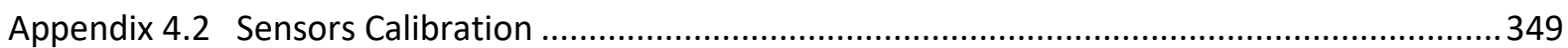

Appendix 4.3 Sensors Unit Connection Capability Experiment …................................................352

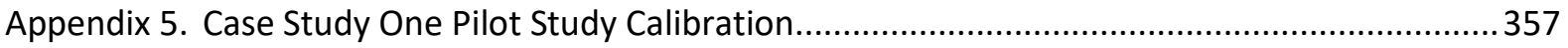

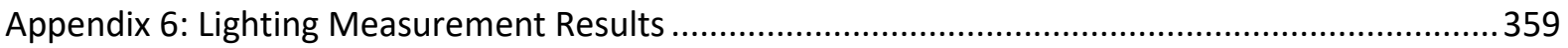

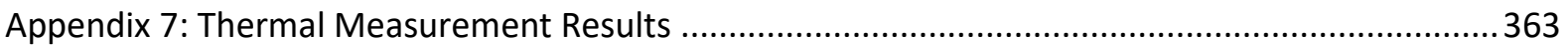

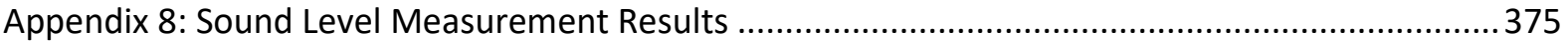

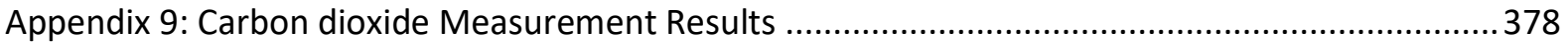

Appendix 10: Policy Output at the New Zealand Ministry of Education (MoE) .................................381

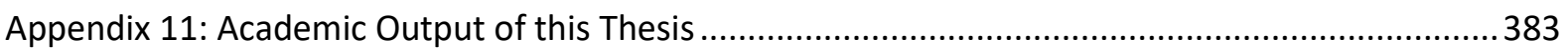




\section{List of Figures}

Figure 1: Estimated number of primary school buildings per year built in New Zealand .......................29

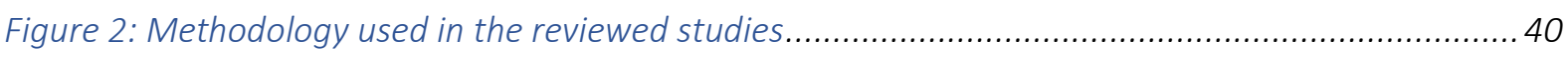

Figure 3: Number of studies investigated in the different school types .............................................40

Figure 4: Number of studies showing the association between IEQ and learning performance ............ 41

Figure 5: Number of studies showing the association between IEQ and Health ..................................49

Figure 6: Frequency of use of the light programs during classes. Source: Barkmann et al., (2012) .......58

Figure 7: Illumination levels in the measured school classrooms. Source: Singh \& Arora, (2014)..........59

Figure 8: Performance of school work as a function of classroom temperature, Source: Wargocki \& Wyon, (2017)...

Figure 9: The performance of psychological tests and school tasks based on speed and reaction time and accuracy at which the tests and tasks were performed by pupils, Source: Wargocki et al., (2017) 78 Figure 10: $\mathrm{CO}_{2}$ concentration and performance index. Positive scores correspond with poor performance and negative scores with good performance. Source: Myhrvold et al., (1996)

Figure 11: Clustering of $\mathrm{CO}_{2}$ concentration readings below 1000 ppm (low) and above 2000 ppm (high), used to classify the test sessions for analysis. Source: Coley \& Greeves, (2004).

Figure 12: Floor plan of case study one classroom with internal classroom images showing furniture

Figure 13: Floor plan of case study two classroom with internal classroom images showing furniture

Figure 14: Floor plan of case study three classroom with internal classroom images showing furniture

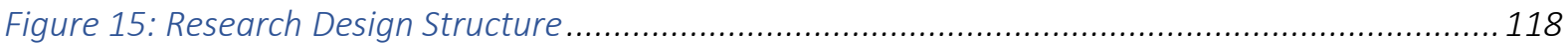

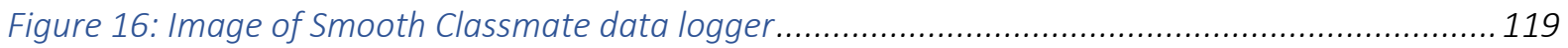

Figure 17: Average monthly outdoor temperature in Wellington, New Zealand .............................. 122

Figure 18: Hourly dry bulb temperature per month in Wellington, New Zealand .............................. 123

Figure 19: Average monthly outdoor humidity and dry bulb temperature in Wellington, New Zealand

Figure 20:Plan annotation of 7 sensors placed within a unit in the flexible learning classroom...... 126

Figure 21:Image of modelled external environment and internal environment of the classroom building

Figure 22: Plan annotation of 4 sensors placed within a unit in the flexible learning classroom and interior images

Figure 23: Plan annotation of 5 sensors placed within a unit in the single modular building..... 
Figure 24: Interior Image Showing Openings Connecting Learning Spaces and Building Characteristics

Figure 25: Interior image of case study one classroom showing Interior image of case study one classroom showing furniture's and fixtures, individually powered electric heater and connection between teaching space and breakout space. 130

Figure 26: Internal image showing the relationship between break out and teaching spaces..... 131

Figure 27: Ministry of Education's Climate Zones, Source: DQLS (2017) .......................................... 133

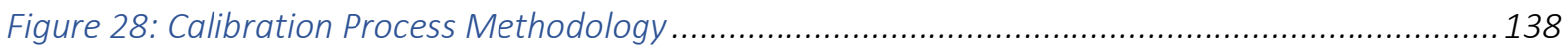

Figure 29: Pictures showing sensors on the wall of an occupied design classroom ........................... 149

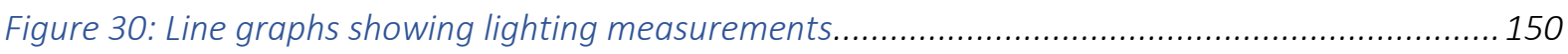

Figure 31: Line graphs showing temperature measurements ..................................................... 151

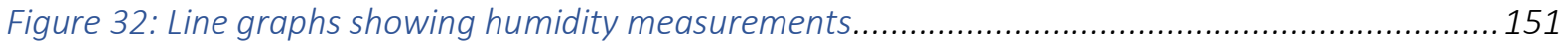

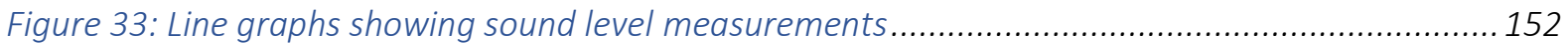

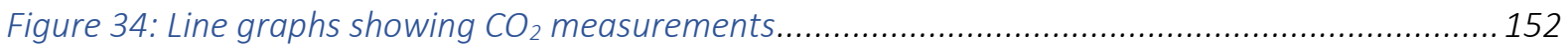

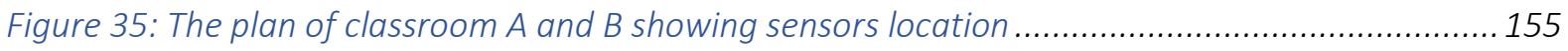

Figure 36: Comparison of Summer Illuminance Distribution on the Horizontal Plane with that of a One Point Sensor on the Long and Short Walls in a two-side lit and one-side lit classroom 158

Figure 37: Comparison of Winter Illuminance Distribution on the Horizontal Plane with that of a One Point Sensor on the Long and Short Walls in a two-side lit and one-side lit classroom 160

Figure 38: Comparison of Annual Illuminance Distribution on the Horizontal Plane with that of a One Point Sensor on the Long and Short Walls in a two-side lit and one-side lit classroom ...................... 162

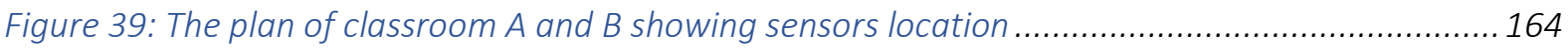

Figure 40: UDI and DA Comparison between the Horizontal Plane and Vertical Wall Sensors in

Classroom B 164

Figure 41: UDI and DA Comparison between the Horizontal Plane and Vertical Wall Sensors in Classroom B......

Figure 42: Comparison of Annual Illuminance at the Centre of the Horizontal Plane with that of the Vertical Walls. 166

Figure 43: Average Illuminance Levels at 11am in the month of February.... 168

Figure 44: Image showing sensors paired on the wall of an occupied design classroom 170 Figure 45: Plan of case study classrooms showing orientation (A sensors horizontal, on working plane; B sensors vertical, on adjacent wall) and colour annotation of the sensors..... 172 Figure 46: Line graphs showing illuminance trends between 8 am-3 pm during non-school days in all three case studies (A sensors horizontal, on working plane; B sensors vertical, on adjacent wall)......175 
Figure 47: Line graphs showing measured sunshine in minutes within the hours of 8 am to 3 pm in nonschool and school days in all three case studies. Source: NIWA

Figure 48: Sparklines showing illuminance visual patterns $<=2000 l u x$ between 8 am to $3 \mathrm{pm}$ in the nonschool days

Figure 49: Line graphs showing illuminance trends between 8 am - 3 pm during school days in all three case studies (A sensors horizontal, on working plane; B sensors vertical, on adjacent wall)......

Figure 50: Images showing the use of blinds to minimise solar penetration and dimming of artificial lighting in case study three.....

Figure 51: Sparklines showing illuminance visual patterns $<=2000 l u x$ between 8 am to $3 \mathrm{pm}$ in the school days

Figure 52: Comparison of illuminance correlation between horizontal (A2) and vertical sensors (B3) 184

Figure 53: Comparison of ratio between horizontal and vertical sensors

Figure 54: Sun Path (Source: CBPR, Victoria University of Wellington) and shade diagrams of the case study building ......

Figure 55: Images showing illustration of how to use a one-point sensor for illuminance prediction .193 Figure 56: Line graphs showing temperature trends between 8 am - 3 pm during non-school days in all three case studies (A sensors horizontal, on working plane; B sensors vertical, on adjacent wall)......196 Figure 57: Sparklines showing temperature visual patterns between 8 am to $3 \mathrm{pm}$ in the non-school days

Figure 58: Line graphs showing relative humidity trends between 8 am - 3 pm during non-school days in all three case studies (A sensors horizontal, on working plane; B sensors vertical, on adjacent wall)

Figure 59: Sparklines showing relative humidity visual patterns between 8 am to $3 \mathrm{pm}$ in the nonschool days

Figure 60: Line graphs showing temperature trends between 8 am - 3 pm during non-school days in all three case studies (A sensors horizontal, on working plane; B sensors vertical, on adjacent wall)......202 Figure 61: Sparklines showing temperature visual patterns during school days

Figure 62: Line graphs showing relative humidity trends between 8 am-3 pm during the school days in all three case studies (A sensors horizontal, on working plane; B sensors vertical, on adjacent wall)

Figure 63: Sparklines showing relative humidity patterns during school days......

Figure 64: Comparative ratio between horizontal and vertical sensors.....

Figure 65: Comparative ratio between horizontal and vertical sensors.....

Figure 66: Comparison of ratio between horizontal and vertical sensors 
Figure 67: Comparative ratio between horizontal and vertical sensors.....

Figure 68: Comparative ratio between horizontal and vertical sensors.

Figure 69: Comparative ratio between horizontal and vertical sensors.

Figure 70: Images showing the heating system used in the classroom

Figure 71: Images showing illustration of how to use a one-point sensor for thermal performance prediction

Figure 72: Line graphs showing sound levels between 8 am - 3 pm during non-school days (A sensors horizontal, on the working plane; B sensors vertical, on adjacent wall)

Figure 73: Sparklines showing sound level visual patterns between 8 am to $3 \mathrm{pm}$ in the non-school days

Figure 74: Line graphs showing sound levels between 8 am - 3 pm during school days (A sensors horizontal, on the working plane; B sensors vertical, on adjacent wall)

Figure 75: Sparklines showing sound level visual patterns between 8 am to $3 \mathrm{pm}$ in the school days 239

Figure 76: Comparison of ratio between horizontal and vertical sensors

Figure 77: Comparison of ratio between horizontal and vertical sensors.....

Figure 78: Comparison of ratio between horizontal and vertical sensors

Figure 79: Illustration of how to use a one-point sensor to measure $\mathrm{CO}_{2}$ at scale in buildings.....

Figure 80: Line graphs showing $\mathrm{CO}_{2}$ trends between $8 \mathrm{am}-3 \mathrm{pm}$ during non-school days (A sensors horizontal, on the working plane; B sensors vertical, on adjacent walll.....

Figure 81: Sparklines showing $\mathrm{CO}_{2}$ visual patterns between 8 am to 3 pm in the non-school days.... 254

Figure 82: Line graphs showing $\mathrm{CO}_{2}$ trends between $8 \mathrm{am}-3 \mathrm{pm}$ during school days (A sensors horizontal, on the working plane; B sensors vertical, on adjacent wall) ........................................... 256

Figure 83: Sparklines showing $\mathrm{CO}_{2}$ visual patterns between 8 am to 3 pm in the school days ............257

Figure 84: Comparison of ratio between horizontal and vertical sensors ......................................... 259

Figure 85: Comparison of ratio between horizontal and vertical sensors .......................................260

Figure 86: Comparison of ratio between horizontal and vertical sensors .......................................2 261

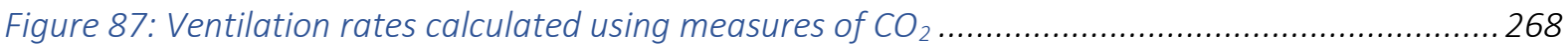

Figure 88: Illustration of how to use a one-point sensor to measure $\mathrm{CO}_{2}$ at scale in many buildings.. 271

Figure 89: A spider plot summarizing the weighting schemes of the various IEQ studies...................2276

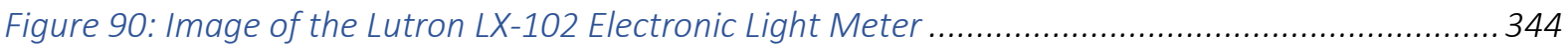

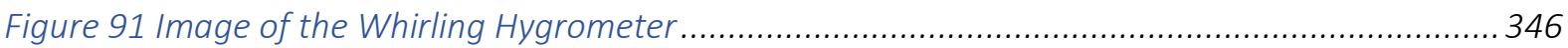

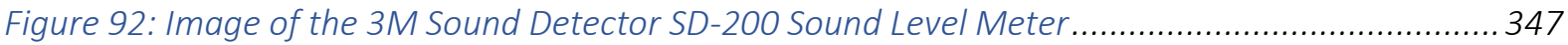

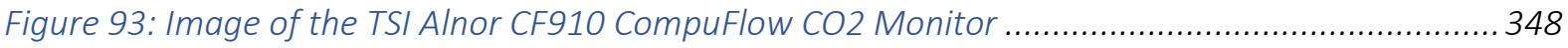

Figure 94: Images showing sensors on the wall of an occupied design classroom ............................349 
Figure 95: Plan and interior picture showing the location of sensors within the test environment

Figure 96: Pictures showing the location of the Wi-Fi AP and Sensor 1006 located at the centre of the space

Figure 97: Pictures showing the Wi-Fi Analyzer image for Sensors 1117 and 1041 respectively 355

Figure 98: Pictures showing the Wi-Fi Analyzer image for sensors 1075 and 1057 respectively.... 355 Figure 99: Line graphs showing illuminance trends between 8 am - 3 pm during non-school days in all three case studies

Figure 100: Sparklines showing illuminance visual patterns $<=2000 l u x$ between 8 am to 3 pm in the non-school days.....

Figure 101: Line graphs showing illuminance trends between 8 am - 3 pm during school days in all three case studies.

Figure 102: Sparklines showing illuminance visual patterns <=2000lux between 8 am to 3 pm in the non-school days

Figure 103: Line graphs showing temperature trends between 8 am - 3 pm during school days

Figure 104: Sparklines showing temperature visual patterns between 8 am to 3 pm in the non-school days

Figure 105: Line graphs showing relative humidity trends between 8 am - 3 pm during non-school days

Figure 106: Sparklines showing relative humidity visual patterns between 8 am to 3 pm in the nonschool days

Figure 107: Line graphs showing temperature trends between 8 am - 3 pm during school days 367

Figure 108: Sparklines showing temperature visual patterns between 8 am to 3 pm in the school days

Figure 109: Line graphs showing relative humidity trends between 8 am - 3 pm during school days 369 Figure 110: Sparklines showing relative humidity visual patterns between 8 am to 3 pm in the school days

Figure 111: Line graphs showing sound levels between 8 am - 3 pm during school days

Figure 112: Sparklines showing sound level visual patterns between 8 am to 3 pm in the school days

Figure 113: Line graphs showing $\mathrm{CO} 2$ trends between 8 am - 3 pm during school days.....

Figure 114: Sparklines showing $\mathrm{CO}_{2}$ visual patterns between 8 am to 3 pm in the school days 


\section{List of Tables}

Table 1: Keywords and overview of the systematic literature review process ......................................36

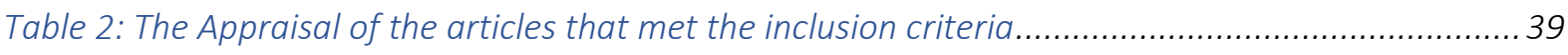

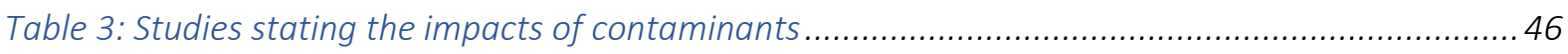

Table 4: Summary of Lighting Levels and Learning Performance Target Range ................................6 60

Table 5: Summary of temperature and learning performance target range ...................................... 65

Table 6: Summary of sound levels and learning performance target range ….................................... 74

Table 7: Summary of carbon dioxide levels and learning performance target range ..........................82

Table 8: Illuminance based metrics for assessing daylight quality in classrooms. Source: (Costanzo et al., 2017a)

Table 9: Sensor location considerations in studies that have objectively measured thermal conditions in Classrooms.

Table 10: Environmental factors that affect heat dissipation from the body (adapted from Szokolay, (2008).

Table 11: Sensor location considerations in studies that have objectively measured ambient noise in classrooms.

Table 12 Sensor location considerations in studies that have objectively measured $\mathrm{CO}_{2}$ in Classrooms

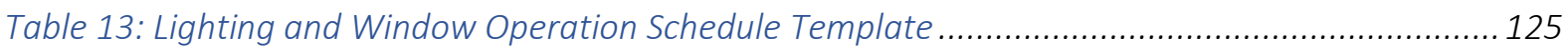

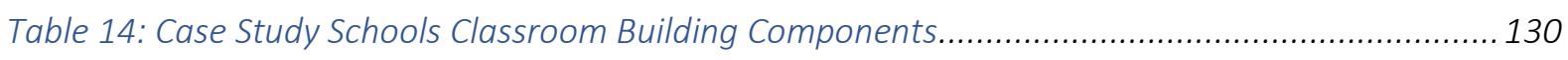

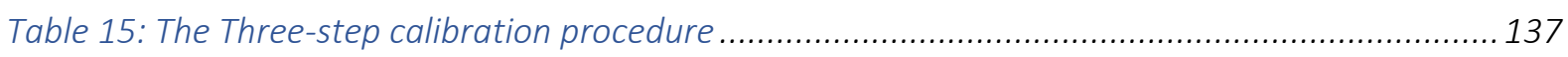

Table 16: Sources of uncertainties from onsite spot measurement calibration ................................. 139

Table 17: Data loggers' calibration table showing the variation between the reference sensor and

Smooth Sensors

Table 18: Sound Level Comparison Chart. Sources: (Richard, 1970; Sengpielaudio, 2018)................. 144

Table 19: Sound Ratio Factor Comparison Chart. Sources: (Richard, 1970; Sengpielaudio, 2018) ...... 144

Table 20: Comparative ratio analysis of the relationship between temperature levels at the central horizontal sensor A2 with vertical wall sensors B1-4 respectively.....

Table 21: Comparative ratio analysis of the relationship between temperature levels at the central horizontal sensor A2 with vertical wall sensors B1-4 respectively.....

Table 22: Comparative ratio analysis of the relationship between temperature levels at the central horizontal sensor A2 with vertical wall sensors B1-4 respectively.....

Table 23: Comparative ratio analysis of the relationship between relative humidity levels at the central horizontal sensor A2 with vertical wall sensors B1-4 respectively. 
Table 24: Comparative ratio analysis of the relationship between relative humidity levels at the central horizontal sensor A2 with vertical wall sensors B1-4 respectively

Table 25: Comparative ratio analysis of the relationship between relative humidity levels at the central horizontal sensor A2 with vertical wall sensors B1-4 respectively

Table 26: Average temperature in the non-school days from 8 am-3 pm 216

Table 27: Average temperature in the non-school days from 8 am-3 pm 216

Table 28: Average temperature in the non-school days from 8 am-3 pm 216

Table 29: Average relative humidity in the non-school days from 8 am-3 pm........... 217

Table 30: Average relative humidity in the non-school days from $8 \mathrm{am}-3 \mathrm{pm}$

Table 31: Average relative humidity in the non-school days from $8 \mathrm{am}-3 \mathrm{pm}$

Table 32: Average temperature in the school days from 8 am-3 pm.

Table 33: Average temperature in the school days from 8 am-3 pm.

Table 34: Average temperature in the school days from 8 am-3 pm.

Table 35: Average relative humidity in the school days from 8 am-3 pm.....

Table 36: Average relative humidity in the school days from $8 \mathrm{am}-3 \mathrm{pm}$

Table 37: Average relative humidity in the school days from 8 am-3 pm

Table 38: Summer PMV and PPD Analysis.....

Table 39: Autumn PMV and PPD Analysis

Table 40: Summer Adaptive Comfort Model Analysis.

Table 41: Autumn Adaptive Comfort Model Analysis

Table 42: Ratio Analysis comparing the relationship between sound levels at the central horizontal sensor A2 with vertical wall sensors $B 1-4$ respectively

Table 43: Ratio Analysis comparing the relationship between sound levels at the central horizontal sensor A2 with vertical wall sensors B1-4 respectively.....

Table 44: Ratio Analysis comparing the relationship between sound levels at the central horizontal sensor A2 with vertical wall sensors B1-4 respectively......

Table 45: Average sound levels in the non-school days from 8 am-3 pm

Table 46: Average sound levels in the non-school days from 8 am-3 pm

Table 47: Average sound levels in the non-school days from 8 am-3 pm

Table 48: Average sound levels in the school days from 8 am-3 pm.

Table 49: Average sound levels in the school days from 8 am-3 pm.

Table 50: Average sound levels in the school days from 8 am-3 pm.

Table 51: Ratio Analysis comparing the relationship between $\mathrm{CO}_{2}$ levels at the central horizontal sensor A2 with vertical wall sensors $B 1-4$ respectively. 
Table 52: Ratio Analysis comparing the relationship between $\mathrm{CO}_{2}$ levels at the central horizontal sensor A2 with vertical wall sensors $B 1-4$ respectively......

Table 53: Ratio Analysis comparing the relationship between $\mathrm{CO}_{2}$ levels at the central horizontal sensor A2 with vertical wall sensors $B 1-4$ respectively.

Table 54: Average $\mathrm{CO}_{2}$ levels in the non-school days from $8 \mathrm{am}-3 \mathrm{pm}$ 263

Table 55: Average $\mathrm{CO}_{2}$ levels in the non-school days from 8 am-3 pm. 263

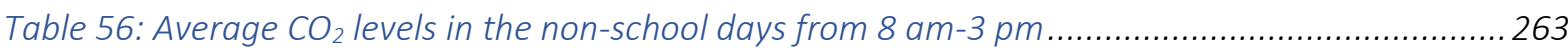

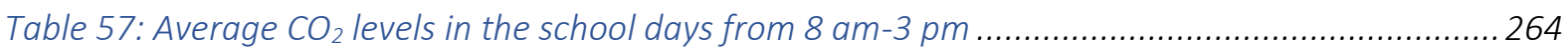

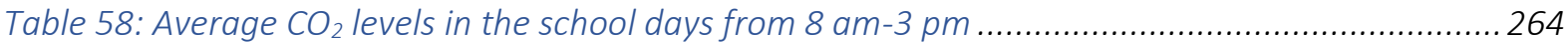

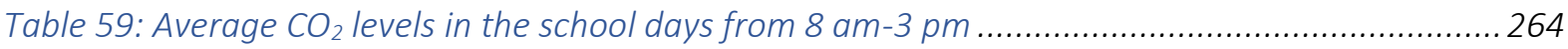

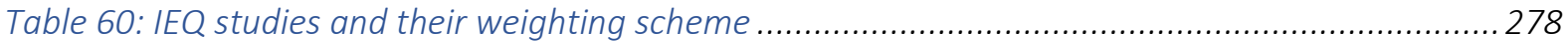

Table 61: The importance of each IEQ variable relative to the other factors....................................2.279

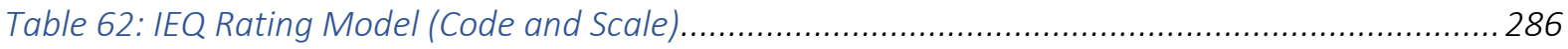

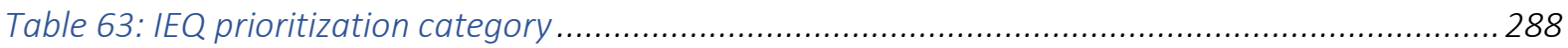

Table 64: Systematic appraisal of the articles that met the inclusion criteria .................................... 328

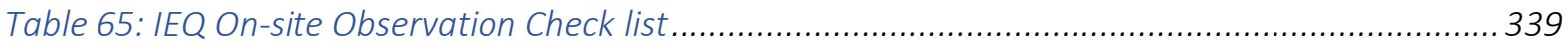

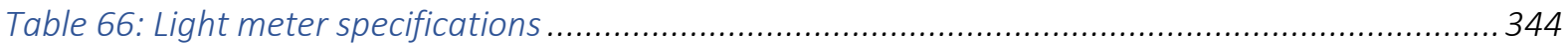

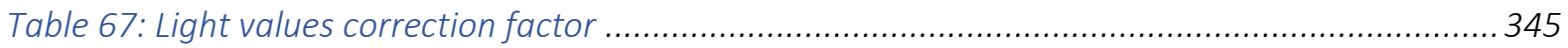

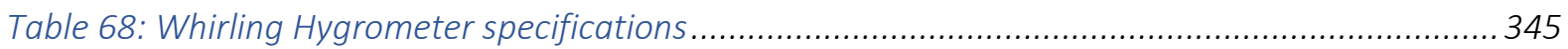

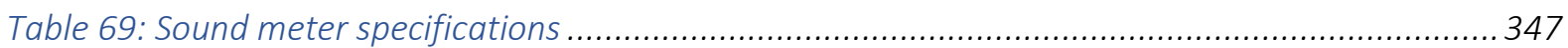

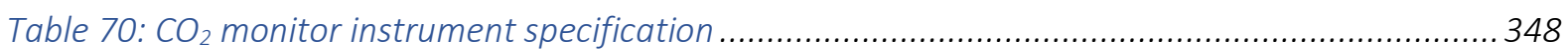

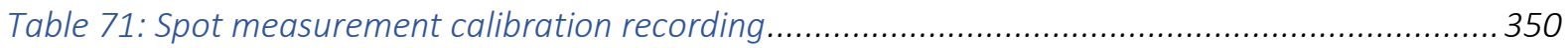

Table 72: Pilot Study One Spot Measurement Calibration Table ..................................................... 351

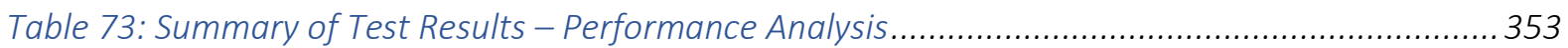

Table 74: Case Study One Pilot Study Spot Measurement Calibration Table ..................................... 358

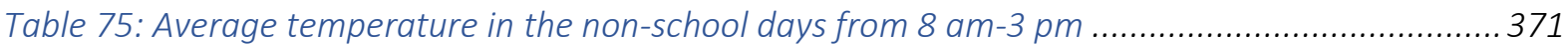

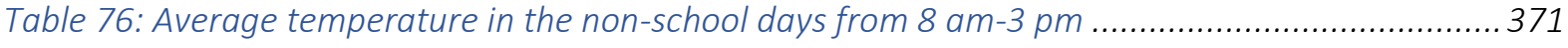

Table 77: Average temperature in the non-school days from 8 am-3 pm ....................................... 371

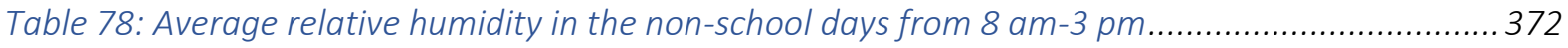

Table 79: Average relative humidity in the non-school days from 8 am-3 pm..................................372

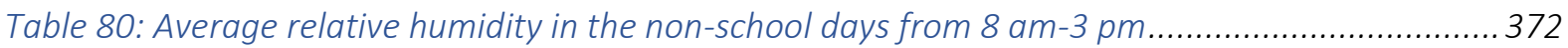

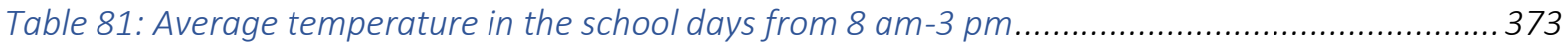

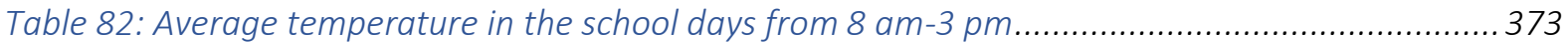

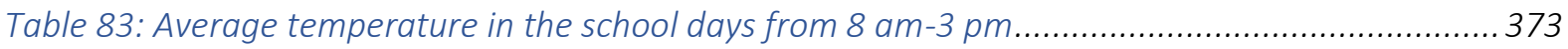


Table 84: Average relative humidity in the school days from 8 am-3 pm 374

Table 85: Average relative humidity in the school days from $8 \mathrm{am}-3 \mathrm{pm}$ 374

Table 86: Average relative humidity in the school days from $8 \mathrm{am}-3 \mathrm{pm}$ 374

Table 87: Average sound levels in the school days from 8 am-3 pm. 377

Table 88: Average sound levels in the school days from 8 am-3 pm. 377

Table 89: Average sound levels in the school days from 8 am-3 pm. 377

Table 90: Average $\mathrm{CO}_{2}$ levels in the school days from $8 \mathrm{am}-3 \mathrm{pm}$ 380

Table 91: Average $\mathrm{CO}_{2}$ levels in the school days from $8 \mathrm{am}-3 \mathrm{pm}$ 380

Table 92: Average $\mathrm{CO}_{2}$ levels in the school days from $8 \mathrm{am}-3 \mathrm{pm}$ 380 


\section{List of Abbreviation}

\begin{tabular}{|l|l|}
\hline Abbreviation & Description \\
\hline ASHRAE & $\begin{array}{l}\text { American Society of Heating, Refrigerating and Air-Conditioning } \\
\text { Engineers }\end{array}$ \\
\hline BRANZ & Building Research Association of New Zealand \\
\hline CBDM & $\begin{array}{l}\text { Climate Based Daylight Modelling } \\
\text { Carbon Dioxide }\end{array}$ \\
\hline CO $_{2}$ & Daylight Autonomy \\
\hline DA & Decibel (A-weighted) \\
\hline dBA & Heating, Ventilation, And Air Conditioning \\
\hline HVAC & Indoor Air Quality \\
\hline IAQ & Indoor Environmental Quality \\
\hline IEQ & Lux (Illuminance) \\
\hline LX & Modern Learning Environment \\
\hline MLE & Ministry of Education \\
\hline MoE & Noise Reduction Coefficient \\
\hline NRC & Celsius \\
\hline 'C & Predicted Mean Vote \\
\hline PMV & Predicted Percentage Dissatisfied \\
\hline PPD & Parts Per Million \\
\hline PPM & Relative Humidity \\
\hline RH & Reverberation Time \\
\hline RT & Sound Level Measurement \\
\hline SLM & Statistical Package for the Social Sciences \\
\hline SPSS & Sound Transmission Coefficient \\
\hline STC & Useful Daylight Illuminance \\
\hline UDI & Volatile Organic Compound \\
\hline VOC & Wireless Fidelity (Network) \\
\hline WiFi & \\
\hline
\end{tabular}




\section{CHAPTER ONE: INTRODUCTION}

\subsection{Introduction}

Indoor Environmental Quality (IEQ) as a phrase is typically used to refer to the quality of the conditions inside a building's environment in relation to the comfort, health, and wellbeing of its occupants. Many variables influence this aspect of the quality of the indoor environment including external conditions (air pollution, external temperature), building (construction materials, furniture), building services (HVAC systems) and people and activities (HVAC use, cleaning), etc., (Almeida et al., 2015). But research suggests that among these variables, lighting quality, thermal quality, acoustic quality and Indoor air quality (IAQ) are perceived as the four major variables that have a significant effect on building occupants' health and wellbeing (Ackley, Donn, \& Thomas, 2017; Akpan-idiok \& Ackley, 2017; Aturupane, Glewwe, \& Wisniewski, 2013; Barrett \& Zhang, 2009; Dorizas, Assimakopoulos, \& Santamouris, 2015; Frontczak, Andersen, \& Wargocki, 2012). This is because, they are associated with the visual, acoustic and thermal comfort and energy-efficiency design of a building (Bluyssen, Zhang, Kim, Eijkelenboom, \& Ortiz-Sanchez (2019); Bluyssen, Kim, Eijkelenboom, \& Ortiz-Sanchez (2020); De Dear, Kim, Candido, \& Deuble, 2015; Figueiro, Rea, Rea, \& Stevens, 2002; Kruger \& Zannin, 2004; Li \& Wong, 2007).

These variables are of primary importance in schools because they impact on students' health, comfort, and performance - the classroom environmental quality can affect children's ability to concentrate and engage in learning (Pellegrino et al., 2015). A child spends about 900 hours in school buildings yearly (52 (weeks) - 16 (vacation weeks) x 5 (days per week) x 5 (hours per day in classroom) $=900$ hours. When this figure is multiplied by 13 years (from year 1 to year 13 in New Zealand school system) they spend an average of 11,700 hours of their lives in school buildings - which is about $15 \%$ of their waking lives ${ }^{1}$. Considering the number of hours spent in the classroom, the impact of IEQ in school settings remains a subject of concern for many scholars and parents and teachers (Ackley et al., 2017; Cheryan et al., 2014; Heschong Mahone Group, 1999; Krüger \& Dorigo, 2008).

\footnotetext{
${ }^{1}$ (Total waking hours over that time is: 13 (years) $\times 52$ (weeks) $\times 7$ (days) $\times 16$ (estimated waking hours per day) $=75,712$ hours.
} 
Studies show that IEQ in classrooms can facilitate or hinder learning performance. The results are robust even when statistically controlling for other variables such as the socioeconomic status of students, absenteeism, grade level, teacher bias, etc. (Crampton, 2009; Heschong Mahone Group, 1999; Tanner, 2008). For example, a daylight study by Heschong Mahone Group, (1999) showed that, even with the analysis of the teacher characteristic, student absenteeism data, and grade level variables, the daylight variable stayed highly significant as a factor that impacts learning performance. Unlike these studies, which examined the effect of individual IEQ variables, in building design, IEQ variables are interlinked. In the literature review reported in Chapter 2, none of the one hundred and fifty health and learning performance studies investigated the four IEQ variables together and the comparison of these studies is difficult due to differences in study design, outcome parameters and climate. In a teacher survey analysis, Heschong et al., (1999) stated that thermal and visual comfort, acoustic and adequate ventilation were all frequently listed as top priorities. This holistic concern for all these four IEQ variables raises concerns about the relative contributory effect of each to learning performance.

If researchers, architects and planners are too strongly affirm to policymakers that the combined effects of IEQ should be top priorities when considering changes to classroom environments, the relative contributory effect of each of the four leading IEQ variables will be of interest. Also, a scalable and cost effective IEQ evidence base measurement protocol and operational analysis models will be required. For example, in New Zealand, the Ministry of Education (MoE) have at least one internal environmental measurement point recording light, temperature, humidity, sound, and carbon dioxide levels in about 90 selected schools across the country. The objective of this measurement process is to understand the indoor condition of New Zealand schools to inform proactive asset management decisions. If this is to be a nationwide tool collating thousands of environmental data, in a world looking for evidence based policy driven decisions and considering that the volume of the MoE data will be enormous, this gives concerns on whether a one-point sensor measurement can be representative of the IEQ conditions in a space. 
The purpose of this study was to:

- firstly, determine the adequacy of using a one-point sensor to predict the distribution of IEQ in classrooms;

- secondly, to develop a monitoring protocol for measuring multiple IEQ variables at scale in school buildings to identify good and poor learning spaces (in this thesis, the word "scale" refers to a large property portfolio); and

- given that the output of IEQ measurements will result in big data, the third purpose is to propose an analytical framework to evaluate and report measured IEQ for decision making.

The following sections explain these purposes further.

\subsection{Research Gap}

The importance of good indoor environmental quality in buildings cannot be underestimated, especially in educational buildings. Poor daylight, high temperatures, poor acoustics and low air quality in the classroom are significantly associated with poor student performance (Barrett, Zhang, Davies, \& Barrett, 2015; Chatzidiakou, Mumovic, Summerfield, Tàubel, \& Hyvärinen, 2014; Heschong, 2003; Wall, 2010; Tanner, 2008; Wargocki \& Wyon, 2013). In this thesis, one hundred and fifty relevant scholarly articles that have examined the influence of indoor environmental quality (IEQ) on learning performance and health in schools were systematically appraised. Among these many published articles, reviews and reports suggesting the influence of IEQ on learning performance and health in classrooms, the analysis revealed that there is no idea of the combined effects of the various variables of IEQ in classrooms. A possible reason is the difficulties associated with summarizing and comparing all the diverse types of evidence of IEQ influence in classrooms.

Over the years, many countries have conducted IEQ measurements with the aim to set guidelines and standards and have consequently developed various regulations. In this thesis, I had initially sought to find precedents for the influence of combined IEQ measurements on learning performance in schools and found none. I had also set out to find standards for measuring or characterizing IEQ in classrooms and found nothing. There is no coherent guidance on representative placement of sensors. The variance in the number of sensors used in previous studies and the different placement height of sensors within a space 
illustrates the challenges of establishing the most appropriate approach towards field measurement of IEQ variables, especially in occupied classrooms. While there is a range of subjective approaches for measuring IEQ in buildings (Barkmann, Wessolowski, \& SchulteMarkwort, 2012; Coley \& Beisteiner, 2016; De Dear et al., 2015; Evans \& Maxwell, 1997; Hygge, 2003; Parkinson \& De Dear, 2016; Santamouris et al., 2008; Singh \& Arora, 2014; Wargocki \& Wyon, 2017), there is variability in the positioning of sensors by different researchers to characterise the IEQ levels in classrooms. For example, the lighting researcher very often looks at desktop illuminance imagining that is the task to be illuminated. The thermal comfort researcher would typically want to measure at the height of the principal body mass of a person, and IAQ is at the nose height. Whereas, the acoustician will prefer measurements to be taken outside the sound field of the teacher and somehow representative of the whole volume (Reverb time for example). Given the lack of precedents in combining IEQ measurements into a single measure (monitoring with a single multivariable sensor) and how to characterize a whole space (classroom) where daylight and $\mathrm{CO}_{2}$ levels and even thermal environment can vary across a space, a set of more fundamental questions about IEQ measurement strategy (where, what and how to measure) in a national school portfolio arose.

Monitoring a building's performance will require the use of data loggers (sensors) and in recent years, there is commercially available emerging technology capable of combining multiple environmental sensors into a single device that has a robust capability to simultaneously measure lighting, temperature, humidity, sound levels and carbon dioxide levels in buildings. These Internet of Things (IOT) devices are currently used to measure the IEQ of schools, hospitals, offices and homes. The output of these IEQ measurements will result in big data. While big data is advantageous due to its predictive analytic capability, the mechanism for easily monitoring, collecting and processing IEQ big data and how to report it has proven challenging. Hence, the rationale to investigate whether a one-point sensor can be representative of the environmental condition within a classroom and where will be the best place to locate it? This study uses scientific evidence to develop a monitoring protocol for measuring IEQ at scale in school buildings to identify good and poor IEQ in spaces and proposes an analytical framework to evaluate and report measured IEQ big data suited for use by organisations with large portfolios of buildings, such as school and housing authorities. 
However, the focus of this thesis is the school building portfolio managed by the New Zealand Ministry of Education.

\subsubsection{Rationale of the Study: Relevance to New Zealand}

The Ministry of Education owns the second largest social property portfolio in New Zealand, with more than 15,000 buildings and over 35,500 teaching spaces in more than 2,100 schools that have a replacement value of about $\$ 28.7 b$ (Ministry of Education, 2020).

The school property development in New Zealand can be grouped into four distinct phases:

1. Before 1950: This era was categorised by building traditional classroom blocks.

2. From 1950-1980: Under the then Ministry of Works, large school building programmes were undertaken to meet the needs of the post-war baby boom. These buildings were standardised designs based on the "school block" principle and built to save time and money (Ministry of Education, 2011). A significant portion of the portfolio is made up of these standardised buildings, which were made from solid timber construction with internal load bearing walls. Many of these buildings remain uninsulated and are inefficient in comparison with modern buildings (Ministry of Education, 2011).

3. Post 1980-1990: In this era, large numbers of prefabricated buildings were moved onto existing school sites to respond to demographic changes (Ministry of Education, 2011). These buildings are of lightweight timber frame construction and are often well elevated above the ground on supports. These design types, including internal wall lining details could amplify sound, which could result in poor acoustic performance and learning environments that are less than optimal.

4. Post 1990s: With the advent of a decentralised property approach from the early 1990s onwards, the building stock was diversified with many bespoke-designed buildings. In recent years, the portfolio has been further diversified through changes in the way teaching and learning activities are arranged at schools with the introduction of open plan teaching in some new schools - innovative design with emphasis on spaces that support flexible styles of teaching and learning. The large open plan building built in this era are likely to have good thermal insulation treatments, but prone to overheating issues due to large glazing areas. In 2020, the Ministry released Te Rautaki Rawa Kura - The School Property Strategy 2030. This 
strategy is aimed at lifting the quality of NZ's physical learning environments, by delivering the objectives of quality learning environments and increased environmental awareness with a move towards sustainability (Ministry of Education, 2020).

Since about 2010, systemic weathertightness failure due to poor design, materials used and property damage caused by the $2010 / 2011$ Christchurch earthquakes and population growth have challenged the management of New Zealand's school building portfolio (Ministry of Education, 2020).

Studies (Bennett et al., 2019; Boulic et al., 2018; Taptiklis et al., 2017; Wilson et al., 2002; Bassett \& Gibson P, 1999) suggest that some primary school classrooms in New Zealand may likely be prone to poor indoor environmental quality. This is due to the combination of building design, type of material used and construction with the nature of the occupancy, management and maintenance of the space. The average age of some New Zealand classroom (more than 55 years old) means they were constructed under early building codes where minimum insulation standards were the norm. For example, Figure 1 shows a breakdown of primary school buildings per year built. The bar chart indicates that majority of New Zealand primary school buildings were built between 1950 to 1980 and a large number of these buildings were built with the standard classroom designs such as the Nelson block, Avalon, Dominion, Canterbury and Formula blocks respectively.

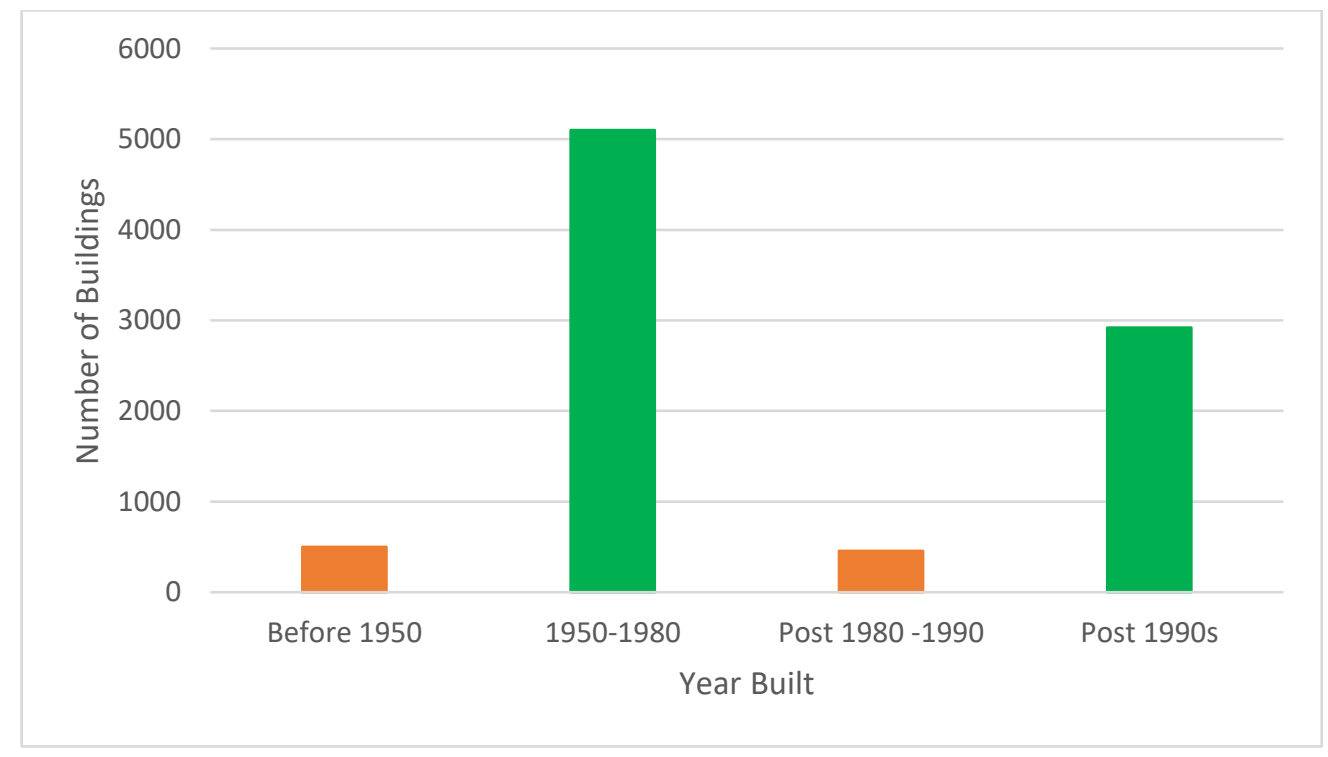

Figure 1: Estimated number of primary school buildings per year built in New Zealand 
To provide some general context, studies (Bennett et al., 2019; Taptiklis, Phipps, \& Plagmann, 2017; Wang, Boulic, \& Phipps, 2016; Mclntosh, 2011; Misni, 2012; Whitlock \& Dodd, 2006; Wilson et al., 2002; Bassett \& Gibson P, 1999) suggest that some New Zealand primary school classrooms can be categorised as:

- small, rectangular wooden rooms;

- with generous amounts of glazing;

- built inexpensively, and ageing;

- situated on piles;

- opening directly to the outdoors (without internal corridors);

- no or limited insulation, either in walls, ceilings or under-floor, because they were built in accordance with older building codes;

- individually heated only while in use and naturally ventilated through openable windows as shown in the case study classrooms, but fully carpeted;

- have ceilings of low-density fibreboard;

- uninsulated skillion roof forms; and

- still may contain materials such as asbestos.

Given the above factors, the Ministry of Education (MoE) in New Zealand has been carrying out a range of programmes targeted at renovating affected buildings. This includes:

- The small schools internal environmental monitoring pilot: This was carried out in 2017 and the findings of the pilot informed the "Improving Classrooms in Small or Remote Schools" programme, which is reported in more details below

- The Weathertightness remediation programme: This programme addresses school buildings that have been subject to destructive testing reports as part of the Ministry's national survey of buildings with weathertightness issues, and the aim was to keep school buildings weathertight

- National Transportable Programme (NTP): This programme provides modular buildings for new spaces at schools

In early 2017, and following discussions with the Ministry of Education regarding their plans on improving IEQ in buildings, it was clear that the Ministry was looking at using 
environmental data loggers to collate evidence based IEQ data to guide proactive asset management (remediation of existing buildings in a timely and cost-effective way) and investment decisions. Over the course of this thesis, and following the release of Te Rautaki Rawa Kura - The School Property Strategy 2030, the Ministry launched more programmes such as:

- Te Haratau: This programme is aimed at delivering the strategic objectives of quality learning environments and involves the collection and analyses of internal environmental data, condition and operational efficiency data of school assets for property planning and making evidence-based decisions

- The "Improving Classrooms in Small or Remote Schools" programme: This is a fouryear programme aimed at improving the IEQ of up to 600 state schools that are small or remote in New Zealand. The Ministry is looking to improve thermal performance, lighting performance, acoustic performance and energy efficiency. Data measured using environmental data loggers would be used to inform improvements, which include interventions such as installing LEDs, acoustic panels and thermal insulation in classrooms

- The Ministry is currently updating the Designing Quality Learning Spaces (DQLS) suite of design requirements for building quality learning environments for schools. The DQLS suite provides the framework for assessing the internal environment quality of school buildings and covers the four main IEQ factors: lighting and visual comfort, acoustics, indoor air quality and thermal comfort requirements. These requirements form part of a set of documents for Designing Schools in New Zealand - Requirements and Guidelines (DSNZ), which is the overarching guidance for school design

Through these programmes, the Ministry aims to undertake continuous remediation of school buildings. The aim of this thesis was to provide scientific evidence that could support a range of Ministry building performance programmes, by developing a methodological approach for measuring, analysing and reporting IEQ at scale (in many buildings) and so that the same process could be used in any large property portfolio. The findings of this thesis has provided insights to inform some of the Ministry programmes over time (Appendix 10). 


\subsection{Research Aims}

This research was conducted to address one primary goal and three secondary objectives. The primary aim of this thesis was to investigate if the data derived from a one-point sensor measurement on a wall can predict the environmental quality in a space and reliably summarise a classroom environment to identify good and poor classrooms to inform possible interventions and so that the combined relationship between IEQ and student performance might be studied.

\subsection{Research Questions}

This study firstly summarises in a systematic way, the existing findings on the influence of IEQ on learning performance and health in schools and evaluates the strength and consistency of the literature. Thereafter, an appraisal of existing IEQ measurement practices and sampling locations was carried out and how this influence the spatial distribution of IEQ in classrooms. This was to identify the work done in IEQ measurement practice and determine the current limitations in establishing representative locations for sensors in classrooms. The outcome of these appraisals led to the following two specific research questions:

1. Can a one-point sensor measurement on the wall be representative of the environmental condition within a classroom and where might be the best location to position it?

2. Can multiple IEQ variables be measured at scale and analysed to identify good and poor IEQ classrooms?

\subsection{Research Objectives}

To measure IEQ at scale (in a national school property portfolio) to identify good and poor IEQ spaces, this study first describes basic aspects to be considered when working out a sampling strategy for the measurements of IEQ. Secondly, it examines how the five key IEQ variables are distributed within an occupied classroom and how this distribution is affected by different parameters. The outcome of these analyses provides a methodological approach for future researchers to monitor indoor environment quality strategically and efficiently with reliable placement of sensors. To the best of the researcher's knowledge, no major research studies have so far been undertaken regarding the variations of the five IEQ variables within an occupied classroom with varying design types and occupancy patterns. 
The extensive systematic literature review (Chapter 2) showed that there is lack of an integrated approach to assess IEQ in school buildings. This study addresses the need for a holistic measurement protocol of IEQ that will be useful in simultaneously investigating the interaction between building design (microenvironment, building characteristics, and meteorological parameters) and students' perception of IEQ with learning performance in schools. The following objectives relate to the outputs of this thesis:

1. To assess the adequacy of using a one-point multi-variable sensor to predict the IEQ condition across a classroom.

2. To ascertain the best location to measure multiple IEQ variables in classrooms.

3. To propose a model for measuring and analysing IEQ at scale (in many classrooms) to inform policy-driven interventions (design decisions).

\subsection{Thesis Structure}

This thesis is divided into nine related chapters. Summary of these chapters is presented below:

\section{Chapter One:}

The highlights of the study are introduced in this chapter. These include the problem statement, research gap, such as the issues related to monitoring and understanding the combined influence of IEQ on learning performance in schools. Also presented in this chapter is the process of achieving the study goals through the research aims, questions and objectives.

\section{Chapter Two:}

This chapter describes the research gap identified through a systematic literature review process which identifies the influence of IEQ on students learning performance and health in schools and the IEQ range that enhances learning performance. It includes a discussion of the themes arising out of the review and the trends observed.

\section{Chapter Three:}

The concept of measuring IEQ in schools and the challenges of IEQ monitoring is critically reviewed in this chapter. The aim is to provide an understanding of the measurement techniques used by previous studies in monitoring IEQ in classrooms. This includes an 
appraisal of the number of data loggers deployed for monitoring and the locations they were placed within the space.

\section{Chapter Four:}

This chapter describes the philosophies and approaches that informed the research methodology and framework. The various tools and methods used for data analysis, the process and nature of the collected data are explained in detail. Furthermore, the geographical context and case study school buildings are described, and the validity and reliability of the study instruments, such as the calibration analysis of data loggers used for monitoring are explained.

\section{Chapter Five, Six, Seven and Eight:}

These chapters analyse and discuss the findings on whether a one-point sensor can predict the distribution of each IEQ variable (lighting, temperature, relative humidity, sound levels and $\left.\mathrm{CO}_{2}\right)$ in a space. Firstly, a daylight modelling simulation is presented and thereafter quantitative results of data collected from data loggers used for objective physical measurement of all five IEQ variables in each of the selected case study schools are presented. Graphical and statistical analysis is used to explain the identified trends and insights on whether a one-point sensor could predict the IEQ variable in a space. This data provided a clear picture of the factors influencing IEQ variability and insights on how to use a one-point sensor to predict IEQ are discussed.

\section{Chapter Nine:}

This chapter presents the last part of the analysis within the assessment framework. This chapter firstly summarises the IEQ ranges that enhances learning performance to inform the determination and distribution of an IEQ code and scale and the design of an IEQ analysis and reporting model.

\section{Chapter Ten:}

The findings and conclusions drawn from the various analyses are presented in this chapter. The main goal of the study and limitations is discussed. The overall summary provides new insights and perspectives into the processes of monitoring IEQ at scale in schools and the application of the proposed IEQ rating model. This is followed by insights on the potentials of using this model as the basis of evidence-based analysis of the influence of IEQ on students' 
learning performance, given that the IEQ model enables the direct link of measured IEQ data with measured student performance. 


\section{CHAPTER TWO: LITERATURE REVIEW - THE INFLUENCE OF IEQ ON}

\section{STUDENTS' LEARNING PERFORMANCE AND HEALTH IN SCHOOLS}

\subsection{The Systematic Literature Review Process}

Three hundred and eighteen potentially relevant scholarly articles were retrieved from computerised searches using four search databases (Science Direct, Scopus, PubMed and Google Scholar) and the reference list of Wall, (2016). As shown in Table 1 and 2, the search was achieved using a combination of the following keywords:

Table 1: Keywords and overview of the systematic literature review process
\begin{tabular}{|l|l|}
\hline S/N & Keywords \\
\hline 1. & Daylight and Schools \\
\hline 2. & Daylight and Classrooms \\
\hline 3. & Daylight and Educational Buildings \\
\hline 4. & Daylight and Learning \\
\hline 5. & Thermal Comfort and Schools \\
\hline 6. & Thermal Comfort and Classrooms \\
\hline 7. & Thermal Comfort and Educational Buildings \\
\hline 8. & Thermal Comfort and Learning \\
\hline 9. & Acoustics and Schools \\
\hline 10. & Ventilation and Schools \\
\hline 11. & Health in Schools \\
\hline
\end{tabular}

Topic: The influence of IEQ on students learning performance and health in schools

Keywords: Daylight, Thermal Comfort, Acoustics, Air Quality, Learning Performance, Health Schools, Classrooms and Educational Buildings health in schools

Database: Science Direct, PubMed, Scopus and Google Scholar 318 potentially relevant scholarly articles were retrieved

Extracted Articles: 150 scholarly articles were related to my inclusion criteria

Dependent Variables: Learning performance and health Independent Variables: Daylight, Thermal Comfort, Acoustics, Air Quality

Results: S - Significant, NS - Not significant and R - Relationship

A general search of indoor environmental quality in school buildings, its effects on learning performance and health was also performed on google. 


\subsubsection{Inclusion and Exclusion Criteria}

The following criteria were considered:

- Articles were limited to English publications for all years to present in all searched database.

- Articles were selected based on their relevance to indoor environmental quality in school buildings.

- Articles that had little or no reference to architectural design features were excluded.

- Articles that lacked associations between IEQ and learning performance, health and wellbeing, productivity and energy use in a school setting were excluded.

- After full-text reading of the selected articles, articles were either included or excluded based on their relevance to indoor environmental qualities and their influence on school building occupants.

\subsubsection{Classification of the Papers}

The 318 articles resulting from the refined search were catalogued in a Mendeley database that stored at a minimum the titles, abstracts, and keywords. A second refinement was performed using titles and abstracts to exclude papers that lacked measurable associations between IEQ and learning performance and health in a school. Duplicate articles and other works that did not have information related to the study's inclusion criteria were also disregarded. Thus, from the 318 articles, 150 articles were selected and read in detail.

\subsubsection{Data Extraction}

Table 2 below evaluates the statistical evidence in the articles retrieved through the systematic literature review process. It is categorised into four segments, these are: description, dependent variables, independent variables, and others. The description segment presents the author's name and year of publication. The dependent variables are learning performance and health. The independent variables are daylighting (D), thermal comfort $(T)$, acoustics $(A)$, indoor air quality (IAQ), socio-economic considerations (SEC) and environment (ENV). The environment variable includes general physical environmental variables such as light, colour, nature, and miscellaneous building components etc. It should be noted that articles that were literature reviews, policy documents and reports which generally appraised IEQ of other studies as well as those that did not consist of the identified independent variables were categorised under the environment variable. The others segment 
in the Table presents the ranking of the articles and methodology used, the country, climate (hot or cold), type of school building and the number of students, classrooms and schools investigated in these studies. Under the school type column, traditional primary schools are represented as TPS, traditional secondary schools as TSS and modern learning environments as MLE. An MLE is an open, flexible learning space with two or more teaching spaces that supports collaborative learning and can serve a wide range of flexible functions, and provide access and openness to resources (Ministry of Education, 2016). Classrooms are represented as $\mathrm{CR}$ and schools as $\mathrm{SCH}$. 
Table 2: The Appraisal of the articles that met the inclusion criteria

This table consists of a sample of 4 out of the 150 articles to illustrate how the data were extracted from the studies that met the inclusion criteria. Each of the 150 studies was systematically analysed and then designated a symbol. In some cases, multiple symbols were given based upon the total number of independent variables identified in a study. The table below consist of numerous symbols that are placed into cells. The first is identified as $\mathbf{R}$, which represents that a relationship between the independent and dependent variables were found. The symbol $\mathbf{S}$ indicates that there was an association while the symbol $\mathbf{N S}$ signifies that there was no relationship found between the dependent and the independent variable. Where the cell of independent variable is indicated with a symbol, but no symbol is indicated in the dependent variable cell, this means that; there was an association of the independent variable as indicated by the symbol to school setting or other dependent variables not considered in this study. The full table is in Appendix One.

\begin{tabular}{|c|c|c|c|c|c|c|c|c|c|c|c|c|c|c|}
\hline \multicolumn{2}{|c|}{ DESCRIPTION } & \multicolumn{2}{|c|}{ DEPENDENT VARIABLES } & \multicolumn{6}{|c|}{ INDEPENDENT VARIABLES } & \multicolumn{5}{|l|}{ OTHERS } \\
\hline$S / N$ & STUDIES & $\begin{array}{l}\text { LEARNING } \\
\text { PERFORMANC } \\
\text { E }\end{array}$ & $\begin{array}{l}\text { HEALT } \\
\text { H }\end{array}$ & D & $\mathbf{T}$ & A & IAQ & SEC & ENV & Rank $\left({ }^{2}\right)$ & METHOD & Country & $\begin{array}{l}\text { School } \\
\text { Type }\end{array}$ & $\begin{array}{l}\text { No of } \\
\text { Students }\end{array}$ \\
\hline 1. & $\begin{array}{l}\text { (Nicklas \& Bailey, } \\
\text { 1997) }\end{array}$ & $*$ & & $S$ & & & & & & 4 & Measured & USA & TPS & $24 \mathrm{SCH}$ \\
\hline 2. & (Cheryan et al., 2014) & $*$ & & & & & & & $\mathrm{R}$ & 3 & Lit Rev & - & - & - \\
\hline 3. & $\begin{array}{l}\text { (Heschong, Group, } \\
\text { 1999) }\end{array}$ & * & & $S$ & & & & $S$ & & 5 & Measured & USA & TPS & $\begin{array}{l}21000 \\
\text { Students } \\
3 \mathrm{SCH} \\
2000 \mathrm{CR}\end{array}$ \\
\hline 4. & $\begin{array}{l}\text { (Wargocki \& Wyon, } \\
\text { 2007) }\end{array}$ & $*$ & & & $S$ & & & & & 4 & Measured & Denmark & TSS & $2 \mathrm{CR}$ \\
\hline
\end{tabular}

\footnotetext{
(2) Note: In the ranking column:

5 - Articles that showed a significant (S) association between the dependent and independent variable and considered socio-economics

4 - Articles that showed a significant (S) association between the dependent and independent variable and did not consider socio-economic

3 - Literature reviews and reports that showed a relationship of an independent variable

2 - Articles that suggested there is a relationship

1 - Articles that had a non-significant association
} 


\subsubsection{Summary}

From the 150 articles reviewed, 50 studies investigated through measurements (experiments), 30 investigated through surveys and 70 studies were literature reviews, reports, or policy documents (Figure 2). None of the studies conducted their investigation using simulation.

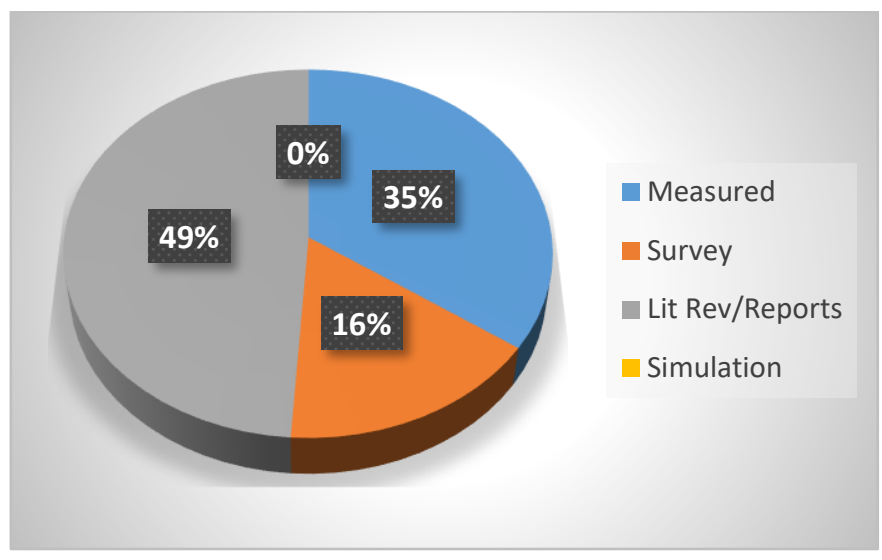

Figure 2: Methodology used in the reviewed studies

As shown in Figure 3, thirty-four studies were in a traditional primary school (TPS); ten studies were in a traditional secondary school (TSS); one study was investigated in a TPS and TSS, and only three of the studies were in a secondary school modern learning environment (MLE) refer to Section 4.2.1 for more information about MLE's.

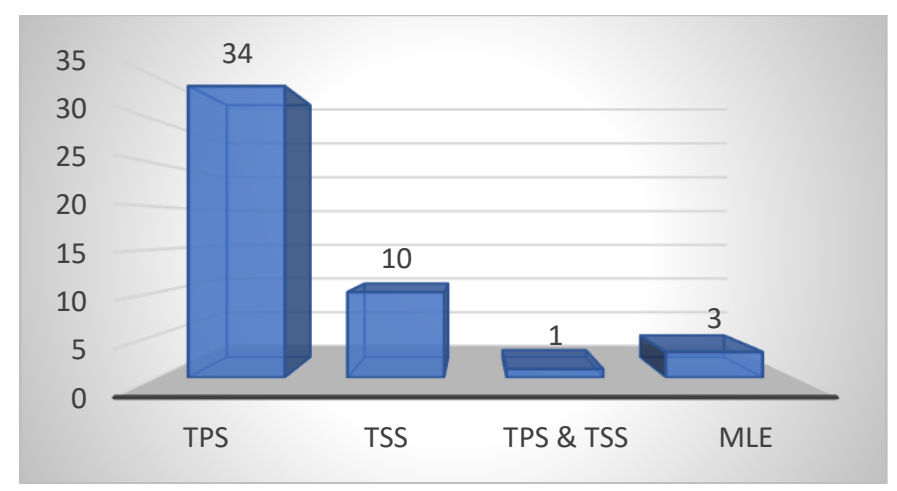

Figure 3: Number of studies investigated in the different school types

Nineteen of the 50 studies investigated through measurements showed a significant relationship between IEQ and learning performance as well as health, while 53 studies suggested that there is a relationship between these factors. Most of these studies also considered some elements of IEQ variables. Some of the studies were dissertations carried out in the fields of education while many of the studies were carried out by educational psychologists. 


\subsection{IEQ and Learning Performance in Schools}

This section discusses in detail the findings of the various studies that have shown an association between IEQ and students' learning performance. This is under the following headings: daylight and learning performance, thermal comfort and learning performance, acoustics and learning performance and indoor air quality and learning performance.

\subsubsection{Daylight and Learning Performance}

Within the specific focus on IEQ and students' learning performance, only three articles (Figure 4) showed a statistically significant association between daylighting (D) and improved learning performance. Nicklas \& Bailey, (1997) compared the test scores of students in daylit schools to those in non-daylit schools. The findings reveal that students in the daylit schools performed better than the students in the non-daylit schools by 5 to $14 \%$. Similarly, a study carried out by Heschong Mahone Group, (1999) established a statistical association between daylighting and student performance. The study compared the school records of 21,000 students from 3 school districts in 3 states in California with daylighting conditions in over 2,000 classrooms. They found that classrooms with the most daylight had a $26 \%$ higher learning performance rate in reading tests and $20 \%$ in mathematics tests in one year than those with the least. Their result also indicated that students with the largest windows progressed $23 \%$ better in reading test and $15 \%$ better in math test than those with the least. There was a $7 \%$ to $18 \%$ higher educational progress in classrooms where windows were openable than those with fixed windows, regardless of air conditioning. Also, they reported that the influence of daylight in schools could directly help the students by improving their mood or help to indirectly improve the teacher's mood. When teachers were interviewed, their perception that windows and daylight improved the learning mood of their students by keeping them calm and improving their attention spans agreed with the positive effects of daylight on students' learning performance.

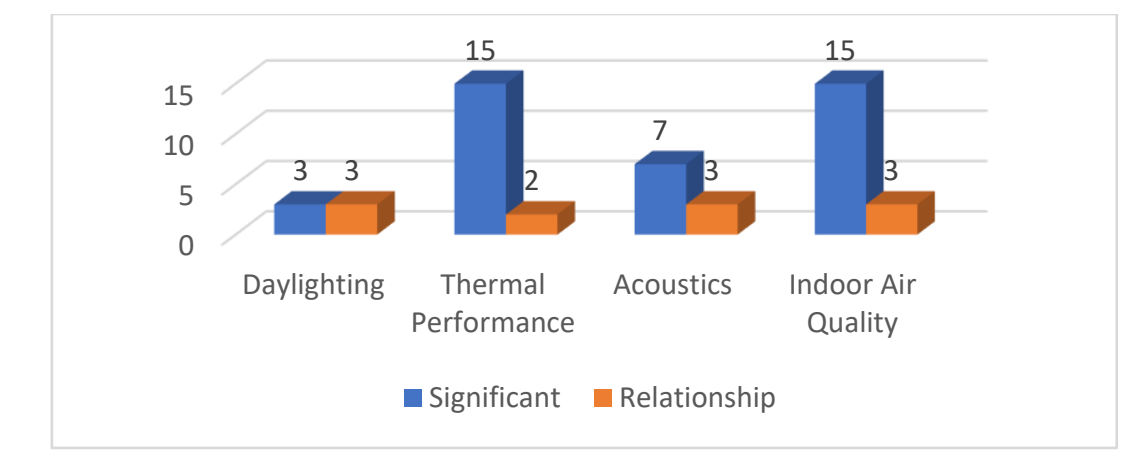

Figure 4: Number of studies showing the association between IEQ and learning performance 
Furthermore, in New Zealand, a study by Jackson, (2006) explored the possibility of generalizing the findings of the Heschong Mahone Group (1999) study by replicating their methodology in the New Zealand context. Their study found a correlation between daylight and improvement in students' test score and established that the HMG process could be replicable in another environment. Their study noted that an important aspect of measuring daylight quality is the degree to which direct sunlight penetration into classrooms may cause glare which can lead to negative student performance. Their study found some difficulty in establishing a sufficiently broad range of classrooms so that poor daylight scores would fit into the analysis. Daylighting in most schools was in the middle of the range with most classrooms having neither excessively good nor poor daylight.

Though there is a significant association between good quality daylight and positive student performance, there is a question about what causes the improvement in students' performance in classrooms with good quality daylight. Recent studies (Barkmann et al., 2012; Bellia et al., 2015; Heschong et al., 1999; Küller \& Lindsten, 1992; Mirrahimi et al., 2012) have suggested that the positive effect of daylight on students learning is because of its effects on melatonin suppression in the body. When classrooms are adequately daylit, melatonin production becomes suppressed leading to an increase in alertness and concentration that will enhance learning performance. This assertion is affirmed by Bellia et al., (2015) whose study suggested that in the presence of daylight during typical clear and overcast winter days in Italy melatonin was suppressed.

The common conclusion of these three daylight studies is that they support the argument that there is a well-founded and predictable influence of daylighting on students' learning performance. The study by the Heschong Mahone Group (1999) remains one of the most conclusive studies relating daylight and improvement in students' performance to date because they use a large pre-existing data set to show the effects of the physical environment on students' performance by showing the association between building design and social aspects of the school environment. Though the study by Jackson, (2006) agrees with this, they argue that "There can be no guarantees that daylight will always be successful in maximising human performance". However, their study findings could not be generalised to the entire 
New Zealand context because their data set was insufficient to meet the target 95\% confidence level which was required to make these generalizations.

\subsubsection{Thermal Comfort and Learning Performance}

Fifteen articles (Figure 4) showed a statistically significant association between thermal comfort $(T)$ and improved performance. Seven of these fifteen studies were carried out in office buildings while eight were carried out in school settings; of these eight, three were investigated through surveys while five were investigated through measurements. The evidence associating thermal comfort with improved learning performance is found in a study carried out by Wargocki \& Wyon, (2007). They stated that research carried out by Wyon, Andersen, \& Lundqvist, (1979) showed the magnitude of the negative effect of temperature on students' performance. Their research strategically exposed 10-year-old children to three different classroom temperatures of $20^{\circ} \mathrm{C}, 27^{\circ} \mathrm{C}$, and $30^{\circ} \mathrm{C}$ for two hours and another set of 11- to 12-year-old children were similarly exposed to a temperature of $20^{\circ} \mathrm{C}$ in two classes and $30^{\circ} \mathrm{C}$ in another two classes in the morning and the afternoon. To achieve the various temperature levels in these experiments, temperatures were artificially raised. The children performed maths arithmetic and reading tasks to assess their speed of work and the number of errors made. The performance of the children was significantly lower at a higher temperature of $27^{\circ} \mathrm{C}$ and $30^{\circ} \mathrm{C}$ as compared to those in the lower temperature of $20^{\circ} \mathrm{C}$. The reading speed of the children reduced and a lower rate of working in the numerical tasks was identified in the classes with higher temperatures. The negative effects of raising classroom temperatures were more significant in the afternoon than in the morning, which is thought to be due to fatigue.

Another study by Wargocki \& Wyon, (2007) carried out an intervention experiment to investigate the influence of high indoor temperatures on students' performance in Danish classrooms. 10-12-year old children were given reading and mathematics task to assess their speed and accuracy of task performance. The decrease in the classroom temperature from $25^{\circ} \mathrm{C}$ to $20^{\circ} \mathrm{C}$ had a positive effect on students' performance. For every $1^{\circ} \mathrm{C}$ temperature decrease, the children's average speed of task performance increased by about $2 \%$. This is within what people might term comfortable - hence, these differences might not even be noticeable. This finding argues for an infinitesimally small change when temperature decreases by $5^{\circ} \mathrm{C}$. 
Many Scholars have been investigating the temperature range related to better learning. They suggest that the optimal temperature range for learning reading and math appears to be between $22^{\circ} \mathrm{C}$ and $25^{\circ} \mathrm{C}$ (De Dear et al., 2015; Fabbri, 2013; Earthman, 2004; Katafygiotou \& Serghides, 2014b; Schneider, 2002). This assertion is in line with the findings of Allen \& Fischer, (1978) who investigated the influences of temperature on students' learning. Their study showed that, when the undergraduates learned a test of word associations in a $22^{\circ} \mathrm{C}$ classroom, they performed best, but performed worst when the temperatures became more extreme in either direction. Temperature levels that enhances learning performance is explained further in details in Section 2.2.2 below.

Overall, these studies agree that an increase in temperature above $25^{\circ} \mathrm{C}$ negatively affects students' learning and task performance while the study by Wargocki \& Wyon, (2007) suggested that cooler down to $20^{\circ} \mathrm{C}$ is better, but none of the researchers has looked at how far this trend can go before discomfort affects performance. Most of the studies on the impact of thermal comfort on students learning performance were intervention studies conducted in controlled spaces. New findings may be revealed if the effect of very low temperatures on learning performance is conducted; also, a comparison of students' learning performance in naturally ventilated classrooms during the summer when temperatures are high and during the winter when temperatures are lower without HVAC systems will be interesting to explore.

\subsubsection{Acoustics and Learning Performance}

Seven articles (Figure 4) showed a statistically significant association between acoustics (A) and learning performance. For example, Evans, \& Maxwell, (1997) compared reading test scores of students in two schools with matching demographic factors. While one of the schools was in a quiet neighbourhood the other was in a flight path of a major airport. The study found a significantly worse performance of students on the flight path school than those in the quiet neighbourhood school. In Sweden, pre-recorded noises of aircraft, road traffic, train, or verbal were compared with that of quiet conditions in an experimental demonstration consisting of 12 - to 14 -year-old students. The test of reading comprehension showed that students performed significantly worse when exposed to aircraft or road traffic noise than in quiet conditions. There was no interference of reading comprehension by noise from trains (Dockrell \& Shield, 2006; Hygge, 2003). These studies showed that intrusion of external noise affects learning in schools. They demonstrate the need for facilities and 
features surrounding the school environment to be taken into consideration in the design. Acoustic materials for the walls, roof, floor and windows should be selected to minimise external sources of noise entering the classrooms. Noise levels in schools and classroom are of great concern to teachers. A study by Lackney, (1999) found that teachers believe that noise impairs learning performance and noise causes more discomfort and decreases teacher's efficiency more than for students. In New Zealand, a survey that gathered the perception of teachers about noise showed that $71 \%$ of the teachers reported that classroom noise is a problem (Valentine, 1993). The likely sources of the internal noise in classrooms are from students' conversations, equipment's and the properties of the room itself. Poor acoustic properties have the potentials of affecting the quality of teaching, learning and ultimately performance. The studies (Dockrell \& Shield, 2006; Evans \& Maxwell, 1997; Hygge, 2003) have shown that high noise levels negatively affect learning. Teachers appear to be concerned with high noise levels because it affects teaching communication, leads to discomfort, and negatively affects learning performance. Poor acoustics could cause students to misunderstand the directives of their teachers; it could negatively influence the teacher, which can then adversely impact the students. Unfortunately, the number of studies showing acoustic problems in schools is limited, hence the need for more research to identify the possible common sources of noise within the school environment which can affect learning.

\subsubsection{Indoor Air Quality (IAQ) and Learning Performance}

On the association between indoor air quality (IAQ) and learning performance, fifteen articles showed a statistically significant association. For example, in Denmark, the second intervention experiment carried out by Wargocki \& Wyon, (2007) in two classrooms of 10-to 12-year-old children during the late summer period associated improved student performance with an increase in classroom ventilation rates. It was found that an increase in the outdoor air supply rate from 5.2 to $9.6 \mathrm{~L} / \mathrm{s}$ per person significantly improved their test performance. This suggests that air temperature, humidity and airflow are important components that determine indoor air quality in buildings. Air temperature is affected by relative humidity and indoor air, outdoor humidity and surface temperatures impacts on the accumulation of moisture within a building envelope. Walinder, Norback, Wieslander, Smedje, \& Erwall, (1997) compared a naturally ventilated primary school with a mechanically ventilated school in Sweden. They found a high level of indoor air pollutants (respirable dust, 
bacteria, mould and VOCs) which was due to inadequate outdoor air supply and were 2 - 8 times higher in the naturally ventilated school. This, they state, may cause swelling of the nasal mucosa in the upper airways. This shows a need for adequate flow in classrooms because inadequate air supply could lead to contamination of the air within the space which may lead to health issues that will adversely affect learning performance. In England, an intervention experiment was conducted by Bakó-Biró, Clements-Croome, Kochhar, Awbi, \& Williams, (2012) to investigate the effects of classroom ventilation on pupils performance and learning. The concentrations of carbon dioxide and other parameters were monitored in two selected classrooms for three weeks. The results show that compared with the low ventilation conditions, the higher ventilation rates had a significant, rapid and more precise responses for Word Recognition (15\%), Colour Word Vigilance (2.7\%), Choice Reaction (2.2\%), and Picture Memory (8\%). This study agrees with the assertion that increased ventilation rates could improve learning performance.

In as much as air movement, relative humidity and air temperature determine the condition of indoor air, good air quality can be examined by the number of contaminants which could lead to health problems. Contaminants are mostly categorised as, inorganic compounds (carbon monoxide, sulphur dioxide, oxides of nitrogen, carbon dioxide, sand, etc.,), organic compounds (urea formaldehyde foam insulation, etc.)), particulate matter (sprays, mist and dust, etc.,), and biological contaminants (house dust mites, pollens, animal and insect excreta, microbes such as fungal spores, viruses, bacteria and algae, etc.,) (Mclntosh, 2011). Particulate matter can cause respiratory difficulties, coughing, sneezing, dry eyes, throat, nose and skin irritation, and contact lens problems. Table 3 presents the impacts of contaminants reported by different authors.

Table 3: Studies stating the impacts of contaminants

\section{$\mathbf{S} / \mathbf{N}$ studies Impacts of Contaminants}

1. Carrer, Franchi, The authors state that there is often a high concentration of Valovirta, \& Sanco, particulate matter in classrooms than in offices because children (1990) have higher indoor physical activities and they easily carry the particles on their shoes.

2. Armstrong \& Liaw, Biological contaminants can actively grow in classrooms with (2003). poor indoor air quality 
3. Fung \& Clark, (2004); Where there is high humidity, water or dampness, fungi are most Miller, (2004); Reed, likely to grow

Lyons, Thompson \& Bean, (2010)

4. Su, (2017)

5. Mclntosh, (2011)

When contaminants become airborne, it causes infections, respiratory diseases, and allergy and asthma attacks.

The study stated that $83 \%$ of classrooms in their study had bacterial counts like those found in water treatment plants or higher. Where there is high humidity, bacteria, fungi and colonies of dust mites will grow rapidly.

High $\mathrm{CO}_{2}$ levels which exceed 1000 ppm are associated with lack of fresh air in a building (Daisey et al., 2003; Kruisselbrink et al., 2016). This is in the context that the natural levels in the atmosphere are 400ppm. In Greece, Dorizas et al., (2015) carried out an experimental campaign in nine primary schools to assess the pollutant levels and students' perception during a mode at which the heating and cooling systems of the building do not operate. They found that a $17 \%$ increase in the indoor $\mathrm{CO}_{2}$ concentrations leads to a reduction in students' performance by $16 \%$ and a positive correlation trend between their marks and the ventilation rates. In Norway, Myhrvold, Olsen, \& Lauridsen, (1996) conducted a statistical study which assessed indoor air quality in twenty-two classrooms in different European schools on about 550 students. They mean $\mathrm{CO}_{2}$ values during the daytime were grouped into 3 groups with the percentages of pupils in each group in parenthesis: 0-999 ppm (48.9\%), 1000-1499 ppm (24.9\%) and $1500-4000 \mathrm{ppm}(26.4 \%)$. They found that compared to classes with lower $\mathrm{CO}_{2}$ levels, there was a decrease in students' performance on concentration test and increased cases of health issues in classrooms with high $\mathrm{CO}_{2}$ levels. The reported studies on IAQ association with learning performance have shown that high $\mathrm{CO}_{2}$ levels have a significant effect on students' performance in schools, but the detailed nature of its influence is not straightforward because the nature of task carried out, the duration of exposure, the sociocultural background of the students, means of adaption available, could all have different levels of contribution in determining the overall effect on performance. Furthermore, these results establish that issues of IAQ in classrooms appear as the major IEQ variable that leads to health problems. This informed the need to appraise the influence of IEQ on health reported in the next section. 


\subsection{IEQ and Health and Wellbeing in Schools}

This section appraises and discusses in detail the findings of the various studies that have shown an association between IEQ and health in schools. This is presented under the same environmental variables as earlier (Daylight, thermal environment, acoustics, and indoor air quality).

\subsubsection{Daylight and Health}

On the association between IEQ and health in schools, four articles (Figure 5) showed a statistically significant association between daylighting and health, but only two of the four articles showed this association specifically in a school setting. The first was the study carried by Hathaway, WE., Hargreaves, J., Thompson, G., Novitsky, (1992) who looked into the effects of various lighting systems on elementary school students' dental health. Their findings revealed that over a 2-year period and compared to students who did not receive ultraviolet light supplements, students who received the supplements had developed fewer dental caries, significant gains in weight and height and better academic performance and attendance. This suggests that daylight is a very vital element for the prevention of teeth cavities and dental decay in children. The second study was carried out by Küller \& Lindsten, (1992) to assess the effects of light on sick leave and the production of stress hormones. They identified that the basic hormone pattern may be distorted by working in classrooms with poor daylight. This they said could likely influence a child's ability to concentrate, and their annual body growth and sick leave. However, a review by McColl \& Veitch, (2001) stated that "the evidence from these studies does not show dramatic effects of ultraviolet light on students because many of these claims are based on poor quality experiments and effects that are observed tend to be small, and often cannot be firmly attributed to light sources". For example, these studies were not well-controlled investigations because the presence of daylight in some or all the case study rooms used for the investigations of ultraviolet light is potentially a confounding factor and was inconsistently reported. Hence, McColl \& Veitch, (2001) concluded that "it is impossible to characterize precisely to which stimulus conditions subjects responded if they were in rooms with windows".

Daylighting is widely believed to promote health because it is known to increase the production of Vitamin D as its deficiency is caused by lack of adequate exposure to daylight (Edwards \& Torcellini, 2002; Nathaniel, 2008). Exposure to high illumination levels is said to 
be key to help in the regulation of the body's circadian rhythms and it has been associated and recognized as a treatment for seasonal affective disorder (Zeitzer et al., 2000). Poor lighting (daylight or artificial) makes reading visually stressful for students and could cause eye strain. There is a relationship between daylighting with boosting morale, improved mood, decrease eye strain and reduce fatigue (Claude, 1986; Edwards \& Torcellini, 2002).

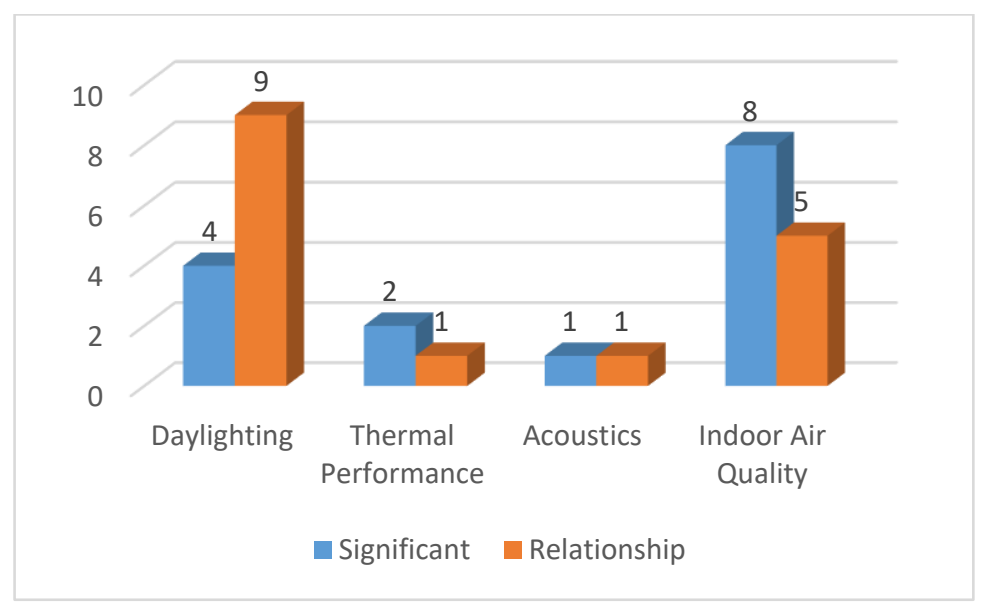

Figure 5: Number of studies showing the association between IEQ and Health

The reviewed studies show the positive effect of daylighting in schools. Adequate daylight is good for school children because it helps them to sleep at night and a bit wakes them up earlier in the day. When people receive enough daylight within the day, their nocturnal melatonin production occurs sooner, and they can enter into sleep more easily at night (Nathaniel, 2008). Light suppresses the brain hormone production of melatonin and increases alertness. Secreted primarily at night, melatonin influences the body's immunological functions, by triggering a host of biochemical activities, such as the production of estrogen (Heschong Mahone Group, 1999; Zeitzer et al., 2000).

\subsubsection{Myopia and Daylight in Schools}

Scientific evidence suggests that children spending much time outdoors are crucial in reducing myopia progression and healthy development of their eye (Cohn, 1886; Kathryn, lan, Wayne, George, Paul, \& Seang-Mei, 2008; Morgan, Xiang, Rose, Chen \& He, 2012; Wu, Tsai, Wu, Yang \& Kuo, 2013). This assertion is still being debated and explored. These researchers strongly suggest that the amount of light a child get as they grow determines whether they will develop myopia. Currently, there is no evidence that daylight in classrooms prevents myopia (Hobday, 2015), but there are limited studies that have shown that daylight in classrooms reduces the progression of myopia in children. In Taiwan, Wu, Tsai, Wu, Yang, \& Kuo, (2013) 
conducted an intervention study on 571 students to examine the relationship between schools, age, gender, baseline refraction, and myopia prevalence. While some schools had children going outdoors for a break, the other schools were a controlled group. After a year, new cases of myopia were significantly lower in the group of schools where the children were let to go outdoors during breaks than in the control group ( $8.41 \%$ vs. $17.65 \%$ P_0.001). They conclude that; "clinical trials support outdoor time as an effective intervention in reducing the progression of myopia". Similarly, in China, Morgan, Xiang, Rose, Chen, He, (2012) conducted a study in Guangzhou and found that there was an association with a reduction in myopia onset by the participation of students in an additional outdoor class after school each day. In Sydney and Singapore respectively, a study was conducted to compare the myopic prevalence and risk factors in 6 and 7-year-old children of Chinese ethnicity. A total of 124 primary school children participated in the study in Sydney while 628 participated from Singapore. The researchers found that the prevalence of myopia was significantly lower in Sydney (3.3\%) than in Singapore (29.1\%) (Kathryn et al., 2008). They concluded that the lower prevalence of myopia in the children in Sydney was associated with increased hours of outdoor activities and that; "though they do not know exactly what activity protects from myopia, they do know from their findings that the total time spent outdoors was protective" (Kathryn et al., 2008; Lam et al., 2008). Though these studies cite time spent outdoors to be crucial in reducing myopia, it is not clear whether the progression of myopia in children who already have the condition could be regulated by the time outdoors. These studies did not also show what could be the precise biological mechanism through which outdoor activity impacts on the progression of myopia in children. The strongest assertion of these studies is that daylight is a key environmental variable that helps in reducing the progression of myopia because it stimulates the release of the retinal transmitter dopamine (An organic chemical that plays an important role in the brain and body), which is known to inhibit axial growth of the eye. Children who are exposed to lower levels of light appear to be at a greater risk of myopia progression. However, these studies do not state the amount of light needed, its intensity, the range of illuminance values, and spectral composition that affect refractive development. Myopia appears to be caused by several other factors which there may be other potential contributors to its onset and progression, but this review show that there is some evidence that argues that daylight plays an important role in reducing the progression of myopia in children in schools. This further supports the argument that daylight is an important 
indoor environmental quality variable that could enhance student's health and wellbeing in schools thereby enhancing learning performance.

\subsubsection{Temperature and Health}

Only two articles (Figure 5) showed a statistically significant association between thermal comfort and health. Of the two, only one of the articles showed this association in a school setting. This was the study by Puteh, Adnan, Ibrahim, Noh, \& Che'Ahmad, (2014) who conducted a survey to identify and investigate students' perceptions towards classroom thermal comfort and the schools' surroundings in Malaysia. The study findings reveal that due to contaminated air (poor indoor air quality) caused by heat, watery eyes, redness and blurring of the eyes were the most frequent health problems identified by the students.

\subsubsection{Acoustics and Health}

Only one article showed a statistically significant association between acoustics and health. In Egypt, teachers were assessed for vocal levels and effects of experienced noise in classrooms and throat symptoms as well as their effects on working and social activities. It was found that $48 \%$ reported moderate or severe dysphonia (difficulty in speaking caused by a virus) within the last 6 months. Frequent feelings of being in noise were reported by all the teachers and $82 \%$ of them felt it mostly during the working day which made them raise their voice (Abo-Hasseba et al., 2016).

\subsubsection{Indoor Air Quality (IAQ) and Health}

Eight articles (Figure 5) showed a statistically significant association between IAQ and health. Studies have associated the prevalence of allergic and respiratory diseases among school children with poor indoor air quality in classrooms (Dorizas et al., 2015; Ferreira \& Cardoso, 2014; Salthammer et al., 2016). In Portugal, Ferreira \& Cardoso, (2014) found that $\mathrm{CO}_{2}$ concentration which went as high as $1,942 \mathrm{ppm}$ were above the maximum reference value, especially during the fall and winter seasons. Wheezing, sneezing, rales, rhinitis, asthma, irritation of mucous membranes, cough, headache, and poor concentration were the associated health symptoms identified. Another study carried out by Cartieaux et al., (2011) observed that respiratory symptoms as well as respiratory diseases such as asthma and allergies caused by several pollutants in the classroom, were predominantly prevalent. Smedje \& Norbäck, (2001) found a positive association between mould and airborne bacteria 
and asthma in school children. From these studies, it is possible to infer that there is a relationship between the concentrations of pollutants and the onset of health problems in school children. To have a clearer representation of the predominant symptoms caused by IEQ in schools, Dorizas et al., (2015) carried out an experimental investigation in nine primary schools in Greece, for 32 days. They predominantly observed health symptoms affecting the students in the schools were fatigue, allergies, and nose irritation, this significantly correlated to the levels of indoor particulate matter and $\mathrm{CO}_{2}$ concentrations. Girls appeared to be more sensitive to health effects than boys. However, correlation is not causation, they may have observed good correlation because $\mathrm{CO}_{2}$ is an indicator of poor fresh air, associated with particulates, or some other pollutant. $\mathrm{CO}_{2}$ is often measured because it is a good surrogate of other indoor air pollutants.

There are reported associations between ventilation and health in schools. When ventilation rate is low, it can increase exposure to indoor air pollutants which is presumed to be the key reason for adverse influence on occupants' health (Fisk et al., 2013; Satish et al., 2012; Sundell et al., 2011). Sundell et al., (2011) study on ventilation and health found that low ventilation rates are associated with more respiratory symptoms in schools: respiratory infections, inflammation, short-term sick leave and asthma symptoms could increase with lower ventilation rates. Mendell et al., (2013) investigated the association of classroom ventilation with reduced illness absence in 162 3rd-5th-grade classrooms in twenty-eight California elementary schools in three school districts. They found a statistically significant $1.6 \%$ reduction in illness absence per additional litre per second per person (I/s per person) of ventilation provided. This they stated is a smaller change in illness absence per unit of ventilation rate and that the evidence associating inadequate classroom ventilation rates with increased illness absence are limited. They suggest that absence due to illness may further considerably decrease when ventilation rates are increased above $10 \mathrm{l} / \mathrm{s}$-person even up to $15 \mathrm{l} / \mathrm{s}$-person or higher. Ventilation experiments that have measured ventilation rates are those where the ventilation can be controlled for some time and this is far easier with mechanical systems. Though findings reveal that classrooms $\mathrm{CO}_{2}$ levels can be significantly reduced by installing a $\mathrm{CO}_{2}$ controlled mechanical ventilation system, it can be challenging to conduct controlled experiments. The operation of both systems requires access to cheap and reliable sensors to monitor how much fresh air is available in the space. 
IEQ assessed by Turunen et al., (2014) with measurements of ventilation rate and thermal conditions of classrooms in fifty-six Finnish schools. Fatigue (7.7\%), stuffy nose (7.3\%), and headache $(5.5 \%)$ were the most common weekly symptoms in the spring semester. Noise (11\%), stuffy air/poor indoor air quality (IAQ) (7.0\%), self-reported high indoor temperature and dust were the most frequently reported IEQ factors causing daily inconvenience in classrooms. This may indicate a low ventilation rate or low indoor temperature in the classrooms. In New Zealand, low indoor temperatures at home are associated with asthmatic conditions that resulted in students' absenteeism in school (Free, Howden-Chapman, Pierse, \& Viggers, 2010; Boulic, 2012). The correlation between poor indoor air quality and absenteeism in schools is supported by another study in the US. Leigh, (2012) reports that the American Lung Association found that poor indoor air quality leads to asthma and caused American children to miss more than 14.4 million school days in 2008 due to absenteeism. Most IEQ studies suggest that absenteeism is caused by poor indoor air which affects students' health. A study by Rosén \& Richardson, (1999) showed that by improving indoor air quality reduced absenteeism in two schools for 3 years.

\subsubsection{IEQ and Energy use in Schools}

To achieve energy efficiency and adequate indoor environment in school buildings and to improve their sustainability, daylight remains a fundamental resource (Pellegrino et al., 2015). In a sustainability assessment of government school buildings in Portugal, it was reported that to improve energy performance without incurring operational and additional construction costs, daylight and solar gains are primary passive strategies to explore. The results showed that though indoor daylight level within the building was insufficient during the winter season, solar gains were useful in reducing the heating load during this period (Carlos, 2016). Developing ratings for energy efficiency in schools is important to identify best practices related to energy efficiency (Gaitani et al., 2010). In Cyprus, Katafygiotou \& Serghides, (2014a) investigated energy efficiency in nine schools and showed that there is a relationship between poor indoor conditions and low-energy efficiency of buildings. They suggest that this may occur because of inefficient insulation of the buildings and the mismanagement of air conditioning systems, heating, and ventilation components of the buildings.

In Greece, Gaitani et al., (2010) evaluated data on energy consumptions from 1,100 schools from all the districts of Greece. The study found that low energy consumption was observed, 
and significant positive correlations were found between indoor air pollutants and energy consumption for both electricity and oil. This assertion is confirmed by earlier research carried out in Greece by Theodosiou \& Ordoumpozanis, (2008) who investigated the energy efficiency and air quality of public nursery and elementary school buildings in the city of Kozani, located in the cold climatic zone of Greece. The average thermal energy consumption of school buildings in Greece is estimated to be close to $31 \mathrm{kWh} / \mathrm{m}^{2}$ for the entire Greek region and $46 \mathrm{kWh} / \mathrm{m}^{2}$ for the coldest climatic zone in Greece where the buildings were located. Compared with the reported average thermal consumption of Greek school buildings, the examined buildings were found to consume less electricity $\left(7.5-9.3 \mathrm{kWh} / \mathrm{m}^{2}\right)$ for nursery and elementary schools respectively. This is suggested to be mainly due to the absence of airconditioners in the examined building stock and the lower urban build density that limits overshadowing by adjacent buildings and permits better natural lighting opportunities. They concluded that the reason for the high number of reported problems is due to the lack of interest concerning energy efficiency and air quality problems in school buildings since no action has been taken over the years. Perez \& Capeluto, (2009) suggest that daylit classrooms would use less artificial lighting almost all year round. This could present great potentials for a reduction in heat loads, cooling and energy reduction and energy-conscious design of school buildings can contribute to significant energy savings. They observe in their sensitivity analysis simulation of energy performance that size of the window, infiltration, ventilation, and daylighting are variables with great influence in reducing energy consumption. Considering the limited scientific research on the relationship between well daylit classrooms and energy efficiency, there appears to be a gap in this area making it worth further research. 


\subsection{Summary of IEQ and Learning Performance and Health in Schools}

Generally, the studies have shown that daylight, temperature, acoustics and IAQ do not only define the quality of the indoor environment but have a significant influence on student's health and learning performance in schools. The studies inferred that poor IEQ conditions could lead to health issues, which will increase student's absenteeism from school and adversely impact on learning performance. Therefore, providing an optimum learning environment could support effective teaching and learning, which could lead to improvements in learning performance. Though the studies have shown the influence of IEQ on students learning performance and health, none of the articles has shown a statistically significant relationship combining these four independent variables as well as socio-economic considerations on student's health and performance. This presents an interesting topic for further research.

In the reviewed studies, the measure of IEQ conditions was mostly subjective. The few studies that carried out objective physical measurements reported that due to the difficulty in interpreting a large set of environmental data, the monitored data was not included in their study results. This gives concerns about the best way for monitoring multiple IEQ variables at scale for many classrooms to categorise the good and poor classrooms for comparison of the combined impact of the four IEQ variables on student's health and performance. Hence, it is possible to infer that understanding IEQ measurement and analysis protocol is a fundamental question that requires addressing. This will provide reliable evidence based IEQ data for use in evaluating the combined influence of IEQ on students learning performance in schools and the relationship between IEQ and building design to inform interventions for the maintenance and management of school buildings. 


\subsection{Determination of IEQ and Learning Performance Target Range}

Based on the literature above, this section presents insights on the target range of acceptable IEQ levels that support improvement in learning performance to determine a performance rating framework (IEQ rating model).

\subsubsection{Determination of Lighting and Learning Performance Target Range}

In Table 4 below, empirical studies that have measured indoor illumination levels in classrooms and compared with student performance indicators such as cognitive ability, concentration and satisfaction are appraised to determine the lighting performance target range which informs the design of the IEQ rating model in Chapter Nine. The findings reveal that performance levels have been used to determine optimal lighting conditions with considerations of specific factors such as spectral distribution on visual comfort, glare and contrast, etc. For example, Lifberg, Lifstedt, Nilsson, \& Wyon, (1975) investigated the combined temperature and lighting effects on the performance of repetitive tasks with different visual content in a school. Illuminance levels were varied between 60, 250 and 1000 lux while temperature varied between 22 and $27^{\circ} \mathrm{C}$. They found an interaction between illuminance level, temperature, and time-of-day. The performance was improved in high illuminance (1000 lux) and the warmer condition in the afternoon. The addition test improved with increased illuminance at the lower temperature in the morning. As reported in Balazova et al., (2007), a study by Bánhidi, Száday, \& Antalovics, (1998) compared the influence of two combinations of lighting levels (280 and 920 lux) on performance and physiological measures. They found that at lower lighting levels, the number of characters written decreased and was best at 920 lux.

Hathaway et al., (1992) investigated the effects of various lighting systems on elementary school students' academic achievement, growth and development, attendance, dental health, and vision academic achievement. Measured average illuminance levels of several participating classrooms in the five schools ranged from 250-540 lux, 300-900 lux, 220-450 lux and 280-450 lux. The complete Canadian test of basic skills including vocabulary, reading, language, work-study, and mathematics was administered to the subjects. The results indicated that in the different lighting environments, the light had influenced students' rates of achievement. This may be because the illuminance levels were within a moderate perceived acceptable level. Hygge \& Knez, (2001) examined the effect of ventilation noise (38 
and $58 \mathrm{dBA}$ ) heat $\left(21^{\circ} \mathrm{C}\right.$ and $27^{\circ} \mathrm{C}$ ) and light (300 and 1500 lux) on cognitive performance. Their findings showed that at 1500 lux, there was a better long-term recall than at 300 lux and the lower noise levels than the higher levels. At 1500 lux, and in the low noise condition, there was a better free recall in $21^{\circ} \mathrm{C}$ than in the higher temperature level. This study is another indicator of over 1000 lux is desirable, cooler temperatures are desirable and suggest that provided there are no instances of glare, a wider range of illuminance threshold could support learning performance and lower noise and temperature levels (optimum levels) increases performance. In ninety classrooms across eleven schools in the United Kingdom, Winterbottom \& Wilkins, (2009) examined aspects of classroom lighting that can promote discomfort and impair task performance through glare. The mean measured illuminance at pupils' desks ranged from excessive (>2500 lux) to inadequate (38 lux) levels. Mean illuminance at pupils' desks with a combination of daylight and artificial lighting (blinds open, lights on) was 1168 lux, with blinds open and lights off, mean illuminance was lower (807 lux). The results showed that in $88 \%$ of classrooms illuminance ranges were more than $300-500$ CIBSE recommended design illuminance standard for schools, mean illuminance was more than $25 \%$ above 500 lux and in $84 \%$ of classrooms, illuminance was more than 1000 lux. The authors argue that "there is some evidence for increased discomfort at illuminance above 1000 lux and separate evidence above 2500 lux in uniformly lit rooms". They concluded that excessive illuminance levels (>2500 lux) inhibit pupils' task performance, impair visual performance, and causes a headache, which reduces motivation and increases 'off-task' behaviours.

Furthermore, Barkmann, Wessolowski, \& Schulte-Markwort, (2012) investigated the effect of lighting that is variable in illuminance and colour temperature on student performance and attitude measures. The experiments were carried out over nine months in two classrooms each (one classroom served as an intervention group, while the other served as a control group) in two separate schools. The effects of seven variable lighting program (Standard $300 \mathrm{~lx}$, focus on board - bright (1000 Ix), low (300 Ix), the board only - lights switched off, concentrate - very bright, cold light (1060 lx), activate - slightly brighter and colder compared with standard lighting (675 Ix), relax - which is slightly warmer compared with standard lighting (325 lx), and extreme relax - which is a more extreme variant of the program used when no reading or writing is being performed $(275 \mathrm{~lx})$ ), were assessed using standardized 
test modules. The results indicated that "students made fewer errors, particularly fewer errors of omission, on a standardized test of attention under the "Concentrate" lighting program" compared to students using the standard program. Similarly, reading comprehension and reading speed results improved under the "Concentrate" program. The authors stated that these effects may likely be due to neuronal and hormonal effects of lighting on vision. Using standardized surveys of students and teachers, Figure 6 shows the frequency of use of the various lighting programs. The Pie chart indicates when students were given control themselves - the activate $-675 \mathrm{Ix}(26.7 \%)$, concentrate $-1060 \mathrm{Ix}(23.5 \%)$, and relax $3251 \times(21.3 \%)$ programs were the frequently used illuminance levels. This suggested that illuminance levels within these ranges were acceptable by teachers and students.

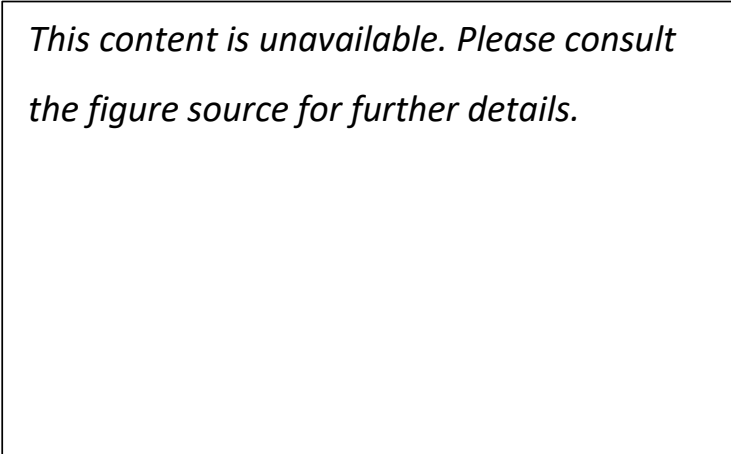

Figure 6: Frequency of use of light programs during classes. Source: Barkmann et al., (2012)

The impact of classroom illuminance on students' concentration performance through measuring both coordination of speed and accuracy of performance was carried out by Singh \& Arora, (2014). As shown in Figure 7 below, the average measured illuminance in two classrooms in the green-rated school was 570 and $760 \mathrm{~lx}$ while that of the non-green rated school was 195 and 269 Ix respectively. They found that classroom lighting had a significant relationship with students' concentration performance ( $p$-value- 0.013$)$ and that students in the green-rated school had higher lighting satisfaction (daylight - 91.7\% and artificial light 83.3\%) than those in the non-green rated school. However, the study did not provide information on how they choose the classrooms in each school, the measurement duration (time of the day), how daylight was accounted for, and whether the electric lights were on in both schools. It is possible that the higher lighting satisfaction reported in the green rated school may have been due to extra daylight at the school. Even within the same school, there could be a great variation in lighting levels per classroom depending on the external 
environment. Hence, the lighting levels (daylight and artificial light) at both schools is potentially a confounding factor and was not taken into consideration.

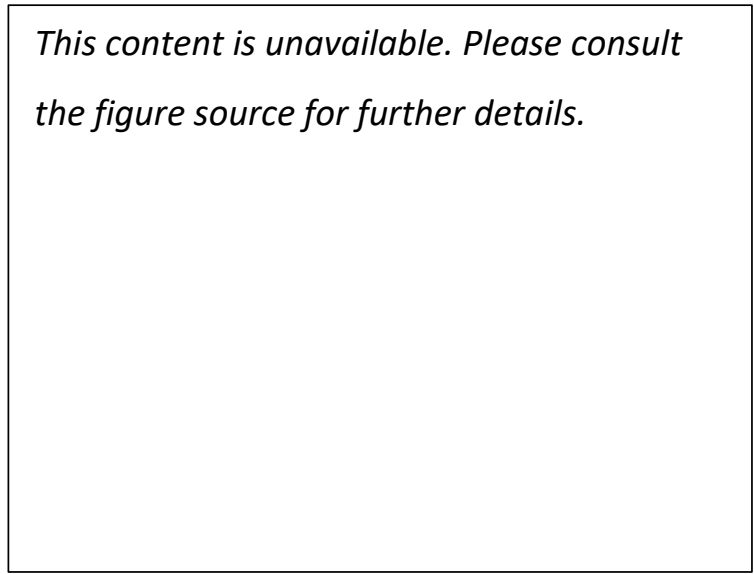

Figure 7: Illumination levels in the measured school classrooms. Source: Singh \& Arora, (2014)

The reviewed studies on illuminance thresholds that enhances performance in schools have shown that there is evidence that the onset of scarce $(<300 \mathrm{Ix})$ or excessive $(>2500 \mathrm{Ix})$ illuminance decreases performance due to visual discomfort which could cause headache, reduce motivation and increase 'off-task' behaviours. From the evidence of actual tests, the data showed that at least \pm 1000 lux is the optimum light levels that enhance performance in schools. Therefore, it is important to consider intermediate appropriate illuminance thresholds that take into consideration the quality (not scarce) and quantity (not excessive restrict glare to reasonable levels) of lighting within a space. 
Table 4: Summary of Lighting Levels and Learning Performance Target Range

S/N AUTHORS

(Lifberg et al., 1975)

1.

3. (Bánhidi et al., 1998)

(Winterbottom \& Wilkins, 2009)

\section{LIGHTING STUDIES SCALE}

Illuminance levels were varied between 60, 250 and 1000 lux.

The Performance was improved in high illuminance and the addition test improved with increased illuminance.

Measured average illuminance levels ranged from 250-540 lux, 300-900 lux, 220-450 lux and 280-450 lux.

Light influenced students' rates of achievement.

Compared two combinations of lighting levels (280 and 920 lux)

They found that at the lower lighting level, the number of characters written decreased.

Illuminance levels (300 and 1500 lux).

At 1500 lux, there was a better long-term recall than in 300 lux.

The mean measured illuminance at pupils desks ranged from excessive (>2500 lux) to inadequate (38 lux) levels. Other levels were: 1168 lux and 807 lux.

Excessive illuminance levels above $>2500$ lux inhibit pupils' task performance and impair visual performance.
Good: An acceptable illuminance range: $300-$ $20001 x$

Poor: range $<300$ and $>2500$

(Chapter nine (Table 62) presents the application of this scale in the IEQ rating model)
The rationale for this scale is that:

- the empirical studies on the effects of lighting on learning performance agree that at least \pm 1000 lux is the optimum light levels that enhances performance in schools;

- that when illuminance is scarce $(<300)$ or excessive (>2500), performance decreases due to visual discomfort which could cause headache, reduce motivation and increase 'offtask' behaviours;

- the best illuminance range considers the quality (not scarce) and quantity (not excessive - restrict glare to reasonable levels) of lighting within a space;

- given the variability of lighting in classrooms, the best scale considers intermediate thresholds (within low and high illuminance) when appropriate illuminance can be attained;

- considers the availability of enough lighting on the working plane aimed at enabling teachers and students to easily carry out visual tasks; and

- the poor scale is determined by thresholds that activate the onset of scarce or excessive illuminance. 
6. (Barkmann et al., 2012)

7. (Singh \& Arora, 2014)
Considered seven variable lighting programs:

- $\quad$ Standard - (300 lx)

- Focus on board - bright (1000 Ix) Low (300 Ix)

- Board only - lights switched off

- Concentrate - very bright, cold light (1060lx)

- Activate - slightly brighter and colder compared with standard lighting (675 Ix)

- Relax - which is slightly warmer compared with standard lighting (325 Ix)

- Extreme relax - which is a more extreme variant of the program used when no reading or writing is being performed (275 (x))

Students made fewer errors, particularly fewer errors of omission, on a standardized test of attention under the "Concentrate" lighting program" compared to students using standard program.

Measured illuminance was:

Green rated classrooms: 570.38 and 760.63 Ix Non-green rated classrooms: 195.84 and 269.16 Ix.

Classroom lighting had significant relation with students' concentration performance ( $p$ value0.013). 


\subsubsection{Determination of Temperature and Learning Performance Target Range}

In Table 5, empirical studies that report the perceived temperature levels that correlate with improvement in learning performance were appraised to determine the best and poor temperature range for the IEQ rating model. The Table reveals that many researchers have been studying the temperature range associated with improvement in students' learning performance. For example, in 70 elementary schools, (Haverinen-Shaughnessy \& Shaughnessy, 2015) measured temperatures for seven days and the mean internal temperature was $23^{\circ} \mathrm{C}$ and varied between $20^{\circ} \mathrm{C}$ and $25^{\circ} \mathrm{C}$. The temperature data was compared against the state-wide learning achievement data. The findings indicated that for each 1 decrease in temperature (0.5\%/degree), there was a $12-13 \%$ increase in mathematics score. Similarly, and from New York City high schools, a report by Park et al., (2016) appraised the school-leaving examination results of more than 4.5 million pupils and found that in comparison to the results obtained when the examination was taken on a day when the ambient temperature was $22^{\circ} \mathrm{C}$, there was an increased risk of failing to pass by $12.3 \%$ in examinations that were taken in days when the ambient temperature was $32^{\circ} \mathrm{C}$. The report stated that an increased number of hot days above $27^{\circ} \mathrm{C}$ prior to taking the school-leaving examination, negatively influenced the examination results and impacted on learning and that an increase in temperature of $1^{\circ} \mathrm{C}$ will reduce the examination score by $0.4 \%$.

Perez, Montano, \& Perez, (2005) organized two phases of experiments where students performed the task (identification, recreation, and naming basic shapes and colours, and solving basic math equations) under variable stages of temperature control in the six classes. In phase one, a temperature of $21^{\circ} \mathrm{C}$ yielded an $86.7 \%$ test score, temperature of $22^{\circ} \mathrm{C}$ yielded an $86.9 \%$ test score, and the temperature of $23^{\circ} \mathrm{C}$ yielded an $82.7 \%$ test score. Due to the lack of control in classroom temperatures, the results of phase one were inconclusive. However, phase two of the study included significant temperature changes which showed more significance in the results compared to phase one. The classroom was categorized into cold, control and hot temperatures respectively. A cold temperature of $16^{\circ} \mathrm{C}$ yielded a $76 \%$ test score, a temperature of $22^{\circ} \mathrm{C}$ yielded a $90 \%$ test score and a temperature of $27^{\circ} \mathrm{C}$ yielded a $72 \%$ test score. The results indicated that at lower and higher temperatures there was a decrease in the performance tasks of identification and re-creation of shapes and colours, and basic math equations. However, at a moderate temperature of $22^{\circ} \mathrm{C}$, there was a $\pm 15 \%$ 
increase in performance. This suggests that moderate temperature ranges enhance learning performance. However, the authors stated that "the data was not strong enough to conclude exactly the amount of effect that temperature variation has on attention span".

A study by Schoer \& Shaffran, (1973) assigned 10-12 year old pupils in matched pairs to either a classroom without cooling, with a temperature of $26^{\circ} \mathrm{C}$ and an adjacent classroom with airconditioning, with a temperature of $22.5^{\circ} \mathrm{C}$. The different groups worked every school day for 6-8 weeks in the same classroom. The authors found that on an average of $5.7 \%$, the performance of the pupils at $22.5^{\circ} \mathrm{C}$ was better. Harner, (1974) carried out a study on the effects of thermal environment on learning skills and found that the best temperature range for learning mathematics and reading and math is $20-23^{\circ} \mathrm{C}$ and that temperatures above this range decrease the ability to learn these subjects. As shown in Figure 8, an experiment by Wargocki \& Wyon, (2007) found that when the temperature was reduced from $25^{\circ} \mathrm{C}$ to $20^{\circ} \mathrm{C}$, the learning performance of students improved.

This content is unavailable. Please consult the figure source for further details.

Figure 8: Performance of school work as a function of classroom temperature, Source: Wargocki \& Wyon, (2017)

As reported in Wargocki \& Wyon, (2017), an earlier study by Wyon, (1970), exposed 9-10year-old children in three parallel classes to temperatures: 20,27 and $30^{\circ} \mathrm{C}$ for two hours. Concurrently, and in another four classes, 11-12-year-old children were exposed to 20 and $30^{\circ} \mathrm{C}$ in the morning and afternoon and all temperatures were encountered in a balanced order. The students performed several numerical and language-based tasks to quantify their rate of working and the number of errors. The results indicated that at the highest temperature $\left(30^{\circ} \mathrm{C}\right)$, the children performed schoolwork significantly more slowly compared with the lower temperature $\left(20^{\circ} \mathrm{C}\right)$ for both tasks, especially during the afternoon as children started to get fatigued. The behavioural observations indicated that at higher temperatures, 
girls were significantly restless, although they continue to work, while boys behaved more undisciplined such that their work was interrupted. The authors concluded that the magnitude of the negative influence of temperature on learning performance was as great as $30 \%$.

In two identical climate chambers, Balazova et al., (2007) investigated the impact of simultaneous short-term exposure to noise on human perception and performance. The subjects were exposed to combinations of two levels of operative temperature $\left(23^{\circ} \mathrm{C}\right.$ and $28^{\circ} \mathrm{C}$ ). The results demonstrated that at the warmer temperature and despite the short time allocated for the performance of the addition task, there was a significant decrease in performance and subjects reported a highly significant reduction in their thermal acceptability and their ability to concentrate in the warmer condition. Fang, Clausen, \& Fanger, (1998) found a significant decrement of subjects' acceptability with increasing temperature (from 18 to $28^{\circ} \mathrm{C}$ ) and humidity levels (from 30 to $70 \%$ ). As reported in Balazova et al., (2007), a study by Bánhidi et al., (1998) also compared the influence of two combinations of temperature $\left(20\right.$ and $\left.30^{\circ} \mathrm{C}\right)$ on performance and physiological measures. At the warmer temperature, the number of characters written decreased. Wargocki \& Wyon, (2017) states that the mechanism by which mental work is affected by the thermal environment include attention and distraction, arousal, motivation and distraction, acute health symptoms and manual dexterity, etc. These studies stated that the physiological responses experienced by an increase in temperature are associated with difficulty in concentrating and thinking clearly, which can reasonably be expected to have direct negative effects on cognitive performance.

Overall, the reviewed studies have shown that performance tends to reduce at warmer temperatures and colder temperatures (one study looked at a colder temperature of $16^{\circ} \mathrm{C}$ reduces speed in performing a manual task. However, moderate temperatures $\left(20^{\circ} \mathrm{C}\right.$ as ideal) appear to reduce the arousal/stress level and are the indicative range for enhanced learning performance. Climate and adaptation also largely determined the thermal comfort range. Students in the tropics preferred a higher temperature range than those in temperate or subpolar climates. Table 4 below determines the temperature and learning performance target range adopted in this study. 
Table 5: Summary of temperature and learning performance target range

\section{S/N}

1.

(Haverinen-Shaughnessy \&

Shaughnessy, 2015)

2. (Wargocki \& Wyon, 2007)

\section{TEMPERATURE STUDIES SCALE}

At a temperature range of $20-25^{\circ} \mathrm{C}$ and for each $1^{\circ} \mathrm{C}$ decrease in temperature $(0.5 \% /$ degree $)$, there was a $12-13 \%$ increase in mathematics score.

When the temperature was reduced from $25^{\circ} \mathrm{C}-20^{\circ} \mathrm{C}$, the performance of students on two numerical tasks and two language-based tasks improved.

In phase one experiment: Temperature changes of $210 \mathrm{C}$ yielded an $86.7 \%$ test score, $220 \mathrm{C}$ yielded an $86.9 \%$ test score, and $230 \mathrm{C}$ yielded an $82.7 \%$ test score.

In phase two experiment: The classroom was categorized into cold, controlled and hot temperatures respectively. A cold temperature of $160 \mathrm{C}$ yielded a $76 \%$ test score, a controlled temperature of $220 \mathrm{C}$ yielded a $90 \%$ test score and a hot temperature of $27 \mathrm{oC}$ yielded a $72 \%$ test score.

The results suggested that moderate temperature ranges enhance learning performance.

\section{RATIONALE}

The rationale for this scale is that:

temperature range: 18

$25^{\circ} \mathrm{C}$

Poor: range $<15^{\circ} \mathrm{C}$ and

$>28^{\circ} \mathrm{C}$

(Chapter nine (Table 62) presents the application of this scale in the IEQ rating model)

- the empirical studies on the effects of temperature on learning performance agree that not too warm and not too cold temperatures enhanced learning performance;

- the reported change in performance followed the psychological theory of arousal (at optimum levels, there was an increase in motivation to perform actions);

- $\quad$ it is not feasible to provide every student in a classroom with the temperature that best suits every individual;

- hence, the good temperature range allowed for considerable adaptability to indoor temperature variations;

- it considers occupants clothing and the activity being performed in the classroom;

- it considers occupants ability to be able to control windows and adjust any mechanical systems; and

- the poor temperature range (too warm or too cold) leads to a decrease in learning performance. 
4. (Dear et al., 2015)

5. (Park et al., 2016)

6. (Schoer \& Shaffran, 1973)

7. (Wyon, 1970)

8.

(Dorizas et al., 2015)

9. (Wyon, Andersen, \& Lundqvist, 1979)

10. (Harner, 1974)
Acceptable summertime temperature range for students was $19.5-26.6^{\circ} \mathrm{C}$ and the students neutral and preferred indoor operative temperature was $22.5^{\circ} \mathrm{C}$

In comparison to temperatures at $22^{\circ} \mathrm{C}$, there was an increased risk of failing to pass by $12.3 \%$ in examinations that were taken in days when the ambient temperature was $32^{\circ} \mathrm{C}$.

Hot days above $27^{\circ} \mathrm{C}$ prior to taking the schoolleaving examination, negatively influenced the examination results and impacted on learning and an increase in temperature of $1^{\circ} \mathrm{C}$ reduced examination score by $0.4 \%$.

At a temperature range of $22.5-26^{\circ} \mathrm{C}$, and on an average of $5.7 \%$, the performance of the pupils at $22.5^{\circ} \mathrm{C}$ was significantly better.

At temperatures of $20^{\circ} \mathrm{C}, 27^{\circ} \mathrm{C}$ and $30^{\circ} \mathrm{C}$, children performed schoolwork significantly more slowly at the highest temperature than in lower temperatures.

At a temperature range of $22.5-25^{\circ} \mathrm{C}$ students were totally satisfied with their environment at the lower temperature and were totally dissatisfied at the higher.

When the temperature increased from $20^{\circ} \mathrm{C}$ to $29^{\circ} \mathrm{C}$, learning performance decreased.

Best temperature range for learning

mathematics and reading and math is $20-23^{\circ} \mathrm{C}$ and temperatures above this range decrease

the ability to learn these subjects. 
11. (Balazova, Clausen, \& Wyon, 2007)

12. (Bánhidi et al., 1998)

13. (Lîfberg et al., 1975)

14. (Staffan Hygge \& Knez, 2001)

15. (Fang et al., 1998)
At two levels of operative temperature $\left(23.5^{\circ} \mathrm{C}\right.$ and $28^{\circ} \mathrm{C}$ ), the additional test was performed significantly less well in the warmer

temperature.

At a temperature range of $20^{\circ} \mathrm{C}$ and $30^{\circ} \mathrm{C}$, the number of characters written decreased at the warmer temperature.

A temperature between $22^{\circ} \mathrm{C}$ and $27^{\circ} \mathrm{C}$. There was an improved performance at the lower temperature.

At temperatures of $21^{\circ} \mathrm{C}$ and $27^{\circ} \mathrm{C}$, there was a better free recall in $21^{\circ} \mathrm{C}$ than in the higher temperature level.

Temperature (from $18^{\circ} \mathrm{C}$ to $28^{\circ} \mathrm{C}$ ) and humidity levels (from 30 to $70 \%$ ).

Higher temperature and humidity significantly decreased subjects' acceptability of their thermal environment. 


\subsubsection{Student's Perception of Comfortable Temperature Ranges}

Measured data and surveys from many studies have found temperature to be the most influential indoor environmental component in determining student perceptions of classrooms (Earthman, 2004; Yao, Liu, \& Li, 2010). Researchers have shown that students easily accept slightly cool thermal conditions (Hwang, Lin, \& Kuo, 2006) and would prefer a slightly warm environment (Puteh, Ibrahim, Adnan, Che'Ahmad, \& Noh, 2012), and high temperatures above $23^{\circ} \mathrm{C}$ could influence students' performance (Lackney, 1999). In an evaluation of thermal sensation in university classrooms in Italy, Nico, Liuzzi, \& Stefanizzi, (2015) found that the students' vote of comfort was judged by the different thermal conditions of the surveyed thermal zones and the environment's architectural geometry. On the association of gender with thermal sensation, women felt colder than men, they perceived the classroom to have a greater percentage of discomfort and preferred a warmer environment. Choi, Aziz, \& Loftness, (2010) findings affirm that compared to males, females are more dissatisfied with their thermal environments. This assertion agrees with the findings of Karjalainen, (2007) who reports that females prefer higher room temperatures than males, they are less satisfied with room temperatures and feel both uncomfortably cold and uncomfortably warm more often than males.

A study by Dorizas, Assimakopoulos, \& Santamouris, (2015) found that students were totally satisfied with their environment at a median indoor temperature of $23.32^{\circ} \mathrm{C}$ and were totally dissatisfied at temperatures greater than $25^{\circ} \mathrm{C}$. In three distinct subtropical climate zones in Australia, De Dear et al., (2015) carried out a study during the summer in a mixture of airconditioned, evaporative-cooled and naturally ventilated classrooms in nine schools to empirically define the preferred temperatures, neutral temperatures and acceptable temperature ranges for Australian school children. They found that the students' neutral and preferred indoor operative temperature was about $22.5^{\circ} \mathrm{C}$. They stated that "the school children demonstrated considerable adaptability to indoor temperature variations, with one thermal sensation unit equating to approximately $4^{\circ} \mathrm{C}$ operative temperature". The authors concluded that a temperature range of $19.5-26.6^{\circ} \mathrm{C}$ was an acceptable summertime range for Australian students.

In India, Mishra \& Ramgopal, (2015a, 2015b) conducted surveys in undergraduate classrooms to analyse thermal preference and thermal acceptability votes of occupants. Diurnal variation 
of temperature that would be acceptable to $80 \%$ or more occupants were found to be a 4 oC wide band. Observations showed a significant level of occupant adaptation to the naturally ventilated classroom environment and broad comfort zones. Student (80\%) responses to thermal acceptability were found around $22.1^{\circ} \mathrm{C}$ and about $79 \%$ of responses accepted their thermal environment. In Australia, De Dear et al., (2015) during the summer season and in three distinct subtropical climate zones conducted a survey in a mixture of air-conditioned, evaporative-cooled and naturally ventilated classrooms in nine schools. The students' neutral and preferred temperature was found to be an indoor operative temperature of about $22.5^{\circ} \mathrm{C}$. This they note is generally cooler than expected for adults under the same thermal environmental conditions and presents $19.5^{\circ} \mathrm{C}$ to $26.6^{\circ} \mathrm{C}$ as an acceptable summertime temperature range for Australian students. In the United Kingdom, Montazami, Gaterell, Nicol, Lumley, \& Thoua, (2017) examined data of thermal comfort surveys and collected the perception of 662 pupils in naturally ventilated classrooms from eight primary schools. Their findings concur with the argument of De Dear et al., (2015) by suggesting that there is a difference between the thermal perception of children and adults and children prefer an average of $3^{\circ} \mathrm{C}$ cooler temperature than adults within their classroom. In Greece, an experimental IEQ campaign survey of 193 students revealed that students perceived the thermal environment of their classrooms as rather warm and preferred a cooler environment (Dorizas et al., 2015). Parkinson \& De Dear, (2016) noted that the diversities in thermal preferences suggests that the criteria for evaluating comfort may need to be reconsidered because the provision of thermal comfort using centralised mechanical systems has been flawed by the concept of a one-size-fits-all approach. This implies that building service standards will have to concentrate more on providing individuals with appropriate thermal conditions. However, through fieldwork research on adaptive comfort models, findings indicated that thermal preferences of individuals are dependent on the way people interact with their environment, their behavioural modifications, and their adaptation to match the thermal environment (De Dear, Leow, \& Ameen, 1991). For example, students and teachers in naturally ventilated classrooms may adjust to increased temperature levels over the course of a day by opening their windows and the use of fans, while the use of heating systems and closing the windows could be a modification to lower (colder) temperature levels. Studies (Katafygiotou \& Serghides, 2014b; Wargocki \& Wyon, 2013; Wargocki et al., 2007; Zhang et al., 2019) suggest that people's perceptions of the thermal conditions in a building are 
determined by air temperature, mean radiant temperature, relative humidity, air velocity, clothing and activity level.

The thermal performance of classrooms is a vital aspect of the indoor environment that promotes comfort. In the literature, studies (Katafygiotou \& Serghides, 2014b; Wargocki \& Wyon, 2013; Wargocki, Wyon, Lynge-Jensen, \& Bornehag, 2007; Zhang, de Dear, \& Hancock, 2019) have shown an association between temperature and improved learning. These studies agree that moderate changes in room temperature, even within the comfort zone or an increase in temperature above $25^{\circ} \mathrm{C}$ negatively affects students' learning and task performance while lower temperatures within the adaptive comfort zone enhanced learning. Enhancing thermal performance in classrooms should be a top priority because of the high occupancy levels in classrooms and due to its negative influence on health and learning performance. 


\subsubsection{Determination of Sound Level and Learning Performance Target Range}

In Table 6, empirical studies that report the perceived noise levels that correlate with improvement in learning performance were appraised to determine the best and poor noise ranges. There is a wealth of research over the last 35 years that have documented the detrimental effects of noise on all aspects of performance in classrooms. Such as the effects of noise levels on cognitive processing, learning attainment, numeracy tasks and reading, concentration, memory and attention. These studies have also investigated varied acoustical environments such as aeroplane and traffic noise external distractions and internal classroom distractions. This is presented under the following sub-headings: external noise levels and learning performance and internal noise levels and learning performance.

\subsubsection{The Impact of External Noise Levels on Learning Performance}

Many years ago, Cohen, Evans, Krantz, \& Stokols, (1980) examined the physiological, motivational, and cognitive effects of aircraft noise on children. Classrooms in noisy schools in the air corridor of Los Angeles International Airport had an overall peak noise level of 74 $\mathrm{dBA}$ (highest reading was $95 \mathrm{dBA}$ ) and in the quiet schools $56 \mathrm{dBA}$ (highest reading was 68 dBA). The results revealed a physiological response to noise and on uncontrollable noise as a factor in helplessness, a general deficit in the puzzle task performance and increased distractibility. The authors suggested that "noise-school children are more likely to fail on a cognitive task and are more likely to give tip before the time to complete the task has elapsed". This is supported by Sanz, García, \& García, (1993), which examined the influence of road traffic noise on performance in two public schools in Valencia, Spain. The noise levels considered in the first school (Quiet) ranged between 47.5 and $69.1 \mathrm{dBA}$, with a mean of 57.9 $\pm 2.5 \mathrm{dBA}$ in the morning and $57.3+1.4 \mathrm{dBA}$ in the afternoon and in the second school (noisy), values ranged between 58.5 and $76.6 \mathrm{dBA}$, with a mean of $64.4+1.1 \mathrm{dBA}$ in the morning and $66.2 \pm 3.5 \mathrm{dBA}$ in the afternoon. They found that the children's attention tests results were consistently better in the quiet school compared to that of the noisy school. They concluded that primary and secondary school students exposed to noise levels around $70 \mathrm{dBA}$ reduced their ability to concentrate. Studies by Evans \& Maxwell, (1997) compared the performance of students 100 students enrolled in two New York City schools, one was in a quiet neighbourhood and the other was in the flight path of a major New York metropolitan airport. The average sound levels in the flight path school was $65 \mathrm{dBA}$ with a peak exceeding $90 \mathrm{dBA}$ 
during frequent overhead flights. The results revealed that in the reading tests, students exposed to air-traffic noise performed $20 \%$ lower than those in the quite neighboured school. From 11,000 children in 123 primary schools, around Heathrow Airport, Haines, Stansfeld, Head, \& Job, (2002) compared their National Standard Scores (SATs) with eight noise exposure dBA levels $(1=\langle 54,2=54>57,3=57>60,4=60>63,5=63>66,6=66>69,7=69>72,8=$ $>72$ ). They found that in a dose-response function, the school performance in reading and mathematics was adversely associated with chronic exposure to aircraft noise, but this association was influenced by socioeconomic factors. Lercher, (2003) examined the traffic noise annoyance in school children and found a lower annoyance response at $50 \mathrm{dBA}$ compared to a higher annoyance response at exposure levels as high as $80 \mathrm{dBA}$. Vilatarsana, (2004) examined the relationship between noise levels and its impacts on the learning performance of approximately 1,539 students and if the noise exposure over time had a direct impact on learning. Thirty-five primary or elementary school in the surrounding area of the Heathrow Airport in Hounslow were examined. The noise exposure levels ranged from $55 \mathrm{dBA}$ and exceeded $80 \mathrm{dBA}$. The authors found that noise from the environment such as aircraft noise, car or train was associated with a decrease in cognitive performance.

\subsubsection{The Impact of Internal Noise Levels on Learning Performance}

In an experiment by Christie \& Glickman, (1980), classroom noise (activities) of fourth-grade children was tape-recorded and played in the actual experiment using a stereo cassette deck and amplified through speakers. Half of a total of 156 elementary students were assigned into a noisy classroom environment of $70 \mathrm{dBA}$ and the next half in a quiet classroom of $40 \mathrm{dBA}$ to examine the effects of classroom noise on children's intellectual performance. The results indicated that the students' performance on task varied as a function of classroom noise levels. Pizzo, (1981) examined the relationship between a quiet (40 dBA) and a noisy (75dBA) acoustic environment to determine the effect on student's achievement and attitude. An audio recording of classroom noise made previously was used to generate the noise in the experimental condition. The results showed that subjects in a quiet sound environment achieved significantly higher achievement and attitude scores compared to those in a noisy environment. Hygge, (1991) reported that long-term memory recall was better at an equivalent sound level of $38 \mathrm{dBA}$ compared to $66 \mathrm{dBA}$ (a conversational speech condition). In another study, Hygge, (2003) carried out ten noise experiments with 1358 children aged 12- 
14 years with single and combined noise sources of $55 \mathrm{dBA}$ and $66 \mathrm{dBA}$ (the noise was introduced through two loudspeakers in each front corner of the classroom). "The choice of noise levels was guided by the consideration that $55 \mathrm{dBA}$ is the level recommended as the maximum outdoor level for 24-hour exposure, and by pre-experimental trials with the $66 \mathrm{dBA}$ level, which indicated a noise vs. quiet effect". Results showed a strong noise effect on recall and a smaller, but significant effect on recognition. In the same study by Balazova, Clausen, \& Wyon, (2007) and reported earlier, subjects were also exposed to combinations of two noise levels (52 dBA and $60 \mathrm{dBA}$ ). Using a CD player and one speaker in each chamber, a recording of traffic noise was played inside the chambers. The result showed that at the higher sound level and despite the short time allocated for the performance of the addition task, there was a significant decrease in performance and subjects reported a highly significant reduction in their ability to concentrate. As reported in Balazova et al., (2007), and like the earlier reported lighting and temperature experiments, a study by Bánhidi et al., (1998) also compared the influence of combinations of noise levels (60 and $70 \mathrm{~dB})$ on performance and physiological measures. The performance of a game (Tetris, a falling blocks puzzle video game requiring high concentration and logical thinking) significantly decreased at elevated noise levels.

Overall, the review has shown that studies linking acoustics to learning are consistent and convincing and that fundamental to good academic performance, is good acoustics. These studies agree that excessive noise levels cause stress, influence reading comprehension, verbal interaction, cognitive task, inability to concentrate, blood pressure, and lack of extended application to learning tasks. The studies also agree that the nature of tasks performed in a type of setting, and/or intensity of noise, duration and/or meaning of noise vary the effects of noise on humans. Based on the evidence determining the physiological effect of noise level ranges on learning performance, the IEQ code of this study as shown in Chapter nine adopts a target range of $<40 \mathrm{dBA}$ for unoccupied classrooms and $<75 \mathrm{dBA}$ for occupied classrooms. 
$\mathbf{S} / \mathbf{N}$

AUTHORS

1. (Cohen et al., 1980)

2. (Hygge, 1991)

(Hygge, 1993)

4. (Sanz et al., 1993)

\section{SOUND LEVEL STUDIES SCALE}

Noisy schools: 74 dBA (highest reading was 95 dBA).

Quiet school: $56 \mathrm{dBA}$ (highest reading was 68 dBA).

Prolonged noise exposure affected cognitive processes in noisy schools compared to the quiet schools.

Long-term memory recall was better at an equivalent sound level of $38 \mathrm{dBA}$ compared to $66 \mathrm{dBA}$.

Noise sources of $55 \mathrm{dBA}$ and $66 \mathrm{dBA}$. The strong noise influenced recall recognition task.

Quiet School: sound levels ranged between 47.5 and $69.1 \mathrm{dBA}$, with a mean of $57.9 \pm 2.5 \mathrm{dBA}$ in the morning and $57.3+1.4 \mathrm{dBA}$ in the afternoon.

Noisy school: values ranged between 58.5 and $76.6 \mathrm{dBA}$, with a mean of $64.4+1.1 \mathrm{dBA}$ in the morning and $66.2 \pm 3.5 \mathrm{dBA}$ in the afternoon.

Children's attention tests results were consistently better in the quiet school compared to that of the noisy school.

\section{SCALE ADOPTED}

Occupied Classrooms

Good: acceptable sound

level range: $<75 \mathrm{dBA}$

Poor: range $>75 \mathrm{dBA}$

Unoccupied Classrooms

Good: acceptable sound

level range: $<40 \mathrm{dBA}$

Poor: range $>55 \mathrm{dBA}$

(Chapter nine (Table 62) presents the application of this scale in the IEQ rating model)
The rationale for this scale is that:

- the empirical studies on the effects of noise on learning performance agree that higher noise levels above a normal conversational speech condition will impact on performance, while levels below enhance performance;

considers that excessive noise levels cause increased student dissatisfaction with their classrooms, causes stress, influence reading comprehension, verbal interaction, cognitive task, inability to concentrate, blood pressure, and lack of extended application to learning tasks;

- considers the nature of tasks performed in classrooms and/or intensity of noise, duration and/or meaning of noise; and

- considers the degree to which noise interferes with teaching communication. 
5. (Evans \& Maxwell, 1997)

6. (Haines et al., 2002)

7. (Lercher, 2003)

8. (Vilatarsana, 2004)

9. (Balazova et al., 2007)

10. (Bánhidi et al., 1998)
Average sound levels in the flight path school was $65 \mathrm{dBA}$ with a peak exceeding $90 \mathrm{dBA}$ during frequent overhead flights.

In the reading test, students performed 20\% lower than those in the quite neighboured school.

Eight noise exposure dBA levels $(1=<54$ $2=54>57,3=57>60,4=60>63,5=63>66,6=$ $66>69,7=69>72,8=>72$ ).

School performance in reading and mathematics was associated (poorer) with higher noise levels.

Found a lower identical annoyance response at 50 dBA compared to a higher annoyance response at exposure levels as high as $80 \mathrm{dBA}$.

Noise exposure levels ranged from $55 \mathrm{dBA}$ and exceeded $80 \mathrm{dBA}$.

High noise levels were associated with a decrease in cognitive performance.

Two noise levels: $52 \mathrm{dBA}$ and $60 \mathrm{dBA}$.

At a higher sound level, there was a significant decrease in performance and reduction in the ability to concentrate.

Two noise levels: $60 \mathrm{dBA}$ and $70 \mathrm{dBA}$.

Performance significantly decreased at elevated noise levels. 
11 (Christie \& Glickman, 1980)

(Pizzo, 1981)
Noisy classroom environment of $70 \mathrm{dBA}$ and quiet classroom of $40 \mathrm{dBA}$.

Students' performance on task varied as a function of classroom noise levels.

Quiet environment (40 dBA) and Noisy (75 dBA) acoustic environments.

Subjects in a quiet sound environment achieved significantly higher achievement and attitude scores compared to those in the noisy environment. 


\subsubsection{Typical Noise Levels in Classrooms}

On the typical noise levels identified in school classrooms, a review of studies by Shield, Greenland, \& Dockrell, (2010) stated the typical noise levels for primary schools is 44 dBA for when the pupils are silent and $56 \mathrm{dBA}$ when they are engaged in quiet activities, such as silent reading, 70-77 dBA for group work and 65 dBA for individual work. Studies (Canning et al., 2015; Cutiva \& Burdorf, 2015; Fidêncio et al., 2014; S Hygge, 1993; Kristiansen et al., 2015; Mikulski \& Radosz, 2011; Rashid \& Zimring, 2008) recommend that to avoid interference, an occupied classroom will typically have noise level between 50 and $70 \mathrm{dBA}$ when pupils are engaged in similar activity and a maximum average noise level of $60 \mathrm{dBA}$. In unoccupied classrooms, ranges from 35 to 45 dBA were recommended. Walsh, (1975) measured noise levels in classrooms and related these to teachers' subjective dissatisfaction levels. The author recommends 55 and $65 \mathrm{dBA}$ as the maximum acceptable noise level in occupied classrooms and suggested that the acceptable noise region corresponds to levels $<55 \mathrm{dBA}$; the marginal region corresponds to levels between 55 and $65 \mathrm{~dB}$ while the unacceptable region occurs at levels above $>65 \mathrm{dBA}$.

Many countries have different national standards for background noise levels in classrooms. The American standard ANSI-S12.60 suggests that classrooms should have a background noise level lower than $35 \mathrm{dBA}$. Some studies have measured noise levels in classrooms to compare with different international and national standards. For example, a study carried out by Knecht et al., (2002) measured background noise in 32 elementary school classrooms. They found that the background noise level ranged from 32 to $67 \mathrm{dBA}$ in the classrooms, with only 4 of the classrooms being below the American standard of 35 dBA. Kiri, (2016) statistically analysed 25 studies and found that the background noise when the classrooms were unoccupied ranges from 22 to $70 \mathrm{dBA}$, and the sound levels when occupied ranges from 48 to $85 \mathrm{dBA}$. This is supported by a Canadian survey of university classrooms by Hodgson, Rempel, \& Kennedy, (1999) who found that an empty classroom with a typical background noise level of $35 \mathrm{dBA}$ increased when students were present to $56 \mathrm{dBA}$. A study in Egypt by Ali, (2013) found that in occupied classrooms, the measured sound levels ranged between 61.3 dBA and 73.2 dBA. In Hawai, Pugh et al., (2006) examined background noise levels in 79 School days urban public and private school classrooms. They found that background noise levels in all classrooms were above the $35 \mathrm{dBA}$ of the American standard. In New Zealand, the 
Ministry of Education's guide on school acoustics suggests a background noise level of between $<45 \mathrm{dBA}$ for new school buildings (DQLS, 2016) - this is a background noise level recommendation for unoccupied spaces.

\subsubsection{Determination of Carbon Dioxide and Learning Performance Target Range}

In Table 7, empirical studies that report the perceived $\mathrm{CO}_{2}$ concentration levels that correlate with improvement in learning performance were also appraised to determine the best and poor $\mathrm{CO}_{2}$ concentration range. As shown in Figure 9, a study by Wargocki, Porras-Salazar, \& Bahnfleth, (2017) predicted a $12 \%$ (the speed at which the tasks are performed) and $3 \%$ (errors made while performing the task) average improvement in the performance of psychological tests and school tasks by reducing $\mathrm{CO}_{2}$ concentration from 2,000 ppm to 1,000 $\mathrm{ppm}$. The authors stated that "this change will increase the number of pupils passing exams by $12 \%$ and is further estimated to result in about 6 out of 100 pupils improving their performance and to reduce absence by 0.5 days per student in a 200 days long school year".

This content is unavailable. Please consult the figure source for further details.

Figure 9: The performance of psychological tests and school tasks based on speed and reaction time and accuracy at which the tests and tasks were performed by pupils, Source: Wargocki et al., (2017) 
An earlier study by Myhrvold, Olsen, \& Lauridsen, (1996) investigated the relationship between $\mathrm{CO}_{2}$ concentration and students' performance and health. The mean $\mathrm{CO}_{2}$ concentration during the daytime at the school ranged from 601 to $2827 \mathrm{ppm}$. The $\mathrm{CO}_{2}$ values were categorized into three groups with the percentage of pupils in each group: The first group was 0-999 (48.9\%), the second was $1000-1499$ ppm (24.9\%) and the third group was 1500-4000 ppm (26.4\%). As shown in Figure 10, the results revealed that the environments with high $\mathrm{CO}_{2}$ concentration were associated with poor performance while environments with low $\mathrm{CO}_{2}$ showed good performance.

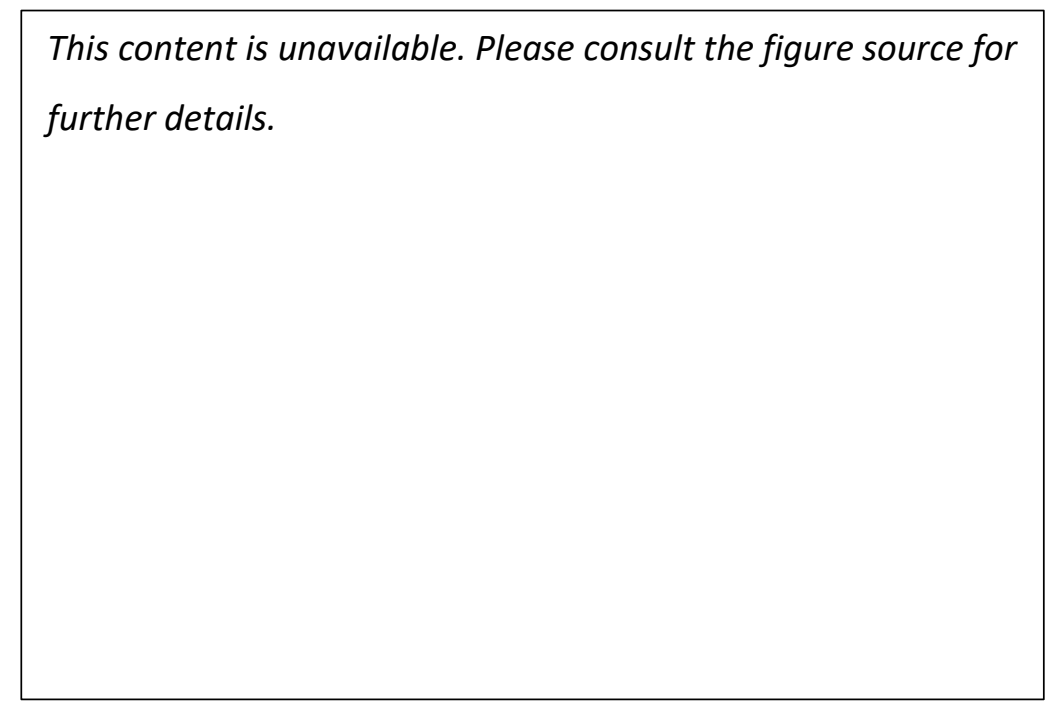

Figure 10: $\mathrm{CO}_{2}$ concentration and performance index. Positive scores correspond with poor performance and negative scores with good performance. Source: Myhrvold et al., (1996)

An experiment which investigated the effect of increased classroom ventilation rate on the performance of children aged 10-12 years was carried out by Petersen, Jensen, Pedersen, \& Rasmussen, (2016), a double-blind crossover intervention was carried out in two classrooms, in two schools, where four different performance tests were used as surrogates for shortterm concentration and logical thinking. The outdoor air supply rate was increased from an average of 1.7 to $6.6 \mathrm{l} / \mathrm{s}$ per person to decrease $\mathrm{CO}_{2}$ concentration from an average of approximately $1500 \mathrm{ppm}$ to $900 \mathrm{ppm}$. The results showed that a reduction in $\mathrm{CO}_{2}$ concentration by increasing the classroom ventilation rate increased the number of correct answers and decreased the number of errors in the four different performance tests Analysis of the total sample suggested the number of correct answers was improved significantly in four of four performance test (addition (6.3\%), number comparison (4.8\%), grammatical reasoning (3.2\%), and reading and comprehension (7.4\%). In a study by (Bakó-Biró et al., 2012) the pupils and teachers in the classrooms studied were usually exposed to $\mathrm{CO}_{2}$ 
concentrations up to $5000 \mathrm{ppm}$. More than 200 pupils carried out computerized performance tasks during the experiment and the results revealed that at the higher ventilation rates compared with the low ventilation conditions (1000 ppm), there were significantly faster and more accurate responses for "Choice Reaction (by 2.2\%), Colour Word Vigilance (by 2.7\%), Picture Memory (by 8\%) and Word Recognition (by 15\%)". As shown in Figure 11, students in an experiment carried out by Coley \& Greeves, (2004) completed an average of 4 test sessions in both the low (mean $\mathrm{CO}_{2}$ level $690 \pm 122$, range 501-983 ppm) and high (mean $\mathrm{CO}_{2}$ level $2909 \pm 474$, range $2096-4140 \mathrm{ppm}) \mathrm{CO}_{2}$ conditions, which equates to ventilation rates of 13 and $1.5 \mathrm{l} / \mathrm{s}$ per pupil. The results indicated that there was a decrement in Power of Attention of approximately $5 \%$ at increased levels of $\mathrm{CO}_{2}$. The authors stated that compared to low $\mathrm{CO}_{2}$ conditions (readings below 1000 ppm), higher levels of $\mathrm{CO}_{2}$ (readings above 2000 ppm) will likely make students less attentive and concentrate less, which over time could impact on learning performance.

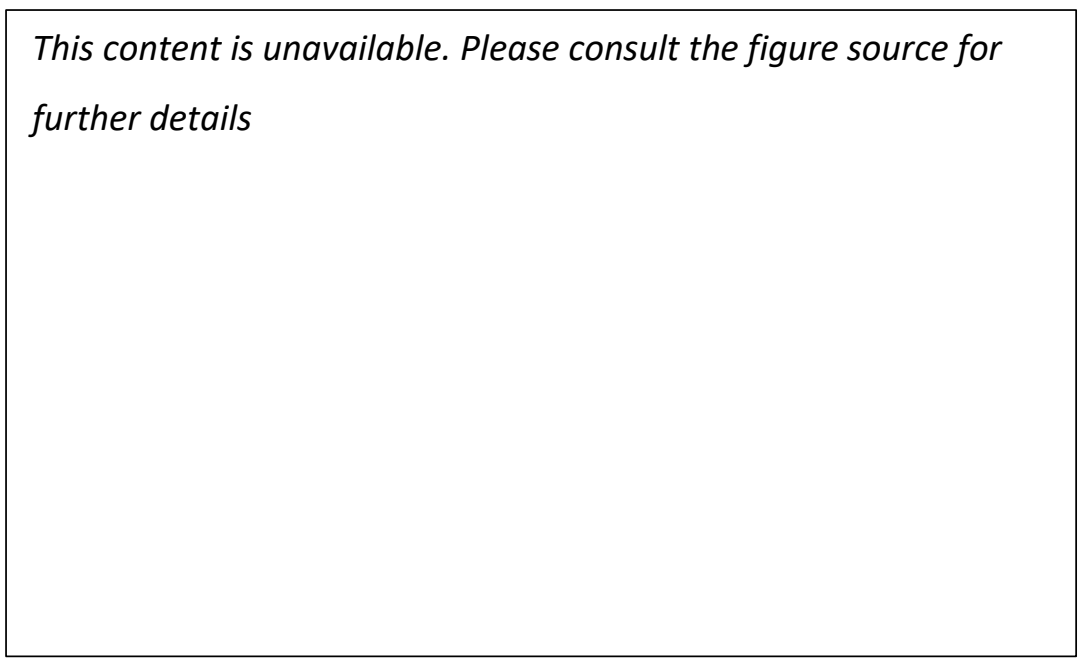

Figure 11: Clustering of $\mathrm{CO}_{2}$ concentration readings below 1000 ppm (low) and above 2000 ppm (high), used to classify the test sessions for analysis. Source: Coley \& Greeves, (2004)

A study by Kajtár \& Herczeg, (2012) showed that exposure to $\mathrm{CO}_{2}$ at $3000 \mathrm{ppm}$ decreased performance of the proof-reading task (mental performance) compared to exposure to a 600 ppm. Subjects evaluated air quality as poor and unpleasant when $\mathrm{CO}_{2}$ concentration increased up to $3000 \mathrm{ppm}$. The authors concluded that when subjects spend 2 to 3 hours in a closed space with 3000 ppm or higher $\mathrm{CO}_{2}$ concentration in the air, their well-being as well as the capacity to concentrate attention declines. This is supported by (Santamouris et al., 2008) study, which found that compared with what was observed at $600 \mathrm{ppm}$, at $\mathrm{CO}_{2}$ concentrations of $1000 \mathrm{ppm}$ and $2500 \mathrm{ppm}$ cognitive functioning was negatively affected. The authors carried 
out a meta-analysis of reported $\mathrm{CO}_{2}$ levels in 287 classrooms of 182 naturally ventilated schools and 900 classrooms from 220 mechanically ventilated schools worldwide and found that in naturally ventilated classrooms, the median level was $1410 \mathrm{ppm}$ and $910 \mathrm{ppm}$ in mechanically ventilated classrooms. In 60 naturally ventilated primary school classrooms in Scotland, Gaihre et al., (2014) measured the concentration of $\mathrm{CO}_{2}$ over a 3-5 day period. The $\mathrm{CO}_{2}$ concentration over the schools ranged from 922-1310 ppm and averaged at $1086 \mathrm{ppm}$. The findings showed that an increase of $100 \mathrm{ppm}$ of $\mathrm{CO}_{2}$ correlated to a $0.2 \%$ increase in absence rates (assuming schools are open on 190 days per year, this roughly equates to 1 half-day of school per annum), but not academic attainments. The increase in absence rate could potentially influence students' learning performance. The literature review of IEQ and health in Chapter 2 reported that there is a relationship between increased $\mathrm{CO}_{2}$ concentration levels and adverse health outcomes which leads to increased sick leave in schools and that the influence of IEQ on health is associated with reduced learning performance. This is supported by Shendell et al., (2004) study in 434 American classrooms, student absence decreased by $10-20 \%$ when the difference between indoor and outdoor $\mathrm{CO}_{2}$ concentrations $\mathrm{CO}_{2}$ concentration increases by $1000 \mathrm{ppm}$. The above studies agree that elevated $\mathrm{CO}_{2}$ levels above 1000 ppm indicate low ventilation rates and that high levels of $\mathrm{CO}_{2}$ are a proxy for other pollutants and poor IAQ. Table 6 shows the target range adopted for the IEQ rating model reported in Chapter nine below. 
Table 7: Summary of carbon dioxide levels and learning performance target range

\begin{tabular}{|c|c|c|c|c|}
\hline $\mathbf{S} / \mathbf{N}$ & AUTHORS & $\mathrm{CO}_{2}$ STUDIES SCALE & SCALE ADOPTED & RATIONALE \\
\hline 1. & (Wargocki et al., 2017) & $\begin{array}{l}\text { Reducing } \mathrm{CO}_{2} \text { concentration from } 2,000 \text { ppm to } \\
1,000 \text { ppm improved students' performance in } \\
\text { psychological tests and school tasks. }\end{array}$ & \multirow{3}{*}{$\begin{array}{l}\text { Good: acceptable } \mathrm{CO}_{2} \\
\text { range: }<1000 \mathrm{ppm} \\
\text { Poor: range }>3000 \mathrm{ppm} \\
\text { (Chapter nine (Table 53) } \\
\text { presents the application of } \\
\text { this scale in the IEQ rating } \\
\text { model) }\end{array}$} & \multirow{4}{*}{$\begin{array}{l}\text { The rationale for this scale is that; } \\
\text { - } \text { the empirical studies on the effects of } \mathrm{CO}_{2} \text { on } \\
\text { learning performance agree that lower } \mathrm{CO}_{2} \\
\text { levels (<1000 ppm) enhance learning, while } \\
\text { levels above } 3000 \mathrm{ppm} \text { will likely make } \\
\text { students less attentive and concentrate less, } \\
\text { which over time could impact on learning } \\
\text { performance; } \\
\text { the good } \mathrm{CO}_{2} \text { range considers that when } \mathrm{CO}_{2} \\
\text { exceeds } 1000 \text { ppm (about twice the outside } \\
\text { levels), empirical studies suggested that there } \\
\text { is an increased susceptibility to physiological } \\
\text { effects which results in drowsiness, } \\
\text { headaches and the inability to concentrate. }\end{array}$} \\
\hline 2. & (Myhrvold et al., 1996) & 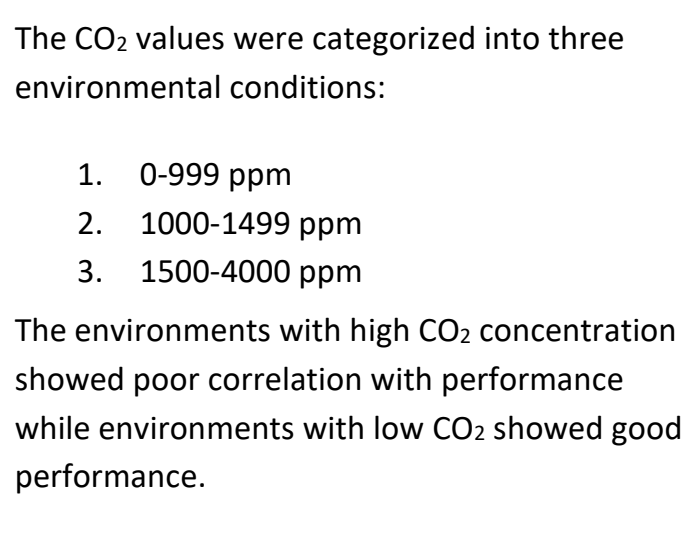 & & \\
\hline 3. & (Petersen et al., 2016) & $\begin{array}{l}\text { A reduction in } \mathrm{CO}_{2} \text { concentration by } \\
\text { approximately } 1500 \mathrm{ppm} \text { to } 900 \mathrm{ppm} \text { increased } \\
\text { the number of correct answers and decreased } \\
\text { the number of errors in performance tests. }\end{array}$ & & \\
\hline 4. & (Bakó-Biró et al., 2012) & $\begin{array}{l}\text { A reduction in } \mathrm{CO}_{2} \text { concentration from } \\
\text { approximately } 5000 \text { ppm to } 1000 \text { ppm } \\
\text { increased: } \\
\text { - Choice Reaction }-2.2 \% \\
\text { - Colour Word Vigilance }-2.7 \% \\
\text { - Picture Memory - } 8 \% \text { Recognition - } \\
15 \%\end{array}$ & & \\
\hline
\end{tabular}




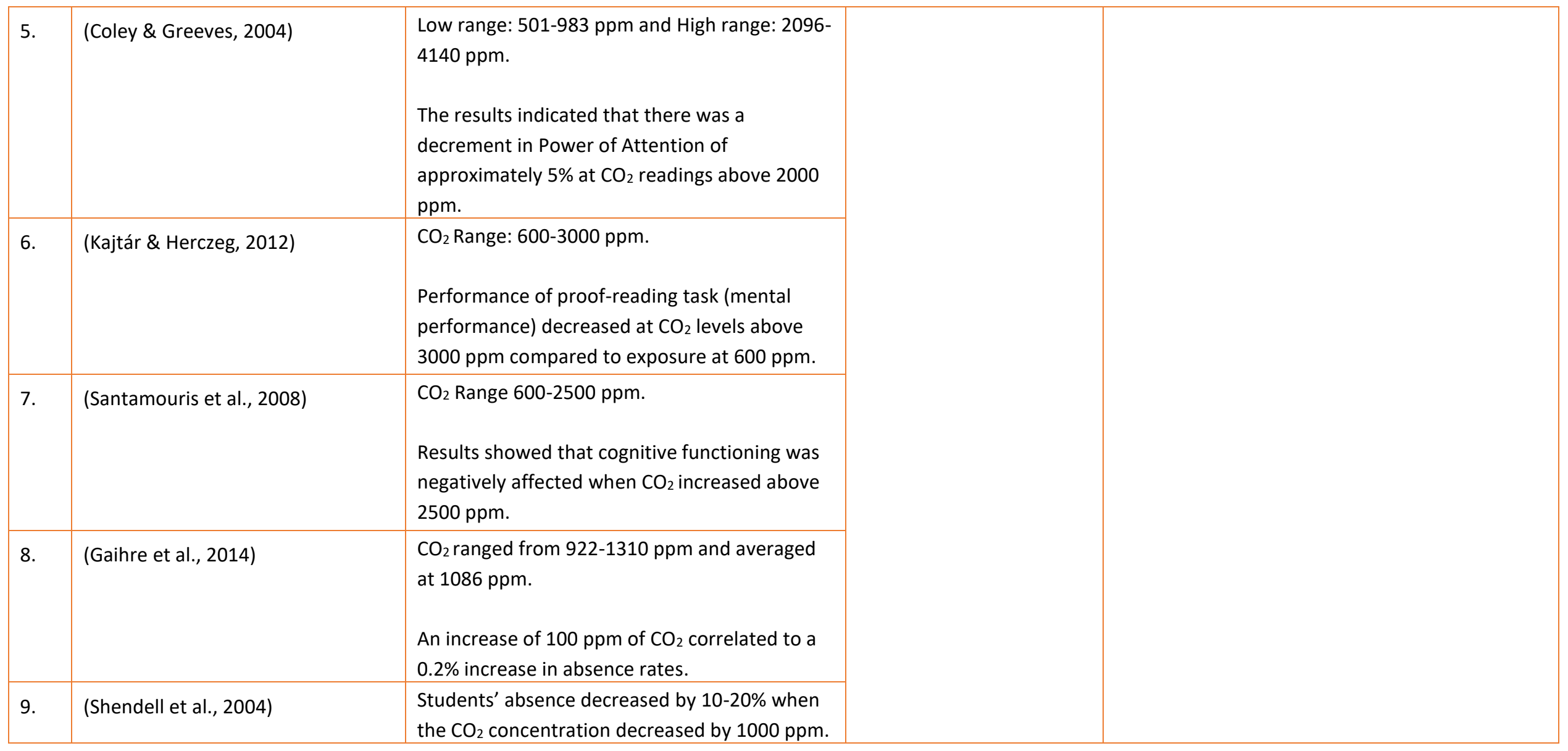




\subsubsection{Summary of IEQ and Learning Performance Target Range}

The empirical studies above have provided a thorough understanding of the impact of IEQ on learning performance in schools and provided a basis for the determination of IEQ and learning performance target range. The reviewed studies have shown that with deteriorating IEQ conditions, there is a decrease in human performance and their acceptability of the indoor environment. This is likely because some of the studies were controlled experiments where the subjects could counteract the uncomfortable conditions and motivated to perform well. Adaptation to the environment could also be a factor. For example, pupils in schools near a flight path or airport may already be conditioned to high noise levels and a controlled study might have two cohorts conditioned in the same environment for months beforehand. Therefore, indoor environmental quality variation in schools are unlikely to have a direct influence on students' learning performance beyond the extremes. In the real-world scenario, it is conceivable that people will avoid working hard in poor conditions and choose to work better in more comfortable conditions if they are aware of the environmental variations in their working conditions during a day. As presented in Chapter nine, this study used the insights of the various IEQ target range to develop an IEQ rating code for reporting large amounts of IEQ data to support decision making. 


\section{CHAPTER THREE: IEQ PHYSICAL MEASUREMENT IN SCHOOLS}

\subsection{Introduction}

Based on the literature, lighting, temperature, acoustics and IAQ are vital environmental variables to quantify aspects of the environment. For example, the quantity and quality of light within a space such as a classroom defines the visual quality of its indoor environment and how it impacts on the functions of the space. Empirical studies have shown the association between IEQ variables and improved learning performance and health in schools and the various IEQ target range that enhances learning performance.

To objectively evaluate the performance of a building will require monitoring the indoor environmental quality conditions. For example, to evaluate visual comfort and glare issues in buildings will require lighting performance measurement. While this could be carried out subjectively, objective physical measurements of IEQ in buildings using data loggers could provide evidence-based data to understand building performance trends and patterns to make more informed design decisions. In time past, individual environmental variable data loggers (sensors) have been used to monitor the performance of buildings, but this does not provide the convenience and cost-effective solution in monitoring the combined IEQ variables simultaneously. But with the current Internet of Things (IOT) technology in the world, there is a growing need for multi-variable sensors that can simultaneously measure multiple IEQ variables using a single device.

In a real-world scenario, there could be many constraints on placing individual variable sensors in many locations in many classrooms to obtain reliable IEQ data, without sealing off usable space. This is due to the activities of students and teachers which could tamper with the sensors. Hence, the use of a limited number of sensors becomes necessary. Light, temperature, sound and $\mathrm{CO}_{2}$ sensors have been deployed in many school buildings around the world to assess the quality of the indoor environment provided by the building. But given that the distribution of IEQ within a space differs widely due to the sun movement, differences in seasons and changing weather conditions, the proper location of a sensor and the number of sensors required within a space is very important in determining the quality of data derived. This chapter appraises studies 
that have measured IEQ in schools to understand the factors these studies took into consideration while carrying out physical measurements of IEQ variables, such as their decisions around the number of sensors used and the placement of the sensors within a classroom.

\subsection{Lighting Measurement Sensors in Classrooms}

In classrooms and given the day to day usage and activities of students, the proper location of an environmental data logger/sensor on the working plane could be a difficult task. Mardaljevic, (2001) supports this assertion by stating that, "for any occupied space, not a least a school classroom, it is practically impossible to obtain a reliable time-series of illuminance measurements taken at desk height without sealing off the area around the sensor - an intervention that would be difficult to both approve and enforce". Hence, it is necessary to consider other means of predicting illuminance on the working plane. Some studies (Mardaljevic et al., 2016; Tzempelikos et al., 2006; Mistrick et al., 2000; Ranasinghe \& Mistrick, 2003) have suggested that as a proxy to measuring illuminance on the work plane, the ceilings and walls of a classroom could be suitable to locate lighting sensors. Ranasinghe \& Mistrick, (2003) suggest that specific illuminance at a task is influenced by the location of a sensor relative to the daylight aperture. They hypothesize that the best performance of a sensor is derived when it is mounted to minimize its view of the window. Also, mounting a sensor with wide spatial sensitivity on the ceiling will make it difficult to track daylight when the sensors receive more direct light from the daylight aperture (Ranasinghe \& Mistrick, 2003). However, Tzempelikos et al., (2006) argue that there is a correlation between illumination recorded by ceiling sensors and horizontal illuminance. Their experimental study placed sensors in strategic positions to monitor daylight levels within an airport space under different sky conditions and shade positions. They found that there was a reliable interior illuminance correlation between the ceiling and horizontal illuminance $\left(R^{2}=0.881\right.$ for illuminance $<1000$ and 0.687 for $\left.>1000\right)$ and suggested that very large façade area with full solar exposure and open shades resulted in the dispersion of values for high illuminances. They concluded that when direct sunlight is eliminated, low illuminance values showed a reliable correlation. These they suggested could minimize the number of sensors needed in a lighting measurement. A study by Mistrick \& Thongtipaya, (1997) in a small office setting showed that when a sensor's view of the window is minimized or eliminated, there is a 
higher correlation between the sensor's sensitivity and the daylight level on the work plane because the sensor will receive light from the wall, and the horizontal surface of the space. On the location of sensors on vertical walls to predict horizontal illuminance, an earlier study by Mardaljevic, (2001) suggested that measured Illuminance at one or more points on a vertical wall could predict the horizontal illuminance in the working plane provided that the evaluation excludes very high illuminance values. This implies that any instances of direct sun on the work plane or wall surfaces should be avoided. This assertion is supported in a later study by Mardaljevic, Brembilla, \& Drosou, (2016) where they showed that illuminance levels on the wall could be a proxy for work plane illuminance in classrooms. Using the Radiance 2-phase Climate Based Daylight Modelling (CBDM), they placed sensors at the centre of the work plane of a side lit classroom $11.2 \mathrm{~m}$ by $7.9 \mathrm{~m}$ and $3.0 \mathrm{~m}$ floor to ceiling, 10 vertical sensors were placed on the long wall and six on the short wall. With the fenestrated side of the room looking towards North (away from the noon sun), they found the best correlation ( 0.97 for both walls) between horizontal and vertical illuminances. They concluded that; "vertical wall illuminance can serve as a proxy for horizontal desk illuminance" and that the relationship between the illuminance performance of the work plane with that of the wall is distinct to the type of space and can be determined using the Climate Based Daylight Modelling (CBDM). Despite these findings, the validation of predicted measures of daylight performance in classrooms has proven to be a challenging prospect.

This is where this thesis deviates from the previous work by investigating whether a one-point sensor measurement could be representative of the lighting quantity within a space. While previous studies have focussed more on the location of sensors for daylight measurement, this thesis advances (Chapter 5 to 8 ) into understanding the distribution of both daylight and artificial lighting within an occupied classroom plus the distribution of temperature, relative humidity, sound levels and $\mathrm{CO}_{2}$ to ascertain the adequacies of using a one-point sensor to determine the IEQ conditions in classrooms. 


\subsubsection{Metrics for Assessing Daylight Quality within a Classroom}

The distribution of daylight within a space differs widely due to the sun movement, differences in seasons and changing weather conditions. In a classroom, the daylight quality relates to the availability of sufficient daylight on the working plane aimed at enabling teachers and students to easily carry out visual tasks (CIBSE, 2010). In building design, daylight could be impacted by parameters, such as the geometrical and physical characteristics of a building's configuration (room shape, window design, materials, etc.); building orientation; internally reflected components on ceilings, walls and floors; interior shading devices for windows such as shade screens, curtains, horizontal mini-blinds and vertical blinds; and site-specific conditions (external reflected components, landscaping, and exterior shading strategies).

To evaluate the quality of daylight within a space, studies have suggested suitable metrics to assess the daylight quality of measurable physical quantities. Table 8 lists the various daylight assessment metrics in classrooms as well as their international benchmarks and standards and states how the daylight quality of this study will be classified.

\begin{tabular}{|c|c|c|c|}
\hline Metrics & Symbol & Recommendation & Reference \\
\hline Illuminance & $E$ & $\begin{array}{l}\text { 1. } E m>300 \text { lux } \\
\text { 2. } E m>300 \text { lux for at least } \\
2000 \mathrm{~h} \\
\text { 3. } 300<E m<3000 \text { on at least } \\
90 \% \text { of the floor area }(A)\end{array}$ & $\begin{array}{l}\text { (CIBSE, 2010; Costanzo et al., } \\
\text { 2017a; Zomorodian et al., 2016) }\end{array}$ \\
\hline $\begin{array}{l}\text { Uniformity } \\
\text { Ratio }\end{array}$ & $U$ & $\begin{array}{l}\text { 1. } U>0.6 \text { on the task area } \\
\text { 2. } U>0.4 \text { in the surroundings } \\
\text { 3. } U>0.3 \text { ( } U>0.7 \text { with glazed } \\
\text { roofs) }\end{array}$ & $\begin{array}{l}\text { (CIBSE, 2010; Costanzo et al., } \\
\text { 2017a; Ho et al., 2008; Korsavi } \\
\text { et al., 2016) }\end{array}$ \\
\hline $\begin{array}{l}\text { Daylight } \\
\text { Factor }\end{array}$ & DF & $\begin{array}{l}\text { 1. An average DF of } 2 \% \text { or } \\
\text { more can be considered } \\
\text { daylit, but electric lighting } \\
\text { may still be needed to } \\
\text { perform visual tasks } \\
\text { 2. When the average DF is } 5 \% \\
\text { or more, a room will appear } \\
\text { strongly daylit and in which } \\
\text { case electric lighting will }\end{array}$ & $\begin{array}{l}\text { (CIBSE, 2010; Ho et al., 2008; } \\
\text { Zomorodian et al., 2016) }\end{array}$ \\
\hline
\end{tabular}




\begin{tabular}{|c|c|c|c|}
\hline & & $\begin{array}{l}\text { most likely not be required } \\
\text { during the day }\end{array}$ & \\
\hline $\begin{array}{l}\text { Useful } \\
\text { Daylight } \\
\text { Illuminance }\end{array}$ & UDI & $\begin{array}{l}\text { 1. Three illumination ranges: 0- } \\
100 \text { lux, } 100-2000 \text { lux, and } \\
\text { over } 2000 \text { lux. }\end{array}$ & (Mardaljevic \& Nabil, 2005) \\
\hline $\begin{array}{l}\text { Daylight } \\
\text { Autonomy }\end{array}$ & DA & $\begin{array}{l}\text { 1. A target illuminance of } 300 \\
\text { lux for } 50 \% \text { of the occupied } \\
\text { area }\end{array}$ & (Reinhart \& Walkenhorst, 2001) \\
\hline $\begin{array}{l}\text { Spatial } \\
\text { Daylight } \\
\text { Autonomy }\end{array}$ & sDA & $\begin{array}{l}\text { 1. Preferred: sDA300/50\% > } \\
75 \% \text { on occupied area } \\
\text { 2. Acceptable: sDA300/50\% > } \\
55 \% \text { on occupied area }\end{array}$ & $\begin{array}{l}\text { (Costanzo et al., 2017a; } \\
\text { Zomorodian et al., 2016) }\end{array}$ \\
\hline $\begin{array}{l}\text { Annual } \\
\text { Sunlight } \\
\text { Exposure }\end{array}$ & ASE & $\begin{array}{l}\text { 1. Preferred: ASE1000/250h < } \\
3 \% \text { on occupied area } \\
\text { 2. Acceptable: ASE1000/250h < } \\
7 \% \text { on occupied area }[16] \\
\text { Sufficient: ASE1000/250h < } \\
\text { 10\% on occupied area }\end{array}$ & $\begin{array}{l}\text { (Costanzo et al., 2017a; USGBC, } \\
\text { 2014; Zomorodian et al., 2016) }\end{array}$ \\
\hline
\end{tabular}

To interpret the illuminance values of the simulation results reported in $\underline{\text { Chapter } 5}$ below, UDI and DA are the illuminance-based metrics explored because they are climate-based daylight metrics for determining the distribution of daylight in a space over time. Combining UDI and DA would produce highly detailed analysis and helps to easily absorb and interpret a large data set of illuminances (Kleindienst et al., 2008). 


\subsection{Thermal Measurement Sensors in Classrooms}

To carry out any objective thermal condition measurement, the calibration of sensors, the number of sensors and the location of the sensors within a space is critical to the quality of data derived. In an occupied classroom, locating sensors to collate reliable environmental data could be a very difficult task because of the functions and usage of the space. Table 9 reviews the number of sensors used by some previous thermal comfort studies to measure air temperature and relative humidity in classrooms as well as the positioning of the sensors during instrumentation.

In Table 9, there is no consistency in the number of sensors used in each of the studies and a height ranging from $0.1 \mathrm{~m}$ to $2.5 \mathrm{~m}$ was used to locate the sensors. De Dear et al., (2015) stated that their "rationale was to locate sensors outside the classroom's days zone because of the need to protect the sensors from student's tampering". In Haddad et al., (2016), they located their sensors in three different heights and stated that "this was primarily because children's childspecific measuring heights are not included in the commonly used standards". Wong \& Khoo, (2003) suggested that their choice of sensor location height of $1.0 \mathrm{~m}$ above the floor level was because it represented the height of the occupants at the seated level. This assertion is supported by Lee, Biasio, \& Santini, (1996) which stated that sensors should be located in a central location at average height within a space. Humphrey, (1977) suggest that the best placement for temperature sensors in classrooms is in places which did not receive direct sun during school hours. When exposed to direct irradiation from the sun, lighting sources, and thermal sources such as the human body, or the walls of a room, temperature sensors are susceptible to errors. Mahyuddin, Awbi, \& Alshitawi, (2014) states that temperature sensors should be placed avoiding radiators and cooling systems, away from windows and should not be exposed to direct sun and temperature is best measured at or near the head height of around 1.5 to $2 \mathrm{~m}$ away from the floor level. However, the variance in the number of sensors used in instrumentation in previous studies and the different placement height of the sensors within the space illustrates the challenges of establishing the most appropriate approach towards field measurement of thermal comfort variables, especially in occupied classrooms. 
On the spatial distribution of temperature across a space, Haddad et al., (2016) suggested that "during the heated season in non-ventilated classrooms, apart from patches of direct sunlight, there was little variation of temperature caused by radiant temperature asymmetry and vertical thermal stratification". In De Dear et al., (2015) adaptive thermal comfort study in Australian classrooms, they found that "in all classrooms surveyed there was no evidence that temperatures recorded by the wall mounted sensors differed significantly from those experienced by the students as a result of vertical thermal stratification or radiant asymmetry". Koch-Nielsen, (2002) suggested that air temperature measurement is indicated by a thermometer exposed to the air, but sheltered from direct solar radiation, and placed at a height of 1.5 to $2 \mathrm{~m}$ above the ground.

Temperature variation within a room usually causes variation in relative humidity, because if the moisture content in the air remains unchanged and there is a temporal increase (variation) in temperature, the relative humidity usually decreases and vice versa. For example, it is typical that when temperature increases as the sun rise during the day, relative humidity will usually drop rapidly until it is lowest just after midday. But as temperature decreases during the night, relative humidity increases and is usually high at midnight. Studies (Mallick, 1996; Olgyay, 1963) suggest that that in large rooms with several microenvironments, it may be advisable to measure air temperature and relative humidity in several places. Measuring air temperature and relative humidity at one measuring point may not provide a basis for calculating the probable temperature and humidity at the other places especially in naturally ventilated buildings. Hence, it is logical to temporarily install several combined humidity and temperature measuring points to test the spatial relationship of temperature and humidity across a space. This thesis assesses the distribution of temperature and humidity across an occupied classroom to determine the adequacy of using a one-point sensor to predict the thermal performance of a classroom.

Table 9: Sensor location considerations in studies that have objectively measured thermal conditions in Classrooms.

\begin{tabular}{|l|l|l|l|l|l|}
\hline S/N & Author & Title & $\begin{array}{l}\text { No of Sensors } \\
\text { and Duration }\end{array}$ & Sensor Position & $\begin{array}{l}\text { Variables } \\
\text { measured }\end{array}$ \\
\hline $\mathbf{1 .}$ & $\begin{array}{l}\text { (Zeiler } \\
\text { Boxem, 2009) }\end{array}$ & $\begin{array}{l}\text { Effects of thermal } \\
\text { activated building } \\
\text { systems in schools } \\
\text { on thermal comfort } \\
\text { in winter. }\end{array}$ & $\begin{array}{l}5 \text { sensors } \\
\text { mins }\end{array}$ & $\begin{array}{l}\text { Sensors were placed } \\
\text { together in a tripod } \\
\text { stand with a small cage } \\
\text { to protect the sensors, } \\
\text { at 1.1m height above }\end{array}$ & $\begin{array}{l}\text { Air temperature, } \\
\text { radiant } \\
\text { temperature, } \\
\text { and air velocity } .\end{array}$ \\
\hline
\end{tabular}




\begin{tabular}{|c|c|c|c|c|c|}
\hline & & & & $\begin{array}{l}\text { floor level at the centre } \\
\text { of the room. }\end{array}$ & \\
\hline 2. & $\begin{array}{l}\text { (N. H. Wong \& } \\
\text { Khoo, 2003) }\end{array}$ & $\begin{array}{l}\text { Thermal comfort in } \\
\text { classrooms in the } \\
\text { tropics. }\end{array}$ & 5 sensors & $\begin{array}{l}\text { Sensors were placed at } \\
\text { a height of } 1.0 \mathrm{~m} \text { above } \\
\text { the floor in an occupied } \\
\text { classroom. }\end{array}$ & $\begin{array}{l}\text { Air temperature, } \\
\text { relative humidity } \\
\text { and air velocity. }\end{array}$ \\
\hline 3. & $\begin{array}{l}\text { (Martha C. } \\
\text { Katafygiotou \& } \\
\text { Serghides, } \\
\text { 2014) }\end{array}$ & $\begin{array}{l}\text { Thermal comfort of } \\
\text { a typical secondary } \\
\text { school building in } \\
\text { Cyprus. }\end{array}$ & - & $\begin{array}{l}\text { "Recorded in the most } \\
\text { representative spaces } \\
\text { of the building." }\end{array}$ & $\begin{array}{l}\text { Air temperature } \\
\text { and relative } \\
\text { humidity. }\end{array}$ \\
\hline 4 & $\begin{array}{l}\text { (Kwok \& Chun, } \\
\text { 2003) }\end{array}$ & $\begin{array}{l}\text { Thermal comfort in } \\
\text { Japanese schools. }\end{array}$ & 1 sensor & $\begin{array}{l}\text { Measurements were } \\
\text { taken at a height of } 1.1 \\
\mathrm{~m} \text { ( } 43 \text { inches) above the } \\
\text { floor during classroom } \\
\text { visits. }\end{array}$ & $\begin{array}{l}\text { Air temperature, } \\
\text { globe } \\
\text { temperature, } \\
\text { relative humidity } \\
\text { and air velocity. }\end{array}$ \\
\hline 5 & $\begin{array}{l}\text { (M.A. } \\
\text { Humphreys, } \\
1977)\end{array}$ & $\begin{array}{l}\text { A study of the } \\
\text { thermal comfort of } \\
\text { primary school } \\
\text { children in summer. }\end{array}$ & 2 sensors & $\begin{array}{l}\text { Sensors placed at } \\
\text { heights between } 0.5 \\
\text { and } 1.5 \mathrm{~m} .\end{array}$ & - \\
\hline 6 & $\begin{array}{l}\text { (Haddad et al., } \\
\text { 2016) }\end{array}$ & $\begin{array}{l}\text { Revisiting thermal } \\
\text { comfort models in } \\
\text { Iranian classrooms } \\
\text { during the warm } \\
\text { season. }\end{array}$ & 3 sensors & $\begin{array}{l}\text { Sensors placed at a } \\
\text { height of } 1.1,0.6 \text { and } \\
0.1 \mathrm{~m} \text { above the floor at } \\
\text { the centre of the space. }\end{array}$ & $\begin{array}{l}\text { Air temperature, } \\
\text { globe } \\
\text { temperature, air } \\
\text { velocity and } \\
\text { relative humidity. }\end{array}$ \\
\hline 7 & $\begin{array}{l}\text { (Teli et al., } \\
2014)\end{array}$ & $\begin{array}{l}\text { The role of a } \\
\text { building's thermal } \\
\text { properties on } \\
\text { pupils' thermal } \\
\text { comfort in junior } \\
\text { school classrooms } \\
\text { as determined in } \\
\text { field studies. }\end{array}$ & $\begin{array}{l}2 \text { sensors } \\
5 \mathrm{~min}\end{array}$ & $\begin{array}{l}\text { Sensors were placed as } \\
\text { centrally in the } \\
\text { classroom as possible } \\
\text { and were mounted on } \\
\text { the wall, } 2 \mathrm{~m} \text { above the } \\
\text { floor level. }\end{array}$ & $\begin{array}{l}\text { Dry bulb } \\
\text { temperature and } \\
\text { relative humidity. }\end{array}$ \\
\hline 8 & $\begin{array}{l}\text { (R De Dear et } \\
\text { al., 2015) }\end{array}$ & $\begin{array}{l}\text { Adaptive thermal } \\
\text { comfort in } \\
\text { Australian school } \\
\text { classrooms. }\end{array}$ & $\begin{array}{l}1 \text { sensor per } \\
\text { classroom } \\
15 \mathrm{~min}\end{array}$ & $\begin{array}{l}\text { The sensor was wall- } \\
\text { mounted between } 2.0 \\
\text { and } 2.5 \mathrm{~m} \text { above floor } \\
\text { level within each } \\
\text { classroom. }\end{array}$ & $\begin{array}{l}\text { Air temperature } \\
\text { and globe } \\
\text { temperature, } \\
\text { humidity and } \\
\text { airspeed. }\end{array}$ \\
\hline
\end{tabular}

\subsubsection{Air Temperature}

Air temperature is commonly used as an indicator of thermal comfort (Mallick, 1996). Changes in air temperature will normally change a person's perceived comfort levels (De Dear et al., 2015; Jin, Zhang, \& Zhang, 2017; Tham \& Willem, 2010; Wyon et al., 1979). Air temperature is measured using a dry bulb thermometer and it should always be considered in relation to other 
environmental and personal factors (Givoni, 1969; Montgomery, 1987; Olgyay, 1963). Koenigsberger, Ingersoll, Mayhew, \& Szokolay, (1980) state that the season, latitude, the amount of cloud cover, and the time of year are the main factors that determine outdoor temperatures and do drive the indoor conditions (determine air temperature). During the day, the coldest temperature is usually just before sunrise and the hottest temperature is usually experienced two hours afternoon after which temperature starts to decrease continuously through the night (Mallick, 1996). Air temperature is characterised as the most noticeable climatic variable because it largely determines heating and cooling energy use (Krigger \& Dorsi, 2004). Thermal condition studies have concentrated more on the range of temperature that makes building occupants feel comfortable, but little is known about the best methodological process of using limited sensors to measure reliable temperature data especially in classrooms.

\subsubsection{Relative Humidity}

Relative humidity is defined as the ratio between the actual amount of water vapour in the air and the maximum amount of water vapour that the air can hold at that air temperature (Berglund, 1998; CIBSE, 2006). Studies (ANSI/ASHRAE55-2004, 2004; Bobenhausen, 1994; De Dear et al., 1991; Givoni, 1969; Hayakawa, Isoda, \& Yanase, 1989; Olgyay, 1963; Salmon, 1999) suggest that the range of ideal comfortable humidity is between 20 and $70 \%$ - can be undetectable within the comfort zone (McIntyre, 1980), and the acceptable levels for comfort are between a range of 45 and 70\% (Oughton \& Hodkinson, 2002). Djamila et al., (2014) supports this argument by stating that occupants in their extensive field investigation were thermally comfortable at wide humidity range and the mean humidity corresponding to the optimum comfort temperature was close to $73 \%$. In naturally ventilated spaces where outdoor climatic conditions influence the indoor thermal environment, humidity may be higher than $70 \%$ on warm days (Djamila et al., 2014).

The variability of humidity within a space is dependent on whether there are drying processes where water vapour is given off. Indoor environments with high humidity (above $80 \%$ ) will prevent the evaporation of moisture from the human body because high levels of humidity have a lot of vapour in the air and one of the main methods of heat loss in humans is the evaporation of moisture exuded through the pores of the skin (ANSI/ASHRAE55-2004, 2004). Li et al., (2017) 
simulated the effects of air humidity cycle from $80 \%$ to $20 \%$ and back to $80 \%$ on an aircraft at $20^{\circ} \mathrm{C}$ and $28^{\circ} \mathrm{C}$ using heat transfer analysis. They found that due to changes in evaporative heat loss, humidity affected both human heat storage and skin temperature. Jing et al., (2013) carried out an experiment in an environmental chamber and found that for higher temperatures, the relative humidity could have a significant effect on skin temperature and thermal comfort. Szokolay, (2008) grouped the variables that affect heat dissipation from the body (and thus also thermal comfort) into three sets as shown in Table 10:

\begin{tabular}{|c|c|c|}
\hline Table 10: Environmental factors that affect heat dissipation from the body & (adapted from Szokolay, (2008). \\
\hline Environmental & Personal & Contributing factors \\
\hline Air temperature & Metabolic rate (activity) & Food and drink \\
\hline Air movement & Clothing & Body shape \\
\hline Humidity & State of health & Subcutaneous fat \\
\hline Radiation & Acclimatization & Age and gender \\
\hline
\end{tabular}

Szokolay, (2008) argues that among the environmental factors listed in Table 9, the dominant environmental factor is air temperature because it determines convective heat dissipation. Air movement produces a physiological cooling effect through the acceleration of convection, which changes the skin and clothing surface heat transfer coefficient (reduces surface resistance), as well as increases evaporation from the skin. Szokolay, (2008) affirms that "humidity between 30$65 \%$ do not have much effect, but high humidity restricts evaporation from the skin and in respiration, whilst very low humidity's lead to drying out of the mucous membranes (mouth, throat) as well as the skin, thus cause discomfort".

Compared to air temperature, humidity levels in real buildings do not change significantly and within a certain range such as $40 \%-70 \%$ building occupants are not very sensitive to any changes in humidity (CIBSE, 2006). Many researchers have suggested that changes in humidity may not impact human thermal comfort level, when the air temperature, airspeed, and radiation temperature are in a comfortable range (Bauman et al., 1996; Djamila et al., 2014; Nevins et al., 1966; Olgyay, 1963). However, the effect of high humidity on thermal comfort becomes more obvious when there is an increase in temperature and metabolic rate ( $L$ Jin et al., 2017; Jing et al., 2013). Bauman et al., (1996) affirm that under increased metabolic rate, humidity affects occupant thermal sensation. Nevins et al., (1966) investigated 72 combinations of humidity and 
temperature and found that with a $10 \%$ decrease of relative humidity, the acceptable temperature could be increased by $0.3{ }^{\circ} \mathrm{C}$. Kong et al., (2019) carried out a comparative experiment in a controlled chamber to investigate the effect of humidity on human's thermal comfort and their humidity adaptation. During the experiment, the humidity was changed between $20 \%$ and $90 \%$ at a set air temperature of $25^{\circ} \mathrm{C}$ and $28{ }^{\circ} \mathrm{C}$ respectively. They found that participants showed stronger thermal responses when the humidity was over $70 \%$. They concluded that the changing point between high humidity environments and low humidity environments was at $70 \%$. Therefore, the effect of humidity on thermal comfort is more significant when operative temperatures are above $28^{\circ} \mathrm{C}$. Whereas at lower operative temperatures below $25^{\circ} \mathrm{C}$, humidity may improve thermal comfort. It seems that when the air temperature is within a comfortable range, the influence of humidity on thermal comfort is modest (Bauman et al., 1996; Berglund, 1998; Ling Jin et al., 2017; Parsons, 1993). Generally, in naturally ventilated spaces, the separation between temperature and relative humidity seems neither possible nor necessary, because the two parameters are highly correlated (Djamila et al., 2014). Maintaining acceptable temperature and relative humidity in buildings could be achieved through effective ventilation which is necessary for buildings to: provide fresh air and remove stale air, moderate indoor temperatures and humidity levels and reduce the accumulation of moisture, carbon dioxide and other pollutants that could build up during occupied periods.

Monitoring the thermal performance of a building will require the use of temperature and humidity sensors to collate data over time to understand how the various trends and patterns relate to the building design and local microclimate. From the review, it is possible that dependent on the ventilation strategy and building design, temperature and humidity could vary depending on the time of the day. While the focus of many studies has been on setting operative thermal comfort range, little is known about the best monitoring protocol for using limited sensors to reliably measure thermal comfort at scale in buildings to inform design decisions. In Chapter 6 below, the results of using a one-point sensor to predict the thermal performance of classrooms are presented. 


\subsection{Acoustic Measurement Sensors in Classrooms}

Architectural acoustics is generally defined as the science that determines how sound is transmitted in a space by studying the properties of a building. A literature review of acoustics in schools by Pugh, Miura, \& Asahara, (2006) suggested that to study the acoustics of a classroom, verification of all sounds present on the site is vital. Studies have related poor acoustics in schools to poor academic performance of students and health related issues. Parameters that reveal the acoustic quality of spaces include, the reverberation time (RT) of the enclosure, the overall level of the background noise, and the speech transmission index (STI) (Bradley \& Sato, 2008; Crandell \& Smaldino, 2000; Sato \& Bradley, 2008; Canning et al., 2015). In the assessment of classroom acoustics, studies (Crandell \& Smaldino, 2000; Crukley et al., 2011; H. A. Knecht et al., 2002) have shown that the measurement of background noise levels (also referred to as ambient noise) is particularly important as a good indicator of the acoustic performance of a building because background noise is known to adversely affect speech perception and speech recognition - could hinder a person's ability to listen to what they want or need to hear.

Noise generally refers to a sound that disturbs an activity. In classrooms, when unwanted noise affects the transmittance of speech from the teacher to the students, it impacts on learning performance of the students. Also, it increases the burden of the teacher who has to speak louder. According to Crukley et al., (2011); Crandell \& Smaldino, (2000) noise refers to any unpleasant auditory stimuli that hinder a child from effectively hearing and understanding what they are taught. Internal and external noise are the two sources of noise in classrooms. Internal noise sources include individuals talking, movement of furniture and fixtures, and sound from heating, ventilating, and air-conditioning (HVAC) systems, etc. External noise sources include noise from strong wind, rain, aeroplane, traffic, local construction, automobile traffic, and playgrounds, etc. Considering the different sources of noise, classrooms have been found to

often experience a high level of noise. Crandell \& Smaldino, (2000) suggested that noise in a classroom often varies considerably over time, making it difficult to measure classroom noise reliably in a simple manner.

On the measurement of sound levels in schools, Table 11 reviews the number of sensors used by some previous studies to measure sound levels in classrooms as well as the positioning of the 
sensors during instrumentation. Unlike the measurement of lighting, temperature and $\mathrm{CO}_{2}$ where researchers specified their preferred heights for locating sensors, Table 11 shows that the acoustic measurement studies did not make much references to their sound level meter position height. Ali, (2013) suggested that their sound level sensor was placed in the middle of the classroom, at a height corresponding to the position of the student's ears. Similarly, Zannin \& Zwirtes, (2009) evaluated the acoustic performance in classrooms and stated that noise was measured at a single spot positioned at the centre of the classroom. But these authors did not state the rationale for the choice of this location and height and whether this was representative of the entire space. There was also little or no emphasis on if the location of a sound level sensor impacts on the decibel data derived despite that internal and external sound levels in classrooms will considerably vary depending on the function of the space and time. Hence, it can be inferred that the reviewed studies did not suggest any identified standard for measuring noise in schools. This assertion is supported by Dockrell \& Shield, (2006) who pointed out that there is difficulty in deciding what sound measurement represents a 'typical' classroom noise level owing to the lack of a standard method for measuring noise in schools. Fidêncio, Moret, \& Jacob, (2014) carried out a systematic literature review of noise measurements in classrooms and concluded that there is no standardized methodology that can be used for measurements of noise in classrooms and that the procedures for evaluating noise exposure have different methodologies. Given this, and the variance of different sources of noise, Chapter 7 of this thesis reports on whether a one-point sound level sensor measurement on the walls is sufficient to determine the noise and sound levels across a classroom to provide a useful indication of the acoustic properties of the classroom; and where might be the best place to locate a one-point sensor. 
Table 11: Sensor location considerations in studies that have objectively measured ambient noise in classrooms

\begin{tabular}{|c|c|c|c|c|c|}
\hline S/N & Author & Objectives & $\begin{array}{l}\text { No of Sensors } \\
\text { and Duration }\end{array}$ & $\begin{array}{l}\text { Sensor Position and No } \\
\text { of Rooms }\end{array}$ & $\begin{array}{l}\text { Other Variables } \\
\text { measured }\end{array}$ \\
\hline 1. & $\begin{array}{l}\text { (Dockrell \& } \\
\text { Shield, 2006) }\end{array}$ & $\begin{array}{l}\text { External and internal } \\
\text { noise surveys of London } \\
\text { primary schools. }\end{array}$ & $\begin{array}{l}\text { One } \\
5 \text { mins } \\
\text { Occupied and } \\
\text { School days }\end{array}$ & Spot measurements. & $\begin{array}{l}\text { Internal and external } \\
\text { noise } \\
\text { measurements. }\end{array}$ \\
\hline 2. & $\begin{array}{l}\text { (S. A. A. Ali, } \\
\text { 2013) }\end{array}$ & $\begin{array}{l}\text { An investigation into the } \\
\text { effects of school noise on } \\
\text { learning achievement and } \\
\text { annoyance in Assiut city. }\end{array}$ & $\begin{array}{l}\text { One } \\
\text { Occupied } \\
20 \text { mins }\end{array}$ & $\begin{array}{l}\text { The sound level sensor } \\
\text { was placed in the middle } \\
\text { of the classroom, at a } \\
\text { height corresponding to } \\
\text { the position of the } \\
\text { students' ears. }\end{array}$ & $\begin{array}{l}\text { Noise level } \\
\text { measurements. }\end{array}$ \\
\hline 3. & $\begin{array}{l}\text { (Wilson et al., } \\
\text { 2002) }\end{array}$ & $\begin{array}{l}\text { Investigation of the } \\
\text { acoustic characteristics of } \\
\text { New Zealand primary } \\
\text { school classrooms. }\end{array}$ & $\begin{array}{l}1 \text { Sensor } \\
1 \text { day } \\
\text { Occupied and } \\
\text { School days } \\
\text { Classrooms }\end{array}$ & Not Specified. & $\begin{array}{l}\mathrm{R} / \mathrm{T} \text { and clarity, } \\
\text { recordings of } \\
\text { classrooms noise. }\end{array}$ \\
\hline 4. & $\begin{array}{l}\text { (Abdelouahab et } \\
\text { al., 2013) }\end{array}$ & $\begin{array}{l}\text { Evaluated the acoustic } \\
\text { comfort in different } \\
\text { teaching room and } \\
\text { proposed acoustic } \\
\text { correction when this } \\
\text { comfort is insufficient. }\end{array}$ & School days & $\begin{array}{l}\text { Five sounds source and } \\
\text { five sound receiver } \\
\text { positions were used. }\end{array}$ & $\begin{array}{l}\text { Measurements of } \\
\text { sound and } \\
\text { reverberations time. }\end{array}$ \\
\hline 5. & $\begin{array}{l}\text { (Trombetta \& } \\
\text { Paulo, 2012) }\end{array}$ & $\begin{array}{l}\text { The present work } \\
\text { involved an evaluation of } \\
\text { the acoustic quality of } \\
\text { real classrooms built } \\
\text { according to the standard } \\
\text { design. }\end{array}$ & $\begin{array}{l}\text { School days } \\
\text { Classrooms }\end{array}$ & $\begin{array}{l}\text { The noise inside } \\
\text { classrooms were } \\
\text { assessed based on a 3- } \\
\text { minute } \\
\text { measurement at each } \\
\text { point. }\end{array}$ & $\begin{array}{l}\text { Reverberation Time, } \\
\text { Speech Transmission } \\
\text { Index, Sound } \\
\text { Insulation of } \\
\text { Façades, and } \\
\text { External and Internal } \\
\text { Sound Pressure } \\
\text { Level. }\end{array}$ \\
\hline 6. & $\begin{array}{l}\text { (Zannin \& } \\
\text { Zwirtes, 2009) }\end{array}$ & $\begin{array}{l}\text { Evaluation of the acoustic } \\
\text { performance of } \\
\text { classrooms in public } \\
\text { schools. }\end{array}$ & $\begin{array}{l}1 \text { sensor } \\
10 \text { Mins } \\
\text { Occupied and } \\
\text { School days } \\
\text { hours }\end{array}$ & $\begin{array}{l}\text { The noise was measured } \\
\text { at a single spot } \\
\text { positioned at the centre } \\
\text { of the classroom. }\end{array}$ & $\begin{array}{l}\text { Measurements of } \\
\text { sound and } \\
\text { reverberations time. }\end{array}$ \\
\hline 7. & $\begin{array}{l}\text { (Cutiva \& } \\
\text { Burdorf, 2015) }\end{array}$ & $\begin{array}{l}\text { Investigated the } \\
\text { association between } \\
\text { objectively measured and } \\
\text { self-reported physical }\end{array}$ & $\begin{array}{l}\text { School days } \\
\text { Classrooms }\end{array}$ & $\begin{array}{l}\text { The first position was } \\
\text { defined as the most } \\
\text { common location where } \\
\text { the teacher (or worker) }\end{array}$ & $\begin{array}{l}\text { Objective } \\
\text { measurements of } \\
\text { sound levels (SLs) } \\
\text { using the frequency }\end{array}$ \\
\hline
\end{tabular}




\begin{tabular}{|c|c|c|c|c|c|}
\hline & & $\begin{array}{l}\text { conditions at school with } \\
\text { the presence of voice } \\
\text { symptoms among } \\
\text { teachers. }\end{array}$ & & $\begin{array}{l}\text { was located most of the } \\
\text { time during the lecture } \\
\text { (work time). The second } \\
\text { position was close to the } \\
\text { door, and the third } \\
\text { position was close to the } \\
\text { windows. The duration } \\
\text { of each measurement } \\
\text { was } 1 \text { min each. }\end{array}$ & $\begin{array}{l}\text { weighting }(\mathrm{A}) \text {, } \\
\text { temperature, } \\
\text { humidity, and RT at } \\
\text { the workplaces and } \\
\text { SL outside schools. }\end{array}$ \\
\hline 8. & $\begin{array}{l}\text { (Knecht, Nelson, } \\
\text { \& Whitelaw, } \\
\text { 2002) }\end{array}$ & $\begin{array}{l}\text { Evaluate the extent of the } \\
\text { problem of noise and } \\
\text { reverberation in schools. }\end{array}$ & $\begin{array}{l}\text { School days } \\
\text { elementary } \\
\text { classrooms }\end{array}$ & $\begin{array}{l}\text { Randomly selected } 5 \\
\text { points. }\end{array}$ & $\begin{array}{l}\text { Measured } \\
\text { reverberation times } \\
\text { and background } \\
\text { noise levels. }\end{array}$ \\
\hline 9. & $\begin{array}{l}\text { (Pugh et al., } \\
2006 \text { ) }\end{array}$ & $\begin{array}{l}\text { To obtain noise data from } \\
\text { School days classrooms } \\
\text { and document structural } \\
\text { components (e.g., wall, } \\
\text { ceiling, floor, window) } \\
\text { and physical dimensions } \\
\text { (in cubic feet) of each } \\
\text { classroom. }\end{array}$ & $\begin{array}{l}\text { School days } \\
\text { Classrooms } \\
3 \text { mins } \\
\text { interval for } 3 \\
\text { months }\end{array}$ & Five separate locations & $\begin{array}{l}\text { Noise levels } \\
\text { Building } \\
\text { characteristics } \\
\text { elements. }\end{array}$ \\
\hline
\end{tabular}

In this study, background noise levels were measured during unoccupied non-school days and sound levels were measured during occupied school days. While the measurement of background noise levels is useful to ascertain the acoustic performance of a building, sound level measurement during occupied school hours is useful in identifying potential sources of unwanted sound (noise) to act in mitigating these sources. Sato \& Bradley, (2008) opine that the value of background noise as an acoustical index deserves much consideration because the reduction of background noise through acoustic treatment has been shown to improve students' performance in schools. Many studies on acoustics in classroom report background noise levels using single number descriptions. This is carried out by measuring the relative sound pressure level (SPL) of the background noise at a specific point, or points in time by A-weighting decibels, abbreviated as "dBA". Background noise can be measured using a sound level meter. Sound level meters are useful to estimate noise exposure by measuring the intensity of sound at a given moment in an area or environment. 


\subsection{Carbon dioxide Measurement Sensors in Classrooms (Measuring IAQ)}

Many school related studies (Aliboye et al., 2006; Rosbach et al., 2013; Satish et al., 2012) have widely used sensors to measure $\mathrm{CO}_{2}$ levels because of the advantage of requiring relatively simple equipment. However, the literature suggested that these do not guide on representative placement of $\mathrm{CO}_{2}$ sensors. Table 12 shows inconsistency between the different measurement strategies used by researchers in selecting representative locations and the number of $\mathrm{CO}_{2}$ sampling sensors needed in a space. The appraised studies did not examine the variation of $\mathrm{CO}_{2}$ concentration across a space and if the use of a one-point sensor is representative of the $\mathrm{CO}_{2}$ level across a classroom. The literature revealed that some researchers only stated the height of the breathing zone as recommended by some guidelines and did not state the specific location of their sensors while some did not state the whereabouts of the sensors and the sampling methods used for monitoring $\mathrm{CO}_{2}$ levels. The variance in the number of sensors used in these previous studies and the different placement height of the sensors within the space illustrates the challenges of establishing the most appropriate approach towards field measurement of $\mathrm{CO}_{2}$ variables, especially in occupied classrooms.

Most of the $\mathrm{CO}_{2}$ concentration measurement in schools' studies were performed in mechanically ventilated classrooms, hence limited information is available about the $\mathrm{CO}_{2}$ concentration in naturally ventilated classrooms. Most of New Zealand classrooms are low rise naturally ventilated buildings. This study investigates the association between horizontal measuring plane sensors and vertical wall sensors to ascertain the adequacy of using a one-point sensor to measure representative samples of $\mathrm{CO}_{2}$ in a naturally ventilated classroom. These comparisons are extensively discussed through analysis in Chapter 8 below. 
Table 12 Sensor location considerations in studies that have objectively measured $\mathrm{CO}_{2}$ in Classrooms

\begin{tabular}{|c|c|c|c|c|c|}
\hline $\mathbf{S} / \mathbf{N}$ & Author & Title & $\begin{array}{l}\text { No of Sensors } \\
\text { and Duration }\end{array}$ & $\begin{array}{l}\text { Sensor Position } \\
\text { and No of Rooms }\end{array}$ & $\begin{array}{l}\text { Other Variables } \\
\text { measured }\end{array}$ \\
\hline 1. & $\begin{array}{l}\text { (Rosbach et } \\
\text { al., 2013) }\end{array}$ & $\begin{array}{l}\text { A ventilation intervention } \\
\text { study in classrooms to } \\
\text { improve indoor air quality. }\end{array}$ & $\begin{array}{l}1 \mathrm{CO}_{2} \text { Sensor } \\
\text { Log interval was } 4 \\
\text { minutes for } 3 \text { weeks } \\
\text { During Occupancy }\end{array}$ & $\begin{array}{l}\text { A sensor was } \\
\text { placed in the } \\
\text { classroom wall at } \\
\text { a height of } 1.5 \mathrm{~m} \\
\text { from the floor. }\end{array}$ & $\begin{array}{l}\text { Temperature and } \\
\text { relative humidity. }\end{array}$ \\
\hline 3. & $\begin{array}{l}\text { (Ferreira \& } \\
\text { Cardoso, } \\
\text { 2014) }\end{array}$ & $\begin{array}{l}\text { Indoor air quality and } \\
\text { health in schools. }\end{array}$ & $\begin{array}{l}1 \mathrm{CO}_{2} \text { Sensor } \\
1 \text { week } \\
\text { Measurements } \\
\text { began about } 2 \\
\text { hours after } \\
\text { classroom } \\
\text { occupancy. }\end{array}$ & $\begin{array}{l}\text { A sensor was } \\
\text { placed in the } \\
\text { most central } \\
\text { position in each } \\
\text { classroom. }\end{array}$ & $\begin{array}{l}\text { Temperature, } \\
\text { relative humidity, CO, } \\
\text { SO2, VOCs, and } \\
\text { Outdoor air quality. }\end{array}$ \\
\hline 4. & $\begin{array}{l}\text { (Gao et al., } \\
2014 \text { ) }\end{array}$ & $\begin{array}{l}\text { Investigated indoor } \\
\text { climate and window } \\
\text { opening behaviour by } \\
\text { pupils, as well as their } \\
\text { perceptions and } \\
\text { symptoms in classrooms } \\
\text { with different types of } \\
\text { ventilation systems. }\end{array}$ & $\begin{array}{l}1 \mathrm{CO}_{2} \text { Sensor } \\
\text { I month } \\
\text { During occupancy } \\
\text { and }\end{array}$ & $\begin{array}{l}\text { Sensors located } \\
\text { centrally in the } \\
\text { classroom at } 1.6 \text { - } \\
1.8 \mathrm{~m} \text { above the } \\
\text { floor so they } \\
\text { could not be } \\
\text { reached by pupils. }\end{array}$ & $\begin{array}{l}\text { Temperature, } \\
\text { relative humidity. } \\
\text { Outdoor air quality } \\
\text { data were obtained } \\
\text { from an outdoor } \\
\text { monitoring station. } \\
\text { Records were taken } \\
\text { of pre-determined } \\
\text { window opening } \\
\text { protocol. }\end{array}$ \\
\hline 5. & $\begin{array}{l}\text { (Jones \& Kirby, } \\
\text { 2012) }\end{array}$ & $\begin{array}{l}\text { Examination of natural } \\
\text { ventilation strategy based } \\
\text { on the use of a roof } \\
\text { mounted split-duct } \\
\text { Windcatcher ventilator. }\end{array}$ & $\begin{array}{l}1 \mathrm{CO}_{2} \text { Sensor } \\
5 \text { days } \\
\text { Unoccupied } \\
\text { Classroom }\end{array}$ & $\begin{array}{l}\text { Sensors located } \\
\text { centrally and } \\
\text { placed at seated } \\
\text { head height. }\end{array}$ & $\begin{array}{l}\text { Temperature, } \\
\text { relative humidity and } \\
\text { ventilation rates, } \\
\text { Glazing Orientation, } \\
\text { openable windows } \\
\text { and area were noted. }\end{array}$ \\
\hline 6. & $\begin{array}{l}\text { (Bartlett et al., } \\
\text { 2004) }\end{array}$ & $\begin{array}{l}\text { Presented a numerical } \\
\text { method to estimate the } \\
\text { concentration of } \\
\text { occupant-generated } \mathrm{CO}^{2} \\
\text { for the (time-varying) } \\
\text { occupancy typically found } \\
\text { in non-forced ventilated } \\
\text { elementary school } \\
\text { classrooms. }\end{array}$ & $\begin{array}{l}1 \mathrm{CO}_{2} \text { Sensor } \\
\text { Occupied } \\
\text { Classroom }\end{array}$ & $\begin{array}{l}\text { Sensors located } \\
\text { centrally }\end{array}$ & $\begin{array}{l}\text { Outdoor } \mathrm{CO}_{2} \text { level } \\
\text { was measured. }\end{array}$ \\
\hline
\end{tabular}




\begin{tabular}{|c|c|c|c|c|c|}
\hline 7. & $\begin{array}{l}\text { (Dias Pereira } \\
\text { et al., 2014) }\end{array}$ & $\begin{array}{l}\text { Assessment of indoor air } \\
\text { quality and thermal } \\
\text { comfort in Portuguese } \\
\text { secondary classrooms. }\end{array}$ & $\begin{array}{l}1 \mathrm{CO}_{2} \text { Sensor } \\
2 \text { weeks } \\
\text { Occupied } \\
\text { Classroom }\end{array}$ & $\begin{array}{l}\text { Sensors placed at } \\
\text { a height of } 0.6 \mathrm{~m} \\
\text { above the } \\
\text { Floor. }\end{array}$ & $\begin{array}{l}\text { Temperature and } \\
\text { relative humidity, } \\
\text { Outdoor air } \\
\text { temperature from } \\
\text { climatological station } \\
\text { and Classroom } \\
\text { characteristics and } \\
\text { window dimension } \\
\text { was recorded. }\end{array}$ \\
\hline 8. & $\begin{array}{l}\text { (Coley \& } \\
\text { Beisteiner, } \\
\text { 2016) }\end{array}$ & $\begin{array}{l}\text { To investigate Carbon } \\
\text { Dioxide Levels and } \\
\text { Summertime Ventilation } \\
\text { Rates in UK Schools. }\end{array}$ & $\begin{array}{l}1 \mathrm{CO}_{2} \text { Sensor } \\
1 \text { week } \\
\text { Occupied } \\
\text { Classroom }\end{array}$ & $\begin{array}{l}\text { Sensors were wall } \\
\text { mounted at about } \\
1.8 \mathrm{~m} \text { above floor } \\
\text { level. }\end{array}$ & $\begin{array}{l}\text { Temperature and } \\
\text { external } \mathrm{CO}_{2} \text { was } \\
\text { measured. }\end{array}$ \\
\hline 9. & $\begin{array}{l}\text { (Schibuola et } \\
\text { al., 2016) }\end{array}$ & $\begin{array}{l}\text { Investigating natural } \\
\text { ventilation in school } \\
\text { buildings. }\end{array}$ & $\begin{array}{l}1 \mathrm{CO}_{2} \text { Sensor } \\
1 \text { week } \\
\text { Occupied } \\
\text { Classroom }\end{array}$ & $\begin{array}{l}\text { Sensors centrally } \\
\text { installed on a } \\
\text { desk height of } 80 \\
\mathrm{~cm} \text { from the } \\
\text { floor. }\end{array}$ & $\begin{array}{l}\text { Temperature and } \\
\text { relative humidity, } \\
\text { and classroom } \\
\text { characteristics were } \\
\text { recorded. }\end{array}$ \\
\hline 10. & $\begin{array}{l}\text { (Coley \& } \\
\text { Beisteiner, } \\
\text { 2002) }\end{array}$ & $\begin{array}{l}\text { Winter-time ventilation } \\
\text { rates in UK schools. }\end{array}$ & $\begin{array}{l}1 \mathrm{CO}_{2} \text { Sensor } \\
1 \text { week } \\
\text { Occupied and } \\
\text { unoccupied } \\
\text { Classroom }\end{array}$ & $\begin{array}{l}\text { Sensors were wall } \\
\text { mounted at about } \\
1.8 \mathrm{~m} \text { above floor } \\
\text { level. }\end{array}$ & $\begin{array}{l}\text { Temperature and } \\
\text { external } \mathrm{CO}_{2} \text { was } \\
\text { measured. }\end{array}$ \\
\hline 11 & $\begin{array}{l}\text { (Mumovic et } \\
\text { al., 2009) }\end{array}$ & $\begin{array}{l}\text { Winter indoor air quality, } \\
\text { thermal comfort and } \\
\text { acoustic performance of } \\
\text { newly built secondary } \\
\text { schools in England. }\end{array}$ & $\begin{array}{l}3 \text { sensors } \\
16 \text { classrooms in } 9 \\
\text { educational } \\
\text { buildings }\end{array}$ & $\begin{array}{l}\text { Sensors placed at } \\
\text { a height of } 1.1 \mathrm{~m}\end{array}$ & $\begin{array}{l}\text { Temperature and } \\
\text { acoustic were } \\
\text { recorded. }\end{array}$ \\
\hline 12 & $\begin{array}{l}\text { (Sekhar et al., } \\
\text { 2003) }\end{array}$ & $\begin{array}{l}\text { Development and } \\
\text { application of an indoor } \\
\text { air quality audit to an air- } \\
\text { conditioned tertiary } \\
\text { institutional building in the } \\
\text { tropics. }\end{array}$ & $\begin{array}{l}5 \text { sensors } \\
2 \text { air-conditioned } \\
\text { classrooms }\end{array}$ & $\begin{array}{l}\text { Sensors located in } \\
\text { the front and } \\
\text { back rows in the } \\
\text { lecture theatre } \\
\text { respectively. }\end{array}$ & - \\
\hline 13 & $\begin{array}{l}\text { (Chung \& Hsu, } \\
\text { 2001) }\end{array}$ & $\begin{array}{l}\text { Effect of ventilation } \\
\text { pattern on room air and } \\
\text { contaminant distribution. }\end{array}$ & - & $\begin{array}{l}\text { The sensor was in } \\
\text { a } 0.9 \mathrm{~m} \text { height at } \\
\text { the teacher's } \\
\text { desk and } 1.5 \mathrm{~m}\end{array}$ & - \\
\hline
\end{tabular}




\begin{tabular}{|c|c|c|c|c|c|}
\hline & & & & $\begin{array}{l}\text { from the } \\
\text { breathing zone. }\end{array}$ & \\
\hline 14 & $\begin{array}{l}\text { (Wong \& Mui, } \\
\text { 2007) }\end{array}$ & $\begin{array}{l}\text { Evaluation of four } \\
\text { sampling schemes for } \\
\text { assessing indoor air } \\
\text { quality. }\end{array}$ & $\begin{array}{l}2 \text { sensors } \\
17 \text { spaces }\end{array}$ & $\begin{array}{l}\text { Sensors located at } \\
\text { a height of } 1 \mathrm{~m}\end{array}$ & - \\
\hline 15 & $\begin{array}{l}\text { (Noh et al., } \\
\text { 2007) }\end{array}$ & $\begin{array}{l}\text { Thermal comfort and } \\
\text { indoor air quality in the } \\
\text { lecture room with 4-way } \\
\text { cassette air conditioner } \\
\text { and mixing ventilation } \\
\text { system. }\end{array}$ & 1 university room & $\begin{array}{l}\text { The sensor was } \\
\text { located at a } \\
\text { height of } 1.1 \mathrm{~m} \text {. }\end{array}$ & $\begin{array}{l}\text { Temperature, } \\
\text { humidity }\end{array}$ \\
\hline 16 & $\begin{array}{l}\text { (Lawrence \& } \\
\text { Braun, 2007) }\end{array}$ & $\begin{array}{l}\text { A methodology for } \\
\text { estimating occupant } \mathrm{CO}_{2} \\
\text { source generation rates } \\
\text { from measurements in } \\
\text { small commercial } \\
\text { buildings. }\end{array}$ & $\begin{array}{l}1 \text { sensor } \\
3 \text { educational and } \\
\text { commercial rooms. }\end{array}$ & $\begin{array}{l}\text { Sensors were } \\
\text { located at a } \\
\text { height of } 1.5 \text { in } \\
\text { the middle of the } \\
\text { space. }\end{array}$ & - \\
\hline 17 & $\begin{array}{l}\text { (Zeiler \& } \\
\text { Boxem, 2009) }\end{array}$ & $\begin{array}{l}\text { Effects of thermal } \\
\text { activated building systems } \\
\text { in schools on thermal } \\
\text { comfort in winter. }\end{array}$ & 14 classrooms & $\begin{array}{l}\text { Sensors placed at } \\
\text { a } 1.1 \mathrm{~m} \text { height. }\end{array}$ & - \\
\hline 18 & $\begin{array}{l}\text { (Bakó-Biró et } \\
\text { al., 2012) }\end{array}$ & $\begin{array}{l}\text { Ventilation rates in } \\
\text { schools. }\end{array}$ & $\begin{array}{l}3 \text { sensors } \\
20 \text { classrooms }\end{array}$ & $\begin{array}{l}\text { Sensors placed at } \\
\text { a height of } 1.1 \mathrm{~m} \\
\text { in each room. }\end{array}$ & - \\
\hline 19 & $\begin{array}{l}\text { (Sekhar et al., } \\
\text { 2003) }\end{array}$ & $\begin{array}{l}\text { Thermal comfort study of } \\
\text { an air-conditioned lecture } \\
\text { theatre in the tropics. }\end{array}$ & 1 University room & $\begin{array}{l}\text { Sensor placed at a } \\
1.1 \mathrm{~m} \text { height }\end{array}$ & $\begin{array}{l}\text { Temperature and } \\
\text { humidity. }\end{array}$ \\
\hline 20 & $\begin{array}{l}\text { (Grimsrud et } \\
\text { al., 2006) }\end{array}$ & $\begin{array}{l}\text { Continuous } \\
\text { measurements of air } \\
\text { quality parameters in } \\
\text { schools. }\end{array}$ & $\begin{array}{l}85 \text { rooms in } 8 \\
\text { school buildings }\end{array}$ & $\begin{array}{l}\text { Sensors placed at } \\
\text { the breathing } \\
\text { level of a typical } \\
\text { adult. }\end{array}$ & - \\
\hline 21 & $\begin{array}{l}\text { (Lee \& Chang, } \\
\text { 2000) }\end{array}$ & $\begin{array}{l}\text { Indoor and outdoor air } \\
\text { quality investigation at } \\
\text { schools in Hong Kong. }\end{array}$ & 5 rooms & $\begin{array}{l}\text { Sensors located } \\
1 \mathrm{~m} \text { above the } \\
\text { floor level. }\end{array}$ & - \\
\hline 22 & $\begin{array}{l}\text { (Mysen et al., } \\
\text { 2005) }\end{array}$ & $\begin{array}{l}\text { Evaluation of simplified } \\
\text { ventilation system with } \\
\text { direct air supply through } \\
\text { the facade in a school in a } \\
\text { cold climate. }\end{array}$ & Occupied space & $\begin{array}{l}\text { Sensors located at } \\
\text { seated head } \\
\text { height within the } \\
\text { occupied area. }\end{array}$ & - \\
\hline
\end{tabular}




\begin{tabular}{|c|c|c|c|c|c|}
\hline 23 & $\begin{array}{l}\text { (Griffiths \& } \\
\text { Eftekhari, } \\
\text { 2008) }\end{array}$ & $\begin{array}{l}\text { Control of } \mathrm{CO}_{2} \text { in a } \\
\text { naturally ventilated } \\
\text { classroom. }\end{array}$ & 1 room & $\begin{array}{l}\text { Sensors located at } \\
\text { the seated height. }\end{array}$ & - \\
\hline 24 & $\begin{array}{l}\text { (Godwin \& } \\
\text { Batterman, } \\
\text { 2007) }\end{array}$ & $\begin{array}{l}\text { Indoor air quality in } \\
\text { Michigan schools. }\end{array}$ & $\begin{array}{l}6 \text { sensors } \\
64 \text { rooms in } 9 \\
\text { school buildings }\end{array}$ & $\begin{array}{l}\text { Sensors located in } \\
\text { a height of } 1.2 \mathrm{~m} \\
\text { in each room }\end{array}$ & - \\
\hline 25 & $\begin{array}{l}\text { (Norbäck \& } \\
\text { Nordström, } \\
\text { 2008) }\end{array}$ & $\begin{array}{l}\text { An experimental study on } \\
\text { effects of increased } \\
\text { ventilation flow on } \\
\text { students' perception of } \\
\text { the indoor environment in } \\
\text { computer classrooms. }\end{array}$ & 4 rooms & $\begin{array}{l}\text { Sensors located at } \\
\text { a height of } 1.5 \mathrm{~m} \\
\text { in the middle of } \\
\text { the space. }\end{array}$ & - \\
\hline 26 & $\begin{array}{l}\text { (Shendell et } \\
\text { al., 2004) }\end{array}$ & $\begin{array}{l}\text { Association between } \\
\text { classroom } \mathrm{CO}_{2} \\
\text { concentrations and } \\
\text { student attendance in } \\
\text { Washington and Idaho. }\end{array}$ & $\begin{array}{l}400 \text { rooms in } 22 \\
\text { school buildings }\end{array}$ & $\begin{array}{l}\text { Sensors located at } \\
\text { a height of } 1.5 \mathrm{~m} \\
\text { in the middle of } \\
\text { the classrooms. }\end{array}$ & - \\
\hline 27 & $\begin{array}{l}\text { (Geelen et al., } \\
2008 \text { ) }\end{array}$ & $\begin{array}{l}\text { Comparing the } \\
\text { effectiveness of } \\
\text { interventions to improve } \\
\text { ventilation behaviour in } \\
\text { primary schools. }\end{array}$ & $\begin{array}{l}2 \text { sensors each } \\
81 \text { rooms in } 20 \\
\text { primary school } \\
\text { buildings }\end{array}$ & $\begin{array}{l}2 \text { sensors located } \\
\text { at a height of } \\
1.5 \mathrm{~m} \text { in the } \\
\text { middle of each } \\
\text { room }\end{array}$ & - \\
\hline 28 & $\begin{array}{l}\text { (Mi et al., } \\
2006)\end{array}$ & $\begin{array}{l}\text { Current asthma and } \\
\text { respiratory symptoms } \\
\text { among pupils in Shanghai, } \\
\text { China: influence of } \\
\text { building ventilation, } \\
\text { nitrogen dioxide, ozone, } \\
\text { and formaldehyde in } \\
\text { classrooms. }\end{array}$ & 9 school buildings & $\begin{array}{l}\text { Sensors located at } \\
\text { a height of } 1.2 \mathrm{~m}\end{array}$ & - \\
\hline 29 & $\begin{array}{l}\text { (Chien et al., } \\
\text { 2009) }\end{array}$ & $\begin{array}{l}\text { Assessment of air change } \\
\text { rates in chemical } \\
\text { laboratories. }\end{array}$ & $\begin{array}{l}21 \text { rooms in } 2 \\
\text { school laboratories }\end{array}$ & $\begin{array}{l}\text { Sensors located in } \\
\text { the occupied area }\end{array}$ & - \\
\hline 30 & $\begin{array}{l}\text { (Ali, } \\
\text { Almomani, \& } \\
\text { Hindeih, 2009) }\end{array}$ & $\begin{array}{l}\text { Evaluating indoor } \\
\text { environmental quality of } \\
\text { public-school buildings in } \\
\text { Jordan. }\end{array}$ & $\begin{array}{l}2 \text { sensors each } \\
17 \text { rooms }\end{array}$ & $\begin{array}{l}2 \text { sensors located } \\
\text { in the air- } \\
\text { conditioning } \\
\text { system exhaust }\end{array}$ & - \\
\hline 31 & $\begin{array}{l}\text { (Katsoulas, } \\
\text { 2002) }\end{array}$ & $\begin{array}{l}\text { Monitoring and modelling } \\
\text { indoor air quality and } \\
\text { ventilation in classrooms }\end{array}$ & $\begin{array}{l}4 \text { school building } \\
\text { rooms }\end{array}$ & $\begin{array}{l}\text { Sensors located at } \\
\text { a height of } 1.5 \mathrm{~m} \\
\text { on filing cabinet }\end{array}$ & - \\
\hline
\end{tabular}




\begin{tabular}{|c|c|c|c|c|c|}
\hline & & $\begin{array}{l}\text { within a purpose-designed } \\
\text { naturally ventilated } \\
\text { school. }\end{array}$ & & $\begin{array}{l}\text { and } 20 \mathrm{~cm} \text { away } \\
\text { from the sidewall. }\end{array}$ & \\
\hline 32 & $\begin{array}{l}\text { (Conceição et } \\
\text { al., 2008) }\end{array}$ & $\begin{array}{l}\text { Evaluation of local thermal } \\
\text { discomfort in a classroom } \\
\text { equipped with cross flow } \\
\text { ventilation. }\end{array}$ & - & $\begin{array}{l}\text { The sensor was } \\
\text { located at a } \\
\text { height of } 1.2 \mathrm{~m} \text { at } \\
\text { the middle of the } \\
\text { room. }\end{array}$ & $\begin{array}{l}\text { Temperature and } \\
\text { humidity }\end{array}$ \\
\hline 33 & $\begin{array}{l}\text { (Mahyuddin, } \\
\text { Awbi, \& } \\
\text { Alshitawi, } \\
\text { 2014) }\end{array}$ & $\begin{array}{l}\text { The spatial distribution of } \\
\text { carbon dioxide in rooms } \\
\text { with application to } \\
\text { classrooms. }\end{array}$ & $\begin{array}{l}12 \text { sensors } \\
4 \text { University } \\
\text { occupied } \\
\text { classrooms }\end{array}$ & $\begin{array}{l}\text { Sensors located at } \\
0.2 \mathrm{~m}, 1.2 \mathrm{~m} \text { and } \\
1.8 \mathrm{~m} \text { above the } \\
\text { classroom floor. }\end{array}$ & $\begin{array}{l}\text { Temperature and } \\
\text { velocity }\end{array}$ \\
\hline 34 & $\begin{array}{l}\text { (Luther et al., } \\
\text { 2018) }\end{array}$ & $\begin{array}{l}\text { Investigating } \mathrm{CO}_{2} \\
\text { concentration and } \\
\text { occupancy in school } \\
\text { classrooms at different } \\
\text { stages in their lifecycle. }\end{array}$ & $\begin{array}{l}24 \text { naturally } \\
\text { ventilated } \\
\text { classrooms from six } \\
\text { different schools } \\
\text { were assessed. }\end{array}$ & $\begin{array}{l}\text { A single sensor } \\
\text { positioned at a } \\
\text { seated height of } \\
0.6 \mathrm{~m} \text {. }\end{array}$ & $\begin{array}{l}\text { External weather } \\
\text { data recorded }\end{array}$ \\
\hline 35 & $\begin{array}{l}\text { (Bennett et al., } \\
\text { 2019b) }\end{array}$ & $\begin{array}{l}\text { Sources of indoor air } \\
\text { pollution at a New Zealand } \\
\text { urban primary school. }\end{array}$ & $\begin{array}{l}\text { One naturally } \\
\text { ventilated } \\
\text { classroom. }\end{array}$ & $\begin{array}{l}\text { A single sensor } \\
\text { positioned at a } \\
\text { height of } 1.1 \mathrm{~m} \text {. }\end{array}$ & $\begin{array}{l}\text { Temperature, } \\
\text { humidity, } \mathrm{PM}_{2.5}, \mathrm{PM}_{10}\end{array}$ \\
\hline
\end{tabular}

\subsubsection{Determination of IAQ through Measuring $\mathrm{CO}_{2}$ Concentrations}

Indoor Air Quality (IAQ) is influenced by the adequate flow of air in and out of a space and the level of contaminants within the space. Hence, it is necessary to maintain a constant supply of fresh air to dilute contaminants, control indoor humidity, and for user respiration and comfort. In classrooms, air movement could be achieved naturally through cross ventilated spaces, movement of people or it can be created mechanically using fans, furnaces or other devices. The measurable aspect of air movement can be calculated through: the ventilation rate approach (ANSI/ASHRAE55-2004, 2004; CIBSE, 2006) and the concentration of $\mathrm{CO}_{2}$ approach (Mahyuddin $\&$ Awbi, 2012). The ventilation rate approach specifies the minimum rate of ventilation necessary for a space, this is generally expressed in air changes per hour or volume per person over time (litres/second/person), and the calculation is underpinned by the relationship between occupancy levels and available space. The $\mathrm{CO}_{2}$ approach takes into consideration the sharp rise of $\mathrm{CO}_{2}$ concentration when there is a decrease in the number of air changes and is strongly influenced by the available air space per person. Allard, (1998) suggests that "to keep the $\mathrm{CO}_{2}$ concentration to below 1000 ppm for 5000 litres of air space per person, about 5 air changes per 
hour are enough, but if there are only 500 litres of air space available per person, about 25 air changes per hour are needed to achieve the same equilibrium concentration". This implies that in a classroom of about $70 \mathrm{~m}^{2}$ with a ceiling height of $2.5 \mathrm{~m}$, which translates to 175 cubic meters $(70 \times 2.5)$, assuming the space is occupied by 30 people, 175 divided by $30=5.8$ cubic meter per person which equates to 5800 litres of air space per person and about 5 to 6 air changes per hour could be roughly sufficient. The relationship between the various characteristic's components (air temperature, humidity and airflow) that determine indoor air quality is very important. Air temperature is affected by relative humidity and indoor air, outdoor humidity and surface temperatures results in the accumulation of moisture within a building envelope. During the winter period, the heating system is used to warm up the classrooms thereby warming up the classroom air. After school hours, the heating systems are turned off to conserve energy and the classroom doors and windows are locked for security purposes. At this time, and dependent on whether the classroom has been well ventilated during the day, humidity within the space is low and the air moisture is trapped within the space. As the interior surfaces (floors, walls and uninsulated materials) of the classroom cools near the dew point temperature at night, it results in the growth of moulds which pollutes the indoor environment. A study by Li, Marston \& Jones (2013) supports this assertion by stating that, during the day, New Zealand has high levels of relative humidity reaching $70-80 \%$ in coastal areas and about $10 \%$ lower inland. Levels could reach $90-100 \%$ on clear nights and could be high all year round (Li et al., 2013). At high relative humidity greater than $65 \%$, classroom building materials and furniture's releases chemicals such as formaldehyde and carpet and curtains absorb enough moisture to promote microbial growth (Armstrong \& Liaw, 2003). This implies that there are concerns of moisture problems which could lead to the growth of moulds, and when relative humidity is high with low surface temperatures, condensation forms on the surfaces, the air moisture turns into water. On cold surfaces like glass, condensation is more obvious and on plasterboard walls, it could cause fungal growth and odours in poorly ventilated rooms (Armstrong \& Liaw, 2003).

Of the two approaches of measuring air movement, $\mathrm{CO}_{2}$ concentration is the most common approach used to measure IAQ in schools, given that it is often used as a surrogate of the rate of outside air supply per occupant (Daisey et al., 2003). In schools, occupants are a major source of 
$\mathrm{CO}_{2}$ exhalation. In this study, only carbon dioxide is considered as the IAQ variable used to determine the indoor environmental quality in classrooms, because concentrations of carbon dioxide have been reported to be a good indicator of insufficient fresh air.

Many studies (Batterman \& Peng, 1995; Choi et al., 2010; Sundell, 1999; Turunen et al., 2014) of $\mathrm{IAQ}$ in schools have revealed that the amount of $\mathrm{CO}_{2}$ level within a classroom is a determinant of the indoor air quality, and a very useful measure of a room's ventilation effectiveness, given that the lower the concentration level of $\mathrm{CO}_{2}$, the fresher the air quality within a space. In well ventilated classrooms, the $\mathrm{CO}_{2}$ generated by the occupants is diluted by the flow of fresh air, while poorly ventilated rooms do not introduce enough fresh air to dilute the carbon dioxide. Aliboye, White, Graves, \& Ross, (2006) support this assertion by stating that, the concentration of $\mathrm{CO}_{2}$ is a good measure to estimate ventilation rate with $3 \mathrm{~L} / \mathrm{s}$ being equivalent to $2100 \mathrm{ppm}$ of $\mathrm{CO}_{2}$ under equilibrium conditions. "Carbon dioxide is a colourless and odourless gaseous element which, on itself is not a problem, but when at high concentration level, with a concentration of body smells (bio effluents) and other unwanted pollutants, it has a very sharp, acidic odour that is irritating to humans" (Persily, 1997). Two concepts explain the usefulness of $\mathrm{CO}_{2}$ in understanding IAQ: one is the fact that the rate of $\mathrm{CO}_{2}$ emission is dependent on the size of a person, diet and their level of physical activity. The second is that a $\mathrm{CO}_{2}$ level higher than the outdoor level can be used as a tracer gas to study ventilation effectiveness within a space. However, Persily (1997) argues that though " $\mathrm{CO}_{2}$ concentrations can be used to determine specific and limited aspects of IAQ, but they are not an overall indicator of IAQ" because there are other factors such as thermal comfort or concentrations of other contaminants within a space. Carbon dioxide does not provide information on the concentrations of the pollutant from sources such as; the activities of occupants, building materials and furnishes, and other contaminants.

The Occupational Safety and Health Service of New Zealand and the New Zealand Building Code -CLAUSE G4 Ventilation: NZS 4303: 1990 recommend a $\mathrm{CO}_{2}$ maximum limit of 1000 ppm (parts per million). In the United Kingdom, $\mathrm{CO}_{2}$ is used as an IAQ indicator for schools, and the Building Bulletin 101, (2006), prescribes a background fresh air supply rate of 3 litres per second per pupil with the capacity to supply 8 litres per second per pupil as the recommended ventilation rates 
for classrooms with $\mathrm{CO}_{2}$ maximum concentration of $5000 \mathrm{ppm}$ and a mean occupied concentration of 1500 ppm. In Germany, Standard DIN 1946 Teil 2 (1994) recommends a ventilation rate of 8.3 litres per second per pupil for classrooms. ASHRAE Standard 62-2001 (2001) states 8 litres per second per pupil for classrooms in the United Kingdom. Under sedentary conditions, and assuming an outdoor $\mathrm{CO}_{2}$ of $\sim 360 \mathrm{ppm}$, a ventilation rate of 8 litres per second per pupil corresponds to a 1000 ppm maximum indoor metabolic $\mathrm{CO}_{2}$ concentration. Ahmed, Kurnitski, \& Olesen, (2017) study for occupancy internal heat gain calculation in main building categories found that in schools, occupants generate about $17.6 \mathrm{~L} / \mathrm{h}$ of $\mathrm{CO}_{2}$ at a metabolic rate of 1.2 met and a body surface area of $1.68 \mathrm{ADU}\left(\mathrm{m}^{2}\right)$. Many researchers have often taken this value as the recommended maximum concentration for comfort and performance. Due to climate change, external atmospheric concentrations are typically about $400 \mathrm{ppm}$ and it is expected that due to normal respiration rates of occupants $\mathrm{CO}_{2}$ levels in enclosed spaces will naturally increase above atmospheric levels. 


\subsection{Summary}

The review of IEQ measurement protocols revealed that there is inconsistency in the decisions around the number of sensors used by researchers and the placement of the sensors within a classroom. The most obvious reason is the differences in the objectives of these studies. For daylight measurements, the studies suggested that a suitable location for lighting sensors should be away from the glazed area to minimize any influence of direct light, but these studies did not specify the number of sensors required to measure lighting levels that could be representative of an entire space. In the review, researchers used different heights (commonly used heights were $1.1 \mathrm{~m}, 1.5 \mathrm{~m}, 1.6 \mathrm{~m}$ and $1.8 \mathrm{~m}$ ) above the ground and did not specify the most representative area to locate these sensors in a classroom. For temperature measurements, the studies agreed that the best placement for temperature and relative humidity sensors should be away from direct irradiation from the sun, away from the windows and sources of light, cooling and heat such as the human body because temperature sensors are susceptible to radiative errors. Therefore, it is possible to infer that in a real-world building which could be impacted by solar gains at some point in time in a space, and depending on the building orientation and seasonal changes, there is a possibility that temperature and humidity will vary across a space. This variance illustrates the challenges of establishing the most appropriate approach towards field measurement of thermal comfort variables, especially in occupied classrooms. Compared to lighting, temperature and $\mathrm{CO}_{2}$ where researchers specified their preferred heights for locating sensors, studies on sound level measurements did not make much references to the position and height of sound level meters. For $\mathrm{CO}_{2}$ measurements, the most common sensor position heights were, $1.1 \mathrm{~m}, 1.5 \mathrm{~m}$ and $1.6 \mathrm{~m}$ above the ground. The researchers agreed that the best position to locate $\mathrm{CO}_{2}$ sensors was at seated head height - breathing zone in the central position of an occupied zone in an occupied classroom. They suggested that $\mathrm{CO}_{2}$ sensors should be located to avoid exposure to heat sources such as the sun and heating systems and away from windows which could influence the data values due to direct airflow. The variation of $\mathrm{CO}_{2}$ in a space is dependent on the number of occupants in the space (given that occupants' exhalation is the major source of $\mathrm{CO}_{2}$ generation), the airflow concentration and the types of ventilation systems present. When measuring $\mathrm{CO}_{2}$ levels to evaluate ventilation effectiveness, these factors might 
influence the measurement protocol (number of sensors and location). Most $\mathrm{CO}_{2}$ measurement studies were carried out in mechanically ventilated classrooms with limited information about the $\mathrm{CO}_{2}$ concentration in naturally ventilated classrooms.

Given the various factors that influence each IEQ variability as revealed by this review, it is possible to infer that when there is a plan to use a limited number of sensors/sampling locations for IEQ measurements, the knowledge of the spatial distribution of each IEQ variable is important. Measuring IEQ at a single location or height may not be an accurate indicator, or act as a true representation of the environmental performance of a space. The use of one-point sensor measurements in a simple and small building form could realistically be adequate, but there is little or no scientific evidence to support this assertion. To carry out any objective IEQ measurement at scale, the calibration of sensors, the number of sensors and the location of the sensors within a space is critical to obtaining reliable data. Hence, understanding the spatial distribution of lighting, temperature, relative humidity, sound levels and carbon dioxide will be useful to design a measurement protocol for using a limited number of sensors' to monitor these IEQ conditions at scale in many buildings to provide evidence based solutions for optimizing the design of effective ventilation strategies, visual, thermal and acoustic properties of buildings. To the best of the researcher's knowledge, no major research studies regarding the variations of IEQ conditions resulting from varying occupancy patterns and the measurement of IEQ at scale have so far been undertaken in classrooms. These problems have prompted this thesis.

Overall, the insights from this review suggest that across all five environmental variables, a height of $1.1 \mathrm{~m}, 1.5 \mathrm{~m}, 1.6 \mathrm{~m}$ and $1.8 \mathrm{~m}$ was commonly used by most researchers. From the most used heights in previous studies, this study randomly selected a height of $1.5 \mathrm{~m}$ above the ground for the measurement of each IEQ condition on the vertical walls to explore the relationship with IEQ conditions at the central horizontal measuring plane. The sensors placement takes into consideration the various factors influencing variability as reported in this review. These results are presented in Chapters 5 to 8 below. 


\section{CHAPTER FOUR: METHODOLOGY}

\subsection{Introduction}

The extensive literature review above revealed that there is no consensus on the best measurement protocol for IEQ. There was variance in the number of sensors and location (height) by different Authors. This illustrates the challenges of establishing the most appropriate approach towards field measurement of IEQ variables. Due to cost challenges, it could be difficult to measure IEQ in a national school property portfolio using multiple sensors. For example, if there is a plan to measure IEQ at a national level (estimated 35,000 learning spaces owned by the MoE) there might be cost challenges to use multiple sensors (assuming 7 sensors is required per classroom as instrumented in case study one) depending on the cost of each sensor. Therefore, to measure IEQ at scale to identify good and poor IEQ spaces, the use of a one-point sensor will suffice. But in any occupied space, not least a classroom, it can be practically impossible to measure reliable time series of IEQ at multiple locations due to the nature of the day to day activities carried out in the space.

Prior to the literature review on IEQ measurement strategy, and as part of the pilot study, multiple sensors were deployed into case study one classroom as follows:

- A tripod stand was placed at the centre of the classroom

- Three sensors were placed on the tripod stand at a height of $0.8 \mathrm{~m}, 0.4 \mathrm{~m}$ and the floor levels respectively

- Three sensors each were located on a height of $0.8 \mathrm{~m}$ on the desktop in different parts of the space

- A one-point sensor was located on each of the four walls at a head height to prevent tampering

The aim was to understand the relationship across the various sensors to inform the methodological design for this study. Unfortunately, this experiment failed, as only less than $20 \%$ of data were retrieved due to data collection challenges, which is reported in more details in Sections 4.8 and 10.3 below. The data loggers use cables that must be constantly plugged to power mains. The device also sends data wirelessly through a Wi-Fi connection to cloud storage. 
Locating a tripod stand at the centre of the classroom, which is the most usable space was intrusive and impacted on the functions of the space. Due to the daily activities of staff and students in the classroom, this instrumentation was not practicable, given that the power mains were either disconnected, switched off and the sensors covered. This led to a high percentage of missing data. The insights of this experiment suggested that permanently placing multiple data loggers in classrooms may prove difficult.

Given these challenges, a literature review on IEQ measurement strategy as reported in Chapter three was carried out. The aim was to appraise studies that have measured IEQ in schools to understand the factors these studies took into consideration while carrying out physical measurements of IEQ variables, such as their decisions around the number of sensors used and the placement of the sensors within a classroom. The review revealed that there is inconsistency in the decisions around the number of sensors used by researchers and the placement of the sensors within a classroom and the most obvious reason is the differences in the objectives of their studies. Some authors stated that they located sensors outside the centre of the classroom because of the need to protect the sensors from student's tampering and because of the recommendation from the school regarding the regular class action and the behaviour of the students (De Dear et al., 2015; Dias Pereira et al., 2014). Most of the studies (Humphreys, 1977; Chung \& Hsu, 2001; Katsoulas, 2002; Lawrence \& Braun, 2007; Norbäck \& Nordström, 2008; Geelen et al., 2008; Rosbach et al., 2013) located the sensors at a height of $1.5 \mathrm{~m}$ above floor level where it couldn't be touched. Based on the practical experience of the pilot study sensor location challenges (explained above) and the insights from the review, this study adopted a height of $1.5 \mathrm{~m}$ for the location of the vertical wall sensors (refer to Section 4.3.1 below) because it was the most commonly used heights in previous studies and would minimize any tampering.

The focus of this thesis is the school building portfolio managed by the New Zealand Ministry of Education (MoE). In early 2017, the MoE began a pilot in small and isolated schools in New Zealand with the aim to use measured IEQ data to manage its portfolio of buildings. The MoE deployed a one-point multi-variable sensors to measure light, temperature, sound levels and $\mathrm{CO}_{2}$ levels in 22 selected schools. It is intended to use these sensors as a routine measurement in schools to develop an understanding of the performance of New Zealand's school buildings, to 
guide investment decisions. Following discussions with the MoE on their pilot study, an opportunity of getting dozens of IEQ data to compare with student's achievement data, which was the original intent of this thesis came up. But considering that the volume of the MoE environmental data was enormous, the use of a single measuring point made it a subject of concern, given that lighting and $\mathrm{CO}_{2}$ levels and even the thermal environment can vary across a space. Hence, this thesis focused on a set of more fundamental questions about where, what and how to use this multi-variable sensor to measure IEQ in many buildings and get good quality data. If this is to be a nationwide tool collating thousands of data, in a world looking for evidence-based policy, it is imperative to determine whether a one-point sensor measurement can be representative of the IEQ condition of a classroom and how this data could be analysed and reported. This section describes the methods and procedure used to answer the basic research question: can a one-point sensor in each group of (school) buildings provide useful information on the IEQ performance of a portfolio of buildings?

\subsection{Research Design}

Using the New Zealand Ministry of Education portfolio as a case study, three schools were selected to investigate the two research questions. Yin, (2014) defines a case study as "an empirical inquiry that evaluates a contemporary phenomenon in depth and within its real-world context especially when the boundaries between phenomenon and context may not be clearly evident" Case studies involve descriptive, analytical and exploratory analysis of a single, multiple or group investigations to explore the causes of underlying principles and benefits from the prior development of theoretical propositions. Case study experiment uses a rigorous methodological path to test whether scientific theories and models work in the real-world context (Yin, 2014).

Three typical classrooms with heterogeneous physical characteristics were selected for the case study, to maximize differences in environmental conditions. It was hypothesised that the various seasons and building characteristics of the classrooms would generate differences in IEQ parameters. These three classrooms are standardized building designs which are commonly found in many schools across New Zealand. The literature review suggested that building design, orientation and micro-climate are factors that determine whether measured IEQ conditions 
differ significantly in classrooms. Hence, were used in the selection of the case studies classrooms:

1. Building Orientation: Case study one and three were east-west oriented classrooms while case study two was north-south oriented. The criteria used in the selection of the case studies were based on the differences in their orientation. The literature review and the pilot study had revealed that indoor environmental quality of a building could largely be influenced by the orientation of a building. For example, pilot study 2 studio which was north-facing and on the third floor of the building had more sunlight penetrating the space than pilot study 1 which was south-facing and shaded by nearby buildings (Appendix 4). Sun facing (North) or the opposite (Pole facing) have theoretically different distributions of light due to the movement of the sun across the sky and the sun or sky being the major source of light. The pilot study lighting analysis confirmed that in the north facing studio, there was a higher variability of illuminance across the sensor points than the south facing studio which had lower illuminance levels.

2. Building Design: The criteria used in the selection of the case studies were based on the differences in their spatial design, physical conditions, and organizational settings. For example, as shown in Figure 12, case study 1 classroom was a standardised building type predominant in many schools in New Zealand. It was built as three separate cellular (traditional) classrooms that were recently converted to a flexible learning space by creating an opening in the partition wall to visually connect three classrooms. As shown in Figure 13, case study two classroom was a newly built 3-unit flexible learning space, while case study three classroom (Figure 14) was a Modular building with standardized design and prevalent in many New Zealand schools (Ministry of Education, 2020)The rationale was to select classroom designs that are prevalent in most schools around the country, which suit both the traditional classroom design, the modern flexible learning environment and prefabricated buildings. New Zealand classrooms are not as rigid as conventional traditional classrooms. The classroom configuration is intended to provide 
a flexible space to allow collaborative teaching and learning practices. In this thesis, all images of the schools and classrooms were blurred due to reasons of confidentiality.

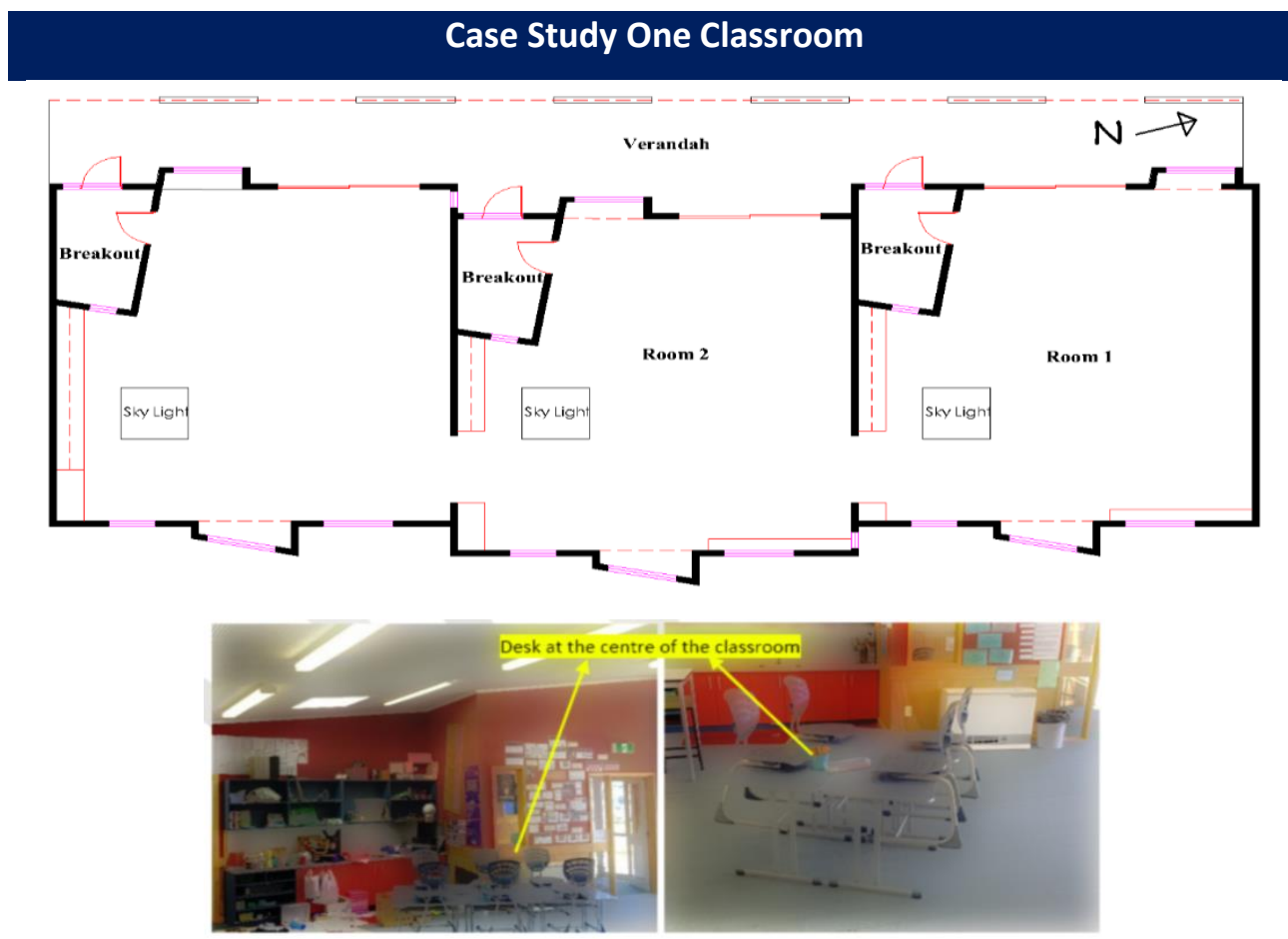

Figure 12: Floor plan of case study one classroom with internal classroom images showing furniture

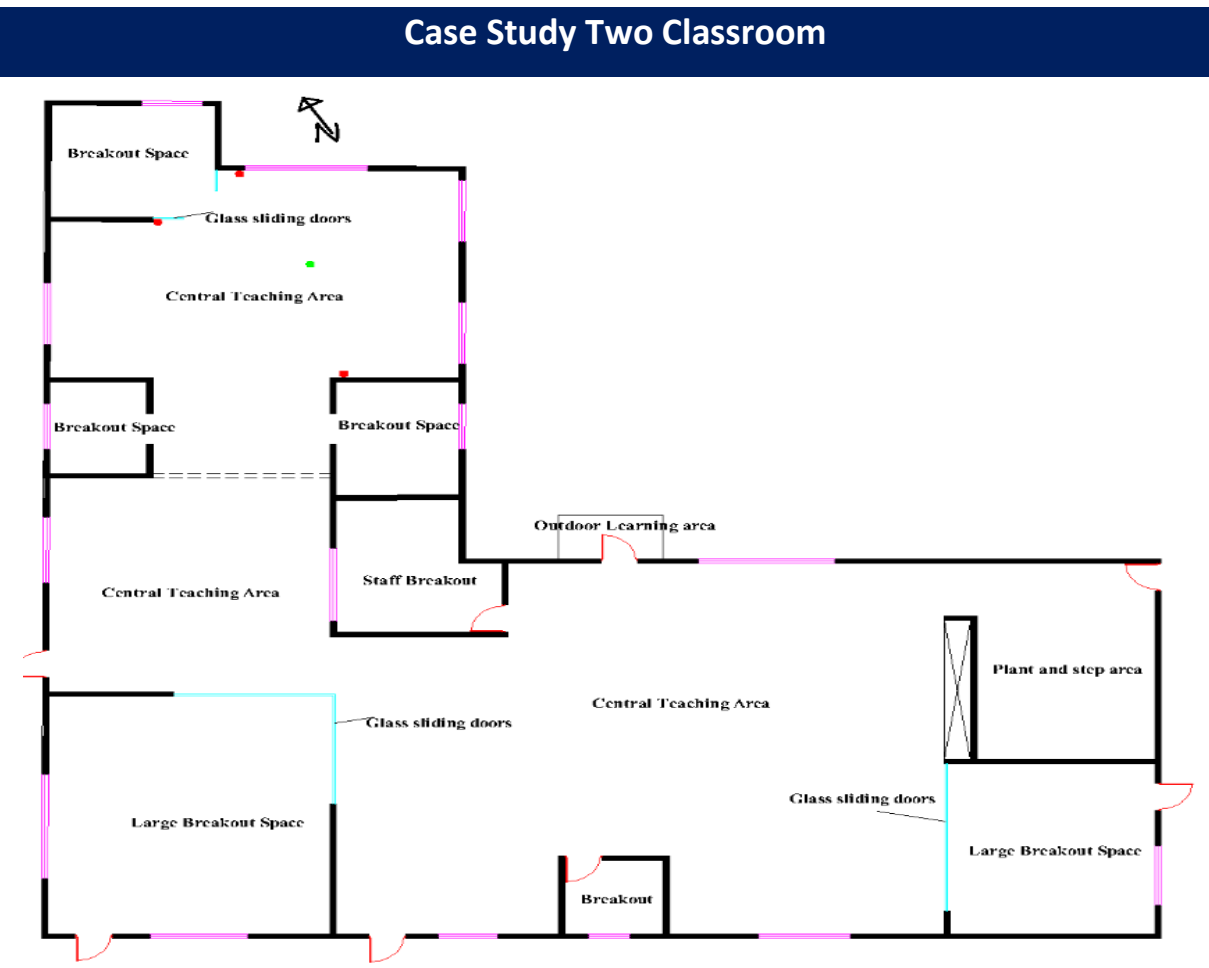




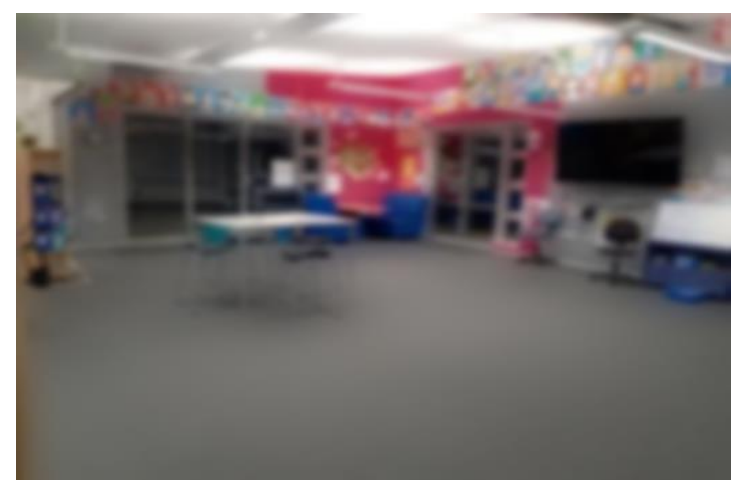

Figure 13: Floor plan of case study two classroom with internal classroom images showing furniture

3. Climate: The criteria used in the selection of the case studies was also because all three schools/classrooms are situated in the Central North (Wellington) region of New Zealand which is characterised by a mixed climate (subtropical and temperate). In Wellington, February is the hottest month with an average temperature of $19^{\circ} \mathrm{C}$, while July is the coldest month with an average temperature of $10^{\circ} \mathrm{C}$. May is the wettest month with an average of $50 \mathrm{~mm}$ of rain (MetService, 2018). However, to extend the findings of this study further will require exploring other climates, given that seasonal variations are important factors influencing the variability of IEQ, and even within the same climate category, there can be many microclimates.

\section{Case Study Three Classroom}

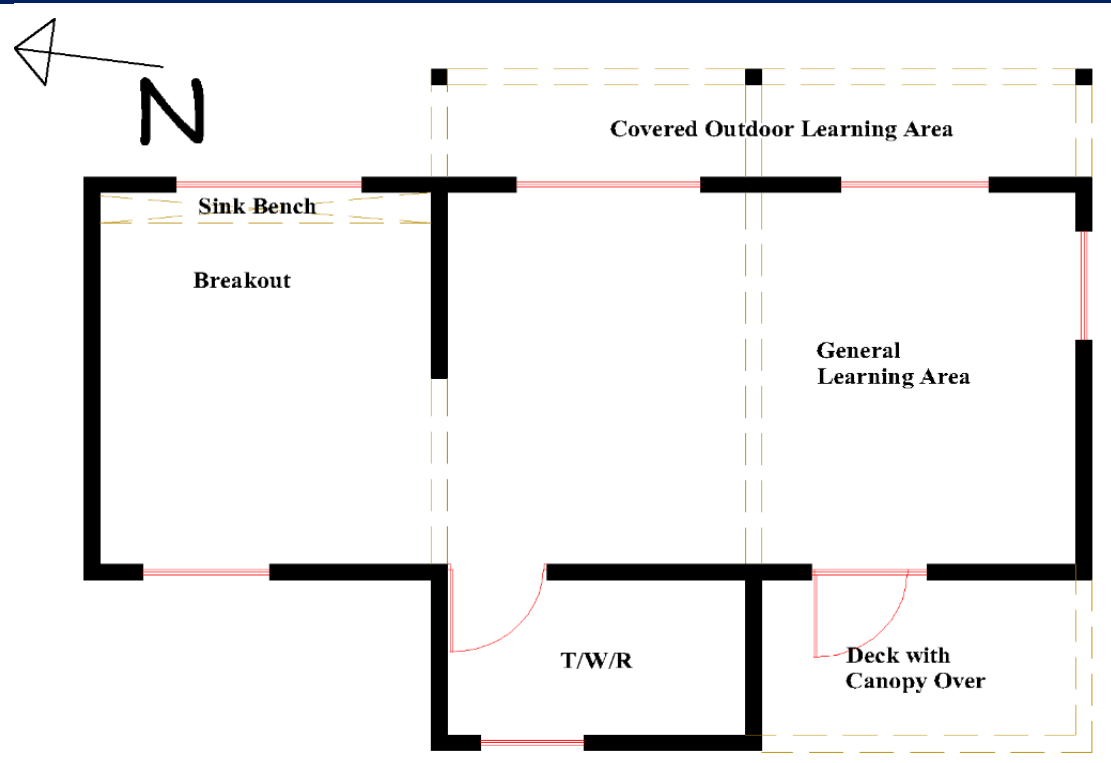




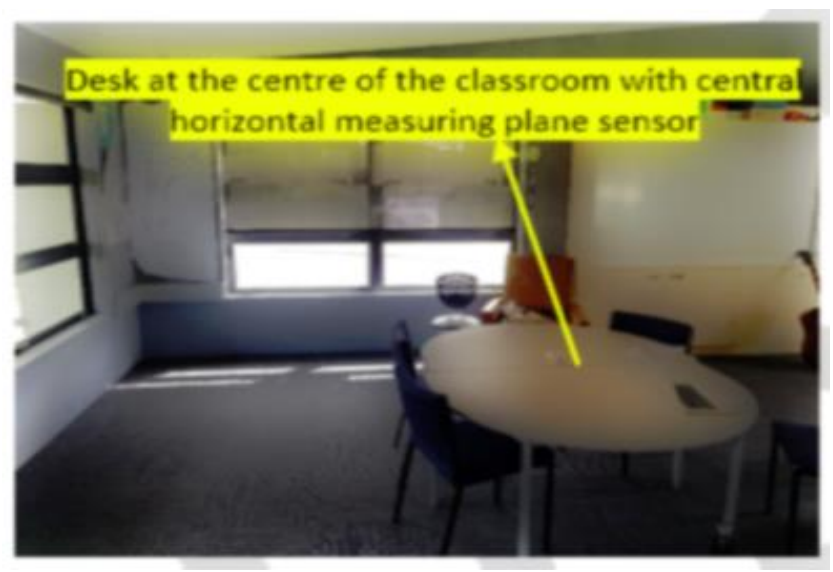

Figure 14: Floor plan of case study three classroom with internal classroom images showing furniture

It was hypothesized that:

- Given the homogeneity of the selected buildings and the different orientations; the analysis of these three classrooms would provide a useful real-world scenario to evaluate whether the plan to provide one sensor in a classroom could provide reliable data, by comparing an array of sensors with one on a wall.

- These cases will provide an opportunity to observe and analyse a phenomenon which is difficult in an occupied classroom.

- They will also show certain conditions and how their underlying processes change over time.

- It is expected that the outcome of this case study experiment will provide evidence for an analytical generalization of the research theoretical statement by providing lessons learned and principles that could apply to other scenarios.

In line with the objectives of this study, Figure 15 shows the pictorial representation of the methodology used in this study to investigate what can be learned from a one-point sensor measurement of lighting, temperature, humidity, sound level and $\mathrm{CO}_{2}$ in comparison to multiple point sensor measurement in a classroom. In this study, data was collected through physical measurements, a survey of building characteristics and onsite observation. These data were collated using Microsoft Excel. All information that might have allowed the identification of an individual or school was stripped from the data and ethical approval was received from Victoria University of Wellington's Human Ethics Committee (HEC) with decision code: 0000026850 and 
the University's human ethics process was followed during the recruitment and deployment of the data loggers. Informed consent was received from the school principals to participate in the study and the Ministry of Education were consulted during the recruitment process. This project was appraised to be low risk because no identifying or personal information of the students were collected. Any identification numbers or descriptions for school sites contained in this thesis have been transformed and are not actual values. The data collection methods are described in detail in the next section.

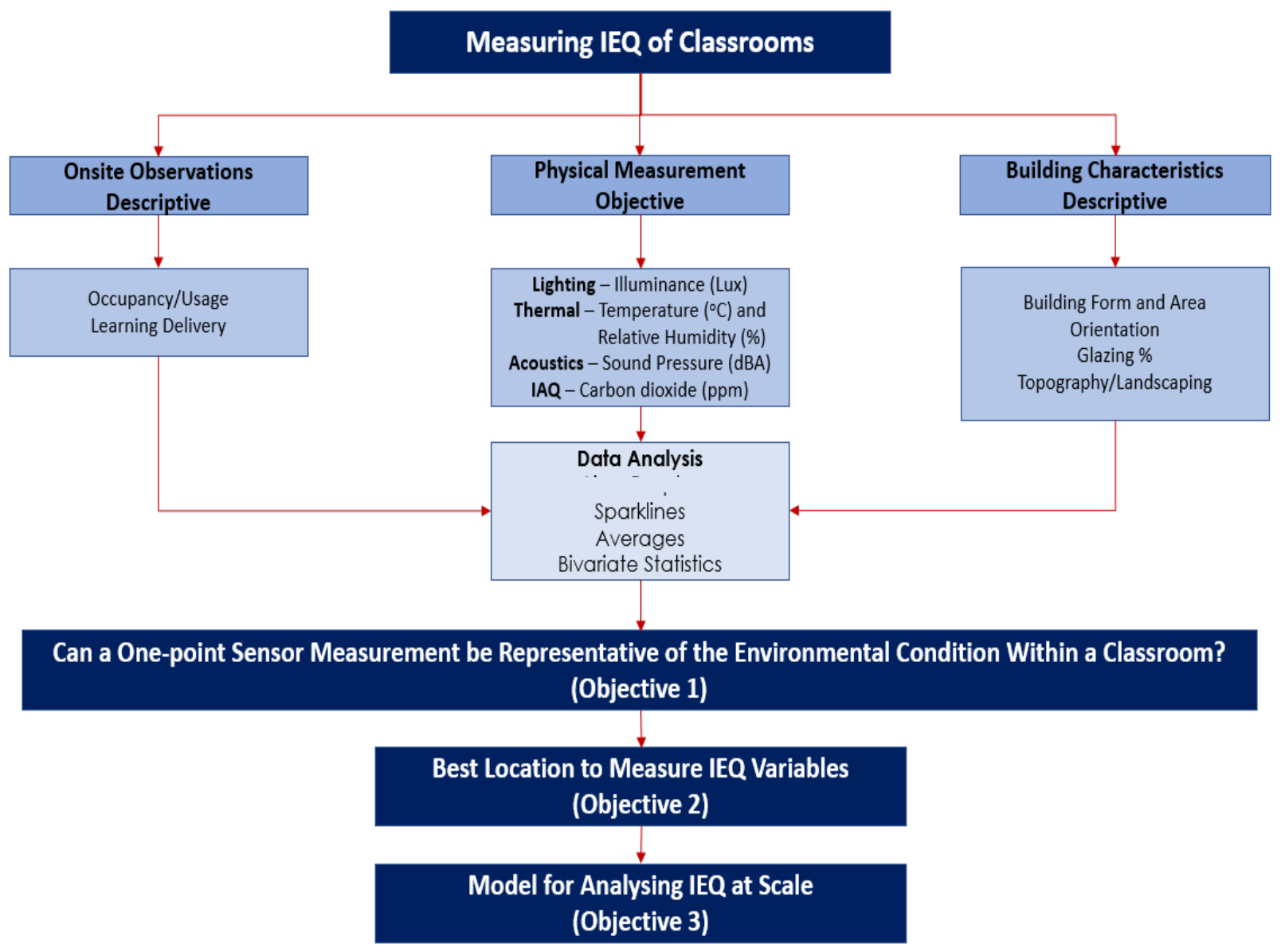

Figure 15: Research Design Structure 


\subsection{Measurement Protocol}

This study aimed to investigate if the data derived from a one-point sensor measurement on a wall can predict the environmental quality in a space. The goal of the investigation was to assess whether a one-point sensor might reliably summarise a classroom environment to identify good and poor classrooms to inform possible interventions and so that the combined relationship between IEQ and student performance might be studied.

\subsubsection{Physical Measurements}

For the physical measurement and in all three case studies, a one-point multi-variable "Smooth Classmate" device that simultaneously measures all five environmental quality variables were located on each of the four vertical walls at a height of $1.5 \mathrm{~m}$ and a horizontal measuring plane sensor was located at the centre of each classroom at a height of $0.8 \mathrm{~m}$ above the ground. "Smooth Classmate" sensor (Figure 16) is an internet-connected monitor that measures lighting, temperature, relative humidity, sound levels, $\mathrm{CO}_{2}$ and motion simultaneously. This is the sensor used by the New Zealand Ministry of Education (MoE) for IEQ measurements in schools and was provided for use in this study by the MoE.

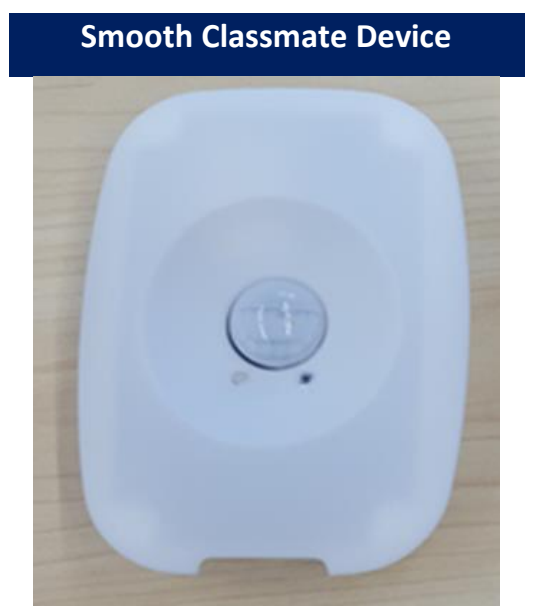

Figure 16: Image of Smooth Classmate data logger

The rationale was to compare the relationship between the vertical wall sensors with that of the sensors on the horizontal measuring plane to ascertain whether a one-point sensor on the vertical wall could be representative of the IEQ condition at the horizontal measuring plane. For example, can a vertical wall sensor serve as a proxy for IEQ at the centre of a classroom? In 
classrooms, the physical layout reflects the teaching style and tables and clusters of desks will typically be organized around the centre of the classroom, given that it will ideally have the most useful space that will be devoid of the influence of the doors, windows and human circulation. For example, in the three case study classrooms (Figures 12, 13 and 14 above), clusters of desks were arranged around the centre of the space, which made it possible to have a surface to locate the central horizontal measuring plane sensors. In the literature, studies suggested that IEQ sensors should be located away from the window to minimize any impact from external conditions such as solar radiation and airflow. Learning spaces come in all shapes and sizes, from rectangular rooms to deep open plans and windows will typically be located away from the centre of the space. Hearing, temperature, light, and quality of air breathed are about the activities undertaken by the students which will typically cluster around the centre of the classroom. The centre of the classroom typically provides the most useful space in a classroom, it is rarely influenced by external environmental factors from the doors and windows and it is most likely an average representative of the IEQ experience of people in a space. Hence, this study hypothesized that given that it is practically impossible to measure reliable time-series of IEQ in multiple locations in a real-world classroom, monitoring the centre of the classroom may provide IEQ data that is indicative of the average IEQ conditions experienced by most occupants'. This informed the rationale to compare whether IEQ measured on the vertical wall can be representative of the IEQ conditions at the centre of the horizontal measuring plane.

The measurement protocol included monitoring of the daily outdoor temperature, relative humidity, lighting, sound, and $\mathrm{CO}_{2}$ Levels. The measurement interval was 10 seconds, that is 6 values per IEQ variable, per minute, and when multiplied by 60 minutes equals to 360 IEQ values per hour and translates to 8,640 IEQ values per day. Given that this study aims to identify trends and patterns between horizontal and vertical sensors, the least possible measurement interval was hypothesized to be useful. This is because the time constant will most likely show certain IEQ conditions (when looking to identify events, like short term peaks (or troughs) in the data) and how the underlying processes change over time. IEQ variables could frequently vary even within a short duration of time in a day and very large time series are likely to underrepresent the factors influencing variability. 
The sensors were positioned in accordance with international recommendations (ISO, 2001), avoiding windows and proximity to any HVAC systems. Caution was taken to avoid any disruption of the day to day learning activities of the pupils and to ensure that the teachers and pupils were comfortable with the deployment. The students in the case study classrooms were within the age bracket of 5-10 years and each classroom unit had an occupancy number of 30 students. The measurements were transmitted automatically and continuously from the schools wirelessly network to an online IEQ database managed by the Ministry of Education (MoE), New Zealand. This data was thereafter collected from the MoE in a JSON format and converted into Excel for analysis. The data was collected for a minimum of 7 days in summer (February), late autumn (May) and Spring (October) and analysed using Excel. The rationale for selecting these three seasons was because, in naturally ventilated classrooms, the variation in daylight and temperature from one point in a space to another is largely due to the intensity and direction of the sun, and these seasons will present the worst-case scenarios. The winter season was not monitored because internal temperature differences during winter in occupied classrooms are more regulated due to the use of heating systems. The classroom doors and windows are usually closed, and the room is heated to a set temperature, thereby reducing the impact of external temperature on the distribution of indoor levels. Also, winter is characterised by overcast sky conditions, thereby reducing the overall daylight levels and the potential for high solar radiation. Given the nature of occupied classrooms (due to the way the occupants use the space), IEQ measurements in the late autumn month of May are not likely to be different across the classroom in comparison to the winter months of June, July and August.

An analysis of the climate data indicated that the three seasons selected are largely representative of the weather conditions across the year. For external temperature levels, there appears to be very little difference between the average monthly temperature levels in May (late autumn) and the winter months of June to August in Wellington. For example, Figure 17 demonstrates that the mean temperature difference between the month of May and the winter months of June, July and August is relatively small. In Figure 18, it can be seen that heating is required in all the months of May, June, July, and August because the dry bulb temperature is 
almost always less than $20^{\circ} \mathrm{C}$ during the school hours of 9am to $3 \mathrm{pm}$. In Figure 19 , outdoor humidity levels are largely $\pm 80 \%$ all year round.

At the opposite extreme, and in Figure 18, the month of February is the warmest month with dry bulb temperatures often between $20-24^{\circ} \mathrm{C}$ and even above $24^{\circ} \mathrm{C}$ in the afternoons. The analyses in Figures 17-19 were retrieved from annual weather data for Wellington downloaded from the energy plus database of standardised weather data for energy performance simulation. This data is derived from 30 years of recorded information and it is intended to be typical of Wellington's weather and Climate Consultant 6.0 software was used to compare the average monthly external temperature, hourly dry bulb temperature and humidity levels.

In the pilot study (Section 4.11) and simulation analysis (Section 5.1), daylight was the variable that had the highest variation across a space. The variation of daylight was mostly due to the intensity of the sun at a point in time and the winter season simulation results showed the best relationship between vertical and horizontal sensors, compared to autumn, spring and summer which generally has more periods of sunshine and higher temperatures. This informed the rationale to also measure the month of February and October, given that temperature, lighting, relative humidity and $\mathrm{CO}_{2}$ levels will be less regulated by the way occupants use a naturally ventilated classroom.

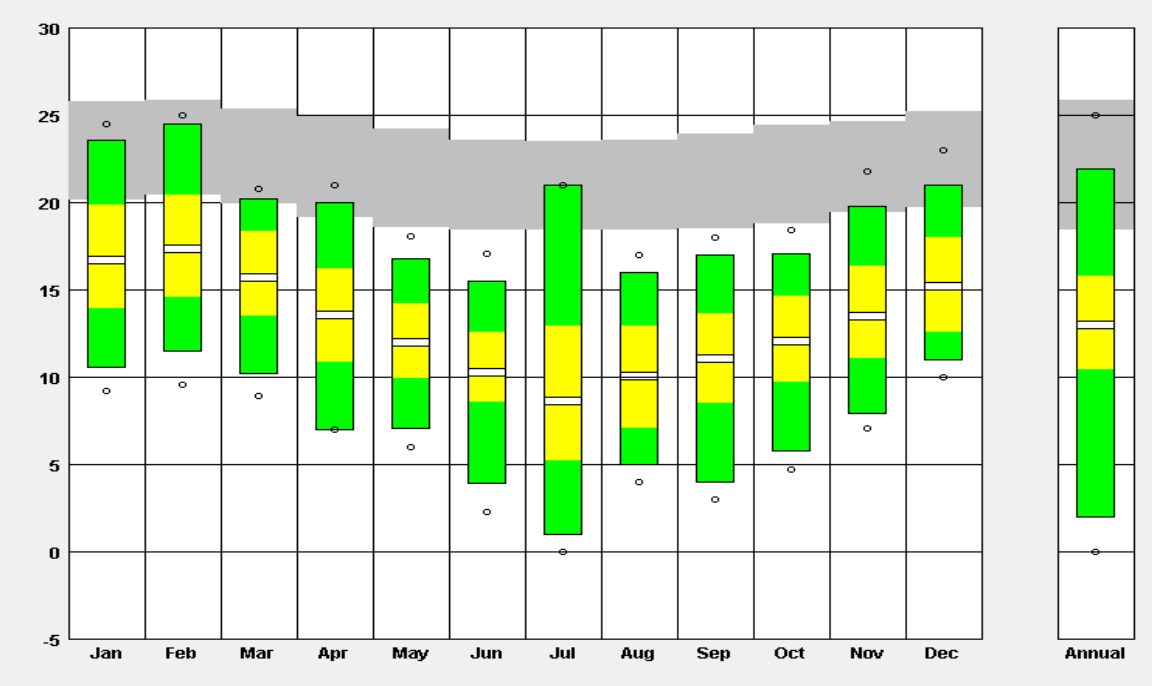

Figure 17: Average monthly outdoor temperature in Wellington, New Zealand

\section{LE GEND}

RECORDED HIGH - 。 DESIGN HIGH AVERAGE HIGH -

MEAN AVERAGE LOW DESIGN LOW RECORDED LOW - 。 COMFORT ZONE 

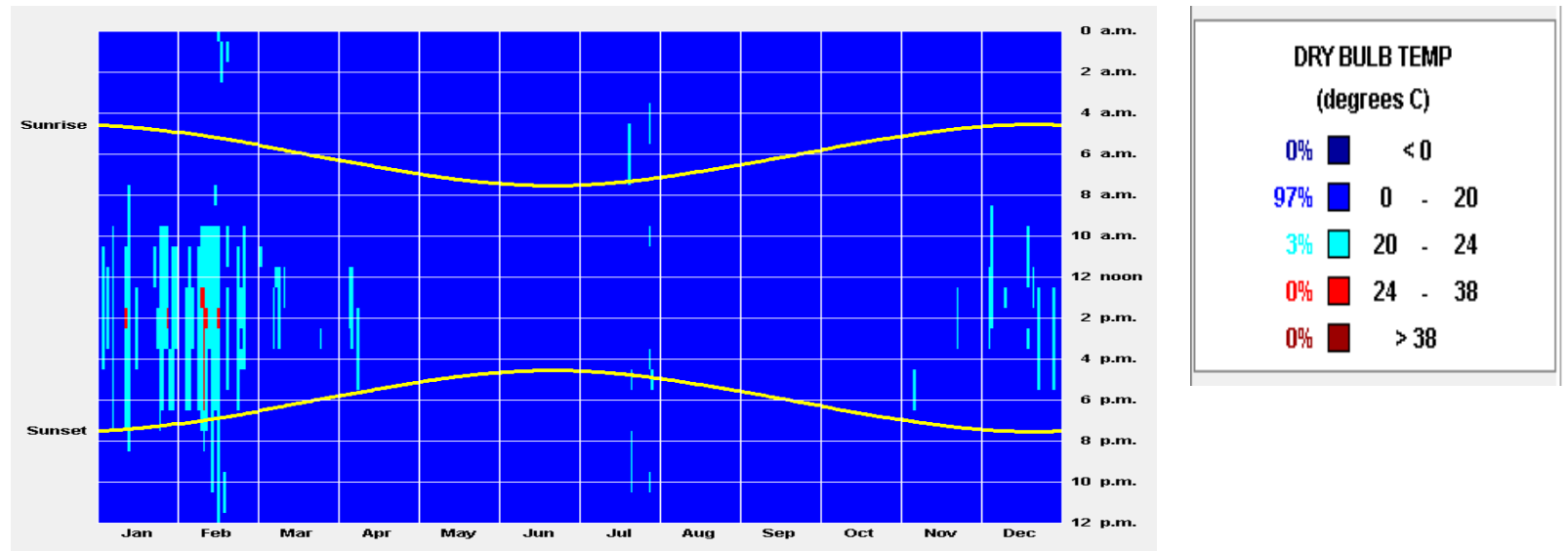

Figure 18: Hourly dry bulb temperature per month in Wellington, New Zealand
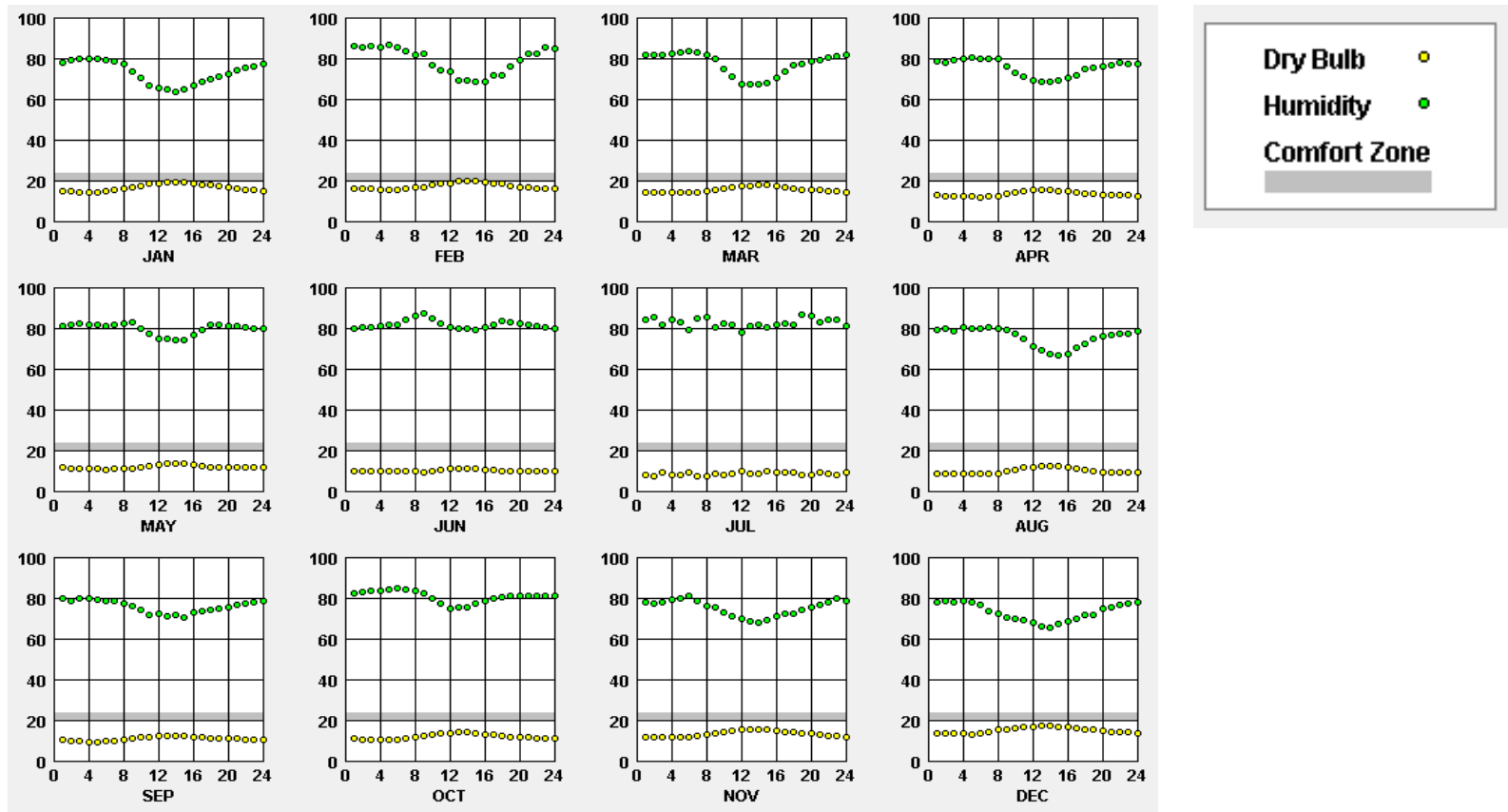

Figure 19: Average monthly outdoor humidity and dry bulb temperature in Wellington, New Zealand

Overall, external environmental factors such as the sun were identified as a major source of IEQ variability in indoor environments, in the literature and simulation analysis. Hence, autumn, spring and summer were chosen for further investigations because these seasons provide worstcase scenarios to explore trends and patterns in the distribution of IEQ in a naturally ventilated space. Other IEQ building indicators, such as window configuration, were also well documented using the templates in Appendix 2 and 3. In all three case study classrooms, calibration of the sensors was carried out immediately after the sensors were deployed and immediately before 
they were removed as explained further in Chapter 4.9 below. More details about the measurement protocol in each case study classroom are explained in the next sections.

\subsubsection{Observations and Survey}

This stage involved the collation and analyses of the physical characteristics of each of the selected classrooms. The researcher carried out observations for one school day in each of the three case study classrooms. This involved using a pre-designed template (Table 13, Appendix 2 and 3 ) to record how the spaces were used by the occupants, such as but not limited to the following: observation of occupant's action to open and close their doors and windows, the use of blinds, movement patterns, break periods and learning activities carried out. During the deployment of sensors, the researcher used reference sensors (refer to Appendix 4.1) to carry out spot measurements in all case study classrooms. For example, when the students gathered in one of the teaching spaces for a class meeting, the reference sensor was used to measure the $\mathrm{CO}^{2}$ levels to provide a benchmark for analysing the data. The observation data and experience was useful in interpreting the trends and patterns of the measured data reported in Chapters 5 to 8 below.

Furthermore, the New Zealand Ministry of Education provided information about the physical conditions of the schools and classrooms from their various facility database, such as the refurbishment and maintenance records and the building age records, etc. This consisted primarily of the initial construction data of the school; school roll and gross area; the number of classrooms; and other resources on-site such as libraries or multipurpose rooms. From onsite surveys, data on space usage observations, site conditions, vegetation patterns, topographic features, building orientation were collated and analysed. The location and weather conditions and other site features such as proximity to major roads were also identified.

The analysis of this data such as the survey of architectural plans and features of the buildings and analysis of the building materials of the interior spaces of the classrooms are discussed in the next section. The observations and survey were carried out to provide insights about visual trends and patterns in the measured data. For example, Table 13 shows the template used to collate lighting and window operation data (see Appendix 2 and 3 for other templates and raw data). 
Table 13: Lighting and Window Operation Schedule Template

\begin{tabular}{|l|l|l|l|}
\hline Lighting Operation Schedule \\
\hline Date & Switch on Time & Switched off Time & Comments \\
\hline $16 / 02 / 2019$ & Off & Off & Weekend \\
\hline $17 / 02 / 2019$ & Nil & Nil & Weekend \\
\hline $18 / 02 / 2019$ & $8: 00 \mathrm{am}$ & $3: 30 \mathrm{pm}$ & $\begin{array}{l}\text { School day: Switch off is dependent on when } \\
\text { the last person leaves the space }\end{array}$ \\
\hline $19 / 02 / 2019$ & $8: 00 \mathrm{am}$ & $3: 30 \mathrm{pm}$ & $\begin{array}{l}\text { School day: Switch off is dependent on when } \\
\text { the last person leaves the space }\end{array}$ \\
\hline
\end{tabular}

\section{Windows and Doors Operation Schedule}

\begin{tabular}{|l|l|l|l|}
\hline Date & Open & Close & Comments \\
\hline $16 / 02 / 2019$ & & Yes & Weekend \\
\hline $17 / 02 / 2019$ & & Nil & Weekend \\
\hline $18 / 02 / 2019$ & Yes & & $\begin{array}{l}\text { Some windows at the East and West walls } \\
\text { were open }\end{array}$ \\
\hline $19 / 02 / 2019$ & Yes & $\begin{array}{l}\text { Some windows at the East and West walls } \\
\text { were open }\end{array}$ \\
\hline
\end{tabular}

\section{4: Case Study One Monitoring Protocol}

In Figure 20, seven sensors annotated as A1-3 (horizontal plane sensors placed on the desk looking upwards) and B1-4 (vertical wall sensors placed on the wall looking at right angles to the horizontal plane) were deployed into the space for 7 days in both summer and autumn of 2019. Given that the three classroom units (Figure 12) were almost identical in terms of plan and glazing, only one unit was instrumented. The aim was to compare the spatial relationship between the multiple horizontal measuring planes sensors (A1-3) positioned at a height of $0.8 \mathrm{~m}$ above the ground with that of the vertical one-point sensors on each of the 4 walls (B1-4) positioned at a height of $1.5 \mathrm{~m}$ above the ground. A single external sensor was also placed at a height of $1.5 \mathrm{~m}$ in the outside covered corridor. The aim was to ascertain whether a one-point sensor on the vertical wall could be representative of IEQ conditions across the horizontal measuring plane. 


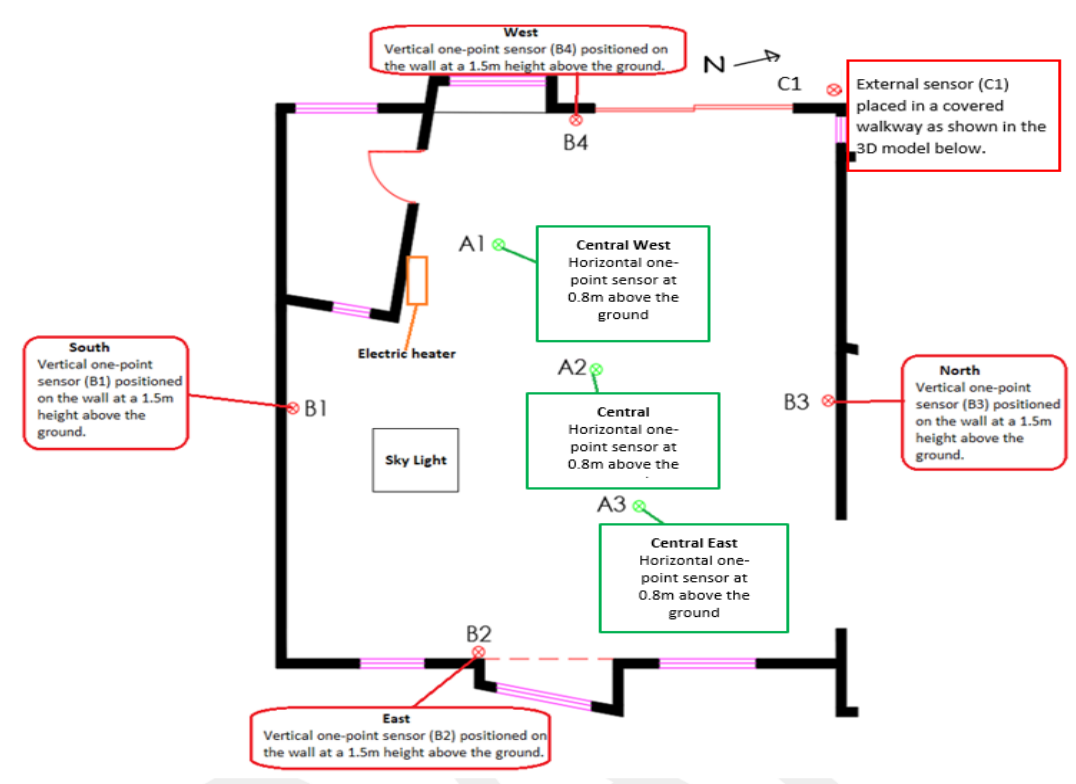

Figure 20:Plan annotation of 7 sensors placed within a unit in the flexible learning classroom

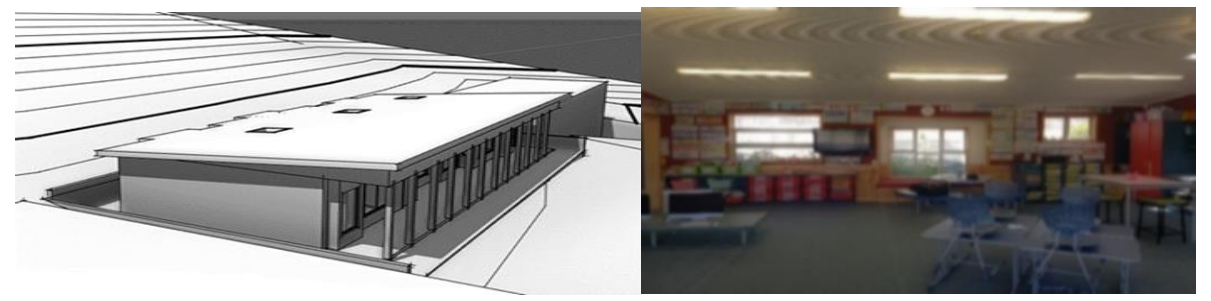

Figure 21:Image of the modelled external environment and internal environment of the classroom building

\section{5: Case Study Two Monitoring Protocol}

In Figure 22, four sensors annotated as A1 (horizontal plane sensors placed on the desk looking upwards) and B1-3 (vertical wall sensors placed on the wall looking at right angles to the horizontal plane) were deployed into the space for 7 days in autumn of 2019. The number of sensors deployed into the classroom was limited by space usage. The rationale was to use this north-south facing classroom as a control to explore whether there will be any difference in the results of this experiment compared to the findings of case study one. The aim was to ascertain whether a one-point sensor on the vertical wall could be representative of IEQ conditions at the centre of the horizontal measuring plane. 

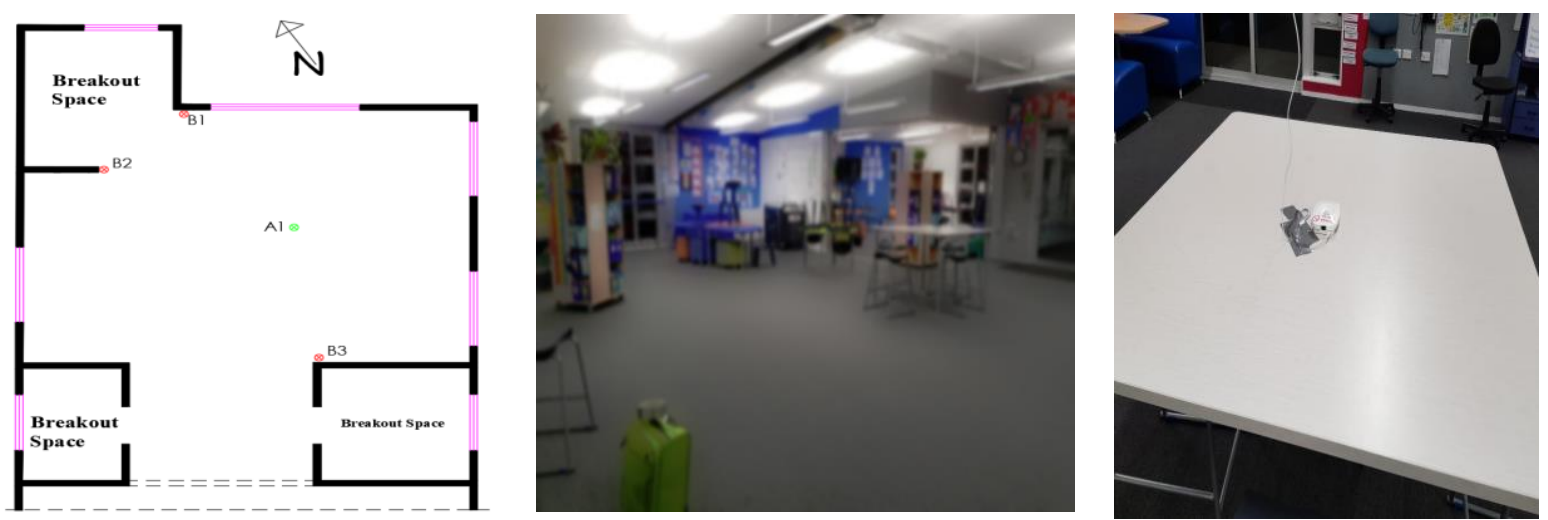

Figure 22: Plan annotation of 4 sensors placed within a unit in the flexible learning classroom and interior images

\section{6: Case Study Three Monitoring Protocol}

In Figure 23, this study went further to investigate the spatial relationship between multiple vertical sensors positioned at a height of $1.5 \mathrm{~m}$ above the ground with that of the horizontal plane sensor measured on the desk in a typical Modular Building. Five data loggers that simultaneously measures all five environmental variables were placed in one sampling point at the centre of the learning space and the centre of the four walls during spring in 2019. The data loggers are annotated as A1 (central sensor - horizontal plane sensor placed on the desk looking upwards) and B1-4 (vertical sensors placed on the wall looking at right angles to the horizontal plane) respectively with the corresponding wall orientation (north, south, east or west) it was placed on. The sensor location was determined following lessons learned from the pilot study and case study one and two.

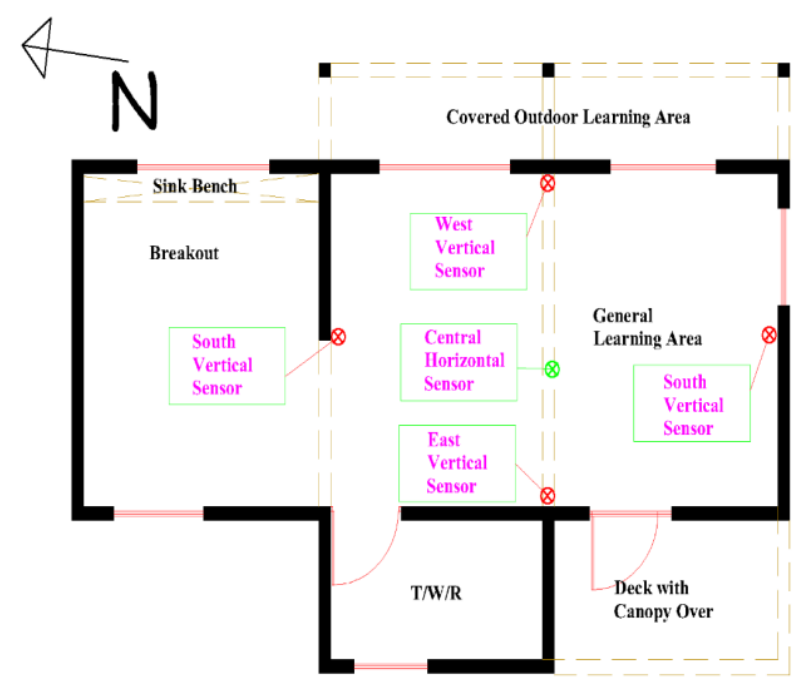

Figure 23: Plan annotation of 5 sensors placed within a unit in the single modular building 


\subsection{Case Study Classrooms Survey}

The need for long-term measurement of IEQ in schools is advantageous, in terms of recorded environmental variables to understand IEQ variation and interaction with building characteristics and how this might inform interventions. The section analyses the case study building design characteristics to provide more insights to understand trends and patterns in the measured data. In this study, three flexible learning spaces with different building characteristics were explored. The rationale was to use an inductive analysis to observe and understand the possible patterns of IEQ variation in occupied and unoccupied spaces, aimed at identifying the best location for a one-point multi-variable sensor for measurement of IEQ at scale in buildings. The classroom selection criteria are further explained below.

\subsubsection{Building Characteristics of Case Study One Classroom}

Case study one classroom is a purpose-built typical classroom which is referred to as an Avalon block. These were generally constructed between 1955 and 1965. The Avalon block was constructed in a wide range of schools across the country. It is a single storey structure that is characterised by near full height and width windows. They were built as a single classroom block with 3 to 4 typical classroom units (teaching spaces). As shown in Figure 24 and 25, the building was recently remediated, and the layout provided the flexibility to create large openings the partition walls, to visually connect the three units and make the spaces more flexible to meet the teaching style of the teachers. Also, the cloakrooms were converted into smaller breakout spaces as shown in Figure 12 above. The building's roof is a corrugated metal roofing with timber framed trusses and a skylight on each of the three classroom units. The building wall is made of light timber framing with timber weatherboards and walls lined with plasterboard. In the recent remediation of the block, the entire wall between all classrooms and the toilet/cloakrooms was demolished. The toilets and cloakrooms were converted into breakout spaces by constructing new walls to form three breakout areas with $3.6 \mathrm{~m} \times 2.2 \mathrm{~m}$ in each of the three classroom units (Figure 12) openings were created between the walls in the three units and new toilet attached to end of the building. The building has a largely glazed front façade to classrooms with a veranda at the entrance and appears to have good natural cross ventilation when windows at both sides of the classroom are open. The veranda has solar control façade system at the western side of 
the classroom especially. The form and orientation of the classroom were arranged to allow effective crossflow ventilation, with a good mix of high and low windows to each side, and a highlevel clerestory window. However, the breakout spaces' position seems to limit the effectiveness of cross ventilation as they can be closed off, and it was observed that occupants opened windows at one side of the building, resulting in single-sided ventilation to the central teaching spaces. The classroom did not require heat pumps for summertime cooling to the central teaching spaces due to the rectangular narrow depth of the buildings which allowed for passive cooling through opening windows to each space, hence these spaces used radiant heating for keeping the space warm.

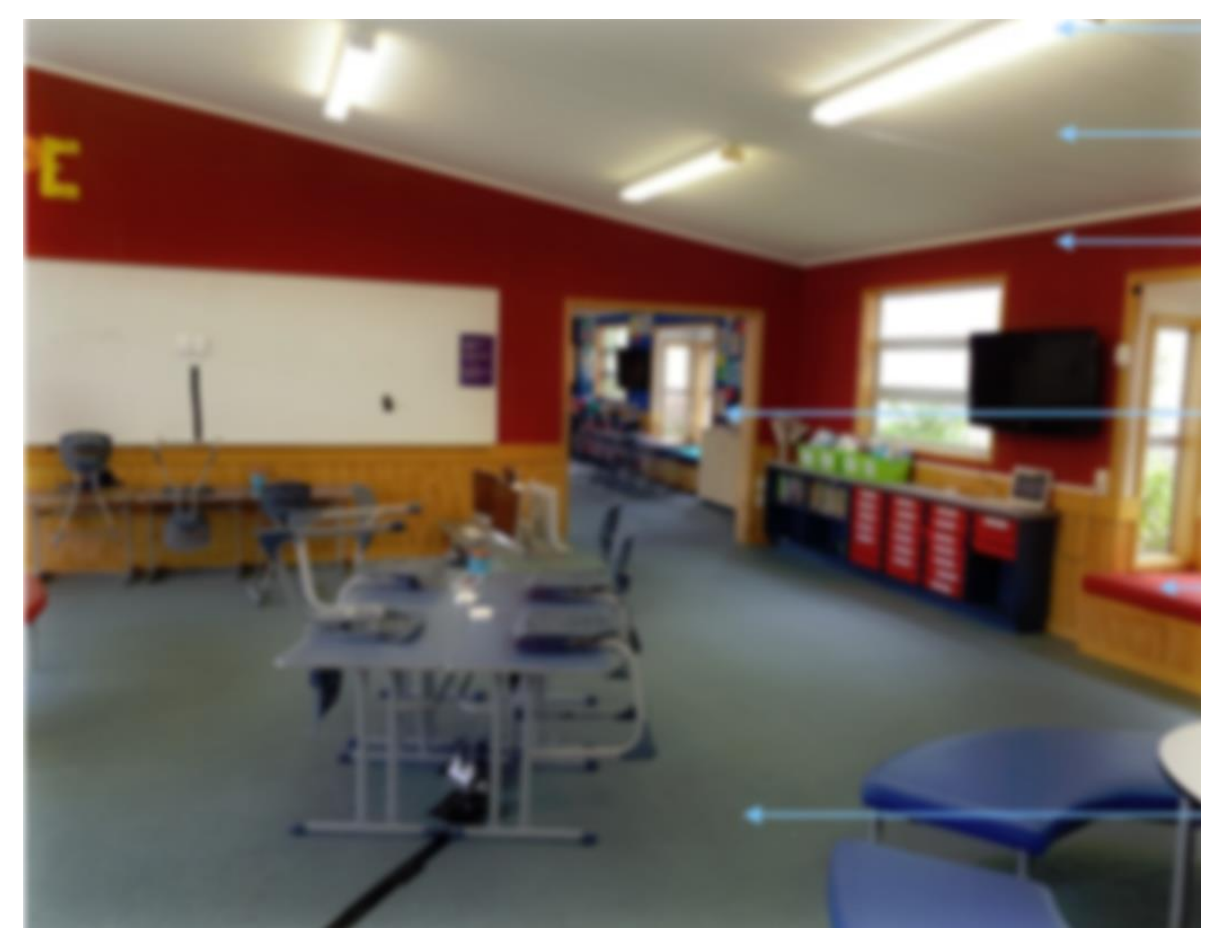

Figure 24: Interior Image Showing Openings Connecting Learning Spaces and Building Characteristics 
Table 14: Case Study Schools Classroom Building Components

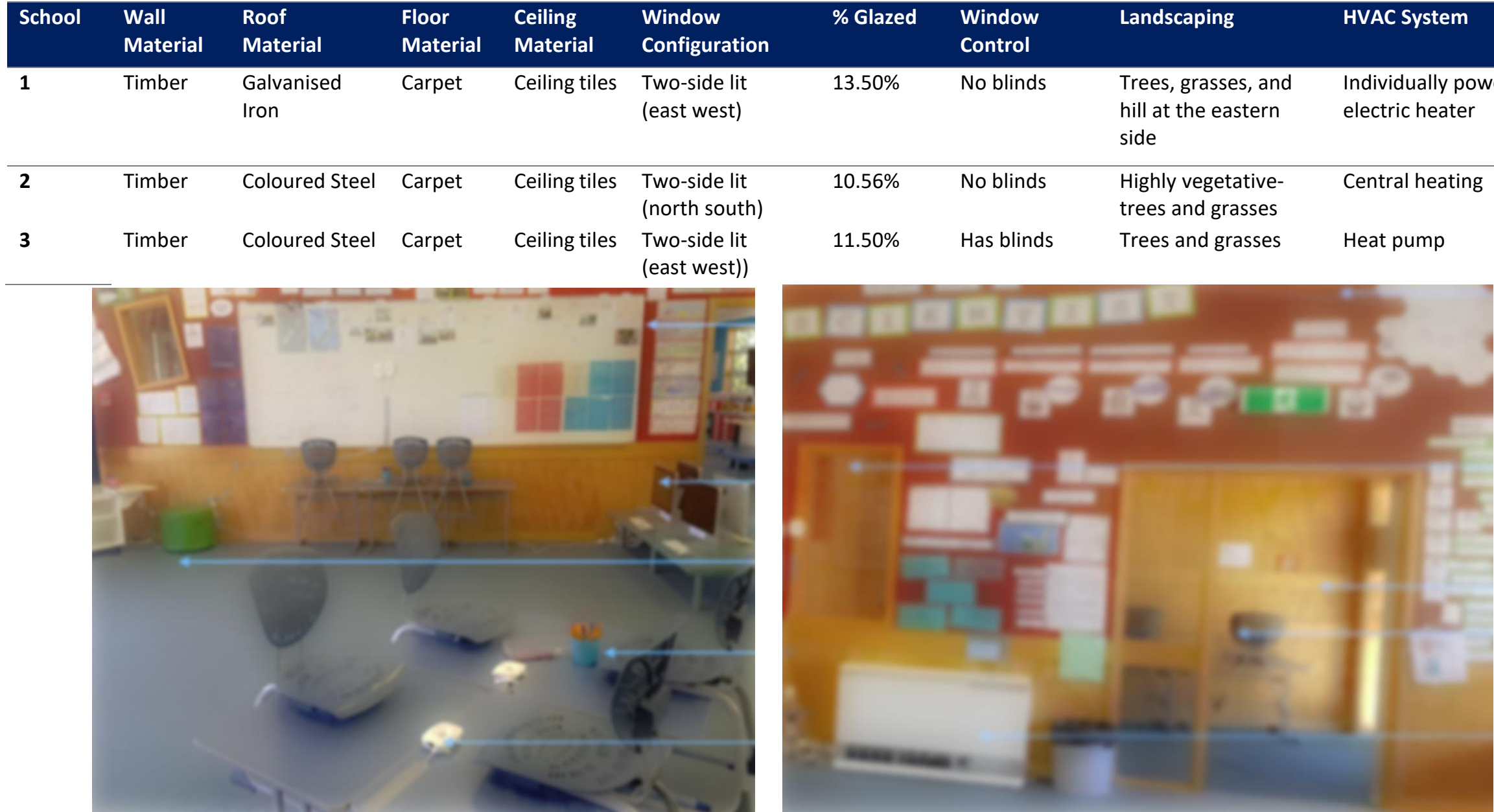

Figure 25: Interior image of case study one classroom showing furniture's and fixtures, individually powered electric heater and connection between teaching space and breakout space. 


\subsubsection{Building Characteristics of Case Study Two Classroom}

Case study two building is a recently built flexible learning space with three-teaching spaces. It is surrounded by distant high hills with the presence of vegetation around the site. The teaching spaces have small and large breakout spaces which are separated with glass partitions (Figure 26). The building's roof is a trapezoidal warm roof system, trapezoidal base deck, with thermal insulation, building wrap and prefinished trapezoidal roofing over. The teaching space ceiling is made of acoustic ceiling panels in suspended exposed 2-way grid, following roof slope and it is suspended between primary steel beams. Roof waterfalls into gutters and downpipes, which connect to stormwater drains. The walls were constructed with timber framing. The school is in a quiet neighbourhood and no instances of high external noise were identified during the observation period.

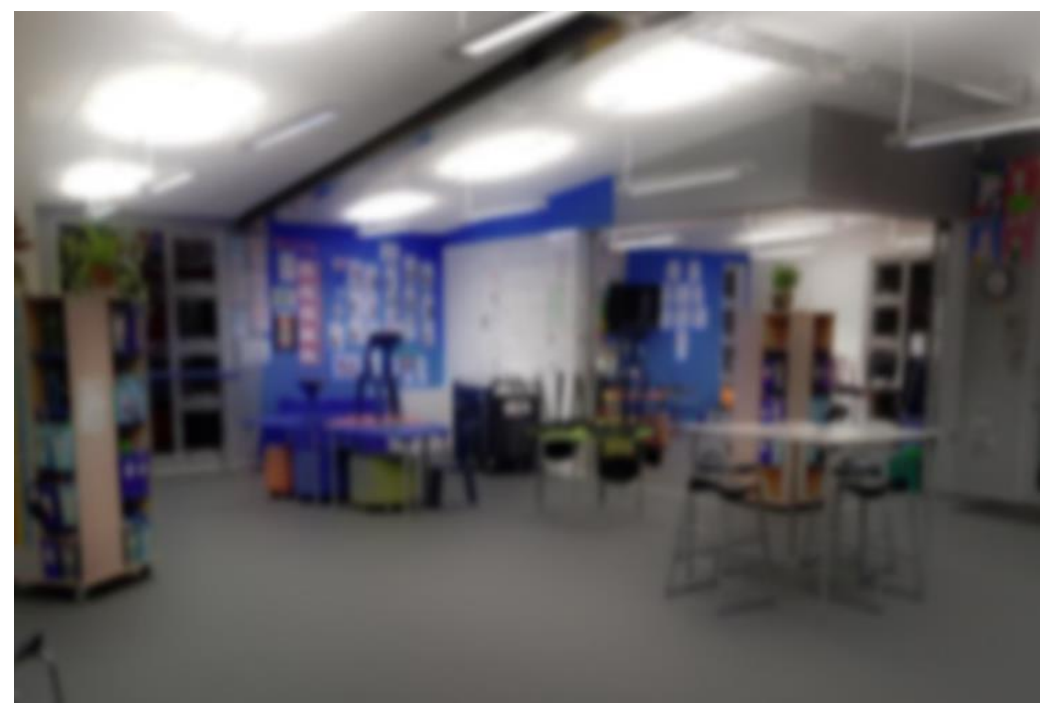

Figure 26: Internal image showing the relationship between break out and teaching spaces

The external windows and doors are made of powder coated aluminium frames which are double glazed and toughened safety glazing. The louvres are in three banks, low, middle and high to allow for manual operation and flexibility. The internal windows are also powder coated aluminium glazing in timber framed walls and are single glazed laminated Hush Glass. The internal sliding doors are powder coated aluminium glazed doors, single and double sliding with the bottom track to doors for acoustic seals while some of the external doors are hinged and with one sliding door. The building has a gas fired boiler unit, located in the plant area under the stairs, vented to outside with in-slab hot water heating pipes. It is a naturally ventilated space 
through manually openable windows and the teaching spaces have a suspended LED fitting with surface mounted fittings to toilets, stair lobby ceilings and external soffits and wall mounted bulkheads to exterior lights. Switching was through a mixture of occupancy sensors and wall mounted switches.

\subsubsection{Building Characteristics of Case Study Three Classroom}

Case study three classroom is a recently built Modular Building with a length of $10.8 \mathrm{~m}$ by $7.7 \mathrm{~m}$ width with a $3.0 \mathrm{~m}$ by $3.6 \mathrm{~m}$ washroom and a canopied deck (outdoor learning area) of $10.8 \mathrm{~m}$ by $2.4 \mathrm{~m}$. Modular Buildings are prefabricated and allow for a variety of sizes and shapes and can be configured either as one module, and combinations of one module in multiples of 2, 3 and 4 classequivalent studios respectively. In New Zealand, the Ministry of Education (MoE) has an ongoing programme that provides Modular Buildings to schools for both short- and long-term space solutions. Although Modular Buildings were initially required as temporary buildings for: (1) roll growth that's unlikely to be sustained; and, (2) replacement buildings at schools with declining rolls, it has over the years become permanent school buildings. The Modular buildings are prefabricated in factories and are designed to be flexible, so they can be used for teaching, staff and student support spaces and can be relocated from one school to another with relative ease. These buildings are standardized designs which are commonly found in many schools across New Zealand. Given the prevalence of Modular Buildings in New Zealand schools, this study investigates the relationship between multiple vertical sensors positioned at a height of $1.5 \mathrm{~m}$ above the ground with that of the horizontal plane sensors positioned on the desk. 


\subsubsection{Summary}

This study focused on the New Zealand context. Geographically, the country comprises two main landmasses, the North Island and the South Island (Figure 27). The climate of New Zealand is complex and varies from cool temperate climates in the far south to a warm subtropical climate in the far north with mean annual temperatures ranging from $10^{\circ} \mathrm{C}$ in the south to $16^{\circ} \mathrm{C}$ in the north (MetService, 2018). Being in the southern hemisphere, the sun is in the north at mid-day in New Zealand. The month of February is usually the warmest while July is the coldest month. The country is divided into three different climate regions due to mountain chains which provide prevailing westerly winds (MetService, 2018) and the Ministry of Education further subcategorises these three climate regions as shown in Figure 27. As an example of a climate, the three case studies were carried out in Wellington which is in the Central Island climate. To extend the findings of this study further may require exploring other climates, given the significant variation in the climate regions from the far north to the far south of the country as shown in Figure 27. Wellington is the capital (urban area) of New Zealand and the third largest urban region in New Zealand, with approximately 413,000 people.

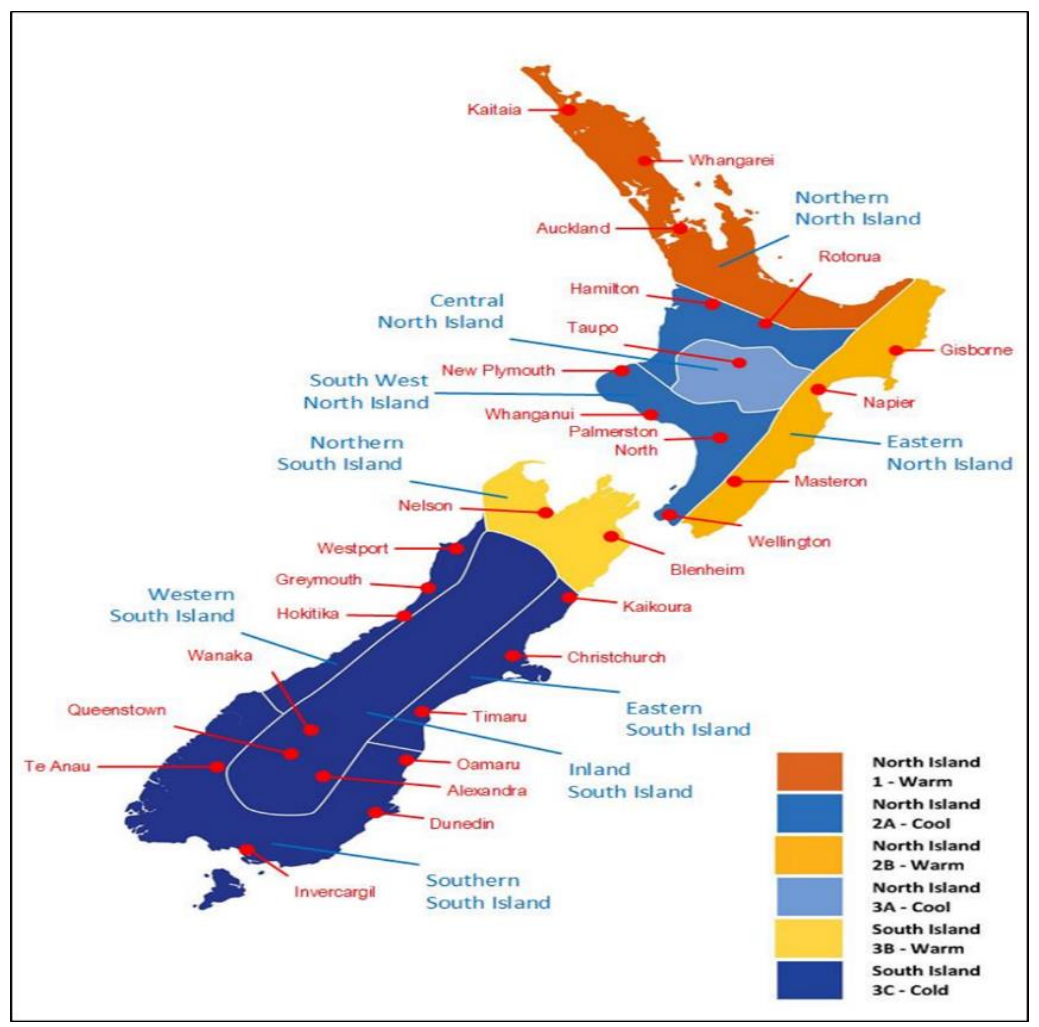

Figure 27: Ministry of Education's Climate Zones, Source: DQLS (2017) 


\subsection{Data Collection Challenges}

In common with any measurement device that requires the use of technology to transmit data wirelessly, there were data challenges in the collation of environmental variables from the case study classroom. The observed challenges were:

- Technology: In the pilot study, the collated data was transmitted wirelessly from the sensors through a mobile Wi-Fi to an online IEQ database managed by the MoE and device providers. It was observed that the sensors intermittently lost connection and failed to transmit data to the server. This was revealed by the high percentage of missing data streams retrieved from the MoE sensors platform. However, subsequent diagnostic revealed that the difficulty to transmit data could have been because of poor internet connection, radiofrequency, and had some relationship with the device. Following this, the MoE contacted the sensor providers to work on fixing the missing data challenges. During the case study school monitoring, the sensors were connected to the school's WiFi which minimized the impact of connectivity issues

- Location of Sensors: There was difficulty in placing multiple sensors in all three case study classrooms. This was due to the usage of the space. The aim was to place an array of horizontal measuring plane sensors, but to minimise any major disruption to student's teaching and learning, so the central horizontal plane sensor was used as a surrogate for the average IEQ conditions that is representative of the usable space in a classroom

- Occupancy and Usage: For the continuous collation of environmental data, it is a requirement that the sensors are constantly plugged into a source of power. Duct tape was used to pin the sensors electrical wires to a surface to avoid potential health and safety risk. The students were also advised not to switch off the power source and a "do not remove" notice was put on the power outlet. However, due to occupancy and usage of the space, there were instances where a sensor was mistakenly disconnected from its source of power. When these instances were observed, the researcher took note of the sensor's code. This did not affect the analysis as the days that had large missing data were excluded 
- External Data Sensor: Though the external data sensor appeared to have worked well during on-site observation, no data was retrieved from the external sensor from the IEQ server in the pilot study monitoring. The MoE contacted the sensors providers to work on fixing this challenge. This was resolved before the case study classroom monitoring. Due to security concerns, an external sensor was deployed in only case study and for the for case study two and three, external weather data from the nearest weather station were retrieved from the online National Climate database (NIWA) and used for analysis in this study

- Difficulty in Accessing and Retrieving Data directly: Given that data was wirelessly transmitted to the MoE and the sensors' providers managed the IEQ server platform, the researcher was not given access to directly access the IEQ server, but the data was retrieved by an MoE staff member and sent to the researcher on JSON file format. The researcher thereafter converted the data into a pre-designed Excel spreadsheet. This challenge generally resulted in delays in receiving collated data and being able to view a real-time dashboard to identify when a sensor losses connection with the IEQ server. Subsequent collaboration with the MoE resolved this challenge

These challenges did not impact the study results and conclusions, because the design focuses on understanding trends and patterns between IEQ conditions recorded by horizontal measuring plane sensors in comparison to vertical wall sensors more so than absolute precision. 


\subsection{Reliability and Validity of Research Data}

Before carrying out any monitoring experiment using devices, it is important to trust the device, understand the deployment process and collated data. The Smooth Classmate Sensors' used for monitoring in this study were a new product specific data logger designed to simultaneously monitor lighting, temperature, humidity, sound levels and $\mathrm{CO}_{2}$ in a single device. Given that this type of multi-variate data logger capability is an emerging technology, it was important to undertake systematic and detailed calibration checks to understand the data logger's mode of operation and the tolerance levels. Therefore, the following measures were taken to ensure that the research data were valid.

\subsubsection{Calibration Approach}

In monitoring and collating a large amount of environmental data, it is important to use sensors that have been calibrated to a known tolerance level, because the quality of the collated data could influence the result derived from the data. Calibrating a sensor provides a procedure to trust the data. Calibration is described as the process of comparing a known (trusted) measurement (the standard) with the measurement derived from deployed sensors. The known measurement could be measurements derived from an already calibrated sensor or that of international standards. Depending on the type of environmental variable that is to be collated or the type of sensor used, there are different ways of calibrating a sensor. For example, temperature sensors are typically calibrated by placing the sensors and the calibration standard into a controlled environment and set it to a cool, a warm and a hot level across the range that the sensor is to experience. The experience of the researcher or analyst carrying out on-site calibration is a factor that should be taken into consideration. A literature review by Reddy, (2006) states that "calibration is highly dependent on the personal judgment of the analyst doing the calibration". This implies that the experience of the researcher carrying out the checks could affect calibration results. Studies (Fabrizio \& Monetti, 2015; Karami, McMorrow, \& Wang, 2018; Penna, Gasparella, Cappelletti, Tahmasebi \& Mahdavi, 2015; Reddy, 2006; Shrestha, 2009) have suggested that there is no generally recognized standardised methodology or guidelines for calibrating environmental sensors. Most calibration procedures appear to use researchers designed calibration method which usually relies on users' judgment and experience. 
In this study and as shown in Table 15, a three-step calibration procedure was used.

Table 15: The Three-step calibration procedure

Procedure

One

Ther

Two

\begin{tabular}{|l|l} 
& f \\
\hline Three & In- \\
& Iab \\
\end{tabular}

Calibration of sensors in a systematic grid (sensors were placed in a horizontal surface and data compared with that of the reference sensor)

Spot measurement calibration at the case study classroom (This is explained further in the next section)

In-depth calibration at the laboratory (A random selection of sensors were calibrated at the Building Research Association of New Zealand (BRANZ) laboratory for the New Zealand Ministry of Education)

In summary, studies (Coakley, Raftery, Molloy, \& White, (2011); Penna, Gasparella, Cappelletti, Tahmasebi, Mahdavi, (2015) have suggested that despite the many calibration related studies, there is still no accepted standard methodology for carrying out calibration. The methods used for calibration are not explicitly described in many studies.

\subsubsection{Spot Measurement Calibration Methodology}

The spot measurement calibration required two main sets of data: the spot measurement data (physical verification) taken from a trusted sensor (reference device) immediately after deploying the data loggers and before uninstalling the data loggers. The time, date and weather condition when taking the spot measurement were also noted. This data was thereafter statistically compared with the data collated from the deployed sensors matching the time and date that was noted. Appendix 4 shows the calibration template designed and used for spot measurement calibration procedure of this study.

The procedure presented in Figure 28 shows the 5 -step process used in the spot measurement calibration to test and evaluate the accuracy of the data loggers used for monitoring in the case study classrooms. Additionally, a detailed outline of the experimental procedure used to evaluate the accuracy of the sensors is presented. 


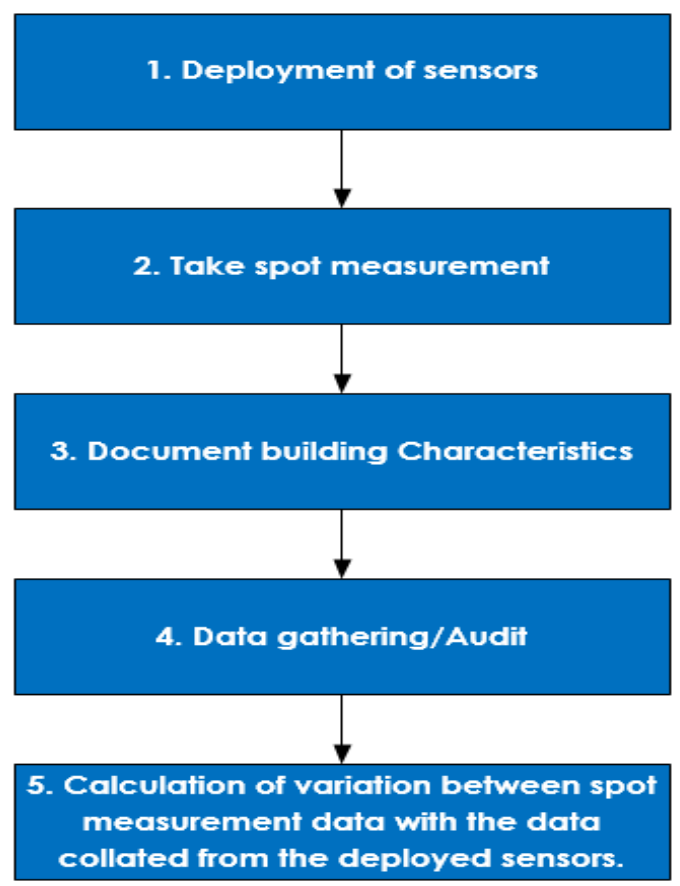

Figure 28: Calibration Process Methodology

As shown in Figure 28, an analytical approach was used for the spot measurement calibration of sensors deployed to collate environmental data in the case study schools. This largely avoided over-reliance on the researcher's knowledge and judgement as this methodology followed a clear evidence-based structure and proven statistical methods. The 5-step methodology is further explained as follows:

1. Sensors were deployed in the case study classroom.

2. Trusted sensors (reference instruments) from Victoria University School of Architecture were used to collate spot measurements of light, temperature, humidity, sound level and $\mathrm{CO}_{2}$ levels immediately after deploying the environmental sensors in the classroom and before uninstalling them. These reference instruments are described in detail in the next section below. The protocol for the spot measurement calibration was simple, a research suited calibrated reference instrument as mentioned above for each of the environmental parameters was taken to the case study building and placed so that it sampled at the same location as the multiple point sensors.

3. A pre-designed template as shown in Appendix 4 was used to observe and document building operational characteristics and record any observed uncertainties. 
4. An Excel spreadsheet was used to manually record the reference instrument data and collate the data retrieved from the MoE sensors.

5. The data was processed to reveal any errors from the multiple sensors minus the true environmental data values recorded. The percentage error equal to the absolute error divided by the true environmental data values were calculated and multiplied by $100 \%$ to determine the calibration offset. This type of sensor performance check was completed for all the multiple sensors located within the classroom. The summary of all calibration results is presented in the next section.

While carrying out spot measurement calibration data collation, it is difficult to rule out the possibilities of having the data influenced by uncertainties. The literature on calibration studies indicated that calibration studies have often overlooked considering uncertainties which are not included in their calibration methodologies. Fabrizio \& Monetti, (2015) states that "it is important to account for uncertainties when carrying out calibration; their identification could impact on the reliability of collated data and may assist calibration for better probabilistic predictions". In Table 16, they suggested that sources of uncertainties from onsite spot measurement calibration include:

Table 16: Sources of uncertainties from onsite spot measurement calibration

\begin{tabular}{|c|c|}
\hline Description & Factors \\
\hline Error in observation & Accuracy of the data reading from the sensor \\
\hline External uncertainty & Weather conditions of the external environment \\
\hline $\begin{array}{l}\text { Building operational } \\
\text { characteristics }\end{array}$ & $\begin{array}{l}\text { Properties of the building, HVAC systems, control and } \\
\text { operation settings, occupancy and general usage of the } \\
\text { buildings }\end{array}$ \\
\hline
\end{tabular}

Given the possibility of these uncertainties in influencing spot measured data, recording and documenting the observations of these factors was useful in understanding any variations in data when computing the calibration analysis. In this study, the occupant usage of the space was considered the most decisive source of uncertainty during the spot measurement calibration collation. In real-world occupied classrooms, occupants determine the use of windows, shading 
devices like blinds and artificial lighting. Hence, precision in documenting their behaviour may not be feasible. Appendix 4 shows the calibration uncertainty observation template designed and used for the calibration procedure of this study. The reference instruments used for calibration procedure one and two are reported in detail in Appendix 4.1.

\subsubsection{Calibration Analysis Summary}

In this study, nine different calibrations were carried out for both calibration procedure one and two. This section presents data for calibration procedure one and summarises the insights from the calibration results.

For calibration procedure one and two, data was collated from the sensors and a comparison between the sensors data with that of the trusted reference instrument was carried out as shown in Table 17 below. The different environmental variables in the Table have different units of measurements. The formula used for calculating the light factor variation (\% change) was; $R / S \times 100$ and the formula used for calculating temperature, sound and $\mathrm{CO}_{2}$ value differences was $-S$, where $\mathrm{R}$ is the reference sensor values and $\mathrm{S}$ is the sensors values.

\section{Lighting Calibration Summary}

In Table 17, the light factor for most of the test scenarios were largely $\pm 200 \%$. This was observed to be due to different light sources (artificial and daylight) within the monitored space. It was observed that the white peripheral of the multi-variable Smooth Sensor' may have impacted on the light readings of the device. In this study, the lighting values were multiplied by a factor of 2

to correct for any variance $\left(\frac{R}{S}=2\right)$. The devices that recorded up to $\pm 300 \%$ at some point in time were not used for monitoring in this study.

\section{Temperature Calibration Summary}

There was a consistent difference of $2^{\circ} \mathrm{C}$ between the reference sensor and the sensors. Hence, temperature data from the sensors were corrected by adding $2^{\circ} \mathrm{C}$. 


\begin{tabular}{|c|c|c|c|c|c|c|c|c|c|c|c|c|c|}
\hline \multicolumn{2}{|c|}{ Description } & \multicolumn{4}{|c|}{ Data from Reference Instrument } & \multicolumn{4}{|c|}{ Data from Sensors } & \multicolumn{4}{|c|}{ Calibration Variation } \\
\hline $\begin{array}{c}\text { Test } \\
\text { Scenario }\end{array}$ & Sensor & $\begin{array}{l}\text { Light } \\
\text { (Lux) }\end{array}$ & $\begin{array}{c}\text { Temp } \\
\text { (Celsius) }\end{array}$ & $\begin{array}{l}\text { Sound } \\
\text { (dBA) }\end{array}$ & $\begin{array}{c}\mathrm{CO}_{2} \\
\text { (PPM) }\end{array}$ & $\begin{array}{l}\text { Light } \\
\text { (Lux) }\end{array}$ & $\begin{array}{c}\text { Temp } \\
\text { (Celsius) }\end{array}$ & $\begin{array}{l}\text { Sound } \\
\text { (dBA) }\end{array}$ & $\begin{array}{c}\mathrm{CO}_{2} \\
\text { (PPM) }\end{array}$ & $\begin{array}{l}\text { Light - } \\
\text { Factor (\%) }\end{array}$ & $\begin{array}{c}\text { Temp - } \\
\text { Diff } \\
\text { (Celsius) }\end{array}$ & $\begin{array}{c}\text { Sound - } \\
\text { Diff } \\
\text { (dBA) }\end{array}$ & $\begin{array}{c}\mathrm{CO}_{2}-\text { Diff } \\
\text { (PPM) }\end{array}$ \\
\hline One & A1 & 218 & 23 & 47 & 710 & 103 & 21 & 50 & 672 & 212 & 2.00 & -3.00 & 38.00 \\
\hline Two & A1 & 200 & 23 & 50 & 671 & 99 & 21 & 53 & 627 & 202 & 2.00 & -3.00 & 44.00 \\
\hline Three & $\mathrm{A} 1$ & 190 & 22 & 49 & 664 & 92 & 20 & 52 & 626 & 207 & 2.00 & -3.00 & 38.00 \\
\hline Four & A1 & 220 & 23 & 47 & 489 & 110 & 21 & 50 & 450 & 200 & 2.00 & -3.00 & 39.00 \\
\hline Five & $\mathrm{A} 1$ & 265 & 24 & 48 & 550 & 129 & 22 & 51 & 510 & 205 & 2.00 & -3.00 & 40.00 \\
\hline One & $\mathrm{A} 2$ & 201 & 22 & 47 & 801 & 95 & 20 & 50 & 764 & 212 & 2.00 & -3.00 & 37.00 \\
\hline Two & $\mathrm{A} 2$ & 204 & 23 & 47 & 734 & 102 & 21 & 50 & 692 & 200 & 2.00 & -3.00 & 42.00 \\
\hline Three & $\mathrm{A} 2$ & 201 & 23 & 47 & 675 & 89 & 21 & 49 & 638 & 226 & 2.00 & -2.00 & 37.00 \\
\hline Four & $\mathrm{A} 2$ & 214 & 22 & 47 & 566 & 105 & 20 & 50 & 539 & 204 & 2.00 & -3.00 & 27.00 \\
\hline Five & $\mathrm{A} 2$ & 240 & 24 & 47 & 606 & 117 & 22 & 50 & 565 & 205 & 2.00 & -3.00 & 41.00 \\
\hline One & A3 & 340 & 24 & 48 & 700 & 175 & 22 & 51 & 662 & 194 & 2.00 & -3.00 & 38.00 \\
\hline Two & $\mathrm{A} 3$ & 345 & 23 & 48 & 659 & 179 & 21 & 51 & 620 & 193 & 2.00 & -3.00 & 39.00 \\
\hline Three & A3 & 302 & 22 & 48 & 689 & 152 & 20 & 50 & 653 & 199 & 2.00 & -2.00 & 36.00 \\
\hline Four & A3 & 320 & 22 & 52 & 462 & 168 & 20 & 55 & 429 & 190 & 2.00 & -3.00 & 33.00 \\
\hline Five & A3 & 332 & 23 & 47 & 533 & 170 & 21 & 50 & 491 & 195 & 2.00 & -3.00 & 42.00 \\
\hline One & B1 & 206 & 22 & 47 & 709 & 102 & 20 & 50 & 669 & 202 & 2.00 & -3.00 & 40.00 \\
\hline Two & B1 & 214 & 23 & 47 & 589 & 105 & 21 & 49 & 546 & 204 & 2.00 & -2.00 & 43.00 \\
\hline Three & B1 & 198 & 22 & 47 & 681 & 97 & 20 & 50 & 645 & 204 & 2.00 & -3.00 & 36.00 \\
\hline Four & B1 & 228 & 22 & 47 & 504 & 109 & 20 & 49 & 463 & 209 & 2.00 & -2.00 & 41.00 \\
\hline Five & B1 & 230 & 22 & 47 & 563 & 111 & 20 & 49 & 523 & 207 & 2.00 & -2.00 & 40.00 \\
\hline One & B2 & 320 & 23 & 49 & 830 & 167 & 21 & 52 & 787 & 192 & 2.00 & -3.00 & 43.00 \\
\hline Two & B2 & 356 & 23 & 49 & 777 & 187 & 21 & 52 & 735 & 190 & 2.00 & -3.00 & 42.00 \\
\hline Three & B2 & 289 & 22 & 49 & 815 & 140 & 20 & 52 & 777 & 206 & 2.00 & -3.00 & 38.00 \\
\hline Four & B2 & 312 & 22 & 49 & 635 & 149 & 20 & 52 & 623 & 209 & 2.00 & -3.00 & 12.00 \\
\hline Five & B2 & 339 & 23 & 49 & 656 & 171 & 21 & 52 & 622 & 198 & 2.00 & -3.00 & 34.00 \\
\hline One & B3 & 318 & 23 & 47 & 778 & 166 & 21 & 50 & 740 & 192 & 2.00 & -3.00 & 38.00 \\
\hline Two & B3 & 321 & 23 & 49 & 503 & 166 & 21 & 52 & 457 & 193 & 2.00 & -3.00 & 46.00 \\
\hline
\end{tabular}




\begin{tabular}{|c|c|c|c|c|c|c|c|c|c|c|c|c|c|}
\hline Three & B3 & 324 & 23 & 49 & 503 & 159 & 21 & 52 & 457 & 204 & 2.00 & -3.00 & 46.00 \\
\hline Four & B3 & 321 & 23 & 49 & 503 & 164 & 21 & 52 & 457 & 196 & 2.00 & -3.00 & 46.00 \\
\hline Five & B3 & 333 & 24 & 47 & 551 & 172 & 22 & 50 & 508 & 194 & 2.00 & -3.00 & 43.00 \\
\hline One & B4 & 226 & 23 & 47 & 804 & 99 & 21 & 50 & 765 & 228 & 2.00 & -3.00 & 39.00 \\
\hline Two & B4 & 212 & 22 & 47 & 739 & 105 & 20 & 50 & 697 & 202 & 2.00 & -3.00 & 42.00 \\
\hline Three & B4 & 220 & 23 & 47 & 665 & 107 & 21 & 49 & 629 & 206 & 2.00 & -2.00 & 36.00 \\
\hline Four & B4 & 235 & 22 & 47 & 576 & 107 & 20 & 50 & 549 & 220 & 2.00 & -3.00 & 27.00 \\
\hline Five & B4 & 242 & 23 & 47 & 609 & 119 & 21 & 50 & 575 & 203 & 2.00 & -3.00 & 34.00 \\
\hline One & B5 & 316 & 23 & 48 & 697 & 159 & 21 & 51 & 666 & 199 & 2.00 & -3.00 & 31.00 \\
\hline Two & B5 & 329 & 24 & 48 & 679 & 156 & 22 & 51 & 640 & 211 & 2.00 & -3.00 & 39.00 \\
\hline Three & B5 & 309 & 23 & 48 & 702 & 144 & 21 & 50 & 678 & 215 & 2.00 & -2.00 & 24.00 \\
\hline Four & B5 & 331 & 22 & 50 & 456 & 162 & 20 & 53 & 431 & 204 & 2.00 & -3.00 & 25.00 \\
\hline Five & B5 & 356 & 24 & 47 & 539 & 117 & 22 & 50 & 499 & 304 & 2.00 & -3.00 & 40.00 \\
\hline One & B6 & 198 & 21 & 47 & 700 & 96 & 19 & 50 & 665 & 206 & 2.00 & -3.00 & 35.00 \\
\hline Two & B6 & 204 & 23 & 48 & 577 & 98 & 21 & 51 & 544 & 208 & 2.00 & -3.00 & 33.00 \\
\hline Three & B6 & 216 & 22 & 47 & 689 & 103 & 20 & 50 & 647 & 210 & 2.00 & -3.00 & 42.00 \\
\hline Four & B6 & 380 & 24 & 47 & 507 & 126 & 22 & 49 & 473 & 302 & 2.00 & -2.00 & 34.00 \\
\hline Five & B6 & 367 & 24 & 47 & 566 & 122 & 22 & 49 & 530 & 301 & 2.00 & -2.00 & 36.00 \\
\hline
\end{tabular}




\section{Relative Humidity Summary}

Relative humidity calibration was carried out by the Building Research Association of New Zealand (BRANZ) in their laboratory. Two sensors were randomly selected from the sensors used for monitoring in this study for an in-depth laboratory calibration check. For both temperature and humidity calibration, the chamber was held at a constant temperature of $5^{\circ} \mathrm{C}, 10^{\circ} \mathrm{C}, 15^{\circ} \mathrm{C}$, $20^{\circ} \mathrm{C}$ and $25^{\circ} \mathrm{C}$ and the relative humidity was altered and allowed to settle and was held reasonably constant for 12 hours for each of these points. There was a consistent offset of $<7 \%$ relative humidity between the reference sensor and Smooth sensor.

\section{Sound Level Calibration Analysis}

In Table 17, the sound levels were measured in decibel (dBA). From the calibration table, the results indicated that the sound level difference between the reference device and the sensors was $\pm 3 \mathrm{dBA}$.

There are general arguments regarding the sound level increase that equates to double the loudness. The theory of psycho-acoustician, Stevens, (1973), indicated that the doubling of the sensation of loudness equates to a $10 \mathrm{~dB}$ sound level difference, this is still a widely accepted rule-of-thumb. In the perception of sound, a $3 \mathrm{dBA}$ increase in sound level is barely noticeable to the human ear, the sound level needs to be raised to about 5 dBA before humans could perceive a significant change' and it takes an increase of $10 \mathrm{dBA}$ before humans could hear "double the sound" (ABD, 2008). Richard, (1970) had earlier suggested that a double sound pressure level equates to a double loudness. ABD, (2008) stated that in physics, a change in $1 \mathrm{~dB}$ equates about a $26 \%$ difference in acoustical energy and yields just over a $7 \%$ change in subjective loudness; and there is a $3 \mathrm{~dB}$ increase for every doubling of acoustical energy or sound intensity, which equates just over a $23 \%$ increase in loudness. Noisehelp, (2018) suggested that an air conditioner with a sound level of $60 \mathrm{dBA}$ will sound twice as loud as a refrigerator with a $50 \mathrm{dBA}$ sound level, whereas the difference in $10 \mathrm{dBA}$ equates to a tenfold increase in sound intensity. However, a dishwasher with a $70 \mathrm{dBA}$ sound level will sound four times as loud as the $50 \mathrm{dBA}$ refrigerator, whereas the sound it makes equates to 100 times as powerful in terms of sound intensity. 
Sengpielaudio, (2018) stated that psycho-acousticians suggests "double the loudness" or "twice as loud" equates to a sound level of $10 \mathrm{~dB}$; ratio doubling means:

- a power level of $+3 \mathrm{~dB}$ (sound intensity level);

- an electric voltage level of $+6 \mathrm{~dB}$ (sound pressure level);

- a loudness level of about $+10 \mathrm{~dB}$ (psychoacoustic).

Hence, the non-exact rule-of-thumb which states that while every sound pressure level of $6 \mathrm{~dB}$ equates a doubling of amplitude, every $10 \mathrm{~dB}$ increase is a doubling of perceived loudness. Table 18 and 19 show sound level dependence and the change of the respective ratios of subjective loudness, objective sound pressure, and sound intensity. Ratio means "how much" or how many times" is the doubling of loudness.

Table 18: Sound Level Comparison Chart. Sources: (Richard, 1970; Sengpielaudio, 2018)

\begin{tabular}{|c|c|c|c|}
\hline $\begin{array}{c}\text { Level } \\
\text { change }\end{array}$ & $\begin{array}{c}\text { Volume } \\
\text { Loudness }\end{array}$ & $\begin{array}{c}\text { Voltage } \\
\text { Sound pressure }\end{array}$ & $\begin{array}{c}\text { Acoustic Power } \\
\text { Sound Intensity }\end{array}$ \\
\hline$+60 \mathrm{~dB}$ & 64 & 1000 & 1000000 \\
\hline$+50 \mathrm{~dB}$ & 32 & 316 & 100000 \\
\hline$+40 \mathrm{~dB}$ & 16 & 100 & 10000 \\
\hline$+30 \mathrm{~dB}$ & 8 & 31.6 & 1000 \\
\hline$+20 \mathrm{~dB}$ & 4 & 10 & 100 \\
\hline$+10 \mathrm{~dB}$ & $2.0=$ double & $3.16=\sqrt{ } 10$ & 10 \\
\hline$+6 \mathrm{~dB}$ & 1.52 times & $2.0=$ double & 4.0 \\
\hline$+3 \mathrm{~dB}$ & 1.23 times & 1.414 times $=\sqrt{2}$ & $2.0=$ double \\
\hline $--- \pm 0 \mathrm{~dB}----$ & $---1.0------$ & $---1.0------$ & $---1.0----$ \\
\hline Log. size & Psycho size & Field size & Energy size \\
\hline $\mathrm{dB}$ change & Loudness multiplier. & Amplitude multiplier & Power multiplier \\
\hline
\end{tabular}

In Table 17 above, a sound level change of $+3 \mathrm{~dB}$ changes the loudness by 1.23 times which equates to double the sound intensity, a sound level change of $+6 \mathrm{~dB}$ changes the loudness by 1.52 times, which is 4 times the sound intensity, while a sound level change of $+10 \mathrm{~dB}$ doubles the loudness and equates to 10 times the sound intensity.

\begin{tabular}{|c|c|c|c|}
\hline $\begin{array}{c}\text { Table 19: Sound Ratio Factor Comparison Chart. Sources: (Richard, 1970; Sengpielaudio, 2018) } \\
\begin{array}{c}\text { Ratio / } \\
\text { Factor }\end{array}\end{array}$ & $\begin{array}{c}\text { Change in Sound } \\
\text { Loudness Level }\end{array}$ & $\begin{array}{c}\text { Change in Sound } \\
\text { Pressure Level }\end{array}$ & $\begin{array}{c}\text { Change in Sound } \\
\text { Power Level }\end{array}$ \\
\hline 40 & $+53.22 \mathrm{~dB}$ & $+32.04 \mathrm{~dB}$ & $+16.02 \mathrm{~dB}$ \\
\hline 30 & $+49.07 \mathrm{~dB}$ & $+29.54 \mathrm{~dB}$ & $+14.77 \mathrm{~dB}$ \\
\hline 20 & $+43.22 \mathrm{~dB}$ & $+26.02 \mathrm{~dB}$ & $+13.01 \mathrm{~dB}$ \\
\hline
\end{tabular}




\begin{tabular}{|c|c|c|c|}
\hline 15 & $+39.07 \mathrm{~dB}$ & $+23.52 \mathrm{~dB}$ & $+11.76 \mathrm{~dB}$ \\
\hline 10 & $+33.22 \mathrm{~dB}$ & $+20 \mathrm{~dB}$ & $+10 \mathrm{~dB}$ \\
\hline 5 & $+23.22 \mathrm{~dB}$ & $+13.98 \mathrm{~dB}$ & $+6.99 \mathrm{~dB}$ \\
\hline 4 & $+20 \mathrm{~dB}$ & $+12.04 \mathrm{~dB}$ & $+6.02 \mathrm{~dB}$ \\
\hline 3 & $+15.58 \mathrm{~dB}$ & $+9.54 \mathrm{~dB}$ & $+4.77 \mathrm{~dB}$ \\
\hline 2 & $+10 \mathrm{~dB}$ & $+6.02 \mathrm{~dB}$ & $+3.01 \mathrm{~dB}$ \\
\hline$----1---$ & $--- \pm 0 \mathrm{~dB}-\cdots--$ & $-\cdots \pm 0 \mathrm{~dB}-\cdots$ & $--- \pm 0 \mathrm{~dB}---$ \\
\hline
\end{tabular}

Loudness formula - pressure formula - intensity formula Source: Sengpielaudio, (2018)

\begin{tabular}{|c|c|}
\hline $\begin{array}{c}\text { Psychoacoustics - } \\
\text { Level change loudness } \\
\Delta L=10 \cdot \log _{2} x\end{array}$ & $\begin{array}{l}\text { Ratio for "loudness" } \\
\qquad x=2^{\frac{\Delta L}{10}}\end{array}$ \\
\hline $\begin{array}{c}\text { Field quantity - } \\
\text { Level change sound pressure } \\
\Delta L=20 \cdot \log _{10} y\end{array}$ & $\begin{array}{l}\text { Ratio for "sound pressure" } \\
\qquad y=10^{\frac{\Delta L}{20}}\end{array}$ \\
\hline $\begin{array}{l}\text { Energy or power quantity - } \\
\text { Level change sound intensity } \\
\qquad \Delta L=10 \cdot \log _{10} z\end{array}$ & $\begin{array}{l}\text { Ratio for "sound intensity" } \\
\qquad z=10^{\frac{\Delta L}{10}}\end{array}$ \\
\hline
\end{tabular}

Tables 18 and 19 shows the difference between "sound loudness", "sound intensity" and "sound pressure". In acoustics, loudness is generally defined as the subjective perception of sound pressure - a sensation that weighs sounds on a scale extending from quiet to loud. The difference between the pressure caused by a sound wave and the ambient pressure of the medium it is passing through is referred to as sound pressure. While sound intensity is the sound power per unit area, in a direction perpendicular to that area. The implication of Tables 45 to 50 below and the findings of the appraised studies suggested that the sound level difference of around $\pm 3 \mathrm{~dB}$ (just noticeable) as shown in the calibration table does not equate to double the loudness.

\section{$\mathrm{CO}_{2}$ Calibration Analysis}

In Table 17, the $\mathrm{CO}_{2}$ offset error was largely $<40 \mathrm{ppm}$ and the variation across the readings is at least \pm 10 ppm, which was within the off-set error range of the reference sensor. 


\subsubsection{Summary}

Generally, this section has described the method and calibration procedure used in this study and the calibration results. Observations during the spot measurement calibration indicated that field measurements could be tricky since the source's characteristics may vary rapidly. For example, while carrying out the lighting spot measurements, it was observed that measuring a combination of natural and artificial lighting could be tricky since the light source's characteristics may change suddenly. A similar variation was identified when taking $\mathrm{CO}_{2}$ and sound spot measurement, the movement of students from one place to another could easily influence the $\mathrm{CO}_{2}$ level recorded against a particular time, likewise, the noise level from student's conversation could result in higher or lower sound level reading at a point in time. This assertion is supported by Bellia, Musto, \& Spada, (2011) who state that "field measurements of daylight could be tricky since there could easily be a variance in the light source characteristics, therefore, there is the need to perform fast measurements on several visual tasks at the same time - this is impossible to achieve with standard instruments". They suggested that the accuracy of the measurements is dependent on the speed of carrying out the spot measurement effectively.

In this study, calibration checks were carried out immediately after deployment in the case study classrooms and before uninstalling the sensors at the end of the monitoring period. The systematic grid and spot measurement calibrations were consistent with the calibration carried out by BRANZ. Overall, the calibration findings did not impact the study results and conclusions, because the study design focuses on understanding trends and patterns between IEQ conditions recorded by horizontal measuring plane sensors in comparison to vertical wall sensors more so than absolute precision and the reading errors identified in this process were relatively small (Sound levels were $\pm 3 \mathrm{dBA}$, relative humidity were $<7 \%$, temperature were $+2^{\circ} \mathrm{C}$ and $\mathrm{CO}_{2} \pm 10$ ppm). Given that the data loggers used for physical measurement in this study were provided by the Ministry of Education (MoE) and are the same data loggers the MoE is using for their pilot study measurement in schools, the outcome of the above calibration experiments provided insightful findings that informed policy decisions at the MoE (refer to Appendix 10). 


\subsection{Method of Data Analysis}

In this study, the results were displayed visually and numerically. Sparklines and line graphs were used to graphically present the results for visual interpretation while statistical analysis using averages, linear regression and ratio analysis were used to numerically interpret the physical measured data. These methods of data analysis are explained further below.

\subsubsection{Line Graphs}

Line graphs were used to visually assess trends and patterns in the IEQ data. Generally, a line graph uses lines to connect and graphically display quantitative data values over a specified time interval to aid in data visualization. Visual representation of data is a useful method to easily spot out patterns in a large set of data to show the relationship between two or more values, comparison of maximum and minimum values, and where there is a decrease or increase in a set of values. Line graphs were used to graphical display a large amount of IEQ data to enable the analysis of the relationship between horizontal measuring plane sensors and vertical wall sensors.

\subsubsection{Sparklines}

Sparklines are tiny graphical representations of a trend which are presented in groups so the trend from one graph to the next can be easily compared. In this analysis, the tiny graphical trend lines were displayed on plans of the space to enable a comparison of the spatial differences in trends of the data.

\subsubsection{Statistical Analysis}

Averages (temperature, relative humidity, sound levels and $\mathrm{CO}_{2}$ ) and linear regression (lighting) were used to assess the extent of variation between horizontal and vertical sensors. A ratio analysis (quantitative method) was also carried out to measure how much a variable has changed between two measurements. A ratio takes one number and divides it into another number to determine a decimal that can be converted to a percentage. Comparative ratio analysis can demonstrate the relationship of a set of variables over time and can be used to estimate likely future performance. 
In this study, a ratio analysis was used to assess how much larger the horizontal illuminance compared to the vertical illuminance - this is illustrated further in Sections 5.3.5, 6.1.3, 7.1.3 and 8.1.3 below. 


\subsection{Pilot Study Experiment - IEQ Measurement Sensors Comparison}

This section shows the results and discussions of the pilot study experiment which informed the research design of this study. This analysis aimed to ascertain the feasibility of carrying out real world measurements by placing multiple sensors in occupied classrooms. Also, to carry out a preliminary assessment on whether there is a relationship between the vertical sensor on the wall and the horizontal sensor on the work plane.

The graphs below present lighting, temperature, humidity, sound and $\mathrm{CO}_{2}$, measurements for a north facing one-side lit classroom at Victoria University of Wellington, School of Architecture. As shown in Figure 29 Fourteen sensors were paired and placed at the centre of the four walls respectively, at a height of $1.5 \mathrm{~m}$, and two paired sensors were placed at the horizontal plane height of $0.8 \mathrm{~m}$ in the centre of the space and another set of two paired sensors at strategic locations on the horizontal plane. The classroom was a mechanically ventilated space of about $10 \mathrm{~m}$ length by $7 \mathrm{~m}$ width. Due to data retrieval challenges as described in section 4.4.3, continuous data were retrieved for only two sensors (Sensor A1 annotated as "vertical" and sensor A2 annotated as "horizontal" in the line graphs below).

The monitoring interval reported are from 8 am to $4 \mathrm{pm}$ for two sensors and the results of two days of monitoring, over the weekend, Saturday and Sunday $6^{\text {th }}$ and $7^{\text {th }}$ October 2018 are reported below. Observation of the occupancy and usage of the room was undertaken. This measurement aimed to carry out a preliminary assessment on whether there is a relationship between the wall mounted vertical sensor and the horizontal sensor on the work plane.

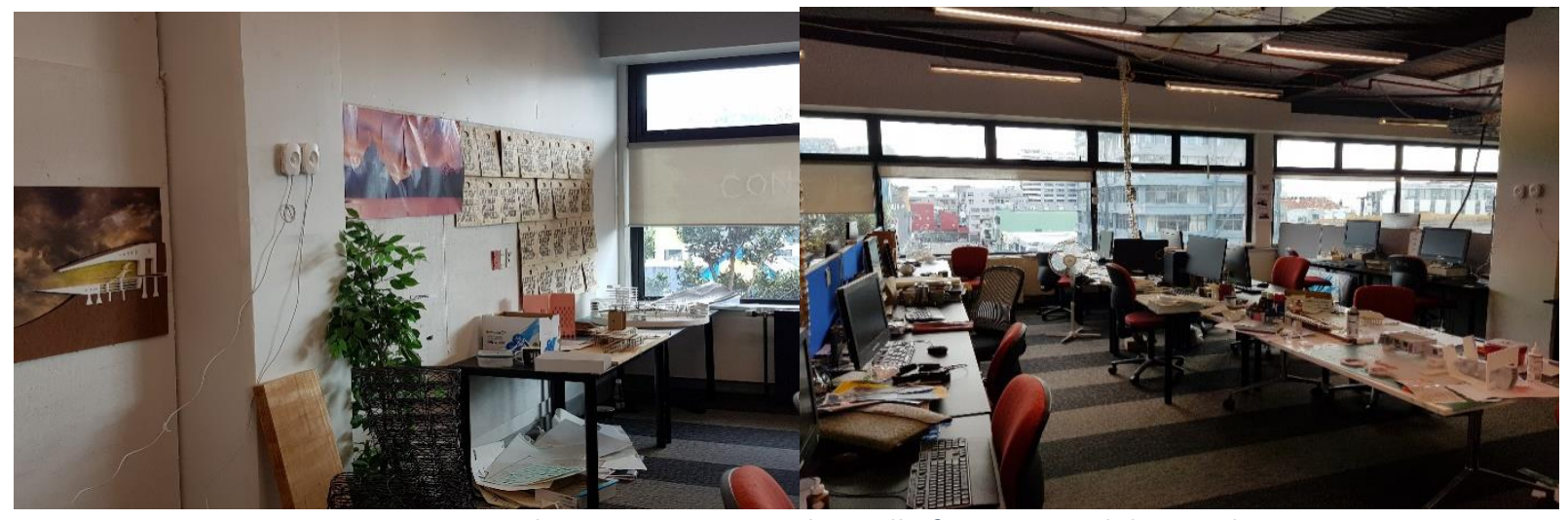

Figure 29: Pictures showing sensors on the wall of an occupied design classroom 
For lighting, Figure 30 shows that both vertical and horizontal sensors appeared to have a similar illuminance trend in the morning hours for both days. However, during the afternoon period, the vertical wall sensor seems to have a slightly higher illuminance trends compared to the horizontal sensor. This was likely due to the movement of the sun to the west during the afternoon. Though the illuminance trends were consistent in both days of monitoring, the line graphs indicated that the relationship between vertical illuminance and horizontal illuminance was not so strong, especially when influenced by increased daylight levels. This assertion was further explored in the results reported in Chapter 5 below.

\section{Spring Lighting Measurements}
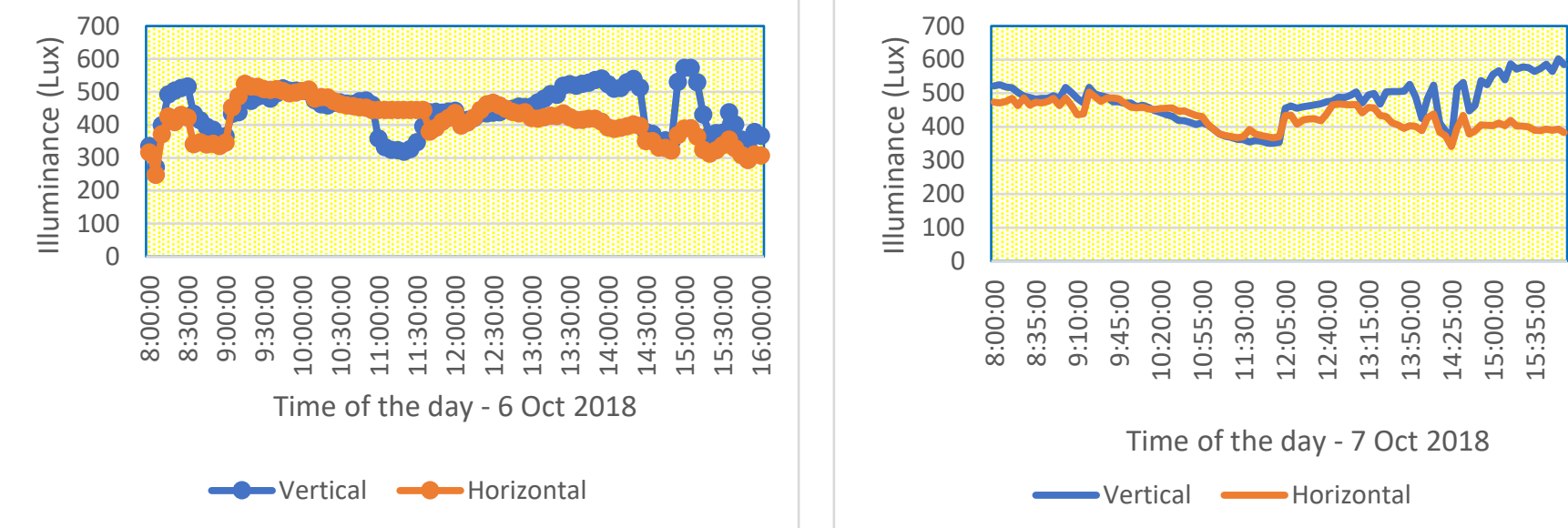

Figure 30: Line graphs showing lighting measurements

In Figure 31, there was a rise in temperature by $1^{\circ} \mathrm{C}$ between 8 am to 10 am, which remained constant after this time frame. The room was a mechanically ventilated space with a central heating and ventilation system. The mechanical system is usually on from 7 am until 6 pm. However, it was observed that during the monitoring period, some windows were open. Given that it was a weekend, the occupancy in the room fluctuated between 5 to 10 persons at a point in time. On the $7^{\text {th }}$ of October, the line graph showed that the relationship between the vertical and horizontal sensors was not as strong as that of the $6^{\text {th }}$ of October. This was observed to be due to increased having more occupants $(10)$ in the room on the $7^{\text {th }}$ of October compared to the $6^{\text {th }}$ of October (5 occupants) and their activity level. For example, it was observed that a user closer the horizontal sensor made use of a standing fan during the period were there was a decrease in temperature by $1^{\circ} \mathrm{C}$. Generally, the temperature levels in the vertical and horizontal 
sensors showed a relationship, which suggested that either of the measuring points could be useful in predicting the other. This assertion was further explored in the results reported in Chapter 6 below.

\section{Spring Temperature Measurements}
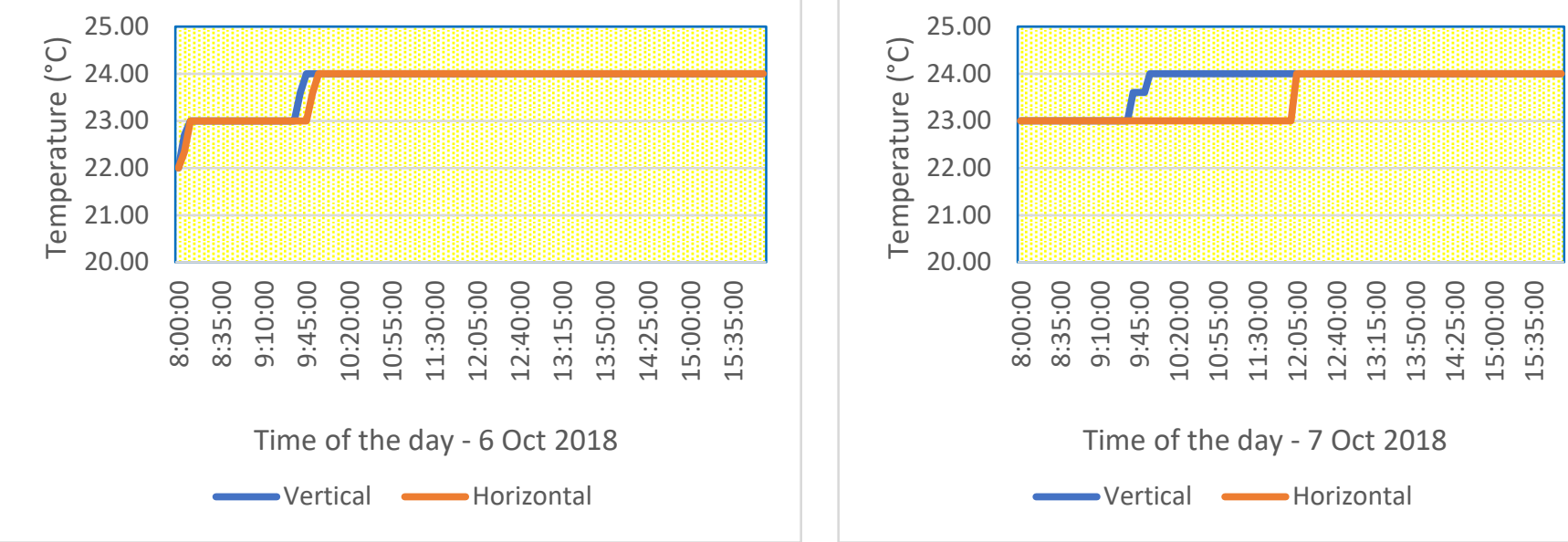

Figure 31: Line graphs showing temperature measurements

In Figure 32, humidity values showed a consistent trend and a relationship with temperature. Generally, if the water vapour content stays the same and the temperature drops, the relative humidity increases. If the water vapour content stays the same and the temperature rises, the relative humidity decreases. This is because colder air doesn't require as much moisture to become saturated as warmer air. Temperature and humidity are directly proportional, if temperature increases, the humidity decreases and vice versa. The line graphs showed that in both days, the difference between the vertical and horizontal sensors' humidity levels was not so great. This assertion was further explored in the results reported in Chapter 6 below.

\section{Spring Humidity Measurements}
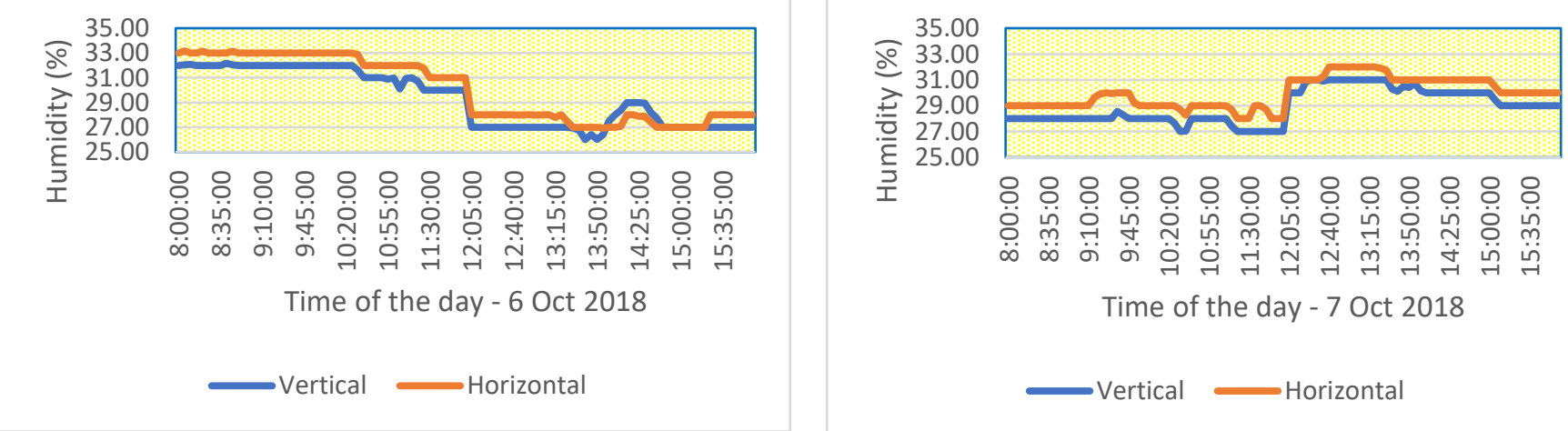

Figure 32: Line graphs showing humidity measurements 
Sound level meters are useful to estimate noise exposure by measuring the intensity of sound at a given moment in an area or environment. In Figure 33, the line graph showed that after 10 am, there was a $+3 \mathrm{dBA}$ increase in sound levels. This was observed to be due to occupancy levels of the space after $10 \mathrm{am}$. It was also observed that there were some extraneous internal noise effects from the mechanical system. The trends between the vertical and horizontal sensors were consistent for both monitored days and the difference between both sensors were not so great (about $<3 \mathrm{dBA}$ ). This assertion was further explored in the results reported in Chapter 7 below.

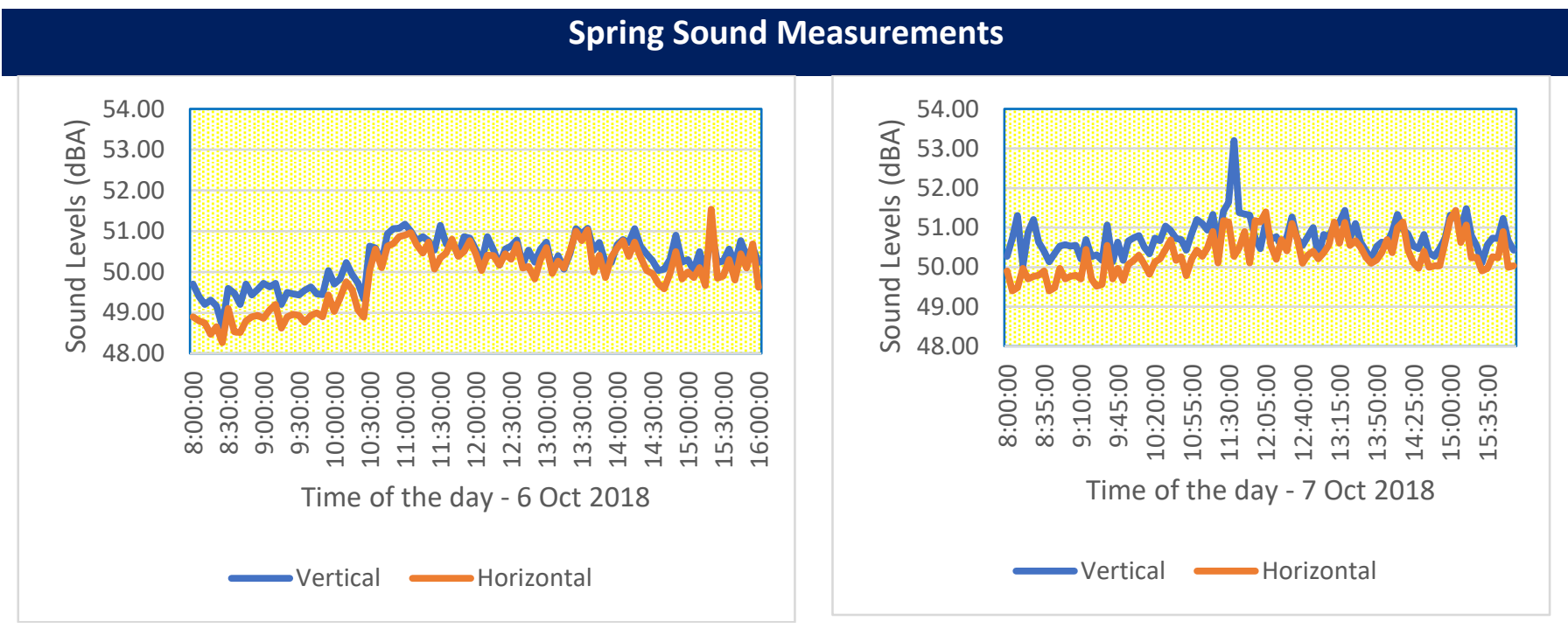

Figure 33: Line graphs showing sound level measurements

In Figure 34, the line graph showed a consistent relationship between the vertical and horizontal sensors. This assertion was further explored in the results reported in Chapter 8 below.

\section{Spring $\mathrm{CO}_{2}$ Measurements}
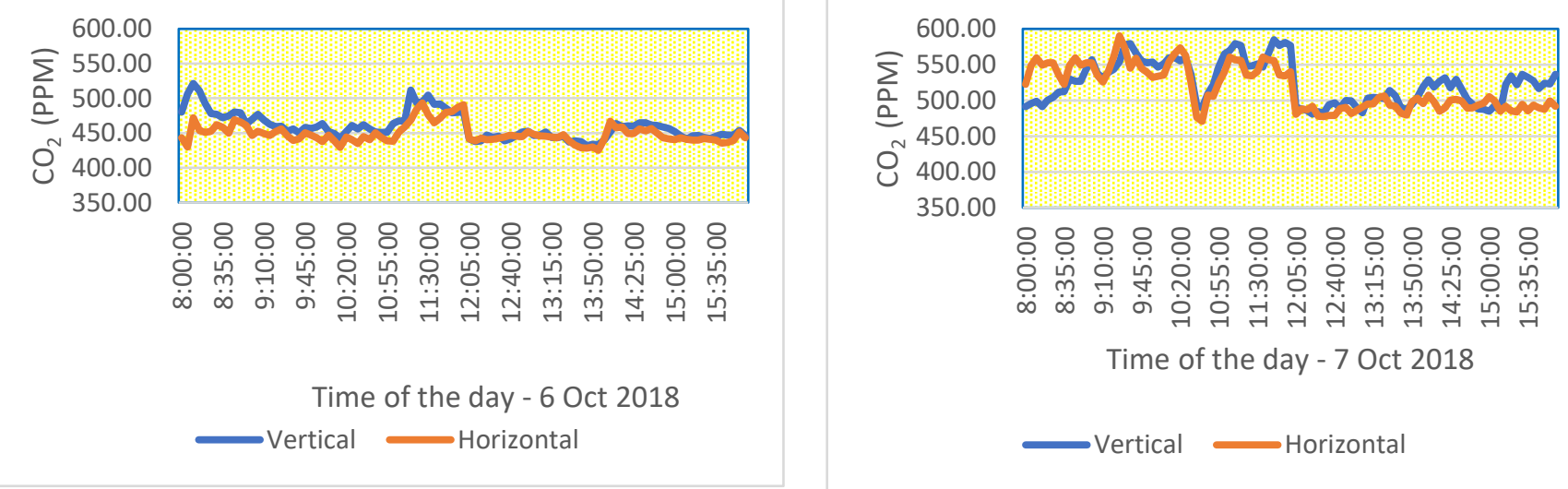

Figure 34: Line graphs showing $\mathrm{CO}_{2}$ measurements 
Generally, the pilot study results showed that the differences between a wall mounted sensor at a height of $1.5 \mathrm{~m}$ above the ground and a centrally positioned horizontal sensor at a desk height of $0.8 \mathrm{~m}$ was not so great for temperature, humidity, acoustics and $\mathrm{CO}_{2}$. This relationship was weaker for lighting levels compared to the other variables. This suggested that among the five variables, lighting had a higher variability across a space. This assertion was investigated further in the three case study classrooms in different seasons using a graphical and visual representation of data as well as statistical analysis as reported in Chapters 5 to 8 below. 


\section{CHAPTER FIVE: CAN A ONE-POINT SENSOR PREDICT THE LIGHTING}

\section{LEVELS IN A CLASSROOM?}

\subsection{Daylight Simulation Modelling Experiment}

This study firstly used a Climate Based Daylight Modelling (CBDM) to investigate the research question of what can be learned from the use of a one-point sensor in one location in a classroom, to estimate lighting performance across a space. Daylighting is focused upon because it has the most spatial variation in a space, the movement of the sun from east to west during a day could result in varying levels of daylight in a space and the depth and building configuration of a space could impact on the distribution of daylight across a space. The rationale for using CBDM is because it makes it possible to calibrate a calculation against measurement and then to systematically study all the other day times of the year, mathematically. CBDM uses realistic sun and sky conditions derived from standardised climate data to predict illuminance (Mardaljevic, 2000; Reinhart \& Herkel, 2000). This section reports the results of simulating the spatial distribution of the yearly daylight levels in a typical classroom model.

\subsubsection{Simulation Methodology}

In recent years, computer simulations have proven to provide realistic and reliable data for real world analysis. Studies (Au \& Donn, 2010; Bian \& Ma, 2017; J Mardaljevic, 2000; Reinhart \& Walkenhorst, 2001) support this assertion by stating that simulation provides realistic measures of predicting daylight within a space and can be used for a "real world analysis". The simulation tool used in this study is Radiance through Honeybee interface, which is a script written in Grasshopper which is a visual scripting language for the 3D modelling programme Rhino (Roudsari \& Pak, 2013). Grasshopper is a free, parametric modelling graphical algorithm editor, while Honeybee is a free, open source environmental plugin for Grasshopper 3D (Roudsari \& Pak, 2013). A Climate Based Daylight Modelling (CBDM) was used to run the simulations of this study, because measuring one moment of daylight may not represent the overall quality of daylight in a space, due to its spatial distribution. The climate specific data used for this study was that of Wellington, New Zealand. In Wellington, February is the hottest month with an average 
temperature of $19^{\circ} \mathrm{C}$ while July is the coldest month with an average temperature of $10^{\circ} \mathrm{C}$. May is the wettest month with an average of $50 \mathrm{~mm}$ of rain (MetService, 2018).

Two classroom iteration design annotated as Plan A and Plan B were modelled in this study. As shown in Figure 35, plan A (two-side lit) is an empty typical classroom space of length $12 \mathrm{~m}$, width $8 \mathrm{~m}$ with a height of $3.2 \mathrm{~m}$. In New Zealand, typical classrooms are referred to as standardised classrooms, which have a reference design guide and are built in most schools across the country. Four continuous sets of windows, each measuring $1.5 \mathrm{~m}$ in width and $1.8 \mathrm{~m}$ high with a sill level of $0.8 \mathrm{~m}$ were located on the $12 \mathrm{~m}$ walls respectively. These windows were on both the North and South-facing walls. Plan B (one-side lit) has the same design configuration of Plan A but the windows were only North Facing. The glazing was on the north wall because this will provide the worst-case scenario due to the variation of direct sunlight on the north façade. As shown in Figure 26, a horizontal calculation grid extended across the work plane of the entire room at a height of $0.8 \mathrm{~m}$ with a $2.0 \mathrm{~m}$ spacing ( $1.0 \mathrm{~m}$ away from the walls) for the columns and rows of the calculation points. On the vertical wall was the one-point measurement sensor located at a $1.5 \mathrm{~m}$ height at the centre of the long (north) and short (west) walls respectively.

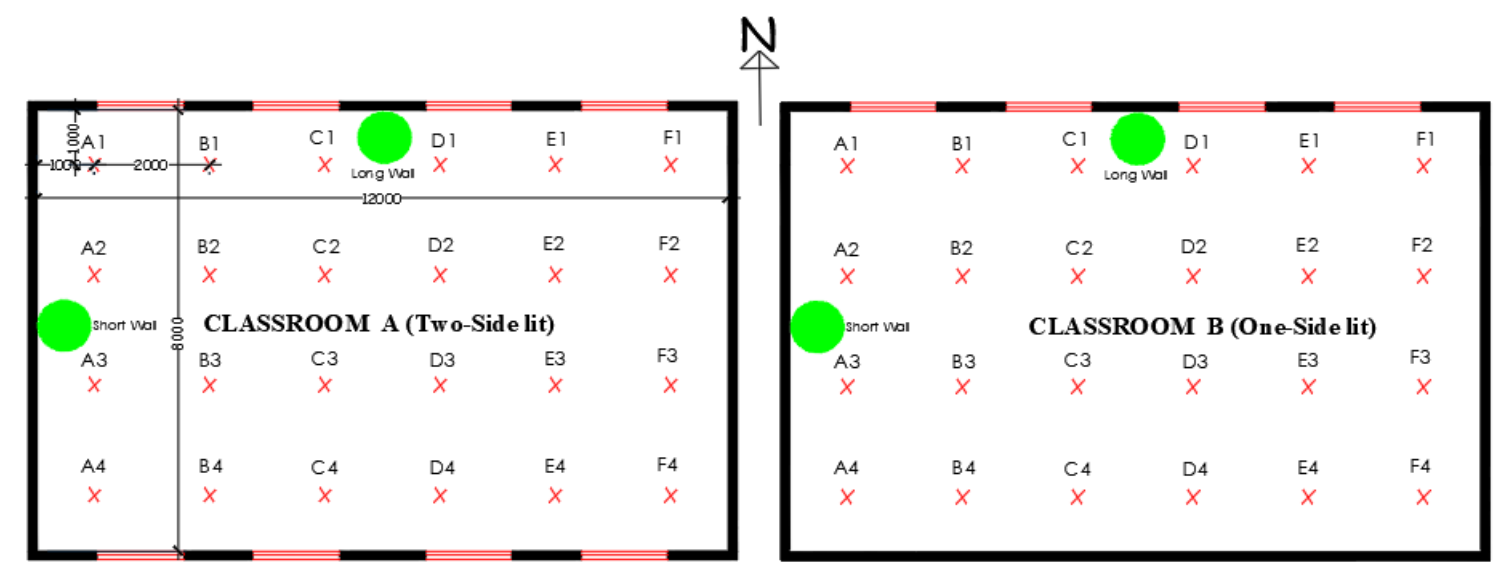

Figure 35: The plan of classroom A and B showing sensors location

Illuminance values were retrieved at 24 sensor points on the horizontal work plane annotated as A1 to F4 respectively, and from the one-point sensor on the vertical walls (Figure 35). It was assumed that both classroom $A$, and classroom $B$ had no internal and external obstructions such as furniture, partition walls, blinds and occupants, buildings, tree, etc. Given that the reflectance of the interior surfaces of a room could impact on the amount and quality of daylight within a 
space, typical reflective values of 0.7 (ceiling), 0.5 (wall), and of 0.2 (floor) (Mardaljevic et al., 2016) were used. The light transmittance of all glazing elements was $70 \%$ for adequate daylight transmittance. The reflective values and light transmittance values are somehow a base case scenario used in this simulation. Neufert, (2000) states that a 1.9 to $2 \mathrm{~m}^{2}$ space is required per student in a standard classroom design, hence the classroom could occupy about 40 students.

To evaluate the quality of daylight within a space, the literature review in Section 3.2.1 suggested suitable metrics to assess the daylight quality of measurable physical quantities. In this study, Useful Daylight Illuminance (UDI) and Daylight Autonomy (DA) are the illuminance-based metrics used to interpret the illuminance values of the simulated data. UDI is defined as the fraction of time in a year when the indoor horizontal daylight illuminance at a given point falls within a given threshold (Mardaljevic \& Nabil, 2005). In studies related to schools, the lower UDI threshold is set to 300 lux, which is in line with international recommended standards (Costanzo et al., 2017b). In this study, the UDI threshold is set to $>300$ to $<2000$ lux. DA is the percentage of the annual daytime hours of occupancy at a point which is sufficient to exceed a benchmark illumination level (Standard IES LM-83-1., 2012). DA can show that for a significant percentage of the annual working hours, there is adequate daylight in a particular point in a space, but it cannot show if this point underperforms during the winter period or in the morning hours (Kleindienst et al., 2008). In the simulation analysis, the DA is set to $>300$ lux. These metrics were used because they are climate-based daylight metrics for determining the distribution of daylight in a space over time and combining UDI and DA would produce highly detailed analysis and helps to easily absorb and interpret a large data set of illuminances (Kleindienst et al., 2008). In this analysis, the school hours ( $8 \mathrm{am}-3 \mathrm{pm}$ ) summer (December, January and February), winter (June, July and August), and annual illuminance of sensor points in the horizontal plane were compared with that of a one-point sensor on the long and short walls (vertical) respectively. The findings of the simulations are reported in Figures 36 to 43 below. 


\subsubsection{Results on the Daylight Distribution in Classroom A and B}

\subsubsection{Summer Illuminance Distribution}

Figure 36 shows the illuminance comparison between sensor points across the horizontal plane

in classroom A and B with that of a one-point sensor measurement on the long (north) and short (west) walls for the 3 months of summer ( $8 \mathrm{am}-3 \mathrm{pm})$. The visual illuminance pattern of most horizontal plane sensors in classroom B were like the visual illuminance pattern of the long and short walls compared to classroom A which shows a difference in illuminance patterns between the horizontal plane and the vertical wall sensors. For example, from the 24 sensor points, 18 sensors (A1-D2 and E1-2) in classroom B shows illuminance patterns similar to that of the long and short walls, whereas, in classroom A, only 12 horizontal sensors (B3, B4, C1-4, D1-4, E1 and E2) show a similar pattern with that of the long wall and 4 horizontal sensors with the short wall. These trends are most likely because, during the summer, the sun is high in the sky and daylight levels within a room can be at a minimum (less direct sunlight penetration into a room). Hence, the one-side lit classroom which received less direct daylight had many points on the horizontal plane that show a similar illuminance pattern with the sensors on the long and short wall compared to the two-side lit classroom which received daylight from both the north and south facing windows. Given that the sun rises from east to west, the variation in illuminance patterns in the east facing sensors F1, 2, 3 and E3 show that as the sun moves during the course of a day, there is an increase in illuminance levels, which peaks around noon before decreasing when the sun moves towards the west. Therefore, it can be inferred that the movement of the sun and the window configuration and orientation were factors that varied the illuminance patterns between the horizontal plane and vertical wall sensors.

However, in both classrooms, the sensors located at the centre of the horizontal plane ( $C$ and $D$, 1-4) shows visual illuminance patterns that appear like that of the long wall and the short wall in classroom B. Given that the sensor on the long wall was north facing, these trends suggest that during the summer, illuminance values derived from a vertical sensor on the northern wall could provide a useful benchmark, to predict illuminance at the centre of the horizontal plane - this assertion is examined further in the winter and annual illuminance analyses below. 

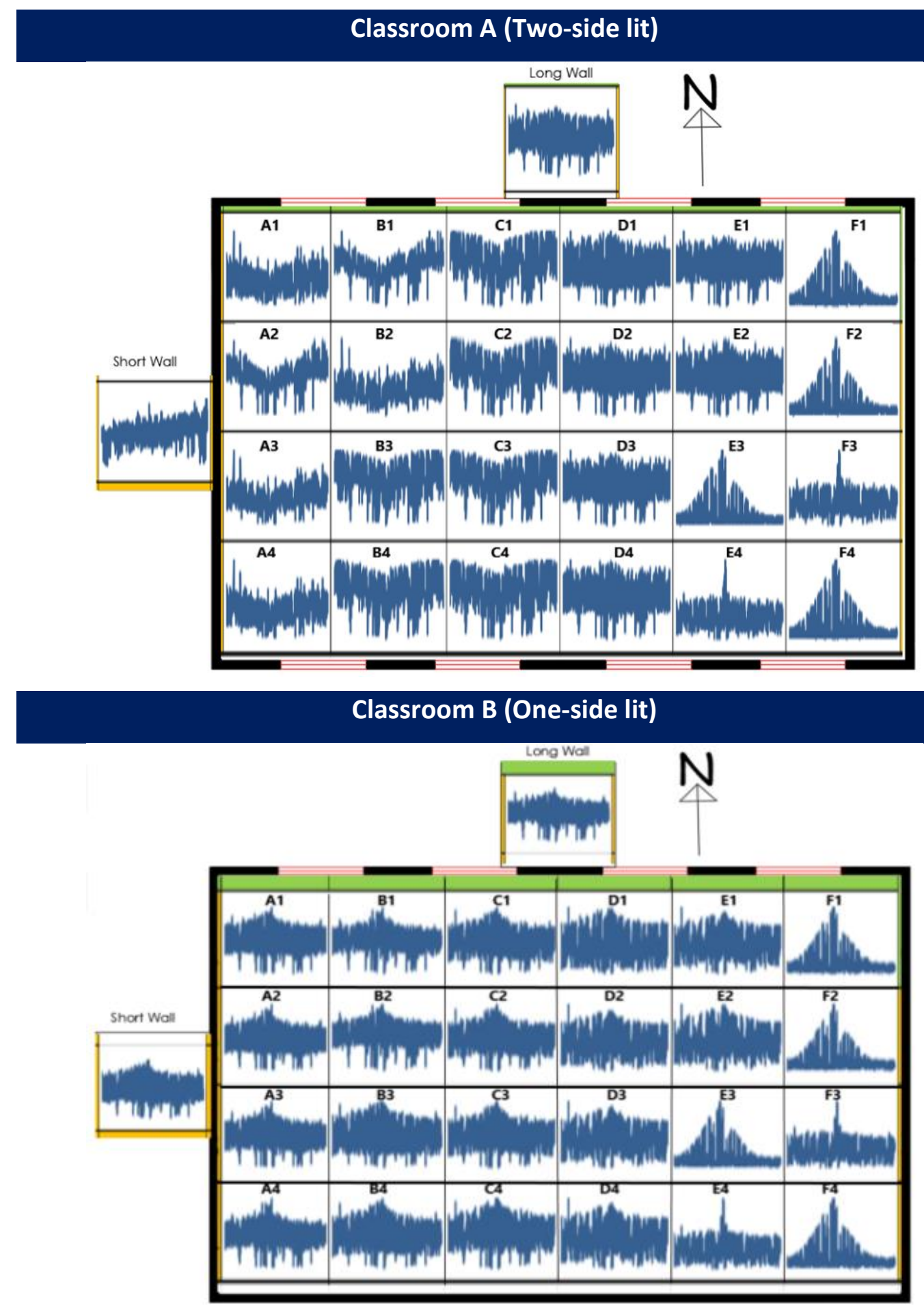

Figure 36: Comparison of Summer Illuminance Distribution on the Horizontal Plane with that of a One-Point Sensor on the Long and Short Walls in a two-side lit and one-side lit classroom 


\subsubsection{Winter Illuminance Distribution}

Figure 37 shows the illuminance comparison between sensor points across the horizontal plane in classroom A and B with that of a one-point sensor measurement on the long (north) and short (west) walls for the 3 months of winter ( $8 \mathrm{am}-3 \mathrm{pm})$. In both classrooms, the visual illuminance pattern of most horizontal plane sensors shows a variation with the illuminance pattern on the long and short walls. For example, the illuminance pattern on the long wall appears different from that of sensor D1 which was relatively located close to the long wall sensor. Also, the illuminance pattern on the short wall appears different from that of sensor A1-4 which were relatively located close to the short wall sensor. This suggests that even sensors positioned relatively close to each other could show a varying level of illuminance. The variation in illuminance patterns during the winter could be due to the low angle of the sun in the sky and daylight saturation can be at their peak and penetrate deep into a space. As shown in the sparklines in classroom $B$, there were varying levels of illuminance even at the southern side of the classroom that had no windows and the sparklines generally show trends of high spikes at a point in time and low illuminance patterns at another point in time depending on the location of a sensor relative to the window.

However, in classroom B, the sensors located at the centre of the horizontal plane $(\mathrm{C} 1, \mathrm{C} 2$ and C4) show visual illuminance patterns that are like that of the long and short walls and also like that of the long wall in classroom B - this assertion is further explored in the annual illuminance analyses below. 


\section{Classroom A (Two-side lit)}
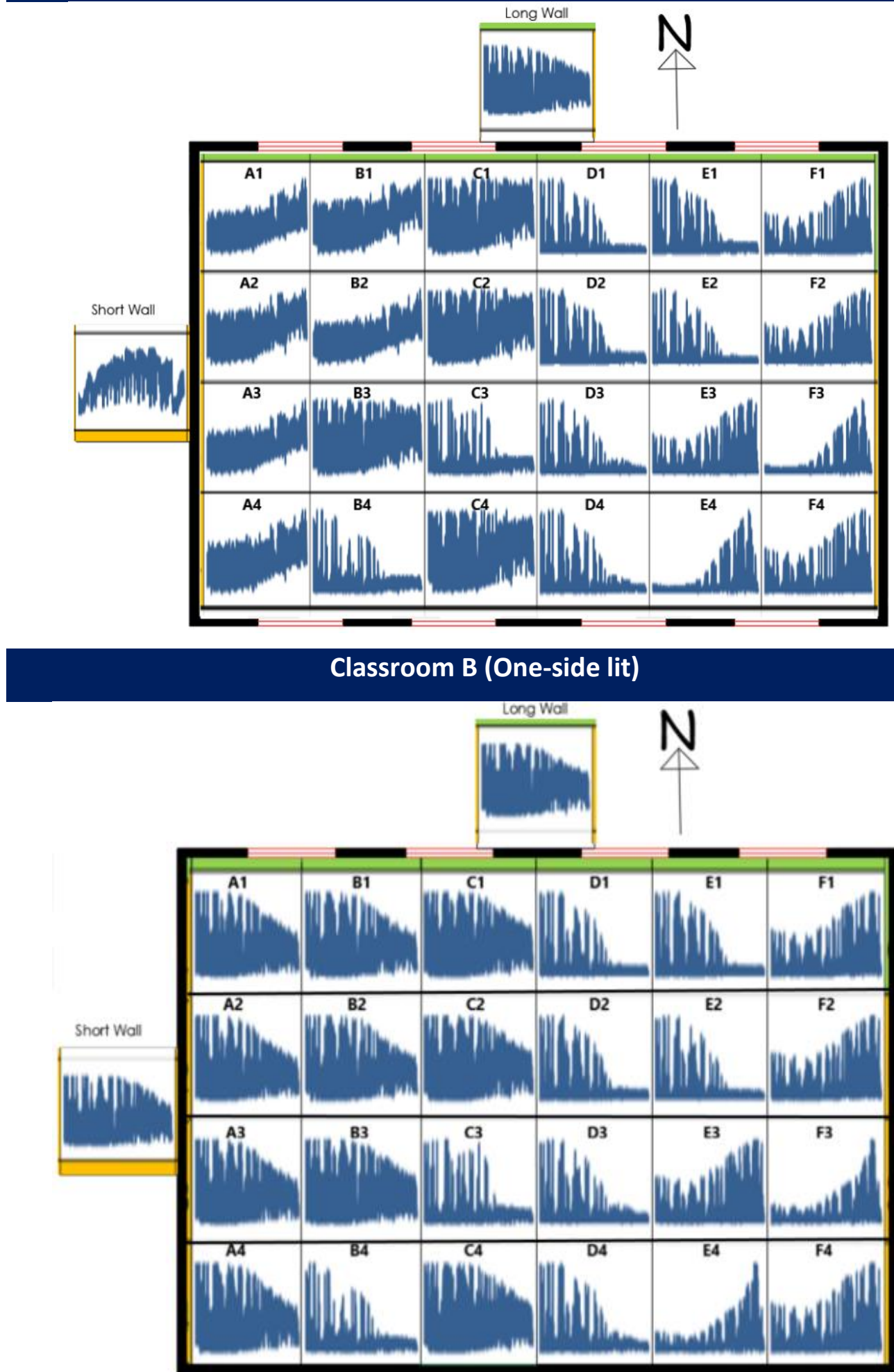

Figure 37: Comparison of Winter Illuminance Distribution on the Horizontal Plane with that of a One-Point Sensor on the Long and Short Walls in a two-side lit and one-side lit classroom 


\subsubsection{Annual Illuminance Distribution}

Figure 38 shows the annual illuminance comparison between sensor points across the horizontal plane in classroom A and B with that of a one-point sensor measurement on the long (north) and short (west) walls between 8 am-3 pm. In both classrooms, the annual visual illuminance pattern of most horizontal plane sensors shows a variation with the illuminance pattern on the long and short walls respectively. For example, the illuminance pattern in sensors D1-4, E1-4 and F1-4 appear different from that of the long and short walls in both classrooms and the illuminance pattern at the western side of the room was different from that of the eastern side of the room. This clearly demonstrates that many of the points in the room are not represented by the wall sensor. Again, the centre of the horizontal plane $(C 1, C 2$ and $C 4)$ shows illuminance patterns that are like the illuminance trend of the long wall. This informed the rationale to plot the illuminance levels at point C2 against the long and short wall illuminance levels in section 5.1.2.5 below. 


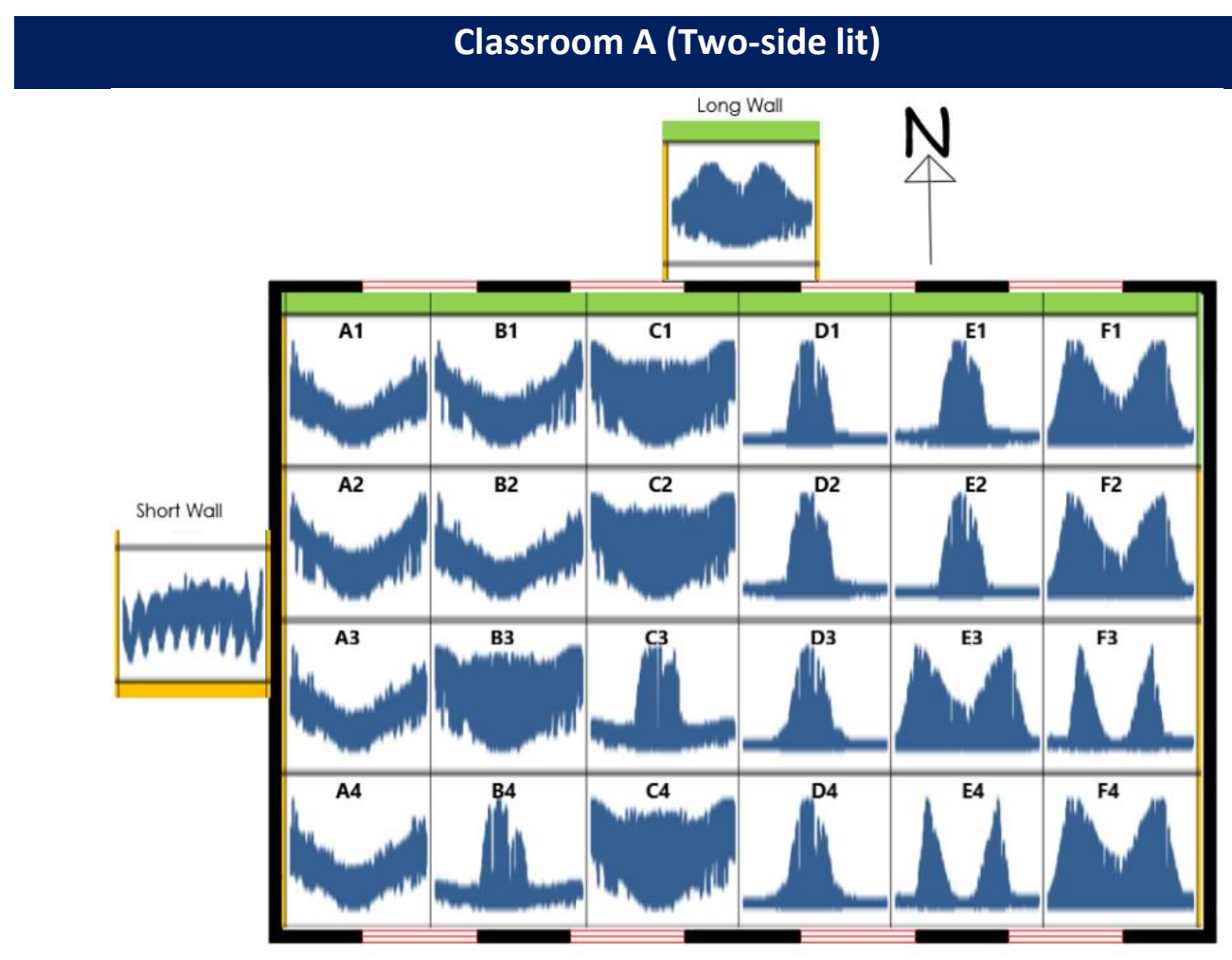

\section{Classroom B (One-side lit)}

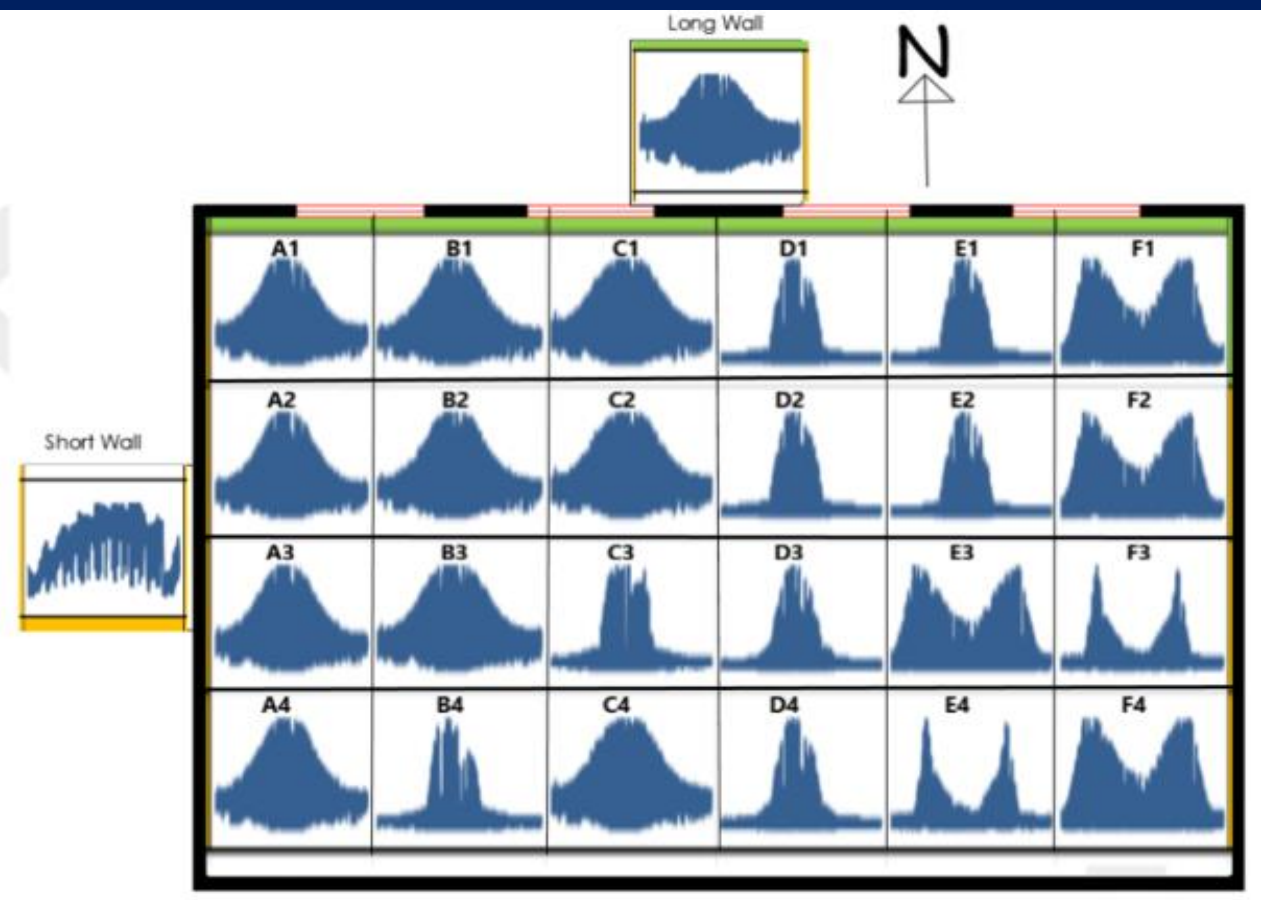

Figure 38: Comparison of Annual Illuminance Distribution on the Horizontal Plane with that of a One-Point Sensor on the Long and Short Walls in a two-side lit and one-side lit classroom 


\subsubsection{Daylight Autonomy (DA) and Useful Daylight Illuminance (UDI)}

To assess the uniformity of daylight in classroom A and B, Figures 40 and 41 shows a comparison of DA ( $>300$ lux) and UDI ( $>300<2000$ lux) on the 24 horizontal plane sensors with that of the onepoint sensor on the long (LW) and short (SW) walls respectively. The green dotted line shows the requirement that the DA must be achieved for $60 \%$ of the work plane area to achieve a good uniform daylight level. The results show that in classroom A, most sensor points on the horizontal plane and the vertical wall sensors achieved an adequate DA and UDI for more than $60 \%$ of the time (above the green line). This implies that a large proportion of the classroom had illuminance values within the acceptable daylight levels. But in classroom B, most sensor points on the horizontal plane achieve a lower DA and UDI trend (less than the acceptable daylight levels below the green line), which was different from that of the long and short walls which achieved an adequate DA and UDI for more than $60 \%$ of the time. Also, in classroom B, the sensors that were located towards the eastern side of the classroom did not achieve the adequate level of uniform daylight on the work plane.

The trends in classroom B has clearly demonstrated that many points in the room are not at all represented by the wall sensor. But similar to the trends of the sparkline analysis, the sensors located at the centre of the horizontal plane ( $\mathrm{C} 1, \mathrm{C} 2, \mathrm{C} 3$ and $\mathrm{C} 4)$ and the sensors on the long and short wall in both classrooms achieved an adequate DA and UDI for more than $60 \%$ of the time (points above the green line). This suggested that illuminance on the wall could predict illuminance at the centre of the horizontal work plane and provide a useful benchmark to predict the illuminance levels in a space in conjunction with the analysis of the building orientation, window configuration and the movement of the sun. The insights about the application of these findings with respect to how to use a one-point sensor to predict daylight are discussed in section 5.1.3 below. 


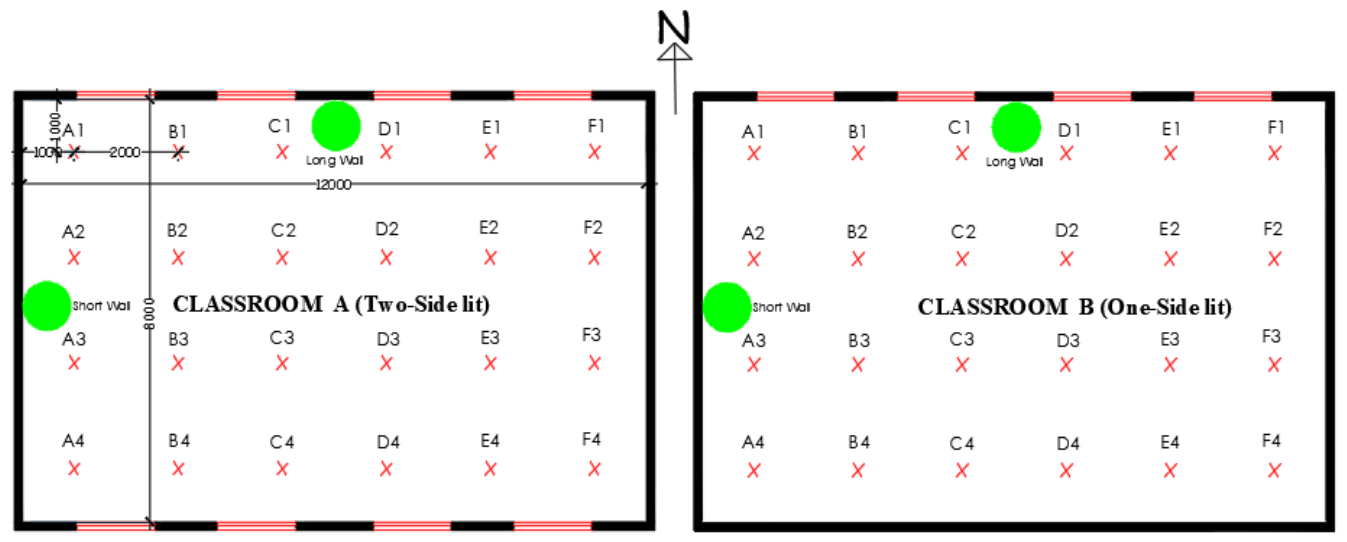

Figure 39: The plan of classroom A and B showing sensors location

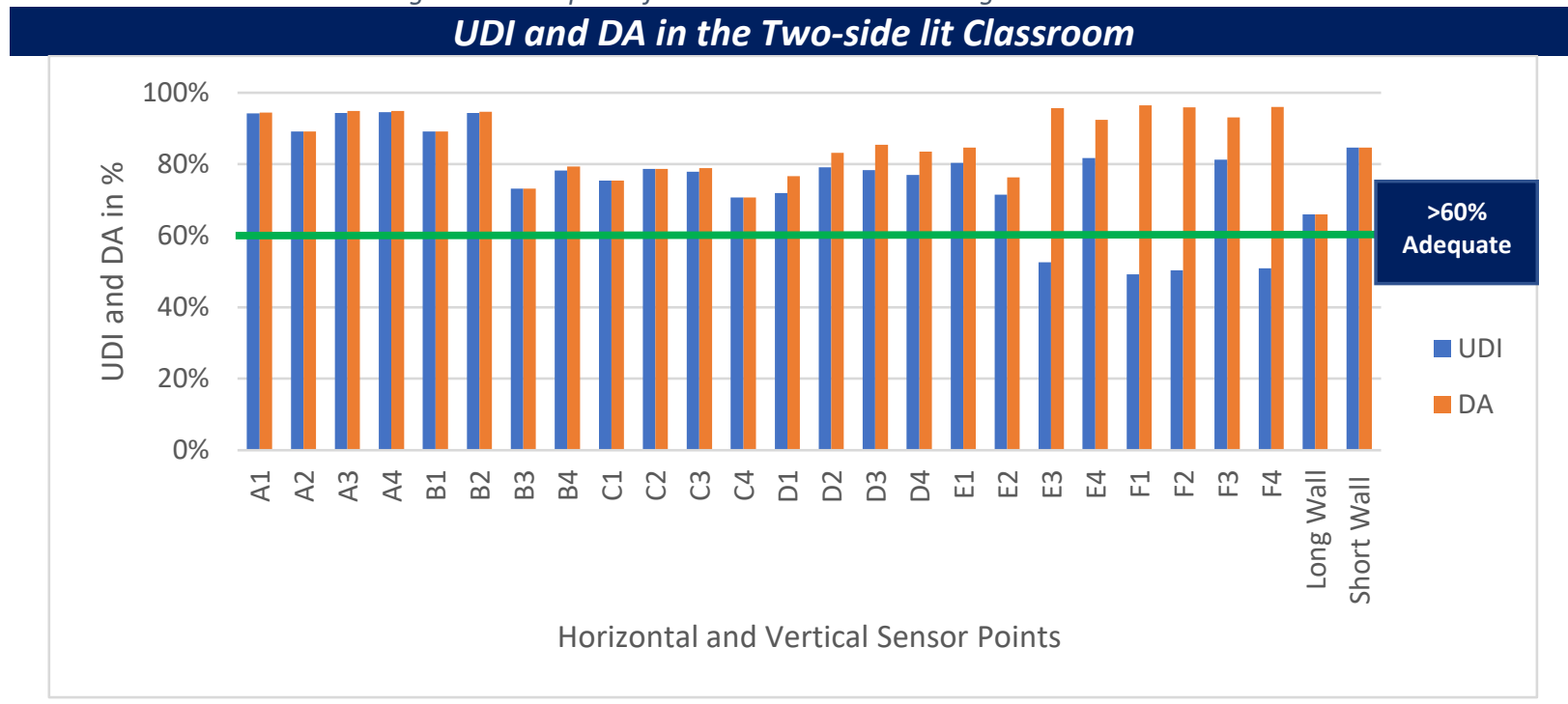

Figure 40: UDI and DA Comparison between the Horizontal Plane and Vertical Wall Sensors in Classroom B

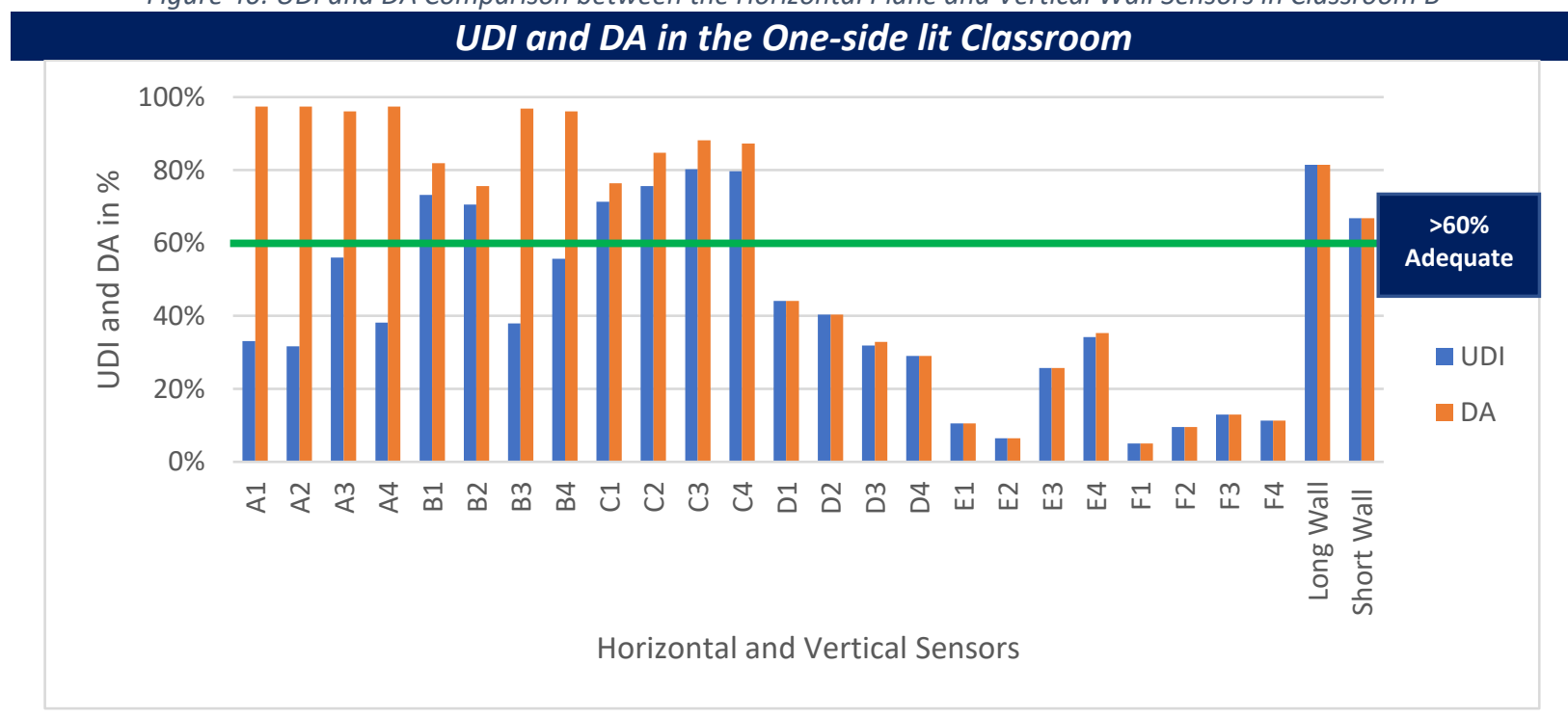

Figure 41: UDI and DA Comparison between the Horizontal Plane and Vertical Wall Sensors in Classroom B 


\subsubsection{Annual Average Illuminance Comparison in Classroom A and B}

The sparklines and DA and UDI analyses have provided indicative trends which suggests that there is a relationship between the central horizontal measuring plane sensor (C2) and the vertical long and short wall sensors, but the magnitude of this relationship is unknown. Hence, sensor C2 was plotted against the long and short wall sensors in both classrooms to understand the extent of their relationship. In Figure 42, a linear regression analysis was carried out. In the two-side lit classroom, there was a moderate correlation between illuminance at the centre of the horizontal plane with that of the long wall and the short walls $\left(R^{2}=0.5\right)$ respectively. Similarly, in the one-side lit classroom, there was a moderate correlation between illuminance at the centre of the horizontal plane with that of the short wall $\left(R^{2}=0.6\right)$, but there was a strong correlation with that of the long wall $\left(R^{2}=0.9\right)$. This indicates that approximately $60 \%$ of the variation in the central horizontal measuring plane sensor (C2) can be explained by the variation in the vertical sensor on the short wall and approximately $90 \%$ of the variation in the central horizontal measuring plane sensor (C2) can be accounted for by the variation in the vertical sensor on the long wall (that is, only approximately $10 \%$ of the variation is attributed to other factors) and the higher this value is the better. These findings support the assertion that illuminance in the vertical plane could predict illuminance at the centre of the horizontal plane. The implication of this result is discussed in section 5.1.3 below. 


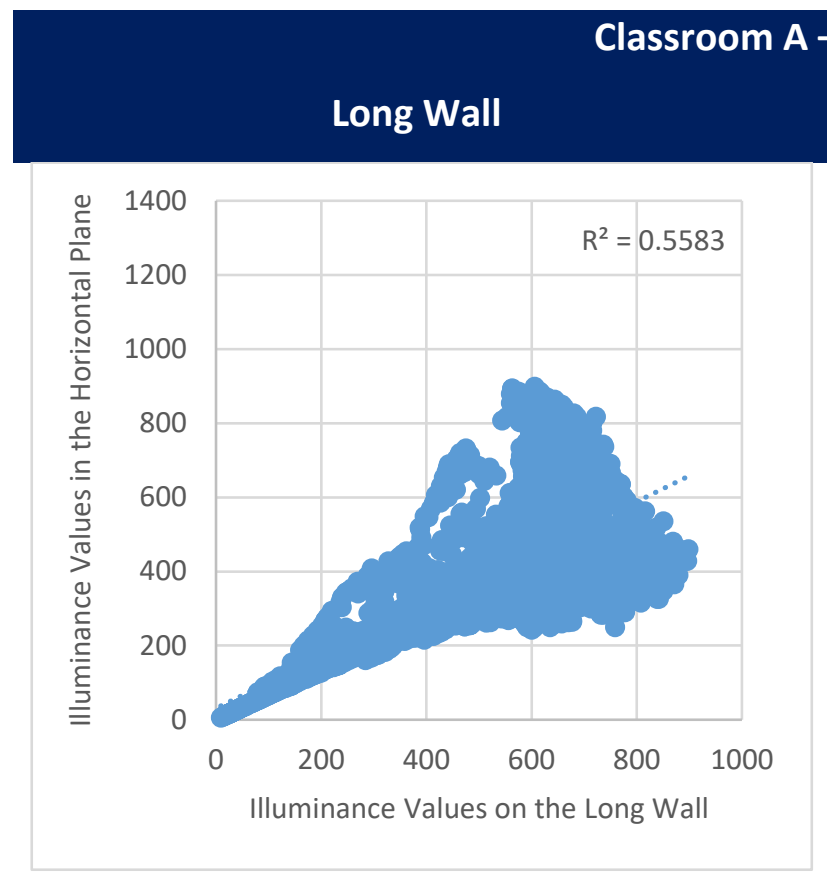

\section{Short Wall}
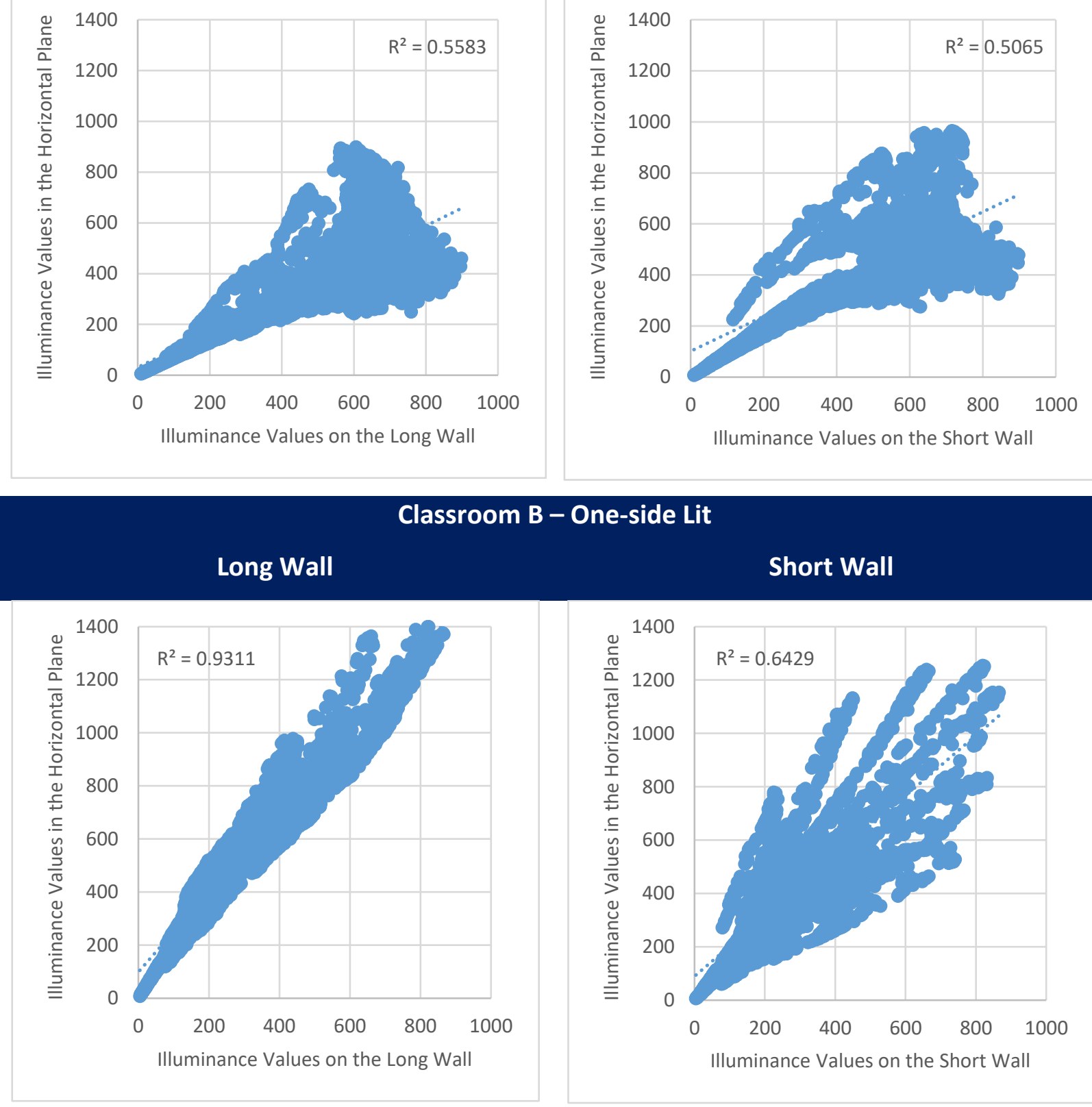

\section{Short Wall}

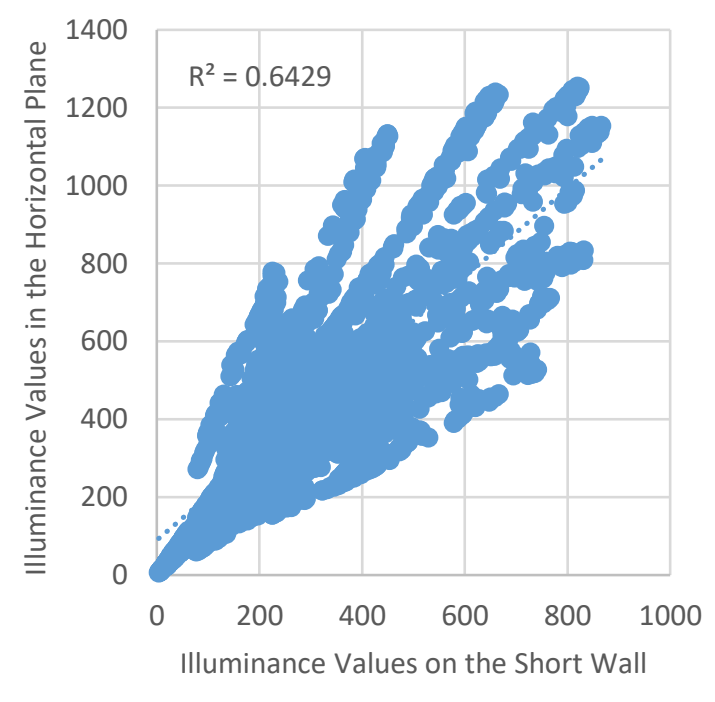

Figure 42: Comparison of Annual Illuminance at the Centre of the Horizontal Plane with that of the Vertical Walls 


\subsubsection{Discussion on Using a One-Point Sensor to Measure the Daylight Performance of}

\section{Classrooms}

If there is a plan to use a single sensor to monitor the daylight performance of a space to determine good and poorly lit classrooms, selecting a point in the space that was important and represented the worst-case or minimal annual illuminance level would be ideal. The aim of the CBDM simulation was to determine such a point and to know how well a single point represents the illuminance levels in the rest of the room. The results revealed that given the dynamic nature of daylight, it is difficult to determine a specific point in a room for use in understanding the daylight distribution (quantity and quality) across a space. The visual patterns in the sparklines illustrated that the movement of the sun and the window configuration and orientation were factors that varied the illuminance trends between the horizontal plane and vertical wall sensors. The DA and UDI results showed that there are some points where there seems to be a relationship but equally there are some that are radically different (going by the patterns of light levels). Hence, the uniformity of daylight is an important characteristic that also varied the illuminance patterns in the room. Therefore, regardless of how representative of a room a onepoint sensor measurement is, it cannot determine how well daylight is spread across a room.

However, the simulation results revealed that a one-point sensor measurement on a vertical wall could predict the illuminance values at the centre of the horizontal work plane, and thus provide a benchmark that could be useful to predict good and poorly lit classrooms. Relative to the above analysis and discussion, the following set of assumptions are proposed for using a one-point sensor to determine good and poorly lit classrooms:

- if a one-point sensor is mounted at the centre of a vertical wall, (irrespective of whether it is a two-side lit classroom or a one-side lit classroom), the illuminance values derived could predict the illuminance values across the centre of the horizontal work plane

- if for example, the illuminance values derived from the one-point sensor measurement on the vertical wall is assumed to be 350 lux, it could be estimated that a similar range of illuminance value will be derived across the centre of the horizontal plane 
- it could also be estimated that points away from the centre of the horizontal plane and nearer to the windows would have higher levels of illuminance value than the value derived from the one-point sensor depending on the distance to the glazed area

- for example, Figure 43 below shows average illuminance levels at $11 \mathrm{am}$ in the month of February used to compare the relationship between the central sensor C2 and the long wall sensor to understand the daylight trends across the four points in central sensor C14 in classroom A and B. In classroom A, the windows were on the north (C1) and south (C4) facing walls while in classroom B, the windows were only on the north facing wall. The bar chart illustrates that the illuminance levels at the central sensor C2 is around the same range with the long wall and sensor points ( $\mathrm{C} 1$ and $\mathrm{C} 4$ ) located towards the windows in the two side lit classroom received illuminance levels higher than sensor $\mathrm{C} 1$ and the long wall sensor

\section{Classroom A - Two-side Lit}

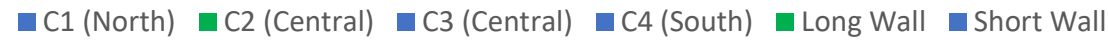

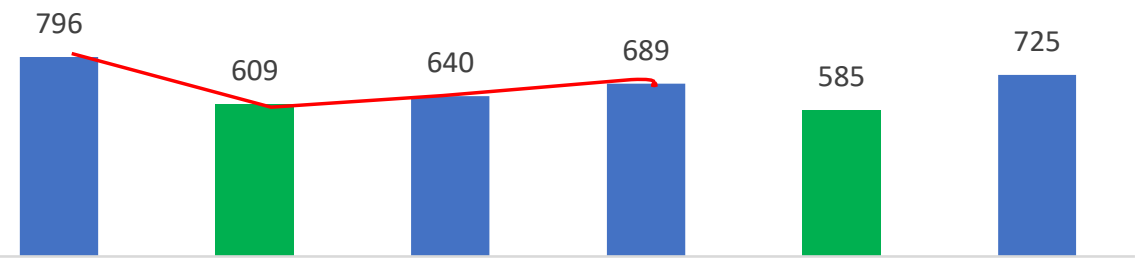

C1 (North) C2 (Central) C3 (Central) C4 (South) Long Wall Short Wall

\section{Classroom B - One-side Lit}

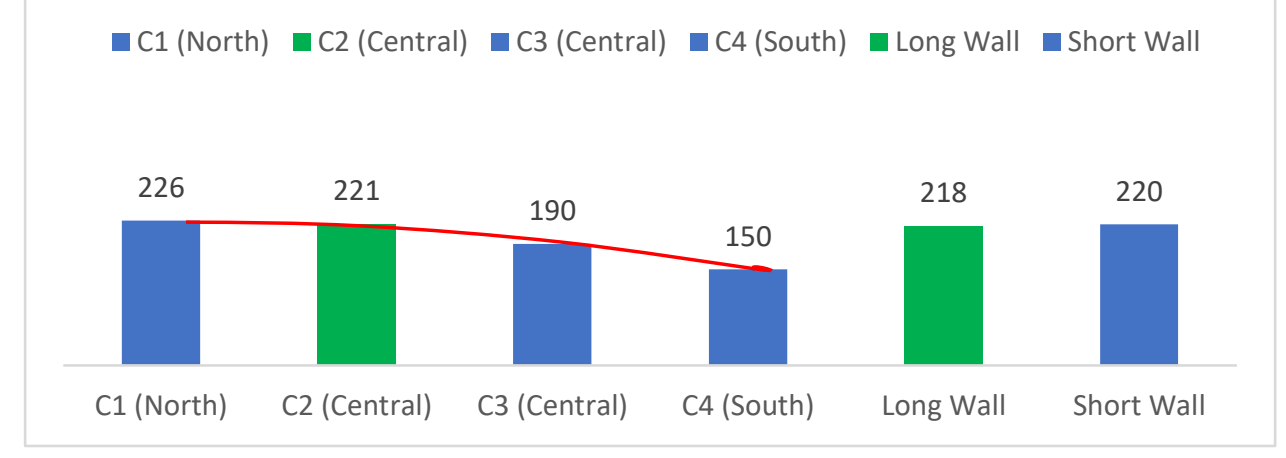

Figure 43: Average Illuminance Levels at 11am in the month of February

- the points away from the window (C4) especially in a one-side lit classroom (Figure 43) will most likely have lower illuminance values 
- applying this prediction approach with a detailed analysis of the building design characteristics such as window configuration and orientation, a one-point measurement on the vertical wall could be useful to identify good and poor classrooms when measuring lighting performance at scale in many buildings and the onset of filtering high illuminance (applying the DA and UDI thresholds) will inform on the existence of high illuminance levels in the space and vice-versa, depending on the illuminance results

- This prediction approach is limited because it may not easily identify the worst-case (glare) or minimal illuminance level. For example, if ten classrooms have good centre room illumination but 2 have too much sun in the area near the windows, a one-point sensor measurement may not identify this. Hence, undertaking a CMDM would be necessary for a more accurate representation of the strong directionality of sun in relation to the classroom geometry, orientation and location. This would measure the uniformity of daylight and any worst-case part of the room would also be identified

Given that this experiment was undertaken for a north-south glazed classroom, this result may not be applicable for an east-west glazed classroom. But the prediction capability of a one-point sensor may be better in an east-west glazed classroom because this orientation receives less direct sunlight between the school hours of 9 am to $3 \mathrm{pm}$. Therefore, for the next stage of this investigation, which is reported in the next chapter, the objective was to compare physical data derived from placing multiple data loggers in an experimental occupied (school day) and unoccupied (non-school day) classroom with that of a one-point sensor measurement on the four walls exploring different orientations (north-south and east-west) in a real-world scenario. Also, the distribution of lighting, temperature, humidity, noise and $\mathrm{CO}_{2}$ was investigated. If a reasonable association can be made between measured illuminance data on multiple points in the horizontal plane and a one-point sensor measurement on the vertical walls, then that would support the proposition that a limited number of sensors could predict IEQ distribution within a space. 


\subsection{Physical Measurement Experiment Methodology}

The daylight simulation results above illustrated that the movement of the sun and the window configuration and orientation were factors that varied the illuminance trends between the horizontal plane and vertical wall sensors. It also provided indicative trends which showed that there is a relationship between illuminance patterns measured on the vertical wall with the central horizontal measuring plane sensor. This informed the rationale to investigate these trends in a real-world classroom to explore different orientations (north-south and east-west) and to investigate the distribution of lighting, temperature, humidity, noise and $\mathrm{CO}^{2}$ in a room.

To begin this investigation, a pilot study was carried out in a north facing one-side lit classroom at Victoria University of Wellington, School of Architecture. Fourteen sensors (data loggers) that simultaneously measures lighting, temperature, sound levels, and $\mathrm{CO}^{2}$ were paired and placed at the centre of the four walls respectively, two paired sensors were placed at the measuring plane height of $0.8 \mathrm{~m}$ in the centre of the space and another set of two paired sensors at strategic locations on the measuring plane. As shown in Figure 44, the vertical sensor was positioned at the centre of the wall at a $1.5 \mathrm{~m}$ height above the ground. The observation of the occupancy and usage of the room was undertaken. The aim of this measurement was to carry out a preliminary assessment on whether there is a relationship between the IEQ levels of the centre of a space with a one-point sensor on the four walls and to pair the sensors to calibrate the instruments (refer to Appendix 4 and Appendix 5 for the results).

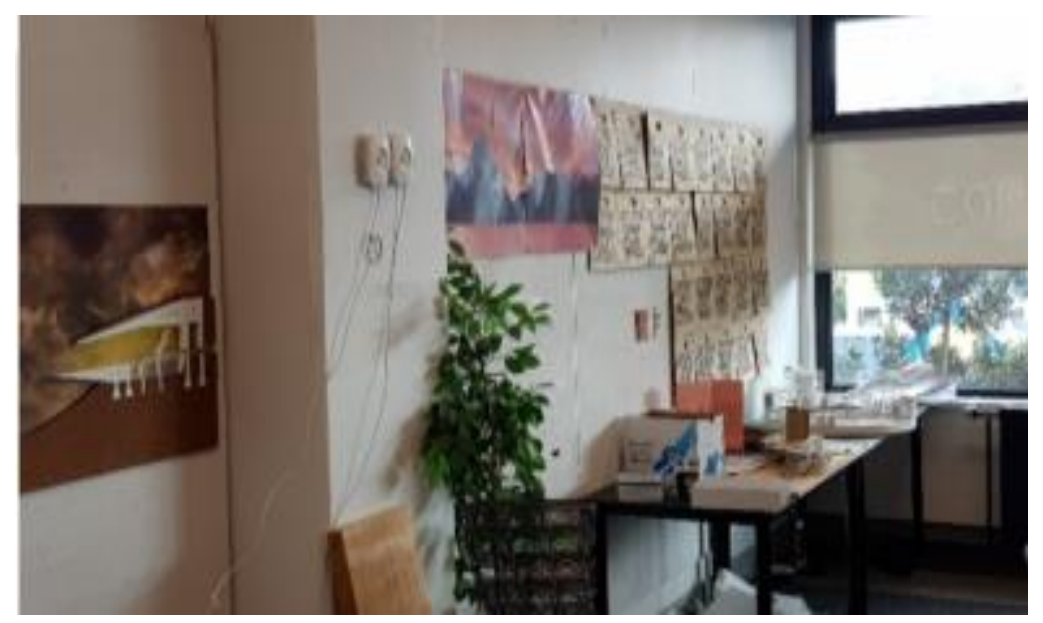

Figure 44: Image showing sensors paired on the wall of an occupied design classroom 
The pilot study results showed that the differences between a wall mounted sensor at a height of $1.5 \mathrm{~m}$ above the ground and a centrally positioned horizontal sensor at a desk height of $0.8 \mathrm{~m}$ was not so great for temperature, humidity, acoustics and $\mathrm{CO}_{2}$. This relationship was weaker for lighting levels compared to the other variables. This suggested that among the five variables, lighting had a higher variability across a space (refer to $\underline{\text { Appendix } 5}$ for the results). This assertion was investigated further in the three case study classrooms in different seasons as reported in Chapters 5 to 8 below.

Using the methods described in the methodology (Chapter 4.10), this Chapter presents the physical measurements results of the three experimental classrooms and modelling of the sitespecific conditions of the classrooms. The aim was to ascertain whether the plan to provide one sensor in a classroom will provide reliable data, by comparing an array of sensors with one on a wall and where might be the best location to measure IEQ (light, temperature, humidity, and $\mathrm{CO}_{2}$ ) in classrooms at scale to identify good and poor classrooms.

In Figure 45, the data loggers were annotated as A1-A3 (central - horizontal plane sensors placed on the desk looking upwards) and sensors B1-4 (vertical sensors placed on the wall looking at right angles to the horizontal measuring plane) respectively with the corresponding wall orientation (north, south east or west) it was placed on. In case study one, three central sensors (A1-3) and four wall sensors (B1-4) were deployed into the space, while in case study two and three, one central sensor (A2) and four wall sensors (B1-4) were deployed into the space. While the aim was to deploy as many multiple sensors as possible into the case study classrooms, the number of sensors deployed was limited by space usage, caution was taken to avoid any disruption of the day to day learning activities and to ensure that the occupants were comfortable with the deployment. Based on lessons learned from the literature review, pilot and simulation study and case study one, it was hypothesized that a sensor located horizontally at the centre of a space could be useful in understanding whether a one-point sensor located on a vertical wall could predict the IEQ conditions on the horizontal measuring plane. As explained in Section 4.3.1, the centre of a standard classroom will typically provide the most useable space in a classroom that may not be largely influenced by external environmental factors from the doors and windows and could reveal the average IEQ conditions that are indicative of the experience of 
occupants'. In this study, sensor A2 represent the horizontal plane sensor placed at the centre of the space in all three case studies. The three case study classrooms were in New Zealand, a southern hemisphere country, with the sun in the north at mid-day. Line graphs, sparklines, hourly averages and ratio analysis were used to analyse the large set of environmental data. Figure 45 show the colour of each sensor as represented in the line graphs below. For example, the central horizontal measuring plane sensor (A2) is annotated with colour red, while the north facing sensor (B3) is annotated with colour green in all three case study classrooms.

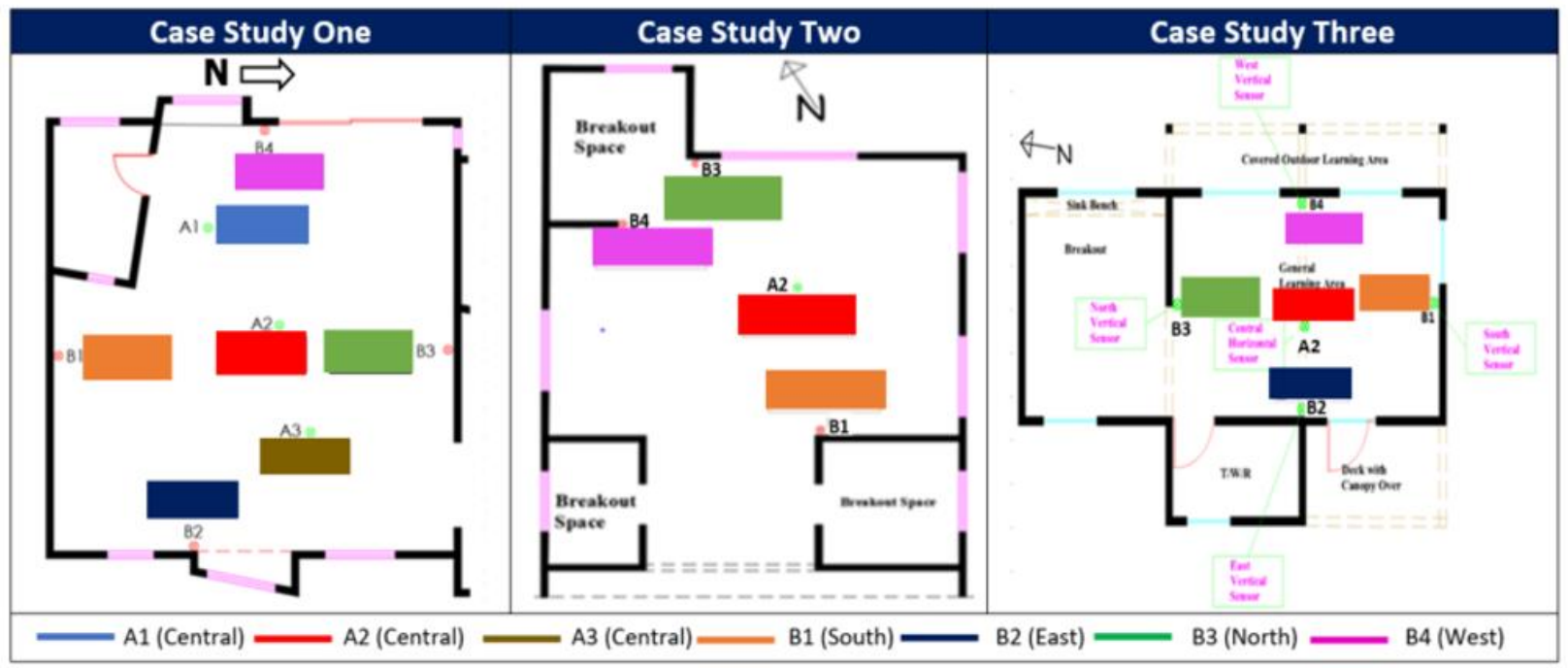

Figure 45: Plan of case study classrooms showing orientation (A sensors horizontal, on a working plane; B sensors vertical, on adjacent wall) and colour annotation of the sensors

The three case study classrooms were naturally ventilated. Case study one and three classrooms were east-west oriented and case study one classroom was situated beside a steep high land at the eastern side, while case study two classroom was north-south oriented. The sensors were deployed into the spaces for 7 days in the summer (case study one), autumn (case study one and two) and spring seasons in 2019 (case study three). As reported in Section 4.3.1 above, these three seasons were chosen for further investigations because they provide worst-case scenarios to explore trends and patterns in the distribution of IEQ in a naturally ventilated space.

For each case study and environmental variable, the collated data were analysed from 8 am to 3 pm under the following categories:

- Non-school days (weekends) 
- School days (weekdays)

The rationale for analysing non-school days and school days was to understand the performance of the space when it is not occupied in comparison to when it is occupied. For example, and for acoustics, sound level measurement during unoccupied non-school hours was useful in understanding the potential impact of external noise sources (whether the internal environment is impacted by noise transfer through the building envelope from outside to the inside) and to ascertain whether the building meets the background noise design goal limit. The analyses of the 24 hours data trends could be relevant to show night-time trends in a building's thermal performance and trends from sunrise to sunset in relation to the external environmental features such as topography and shades. But in this study, only the school hours were analysed because this is the time when the buildings are in most intensive use and the primary factors of variability such as the sun and space usage and occupancy usually occur during this period.

\subsection{Physical Measurement of Lighting Distribution in the Case Study Classrooms}

Following the lessons learned from the pilot study above and daylight simulation experiment above, a glare exclusion threshold of <=2000lx was set for the illuminance analysis of this study. This is because a high peak level of short duration or even an instance of high illuminance value could have an enormous effect on the data analysis. High illuminance levels could lead to glare issues within a space. Murray, O'Flynn, \& Beattie, (2001) state that excessive contrast between light and dark within a building which is caused by the inadequate distribution of daylight in a space, or the sun's position in relation to the building's geometry or viewing the sun reflected on bright surface results in glare. In the literature, various glare exclusion limits were found. For example, Murray, O'Flynn, \& Beattie, (2001) suggested that a 'glare threshold factor' is typically set at 2100 lx. For 'normal circumstances' 7.1 is the factor by which the average background brightness must be multiplied by for an occupant to perceive glare from an object. "If the average background brightness is $300 \mathrm{~lx}\left(300 \mathrm{Cd} / \mathrm{m}^{2}\right)$ any object above $2100 \mathrm{~lx}\left(2100 \mathrm{Cd} / \mathrm{m}^{2}\right)$ will be perceived as a source of glare". 


\subsubsection{Non-School Days Lighting Analysis}

In Figure 46, the non-school days in the different seasons in all three case studies were analysed to explore the relationship between the horizontal measuring plane sensors and the one-point sensors on the vertical wall. The graphical illuminance trends show a variation between the various sensor points. However, sensors A2 (central) and sensor B3 (North) appear to have a similar trend in the rise and fall of illuminance values. In the summer and autumn illuminance trends in case study one, the central horizontal sensor (A2) showed a relationship in illuminance pattern between 8 am and $3 \mathrm{pm}$ with that of the vertical wall sensor (B3) which was located on the northern wall of the east-west oriented classroom. The point in time where there were differences between the horizontal (A1-3) and vertical (B1-4) sensors was during periods where higher illuminance values were recorded. After noon, and in case study one, sensor A1 and B1 in the autumn and summer graphs had illuminance levels that were higher than 2000 lux and showed a wider variation in their illuminance trends. Figure 47 shows that in both summer and autumn and for case study one, there was sunshine around noon. Hence, the high levels of illuminance recorded around noon in the space were due to the impact of the sun which penetrated the building through the skylight (B1) and west-facing windows (A1). However, in case study two and three illuminance levels were $<2000$ lux and case study two show graphical patterns of relationship between horizontal and vertical sensors at lower illuminance levels. These trends suggest that at lower illuminance levels and depending on the impact of the sun at a point in time, there is a lower variation between horizontal and vertical sensors, but at higher illuminance levels, there is a greater variation. The extent of this variation is explored further below using statistical analysis. In Figure 46, the line graph shows that for summer and spring in case study one and three, the lighting levels in the classroom were largely above the acceptable design standard 300 minimum classroom illuminance thresholds (DQLS, 2020), while in the autumn, it was largely $<300$ lux. This was because the summer and spring days had more periods of sunshine hours than the autumn which had some degree of cloudiness (Figure 47). Therefore, during days with clear sky and sunshine, the space may be well illuminated without the use of artificial lighting, because these data are for unoccupied days and therefore the electric light is not on. 


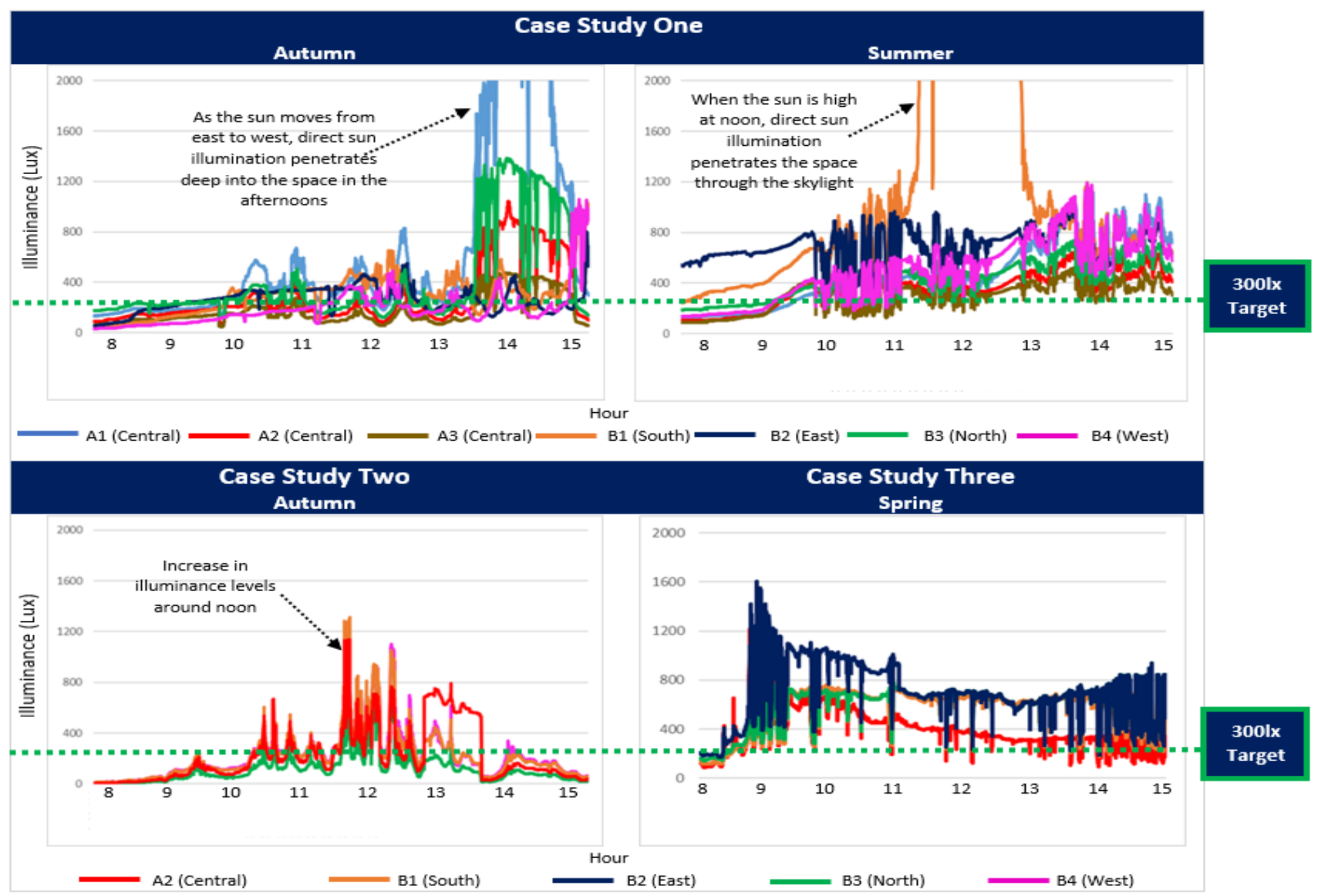

Figure 46: Line graphs showing illuminance trends between 8 am - 3 pm during non-school days in all three case studies (A sensors horizontal, on a working plane; B sensors vertical, on adjacent wall) 


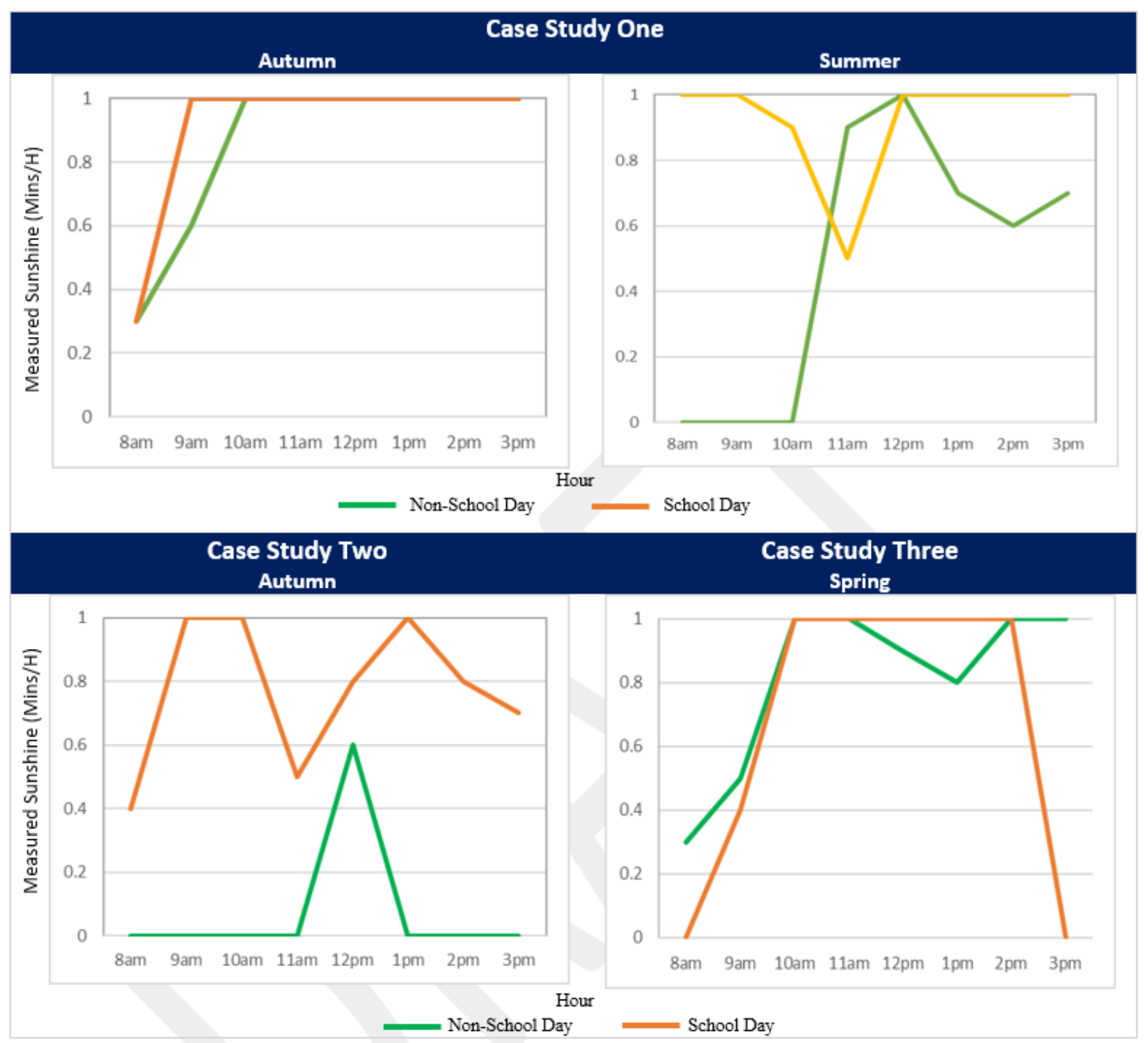

Figure 47: Line graphs showing measured sunshine in minutes within the hours of 8 am to 3 pm in non-school and school days in all three case studies. Source: NIWA

In Figure 48, sparklines were used to explore the relationship between the horizontal and vertical sensors. The visual illuminance pattern of the horizontal measuring plane sensors indicates that there is a variation with the illuminance pattern of the vertical sensors on the walls respectively. However, in case study one, and both autumn and summer, the visual illuminance pattern between the central horizontal measuring sensor (A2) and the vertical wall sensor (B3) appear similar. This showed that for this classroom (with glazing on the east and west walls), sensor B3 (north) could be an ideal position for a one-point vertical sensor, given that it indicates illuminance patterns that appeared like that of the central sensor. This trend is consistent with 
the simulation results which showed that during the summer and because the sun is high in the sky and daylight levels within a room can be at a minimum (less direct sunlight penetration into a room), there was a relationship between the central horizontal plane sensor and the vertical wall sensor. This assertion was explored further in the statistical analysis reported in section 5.3.4 below. However, the visual pattern in case study three showed patterns of variability between sensor A2 and B3 (Lighting levels appear higher in the wall sensors compared to the horizontal sensor where the light levels appear lower).

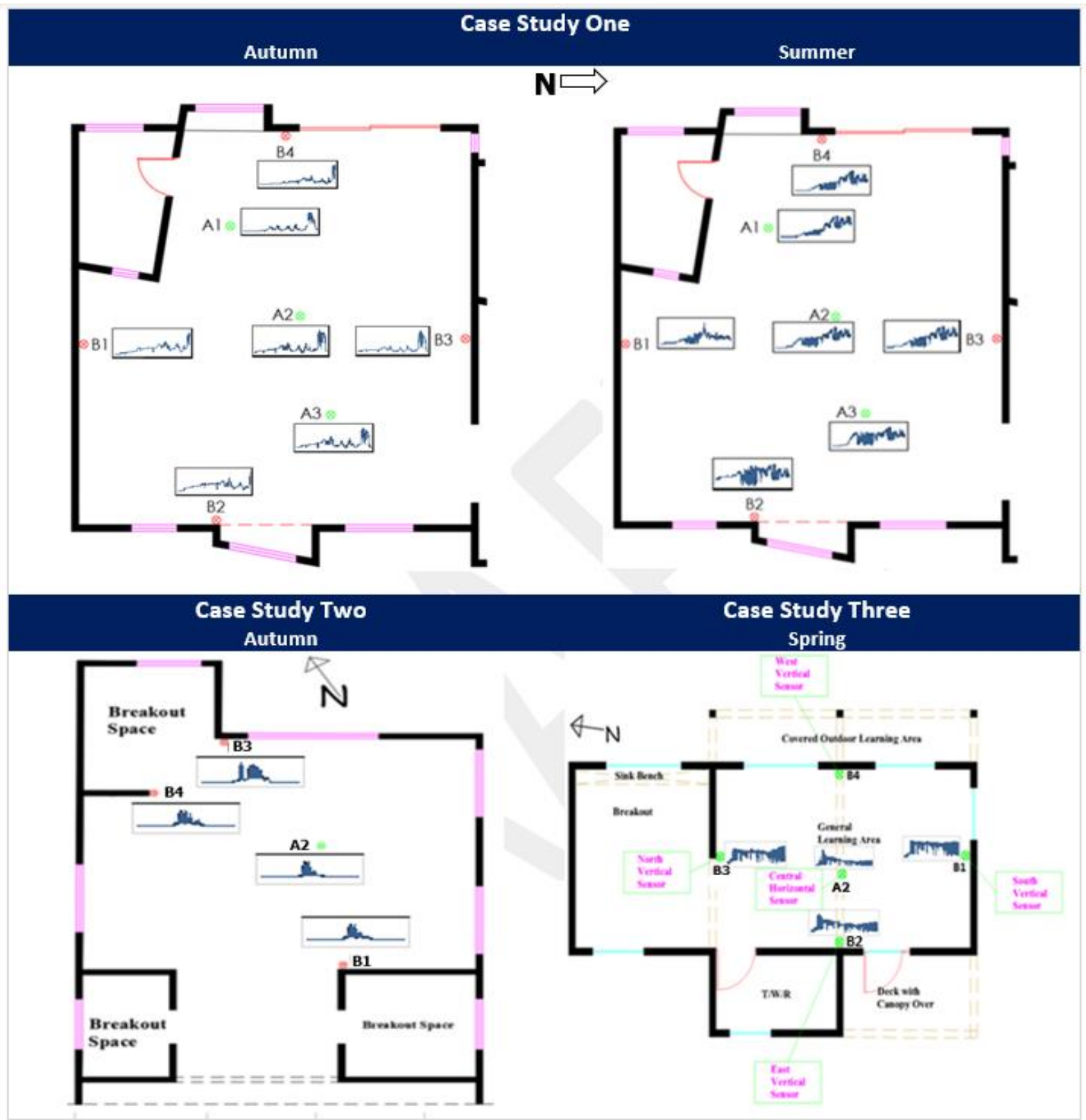

Figure 48: Sparklines showing illuminance visual patterns $<=2000 l u x$ between 8 am to $3 \mathrm{pm}$ in the non-school days 


\subsubsection{School Days Lighting Analysis}

In Figure 49, the graphical trends of illuminance values in case study one and two shows patterns of variability. For example, in case study one, the variability between the central horizontal measuring plane sensor (A1) and the vertical wall sensor (B1) was so great because sensor B1 was impacted by sunlight at noon. This suggested that due to the movement of the sun, it may be difficult to use a one-point sensor to predict the lighting levels across a space. Also, the impacts of artificial lighting resulted in a variation between the central horizontal measuring plane sensor (A1) and the vertical wall sensor (B3) in case study two. This suggests that the complexity of using a single point sensor in an occupied classroom is that to get useful data from it, there needs to be an algorithm that separates the electric light from the daylight.

However, in case study three and compared to the non-school day, the line graph shows graphical patterns of similarity between horizontal plane sensor A2 and vertical plane sensors B1-3 respectively, especially with sensor B3 (North). This was observed to be due to the actions of occupants to regulate the light levels within their space to suit different learning activities. As can be seen in Figure 50 below, this classroom had blinds and dimmer control to regulate the artificial lights. During the one-day observation, it was noted in case study three that when there were instances of high solar penetration (Figure 41), the teachers used the blinds to reduce the amount of sunlight entering the space. Also, when the students carried out a class activity that required the use of screens, the lights were dimmed, and blinds used to control solar penetration. For example, around $10 \mathrm{am}$ and around $12 \mathrm{pm}$ the teachers dimmed the illuminance levels in the space for a screen activity. These trends support the assertion that when glare is limited (high illuminance levels is controlled), a vertical wall sensor could be useful for predicting illuminance at the centre of a space. The magnitude of this relationship is explored in the statistical analysis below.

Also, the quantity of daylight in combination with artificial lighting was analysed. Figure 49 also shows that in all seasons and case studies, the lighting levels were largely above the acceptable 300 minimum classroom illuminance thresholds. The period of lower illuminance levels in case study three was due to occupants' control of glare to carry out a screen activity. In case study one, sensor B1 which was positioned relatively near the skylight still showed instances of glare 
during the summer, but in autumn, it shows lower levels of illuminance due to the low angle of the sun as shown in the sun path diagram in Figure 54 below and the degree of cloudiness. Hence, it is difficult for a single sensor to pick up whether a building is experiencing glare issues and need attention and to detect the electric light illuminance levels. 


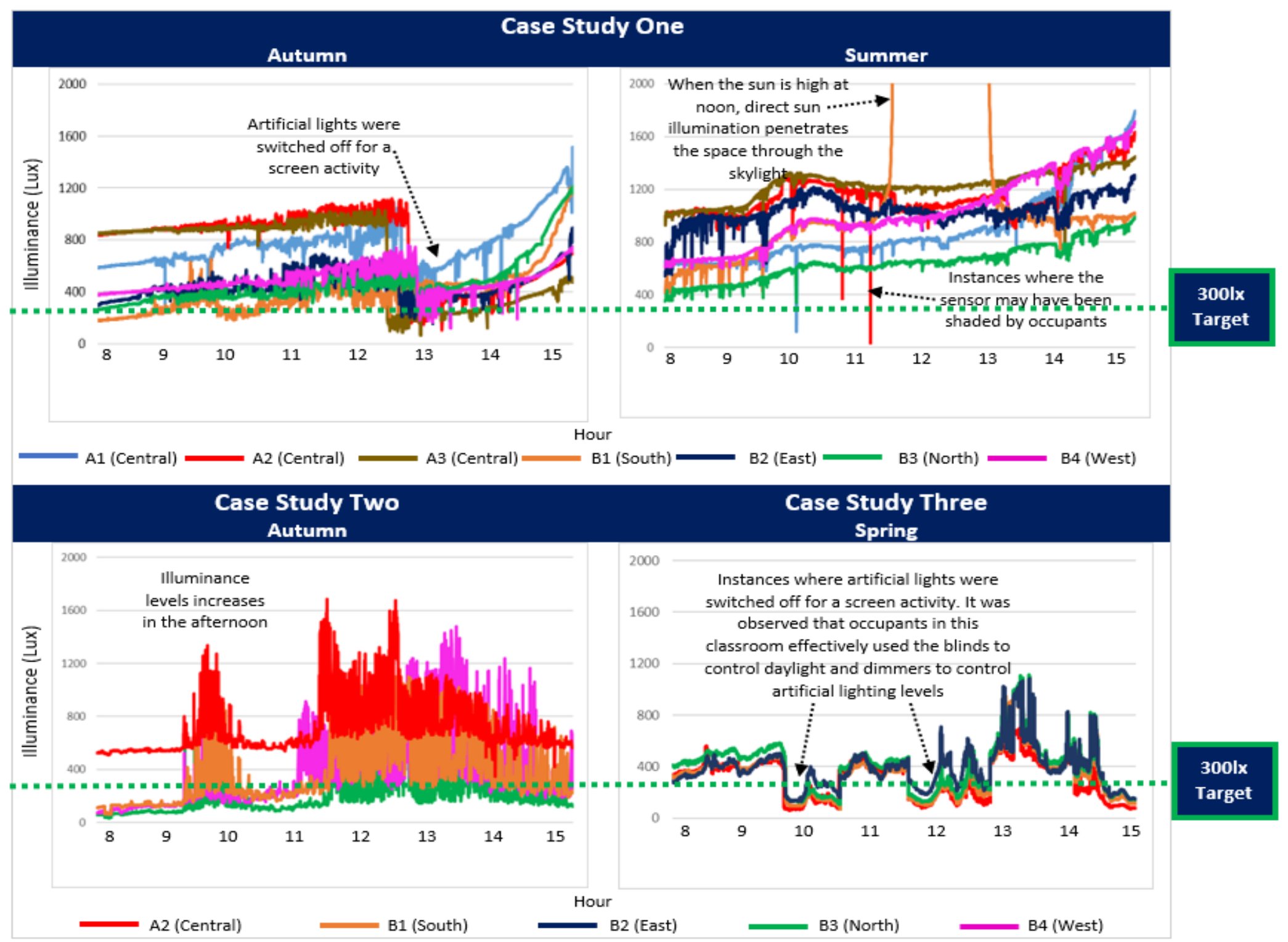

Figure 49: Line graphs showing illuminance trends between 8 am - 3 pm during school days in all three case studies (A sensors horizontal, on a working plane; B sensors vertical, on adjacent wall) 


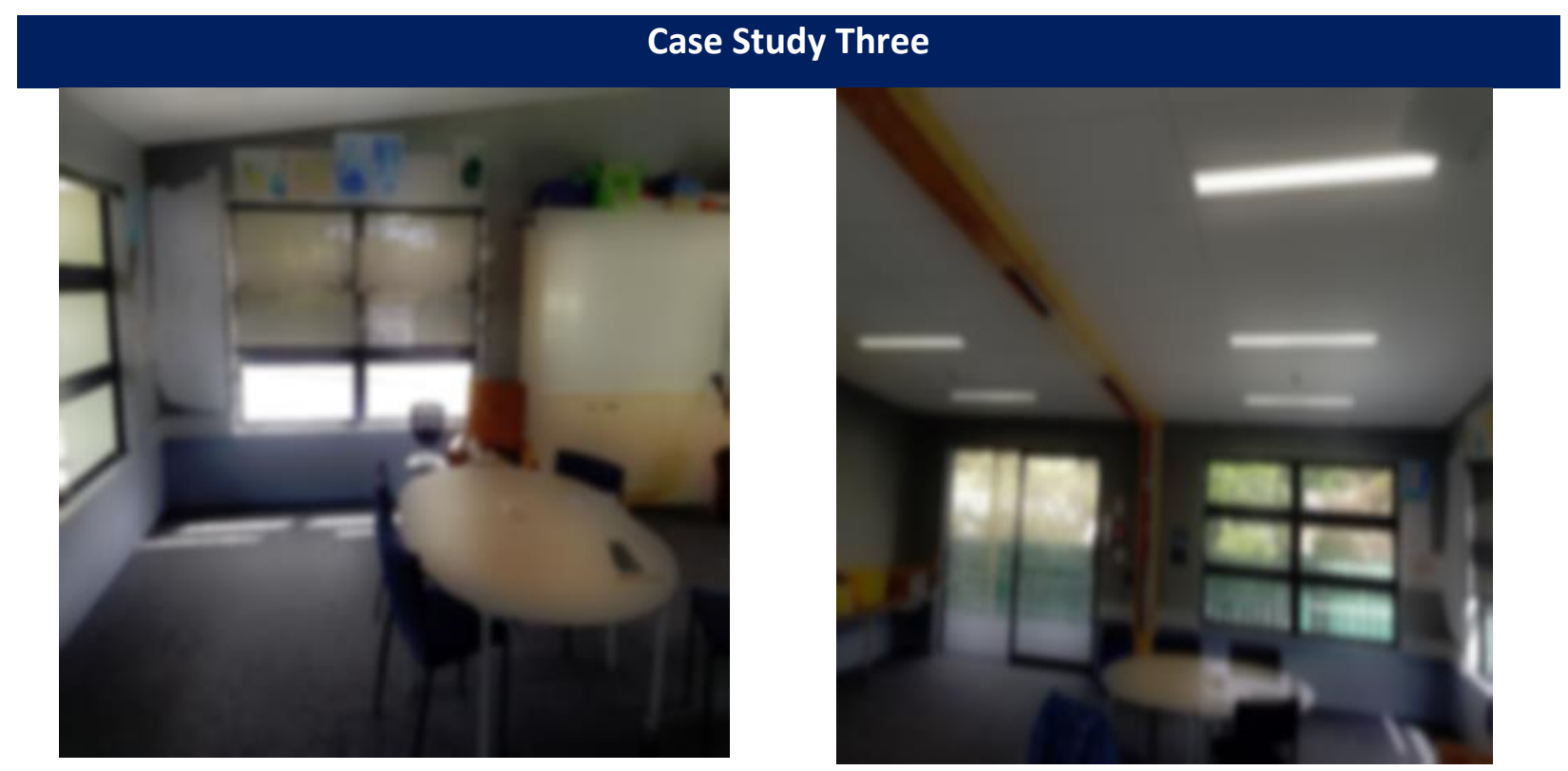

Figure 50: Images showing the use of blinds to minimise solar penetration and dimming of artificial lighting in case study three

In Figure 51, the sparklines visual pattern in the case study one (summer), two and three shows that the horizontal measuring plane sensors (A1-3) had a similar illuminance pattern with the vertical wall sensors (B1-4) respectively. This similarity also appeared stronger between sensors A2 (Central) and B3 (North) in both north-south and east-west orientations. Given that these days were weekdays and the artificial lighting where fixed linear LED lamps, these trends provide a visual indication that even with the influence of artificial lighting when instances of high illuminance were excluded from the calculation, there was a relationship between illuminance levels of a one-point sensor on the vertical wall and that of the central horizontal measuring plane sensor. These findings provide more insights about the simulation results reported in Chapter 5.1 above, which indicated that there is a relationship between illuminance on the vertical wall with illuminance at the centre of the horizontal work plane. 


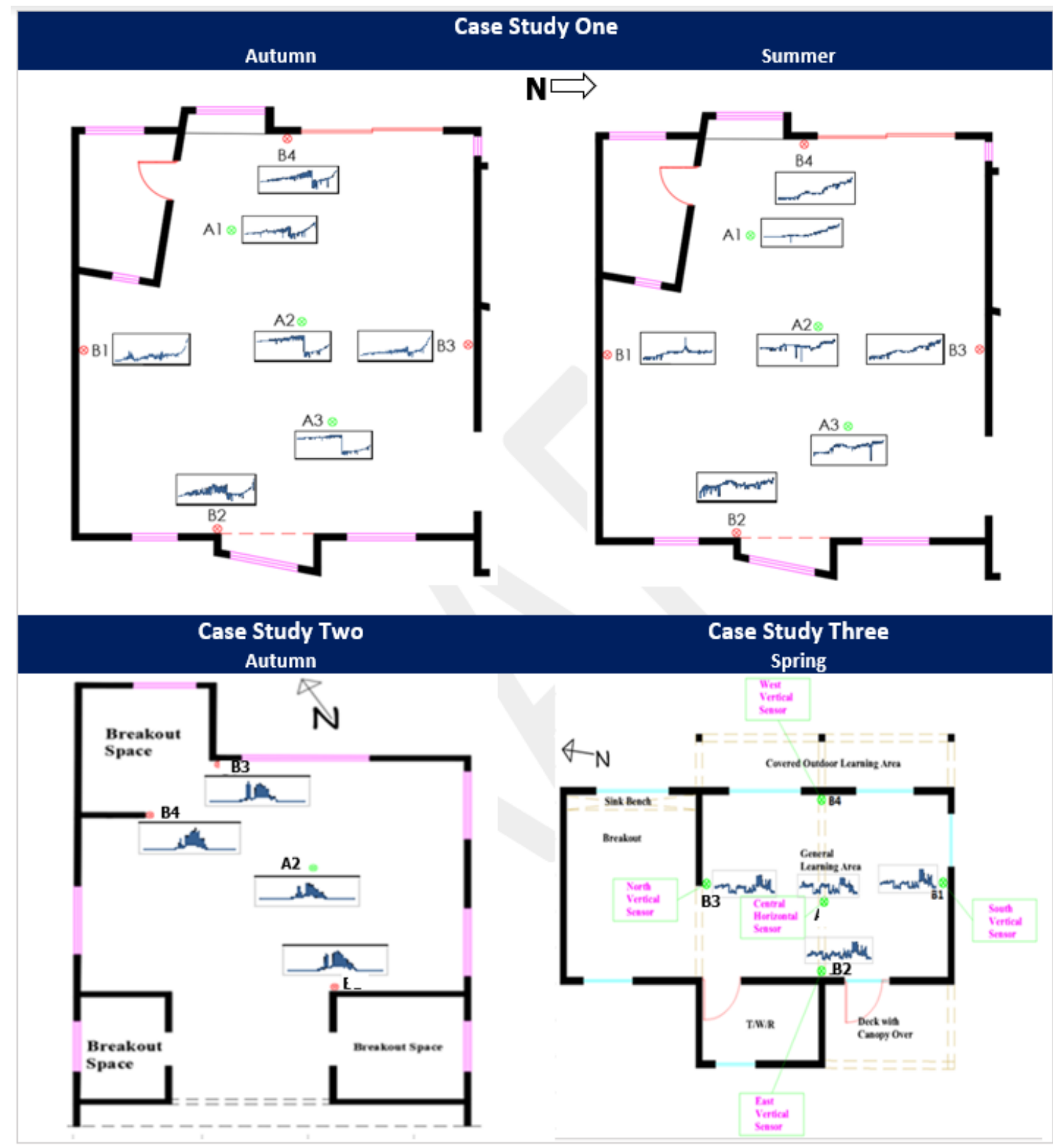

Figure 51: Sparklines showing illuminance visual patterns $<=2000 l u x$ between 8 am to 3 pm in the school days 


\subsubsection{Correlation between Horizontal and Vertical Sensors Lighting Levels}

The results above provided indicative trends which suggested that there is a correlation between the central horizontal measuring plane sensor (A2) and the vertical wall sensor (B3), but the magnitude of this relationship is unknown. Hence, these two sensor points ( $A 2$ and $B 3$ ) were plotted to understand the extent of their relationship. An exclusion threshold of $<=2000 \mathrm{~lx}$ was set to eliminate any instances of glare which could potentially have a significant effect on the data analysis as previously discussed in $\underline{\text { Section } 5.3}$ above.

In Figure 52, a linear regression analysis was carried out for the school day. In all three case studies the graphs indicate that when excessive glare was excluded, there was a strong correlation between the horizontal measuring plane sensor $A 2$ and the vertical wall sensor B3 $\left(R^{2}\right.$ $>0.8$ ) in all seasons and both orientations. To ascertain independent trends, case study one was subdivided into two illuminance intervals. The first illuminance interval was $<800$ lx while the second was 800-2000lx. The results show that both in summer and autumn time, there was a strong correlation $\left(R^{2}=0.97\right)$. And the first illuminance interval $(<8001 x)$ shows a stronger correlation than the second illuminance interval. This indicates that approximately $80 \%$ to $90 \%$ of the variation in the central horizontal measuring plane sensor (A2) can be accounted for by the variation in the vertical wall sensor (B3) (that is, only approximately $10 \%$ to $20 \%$ of the variation is attributed to other factors) and the higher this value is the better. The instances of dispersion of values for higher illuminances (case study two) was due to the influence of artificial lighting from the fixed linear lamps as shown in the line graphs in Figure 49 above. This suggests that higher illuminance levels of even a short duration could have an enormous effect on the statistical analysis. To further explore the correlation between sensor A2 and B3, a comparative ratio analysis was carried out in the next section. 

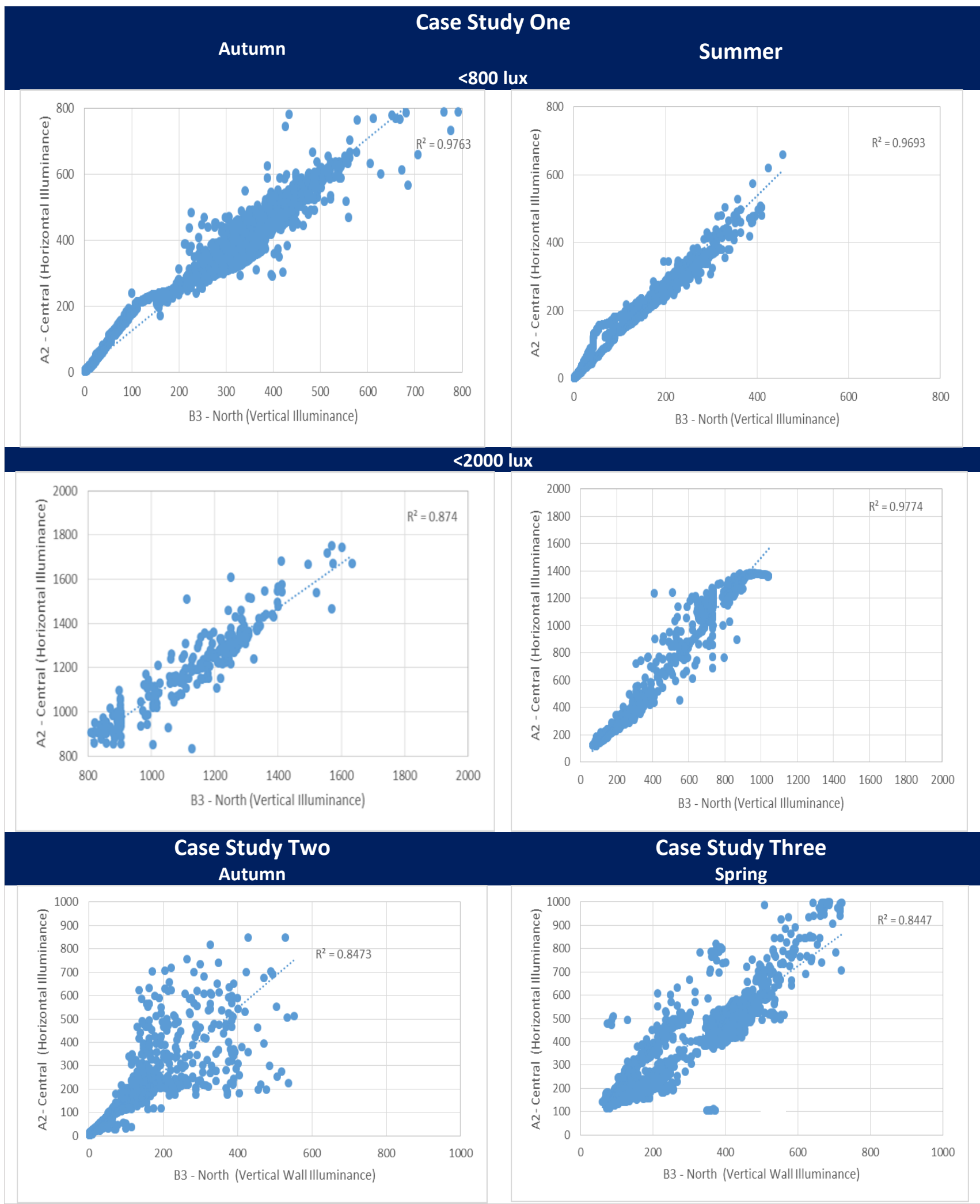

Figure 52: Comparison of illuminance correlation between horizontal (A2) and vertical sensors (B3) 


\subsubsection{Lighting Comparative Ratio Analysis}

A ratio analysis is used to measure how much a variable has changed between two measurements. The ratio indicates that reading $\mathrm{X}$ is twice or half reading $\mathrm{Y}$ and could be described as a two-fold change. In this study, a ratio analysis was used to assess how much larger is the horizontal measuring plane illuminance (A2) compared to the vertical illuminance (B3). This was

calculated by dividing the illuminance values in sensor A2 by that of B3. Figure 53 firstly shows the school day illuminance ratio comparison between sensors A2 and B3 using two illuminance intervals of $<8001 x$ and $800-20001 x$ for case study one and $<=2000$ for case study two and three respectively.

The ratio analysis in Figure 53 shows that for all three case studies in the various seasons and orientations, the relationship between a one-point vertical wall sensor at a height of $1.5 \mathrm{~m}$ above the ground and the horizontal working plane sensor located at the centre of a space at $0.8 \mathrm{~m}$ above the ground was largely less than a one-fold increase in its value. But under the influence of sources of glare such as artificial lighting and sun penetration, the fold increase will be greater (case study two).

These results indicate that when glare is eliminated, a well-positioned vertical sensor in both north-south and east-west oriented classrooms could be useful to predict illuminance levels at the centre of the horizontal measuring plane and could assist with the diagnosis of patterns of lighting performance when measuring lighting in many school buildings. The application of these findings to identify good and poor classrooms is discussed in detail in Sections 5.3.7 and 5.3.8 below. 

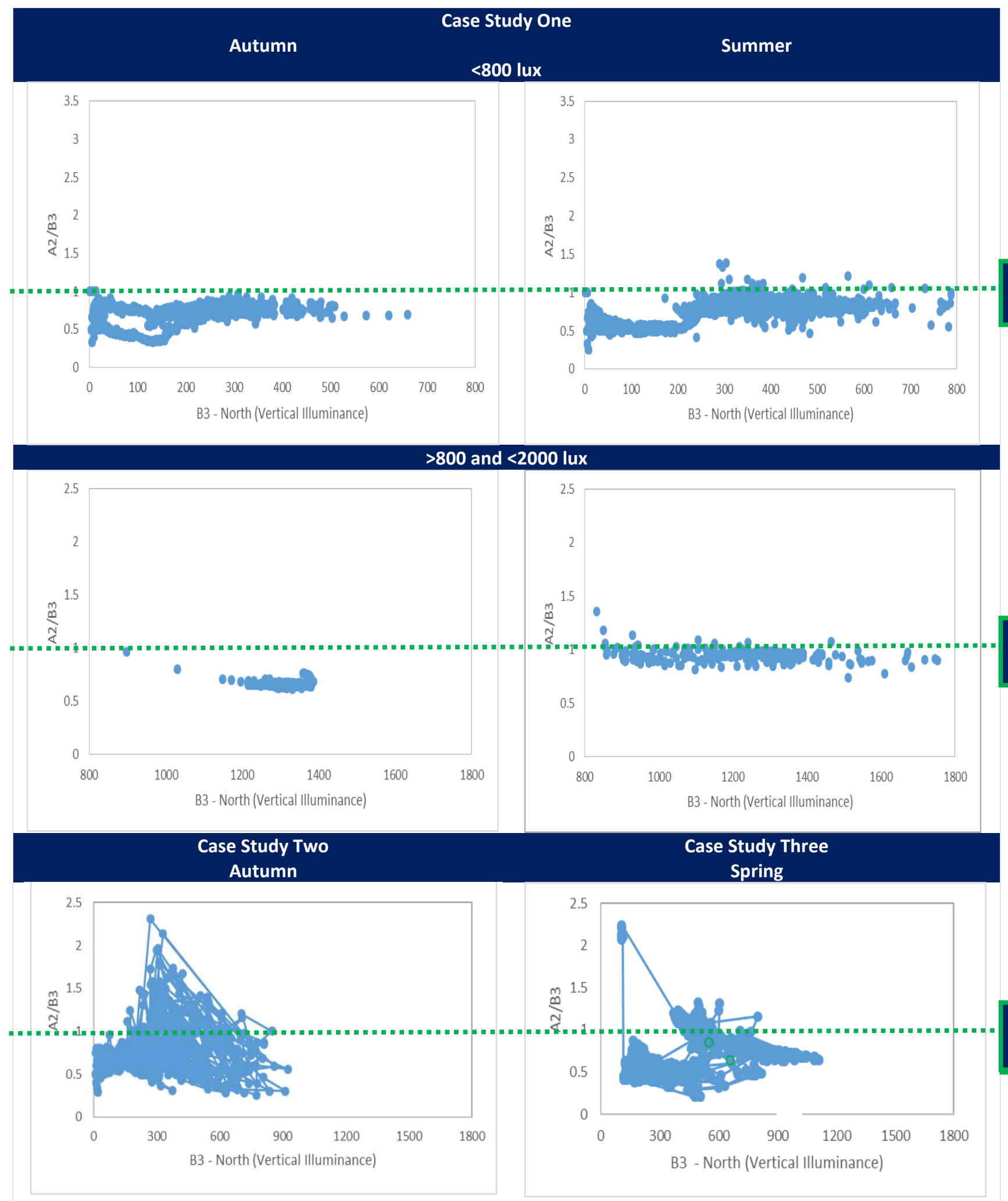

Figure 53: Comparison of the ratio between horizontal and vertical sensors 


\subsubsection{Sun Path and Shade Diagrams}

Given that the path of the sun across the sky is so complex, varying hour by hour and season to season, it was necessary to analyse the sun path and shade to take into consideration the building's location, site's shape, slope and orientation, obstructions such as adjacent buildings, trees and landforms, window placement, and daylight access. This was most important for case study one where the building was situated in a challenging topography (site besides a steep hill). Figure 54 shows the sun path diagram of Wellington, New Zealand. It indicates the altitude (vertical angle) the sun makes with the ground plane and the Azimuth (horizontal angle) between the sun and true north. Comparing the Wellington sun path diagram with case study one classroom site sunshade diagram, everything below the shaded line is shaded, while above the line has sun access, given that the classroom is on the east side of a valley running approximately north south.
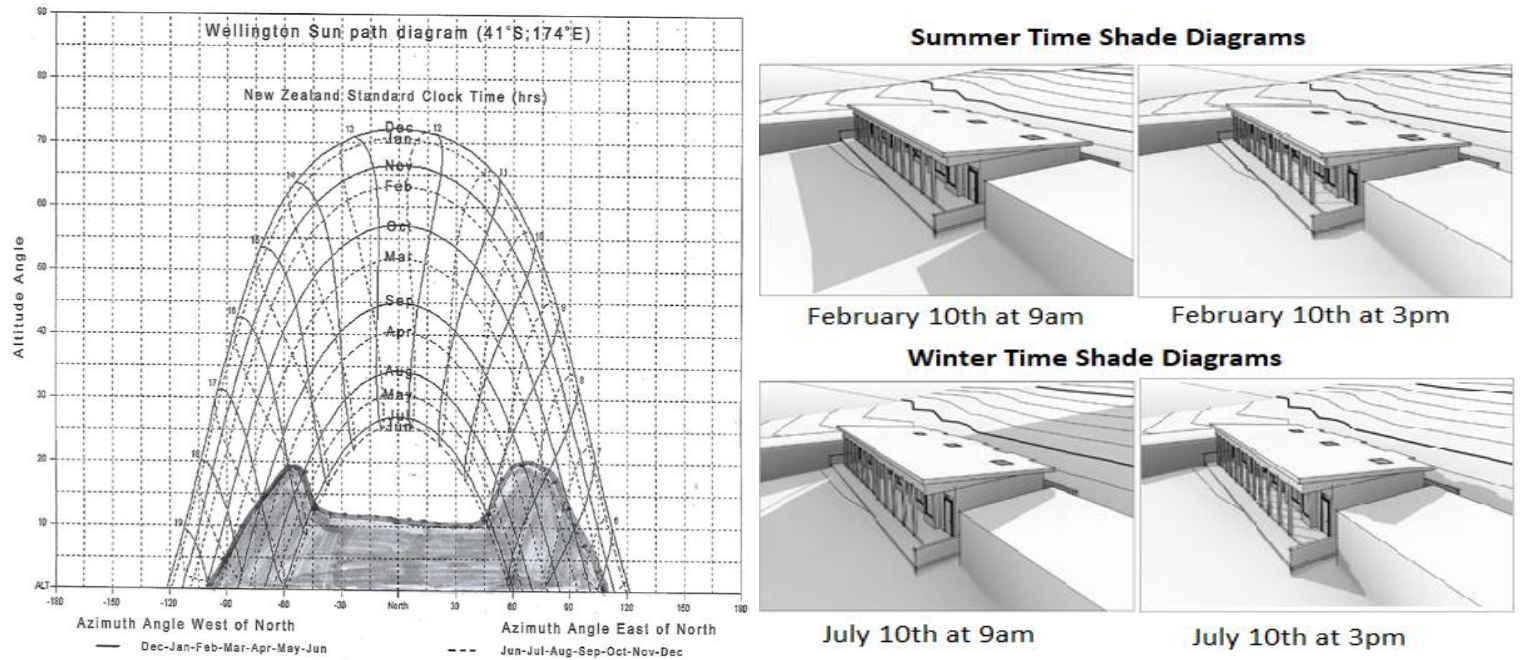

Figure 54: Sun Path (Source: CBPR, Victoria University of Wellington) and shade diagrams of the case study building

In Figure 54, and for case study one, the summer building shade diagrams indicated that at 9 am, the west side of the classroom receives no sunlight because of the angle of the sun at a point in time. However, at $3 \mathrm{pm}$, the western side of the classroom receives much more sunlight while the eastern side receives no sunlight due to the high topography of the site at the east. During the winter periods, the building shade diagrams indicated that at $9 \mathrm{am}$, both the eastern side of the classroom and the western side receives no sunlight due to high topography of the site at the east, and the angle of the sun at this point in time. However, at $3 \mathrm{pm}$, the western side of the 
classroom like during the summer still receives sunlight while the eastern side receives no sunlight. The shade diagrams revealed the impacts of the angle of the sun and the effects of shadows cast by landform around the site which could impact on the spatial distribution of illuminance within the space. Therefore, it can be established that for case study one classroom, during the summer period, south and east-facing sloping sites have limited daylight quantity, while during the winter period both west, south and east-facing sloping site have limited daylight quantity in the mornings, but the western side receives more daylight quantity in the afternoon (as shown in Figure 54 above). Given that the movement of the sun largely impacted on illuminance trends across sensor points in the classrooms, it can be inferred that the analysis of the sun path is important to provide an understanding of how a one-point sensor measurement could be used to predict the lighting levels within a space. 


\subsubsection{Lighting Measurement Discussion}

The reliable prediction of illuminance within a space is vital. For classrooms, the Useful Daylight Illuminance threshold of 300 to 2000 lux at the working plane is considered adequate (Mardaljevic et al., 2016) and the commonly referenced design goal limits for lighting levels is 300 lux on the working plane. In classrooms, there are different working plane heights. Some students may choose to study on the floor, others on different desktop heights ranging from $0.3 \mathrm{~m}$ to about $0.9 \mathrm{~m}$ depending on the furniture design. This difference in work plane height has made it difficult to have a fixed height for measuring and comparing horizontal work plane illuminance levels and further compounds the question of whether a one-point sensor measurement on the vertical wall can predict the lighting level across the horizontal work plane.

In this study, the results indicated that sensors' closer to the glazed area (windows), especially the west-facing sensors showed a great variation in their resulting lighting levels. From the CBDM analysis and observations carried out in the case study classrooms, this variation is presumed to be due to the significant amount of direct daylight received from the window. In case study one, sensors B1 and B2 which were positioned relatively under the skylight received high levels of illuminance values which were above the glare threshold, especially around mid-day and showed a great illuminance variation when compared with the horizontal sensors. In case study two, the influence of artificial lighting on sensor A2 showed a great variation in the illuminance pattern when compared with the vertical wall sensors. These trends revealed that even small variations in sensor points relative to the glazed area and artificial light lamps could produce significant differences in the illuminance distribution across a space. However, the agreement between the horizontal plane and vertical sensors on the wall improves in sensors that were sufficiently distanced away from the window. These findings agree with the literature which stated that sensors positioned more distanced from the window performed better (Mistrick \& Thongtipaya, 1997; Mardaljevic, 2000; Ranasinghe \& Mistrick, 2003). From this data, it might reasonably be inferred that this lack of correlation (variation in illuminance) indicates a room that is not working well. 
In case study one classroom (a two-side lit east-west oriented classroom), there were areas of high illuminance, especially during the summer. Overly high illuminance could cause glare issues which result in visual discomfort when some parts of a space are overly bright (Loe et al., 1999). The analysis indicated that when high illuminance values were excluded from the calculation, there was a strong correlation between sensor A2 which was located at the centre of the classroom and sensor B3 which was located at the centre of the north facing wall. The linear regression analysis showed that approximately $80 \%$ to $90 \%$ of the variation in the central horizontal measuring plane sensor (A2) can be accounted for by the variation in the vertical wall sensor (B3) (that is, only approximately $10 \%$ to $20 \%$ of the variation is attributed to other factors). This trend was consistent in both non-school days when artificial lighting was switched off and the school days when artificial lighting was on and in the various seasons in all three case studies. Hence, it can be inferred that a one-point sensor strategically mounted at the centre of the vertical north wall could provide indicative data to predict illuminance at the centre of the horizontal work plane (if direct light from the windows is eliminated). The three case study classrooms were in New Zealand, a southern hemisphere country, with the sun in the north at mid-day. This suggests that a sensor mounted at the centre of the north wall might receive less direct sunlight during the school hours of 9 am to $3 \mathrm{pm}$ and the results revealed that at lower illuminance values, there is a relationship between vertical and horizontal sensors. These findings are consistent with the literature and provide more insights to understand the CBDM annual simulation experiment which showed that in the various seasons, and both north-facing double and single side-lit classrooms, illuminance on the northern wall sensor $(1.5 \mathrm{~m})$ reliably predicted illuminance at the centre of the horizontal work plane $(0.8 \mathrm{~m})$. Therefore, the findings of this realworld case study of two east-west and a north-south orientated classroom in different seasons demonstrate that this assertion is likely to be valid irrespective of building orientation and season.

The sun path and shade diagrams and sunshine hours indicated that the spatial relationship of illuminance within a space is distinct to the type of space (characteristic of the size and position of glazing) and can best be determined by modelling the space: The sun varies throughout the year and could impact on the spatial distribution of daylight within a space. This makes the 
analysis of the sun's path in relation to site-specific considerations to be a critical environmental factor that needs to be understood when using a one-point lighting sensor to predict the quantity of lighting within a space. Through sun path and shade diagrams, the graphical effects of the varying nature of the sun on a site can be demonstrated taking into consideration the building's location, site's shape, slope and orientation, obstructions such as adjacent buildings, trees and landforms, window placement, and daylight access. Hence, it can be established that the analysis of the sun path is an important rule of thumb in understanding how a one-point sensor measurement within a building could be impacted by the sun movement in a day and in different seasons to facilitate more accurate predictions of lighting quantity within a space.

Like the CBDM simulation experiment results (Section 5.1.3), and relative to the above analysis and discussion, the question arises: how might this observation be used in interpreting a single point wall sensor to indicate good and poorly lit classrooms? Hence, the following set of assumptions are proposed for using a one-point sensor to determine good and poorly lit classrooms:

- in a real-world classroom, if a one-point sensor is strategically mounted at the centre of a vertical wall, where it avoids being in the sun, the illuminance values derived could predict the illuminance values across the centre of the horizontal work plane

- if for example, the illuminance values derived from the one-point sensor measurement on the vertical wall is assumed to be 450 lux, it could be estimated that a similar range of illuminance value will be derived across the centre of the horizontal plane

- it could be predicted that points away from the centre of the horizontal plane and nearer to the windows would have higher levels of illuminance values than the value derived from the one-point sensor, depending on the distance to the glazed area (windows) and the movement of the sun

- the points further away from the window will most likely have lower illuminance values

- this prediction approach could be used to identify good and poor classrooms when measuring lighting performance in many buildings and should be applied in conjunction with the analyses of the factors of variability such as, but not limited to the sun path and 
shade, orientation and window configuration to have a useful benchmark to compare the lighting performance of the most frequently occupied parts of a classroom

Overall, the variance between the wall sensors and other horizontal plane sensors in the case study classrooms and the large variance during instances of high illuminance suggest that it is difficult for a one-point in a space to be representative of the lighting levels in an entire space, given the varying nature of lighting. Therefore, it can be concluded that regardless of how representative of a space a one-point measurement is, it is difficult to quantify how well the lighting is distributed over time in a space.

\subsubsection{How to use a One-Point Sensor for Lighting Prediction}

The measurement of lighting levels is useful in assessing the visual quality of a classroom to inform design decisions such as replacing luminaries for better illumination. The implication of this study is that:

- We can learn how to place a one-point sensor to measure the light characteristic of a room, but not of random sunshine entering the space

- In any occupied space, such as a classroom, it is practically impossible to measure lighting on the working plane to retrieve reliable time series of illuminance without obstructing the functions of the space, hence the use of a one-point sensor will suffice

- To measure lighting in many classrooms, the results illustrate that the illuminance values obtained from a one-point sensor located at a $1.5 \mathrm{~m}$ height on the vertical wall relative to the major window areas (where the sun is unlikely to shine) could be useful to predict the lighting performance of the most frequently occupied parts of a classroom

- There is a ratio between the light on the wall and the light in the centre of the room e.g. if the light at the centre is exactly $3001 x$, then on the wall, it is likely to be $2401 x$. Glare can certainly be figured out, but surely if the light from the sky drops below 300lx the artificial lights can be turned on. Any deviation from this below 300 during occupied hours is likely to be a deliberate choice by the teacher and therefore not a problem

- Therefore, when using a one-point sensor measurement to identify good and poor lighting performance in classrooms, the onset of very high illuminance is an indication of 
glare issues in the classroom and when the illuminance values are far below the $3001 \mathrm{x}$ target, it is an indication of a poorly lit space. Hence, the building characteristics (such as a double or one-side lit space and glazing orientation) should be analysed in conjunction with the measured illuminance data while applying the estimation approach of this study to ascertain good and poor classrooms at scale

- For example, in Figure 55, the typical classroom plan used in the simulation analysis (twoside lit, and one-lit plans) have been used to illustrate how a one-point sensor could be deployed for illuminance prediction in simple classroom forms

- However, it is recommended that in more complex and deep open plan classrooms, it will be ideal to use more sensors for measurement to pick up areas impacted by glare or a Climate Based Daylight Modelling should be undertaken in conjunction with the onepoint sensor measurement

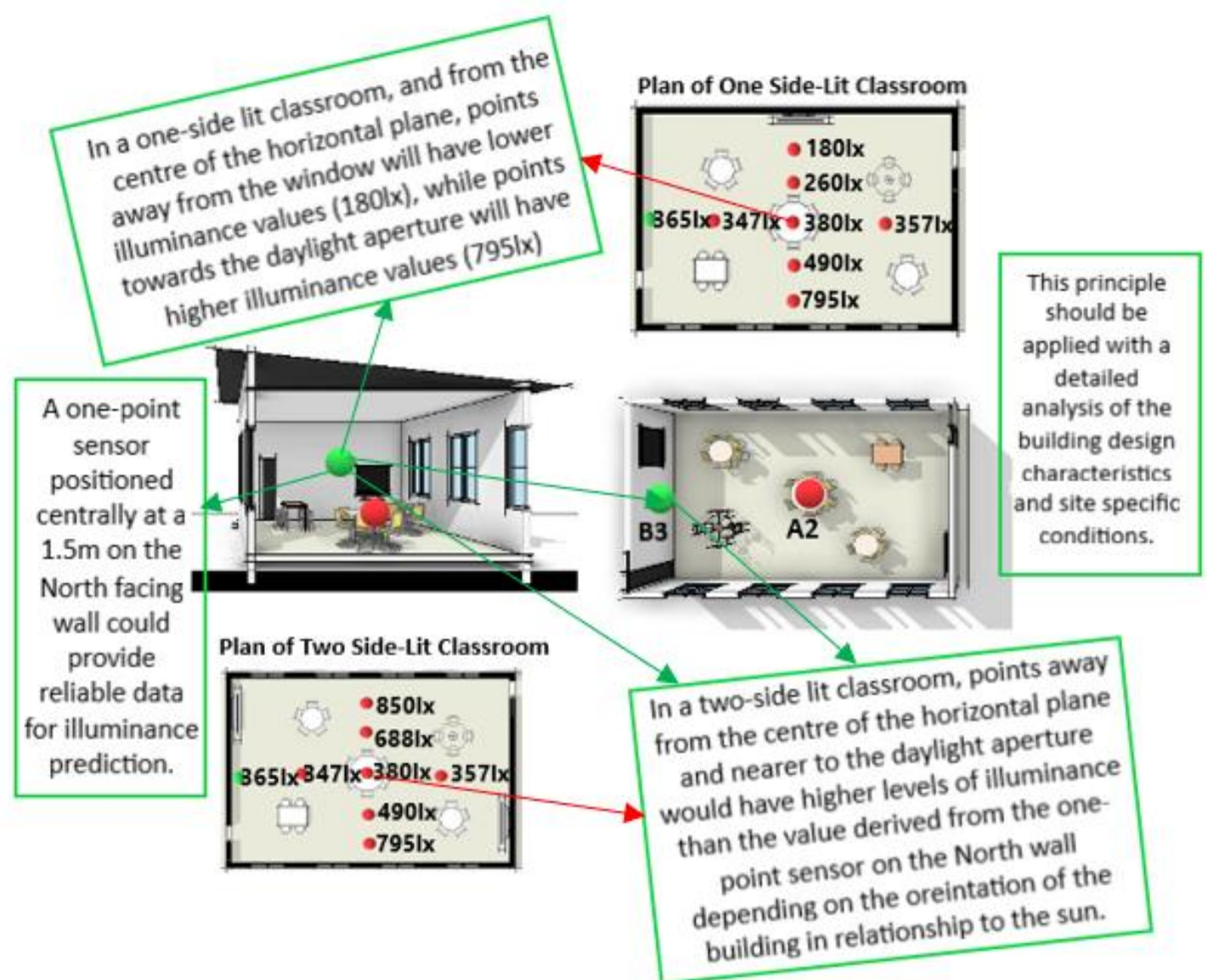

Figure 55: Images showing an illustration of how to use a one-point sensor for illuminance prediction 


\section{CHAPTER SIX: CAN A ONE-POINT SENSOR PREDICT THE THERMAL}

\section{PERFORMANCE IN A CLASSROOM?}

\subsection{Physical Measurement of Temperature and Relative Humidity Distribution in the Case Study Classrooms}

Given that temperature and relative humidity data are commonly used parameters to assess the thermal performance of a building, the goal of this section was to investigate if a limited number of sensors can predict the distribution of temperature and humidity in a classroom, and where might be the most representative placement of a one-point sensor within a classroom. While Chapter 5 focused only on lighting, this Chapter advances into the adequacy of using a one-point sensor to assess the thermal performance of classrooms.

The climate in Wellington is a mild, temperate marine climate, with plenty of wind. The results presented below were collated in February which is the hottest month in New Zealand, a southern hemisphere country and the month of May which is the late autumn period and the month of October. New Zealand's summer season covers December, January and February, winter season covers June, July and August, spring season covers September, October and November and the autumn season covers March, April and May.

\subsubsection{Non-School Days Temperature and Relative Humidity Analysis}

\section{Temperature}

In Figure 56, the non-school days in the different seasons in all three case studies were analysed to explore the relationship between the horizontal measuring plane sensors (A1-3) and the vertical wall sensors (B1-4). The graphical temperature trends show a gradual increase in temperature levels across all sensor points depending on the time of the day in case study one (summer) and case study three. For example, in Figure 56, the summer line graph in case study one, show step by step increase in temperature levels from about $20^{\circ} \mathrm{C}$ around 8 am, to about $24^{\circ} \mathrm{C}$ around $2 \mathrm{pm}$. Given that this period was a non-school day, high temperatures might be expected because of lack of airflow from opening windows, the space will heat up (solar gain) during the day, thereby resulting in varying levels of temperature depending on the location of a sensor relative to the glazed area and the building orientation. 
In the morning hours, the changes in temperature levels between the horizontal sensors' A2 and the vertical wall sensors B1-4 appeared to be sometimes higher than $2^{\circ} \mathrm{C}$ and other times lower than $2^{\circ} \mathrm{C}$, especially after mid-day. For example, during spring in case study three, sensor $\mathrm{A} 2$ recorded about $19^{\circ} \mathrm{C}$ around $12 \mathrm{pm}$ while sensor $\mathrm{B} 1$ recorded about $23^{\circ} \mathrm{C}$ which equates to a $4^{\circ} \mathrm{C}$ difference. Therefore, it could be inferred that at lower temperatures, there is a smaller variation between the horizontal measuring plane sensor and the vertical wall sensor, but due to the influence of heat sources such as the sun, there is a greater variation at higher temperature levels. The line graphs also indicated that for all three case studies in all seasons, the temperature levels were largely within the $18^{\circ} \mathrm{C}$ to $25^{\circ} \mathrm{C}$ acceptable adaptive comfort threshold for naturally ventilated buildings. 


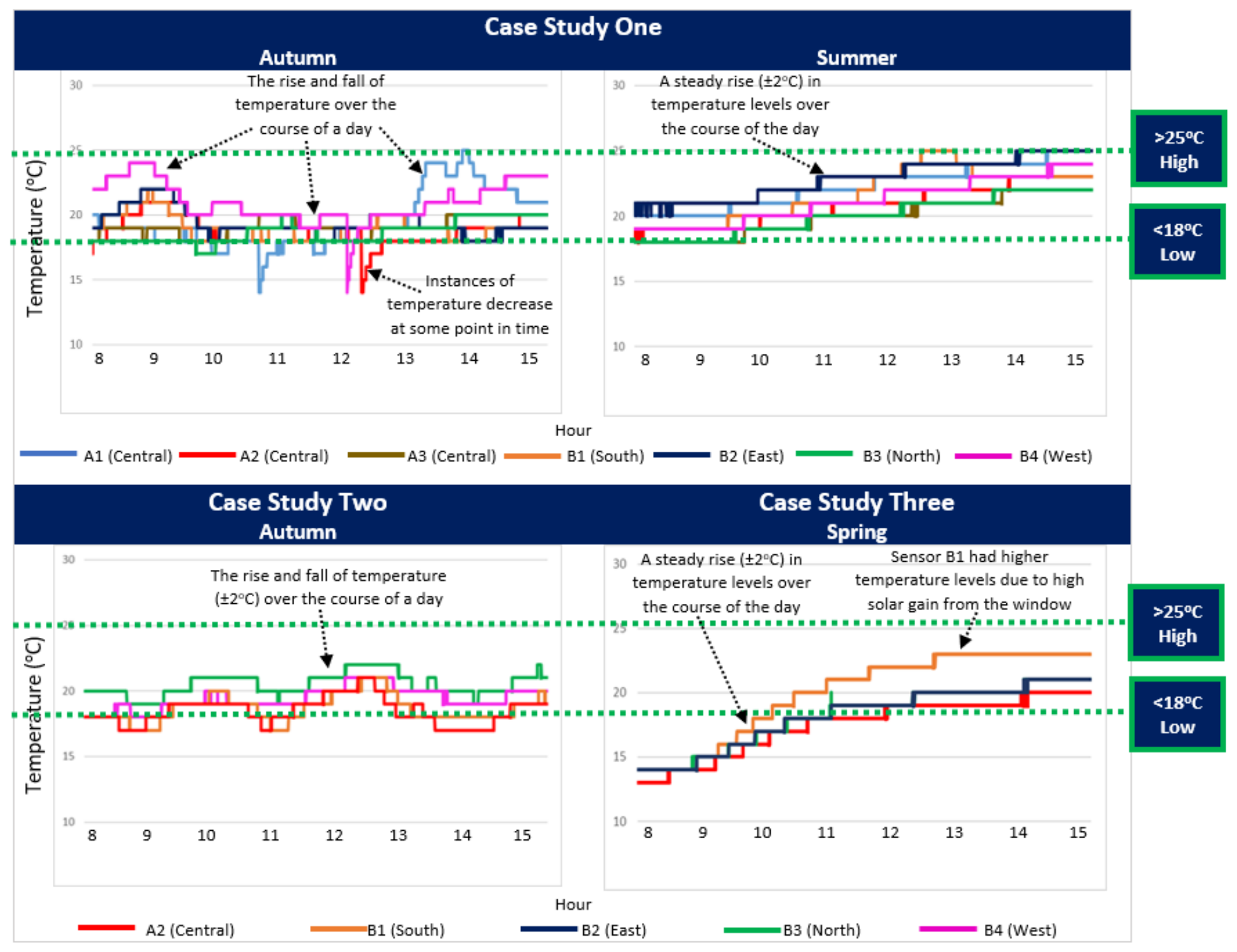

Figure 56: Line graphs showing temperature trends between 8 am - 3 pm during non-school days in all three case studies (A sensors horizontal, on the working plane; B sensors vertical, on adjacent wall) 
In Figure 57 and case study one (summer) and three, the temperature visual pattern of the horizontal measuring plane sensors shows a similar trend with the pattern of the vertical wall sensors. For example, during the summer in case study one, sensors $A 1, A 2$ and $A 3$ show a similar temperature trend with sensors B2, B3 and B4. However, during the autumn in case study one and in case study two, the sparkline show patterns of variability between horizontal and vertical sensors. This illustrates that it is difficult for a one-point sensor to be representative of the temperature levels across a space. However, in case study one (summer), two and three, the temperature levels of the central horizontal measuring plane sensor A2 show a similar pattern with that of the vertical wall sensor B3 (North).

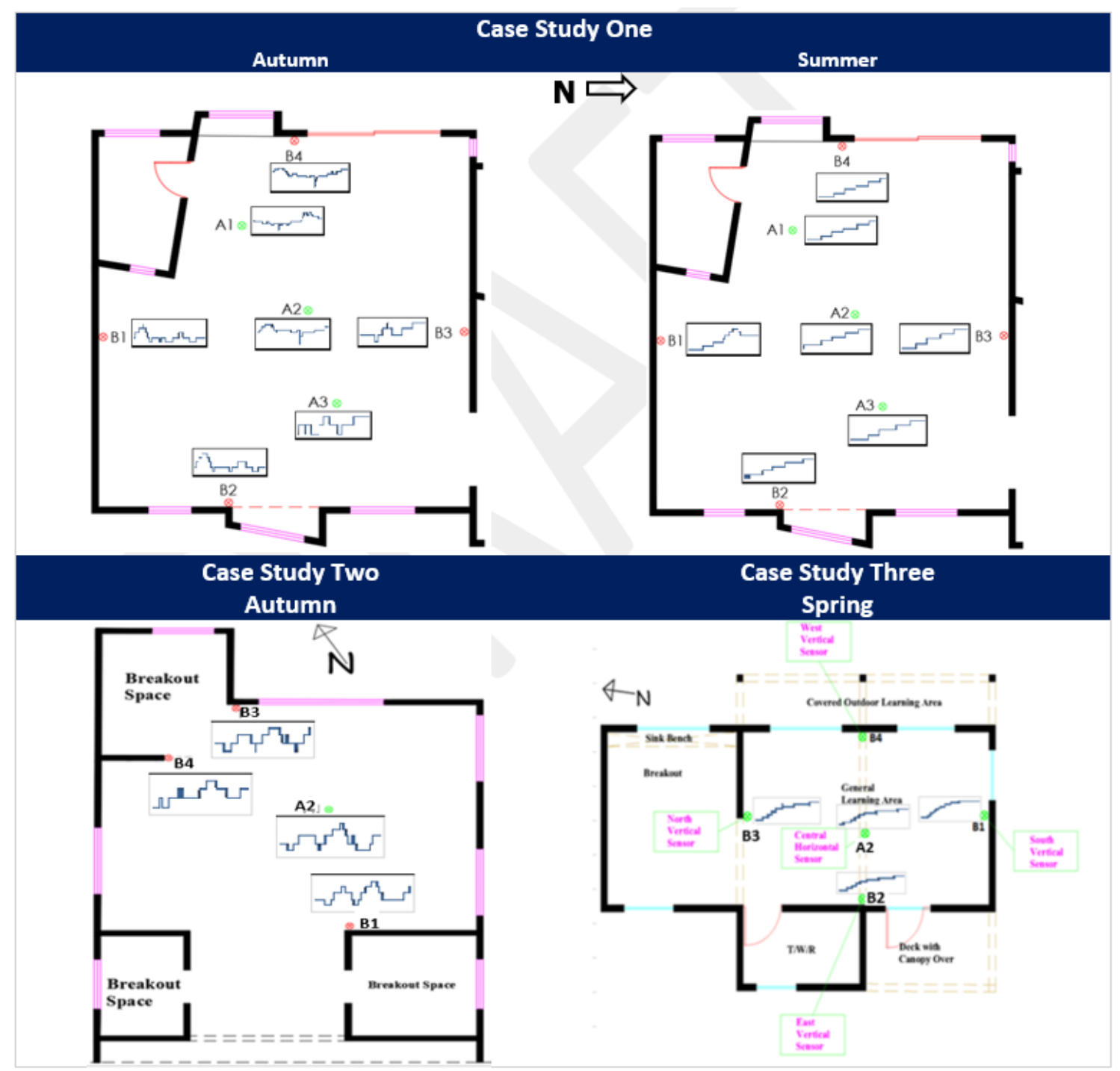

Figure 57: Sparklines showing temperature visual patterns between 8 am to $3 \mathrm{pm}$ in the non-school days 


\section{Relative Humidity}

As can be seen in Figure 58, the graphical humidity levels show patterns of variation between horizontal and vertical sensors. At some point in time during the autumn in case study one, there were instances of high relative humidity around central horizontal sensor A2. Given that this trend was a random occurrence at a short point in time, it is most likely that this increase was due to occupants' breathing around the central sensor. These variances in relative humidity indicates that a one-point sensor measurement may not be representative of an entire space. Given that the extent of this variation is unknown, these trends are investigated further using statistics in Section 6.1.3. In all three case studies, the relative humidity levels were largely within $45 \%$ to $75 \%$ acceptable humidity levels. This threshold is the recommended relative humidity levels for air-conditioned spaces and a higher level of humidity could apply in naturally ventilated spaces, hence, the limit of what is perceptible is broader if a building's humidity is not controlled via mechanical systems. 


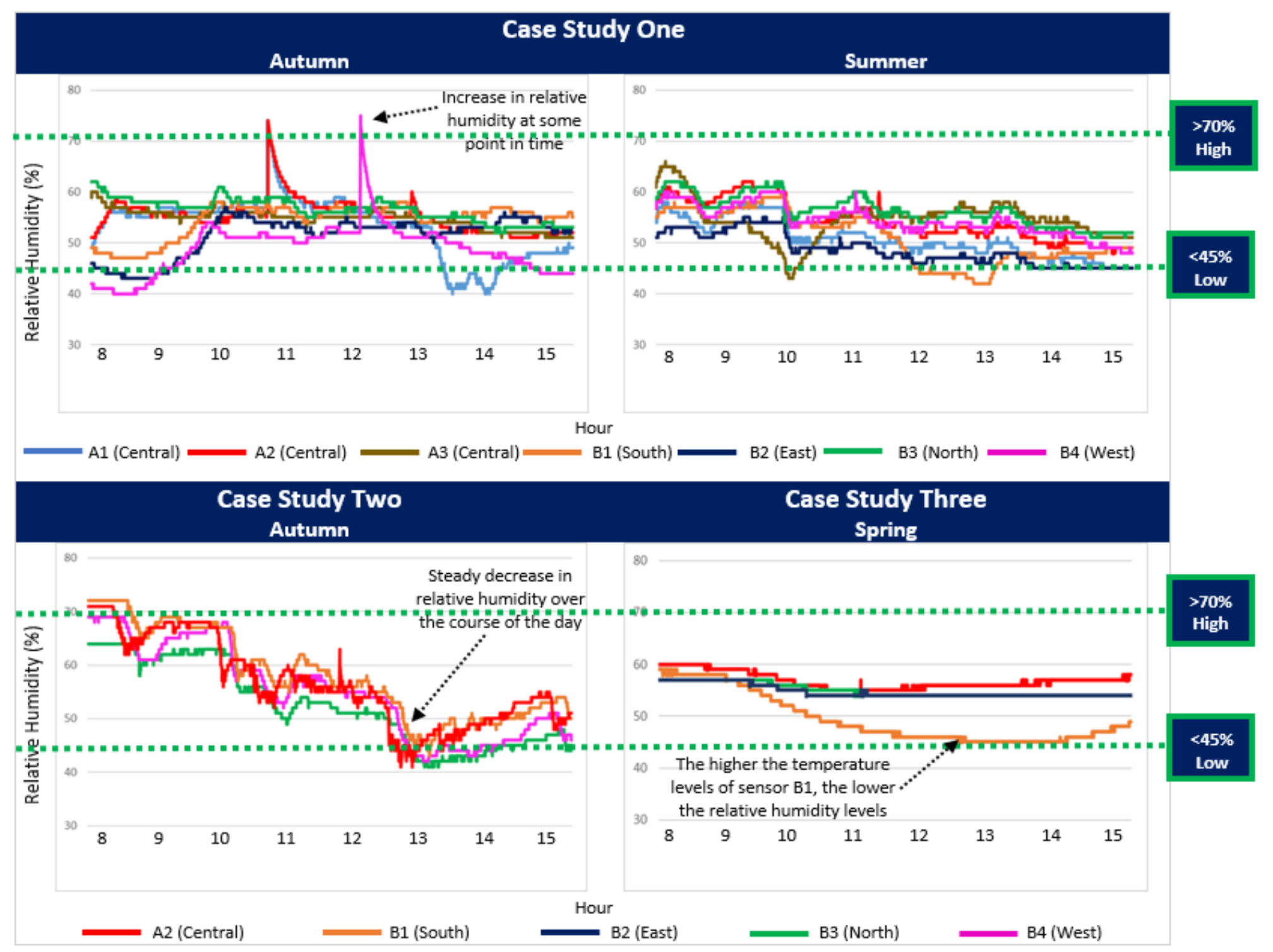

Figure 58: Line graphs showing relative humidity trends between 8 am - 3 pm during non-school days in all three case studies (A sensors horizontal, on the working plane; $B$ sensors vertical, on adjacent wall) 
In Figure 59, the rise and fall of relative humidity levels do not follow a similar pattern. This indicates that there is the variability of relative humidity levels across a space. However, in all three case studies, in all seasons and orientation, the relative humidity levels of the horizontal measuring plane sensor A2 show a similar pattern with that of the vertical wall sensor B3 (North). This suggested that vertical wall sensors could predict relative humidity at the centre of the horizontal measuring plane. This assertion is investigated further in Section 6.1.3.

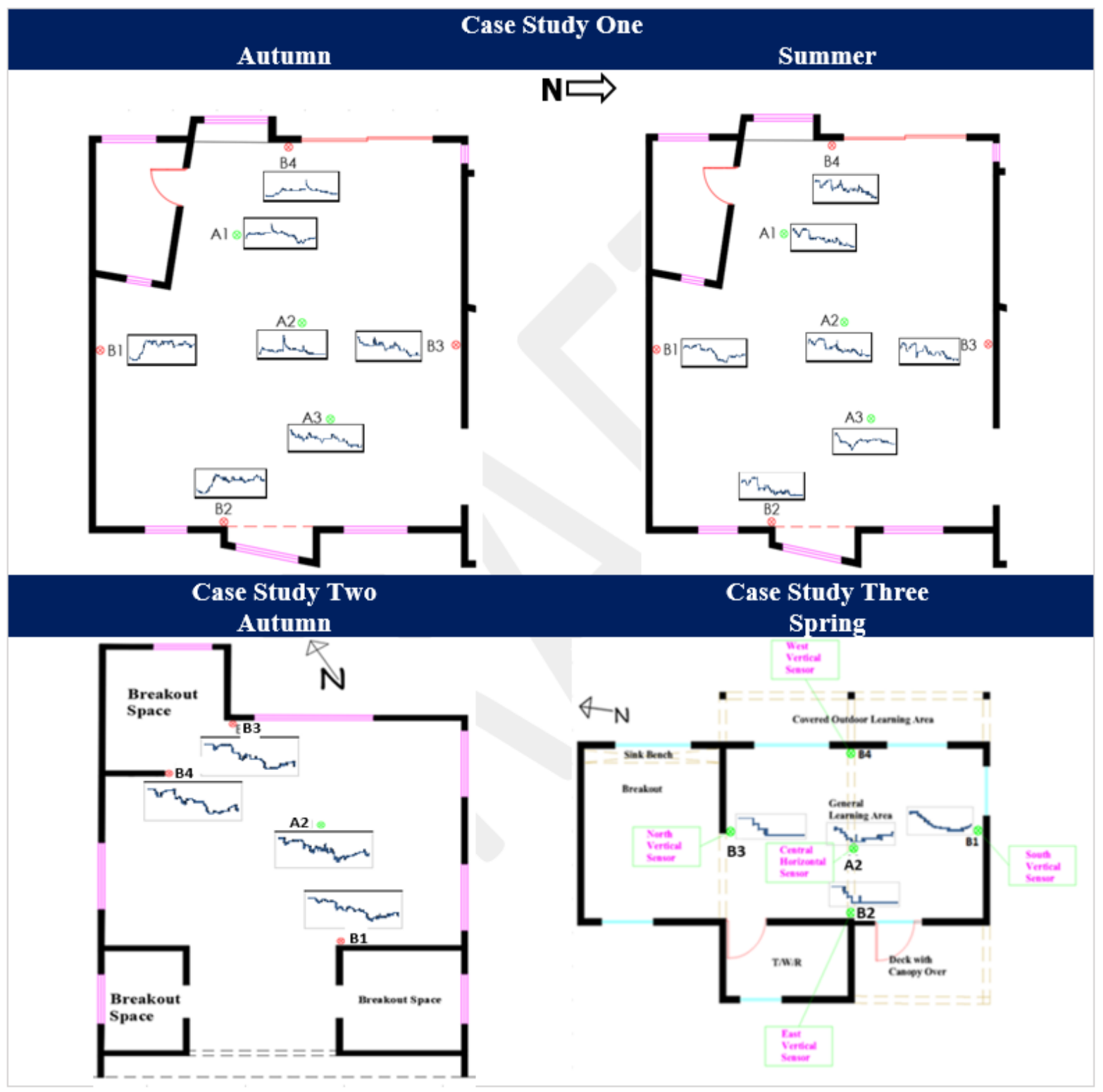

Figure 59: Sparklines showing relative humidity visual patterns between 8 am to $3 \mathrm{pm}$ in the non-school days 


\subsubsection{School Days Temperature and Relative Humidity Analysis}

\section{Temperature}

In Figure 60, the school day's line graph show patterns of variability between horizontal measuring plane and vertical wall sensors. However, there during the autumn and summer in case study one, sensor A2 (Central) and sensor B3 (North) show similar temperature trends which were consistent in case study two as well. But in case study three, there was about $4^{\circ} \mathrm{C}$ difference between sensor B3 and other sensors. This was observed to be because sensor B3 was positioned close to the large glazed door which was usually open during periods of occupancy in warm days. Therefore, it could be inferred that temperature levels across an occupied space will vary due to occupants usage of the space such as the opening of doors and windows for air-flow, heat energy generated by occupants, use of electric systems which generate heat and the intensity of the sun

and its position at a point in time. Like the non-school days, the temperature levels were largely within the $18^{\circ} \mathrm{C}$ to $25^{\circ} \mathrm{C}$ acceptable adaptive comfort threshold for naturally ventilated buildings. 


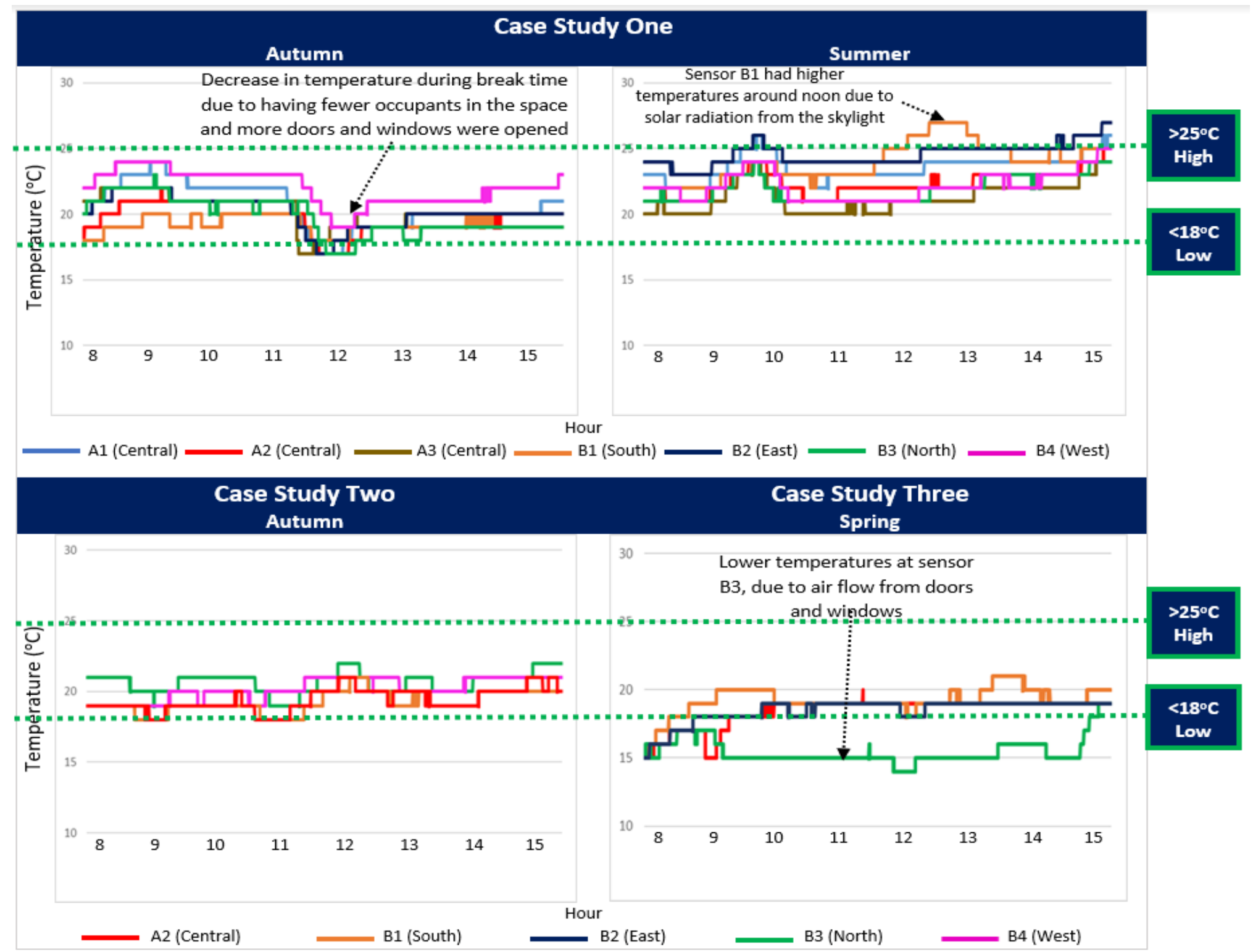

Figure 60: Line graphs showing temperature trends between 8 am-3 pm during non-school days in all three case studies (A sensors horizontal, on the working plane; B sensors vertical, on adjacent wall) 
In Figure 61, and case study one and two, the temperature visual pattern of the horizontal measuring plane sensors shows a relationship (similar trends) with the pattern of the vertical sensors on the walls. For example, during the autumn in case study one, horizontal measuring plane sensor A2 show a similar pattern with vertical wall sensor B3. However, in case study three, sensor B1 and B3 show a different pattern from sensor A2. This suggests that depending on the location of a sensor within a space, the temperature levels may not be consistent.

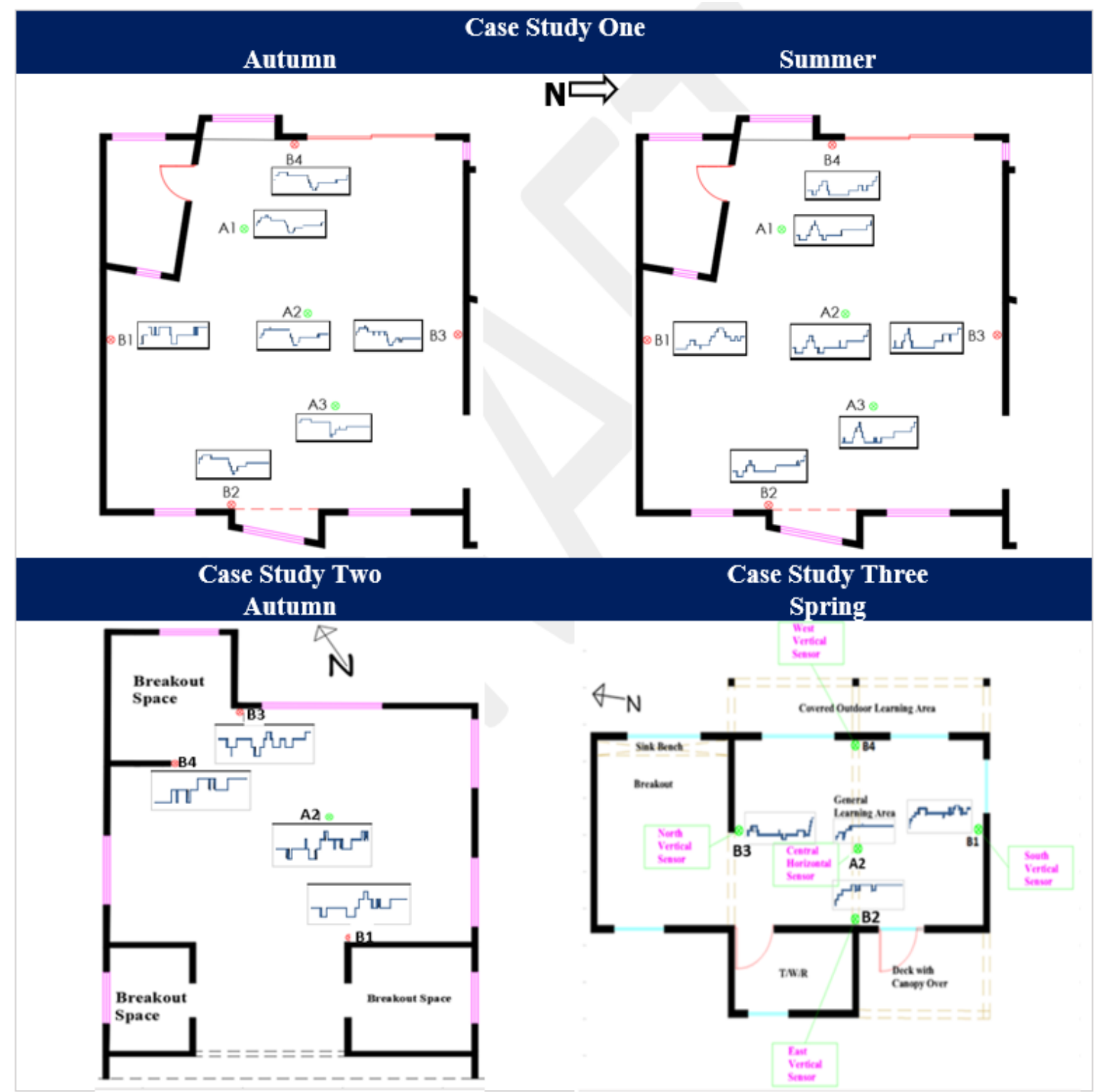

Figure 61: Sparklines showing temperature visual patterns during school days 


\section{Relative Humidity}

In Figure 62, the graphical trends generally show patterns of variability between horizontal and vertical sensors. However, in case study one, the difference in relative humidity patterns between central horizontal plane sensor A2 and vertical wall sensor B3 (North) appeared not so great. But in case study three, there was great variability between sensor A2 and B3 and this was observed to be because sensor B3 was positioned close to the large glazed door which was usually open during periods of occupancy and had lower temperatures. This was consistent with the phenomenon of lower temperatures resulting in higher humidity. Like the non-school days, the humidity levels were largely within the $45 \%$ to $75 \%$ acceptable levels and these trends indicates that due to factors of variability such as occupants' breathing and increase in temperature levels during the course of a day, it is difficult for a one-point sensor to be representative of the relative humidity levels across a space. 


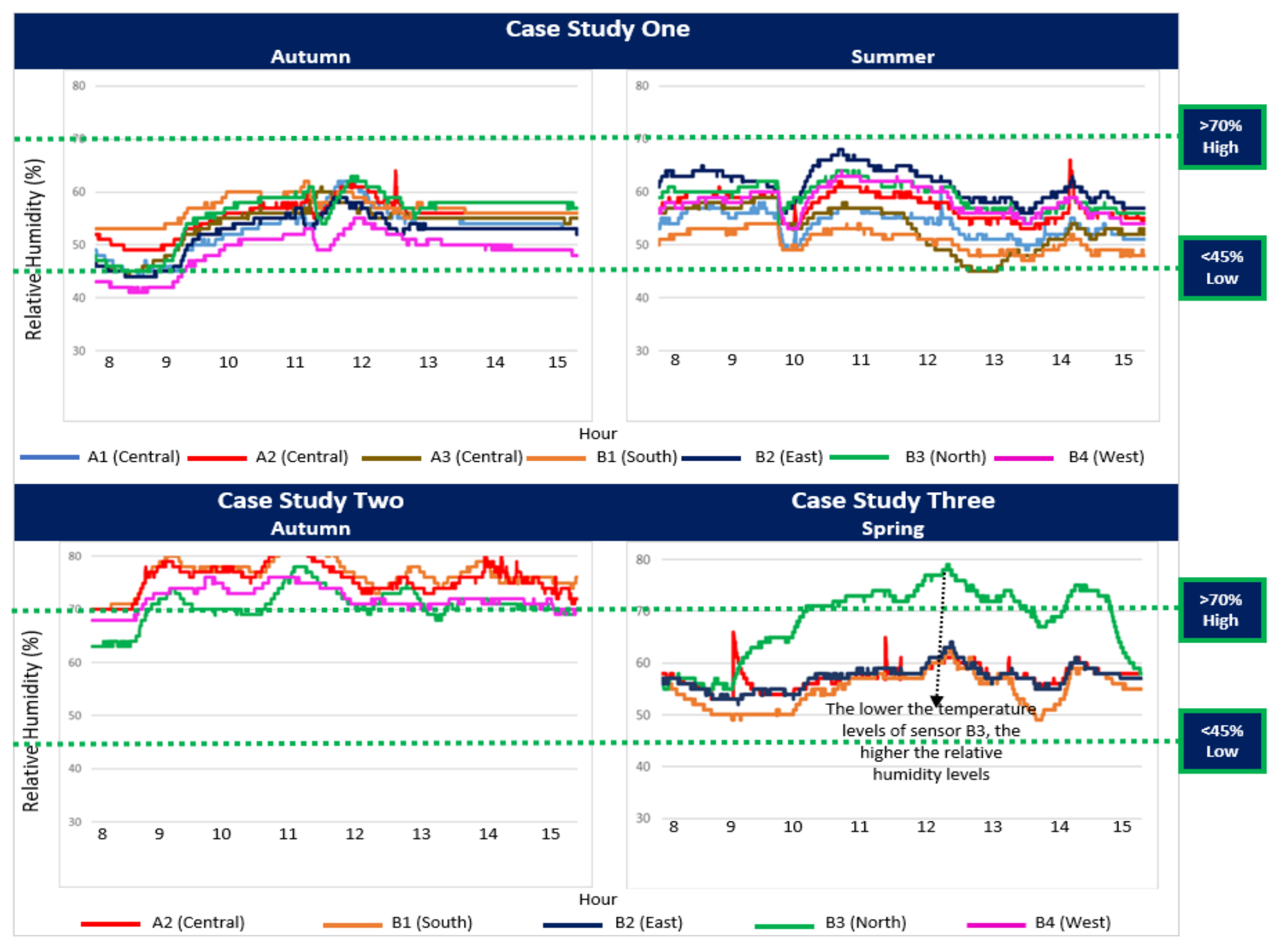

Figure 62: Line graphs showing relative humidity trends between 8 am - 3 pm during the school days in all three case studies (A sensors horizontal, on the working plane; $B$ sensors vertical, on adjacent wall) 
In Figure 63, the sparkline shows patterns of variability between horizontal and vertical sensors. Unlike the non-school days, there was variation in the visual pattern of the central horizontal measuring plane sensor A2 and vertical wall plane sensor B3. For example, in case study three, the vertical wall sensors showed patterns of higher humidity levels compared to the horizontal sensor which showed lower levels.

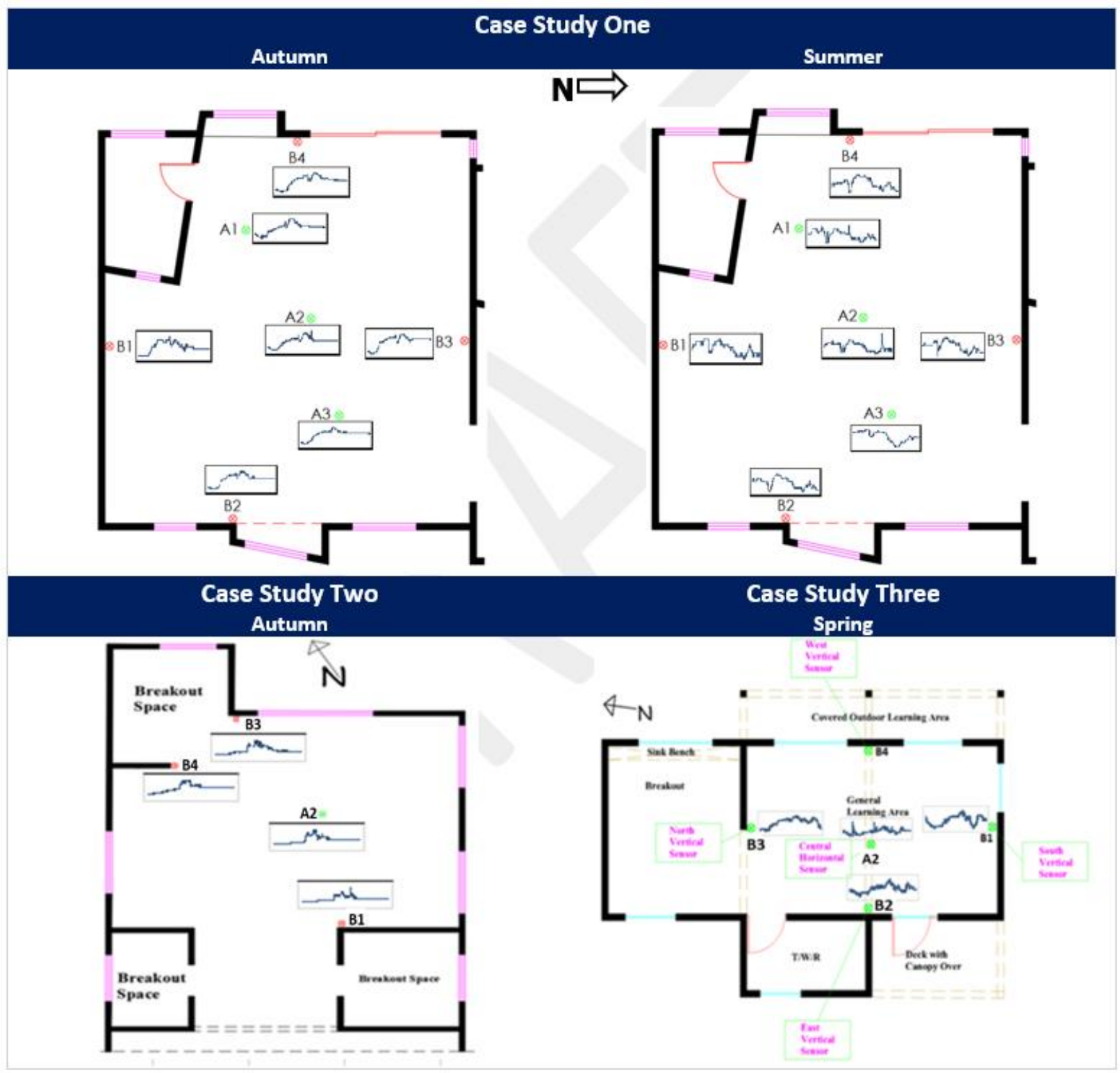

Figure 63: Sparklines showing relative humidity patterns during school days 


\subsubsection{Temperature and Relative Humidity Comparative Ratio Analysis}

In this thesis, the Pearson correlation coefficient was firstly used to assess the statistical relationship between IEQ on the horizontal measuring plane and vertical wall. The results had indicated that for both variables, approximately $80 \%$ of the variation in the central horizontal measuring plane sensor (A2) can be accounted for by the variation in the vertical wall sensor (B3). This suggested that a vertical sensor placed at the centre of the wall could be used to predict temperature and relative humidity levels at the centre of the horizontal measuring plane (the most frequently occupied part of a classroom). Though this initial analysis demonstrated that there was a statistical correlation, but due to time series data, the Pearson method only looks at the strength and directionality of the relationship. In statistics, when measurements are recorded over time autocorrelation is an issue and should be accounted for in the analysis. That is, measurements close together in time hold similar information (compared to independent observations), so the analysis could be skewed when using a statistical method that assume independent data. Hence, a comparative ratio analysis was used to descriptively analyse the time series data.

In Tables 20 to 25 and Figures, 64 to 69 below, the values recorded on the central horizontal sensor A2 was divided by the values on the vertical wall sensors B1-B4 to assess how much larger is the horizontal measuring plane temperature and relative humidity levels (A2) compared to the vertical temperature and relative humidity levels (B1-B4 respectively). The frequency of the data was categorised into four bins depending on the ratio of change between the two compared variables and percentages were used to describe the fold change. In this analysis, the larger the ratio over one in either direction is interpreted to indicate an increasing variation between the horizontal and vertical wall sensors and the closer the ratio to one is interpreted to indicate a strong relationship. Thus, a ratio of one is stronger than a ratio of 2 and the higher percentage of a ratio of one, the better.

In Tables 20 to 25 and Figures 64 to 69 the relationship between the horizontal plane and vertical wall sensors was about $80 \%$ of the time consistent around a ratio of 1-1.5 and indicated that a vertical wall sensor can reliably predict the temperature and relative humidity levels at the centre 
of a classroom. As reported in Section 6.1.2, the large ratio difference in sensor B3, in Figures 12 and 15 was observed to be because this sensor was positioned close to a large glazed door which was usually open during periods of occupancy in warm days. The consistency of these trends indicates that provided the factors of variability (Section 8.2) are taken into account, a vertical wall sensor can predict temperature and humidity levels at the centre of a space and can assist with the diagnosis of patterns when measuring these variables in many school buildings. The application of these findings to identify good and poor thermal conditions is discussed in detail in Sections 6.1.7 below. 
CASE STUDY ONE - SUMMER

Table 20: Comparative ratio analysis of the relationship between temperature levels at the central horizontal sensor A2 with vertical wall sensors B1-4 respectively

\begin{tabular}{|c|c|c|c|c|c|c|c|c|}
\hline \multirow{2}{*}{ Bin } & \multicolumn{2}{|c|}{ A2(Central)/B1(South) } & \multicolumn{2}{|c|}{ A2(Central) /B2(East) } & \multicolumn{2}{c|}{ A2(Central)/B3(North) } & \multicolumn{2}{c|}{ A2(Central)/B4(West) } \\
\cline { 2 - 9 } & Frequency & Percentages & Frequency & Percentages & Frequency & Percentages & Frequency & Percentages \\
\hline $0.5-0.99$ & 510 & $20 \%$ & 566 & $22 \%$ & 0 & $0 \%$ & 0 & $0 \%$ \\
\hline $1.0-1.19$ & 2013 & $80 \%$ & 1957 & $78 \%$ & 1434 & $57 \%$ & 1770 & $70 \%$ \\
\hline $1.2-1.5$ & 0 & $0 \%$ & 0 & $0 \%$ & 1089 & $43 \%$ & 753 & $30 \%$ \\
\hline$>1.5$ & 0 & $0 \%$ & 0 & $0 \%$ & 0 & $0 \%$ & 0 & $0 \%$ \\
\hline
\end{tabular}

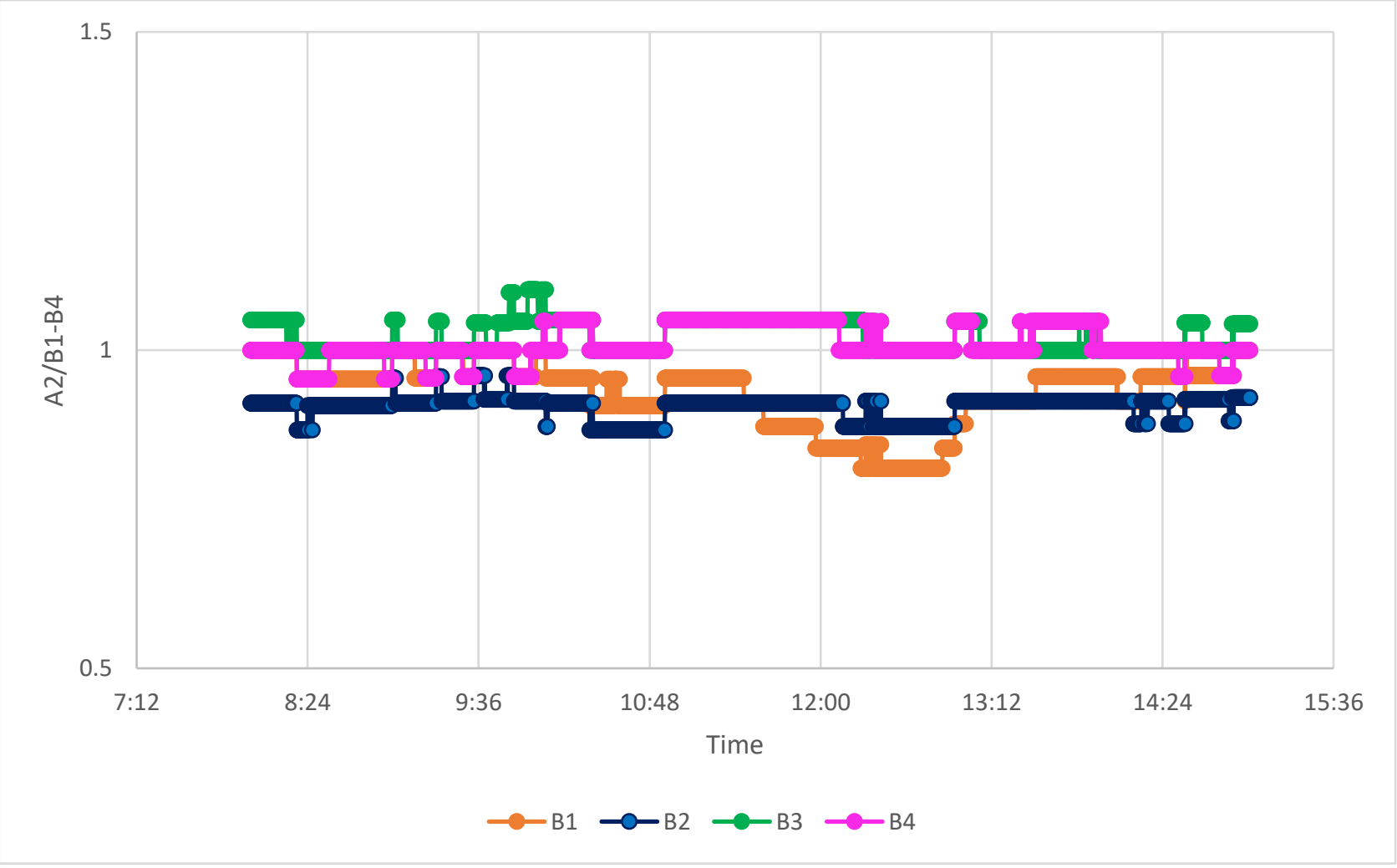

Figure 64: Comparative ratio between horizontal and vertical sensors 


\section{CASE STUDY TWO - AUTUMN}

Table 21: Comparative ratio analysis of the relationship between temperature levels at the central horizontal sensor A2 with vertical wall sensors B1-4 respectively

\begin{tabular}{|c|c|c|c|c|c|c|c|c|}
\hline \multirow{2}{*}{ Bin } & \multicolumn{2}{|c|}{ A2(Central)/B1(South) } & \multicolumn{2}{c|}{ A2(Central) /B2(East) } & \multicolumn{2}{c|}{ A2(Central)/B3(North) } & \multicolumn{2}{c|}{ A2(Central)/B4(West) } \\
\cline { 2 - 9 } & Frequency & Percentages & Frequency & Percentages & Frequency & Percentages & Frequency & Percentages \\
\hline $0.5-0.99$ & 0 & $0 \%$ & 9 & $0 \%$ & 17 & $1 \%$ & 763 & $32 \%$ \\
\hline $1.0-1.19$ & 1288 & $55 \%$ & 2245 & $95 \%$ & 1730 & $63 \%$ & 1591 & $68 \%$ \\
\hline $1.2-1.5$ & 1066 & $45 \%$ & 100 & $4 \%$ & 607 & $26 \%$ & 0 & $0 \%$ \\
\hline$>1.5$ & 0 & $0 \%$ & 0 & $0 \%$ & 0 & $0 \%$ & 0 & $0 \%$ \\
\hline
\end{tabular}

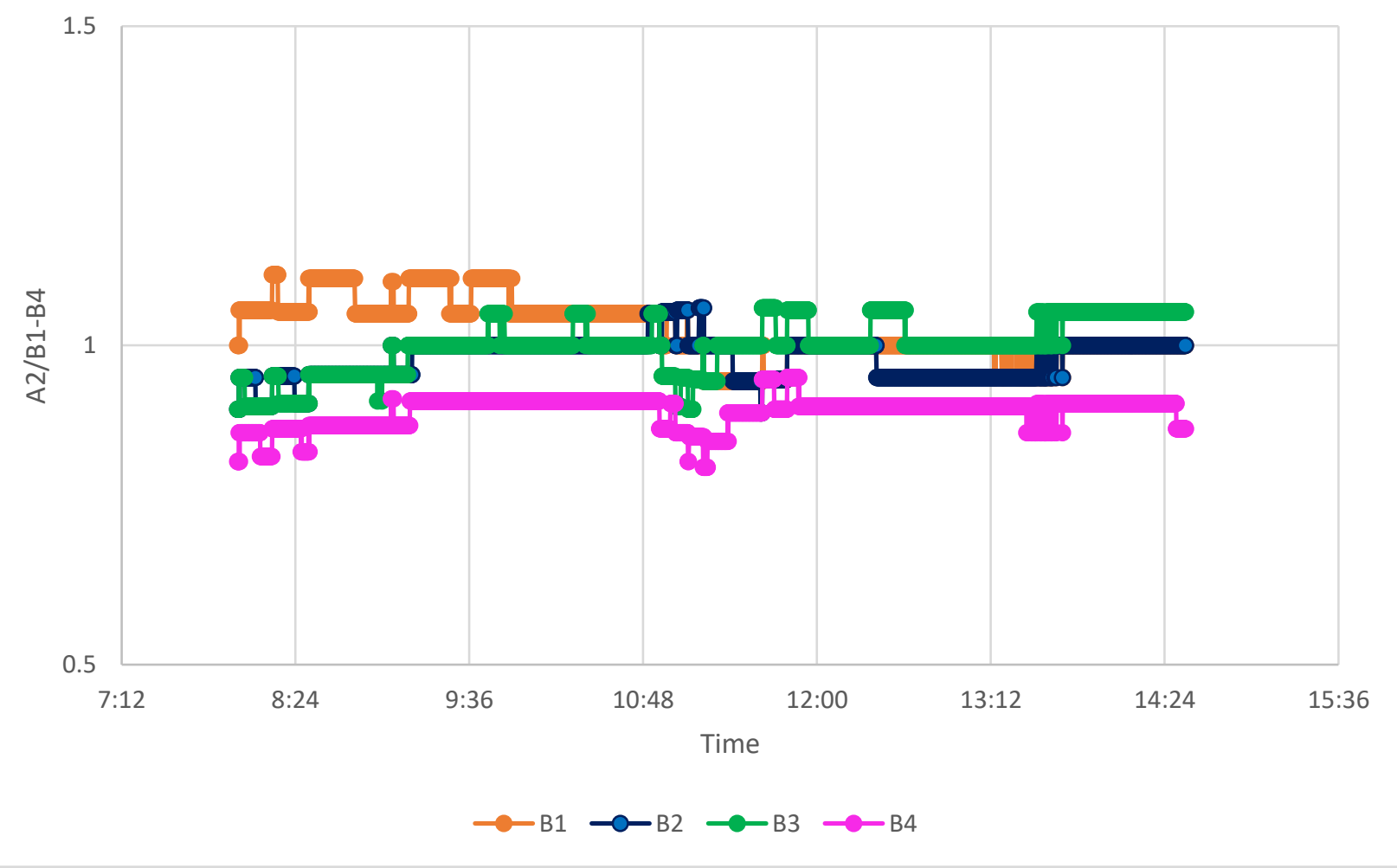

Figure 65: Comparative ratio between horizontal and vertical sensors 
CASE STUDY THREE - SPRING

Table 22: Comparative ratio analysis of the relationship between temperature levels at the central horizontal sensor A2 with vertical wall sensors B1-4 respectively

\begin{tabular}{|c|c|c|c|c|c|c|}
\hline \multirow{2}{*}{ Bin } & \multicolumn{2}{|c|}{ A2(Central)/B1(South) } & \multicolumn{2}{c|}{ A2(Central)/B2(East) } & \multicolumn{2}{c|}{ A2(Central)/B3(North) } \\
\cline { 2 - 7 } & Frequency & Percentages & Frequency & Percentages & Frequency & Percentages \\
\hline $0.5-0.99$ & 442 & $17 \%$ & 82 & $3 \%$ & 53 & $2 \%$ \\
\hline $1.0-1.19$ & 2027 & $80 \%$ & 2189 & $87 \%$ & 354 & $14 \%$ \\
\hline $1.2-1.5$ & 52 & $2 \%$ & 250 & $10 \%$ & 2114 & $84 \%$ \\
\hline$>1.5$ & 0 & $0 \%$ & 0 & $0 \%$ & 0 & $0 \%$ \\
\hline
\end{tabular}

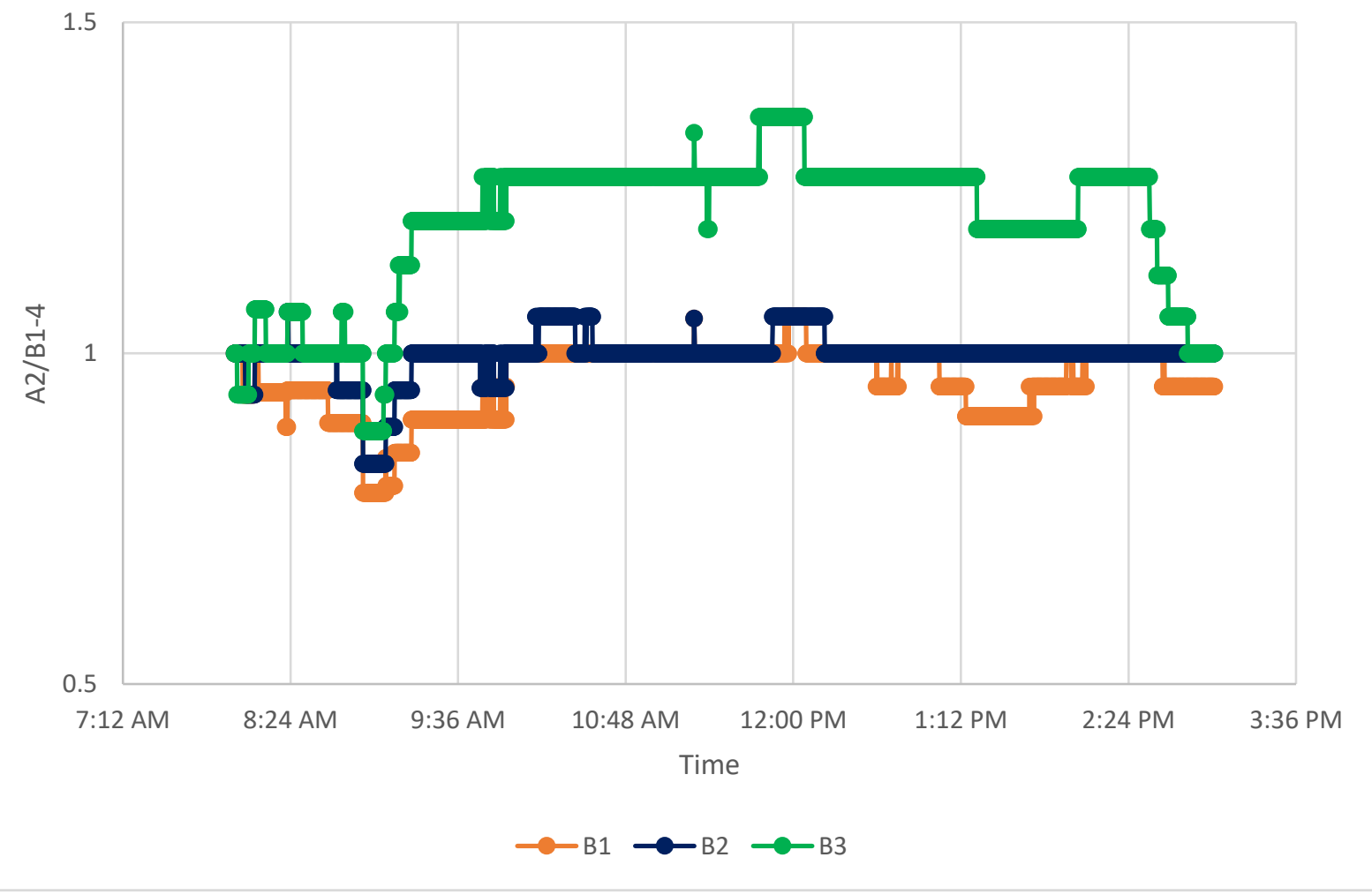

Figure 66: Comparison of ratio between horizontal and vertical sensors 


\section{Relative Humidity}

\section{CASE STUDY ONE - SUMMER}

Table 23: Comparative ratio analysis of the relationship between relative humidity levels at the central horizontal sensor A2 with vertical wall sensors B1-4 respectively

\begin{tabular}{|c|c|c|c|c|c|c|c|c|}
\hline \multirow{2}{*}{ Bin } & \multicolumn{2}{|c|}{ A2(Central)/B1(South) } & \multicolumn{2}{c|}{ A2(Central)/B2(East) } & \multicolumn{2}{c|}{ A2(Central) /B3(North) } & A2(Central)/B4(West) \\
\cline { 2 - 9 } & Frequency & Percentages & Frequency & Percentages & Frequency & Percentages & Frequency & Percentages \\
\hline $0.5-0.99$ & 0 & $0 \%$ & 2385 & $95 \%$ & 1688 & $67 \%$ & 300 & $12 \%$ \\
\hline $1.0-1.19$ & 0 & $0 \%$ & 121 & $5 \%$ & 800 & $32 \%$ & 1664 \\
\hline $1.2-1.5$ & 2523 & $100 \%$ & 17 & $1 \%$ & 35 & $1 \%$ & 559 & $22 \%$ \\
\hline$>1.5$ & 0 & $0 \%$ & 0 & $0 \%$ & 0 & $0 \%$ & 0 \\
\hline
\end{tabular}

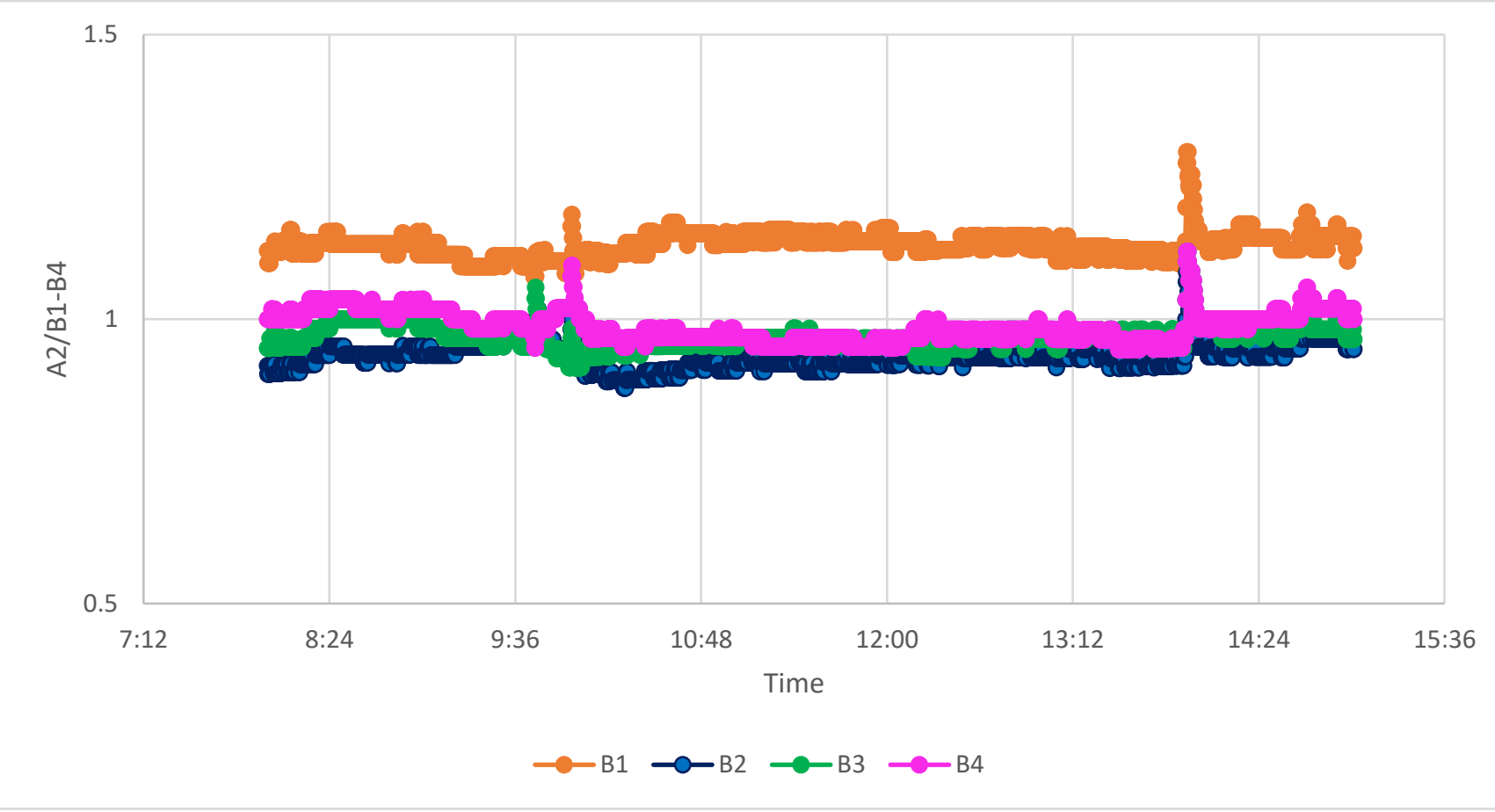

Figure 67: Comparative ratio between horizontal and vertical sensors 
CASE STUDY TWO - AUTUMN

Table 24: Comparative ratio analysis of the relationship between relative humidity levels at the central horizontal sensor A2 with vertical wall sensors B1-4 respectively

\begin{tabular}{|c|c|c|c|c|c|c|c|c|}
\hline \multirow{2}{*}{ Bin } & \multicolumn{2}{|c|}{ A2(Central)/B1(South) } & \multicolumn{2}{|c|}{ A2(Central)/B2(East) } & \multicolumn{2}{|c|}{ A2(Central)/B3(North) } & A2(Central)/B4(West) \\
\cline { 2 - 9 } & Frequency & Percentages & Frequency & Percentages & Frequency & Percentages & Frequency & Percentages \\
\hline $0.5-0.99$ & 500 & $21 \%$ & 0 & $0 \%$ & 700 & $34 \%$ & 0 & $0 \%$ \\
\hline $1.0-1.19$ & 1515 & $65 \%$ & 727 & $31 \%$ & 1108 & $53 \%$ & 0 \\
\hline $1.2-1.5$ & 340 & $14 \%$ & 1628 & $69 \%$ & 547 & $23 \%$ & 2355 & $100 \%$ \\
\hline$>1.5$ & 0 & $0 \%$ & 0 & $0 \%$ & 0 & $0 \%$ & 0 \\
\hline
\end{tabular}

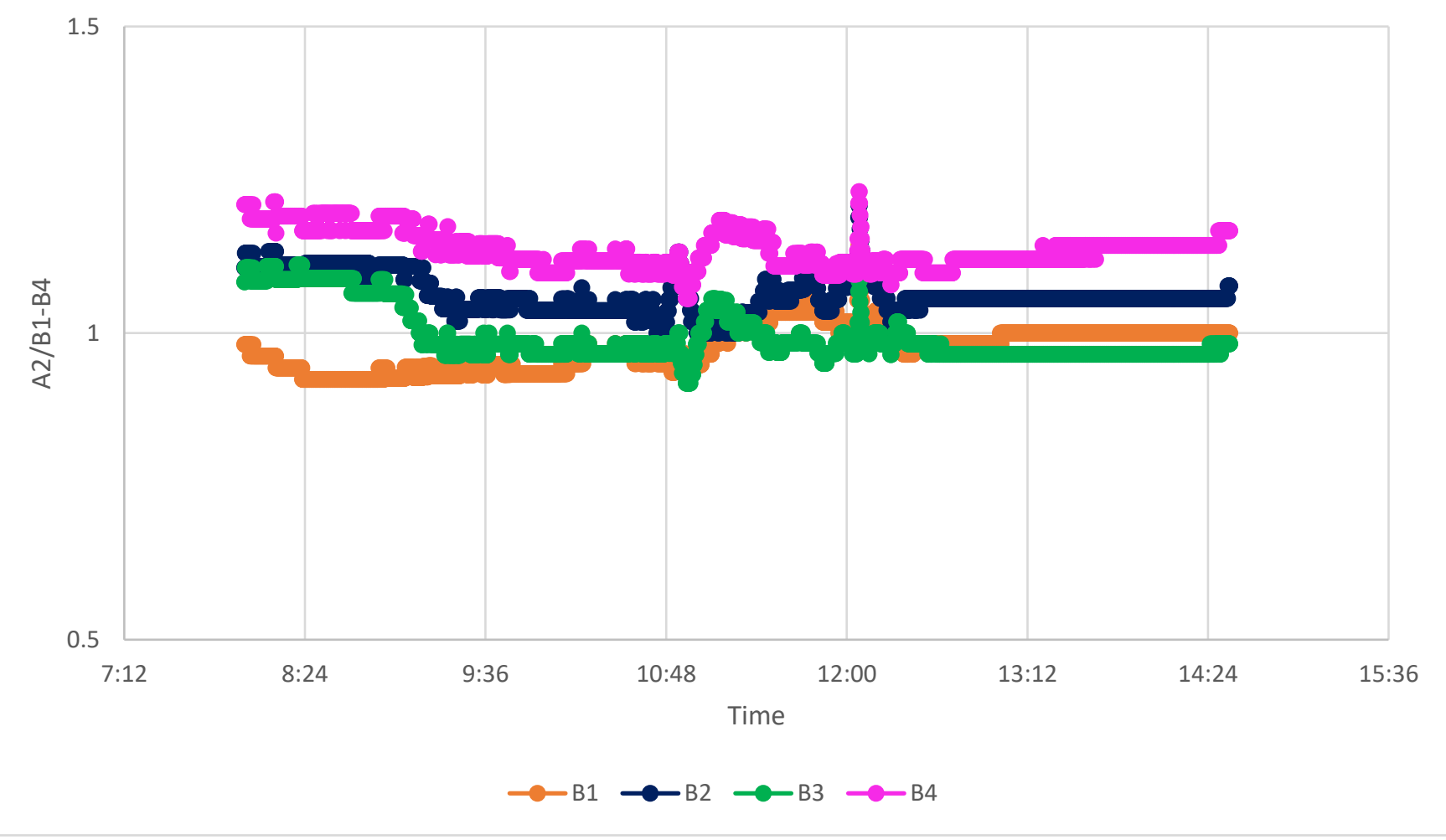

Figure 68: Comparative ratio between horizontal and vertical sensors 


\section{CASE STUDY THREE - SPRING}

Table 25: Comparative ratio analysis of the relationship between relative humidity levels at the central horizontal sensor A2 with vertical wall sensors B1-4 respectively

\begin{tabular}{|c|c|c|c|c|c|c|}
\hline \multirow[b]{2}{*}{ Bin } & \multicolumn{2}{|c|}{ A2(Central)/B1(South) } & \multicolumn{2}{|c|}{ A2(Central) /B2(East) } & \multicolumn{2}{|c|}{ A2(Central) /B3(North) } \\
\hline & Frequency & Percentages & Frequency & Percentages & Frequency & Percentages \\
\hline $0.5-0.99$ & 0 & $0 \%$ & 0 & $0 \%$ & 1934 & $77 \%$ \\
\hline $1.0-1.19$ & 538 & $21 \%$ & 1932 & $77 \%$ & 489 & $19 \%$ \\
\hline $1.2-1.5$ & 1983 & $78 \%$ & 578 & $23 \%$ & 98 & $4 \%$ \\
\hline$>1.5$ & 0 & $0 \%$ & 0 & $0 \%$ & 0 & $0 \%$ \\
\hline
\end{tabular}

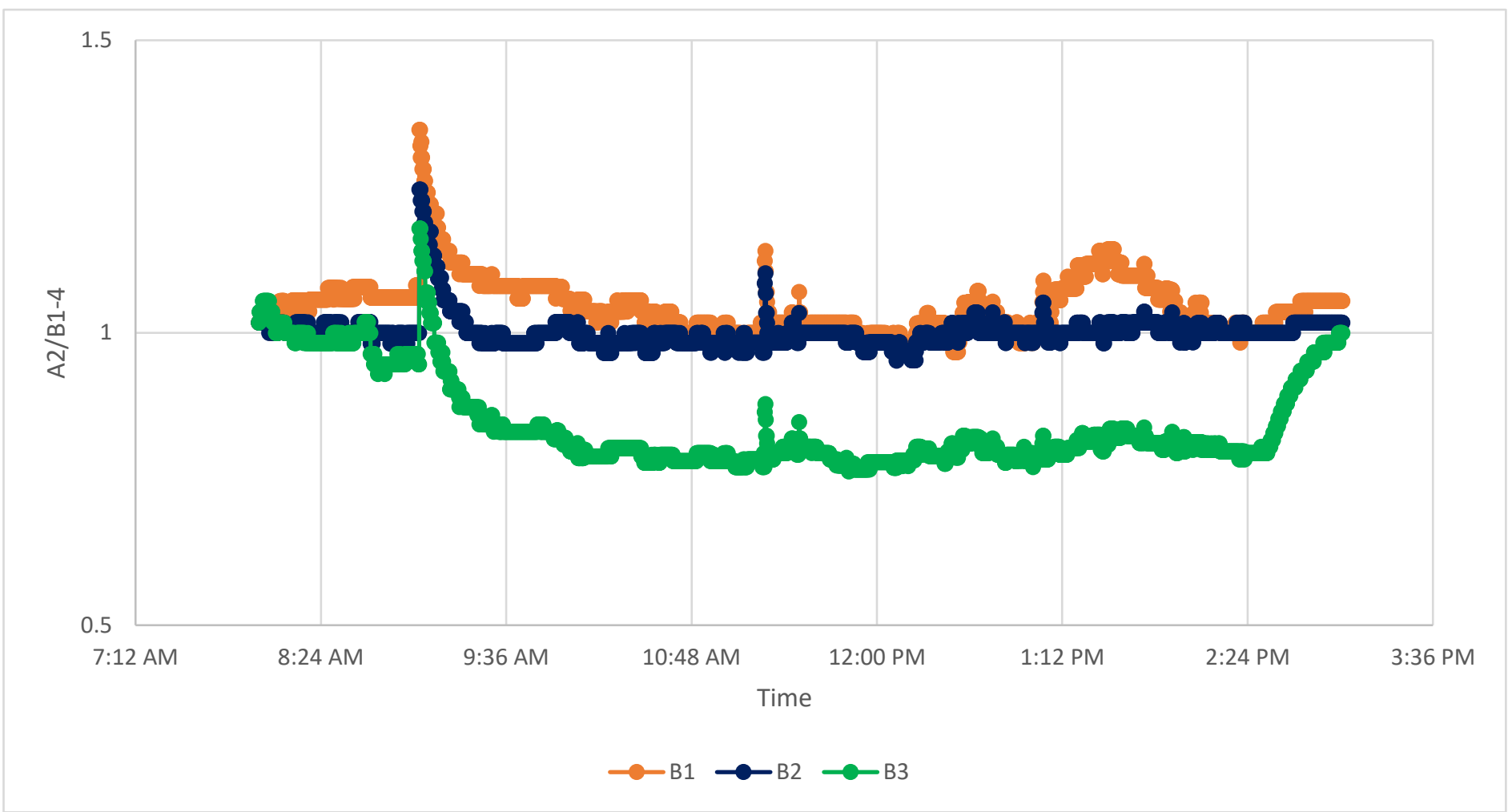

Figure 69: Comparative ratio between horizontal and vertical sensors 


\subsubsection{Comparison between Horizontal and Vertical Sensors Average Temperature and Relative}

\section{Humidity Levels}

In Tables 26 to 37, the average of all the sensor points including the external temperature and humidity levels were analysed for the school hours of 8 am to $3 \mathrm{pm}$ in both non-school and school days in all three case studies. The goal of analysing the averages was to identify the possible range of variation between temperature and relative humidity across the various sensor points. Sensors A1-3 where the spatial horizontal measuring plane sensors while sensors B1-4 where the vertical wall sensors respectively, while sensor $\mathrm{C} 1$ was the external sensor located outside the building in case study one and for case study two and three, external weather data was retrieved from the nearest weather station from the online National Climate database (NIWA). The column annotated as "Diff" represented the calculation of the difference between sensor A2 (Central) and the vertical wall sensor that showed the least relationship in the ratio analysis above to ascertain the level of variation between the sensor points.

\subsubsection{Non-School Days: Average Temperature}

In Tables 26-28, average temperature levels between 8 am to $3 \mathrm{pm}$ in all three case studies for both horizontal and vertical sensors are presented. As shown in the column annotated with "Diff": the average temperature in the central horizontal measuring plane sensor (A2) was subtracted from the vertical wall sensor B1 in case study one and two, and sensor B2 in case study three because these sensors had a higher ratio change Section 6.1.3 above. While the "Diff" column was annotated with a grey fill, the two sensor points used to calculate the difference between horizontal and vertical sensors is annotated with a green fill. For example, in case study one, around $8 \mathrm{am}$ in the autumn, sensor $\mathrm{A} 2$ recorded $17^{\circ} \mathrm{C}$ while sensor $\mathrm{B} 1$ (south) recorded the lowest temperature level of $16^{\circ} \mathrm{C}$ and the difference between these two temperature values was $1^{\circ} \mathrm{C}$.

In Tables 26-28, in all seasons, in all three case studies, the temperature variation between the horizontal measuring plane sensor and the vertical wall sensors were largely $<2{ }^{\circ} \mathrm{C}$ in the nonschool days. However, it was observed that sensors which recorded the highest temperature were those that were impacted by solar gain due to their position at the west or east-facing walls 
respectively. In case study three, the sensor on the south wall (B1) recorded the highest temperature because it was more exposed to the sun than sensors on the other walls (North, East, and West walls were largely shaded by surrounding buildings while the South facing wall was by the Basketball court which was exposed to solar heat gain).

Table 26: Average temperature in the non-school days from $8 \mathrm{am}-3 \mathrm{pm}$

\section{Case Study One - Autumn}

The grey column is the difference between sensor (A2) and the vertical sensor with the least relationship in the ratio analysis

\begin{tabular}{|c|c|c|c|c|c|c|c|c|c|}
\hline Hour & $\begin{array}{c}\text { Central } \\
\mathbf{A} \mathbf{(}\left({ }^{\circ} \mathbf{C}\right)\end{array}$ & $\begin{array}{c}\text { Central } \\
\mathbf{A} \mathbf{2}\left({ }^{\circ} \mathbf{C}\right)\end{array}$ & $\begin{array}{c}\text { Central } \\
\mathbf{A} \mathbf{3}\left({ }^{\circ} \mathbf{C}\right)\end{array}$ & $\begin{array}{c}\text { South } \\
\mathbf{B} 1\left({ }^{\circ} \mathbf{C}\right)\end{array}$ & $\begin{array}{c}\text { East } \\
\mathbf{B} 2\left({ }^{\circ} \mathbf{C}\right)\end{array}$ & $\begin{array}{c}\text { North } \\
\mathbf{B} 3\left({ }^{\circ} \mathbf{C}\right)\end{array}$ & $\begin{array}{c}\text { West } \\
\mathbf{B} 4\left({ }^{\circ} \mathbf{C}\right)\end{array}$ & $\begin{array}{c}\text { Diff } \\
\left({ }^{\circ} \mathbf{C}\right)\end{array}$ & $\begin{array}{c}\text { External } \\
\mathbf{C} \mathbf{(}\left({ }^{\circ} \mathbf{C}\right)\end{array}$ \\
\hline $\mathbf{8} \mathbf{~ a m}$ & 17 & 17 & 17 & 16 & 17 & 16 & 18 & 1 & 14 \\
\hline $\mathbf{9} \mathbf{~ a m}$ & 17 & 17 & 17 & 16 & 17 & 16 & 18 & 1 & 15 \\
\hline $\mathbf{1 0} \mathbf{~ a m}$ & 18 & 18 & 18 & 17 & 17 & 16 & 19 & 1 & 13 \\
\hline $\mathbf{1 1} \mathbf{~ a m}$ & 18 & 18 & 18 & 17 & 18 & 17 & 19 & 1 & 12 \\
\hline $\mathbf{1 2} \mathbf{~ p m}$ & 18 & 18 & 18 & 18 & 18 & 18 & 20 & 0 & 13 \\
\hline $\mathbf{1} \mathbf{~ p m}$ & 19 & 18 & 18 & 18 & 18 & 17 & 19 & 0 & 15 \\
\hline $\mathbf{2} \mathbf{~ p m}$ & 22 & 19 & 19 & 18 & 18 & 18 & 20 & 1 & 20 \\
\hline $\mathbf{3} \mathbf{~ p m}$ & 20 & 19 & 19 & 19 & 19 & 18 & 21 & 0 & 14 \\
\hline
\end{tabular}

Table 27: Average temperature in the non-school days from $8 \mathrm{am}-3 \mathrm{pm}$

\section{Case Study One - Summer}

The grey column is the difference between sensor (A2) and the vertical sensor with the least relationship in the ratio analysis

\begin{tabular}{|c|c|c|c|c|c|c|c|c|c|}
\hline Hour & $\begin{array}{l}\text { Central } \\
\mathrm{A} 1\left(^{\circ} \mathrm{C}\right)\end{array}$ & $\begin{array}{l}\text { Central } \\
\mathrm{A} 2\left({ }^{\circ} \mathrm{C}\right)\end{array}$ & $\begin{array}{l}\text { Central } \\
\mathrm{A} 3\left({ }^{\circ} \mathrm{C}\right)\end{array}$ & $\begin{array}{l}\text { South } \\
\text { B1 }\left({ }^{\circ} \mathrm{C}\right)\end{array}$ & $\begin{array}{c}\text { East } \\
\text { B2 }\left({ }^{\circ} \mathrm{C}\right)\end{array}$ & $\begin{array}{l}\text { North } \\
\text { B3 }\left({ }^{\circ} \mathrm{C}\right)\end{array}$ & $\begin{array}{l}\text { West } \\
\text { B4 }\left({ }^{\circ} \mathrm{C}\right)\end{array}$ & $\begin{array}{l}\text { Diff } \\
\left({ }^{\circ} \mathrm{C}\right)\end{array}$ & $\begin{array}{c}\text { External } \\
\mathrm{C} 1\left({ }^{\circ} \mathrm{C}\right)\end{array}$ \\
\hline $8 \mathrm{am}$ & 20 & 19 & 18 & 19 & 20 & 18 & 19 & 0 & 15 \\
\hline $9 \mathrm{am}$ & 21 & 19 & 19 & 20 & 21 & 19 & 19 & -1 & 16 \\
\hline $10 \mathrm{am}$ & 22 & 20 & 20 & 21 & 22 & 20 & 20 & -1 & 18 \\
\hline $11 \mathrm{am}$ & 22 & 21 & 20 & 22 & 22 & 20 & 21 & -1 & 18 \\
\hline $12 \mathrm{pm}$ & 23 & 22 & 22 & 24 & 24 & 22 & 22 & -2 & 19 \\
\hline $1 \mathrm{pm}$ & 23 & 22 & 21 & 23 & 23 & 21 & 23 & -1 & 21 \\
\hline $2 \mathrm{pm}$ & 25 & 23 & 23 & 23 & 25 & 23 & 24 & 0 & 20 \\
\hline 3 pm & 25 & 23 & 23 & 23 & 25 & 23 & 24 & 0 & 20 \\
\hline
\end{tabular}

Table 28: Average temperature in the non-school days from $8 \mathrm{am}-3 \mathrm{pm}$

Case Study Two - Autumn

Case Study Three - Spring

The grey column is the difference between sensor (A2) and the vertical sensor with the least relationship in the ratio analysis

\begin{tabular}{|c|c|c|c|c|c|c|}
\hline Hour & $\begin{array}{c}\text { Central } \\
\mathbf{A 2}\left({ }^{\circ} \mathbf{C}\right)\end{array}$ & $\begin{array}{c}\text { South } \\
\mathbf{B} 1\left({ }^{\circ} \mathbf{C}\right)\end{array}$ & $\begin{array}{c}\text { West } \\
\mathbf{B} 4\left({ }^{\circ} \mathbf{C}\right)\end{array}$ & $\begin{array}{c}\text { North } \\
\text { B3 }\left({ }^{\circ} \mathbf{C}\right)\end{array}$ & $\begin{array}{c}\text { Diff } \\
\left({ }^{\circ} \mathbf{C}\right)\end{array}$ & $\begin{array}{c}\text { External } \\
\mathbf{C} 1\left({ }^{\circ} \mathbf{C}\right)\end{array}$ \\
\hline $\mathbf{8} \mathbf{~ a m}$ & 20 & 18 & 18 & 18 & 2 & 15 \\
\hline $\mathbf{9} \mathbf{~ a m}$ & 20 & 18 & 18 & 18 & 2 & 16 \\
\hline $\mathbf{1 0} \mathbf{~ a m}$ & 20 & 18 & 18 & 18 & 2 & 16 \\
\hline $\mathbf{1 1} \mathbf{~ a m}$ & 20 & 18 & 18 & 18 & 2 & 17 \\
\hline $\mathbf{1 2} \mathbf{~ p m}$ & 20 & 19 & 18 & 18 & 1 & 17 \\
\hline $\mathbf{1 p m}$ & 20 & 19 & 18 & 19 & 1 & 17 \\
\hline $\mathbf{2} \mathbf{p m}$ & 20 & 19 & 18 & 18 & 1 & 17 \\
\hline $\mathbf{3 p m}$ & 20 & 19 & 18 & 18 & 1 & 16 \\
\hline
\end{tabular}

\begin{tabular}{|c|c|c|c|c|c|c|}
\hline Hour & $\begin{array}{l}\text { Central } \\
\text { A2 }\left({ }^{\circ} \mathrm{C}\right)\end{array}$ & $\begin{array}{l}\text { South } \\
\text { B1 }\left({ }^{\circ} \mathrm{C}\right)\end{array}$ & $\begin{array}{c}\text { East } \\
\text { B2 }\left({ }^{\circ} \mathrm{C}\right)\end{array}$ & $\begin{array}{l}\text { North } \\
\text { B3 }\left({ }^{\circ} \mathrm{C}\right)\end{array}$ & $\begin{array}{l}\text { Diff } \\
\left({ }^{\circ} \mathrm{C}\right)\end{array}$ & $\begin{array}{l}\text { External } \\
\mathrm{C} 1\left({ }^{\circ} \mathrm{C}\right)\end{array}$ \\
\hline $8 \mathrm{am}$ & 14 & 14 & 14 & 14 & 0 & 8 \\
\hline $9 \mathrm{am}$ & 15 & 16 & 16 & 16 & -1 & 10 \\
\hline $10 \mathrm{am}$ & 17 & 20 & 18 & 18 & -2 & 12 \\
\hline $11 \mathrm{am}$ & 18 & 21 & 19 & 19 & -1 & 14 \\
\hline $12 \mathrm{pm}$ & 19 & 22 & 20 & 20 & -1 & 15 \\
\hline $1 \mathrm{pm}$ & 19 & 23 & 20 & 20 & -1 & 15 \\
\hline $2 \mathrm{pm}$ & 20 & 23 & 21 & 21 & -1 & 16 \\
\hline $3 \mathrm{pm}$ & 20 & 22 & 21 & 21 & -1 & 18 \\
\hline
\end{tabular}




\subsubsection{Non-School Days: Average Relative Humidity}

As earlier discussed above, the same calculation process of subtracting the difference between sensor A2 (Central) and the vertical wall sensor that showed the least relationship in the ratio analysis above to ascertain the level of variation between the sensor points was applied in Tables 29-31 below. The average relative humidity in sensor A2 was subtracted from the vertical wall sensor B1 in case study one and two, and sensor B2 in case study three because these sensors had a higher ratio change Section 6.1.3 above. In Tables 29-31, in all three case studies, the relative humidity varies between the horizontal measuring plane sensor and the vertical wall sensors were largely $<7 \%$ in the non-school days. This was further explored in the school days analysis below.

Table 29: Average relative humidity in the non-school days from 8 am-3 pm

\section{Case Study One Autumn}

The grey column is the difference between sensor (A2) and the vertical sensor with the least relationship in the ratio analysis

\begin{tabular}{|c|c|c|c|c|c|c|c|c|c|}
\hline Hour & $\begin{array}{c}\text { Central } \\
\text { A1 (\%) }\end{array}$ & $\begin{array}{c}\text { Central } \\
\text { A2 (\%) }\end{array}$ & $\begin{array}{c}\text { Central } \\
\text { A3 (\%) }\end{array}$ & $\begin{array}{c}\text { South } \\
\text { B1 (\%) }\end{array}$ & $\begin{array}{c}\text { East } \\
\text { B2 (\%) }\end{array}$ & $\begin{array}{c}\text { North } \\
\text { B3 (\%) }\end{array}$ & $\begin{array}{c}\text { West } \\
\text { B4 (\%) }\end{array}$ & $\begin{array}{c}\text { Diff } \\
\text { (\%) }\end{array}$ & $\begin{array}{c}\text { External } \\
\text { C1 (\%) }\end{array}$ \\
\hline $\mathbf{8} \mathbf{~ a m}$ & 52 & 52 & 52 & 53 & 49 & 56 & 47 & -1 & 65 \\
\hline $\mathbf{9} \mathbf{~ a m}$ & 51 & 52 & 52 & 53 & 49 & 56 & 47 & -1 & 56 \\
\hline $\mathbf{1 0} \mathbf{~ a m}$ & 51 & 52 & 52 & 53 & 49 & 56 & 47 & -1 & 76 \\
\hline $\mathbf{1 1} \mathbf{~ a m}$ & 51 & 52 & 52 & 52 & 48 & 56 & 47 & 0 & 73 \\
\hline $\mathbf{1 2} \mathbf{~ p m}$ & 51 & 52 & 52 & 52 & 49 & 56 & 47 & 0 & 70 \\
\hline $\mathbf{1} \mathbf{~ m}$ & 50 & 52 & 52 & 53 & 49 & 56 & 47 & -1 & 61 \\
\hline $\mathbf{2} \mathbf{~ p m}$ & 46 & 51 & 52 & 53 & 50 & 55 & 47 & -2 & 43 \\
\hline $\mathbf{3 ~} \mathbf{~ p m}$ & 48 & 50 & 51 & 53 & 50 & 54 & 45 & -3 & 60 \\
\hline
\end{tabular}

Table 30: Average relative humidity in the non-school days from 8 am-3 pm

\section{Case Study One- Summer}

The grey column is the difference between sensor (A2) and the vertical sensor with the least relationship in the ratio analysis

\begin{tabular}{|c|c|c|c|c|c|c|c|c|c|}
\hline Hour & $\begin{array}{c}\text { Central } \\
\text { A1 (\%) }\end{array}$ & $\begin{array}{c}\text { Central } \\
\text { A2 (\%) }\end{array}$ & $\begin{array}{c}\text { Central } \\
\text { A3 (\%) }\end{array}$ & $\begin{array}{c}\text { South } \\
\text { B1 (\%) }\end{array}$ & $\begin{array}{c}\text { East } \\
\text { B2 (\%) }\end{array}$ & $\begin{array}{c}\text { North } \\
\text { B3 (\%) }\end{array}$ & $\begin{array}{c}\text { West } \\
\text { B4 (\%) }\end{array}$ & $\begin{array}{c}\text { Diff } \\
\text { (\%) }\end{array}$ & $\begin{array}{c}\text { External } \\
\text { C1 (\%) }\end{array}$ \\
\hline $\mathbf{8} \mathbf{~ a m}$ & 45 & 49 & 52 & 48 & 44 & 51 & 48 & 1 & 65 \\
\hline $\mathbf{9} \mathbf{~ a m}$ & 45 & 49 & 52 & 47 & 44 & 51 & 48 & 2 & 65 \\
\hline $\mathbf{1 0} \mathbf{~ a m}$ & 45 & 48 & 51 & 47 & 43 & 51 & 48 & 1 & 63 \\
\hline $\mathbf{1 1} \mathbf{~ a m}$ & 44 & 48 & 51 & 46 & 43 & 51 & 48 & 2 & 62 \\
\hline $\mathbf{1 2} \mathbf{~ p m}$ & 44 & 48 & 51 & 41 & 43 & 51 & 49 & 7 & 58 \\
\hline $\mathbf{1} \mathbf{~ p m}$ & 44 & 48 & 51 & 46 & 45 & 51 & 48 & 2 & 51 \\
\hline $\mathbf{2} \mathbf{~ p m}$ & 44 & 48 & 51 & 48 & 45 & 51 & 47 & 0 & 54 \\
\hline $\mathbf{3} \mathbf{~ p m}$ & 44 & 48 & 51 & 48 & 45 & 51 & 47 & 0 & 56 \\
\hline
\end{tabular}


Table 31: Average relative humidity in the non-school days from 8 am-3 pm

\begin{tabular}{|c|c|c|c|c|c|c|c|c|c|c|c|c|c|}
\hline \multicolumn{7}{|c|}{ Case Study Two - Autumn } & \multicolumn{7}{|c|}{ Case Study Three - Spring } \\
\hline \multicolumn{14}{|c|}{ The grey column is the difference between sensor (A2) and the vertical sensor with the least relationship in the ratio analysis } \\
\hline Hour & $\begin{array}{l}\text { Central } \\
\text { A2 (\%) }\end{array}$ & $\begin{array}{l}\text { South } \\
\text { B1 (\%) }\end{array}$ & $\begin{array}{l}\text { West } \\
\text { B4 (\%) }\end{array}$ & $\begin{array}{l}\text { North } \\
\text { B3 (\%) }\end{array}$ & $\begin{array}{l}\text { Diff } \\
\text { (\%) }\end{array}$ & $\begin{array}{c}\text { External } \\
\text { C1 (\%) }\end{array}$ & Hour & $\begin{array}{l}\text { Central } \\
\text { A2 (\%) }\end{array}$ & $\begin{array}{l}\text { South } \\
\text { B1 (\%) }\end{array}$ & $\begin{array}{c}\text { East } \\
\text { B2 (\%) }\end{array}$ & $\begin{array}{l}\text { North } \\
\text { B3 (\%) }\end{array}$ & $\begin{array}{l}\text { Diff } \\
\text { (\%) }\end{array}$ & $\begin{array}{c}\text { External } \\
\text { C1 (\%) }\end{array}$ \\
\hline 8 am & 63 & 68 & 71 & 70 & -8 & 84 & 8 am & 60 & 58 & 57 & 57 & 3 & 93 \\
\hline $9 \mathrm{am}$ & 63 & 69 & 71 & 71 & -8 & 83 & $9 \mathrm{am}$ & 58 & 54 & 57 & 56 & 1 & 88 \\
\hline $10 \mathrm{am}$ & 64 & 69 & 71 & 71 & -7 & 80 & $10 \mathrm{am}$ & 55 & 49 & 55 & 54 & 0 & 78 \\
\hline $11 \mathrm{am}$ & 64 & 69 & 71 & 70 & -7 & 77 & $11 \mathrm{am}$ & 55 & 47 & 54 & 54 & 1 & 63 \\
\hline $12 \mathrm{pm}$ & 63 & 69 & 71 & 70 & -8 & 76 & $12 \mathrm{pm}$ & 56 & 45 & 54 & 54 & 2 & 55 \\
\hline 1 pm & 63 & 68 & 70 & 69 & -7 & 76 & 1 pm & 56 & 45 & 54 & 54 & 2 & 59 \\
\hline $2 \mathrm{pm}$ & 63 & 68 & 70 & 70 & -7 & 75 & $2 \mathrm{pm}$ & 57 & 47 & 54 & 54 & 3 & 50 \\
\hline 3 pm & 63 & 68 & 70 & 70 & -7 & 79 & 3 pm & 58 & 50 & 55 & 55 & 3 & 46 \\
\hline
\end{tabular}

\subsubsection{School Days: Average Temperature}

In Tables 32-34, the average temperature in sensor A2 was subtracted from the vertical wall sensor B1 in all three case studies because these sensors showed the least relationship. Like the non-school days and in all seasons, in all three case studies, the temperature variation between the horizontal measuring plane sensor and the vertical wall sensors were still largely $<2^{\circ} \mathrm{C}$. However, depending on the influence of occupant's usage in the space such as opening doors and windows, the variation could be wider as shown in case study three, where the difference between sensor $\mathrm{A} 2\left(19^{\circ} \mathrm{C}\right)$ and $\mathrm{B} 3\left(15^{\circ} \mathrm{C}\right)$ at $12 \mathrm{pm}$ was $+4^{\circ} \mathrm{C}$ difference. This was observed to be because sensor B3 (North) was relatively close to the glazed door which was usually kept open during warm days. This resulted in the temperature recorded by sensor B3 to be relatively the same as that of the outdoor temperature. For example, the external temperature levels in case study three were the same as that of sensor B3 at some point in time. 
Table 32: Average temperature in the school days from $8 \mathrm{am}-3 \mathrm{pm}$

Case Study One - Autumn

The grey column is the difference between sensor (A2) and the vertical sensor with the least relationship in the ratio analysis

\begin{tabular}{|c|c|c|c|c|c|c|c|c|c|}
\hline Hour & $\begin{array}{l}\text { Central } \\
\mathrm{A} 1\left({ }^{\circ} \mathrm{C}\right)\end{array}$ & $\begin{array}{l}\text { Central } \\
\mathrm{A} 2\left({ }^{\circ} \mathrm{C}\right)\end{array}$ & $\begin{array}{l}\text { Central } \\
\text { A3 }\left({ }^{\circ} \mathrm{C}\right)\end{array}$ & $\begin{array}{l}\text { South } \\
\text { B1 }\left({ }^{\circ} \mathrm{C}\right)\end{array}$ & $\begin{array}{c}\text { East } \\
\text { B2 }\left({ }^{\circ} \mathrm{C}\right)\end{array}$ & $\begin{array}{l}\text { North } \\
\text { B3 }\left({ }^{\circ} \mathrm{C}\right)\end{array}$ & $\begin{array}{l}\text { West } \\
\mathrm{B} 4\left({ }^{\circ} \mathrm{C}\right)\end{array}$ & $\begin{array}{l}\text { Diff } \\
\left({ }^{\circ} \mathrm{C}\right) \\
\end{array}$ & $\begin{array}{c}\text { External } \\
\mathrm{C} 1\left({ }^{\circ} \mathrm{C}\right)\end{array}$ \\
\hline $8 \mathrm{am}$ & 22 & 20 & 22 & 20 & 21 & 22 & 23 & -2 & 11 \\
\hline 9 am & 23 & 21 & 21 & 20 & 21 & 21 & 23 & 0 & 12 \\
\hline $10 \mathrm{am}$ & 22 & 21 & 21 & 20 & 21 & 21 & 22 & 0 & 13 \\
\hline $11 \mathrm{am}$ & 18 & 19 & 19 & 19 & 18 & 19 & 20 & 0 & 13 \\
\hline $12 \mathrm{pm}$ & 19 & 19 & 19 & 19 & 19 & 19 & 21 & 0 & 15 \\
\hline $1 \mathrm{pm}$ & 20 & 19 & 20 & 19 & 20 & 19 & 21 & 0 & 15 \\
\hline $2 \mathrm{pm}$ & 20 & 20 & 20 & 20 & 20 & 20 & 22 & 0 & 16 \\
\hline 3 pm & 22 & 20 & 20 & 20 & 20 & 20 & 22 & 0 & 20 \\
\hline
\end{tabular}

Table 33: Average temperature in the school days from 8 am-3 pm

Case Study One - Summer

The grey column is the difference between sensor (A2) and the vertical sensor with the least relationship in the ratio analysis

\begin{tabular}{|c|c|c|c|c|c|c|c|c|c|}
\hline Hour & $\begin{array}{l}\text { Central } \\
\text { A1 }\left({ }^{\circ} \mathrm{C}\right)\end{array}$ & $\begin{array}{l}\text { Central } \\
\text { A2 }\left({ }^{\circ} \mathrm{C}\right)\end{array}$ & $\begin{array}{l}\text { Central } \\
\text { A3 }\left({ }^{\circ} \mathrm{C}\right)\end{array}$ & $\begin{array}{l}\text { South } \\
\text { B1 }\left({ }^{\circ} \mathrm{C}\right)\end{array}$ & $\begin{array}{c}\text { East } \\
\text { B2 }\left({ }^{\circ} \mathrm{C}\right)\end{array}$ & $\begin{array}{l}\text { North } \\
\text { B3 }\left({ }^{\circ} \mathrm{C}\right)\end{array}$ & $\begin{array}{l}\text { West } \\
\text { B4 }\left({ }^{\circ} \mathrm{C}\right)\end{array}$ & $\begin{array}{l}\text { Diff } \\
\left({ }^{\circ} \mathrm{C}\right)\end{array}$ & $\begin{array}{l}\text { External } \\
\mathrm{C} 1\left({ }^{\circ} \mathrm{C}\right)\end{array}$ \\
\hline $8 \mathrm{am}$ & 22 & 21 & 21 & 22 & 23 & 21 & 22 & 0 & 17 \\
\hline $9 \mathrm{am}$ & 24 & 23 & 22 & 23 & 24 & 22 & 23 & 1 & 18 \\
\hline $10 \mathrm{am}$ & 23 & 22 & 21 & 23 & 23 & 21 & 21 & 1 & 19 \\
\hline $11 \mathrm{am}$ & 23 & 22 & 21 & 23 & 23 & 21 & 21 & 1 & 20 \\
\hline $12 \mathrm{pm}$ & 24 & 22 & 22 & 24 & 24 & 22 & 22 & 0 & 21 \\
\hline $1 \mathrm{pm}$ & 24 & 23 & 22 & 24 & 24 & 23 & 22 & 0 & 22 \\
\hline $2 \mathrm{pm}$ & 25 & 24 & 23 & 25 & 25 & 23 & 24 & 1 & 22 \\
\hline $3 \mathrm{pm}$ & 27 & 26 & 25 & 26 & 27 & 25 & 26 & 1 & 23 \\
\hline
\end{tabular}

Table 34: Average temperature in the school days from 8 am-3 pm

\begin{tabular}{|c|c|c|c|c|c|c|c|c|c|c|c|c|c|}
\hline \multicolumn{7}{|c|}{ Case Study Two - Autumn } & \multicolumn{7}{|c|}{ Case Study Three - Spring } \\
\hline \multicolumn{14}{|c|}{ The grey column is the difference between sensor (A2) and the vertical sensor with the least relationship in the ratio analysis } \\
\hline Hour & $\begin{array}{l}\text { Central } \\
\text { A2 }\left({ }^{\circ} \mathrm{C}\right)\end{array}$ & $\begin{array}{l}\text { South } \\
\text { B1 }\left({ }^{\circ} \mathrm{C}\right)\end{array}$ & $\begin{array}{l}\text { West } \\
\text { B4 }\left({ }^{\circ} \mathrm{C}\right)\end{array}$ & $\begin{array}{l}\text { North } \\
\text { B3 }\left({ }^{\circ} \mathrm{C}\right)\end{array}$ & $\begin{array}{l}\text { Diff } \\
\left({ }^{\circ} \mathrm{C}\right)\end{array}$ & $\begin{array}{c}\text { External } \\
\mathrm{C} 1\left({ }^{\circ} \mathrm{C}\right)\end{array}$ & Hour & $\begin{array}{l}\text { Central } \\
\text { A2 }\left({ }^{\circ} \mathrm{C}\right)\end{array}$ & $\begin{array}{l}\text { South } \\
\text { B1 }\left({ }^{\circ} \mathrm{C}\right)\end{array}$ & $\begin{array}{c}\text { East } \\
\text { B2 }\left({ }^{\circ} \mathrm{C}\right)\end{array}$ & $\begin{array}{l}\text { North } \\
\text { B3 }\left({ }^{\circ} \mathrm{C}\right)\end{array}$ & $\begin{array}{l}\text { Diff } \\
\left({ }^{\circ} \mathrm{C}\right)\end{array}$ & $\begin{array}{l}\text { External } \\
\mathrm{C} 1\left({ }^{\circ} \mathrm{C}\right)\end{array}$ \\
\hline $8 \mathrm{am}$ & 21 & 19 & 19 & 19 & 2 & 15 & 8 am & 18 & 18 & 17 & 16 & 2 & 9 \\
\hline $9 \mathrm{am}$ & 21 & 20 & 19 & 19 & 1 & 15 & $9 \mathrm{am}$ & 18 & 20 & 18 & 15 & 3 & 10 \\
\hline $10 \mathrm{am}$ & 20 & 20 & 19 & 19 & 0 & 16 & $10 \mathrm{am}$ & 19 & 19 & 19 & 15 & 4 & 11 \\
\hline $12 \mathrm{pm}$ & 21 & 20 & 20 & 20 & 1 & 17 & $12 \mathrm{pm}$ & 19 & 19 & 19 & 15 & 4 & 15 \\
\hline $1 \mathrm{pm}$ & 20 & 20 & 19 & 19 & 0 & 19 & $1 \mathrm{pm}$ & 19 & 20 & 19 & 16 & 3 & 16 \\
\hline $2 \mathrm{pm}$ & 21 & 21 & 20 & 20 & 0 & 19 & $2 \mathrm{pm}$ & 19 & 19 & 19 & 16 & 3 & 16 \\
\hline $3 \mathrm{pm}$ & 22 & 21 & 20 & 21 & 1 & 19 & $3 \mathrm{pm}$ & 19 & 19 & 19 & 19 & 0 & 17 \\
\hline
\end{tabular}




\subsubsection{School Days: Average Relative Humidity}

In Tables 35-37, the average relative humidity in sensor A2 was subtracted from the vertical wall sensor B1 in case study one (autumn) and two, and sensor B2 in case study one (summer) and three because these sensors showed the least relationship with sensor A2. Tables 35-37 shows that like the non-school days, in all three case studies, the relative humidity varies between the horizontal measuring plane sensor and the vertical wall sensors were largely $\pm<7 \%$ in the school days. However, case study three also had high humidity variation at some point in time. For example, at $10 \mathrm{am}$ to $1 \mathrm{pm}$ in case study three, the difference between the horizontal and vertical sensors was up to a $10 \%$ variation at some point in time.

Table 35: Average relative humidity in the school days from $8 \mathrm{am}-3 \mathrm{pm}$

\section{Case Study One - Autumn}

The grey column is the difference between sensor (A2) and the vertical sensor with the least relationship in the ratio analysis

\begin{tabular}{|c|c|c|c|c|c|c|c|c|c|}
\hline Hour & $\begin{array}{c}\text { Central } \\
\text { A1 (\%) }\end{array}$ & $\begin{array}{c}\text { Central } \\
\text { A2 (\%) }\end{array}$ & $\begin{array}{c}\text { Central } \\
\text { A3 (\%) }\end{array}$ & $\begin{array}{c}\text { South } \\
\text { B1 (\%) }\end{array}$ & $\begin{array}{c}\text { East } \\
\text { B2 (\%) }\end{array}$ & $\begin{array}{c}\text { North } \\
\text { B3 (\%) }\end{array}$ & $\begin{array}{c}\text { West } \\
\text { B4 (\%) }\end{array}$ & $\begin{array}{c}\text { Diff } \\
\text { (\%) }\end{array}$ & $\begin{array}{c}\text { External } \\
\text { C1 (\%) }\end{array}$ \\
\hline $\mathbf{8} \mathbf{~ a m}$ & 46 & 50 & 46 & 53 & 45 & 46 & 45 & -3 & 89 \\
\hline $\mathbf{9} \mathbf{~ a m}$ & 50 & 54 & 53 & 57 & 51 & 54 & 48 & -3 & 86 \\
\hline $\mathbf{1 0} \mathbf{~ a m}$ & 54 & 57 & 56 & 60 & 55 & 59 & 51 & -3 & 83 \\
\hline $\mathbf{1 1} \mathbf{~ a m}$ & 58 & 59 & 58 & 59 & 56 & 59 & 52 & 0 & 78 \\
\hline $\mathbf{1 2} \mathbf{~ p m}$ & 57 & 58 & 56 & 57 & 54 & 59 & 52 & -1 & 69 \\
\hline $\mathbf{1} \mathbf{~ m}$ & 54 & 56 & 55 & 56 & 53 & 58 & 50 & 0 & 66 \\
\hline $\mathbf{2} \mathbf{~ p m}$ & 54 & 56 & 55 & 56 & 53 & 58 & 49 & 0 & 64 \\
\hline $\mathbf{3 ~} \mathbf{~ p m}$ & 47 & 55 & 55 & 55 & 53 & 56 & 48 & 0 & 53 \\
\hline
\end{tabular}

Table 36: Average relative humidity in the school days from $8 \mathrm{am}-3 \mathrm{pm}$

\section{Case Study One- Summer}

The grey column is the difference between sensor (A2) and the vertical sensor with the least relationship in the ratio analysis

\begin{tabular}{|c|c|c|c|c|c|c|c|c|c|}
\hline Hour & $\begin{array}{c}\text { Central } \\
\text { A1 (\%) }\end{array}$ & $\begin{array}{c}\text { Central } \\
\text { A2 (\%) }\end{array}$ & $\begin{array}{c}\text { Central } \\
\text { A3 (\%) }\end{array}$ & $\begin{array}{c}\text { South } \\
\text { B1 (\%) }\end{array}$ & $\begin{array}{c}\text { East } \\
\text { B2 (\%) }\end{array}$ & $\begin{array}{c}\text { North } \\
\text { B3 (\%) }\end{array}$ & $\begin{array}{c}\text { West } \\
\text { B4 (\%) }\end{array}$ & $\begin{array}{c}\text { Diff } \\
\text { (\%) }\end{array}$ & $\begin{array}{c}\text { External } \\
\text { C1 (\%) }\end{array}$ \\
\hline $\mathbf{8} \mathbf{~ a m}$ & 56 & 59 & 57 & 52 & 62 & 60 & 58 & 7 & 79 \\
\hline $\mathbf{9} \mathbf{~ a m}$ & 55 & 58 & 57 & 52 & 61 & 60 & 58 & 6 & 73 \\
\hline $\mathbf{1 0} \mathbf{~ a m}$ & 55 & 59 & 56 & 52 & 62 & 62 & 61 & 7 & 71 \\
\hline $\mathbf{1 1} \mathbf{~ a m}$ & 55 & 59 & 54 & 52 & 62 & 61 & 62 & 7 & 67 \\
\hline $\mathbf{1 2} \mathbf{~ p m}$ & 52 & 56 & 50 & 49 & 59 & 58 & 57 & 7 & 60 \\
\hline $\mathbf{1} \mathbf{~ p m}$ & 51 & 55 & 50 & 49 & 59 & 56 & 56 & 6 & 58 \\
\hline $\mathbf{2} \mathbf{~ p m}$ & 52 & 56 & 52 & 49 & 59 & 57 & 55 & 7 & 61 \\
\hline $\mathbf{3 ~} \mathbf{~ p m}$ & 49 & 52 & 52 & 48 & 55 & 55 & 52 & 4 & 60 \\
\hline
\end{tabular}


Table 37: Average relative humidity in the school days from 8 am-3 pm

\section{Case Study Two - Autumn}

Case Study Three - Spring

The grey column is the difference between sensor (A2) and the vertical sensor with the least relationship in the ratio analysis

\begin{tabular}{|c|c|c|c|c|c|c|c|c|c|c|c|c|c|}
\hline Hour & $\begin{array}{l}\text { Central } \\
\text { A2 (\%) }\end{array}$ & $\begin{array}{l}\text { South } \\
\text { B1 (\%) }\end{array}$ & $\begin{array}{l}\text { West } \\
\text { B4 (\%) }\end{array}$ & $\begin{array}{l}\text { North } \\
\text { B3 (\%) }\end{array}$ & $\begin{array}{l}\text { Diff } \\
(\%)\end{array}$ & $\begin{array}{c}\text { External } \\
\text { C1 (\%) }\end{array}$ & Hour & $\begin{array}{l}\text { Central } \\
\text { A2 (\%) }\end{array}$ & $\begin{array}{l}\text { South } \\
\text { B1 (\%) }\end{array}$ & $\begin{array}{c}\text { East } \\
\text { B2 (\%) }\end{array}$ & $\begin{array}{l}\text { North } \\
\text { B3 (\%) }\end{array}$ & $\begin{array}{l}\text { Diff } \\
(\%)\end{array}$ & $\begin{array}{c}\text { External } \\
\text { C1 (\%) }\end{array}$ \\
\hline $8 \mathrm{am}$ & 65 & 69 & 73 & 72 & -8 & 82 & $8 \mathrm{am}$ & 55 & 52 & 56 & 55 & 3 & 92 \\
\hline $9 \mathrm{am}$ & 71 & 74 & 78 & 77 & -7 & 80 & $9 \mathrm{am}$ & 56 & 50 & 63 & 54 & 6 & 86 \\
\hline 10 am & 72 & 75 & 79 & 79 & -7 & 74 & $10 \mathrm{am}$ & 57 & 55 & 72 & 57 & 2 & 82 \\
\hline $11 \mathrm{am}$ & 74 & 73 & 80 & 77 & -6 & 71 & $11 \mathrm{am}$ & 58 & 58 & 74 & 59 & 0 & 78 \\
\hline $12 \mathrm{pm}$ & 72 & 71 & 76 & 74 & -4 & 73 & $12 \mathrm{pm}$ & 59 & 59 & 75 & 60 & 0 & 67 \\
\hline $1 \mathrm{pm}$ & 71 & 72 & 77 & 76 & -6 & 65 & 1 pm & 57 & 53 & 70 & 57 & 4 & 59 \\
\hline 2 pm & 70 & 71 & 75 & 75 & -5 & 63 & 2 pm & 59 & 57 & 69 & 58 & 2 & 49 \\
\hline 3 pm & 67 & 69 & 73 & 72 & -6 & 66 & 3 pm & 58 & 56 & 57 & 56 & 2 & 49 \\
\hline
\end{tabular}

The results in Tables 26-37 above generally illustrates that the differences in temperature and humidity changes across the sensor points were largely $<2{ }^{\circ} \mathrm{C}$ and relative humidity $<7 \%$. It was observed that the variation in temperature and relative humidity levels were a result of solar gain admitted through glazed areas, occupant's usage of the space and sensors positioned close to heating systems resulted in the spatial distribution of temperature and humidity at some point in time. 


\subsubsection{Thermal Comfort Models Analysis}

Given that the results revealed $\mathrm{a}<2^{\circ} \mathrm{C}$ difference between the highest and lowest average temperatures per hour, this study further used PPV and PPD models to ascertain the magnitude of this relationship on occupant's thermal comfort. As discussed in the literature, the thermal comfort of an individual is determined by measuring the comfort zone of a certain value for the occupant (Yun, 2018). The American Society of Heating, refrigerating (ASHRAE) and HVAC Engineers have developed two main thermal comfort modules that categorize thermal environmental conditions for human occupancy through combinations of personal factors and indoor thermal environment that form the thermal conditions suitable to the majority of the occupants. These two models are:

1. The predicted mean vote (PMV) and the predicted percentage dissatisfied (PPD) models.

2. Adaptive thermal comfort models.

The PMV "is based on the principles of heat balance and data collected in a climate controlled environment under stable conditions and the PMV index predicts the mean response of occupants, as per the ASHRAE thermal sensation scale $(-1=$ slightly cool, $-2=$ cool, $-3=$ cold, $0=$ neutral, $+1=$ slightly warm, $+2=$ warm,$+3=$ hot $)$ " (Yun, 2018). Air temperature, mean radiant temperature, mean air humidity, relative air velocity, clothing insulation, and metabolic rate are the six variables that distinguish PMV thermal comfort (Yun, 2018), and most of these variables are obtained using sensors, such as the temperature and humidity variables obtained through deploying sensors into the case study classrooms. However, the assessment of metabolic rate and insulation of clothing is reliant on the individual standards: ISO 9920 (clothing), ISO 8996 (metabolic rate), and ISO 7726 (instruments and methods) (ISO, 1998, 2004, 2005, 2007; ISO 3382-2, 2008). It is important to note that The PMV model has strengths and limitations. Van Hoof, (2008) determined that for metabolic rates and the insulation of clothing the predicted mean vote (PMV/PPD) is difficult to accurately estimate. Yun, (2018) suggest that in terms of heat transfer physiology and physics, the PMV for thermal comfort tries to find the response of environmentally friendly occupants, which is a complex procedure. Also, it does not take into consideration the psychological factors that play a vital role in controlling thermal comfort conditions. Studies (Albatayneh et al., 2019; Humphreys \& Nicol, 2002; Wu et al., 2018; Yun, 
2018) have found that because PMV depends on respondents' physiology and subjective perception, PMV is difficult to use in the real world and could lead to inaccuracies in terms of predicting comfortable conditions. For example, Wu et al., (2018) field study in an air-conditioned office building showed that when compared to the PMV/PPD model with lower energy consumption, the adaptive comfort model improved the thermal acceptance of occupants.

The adaptive comfort model was developed by various empirical and experimental investigations (ASHRAE-55-2010, 2012); while the PMV/PPD model can be applied in air-conditioned buildings, the adaptive thermal comfort model is used for naturally ventilated buildings. The adaptive model theory suggests that people living in warmer climates can tolerate warmer temperatures indoors than those living in colder climates (Soebarto \& Bennetts, 2014). The inclusion of air velocity and humidity for operative temperature calculation requirements is an important strength of the adaptive comfort model. However, data from the occupants related to windows and doors opened or fans running needs to be taken into account to analyse the impact of these two factors on the thermal comfort of the occupant (Hwang et al., 2006). The adaptive comfort model sets out parameters for achieving 80 or $90 \%$ acceptability from occupants but is focused more on cooling spaces rather than heating. It does not apply to students in classrooms because the maximum metabolic rate is 1.3 (occupant of engaged in near sedentary activity 1-1.3 met) and students may reach above 2.0 depending on the activity carried out (Dear \& Brager, 2002). This thesis used the thermal comfort models to explore whether a $2{ }^{\circ} \mathrm{C}$ variation in temperature and $7 \%$ variation in humidity could impact on occupant's comfort, taking into consideration the limitations of these models with respect to the case study classroom.

The three case study classrooms were naturally ventilated spaces. Temperature and relative humidity physical measurement data of case study one was exported into the ASHRAE thermal comfort calculator (Yun, 2018) to calculate both PMV/PPD and adaptive comfort to ascertain the relationship in thermal comfort acceptability across the sensor points. In Tables 38 and 39, the hourly average temperature and humidity data were used to calculate PMV and PPD of the various sensors in one day in both summer and autumn time respectively. There was variation in the PMV and PPD thermal sensation scale. For example, look at sensor A2 and B3 at 8 am, sensor 
A2 recorded a PPD of $13 \%$ while sensor B3 recorded a PPD of $7 \%$ which is nearly half of sensor

A2. This indicated that across the various sensor points, and assuming the space was mechanically ventilated, there will be variation in satisfaction of occupants across the space. Yun, (2018) states that ASHRAE (and CEN) provides a comfort zone consistent with $80 \%$ of satisfied people and this "could" be compared with a PPD equal to 20\% (PMV from -0.85 to 0.85).

Table 38: Summer PMV and PPD Analysis

\begin{tabular}{|c|c|c|c|c|c|c|c|c|c|c|c|c|c|c|}
\hline \multirow[b]{2}{*}{ Time } & \multicolumn{2}{|c|}{ Central West (A1) } & \multirow{2}{*}{$\begin{array}{l}\text { Central } \\
\text { PPV }\end{array}$} & \multirow{2}{*}{$\begin{array}{l}\text { (A2) } \\
\text { PPD }\end{array}$} & \multicolumn{2}{|c|}{ Central East (A3) } & \multicolumn{2}{|c|}{ South Wall (B1) } & \multirow{2}{*}{$\begin{array}{c}\text { East Wa } \\
\text { PPV }\end{array}$} & \multirow{2}{*}{$\begin{array}{l}\text { (B2) } \\
\text { PPD }\end{array}$} & \multicolumn{2}{|c|}{ North Wall (B3) } & \multicolumn{2}{|c|}{ West Wall (B4) } \\
\hline & \begin{tabular}{|l|} 
PPV \\
\end{tabular} & PPD & & & PPV & PPD & PPV & PPD & & & PPV & PPD & \begin{tabular}{l|l} 
PPV & \\
\end{tabular} & PPD \\
\hline 12 a.m. & 0.93 & $24 \%$ & 0.72 & $16 \%$ & 0.53 & $11 \%$ & 0.77 & $18 \%$ & 1.10 & $31 \%$ & 0.63 & $14 \%$ & 0.72 & $16 \%$ \\
\hline 1 a.m. & 0.91 & $23 \%$ & 0.61 & $13 \%$ & 0.40 & $8 \%$ & 0.72 & $16 \%$ & 1.10 & $31 \%$ & 0.53 & $11 \%$ & 0.72 & $16 \%$ \\
\hline 2 a.m. & 0.91 & $23 \%$ & 0.53 & $11 \%$ & 0.33 & $7 \%$ & 0.72 & $16 \%$ & 0.91 & $23 \%$ & 0.53 & $11 \%$ & 0.69 & $15 \%$ \\
\hline 3 a.m. & 0.77 & $18 \%$ & 0.53 & $11 \%$ & 0.33 & $7 \%$ & 0.61 & $13 \%$ & 0.91 & $23 \%$ & 0.47 & $10 \%$ & 0.53 & $11 \%$ \\
\hline 4 a.m. & 0.72 & $16 \%$ & 0.53 & $11 \%$ & 0.33 & $7 \%$ & 0.53 & $11 \%$ & 0.91 & $23 \%$ & 0.33 & $7 \%$ & 0.53 & $11 \%$ \\
\hline 5 a.m. & 0.72 & $16 \%$ & 0.53 & $11 \%$ & 0.32 & $7 \%$ & 0.53 & $11 \%$ & 0.91 & $23 \%$ & 0.33 & $7 \%$ & 0.53 & $11 \%$ \\
\hline 6 a.m. & 0.74 & $17 \%$ & 0.53 & $11 \%$ & 0.33 & $7 \%$ & 0.53 & $11 \%$ & 0.91 & $23 \%$ & 0.36 & $8 \%$ & 0.53 & $11 \%$ \\
\hline 7 a.m. & 0.90 & $23 \%$ & 0.53 & $11 \%$ & 0.33 & $7 \%$ & 0.69 & $15 \%$ & 0.91 & $23 \%$ & 0.53 & $11 \%$ & 0.57 & $12 \%$ \\
\hline 8 a.m. & 0.59 & $13 \%$ & 0.40 & $8 \%$ & 0.16 & $5 \%$ & 0.53 & $11 \%$ & 0.80 & $19 \%$ & 0.33 & $7 \%$ & 0.45 & $9 \%$ \\
\hline 9 a.m. & 0.98 & $26 \%$ & 0.72 & $16 \%$ & 0.59 & $13 \%$ & 0.79 & $19 \%$ & 1.06 & $29 \%$ & 0.62 & $14 \%$ & 0.77 & $18 \%$ \\
\hline 10 a.m. & 0.70 & $16 \%$ & 0.44 & $9 \%$ & 0.16 & $5 \%$ & 0.71 & $16 \%$ & 0.93 & $24 \%$ & 0.34 & $7 \%$ & 0.37 & $8 \%$ \\
\hline 11 a.m. & 0.72 & $16 \%$ & 0.53 & $11 \%$ & 0.24 & $6 \%$ & 0.90 & $23 \%$ & 0.91 & $23 \%$ & 0.33 & $7 \%$ & 0.33 & $7 \%$ \\
\hline 12 p.m. & 0.87 & $22 \%$ & 0.55 & $11 \%$ & 0.34 & $7 \%$ & 1.37 & $44 \%$ & 1.07 & $30 \%$ & 0.47 & $10 \%$ & 0.50 & $10 \%$ \\
\hline 1 p.m. & 0.91 & $23 \%$ & 0.72 & $16 \%$ & 0.53 & $11 \%$ & 1.01 & $27 \%$ & 1.10 & $31 \%$ & 0.69 & $15 \%$ & 0.62 & $13 \%$ \\
\hline 2 p.m. & 1.01 & $27 \%$ & 0.82 & $20 \%$ & 0.66 & $15 \%$ & 1.02 & $28 \%$ & 1.23 & $37 \%$ & 0.78 & $18 \%$ & 0.85 & $21 \%$ \\
\hline 3 p.m. & 1.36 & $43 \%$ & 1.23 & $37 \%$ & 1.05 & $29 \%$ & 1.25 & $37 \%$ & 1.49 & $50 \%$ & 1.11 & $31 \%$ & 1.28 & $39 \%$ \\
\hline 4 p.m. & 1.58 & $55 \%$ & 1.43 & $47 \%$ & 1.21 & $36 \%$ & 1.28 & $39 \%$ & 1.59 & $56 \%$ & 1.28 & $39 \%$ & 1.48 & $50 \%$ \\
\hline 5 p.m. & 1.78 & $66 \%$ & 1.50 & $51 \%$ & 1.32 & $41 \%$ & 1.42 & $46 \%$ & 1.70 & $62 \%$ & 1.37 & $44 \%$ & 1.60 & $56 \%$ \\
\hline 6 p.m. & 1.60 & $57 \%$ & 1.34 & $42 \%$ & 1.12 & $32 \%$ & 1.29 & $40 \%$ & 1.59 & $56 \%$ & 1.17 & $34 \%$ & 1.37 & $44 \%$ \\
\hline 7 p.m. & 1.41 & $46 \%$ & 1.16 & $34 \%$ & 0.92 & $23 \%$ & 1.17 & $34 \%$ & 1.43 & $47 \%$ & 1.01 & $27 \%$ & 1.20 & $36 \%$ \\
\hline 8 p.m. & 1.28 & $39 \%$ & 0.99 & $26 \%$ & 0.74 & $17 \%$ & 1.08 & $30 \%$ & 1.34 & $42 \%$ & 0.91 & $23 \%$ & 1.08 & $30 \%$ \\
\hline 9 p.m. & 1.17 & $34 \%$ & 0.91 & $23 \%$ & 0.72 & $16 \%$ & 0.91 & $23 \%$ & 1.28 & $39 \%$ & 0.74 & $17 \%$ & 0.91 & $23 \%$ \\
\hline 10 p.m. & 1.10 & $31 \%$ & 0.85 & $21 \%$ & 0.54 & $11 \%$ & 0.91 & $23 \%$ & 1.25 & $38 \%$ & 0.72 & $16 \%$ & 0.91 & $23 \%$ \\
\hline 11 p.m. & 1.10 & $31 \%$ & 0.72 & $16 \%$ & 0.53 & $11 \%$ & 0.86 & $21 \%$ & 1.10 & $31 \%$ & 0.72 & $16 \%$ & 0.81 & $19 \%$ \\
\hline
\end{tabular}

Table 39: Autumn PMV and PPD Analysis

\begin{tabular}{|c|c|c|c|c|c|c|c|c|c|c|c|c|c|c|}
\hline \multirow{3}{*}{\multicolumn{3}{|c|}{ 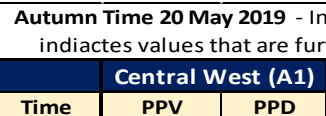 }} & \multirow{3}{*}{\begin{tabular}{l|} 
Central \\
PPV
\end{tabular}} & \multirow{3}{*}{$\begin{array}{l}\text { (A2) } \\
\text { PPD }\end{array}$} & \multirow{2}{*}{\multicolumn{2}{|c|}{ Central East (A3) }} & \multirow{2}{*}{\multicolumn{2}{|c|}{ South Wall (B1) }} & \multirow{2}{*}{\multicolumn{2}{|c|}{ East Wall (B2) }} & \multirow{2}{*}{\multicolumn{2}{|c|}{ North Wall (B3) }} & \multirow{2}{*}{\multicolumn{2}{|c|}{ West Wall (B4) }} \\
\hline & & & & & & & & & & & & & & \\
\hline & & & & & \begin{tabular}{|l|} 
PPV \\
\end{tabular} & PPD & PPV & PPD & \begin{tabular}{|l|l} 
PPV & \\
\end{tabular} & PPD & PPV & PPD & \begin{tabular}{|l|} 
PPV \\
\end{tabular} & PPD \\
\hline 12 a.m. & -0.20 & $6 \%$ & -0.20 & $6 \%$ & -0.20 & $6 \%$ & -0.34 & $8 \%$ & -0.10 & $6 \%$ & -0.44 & $9 \%$ & 0.28 & $7 \%$ \\
\hline 1 a.m. & -0.20 & $6 \%$ & -0.20 & $6 \%$ & -0.20 & $6 \%$ & -0.20 & $6 \%$ & -0.20 & $6 \%$ & -0.44 & $9 \%$ & 0.18 & $6 \%$ \\
\hline 2 a.m. & -0.20 & $6 \%$ & -0.20 & $6 \%$ & -0.20 & $6 \%$ & -0.20 & $6 \%$ & -0.20 & $6 \%$ & -0.44 & $9 \%$ & 0.04 & $5 \%$ \\
\hline 3 a.m. & -0.20 & $6 \%$ & -0.20 & $6 \%$ & -0.20 & $6 \%$ & -0.20 & $6 \%$ & -0.20 & $6 \%$ & -0.44 & $9 \%$ & 0.04 & $5 \%$ \\
\hline 4 a.m. & -0.20 & $6 \%$ & -0.20 & $6 \%$ & -0.20 & $6 \%$ & -0.20 & $6 \%$ & -0.20 & $6 \%$ & -0.44 & $9 \%$ & 0.04 & $5 \%$ \\
\hline 5 a.m. & -0.20 & $6 \%$ & -0.20 & $6 \%$ & -0.20 & $6 \%$ & -0.20 & $6 \%$ & -0.20 & $6 \%$ & -0.44 & $9 \%$ & 0.04 & $5 \%$ \\
\hline 6 a.m. & -0.30 & $7 \%$ & -0.23 & $6 \%$ & -0.20 & $6 \%$ & -0.20 & $6 \%$ & -0.20 & $6 \%$ & -0.48 & $10 \%$ & 0.04 & $5 \%$ \\
\hline 7 a.m. & -0.28 & $7 \%$ & -0.35 & $8 \%$ & -0.13 & $6 \%$ & -0.29 & $7 \%$ & -0.07 & $6 \%$ & -0.37 & $10 \%$ & 0.15 & $6 \%$ \\
\hline 8 a.m. & 0.56 & $13 \%$ & 0.19 & $6 \%$ & 0.48 & $10 \%$ & -0.08 & $5 \%$ & 0.43 & $9 \%$ & 0.46 & $10 \%$ & 0.80 & $19 \%$ \\
\hline 9 a.m. & 0.64 & $14 \%$ & 0.33 & $7 \%$ & 0.37 & $8 \%$ & 0.02 & $5 \%$ & 0.37 & $8 \%$ & 0.35 & $8 \%$ & 0.76 & $17 \%$ \\
\hline 10 a.m. & 0.53 & $11 \%$ & 0.33 & $7 \%$ & 0.33 & $7 \%$ & 0.14 & $5 \%$ & 0.33 & $7 \%$ & 0.31 & $7 \%$ & 0.72 & $16 \%$ \\
\hline 11 a.m. & -0.20 & $8 \%$ & -0.17 & $8 \%$ & -0.16 & $7 \%$ & -0.13 & $6 \%$ & -0.20 & $7 \%$ & -0.06 & $7 \%$ & 0.35 & $9 \%$ \\
\hline 12 p.m. & -0.07 & $5 \%$ & -0.12 & $5 \%$ & -0.03 & $5 \%$ & -0.07 & $5 \%$ & -0.04 & $5 \%$ & -0.21 & $6 \%$ & 0.24 & $6 \%$ \\
\hline 1 p.m. & 0.14 & $5 \%$ & -0.06 & $5 \%$ & 0.14 & $5 \%$ & -0.03 & $5 \%$ & 0.14 & $5 \%$ & -0.07 & $5 \%$ & 0.34 & $7 \%$ \\
\hline 2 p.m. & 0.20 & $6 \%$ & 0.13 & $5 \%$ & 0.14 & $5 \%$ & 0.14 & $5 \%$ & 0.14 & $5 \%$ & -0.06 & $5 \%$ & 0.54 & $11 \%$ \\
\hline 3 p.m. & 0.85 & $26 \%$ & 0.14 & $5 \%$ & 0.10 & $5 \%$ & 0.14 & $5 \%$ & 0.17 & $5 \%$ & 0.02 & $5 \%$ & 0.65 & $14 \%$ \\
\hline 4 p.m. & 0.64 & $18 \%$ & 0.08 & $5 \%$ & -0.03 & $5 \%$ & 0.11 & $5 \%$ & 0.20 & $6 \%$ & 0.05 & $5 \%$ & 0.64 & $14 \%$ \\
\hline 5 p.m. & -0.03 & $5 \%$ & -0.10 & $5 \%$ & -0.12 & $5 \%$ & -0.06 & $5 \%$ & -0.03 & $5 \%$ & -0.25 & $6 \%$ & 0.33 & $7 \%$ \\
\hline 6 p.m. & -0.07 & $5 \%$ & -0.27 & $6 \%$ & -0.19 & $6 \%$ & -0.06 & $5 \%$ & -0.06 & $5 \%$ & -0.27 & $6 \%$ & 0.24 & $6 \%$ \\
\hline 7 p.m. & -0.27 & $6 \%$ & -0.27 & $6 \%$ & -0.27 & $6 \%$ & -0.06 & $5 \%$ & -0.06 & $5 \%$ & -0.42 & $9 \%$ & 0.14 & $5 \%$ \\
\hline 8 p.m. & -0.27 & $6 \%$ & -0.27 & $6 \%$ & -0.27 & $6 \%$ & -0.21 & $6 \%$ & -0.19 & $6 \%$ & -0.47 & $10 \%$ & 0.14 & $5 \%$ \\
\hline 9 p.m. & -0.27 & $6 \%$ & -0.27 & $6 \%$ & -0.27 & $6 \%$ & -0.27 & $6 \%$ & -0.27 & $6 \%$ & -0.47 & $10 \%$ & 0.13 & $5 \%$ \\
\hline 10 p.m. & -0.27 & $6 \%$ & -0.36 & $8 \%$ & -0.27 & $6 \%$ & -0.27 & $6 \%$ & -0.27 & $6 \%$ & -0.47 & $10 \%$ & -0.06 & $5 \%$ \\
\hline 11 p.m. & -0.40 & $9 \%$ & -0.47 & $10 \%$ & -0.42 & $9 \%$ & -0.27 & $6 \%$ & -0.27 & $6 \%$ & -0.53 & $11 \%$ & -0.06 & $5 \%$ \\
\hline
\end{tabular}


In Tables 40 and 41, the average internal temperatures for both summer and autumn was used to estimate the occupants' adaptive thermal comfort range by exploring the $80 \%$ low limit and $80 \%$ high limit. Occupants are required to wear suitable clothing in the adaptive thermal approach. In this calculation, $1 \mathrm{~m}^{2}{ }^{\circ} \mathrm{C} / \mathrm{W}$ for the summer days and $1.3 \mathrm{~m}^{2}{ }^{\circ} \mathrm{C} / \mathrm{W}$ for the autumn days were used for clothing insulation (Clo) and these values were not corrected by the effect of air and movement. The results indicated that for the various sensor points, there was no difference in the adaptive comfort range, due to the temperature values being within $18-25^{\circ} \mathrm{C}$ comfort threshold and all sensors had the same $80 \%$ low and high limits.

Table 40: Summer Adaptive Comfort Model Analysis

\begin{tabular}{|c|c|c|c|c|c|c|c|c|c|c|c|c|c|c|}
\hline \multicolumn{15}{|c|}{ Summer Time - 18 February 2019} \\
\hline & \multicolumn{2}{|c|}{ Central West (A1) } & \multicolumn{2}{|c|}{ Central (A2) } & \multicolumn{2}{|c|}{ Central East (A3) } & \multicolumn{2}{|c|}{ South Wall (B1) } & \multicolumn{2}{|c|}{ East Wall (B2) } & \multicolumn{2}{|c|}{ North Wall (B3) } & \multicolumn{2}{|c|}{ West Wall (B4) } \\
\hline Time & $\begin{array}{c}80 \% \text { Low } \\
\text { Limit }\end{array}$ & $\begin{array}{c}80 \% \text { High } \\
\text { Limit }\end{array}$ & $\begin{array}{c}80 \% \text { Low } \\
\text { Limit }\end{array}$ & \begin{tabular}{|c|}
$80 \%$ High \\
Limit
\end{tabular} & $\begin{array}{c}80 \% \text { Low } \\
\text { Limit }\end{array}$ & \begin{tabular}{|c|}
$80 \%$ High \\
Limit
\end{tabular} & $\begin{array}{c}80 \% \text { Low } \\
\text { Limit }\end{array}$ & $\begin{array}{c}80 \% \text { High } \\
\text { Limit }\end{array}$ & $\begin{array}{c}80 \% \text { Low } \\
\text { Limit }\end{array}$ & $\begin{array}{c}80 \% \text { High } \\
\text { Limit }\end{array}$ & $\begin{array}{c}80 \% \text { Low } \\
\text { Limit }\end{array}$ & \begin{tabular}{|c|}
$80 \%$ High \\
Limit
\end{tabular} & $\begin{array}{c}80 \% \text { Low } \\
\text { Limit }\end{array}$ & \begin{tabular}{|c}
$80 \%$ High \\
Limit
\end{tabular} \\
\hline 12 a.m. & 18.95 & 25.95 & 18.95 & 25.95 & 18.95 & 25.95 & 18.95 & 25.95 & 18.95 & 25.95 & 18.95 & 25.95 & 18.95 & 25.95 \\
\hline 1 a.m. & 18.95 & 25.95 & 18.95 & 25.95 & 18.95 & 25.95 & 18.95 & 25.95 & 18.95 & 25.95 & 18.95 & 25.95 & 18.95 & 25.95 \\
\hline 2 a.m. & 18.95 & 25.95 & 18.95 & 25.95 & 18.95 & 25.95 & 18.95 & 25.95 & 18.95 & 25.95 & 18.95 & 25.95 & 18.95 & 25.95 \\
\hline 3 a.m. & 18.95 & 25.95 & 18.95 & 25.95 & 18.95 & 25.95 & 18.95 & 25.95 & 18.95 & 25.95 & 18.95 & 25.95 & 18.95 & 25.95 \\
\hline 4 a.m. & 18.95 & 25.95 & 18.95 & 25.95 & 18.95 & 25.95 & 18.95 & 25.95 & 18.95 & 25.95 & 18.95 & 25.95 & 18.95 & 25.95 \\
\hline 5 a.m. & 18.95 & 25.95 & 18.95 & 25.95 & 18.95 & 25.95 & 18.95 & 25.95 & 18.95 & 25.95 & 18.95 & 25.95 & 18.95 & 25.95 \\
\hline 6 a.m. & 18.95 & 25.95 & 18.95 & 25.95 & 18.95 & 25.95 & 18.95 & 25.95 & 18.95 & 25.95 & 18.95 & 25.95 & 18.95 & 25.95 \\
\hline 7 a.m. & 18.95 & 25.95 & 18.95 & 25.95 & 18.95 & 25.95 & 18.95 & 25.95 & 18.95 & 25.95 & 18.95 & 25.95 & 18.95 & 25.95 \\
\hline 8 a.m. & 18.95 & 25.95 & 18.95 & 25.95 & 18.95 & 25.95 & 18.95 & 25.95 & 18.95 & 25.95 & 18.95 & 25.95 & 18.95 & 25.95 \\
\hline 9 a.m. & 18.95 & 25.95 & 18.95 & 25.95 & 18.95 & 25.95 & 18.95 & 25.95 & 18.95 & 25.95 & 18.95 & 25.95 & 18.95 & 25.95 \\
\hline 10 a.m. & 18.95 & 25.95 & 18.95 & 25.95 & 18.95 & 25.95 & 18.95 & 25.95 & 18.95 & 25.95 & 18.95 & 25.95 & 18.95 & 25.95 \\
\hline 11 a.m. & 18.95 & 25.95 & 18.95 & 25.95 & 18.95 & 25.95 & 18.95 & 25.95 & 18.95 & 25.95 & 18.95 & 25.95 & 18.95 & 25.95 \\
\hline 12 p.m. & 18.95 & 25.95 & 18.95 & 25.95 & 18.95 & 25.95 & 18.95 & 25.95 & 18.95 & 25.95 & 18.95 & 25.95 & 18.95 & 25.95 \\
\hline 1 p.m. & 18.95 & 25.95 & 18.95 & 25.95 & 18.95 & 25.95 & 18.95 & 25.95 & 18.95 & 25.95 & 18.95 & 25.95 & 18.95 & 25.95 \\
\hline 2 p.m. & 18.95 & 25.95 & 18.95 & 25.95 & 18.95 & 25.95 & 18.95 & 25.95 & 18.95 & 25.95 & 18.95 & 25.95 & 18.95 & 25.95 \\
\hline 3 p.m. & 18.95 & 25.95 & 18.95 & 25.95 & 18.95 & 25.95 & 18.95 & 25.95 & 18.95 & 25.95 & 18.95 & 25.95 & 18.95 & 25.95 \\
\hline 4 p.m. & 18.95 & 25.95 & 18.95 & 25.95 & 18.95 & 25.95 & 18.95 & 25.95 & 18.95 & 25.95 & 18.95 & 25.95 & 18.95 & 25.95 \\
\hline 5 p.m. & 18.95 & 25.95 & 18.95 & 25.95 & 18.95 & 25.95 & 18.95 & 25.95 & 18.95 & 25.95 & 18.95 & 25.95 & 18.95 & 25.95 \\
\hline 6 p.m. & 18.95 & 25.95 & 18.95 & 25.95 & 18.95 & 25.95 & 18.95 & 25.95 & 18.95 & 25.95 & 18.95 & 25.95 & 18.95 & 25.95 \\
\hline 7 p.m. & 18.95 & 25.95 & 18.95 & 25.95 & 18.95 & 25.95 & 18.95 & 25.95 & 18.95 & 25.95 & 18.95 & 25.95 & 18.95 & 25.95 \\
\hline 8 p.m. & 18.95 & 25.95 & 18.95 & 25.95 & 18.95 & 25.95 & 18.95 & 25.95 & 18.95 & 25.95 & 18.95 & 25.95 & 18.95 & 25.95 \\
\hline 9 p.m. & 18.95 & 25.95 & 18.95 & 25.95 & 18.95 & 25.95 & 18.95 & 25.95 & 18.95 & 25.95 & 18.95 & 25.95 & 18.95 & 25.95 \\
\hline 10 p.m. & 18.95 & 25.95 & 18.95 & 25.95 & 18.95 & 25.95 & 18.95 & 25.95 & 18.95 & 25.95 & 18.95 & 25.95 & 18.95 & 25.95 \\
\hline 11 p.m. & 18.95 & 25.95 & 18.95 & 25.95 & 18.95 & 25.95 & 18.95 & 25.95 & 18.95 & 25.95 & 18.95 & 25.95 & 18.95 & 25.95 \\
\hline
\end{tabular}

Table 41: Autumn Adaptive Comfort Model Analysis

\begin{tabular}{|c|c|c|c|c|c|c|c|c|c|c|c|c|c|c|}
\hline \multicolumn{15}{|c|}{ Autumn Time - 20 May 2019} \\
\hline & \multicolumn{2}{|c|}{ Central West (A1) } & \multicolumn{2}{|l|}{ Central } & \multicolumn{2}{|c|}{ Central East (A3) } & \multicolumn{2}{|c|}{ South Wall (B1) } & \multicolumn{2}{|c|}{ East Wall (B2) } & \multicolumn{2}{|c|}{ North Wall (B3) } & \multicolumn{2}{|c|}{ West Wall (B4) } \\
\hline Time & $\begin{array}{c}80 \% \text { Low } \\
\text { Limit }\end{array}$ & $\begin{array}{c}80 \% \text { High } \\
\text { Limit }\end{array}$ & \begin{tabular}{c|}
$80 \%$ Low \\
Limit
\end{tabular} & $\begin{array}{c}80 \% \text { High } \\
\text { Limit }\end{array}$ & $\begin{array}{c}80 \% \text { Low } \\
\text { Limit }\end{array}$ & $\begin{array}{c}80 \% \text { High } \\
\text { Limit }\end{array}$ & $\begin{array}{c}80 \% \text { Low } \\
\text { Limit }\end{array}$ & $\begin{array}{c}80 \% \text { High } \\
\text { Limit }\end{array}$ & $\begin{array}{c}80 \% \text { Low } \\
\text { Limit }\end{array}$ & $\begin{array}{c}80 \% \text { High } \\
\text { Limit }\end{array}$ & \begin{tabular}{c|}
$80 \%$ Low \\
Limit
\end{tabular} & $\begin{array}{c}80 \% \text { High } \\
\text { Limit }\end{array}$ & \begin{tabular}{c|}
$80 \%$ Low \\
Limit
\end{tabular} & $\begin{array}{c}80 \% \text { High } \\
\text { Limit }\end{array}$ \\
\hline 12 a.m. & 18.95 & 25.95 & 18.95 & 25.95 & 18.95 & 25.95 & 18.95 & 25.95 & 18.95 & 25.95 & 18.95 & 25.95 & 18.95 & 25.95 \\
\hline 1 a.m. & 18.95 & 25.95 & 18.95 & 25.95 & 18.95 & 25.95 & 18.95 & 25.95 & 18.95 & 25.95 & 18.95 & 25.95 & 18.95 & 25.95 \\
\hline 2 a.m. & 18.95 & 25.95 & 18.95 & 25.95 & 18.95 & 25.95 & 18.95 & 25.95 & 18.95 & 25.95 & 18.95 & 25.95 & 18.95 & 25.95 \\
\hline 3 a.m. & 18.95 & 25.95 & 18.95 & 25.95 & 18.95 & 25.95 & 18.95 & 25.95 & 18.95 & 25.95 & 18.95 & 25.95 & 18.95 & 25.95 \\
\hline 4 a.m. & 18.95 & 25.95 & 18.95 & 25.95 & 18.95 & 25.95 & 18.95 & 25.95 & 18.95 & 25.95 & 18.95 & 25.95 & 18.95 & 25.95 \\
\hline 5 a.m. & 18.95 & 25.95 & 18.95 & 25.95 & 18.95 & 25.95 & 18.95 & 25.95 & 18.95 & 25.95 & 18.95 & 25.95 & 18.95 & 25.95 \\
\hline 6 a.m. & 18.95 & 25.95 & 18.95 & 25.95 & 18.95 & 25.95 & 18.95 & 25.95 & 18.95 & 25.95 & 18.95 & 25.95 & 18.95 & 25.95 \\
\hline 7 a.m. & 18.95 & 25.95 & 18.95 & 25.95 & 18.95 & 25.95 & 18.95 & 25.95 & 18.95 & 25.95 & 18.95 & 25.95 & 18.95 & 25.95 \\
\hline 8 a.m. & 18.95 & 25.95 & 18.95 & 25.95 & 18.95 & 25.95 & 18.95 & 25.95 & 18.95 & 25.95 & 18.95 & 25.95 & 18.95 & 25.95 \\
\hline 9 a.m. & 18.95 & 25.95 & 18.95 & 25.95 & 18.95 & 25.95 & 18.95 & 25.95 & 18.95 & 25.95 & 18.95 & 25.95 & 18.95 & 25.95 \\
\hline 10 a.m. & 18.95 & 25.95 & 18.95 & 25.95 & 18.95 & 25.95 & 18.95 & 25.95 & 18.95 & 25.95 & 18.95 & 25.95 & 18.95 & 25.95 \\
\hline 11 a.m. & 18.95 & 25.95 & 18.95 & 25.95 & 18.95 & 25.95 & 18.95 & 25.95 & 18.95 & 25.95 & 18.95 & 25.95 & 18.95 & 25.95 \\
\hline 12 p.m. & 18.95 & 25.95 & 18.95 & 25.95 & 18.95 & 25.95 & 18.95 & 25.95 & 18.95 & 25.95 & 18.95 & 25.95 & 18.95 & 25.95 \\
\hline 1 p.m. & 18.95 & 25.95 & 18.95 & 25.95 & 18.95 & 25.95 & 18.95 & 25.95 & 18.95 & 25.95 & 18.95 & 25.95 & 18.95 & 25.95 \\
\hline 2 p.m. & 18.95 & 25.95 & 18.95 & 25.95 & 18.95 & 25.95 & 18.95 & 25.95 & 18.95 & 25.95 & 18.95 & 25.95 & 18.95 & 25.95 \\
\hline 3 p.m. & 18.95 & 25.95 & 18.95 & 25.95 & 18.95 & 25.95 & 18.95 & 25.95 & 18.95 & 25.95 & 18.95 & 25.95 & 18.95 & 25.95 \\
\hline 4 p.m. & 18.95 & 25.95 & 18.95 & 25.95 & 18.95 & 25.95 & 18.95 & 25.95 & 18.95 & 25.95 & 18.95 & 25.95 & 18.95 & 25.95 \\
\hline 5 p.m. & 18.95 & 25.95 & 18.95 & 25.95 & 18.95 & 25.95 & 18.95 & 25.95 & 18.95 & 25.95 & 18.95 & 25.95 & 18.95 & 25.95 \\
\hline 6 p.m. & 18.95 & 25.95 & 18.95 & 25.95 & 18.95 & 25.95 & 18.95 & 25.95 & 18.95 & 25.95 & 18.95 & 25.95 & 18.95 & 25.95 \\
\hline 7 p.m. & 18.95 & 25.95 & 18.95 & 25.95 & 18.95 & 25.95 & 18.95 & 25.95 & 18.95 & 25.95 & 18.95 & 25.95 & 18.95 & 25.95 \\
\hline 8 p.m. & 18.95 & 25.95 & 18.95 & 25.95 & 18.95 & 25.95 & 18.95 & 25.95 & 18.95 & 25.95 & 18.95 & 25.95 & 18.95 & 25.95 \\
\hline 9 p.m. & 18.95 & 25.95 & 18.95 & 25.95 & 18.95 & 25.95 & 18.95 & 25.95 & 18.95 & 25.95 & 18.95 & 25.95 & 18.95 & 25.95 \\
\hline 10 p.m. & 18.95 & 25.95 & 18.95 & 25.95 & 18.95 & 25.95 & 18.95 & 25.95 & 18.95 & 25.95 & 18.95 & 25.95 & 18.95 & 25.95 \\
\hline 11 p.m. & 18.95 & 25.95 & 18.95 & 25.95 & 18.95 & 25.95 & 18.95 & 25.95 & 18.95 & 25.95 & 18.95 & 25.95 & 18.95 & 25.95 \\
\hline
\end{tabular}


The PMV/PPD comfort calculations indicate that there was variation in thermal comfort between the horizontal and vertical sensors. This variation was as a result of differences in air temperature. However, the adaptive comfort analysis indicates that the variation between sensor points was within the $18-25^{\circ} \mathrm{C}$ comfort threshold. "Variations which are under the direct control of the individual occupants do not have a negative impact on thermal comfort, but variations that occur due to factors not under the direct control of occupants could negatively affect comfort" (ANSI/ASHRAE55-2004, 2004). However, and as long as the variations are within the comfort zone, air temperature variations that are experienced by occupants as a result of moving from one location to another with different environmental conditions are allowed (ANSI/ASHRAE55-2004, 2004). The studied classrooms were naturally ventilated and under the direct control of the staff and students who adjusted their windows, switch on and off their heating systems to regulate internal temperatures to suit their comfort. Heat losses depend on metabolic activity and body surface area. The literature suggested that children generally have a higher metabolic rate. Metabolic rate for children 5-6 years is 1.39 met, and 7-12 years is 1.2 met with an average body surface area of $1.68 \mathrm{ADU}\left(\mathrm{m}^{2}\right)$ and Met is the unit of metabolism that equivalent to $58.15 \mathrm{~W} / \mathrm{m} 2$ per body surface area (Ahmed et al., 2017). The authors suggested that because the set point of indoor temperature and humidity levels depend on the seasons, seasonal effect are to be accounted for in estimating the heat losses from occupant's body. Solar heat gain was observed to be a major source of thermal variation across the space and the intensity and movement of the sun at a point are factors that are not under the direct control of occupants. Therefore, it can be inferred that a $2^{\circ} \mathrm{C}$ variation of temperature in the studied classroom could have an impact on the comfort of occupants depending on their location within the space, usage of the space and the time of the day. But a $<7 \%$ relative humidity variation is considered to have no impact on thermal comfort. This is affirmed by Fanger, $(1971,1982)$ who conducted field experiments using surveys and physical measurements in 26 air-conditioned and 10 naturally ventilated classrooms and found that humidity had a minimal impact on thermal comfort. 


\subsubsection{Thermal Measurement Discussion}

To understand the thermal performance of a classroom, the reliable prediction of temperature and relative humidity is important. The results of all three case studies and across all seasons indicated that at some point in time, especially during the morning hours, the line graphs temperature and relative humidity trends showed a similar pattern between the horizontal measuring plane sensors and the vertical wall sensors. However, depending on the time of the day, especially after mid-day, there were variations between horizontal and vertical sensors. For example, in case study one, sensors closer to the windows especially the west-facing sensors showed variations in their resulting temperature and relative humidity levels in the afternoons. This was observed to be due to the intensity and angle of the sun, which penetrated the space thereby resulting in high solar gains. In summer, in case study one, sensor A1, B1 and B2 had higher temperature values due to the location of the sensors. Sensor B1 and B2 were located relatively under the skylight and received high levels of solar gain especially after mid-day. On a relatively sunny day with reasonable solar control, solar gain and ambient heat sources could generally add an average of 25 Watts per square metre $\left(\mathrm{W} / \mathrm{m}^{2}\right)$ to a space, depending on the climate (Chatzidiakou et al., 2012). During spring and in case study three, sensor A2 (Central) recorded an average temperature of $19^{\circ} \mathrm{C}$ around $12 \mathrm{pm}$ while sensor $\mathrm{B} 3$ (North) recorded $15^{\circ} \mathrm{C}$ (outdoor temperature was $15^{\circ} \mathrm{C}$ ) which equates to a $4^{\circ} \mathrm{C}$ difference. This difference was observed to be because sensor B3 was positioned close to the large glazed door which was usually open during periods of occupancy in warm days and the airflow from the large opening resulted in temperature levels that were relatively close to outdoor levels at sensor B3. This trend indicates that due to the influence of heat sources such as the sun, and occupant's usage of a space such as the opening of doors and windows to allow for airflow, there is a variation of temperature levels across a space. However, spaces that are not impacted by these factors will have a stronger relationship between the horizontal measuring plane sensors and the vertical wall sensors.

The daily average results indicated that the difference between the horizontal measuring plane sensor A2 and the highest or lowest vertical wall sensor was largely $<2^{\circ} \mathrm{C}$ and relative humidity was $<7 \%$. Hence, the PMV/PPD and adaptive comfort models were used to explore whether this variation influences comfort. The PMV/PPD comfort calculations indicated that there was 
variation in thermal comfort between the horizontal and vertical sensors and this variation was as a result of differences in air temperature between sensor points. For example, around 8 am, sensor A2 recorded a PPD of $13 \%$ while sensor $B 3$ recorded a PPD of $7 \%$ which is nearly half of sensor A2. This variation between the horizontal and vertical sensors argue that one sensor is not representative of the thermal condition of a space. But the adaptive comfort analysis indicated that the variation was within the $18-25^{\circ} \mathrm{C}$ comfort threshold. The three case study classrooms were naturally ventilated and given that the intensity and movement of the sun (factors that are not under the direct control of occupants) was a major source of thermal variation, there is potential for uneven levels of comfort across the space. Even when the air temperature is within acceptable limits, occupants will most likely feel discomfort depending on their location within the space, their usage of the space and the time of the day. This can be due to direct sunlight or hot or cold windows or heat transfer from walls or ceiling.

The scenario described by this experiment is that;

- In the case study classrooms, there were areas and times of the day that were influenced by solar gain which resulted in variation in temperature and relative humidity in the various sensors. The classrooms gained heat throughout the day from a combination of using heaters, heat from the occupants and solar radiant heat. Figure 70 shows an electric heater used in case study one classroom. It was observed that mostly during the afternoons when the sun moves towards the west for the summer and during the period of occupancy for the autumn time when heaters are switched on, there was variation between horizontal and vertical sensors. This implies that the season, the movement of the sun, the amount of cloud cover, day length, elevation, wind speed, the time of year and the use of heating systems resulted in the diurnal variation of temperature across a space. In meteorology, the word "diurnal" generally refers to changes in temperature from high levels during the day to low levels at night. These factors have the potential to widen or lessen the variation range. 


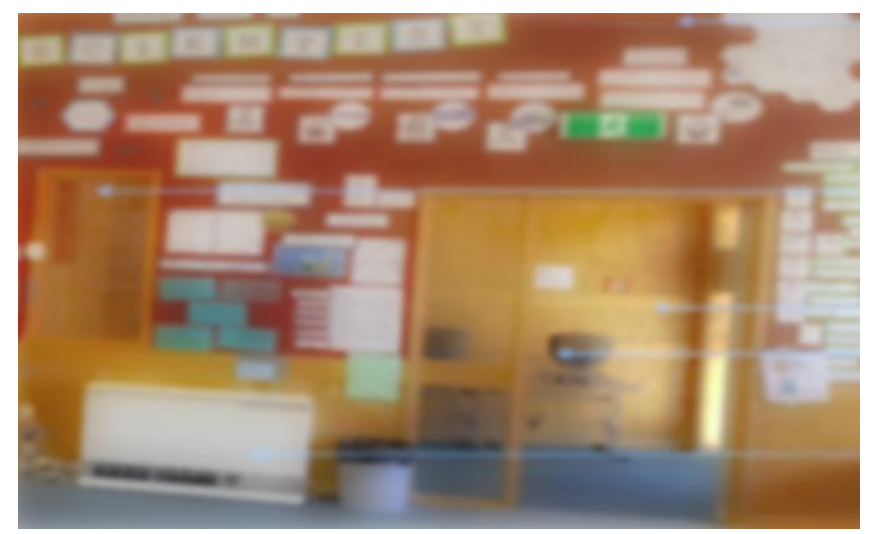

Figure 70: Images showing the heating system used in the classroom

For example, as soon as the classroom is occupied in the morning hours, the results indicated that the temperature increased by up to $5^{\circ} \mathrm{C}$. While this could be due to the heat from the occupants, a study by Chatzidiakou, et al, (2012) state that in most learning environments, solar gain and inside/outside heat transfer are significant sources of incidental heat. Szokolay, (2008) concurs that there is a risk of overheating by solar radiation which is important to consider when analysing the thermal comfort of individuals sitting near glazed areas. Givoni, (1969) stated that "the influence of solar radiation on indoor temperatures is due to indoor heating which is caused by penetration of radiation through glazed or open areas and the effect on temperatures on the external surfaces and roof, and the resulting heat flow". Hence, controlling the impact of solar radiation involves addressing a building orientation, external colour, and the shading of windows and other surface areas (Givoni, 1969). Therefore, an analysis of the sunshine duration and sun-path diagram to depict the sun's apparent movement becomes necessary to consider when using a single temperature and relative humidity sensor to determine the thermal performance of a building.

- The variance in temperature and relative humidity of the sensors around the glazed areas also suggested that the building characteristics such as the size, position and orientation of windows affect sun penetration, thus solar heat input. Szokolay, (2008) states that solar heat gain is influenced not only by surface properties but also by the shape and orientation of the building and design variables that have the greatest influence on the thermal performance of a building are shape, fabric, fenestration and ventilation. While 
solar heat gain could be beneficial during the winter season, but not under warm conditions (summer season), due to the likelihood of discomfort.

- It was also observed that during occupied hours and besides solar heat gain, the temperature levels increased as soon as students arrive by 9 am and during the break time by 11:30 pm, when the students go outdoors to play, the temperature decreases. However, on return from break, the temperature increases again. Given that children have a high metabolic rate, this suggests that heat generated from the body contributed to the overall temperature levels during the school days. Hence, it can be inferred that occupancy, activity levels and the use of equipment within a classroom could contribute to the variation of temperature within a space. Through metabolic processes, the human body continuously produces heat. Studies (Almeida et al., 2016; Hayakawa et al., 1989; Szokolay, 2008) state that the heat output of an average body is often taken as $100 \mathrm{~W}$, but it can vary from over $700 \mathrm{~W}$ in heavy work or vigorous activity (e.g. playing football) to as low as about $70 \mathrm{~W}$ (in sleep). In occupied classrooms, this heat is dissipated to the environment and influences an increase in temperature within the space. Students and teachers are estimated to generate about 60 to $80 \mathrm{~W}$ of heat energy respectively when seated, an equivalent of about $30 \mathrm{~W} / \mathrm{m}^{2}$ of peak heat gain released into the classroom (Chatzidiakou et al., 2012). Also, equipment such as tablets, laptops, TV screens, results in many small heating sources distributed throughout the learning space. This was evident in the high temperature levels pattern in sensor A1 which was relatively close to the glazed area and had high occupancy levels around the sensor and a TV screen. Furthermore, around $6 \mathrm{~W} / \mathrm{m}^{2}$ of heat energy could be released through artificial lights into the learning environment (Chatzidiakou et al., 2012).

The aim of this chapter was to establish with measurements whether a one-point sensor can be representative of the thermal condition (temperature and relative humidity) of a space. Depending on the location of a sensor within a space, and the nearness to heating or cooling sources, the temperature and humidity levels across a space may not be consistent. Therefore, it is difficult for a one-point sensor measurement to be representative of the temperature and relative humidity levels across an entire space. But the comparative ratio analysis results have 
shown that a one-point sensor on the vertical wall can reliably predict the thermal condition at the centre of a space for more than $80 \%$ of the time and this proxy can be used to triage good and poor thermal conditions in classrooms.

\subsubsection{How to use a One-Point Sensor for Thermal Performance Prediction}

The measurement and analysis of temperature and relative humidity is useful in assessing the thermal performance of a building to inform design decisions that are climate response. The commonly referenced design goal limits for temperature levels is $18^{\circ} \mathrm{C}$ to $25^{\circ} \mathrm{C}$ and for relative humidity is $45 \%$ to $70 \%$. As shown in the study results, during periods of occupancy, temperature levels will usually increase owing to different sources of heat such as heat generated by occupants, from equipment's and the level of solar radiation penetrating the space. The results of comparing temperature and relative humidity levels measured with sensors placed on the horizontal working plane with that of sensors placed on the vertical walls indicated that:

- Due to the influence of heat sources such as the sun, and occupant's usage of a space such as the opening of doors and windows to allow for airflow there is a variation of temperature and humidity levels from one part of a space to another

- The extent of variation was determined through the daily average results which showed that the difference between the horizontal measuring plane sensor $\mathrm{A} 2$ and the highest or lowest vertical wall sensor was largely $<2{ }^{\circ} \mathrm{C}$ and could vary up to $\pm 4^{\circ} \mathrm{C}$ under the factors influencing variability while relative humidity was $<7 \%$

- The PMV/PPD comfort calculations indicated that there was variation in thermal comfort between the horizontal and vertical sensors and this variation was as a result of differences in air temperature between sensor points. But the adaptive comfort analysis indicated that the variation was within the $18-25^{\circ} \mathrm{C}$ comfort threshold

- The variation between the horizontal and vertical sensors argue that one sensor is not representative of the thermal condition across a space and occupants will most likely feel discomfort depending on their location within the space, their usage of the space and the time of the day 
- But the analysis showed that while one sensor is not ideal for measuring thermal condition across a space, if a sensor is placed away from glazed areas, in locations that are not exposed to direct irradiation from the sun, avoiding radiators and cooling systems, lighting sources, and from thermal sources such as the human body, a strategically positioned one-point sensor located at a $1.5 \mathrm{~m}$ height on the vertical wall can provide indicative data about the thermal condition of a space

- When using a one-point sensor measurement to identify good and poor thermal conditions in classrooms, the building characteristics (such as a double or one-side lit space, window configuration and orientation) should be analysed in conjunction with the measured temperature and relative humidity data

- For example, in Figure 71, a typical classroom plan was used (two-side lit, and one-lit plans) to illustrate how a one-point sensor could be deployed for reliable thermal performance prediction in simple classroom forms

- This approach can't be used to accurately predict the distribution of temperature and relative humidity for different designs in different locations but provide a good indication of how to use a limited number of sensors to measure thermal condition in a space

- Accurate thermal condition predictions for different designs and specific locations will require the use of more than one sensor 


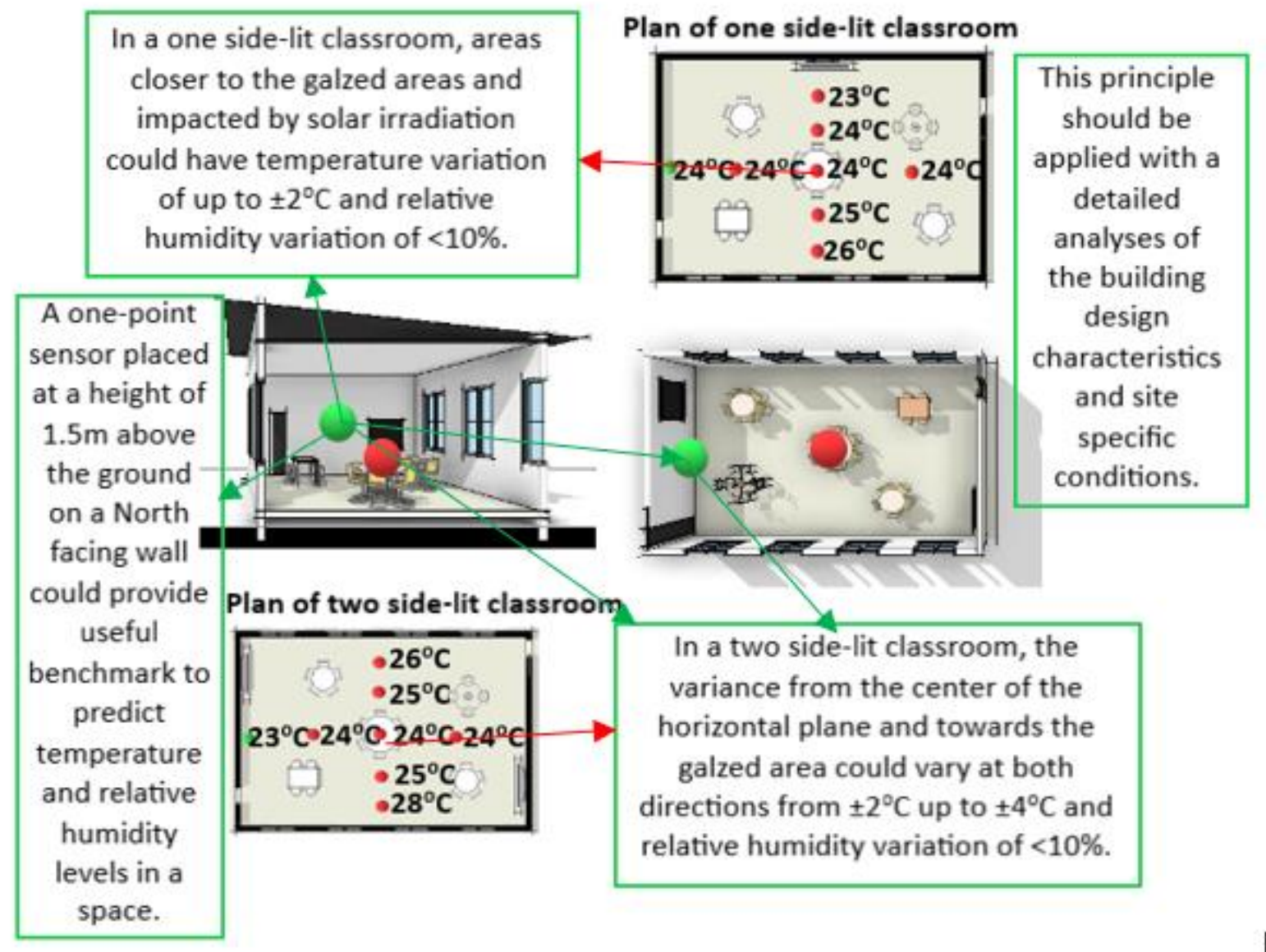

Figure 71: Images showing illustration of how to use a one-point sensor for thermal performance prediction 


\section{CHAPTER SEVEN: CAN A ONE-POINT SENSOR PREDICT THE SOUND}

\section{LEVELS IN A CLASSROOM?}

\subsection{Physical Measurement of Sound Level Distribution in the Case Study Classrooms}

The sound level results were obtained by in situ measurements of ambient noise inside the classrooms and expressed by the continuous equivalent sound level, LAeq, in dBA. In case study one, external noise levels were also measured both in autumn and in summer. Observation of space usage was also documented. The goal of this section was to investigate if a one-point sensor can predict the distribution of sound levels in a classroom, and where might be the most representative placement of a one-point sensor within a classroom. While Chapters 5 and 6 focused only on the lighting and thermal performance variables, this Chapter advances into the adequacy of using a one-point sensor to assess the sound levels of classrooms at scale.

\subsubsection{Non-School Days Sound Levels Analysis}

In Figure 72, the non-school days were analysed to explore the relationship between horizontal measuring plane sensors and vertical wall sensors. In all three case studies and different seasons, the line graphs show a pattern of variation between horizontal measuring plane sensors and vertical wall sensors. For example, during autumn in case study one, the sound levels of horizontal sensor A2 was about $35 \mathrm{dBA}$ while that of the vertical sensor B3 was largely $<35 \mathrm{dBA}$. However, during the summer, the variation between horizontal and vertical sensors appeared not so great. The sound levels in most of the sensor points were largely within 40 to $45 \mathrm{dBA}$ (typical background noise levels in unoccupied spaces). During the autumn, the sound levels increased at some point in time and this could likely be due to the impact of rain and wind noise. It was observed that the reason for higher background noise levels in case study three was due to noise generated from the server, which was located within the classroom. The extent of variation was explored further in the statistical analysis in Section 7.1.4. Data for one set of sensor readings were removed from case study one and two, but this sensor was in different positions in the monitored classrooms (this was sensor B4 in the autumn and B3 in the summer for case study one and sensor B3 in case study two). 


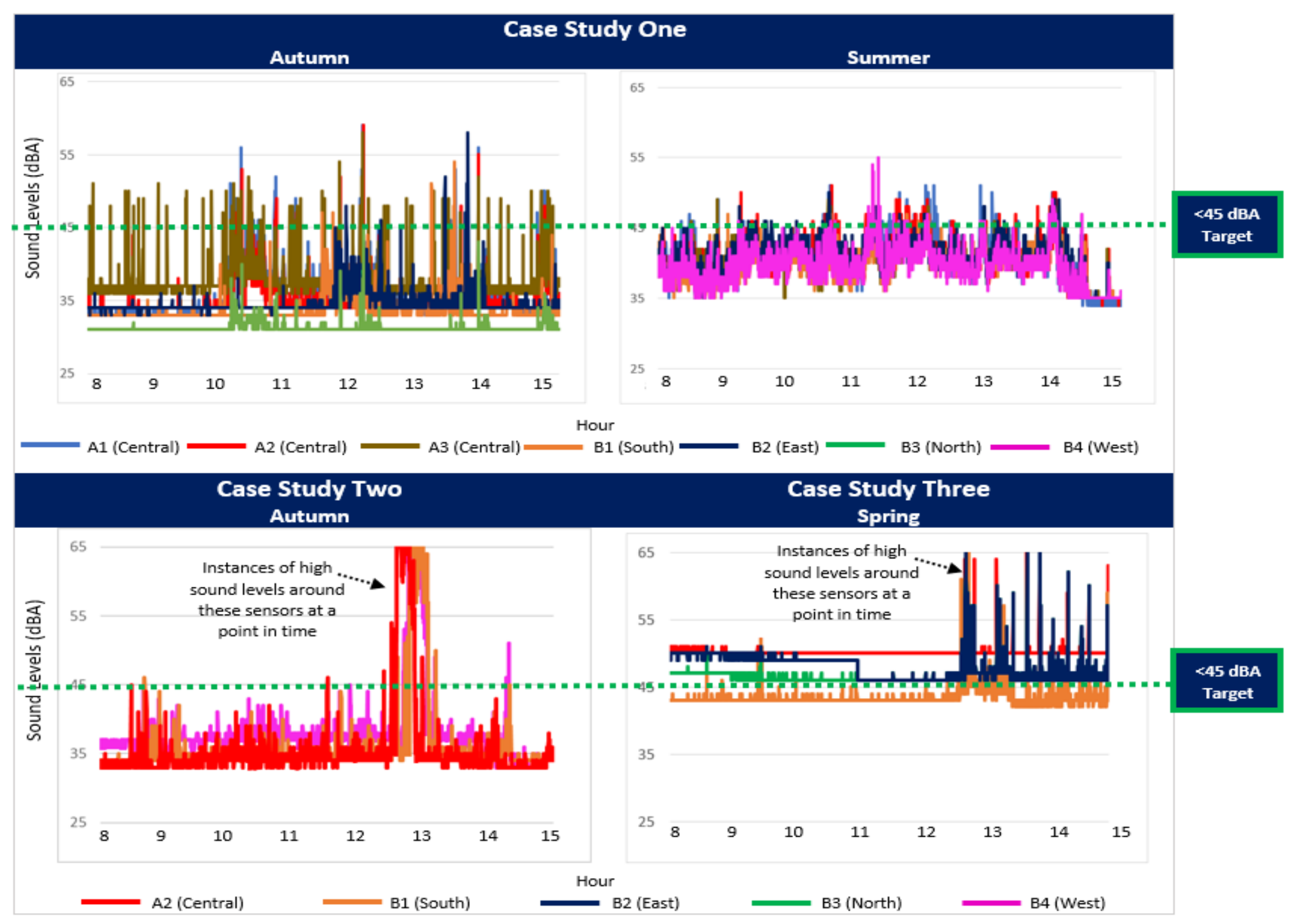

Figure 72: Line graphs showing sound levels between 8 am - 3 pm during non-school days (A sensors horizontal, on the working plane; B sensors vertical, on adjacent wall) 
In Figure 73, the sound level sparkline pattern also showed variations between horizontal measuring plane sensors and vertical wall sensors. For example, during the autumn in case study one, the sound level pattern of sensor A2 appears different from that of vertical wall sensors B3 (sensor A2 appears to show higher sound levels when compared to the visual pattern of B3). However, in case study two, the sound level pattern variation between these two sensors seems not so great. These trends suggest that a one-point sensor sound level measurement may not be representative of the sound levels in an unoccupied space.

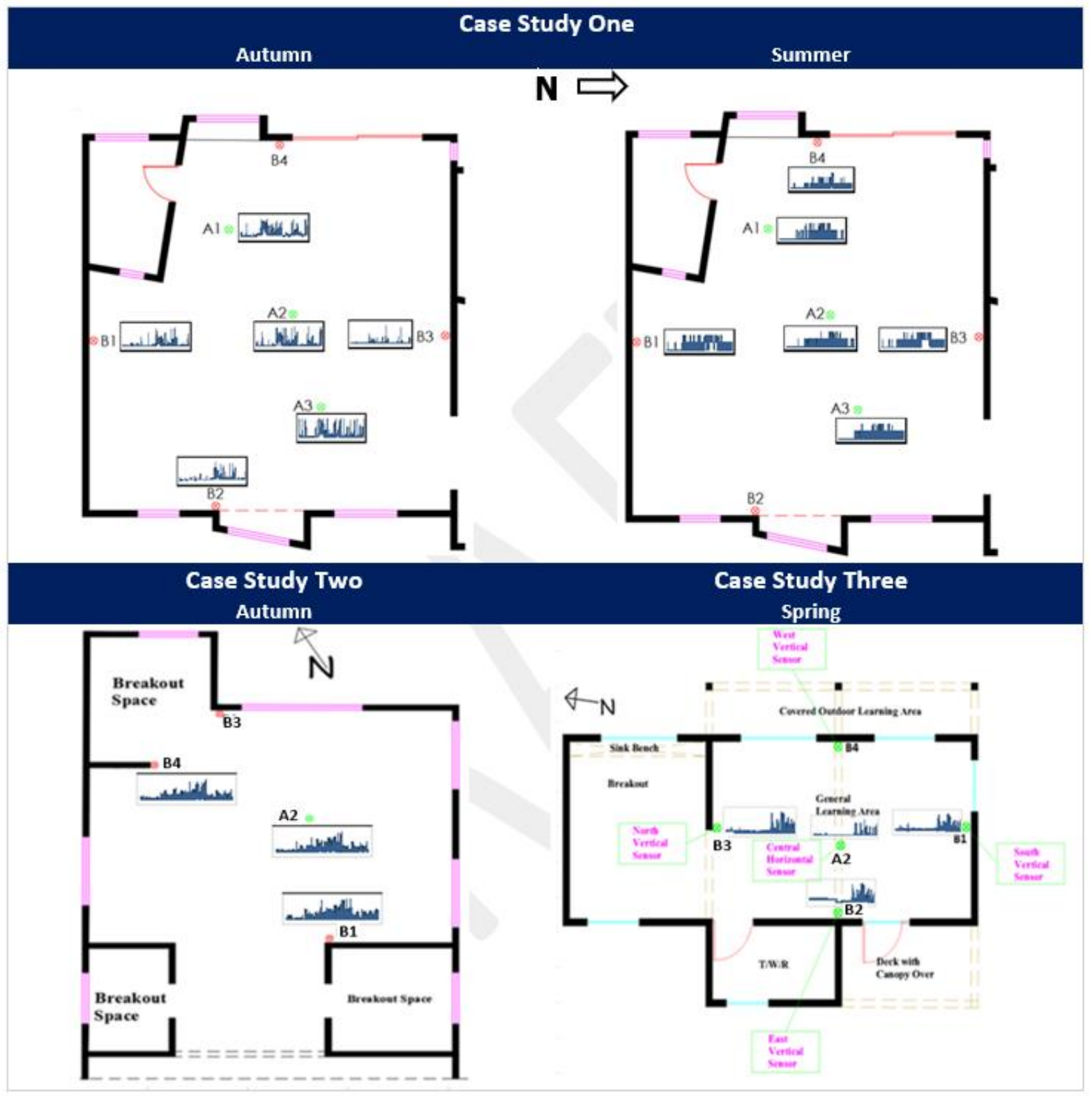

Figure 73: Sparklines showing sound level visual patterns between 8 am to $3 \mathrm{pm}$ in the non-school days 


\subsubsection{School Days Sound Levels Analysis}

In Figure 74, the school days were analysed to explore the relationship between horizontal measuring plane sensors and vertical wall sensors. Unlike the non-school days, the horizontal measuring plane sensors show a similar pattern with the vertical wall sensors. The rise and fall of sound levels followed the same trend across all sensors. For example, around $8 \mathrm{am}$, the sound levels significantly increased from $46 \mathrm{dBA}$ to above $65 \mathrm{dBA}$ in some days especially during the autumn time. In the summer, the sound levels in the classroom appeared $<70 \mathrm{dBA}$, which corresponds to the typical activity noise levels within an occupied classroom. However, during the autumn where occupants were mostly within the space for a long period, the sound levels were higher than $75 \mathrm{dBA}$. These findings are coherent with the literature which suggested that occupied classrooms usually have a sound level range of 50-70 dBA. In Wilson et al., (2002), the researchers found that in New Zealand classrooms, "the average noise levels of 55 dBA were measured in "quiet" classrooms and sound levels of $77 \mathrm{dBA}$ with pupils working". On-site observation revealed that the building occupants and the type of activity carried out were the major source of noise within the space. For example, during the autumn measurement observation in case study one, and around 10:00 am it was observed that noise from the television set distracted some of the students and at around 10:44 am students were involved in a reading activity and around break time (11:30-12 pm), there was a decrease in sound levels. During the summer period, it was observed that external noise from students playing in the school field impacted on the internal sound levels in the classroom due to open windows and doors. New Zealand classrooms are mostly naturally ventilated via openable windows, which result in fluctuations in occupied day's classroom noise levels due to the influence of intermittent external noise sources. The rise and fall in sound levels during the day appeared to be consistent and interrelated across the various sensor points. Given that measuring the closeness of one line to another is not just a visual scan, the extent of the variation or relationship identified in the line graphs is further explored using statistical analysis in the next section below. 


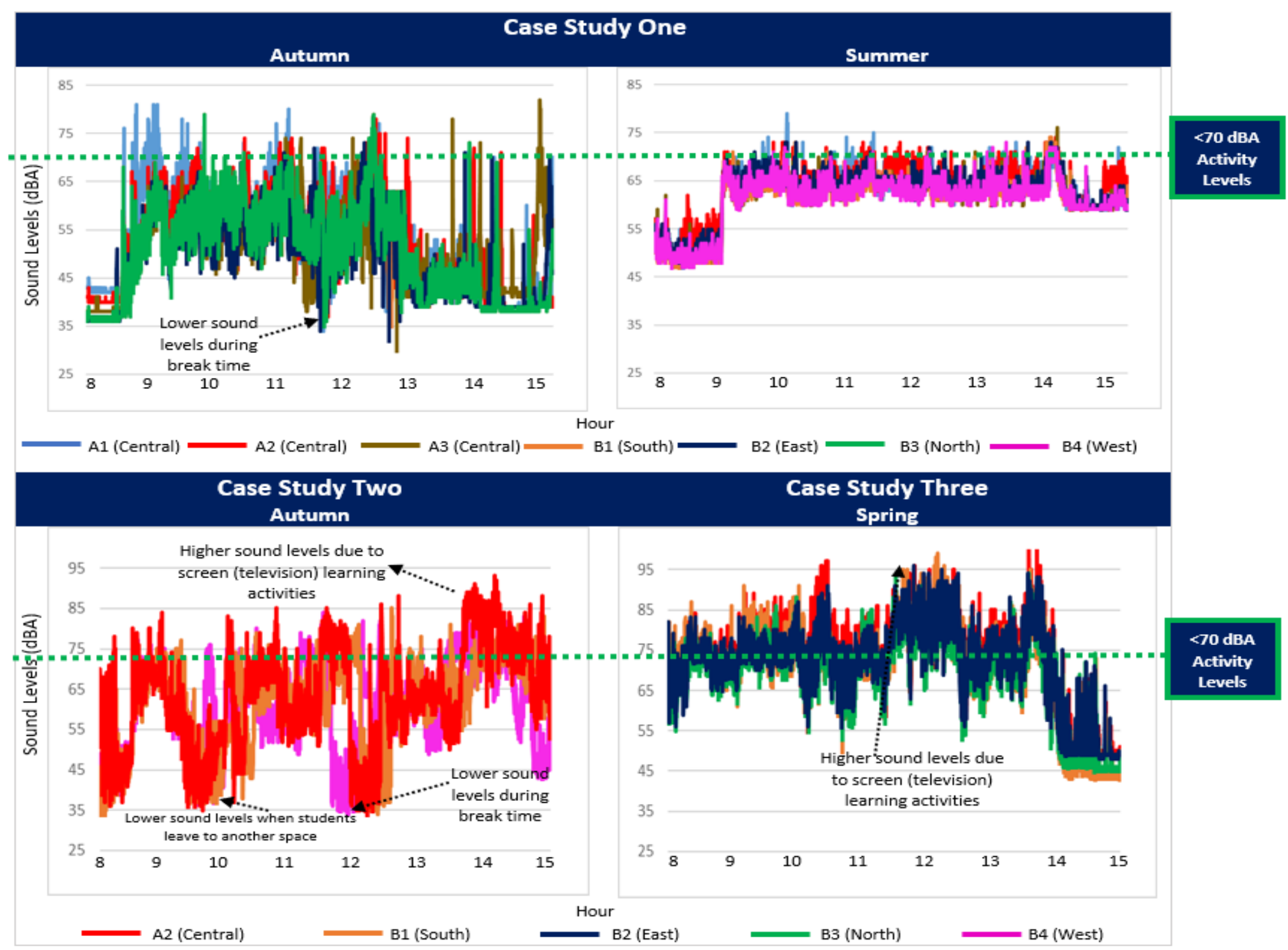

Figure 74: Line graphs showing sound levels between 8 am - 3 pm during school days (A sensors horizontal, on the working plane; B sensors vertical, on adjacent wall) 
In Figure 75, and compared to the non-school days, the sound level pattern of the horizontal measuring plane sensors is like that of the vertical wall sensors, in all seasons. For example, the horizontal plane sensors (A1-3) shows patterns of relationship with the vertical wall sensors (B1 - 4) in all three case studies and all seasons. This period was a weekday, the space was occupied, and there was a movement in and out of the space and across spaces. These trends illustrate that in an occupied classroom, a one-pint sensor on the vertical wall may be useful to predict sound levels on the horizontal measuring plane.

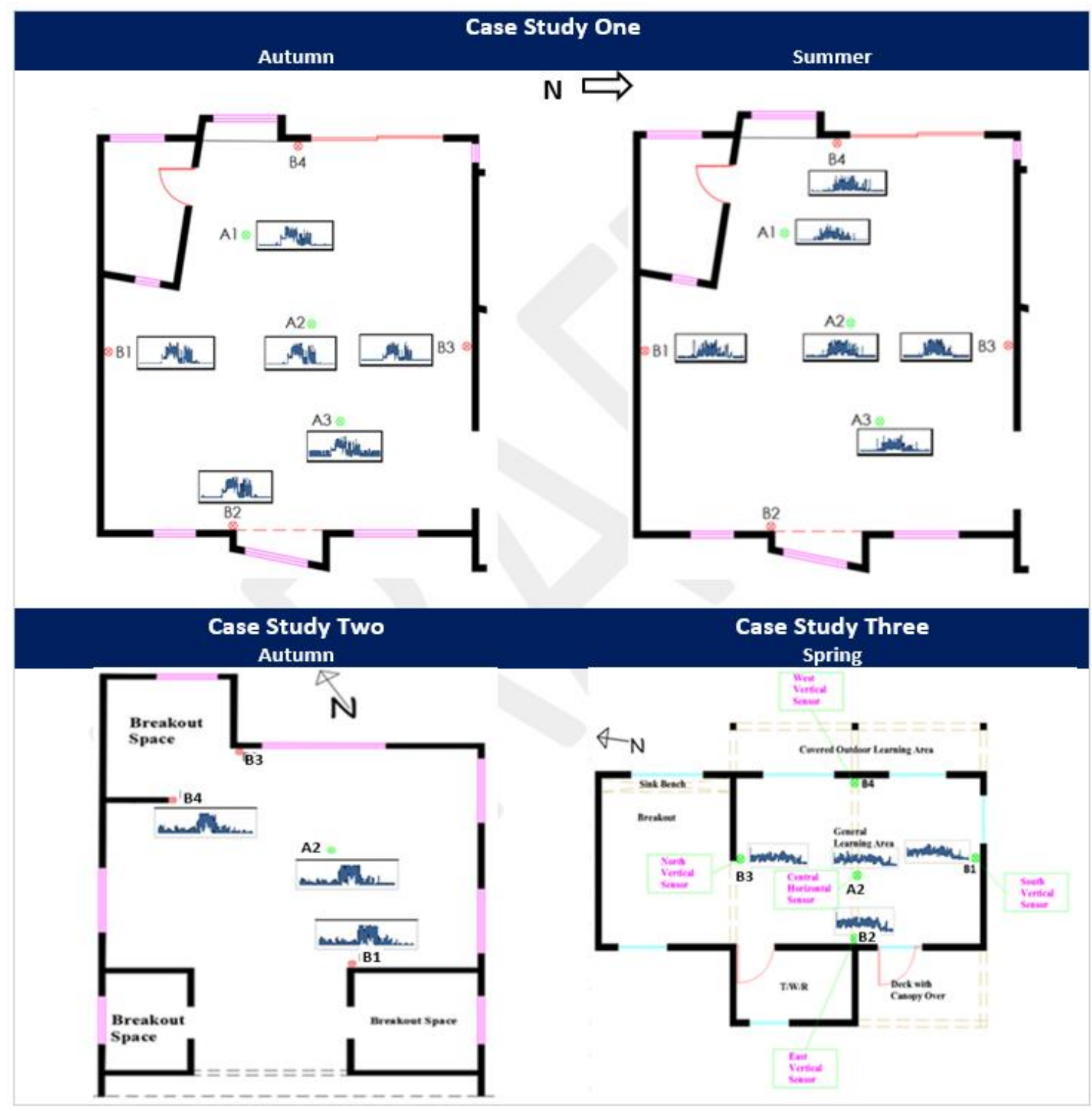

Figure 75: Sparklines showing sound level visual patterns between 8 am to 3 pm in the school days 


\subsubsection{Sound Levels Comparative Ratio Analysis}

As with temperature, a ratio analysis was also used to compare the relationship between sound levels in the central horizontal measure plane sensor with that of the vertical wall sensor.

In Tables 42 to 44 and Figures, 76 to 78 below, the values recorded on the central horizontal sensor A2 was divided by the values on the vertical wall sensors B1-B4. The frequency of the data was categorised into four bins depending on the ratio of change between the two compared variables and percentages were used to describe the fold change.

In Tables 42 to 44 and Figures 76 to 78 the relationship between the horizontal plane and vertical wall sensors was $80 \%$ of the time consistent around a ratio of $1.0-1.5$, which indicated that a vertical wall sensor can reliably predict the sound levels at the centre of a classroom. However, during instances of more frequent and higher noise levels like in case study two, autumn, the ratio appeared larger, which indicates a larger variation in sound levels across a space, compared to lower noise levels. These instances of random and high noise level could be due to noise generated by occupants, given that this was autumn and it was observed that the occupants spent most of their time indoors, even during their break time.

Hence, provided the factors of sound level variability (Section 8.2) are taken into account, a vertical wall sensor can predict sound levels at the centre of a space and can assist with the diagnosis of patterns when measuring sound levels in many school buildings. The application of these findings to identify good and poor acoustic conditions is discussed in detail in Section 7.1.5 below. 


\section{CASE STUDY ONE - SUMMER}

Table 42: Ratio Analysis comparing the relationship between sound levels at the central horizontal sensor A2 with vertical wall sensors B1-4 respectively

\begin{tabular}{|c|c|c|c|c|c|c|c|c|}
\hline \multirow[b]{2}{*}{ Bin } & \multicolumn{2}{|c|}{ A2(Central)/B1(South) } & \multicolumn{2}{|c|}{ A2(Central) /B2(East) } & \multicolumn{2}{|c|}{ A2(Central) /B3(North) } & \multicolumn{2}{|c|}{ A2(Central)/B4(West) } \\
\hline & Frequency & Percentages & Frequency & Percentages & Frequency & Percentages & Frequency & Percentages \\
\hline $0.5-0.99$ & 8 & $0 \%$ & 609 & $24 \%$ & 17 & $1 \%$ & 17 & $1 \%$ \\
\hline $1.0-1.19$ & 691 & $27 \%$ & 1740 & $69 \%$ & 1359 & $54 \%$ & 739 & $29 \%$ \\
\hline $1.2-1.5$ & 1824 & $73 \%$ & 174 & $7 \%$ & 1145 & $45 \%$ & 1767 & $70 \%$ \\
\hline$>1.5$ & 0 & $0 \%$ & 0 & $0 \%$ & 0 & $0 \%$ & 0 & $0 \%$ \\
\hline
\end{tabular}

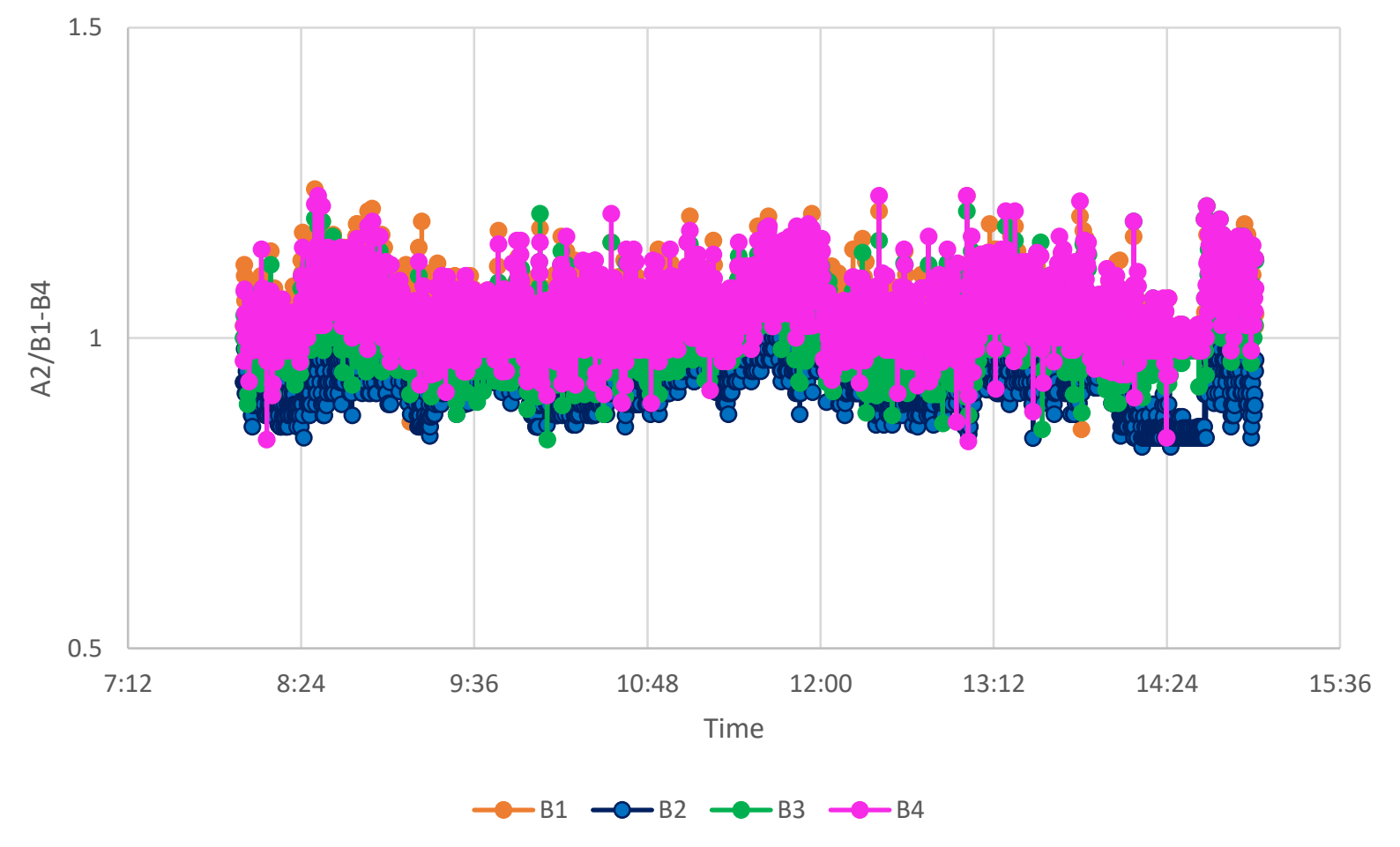

Figure 76: Comparison of ratio between horizontal and vertical sensors 


\section{CASE STUDY TWO - AUTUMN}

Table 43: Ratio Analysis comparing the relationship between sound levels at the central horizontal sensor A2 with vertical wall sensors B1-4 respectively

\begin{tabular}{|c|c|c|c|c|c|c|c|c|}
\hline \multirow[b]{2}{*}{ Bin } & \multicolumn{2}{|c|}{ A2(Central)/B1(South) } & \multicolumn{2}{|c|}{ A2(Central) /B2(East) } & \multicolumn{2}{|c|}{ A2(Central) /B3(North) } & \multicolumn{2}{|c|}{ A2(Central)/B4(West) } \\
\hline & Frequency & Percentages & Frequency & Percentages & Frequency & Percentages & Frequency & Percentages \\
\hline $0.5-0.99$ & 44 & $2 \%$ & 72 & $3 \%$ & 9 & $0 \%$ & 626 & $27 \%$ \\
\hline $1.0-1.19$ & 756 & $32 \%$ & 772 & $33 \%$ & 139 & $6 \%$ & 758 & $32 \%$ \\
\hline $1.2-1.5$ & 1527 & $65 \%$ & 1450 & $62 \%$ & 2030 & $86 \%$ & 939 & $40 \%$ \\
\hline$>1.5$ & 27 & $1 \%$ & 61 & $3 \%$ & 177 & $8 \%$ & 32 & $1 \%$ \\
\hline
\end{tabular}

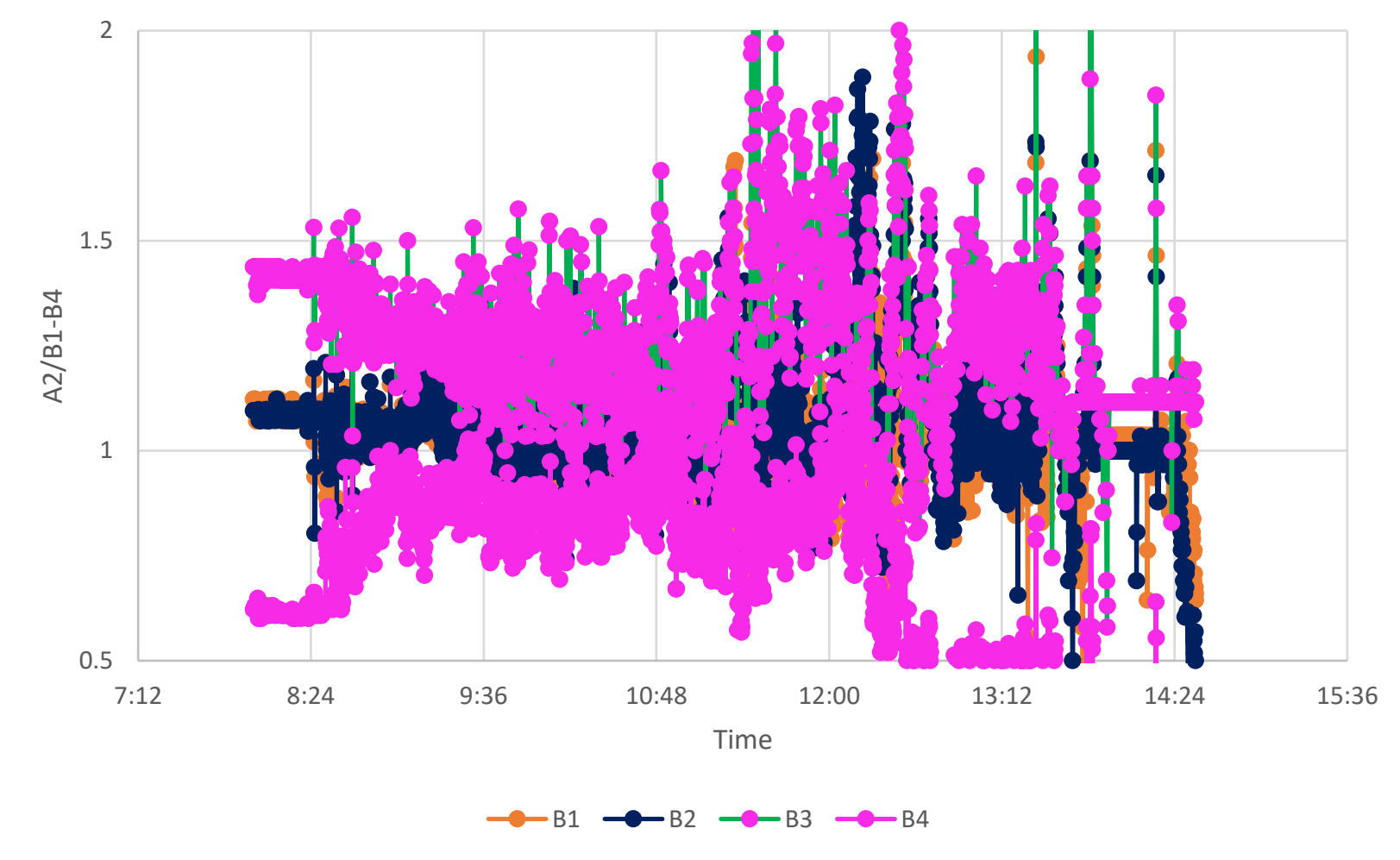

Figure 77: Comparison of ratio between horizontal and vertical sensors 


\section{CASE STUDY THREE - SPRING}

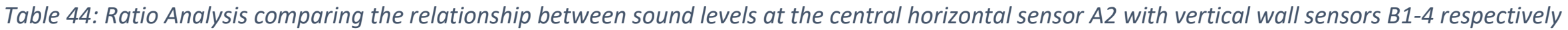

\begin{tabular}{|c|c|c|c|c|c|c|}
\hline \multirow[b]{2}{*}{ Bin } & \multicolumn{2}{|c|}{ A2(Central)/B1(South) } & \multicolumn{2}{|c|}{ A2(Central) /B2(East) } & \multicolumn{2}{|c|}{ A2(Central) /B3(North) } \\
\hline & Frequency & Percentages & Frequency & Percentages & Frequency & Percentages \\
\hline $0.5-0.99$ & 86 & $3 \%$ & 66 & $3 \%$ & 52 & $2 \%$ \\
\hline $1.0-1.19$ & 473 & $19 \%$ & 643 & $26 \%$ & 408 & $16 \%$ \\
\hline $1.2-1.5$ & 1860 & $74 \%$ & 1752 & $69 \%$ & 1965 & $78 \%$ \\
\hline$>1.5$ & 102 & $4 \%$ & 60 & $2 \%$ & 96 & $4 \%$ \\
\hline
\end{tabular}

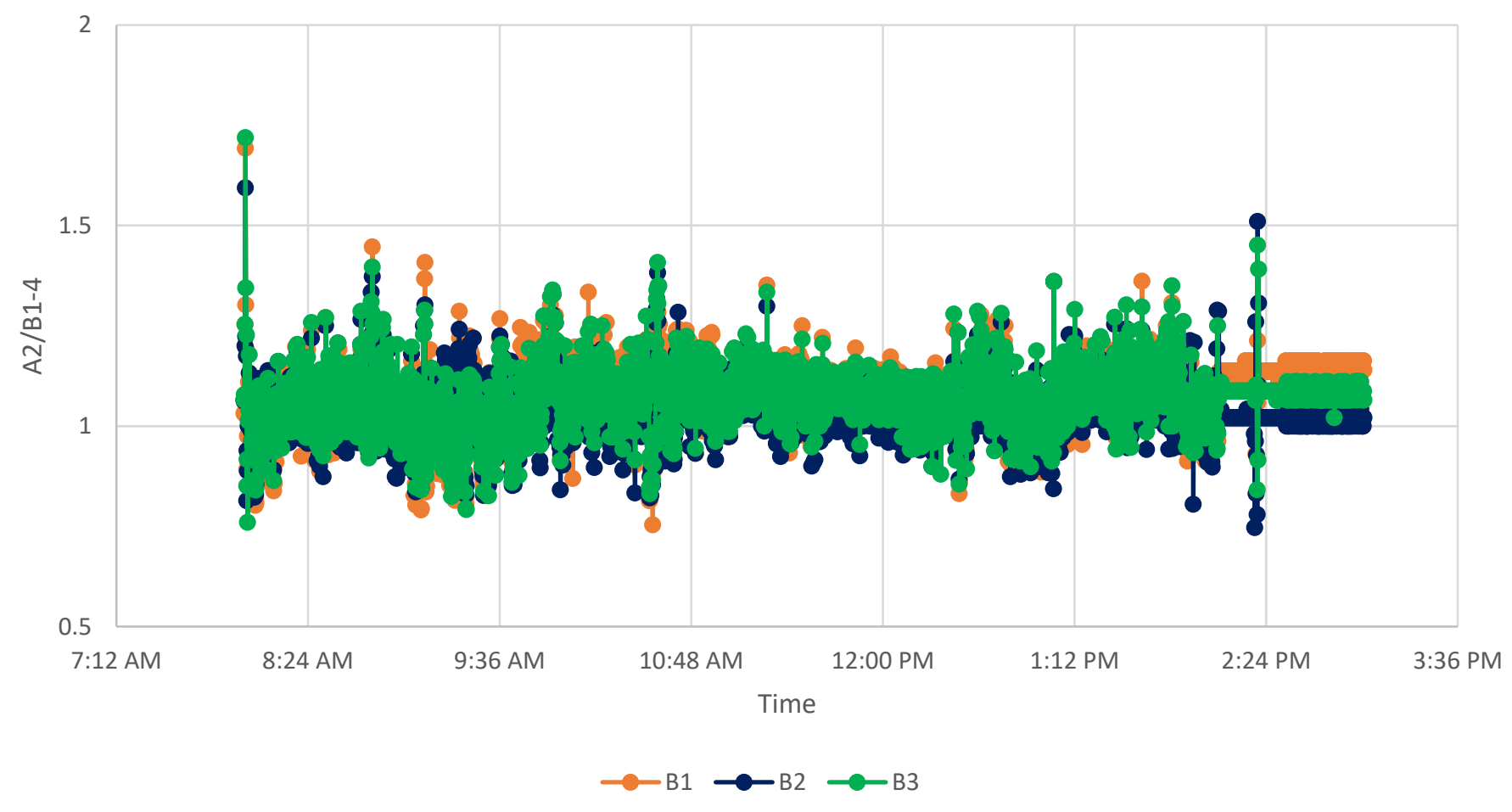

Figure 78: Comparison of ratio between horizontal and vertical sensors 


\subsubsection{Comparison between Horizontal and Vertical Sensors Average Sound Levels}

In Tables 45 to 50, the average of all the sensor points including the external sound levels was analysed for the school hours of $8 \mathrm{am}$ to $3 \mathrm{pm}$ in both non-school and school days in all three case studies. The goal of analysing the averages was to identify the possible range of variation between sound levels across the array of sensors. Sensors A1-3 was the spatial horizontal measuring plane sensors and sensors B1-4 was the vertical wall sensors, while sensor C1 was the external sensor located outside the building for case study one. The column annotated as "Diff" represented the calculation of the difference between sensor A2 (Central) and the vertical wall sensor that showed the least relationship in the ratio analysis above to ascertain the level of variation between the sensor points.

\section{Average Sound Levels}

In Tables 45 to 50, average sound levels between 8 am to $3 \mathrm{pm}$ in all three case studies for both horizontal and vertical sensors are presented. As shown in the column annotated with "Diff": the average sound level in the central horizontal measuring plane sensor (A2) was subtracted from the vertical wall sensor B1 in all three case studies because these sensors had a higher ratio change Section 7.1.3 above. While the "diff" column was annotated with a grey fill, the two sensor points used to calculate the difference between vertical and horizontal sensors is annotated with a green fill. For example, in case study one, around $3 \mathrm{pm}$ in the summer, sensor A2 recorded $45 \mathrm{dBA}$ while sensor B1 (South) recorded $41 \mathrm{dBA}$ and the variation between these two sensors was $+4 \mathrm{dBA}$.

In Tables 45 to 50 and in all three case studies, the sound level variation between the horizontal measuring plane sensors and the vertical wall sensors were largely $<3 \mathrm{dBA}$. Given that a $<3 \mathrm{dBA}$ difference in sound level may not be perceptible, these trends indicate that even under the influence of noise sources, there is a relationship between horizontal measuring plane and vertical wall sensors. Hence, a one-point sensor may be useful in providing reliable data that could be used to predict the sound levels in the space. 


\section{Non-School Days}

Table 45: Average sound levels in the non-school days from 8 am-3 pm

\section{Case Study One Autumn}

The grey column is the difference between sensor (A2) and the vertical sensor with the least relationship in the ratio analysis

\begin{tabular}{|c|c|c|c|c|c|c|c|c|}
\hline Hour & $\begin{array}{c}\text { Central } \\
\text { A1 (dBA) }\end{array}$ & $\begin{array}{c}\text { Central } \\
\text { A2 (dBA) }\end{array}$ & $\begin{array}{c}\text { Central } \\
\text { A3 (dBA) }\end{array}$ & $\begin{array}{c}\text { South } \\
\text { B1 (dBA) }\end{array}$ & $\begin{array}{c}\text { East } \\
\text { B2 (dBA) }\end{array}$ & $\begin{array}{c}\text { North } \\
\text { B3 (dBA) }\end{array}$ & $\begin{array}{c}\text { Diff } \\
\text { (dBA) }\end{array}$ & $\begin{array}{c}\text { External } \\
\text { C1 (dBA) }\end{array}$ \\
\hline $\mathbf{8} \mathbf{~ a m}$ & 33 & 34 & 35 & 33 & 34 & 32 & 1 & 33 \\
\hline $\mathbf{9} \mathbf{~ a m}$ & 34 & 34 & 35 & 34 & 34 & 33 & 0 & 34 \\
\hline $\mathbf{1 0} \mathbf{~ a m}$ & 39 & 38 & 39 & 38 & 38 & 37 & 0 & 39 \\
\hline $\mathbf{1 1} \mathbf{~ a m}$ & 36 & 35 & 37 & 35 & 35 & 34 & 0 & 36 \\
\hline $\mathbf{1 2} \mathbf{~ p m}$ & 35 & 35 & 36 & 34 & 36 & 34 & 1 & 35 \\
\hline $\mathbf{1} \mathbf{~ p m}$ & 35 & 35 & 36 & 34 & 35 & 34 & 1 & 35 \\
\hline $\mathbf{2} \mathbf{~ p m}$ & 36 & 35 & 36 & 33 & 34 & 34 & 2 & 36 \\
\hline $\mathbf{3} \mathbf{~ p m}$ & 35 & 35 & 36 & 34 & 34 & 34 & 1 & 35 \\
\hline
\end{tabular}

Table 46: Average sound levels in the non-school days from 8 am-3 pm

\section{Case Study One- Summer}

The grey column is the difference between sensor (A2) and the vertical sensor with the least relationship in the ratio analysis

\begin{tabular}{|c|c|c|c|c|c|c|c|c|}
\hline Hour & $\begin{array}{c}\text { Central } \\
\text { A1 (dBA) }\end{array}$ & $\begin{array}{c}\text { Central } \\
\text { A2 (dBA) }\end{array}$ & $\begin{array}{c}\text { Central } \\
\text { A3 (dBA) }\end{array}$ & $\begin{array}{c}\text { South } \\
\text { B1 (dBA) }\end{array}$ & $\begin{array}{c}\text { North } \\
\text { B3 (dBA) }\end{array}$ & $\begin{array}{c}\text { West } \\
\text { B4 (dBA) }\end{array}$ & $\begin{array}{c}\text { Diff } \\
\text { (dBA) }\end{array}$ & $\begin{array}{c}\text { External } \\
\text { C1 (dBA) }\end{array}$ \\
\hline $\mathbf{8} \mathbf{~ a m}$ & 40 & 40 & 40 & 40 & 41 & 42 & 0 & 46 \\
\hline $\mathbf{9} \mathbf{~ a m ~}$ & 40 & 40 & 40 & 41 & 40 & 43 & -1 & 46 \\
\hline $\mathbf{1 0} \mathbf{~ a m}$ & 40 & 40 & 40 & 41 & 40 & 42 & -1 & 46 \\
\hline $\mathbf{1 1} \mathbf{~ a m}$ & 40 & 41 & 40 & 41 & 41 & 44 & 0 & 46 \\
\hline $\mathbf{1 2} \mathbf{~ p m}$ & 40 & 40 & 40 & 41 & 41 & 43 & -1 & 46 \\
\hline $\mathbf{1} \mathbf{~ p m}$ & 42 & 43 & 42 & 41 & 41 & 45 & 2 & 46 \\
\hline $\mathbf{2} \mathbf{~ p m}$ & 41 & 43 & 41 & 41 & 41 & 45 & 2 & 46 \\
\hline $\mathbf{3} \mathbf{~ p m}$ & 41 & 45 & 41 & 41 & 41 & 47 & 4 & 47 \\
\hline
\end{tabular}

Table 47: Average sound levels in the non-school days from 8 am-3 pm

\section{\begin{tabular}{l|l} 
Case Study Two - Autumn & Case Study Three - Spring
\end{tabular}}

The grey column is the difference between sensor (A2) and the vertical sensor with the least relationship in the ratio analysis

\begin{tabular}{|c|c|c|c|c|c|c|c|c|c|c|}
\hline Hour & $\begin{array}{c}\text { Central } \\
\text { A2 (dBA) }\end{array}$ & $\begin{array}{c}\text { South } \\
\text { B1 (dBA) }\end{array}$ & $\begin{array}{c}\text { West } \\
\text { B4 (dBA) }\end{array}$ & $\begin{array}{c}\text { Diff } \\
\text { (dBA) }\end{array}$ & Hour & $\begin{array}{c}\text { Central } \\
\text { A2 (dBA) }\end{array}$ & $\begin{array}{c}\text { South } \\
\text { B1 (dBA) }\end{array}$ & $\begin{array}{c}\text { East } \\
\text { B2 (dBA) }\end{array}$ & $\begin{array}{c}\text { North } \\
\text { B3 (dBA) }\end{array}$ & Diff \\
\hline $8 \mathrm{am}$ & 36 & 34 & 34 & 2 & $8 \mathrm{am}$ & 50 & 47 & 47 & 50 & 3 \\
\hline $9 \mathrm{am}$ & 37 & 34 & 34 & 3 & $9 \mathrm{am}$ & 49 & 45 & 46 & 49 & 4 \\
\hline $10 \mathrm{am}$ & 37 & 35 & 34 & 2 & $10 \mathrm{am}$ & 50 & 46 & 46 & 49 & 4 \\
\hline $11 \mathrm{am}$ & 37 & 35 & 35 & 2 & $11 \mathrm{am}$ & 48 & 45 & 46 & 46 & 3 \\
\hline $12 \mathrm{pm}$ & 45 & 42 & 44 & 3 & $12 \mathrm{pm}$ & 48 & 45 & 47 & 47 & 3 \\
\hline $1 \mathrm{pm}$ & 38 & 37 & 37 & 1 & $1 \mathrm{pm}$ & 48 & 47 & 47 & 47 & 1 \\
\hline $2 \mathrm{pm}$ & 35 & 34 & 34 & 1 & $2 \mathrm{pm}$ & 49 & 46 & 47 & 47 & 3 \\
\hline 3 pm & 36 & 36 & 38 & 0 & 3 pm & 50 & 47 & 48 & 48 & 3 \\
\hline
\end{tabular}




\section{School Days}

Table 48: Average sound levels in the school days from 8 am-3 pm

Case Study One Autumn

The grey column is the difference between sensor (A2) and the vertical sensor with the least relationship in the ratio analysis

\begin{tabular}{|c|c|c|c|c|c|c|c|c|}
\hline Hour & $\begin{array}{c}\text { Central } \\
\text { A1 (dBA) }\end{array}$ & $\begin{array}{c}\text { Central } \\
\text { A2 (dBA) }\end{array}$ & $\begin{array}{c}\text { Central } \\
\text { A3 (dBA) }\end{array}$ & $\begin{array}{c}\text { South } \\
\text { B1 (dBA) }\end{array}$ & $\begin{array}{c}\text { East } \\
\text { B2 (dBA) }\end{array}$ & $\begin{array}{c}\text { North } \\
\text { B3 (dBA) }\end{array}$ & $\begin{array}{c}\text { Diff } \\
\text { (dBA) }\end{array}$ & $\begin{array}{c}\text { External } \\
\text { C1 (dBA) }\end{array}$ \\
\hline $\mathbf{8 ~} \mathbf{~ m}$ & 52 & 47 & 45 & 44 & 44 & 44 & 3 & 60 \\
\hline $\mathbf{9} \mathbf{~ a m}$ & 61 & 60 & 55 & 57 & 55 & 57 & 3 & 70 \\
\hline $\mathbf{1 0} \mathbf{~ a m}$ & 61 & 59 & 56 & 59 & 56 & 59 & 0 & 70 \\
\hline $\mathbf{1 1} \mathbf{~ a m}$ & 57 & 56 & 52 & 55 & 53 & 55 & 1 & 66 \\
\hline $\mathbf{1 2} \mathbf{~ p m}$ & 57 & 59 & 57 & 57 & 56 & 57 & 2 & 63 \\
\hline $\mathbf{1} \mathbf{~ p m}$ & 46 & 45 & 44 & 43 & 43 & 43 & 2 & 40 \\
\hline $\mathbf{2} \mathbf{~ p m}$ & 41 & 40 & 47 & 43 & 41 & 40 & -3 & 45 \\
\hline $\mathbf{3} \mathbf{~ p m}$ & 52 & 50 & 52 & 52 & 51 & 52 & -2 & 53 \\
\hline
\end{tabular}

Table 49: Average sound levels in the school days from $8 \mathrm{am}-3 \mathrm{pm}$

Case Study One- Summer

The grey column is the difference between sensor (A2) and the vertical sensor with the least relationship in the ratio analysis

\begin{tabular}{|c|c|c|c|c|c|c|c|c|}
\hline Hour & $\begin{array}{c}\text { Central } \\
\text { A1 (dBA) }\end{array}$ & $\begin{array}{c}\text { Central } \\
\text { A2 (dBA) }\end{array}$ & $\begin{array}{c}\text { Central } \\
\text { A3 (dBA) }\end{array}$ & $\begin{array}{c}\text { South } \\
\text { B1 (dBA) }\end{array}$ & $\begin{array}{c}\text { North } \\
\text { B3 (dBA) }\end{array}$ & $\begin{array}{c}\text { West } \\
\text { B4 (dBA) }\end{array}$ & $\begin{array}{c}\text { Diff } \\
\text { (dBA) }\end{array}$ & $\begin{array}{c}\text { External } \\
\text { C1 (dBA) }\end{array}$ \\
\hline $\mathbf{8} \mathbf{~ a m}$ & 57 & 58 & 56 & 55 & 56 & 57 & 3 & 51 \\
\hline $\mathbf{9} \mathbf{~ a m}$ & 60 & 59 & 58 & 58 & 58 & 60 & 1 & 54 \\
\hline $\mathbf{1 0} \mathbf{~ a m}$ & 58 & 58 & 57 & 56 & 56 & 60 & 2 & 52 \\
\hline $\mathbf{1 1} \mathbf{~ a m}$ & 59 & 61 & 58 & 58 & 58 & 58 & 3 & 53 \\
\hline $\mathbf{1 2} \mathbf{~ p m}$ & 58 & 58 & 57 & 57 & 57 & 60 & 1 & 52 \\
\hline $\mathbf{1} \mathbf{~ p m}$ & 59 & 60 & 58 & 58 & 58 & 59 & 2 & 53 \\
\hline $\mathbf{2} \mathbf{~ p m}$ & 55 & 56 & 54 & 54 & 54 & 58 & 2 & 49 \\
\hline $\mathbf{3} \mathbf{~ p m}$ & 54 & 56 & 54 & 54 & 54 & 58 & 2 & 48 \\
\hline
\end{tabular}

Table 50: Average sound levels in the school days from $8 \mathrm{am}-3 \mathrm{pm}$

\begin{tabular}{|c|c|c|c|c|c|c|c|c|c|c|}
\hline \multicolumn{5}{|c|}{ Case Study Two - Autumn } & \multicolumn{6}{|c|}{ Case Study Three - Spring } \\
\hline \multicolumn{11}{|c|}{ The grey column is the difference between sensor (A2) and the vertical sensor with the least relationship in the ratio analysis } \\
\hline Hour & $\begin{array}{c}\text { Central } \\
\text { A2 (dBA) }\end{array}$ & $\begin{array}{c}\text { South } \\
\text { B1 (dBA) }\end{array}$ & $\begin{array}{c}\text { West } \\
\text { B4 (dBA) }\end{array}$ & $\begin{array}{c}\text { Diff } \\
\text { (dBA) }\end{array}$ & Hour & $\begin{array}{c}\text { Central } \\
\text { A2 (dBA) }\end{array}$ & $\begin{array}{c}\text { South } \\
\text { B1 (dBA) }\end{array}$ & $\begin{array}{c}\text { East } \\
\text { B2 (dBA) }\end{array}$ & $\begin{array}{c}\text { North } \\
\text { B3 (dBA) }\end{array}$ & $\begin{array}{l}\text { Diff } \\
\text { (dBA) }\end{array}$ \\
\hline $8 \mathrm{am}$ & 57 & 56 & 59 & 1 & 8 am & 69 & 68 & 67 & 68 & 1 \\
\hline $9 \mathrm{am}$ & 54 & 52 & 52 & 2 & $9 \mathrm{am}$ & 70 & 68 & 69 & 69 & 2 \\
\hline $10 \mathrm{am}$ & 62 & 62 & 64 & 0 & $10 \mathrm{am}$ & 75 & 68 & 69 & 72 & 7 \\
\hline $11 \mathrm{am}$ & 64 & 66 & 66 & -2 & $11 \mathrm{am}$ & 76 & 70 & 71 & 74 & 6 \\
\hline $12 \mathrm{pm}$ & 58 & 56 & 56 & 2 & $12 \mathrm{pm}$ & 75 & 71 & 70 & 72 & 4 \\
\hline $1 \mathrm{pm}$ & 69 & 68 & 69 & 1 & $1 \mathrm{pm}$ & 70 & 66 & 66 & 67 & 4 \\
\hline $2 \mathrm{pm}$ & 70 & 72 & 72 & -2 & $2 \mathrm{pm}$ & 54 & 47 & 48 & 51 & 7 \\
\hline $3 \mathrm{pm}$ & 52 & 54 & 54 & -2 & 3 pm & 52 & 43 & 46 & 49 & 9 \\
\hline
\end{tabular}




\subsubsection{Sound Level Measurement Discussion}

Measurement of sound levels is an important variable for the assessment of the acoustic performance of a space, given that it requires less cumbersome equipment's and provides a useful measure to determine classrooms with good or poor acoustic performance without interfering with the functions of the space while in use. If measuring sound levels at scale to understand which spaces have a critical acoustic performance or to determine sources of noise, it might not be cost effective and could be practically difficult to deploy multiple sound level sensors in each space, especially in occupied spaces. Hence, the use of a single sensor per space may suffice. In the literature, the review of acoustic studies did not provide a consensus answer on whether a one-point sound level measurement could be representative of the sound levels in a space and where might be the best position to locate a single sound level meter. The sound level results of this thesis illustrate that:

- In the case study classrooms, there was variation between horizontal measuring plane sensors and vertical wall sensors. This variation was distinct to the type of space and the activity levels carried out in the classroom at a point in time. The extent of variation between the highest and lowest hourly average sound level distribution was largely $<3$ dBA for both occupied and unoccupied days in all three case studies and in all seasons. Given that a $<3 \mathrm{dBA}$ change may not be perceptible, this equates to a not so great variation of average sound level distribution within the space.

- Occupancy ratio impacted on the sound levels during occupied school days: When the spaces where occupied, there were periods of high sound levels recorded in the classroom which resulted in instances of variations in sound level distribution. Though no significant external noise sources were identified, noise generated by occupants was observed to be a major source of noise during occupied days. Wilson et al., (2002) suggest that New Zealand classrooms largely have high levels of student generated noise and intrusive external noise due to open windows. They also suggested that in occupied classrooms and throughout the course of a day, the signal-noise-ratios are constantly fluctuating, and single sound level values do not give an indication of the range a child encounter. This suggests the need to analyse continuous sound levels over a long period. 
- During the unoccupied non-school days, the sound levels were largely within 40 to 45 dBA. But in case study three, noise generated from the server, which was located within the classroom, was a major source of slightly higher sound levels. During the occupied school days, the sound levels were largely $<70 \mathrm{dBA}$, which is coherent with noise levels measured in classrooms by other researchers as stated in the literature. For example, Shield \& Dockrell, (2003) literature review on the effect of noise on children in schools suggested that "a continuous level of $65 \mathrm{~dB}(\mathrm{~A})$ LAeq is the average sound level measured in classrooms when children were sitting and working individually". Valentine, (1993) stated that in classrooms average noise levels of $77 \mathrm{dBA}$ were measured with pupils working. The authors stated that in comparison to the overseas classroom which is influenced by high background noise levels from heating/air-conditioning/mechanical ventilation, New Zealand classrooms typically have lower levels of noise due to the use of carpets. But it's influenced by intrusive external noise due to open windows and student generated noise. This is affirmed in the results of this analysis which revealed that student generated noise was a major source of high noise levels within the classrooms.

Given that sound level measurement is a logarithmic scale and a sound level increase of $3 \mathrm{~dB}$ is just noticeable, the subjective variation of $<3 \mathrm{dBA}$ between horizontal measuring plane and vertical wall sensors may not be so great and the ratio change was largely $>1.5$. Hence, it can be concluded that a vertical wall mounted sensor at a height of $1.5 \mathrm{~m}$ can provide a useful benchmark for predicting sound levels in a space, in conjunction with detailed documentation and analyses of the sources of noise within the space.

\subsubsection{How to use a One-Point Sensor for Sound Levels Prediction}

The measurement and analysis of sound levels in unoccupied spaces are commonly used to ascertain poor acoustic design or lack of acoustic treatment in a building, and in occupied spaces, it is used to ascertain the sources and magnitude of internal and external noise to act in mitigating these sources. The commonly referenced design goal limits for background noise levels in unoccupied classrooms is 40 to $45 \mathrm{dBA}$. As shown in the study results, during periods of occupancy, sound levels will usually increase owing to learning activities of the students such as 
delivering learning through streaming a video, conversations between occupants, music, footsteps, and moving and dropping of objects and furniture. In the literature, studies indicated that activity noise levels are typically between 65 to $75 \mathrm{dBA}$ - normal voice at $1 \mathrm{~m}$ and can be greater than $75 \mathrm{dBA}$ in some schools.

The results of comparing sound levels measured with sensors placed on the horizontal working plane with that of sensors placed on the vertical walls illustrate that:

- In classrooms and due to the various sources of sound, the sound could originate from different parts of a space simultaneously (here and there) and varies randomly and it may take time for sound to travel from one-point to another due to different soft finishes in classrooms which could absorb the sound. This variation in sound from one part of space to another suggests that it is difficult for a one-point sensor measurement to be representative of the sound levels across a space

- If measuring sound levels at scale in classrooms, the insights from the experiment illustrate that irrespective of the location of the sensors, there were variations in sound levels across different sensor points. This variation may not be noticeable, hence in unoccupied spaces, a strategically positioned one-point sensor could be useful to provide indicative data about the sound levels in a space to identify spaces that have good or poor acoustic performance (spaces that meet the commonly referenced design goal target of $<40 \mathrm{dBA})$

- When undertaking measurements in occupied classrooms, the sensors' location should avoid any disruption of the teachers work and should not disturb or distract the children, and not within the direct sound field of the teacher and above the nearest reflecting room surface

- This approach can't be used to accurately predict the sound level in different parts of a space, such as a complex form, but provides a good indication of spaces with a good or poor acoustic performance for a more detailed acoustic verification in spaces with higher sound levels 
- $\quad$ Figure 79 uses a typical simple classroom typology to illustrate how to use a one-point sensor to measure sound levels at scale in buildings

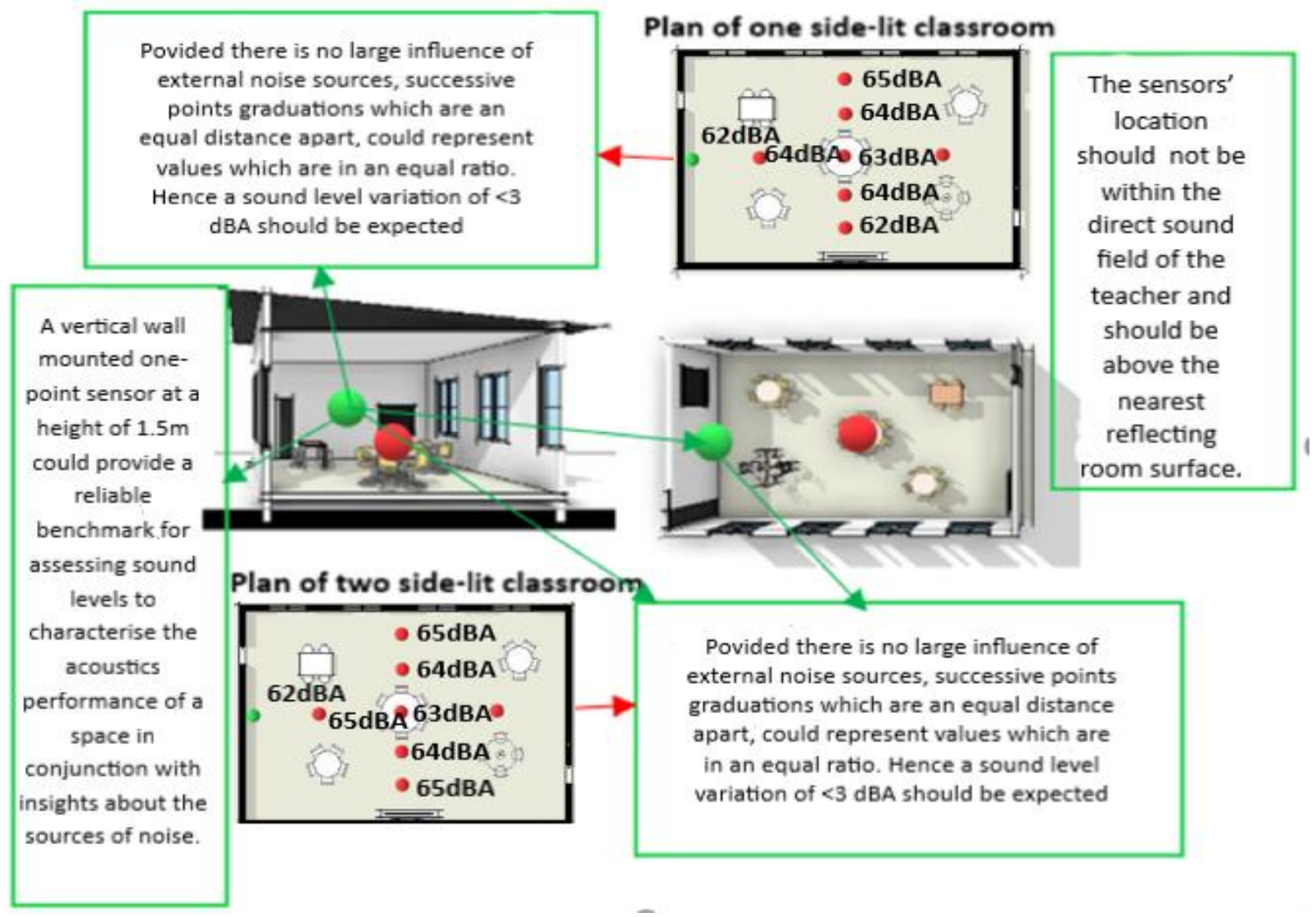

Figure 79: Illustration of how to use a one-point sensor to measure $\mathrm{CO}_{2}$ at scale in buildings

To evaluate the acoustic quality of classrooms using a one-point sound level data will require considering the following considerations:

- In occupied classrooms, it is critical to obtain values from measurements considering open and closed windows respectively. When the windows are open, the measurement will show values of external noise impacts into the space. With open windows and to control for extraneous internal noise effects, all air conditioning units and/or fans that were present in classrooms should be turned off

- The current activity and occupancy (number of teachers and children) of the classroom should be noted 
- The occurrence of any noticeable noise events, internal or external, during the measurement period should be noted (note any occurrences of high noise levels and identify the sources). For example, during spot measurements in case study three, it was noted that server located inside the classroom was a source of background noise that was above the recommended $<45 \mathrm{dBA}$. This added about $3 \mathrm{dBA}$ to the background noise levels of the classroom when the server is off

- Age of the students should be noted

- The activity level in the class should be noted

Several factors could affect noise level readings, especially in an occupied classroom. These factors include;

- The distance between the source of the sound and the meter

- The direction the noise source is facing relative to the meter

- Noise measurements taken indoors can reverberate while in outdoor measurements noise can dissipate

Hence, to ensure that a sound level value is useful, it is important to specify the conditions under which the reading was taken, especially the distance from the source. 


\section{CHAPTER EIGHT: CAN A ONE-POINT SENSOR PREDICT THE INDOOR AIR QUALITY IN A CLASSROOM?}

\subsection{Physical Measurement of $\mathrm{CO}_{2}$ levels in the Case Study Classrooms}

This study considers $\mathrm{CO}_{2}$ monitoring as an indicator of ventilation effectiveness and surrogates for indoor air quality conditions. Besides measuring $\mathrm{CO}_{2}$, the multi-variable sensors also measured temperature, relative humidity, lighting and sound levels. While these variables have been discussed above, this Chapter focuses only on the $\mathrm{CO}_{2}$ results to determine what can be learned from having a one-point $\mathrm{CO}_{2}$ sensor on the vertical wall in comparison to the spatial distribution of $\mathrm{CO}_{2}$ on the horizontal measuring plane.

\subsubsection{Non-School Days $\mathrm{CO}_{2}$ Analysis}

In Figure 80, the non-school days were analysed to explore the relationship between horizontal measuring plane sensors and vertical wall sensors. In all three case studies and in the different seasons, the line graph trend shows that there is the variability of $\mathrm{CO}_{2}$ concentration between horizontal measuring plane sensors A1-2 and vertical wall sensors B1-4. For example, in Figure 62 , and during the autumn in case study one, when the central horizontal measuring plane sensor A2 (central) had $\mathrm{CO}_{2}$ levels of $410 \mathrm{ppm}$, the vertical wall sensor (North) $\mathrm{B} \mathrm{CO}_{2}$ levels of about $490 \mathrm{ppm}$. This equates to an $80 \mathrm{ppm}$ variation and shows that even during unoccupied days, there is a variation of $\mathrm{CO}_{2}$ levels within a space and a one-point sensor may not be representative of the $\mathrm{CO}_{2}$ levels within an entire unoccupied space. However, during the summer in case study one and the autumn in case study two, the $\mathrm{CO}_{2}$ patterns in the central horizontal measuring plane sensor (A2) were like that of the vertical wall sensor (B3). These trends were further investigated in the sparklines analysis below. 


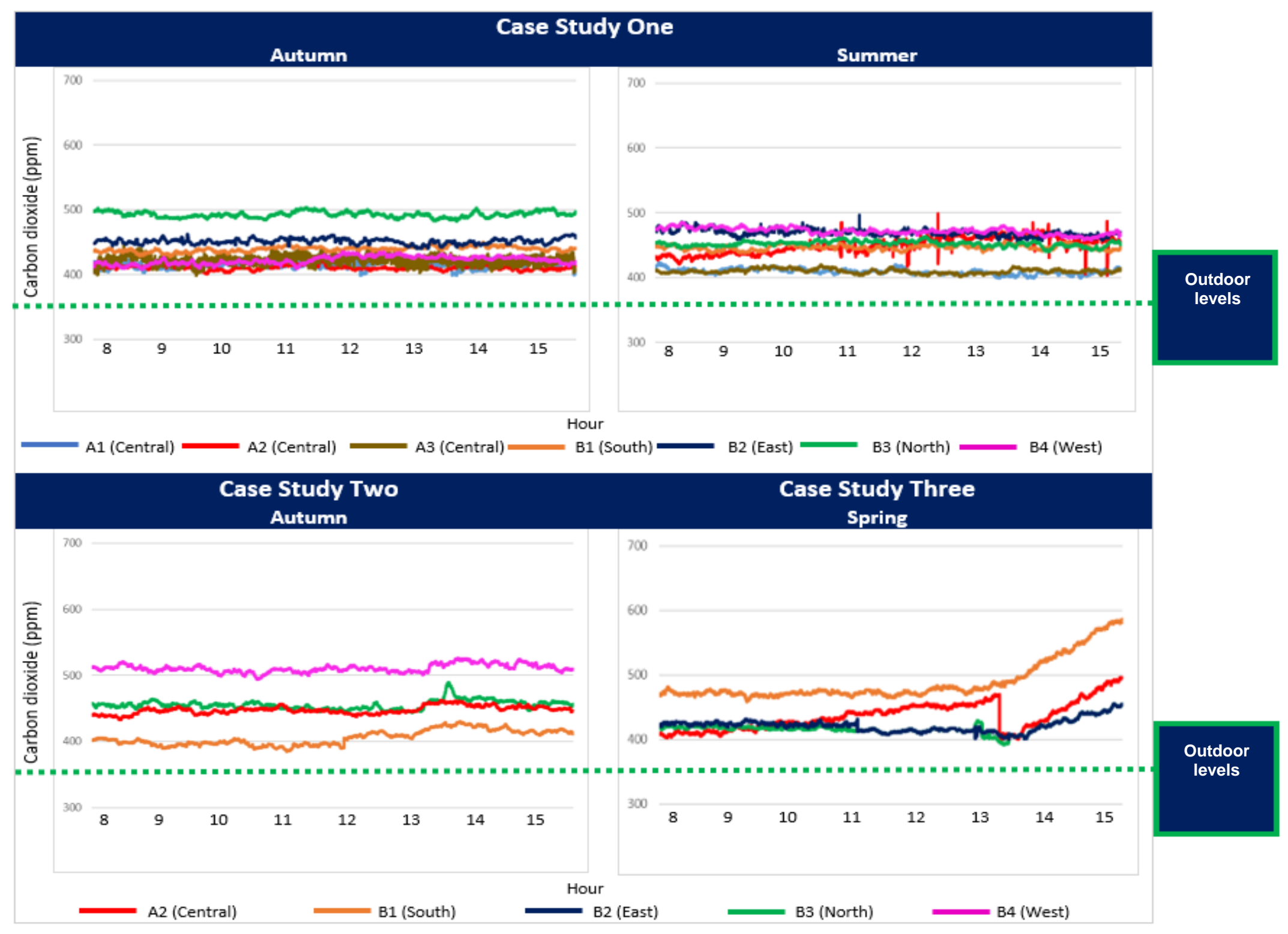

Figure 80: Line graphs showing $\mathrm{CO}_{2}$ trends between $8 \mathrm{am}-3 \mathrm{pm}$ during non-school days (A sensors horizontal, on the working plane; B sensors vertical, on adjacent wall) 
In Figure 81, the $\mathrm{CO}_{2}$ sparkline pattern also shows variations between horizontal measuring plane sensors and vertical wall sensors. For example, the visual pattern in sensor A2 and B3 varied in all three case studies. As shown during the summer in case study one, when there was a decrease in the $\mathrm{CO}_{2}$ levels in sensor $\mathrm{A} 2$, there were patterns of higher $\mathrm{CO}_{2}$ levels in sensor $\mathrm{B} 3$. This is consistent with the line graph trend and supports the assertion that even in unoccupied spaces, there is a spatial variation of $\mathrm{CO}_{2}$ concentration across a space. The magnitude of this variation is investigated using comparative ratio analysis in Section 8.1.3 below.

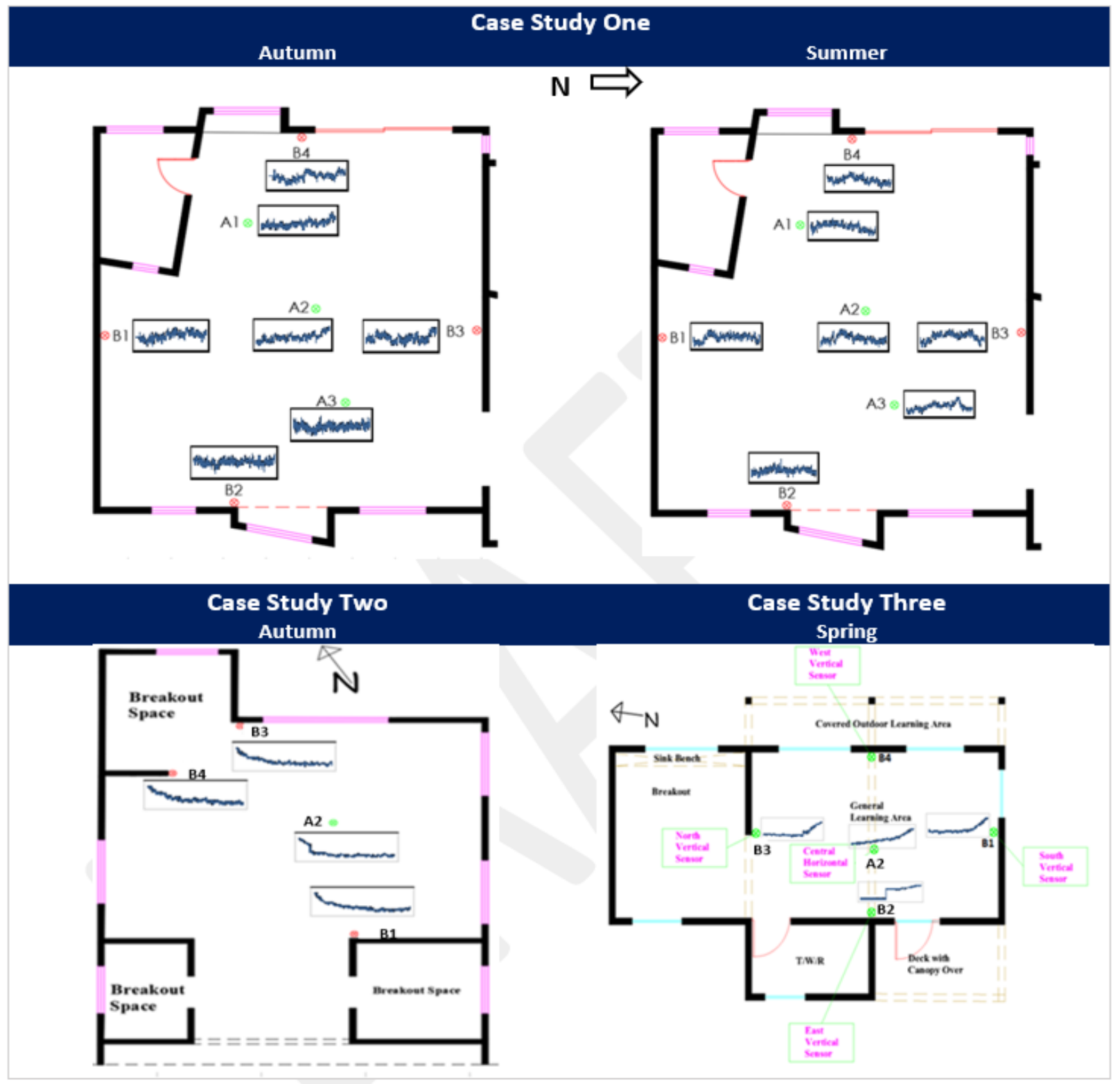

Figure 81: Sparklines showing $\mathrm{CO}_{2}$ visual patterns between 8 am to $3 \mathrm{pm}$ in the non-school days 


\subsubsection{School Days $\mathrm{CO}_{2}$ Analysis}

In Figure $82, \mathrm{CO}_{2}$ concentrations appear to rise and fall at different periods in a typical school day and follow a similar pattern in all three case studies and seasons. The $\mathrm{CO}_{2}$ level rises from a base of about $400 \mathrm{ppm}$ (close to external atmospheric $\mathrm{CO}_{2}$ concentrations) to a peak of about 2,300 ppm. During the one day observation reported in Section 4.3.2 above, a reference handheld $\mathrm{CO}_{2}$ sensor was used to carry out spot measurements at different times of the school day. It was observed that the fluctuations in $\mathrm{CO}_{2}$ levels were due to occupancy and occupant's actions to the opening and closing of doors and windows. As shown in case study one, the spikes in sensors A1 and $A 2$ was due to the location of these sensors at the central area of the classroom and from the observation of space usage, students like to converge around the central area. These two sensors had the highest $\mathrm{CO}_{2}$ levels at some point in time. For example, the summer line graph in case study one shows sudden spikes of high and low $\mathrm{CO}_{2}$ levels at a point in time, while the autumn graph shows high levels of $\mathrm{CO}_{2}$ in the morning hours which remained constant for a longer period. This illustrates that instances of window opening during the summer potentially reduced the $\mathrm{CO}_{2}$ levels while the windows were closed for a longer period during the autumn where heaters were used to warm up the space.

Though the line graph patterns show a relatively consistent rise and fall of $\mathrm{CO}_{2}$ levels across sensor points, the trend shows that like the non-school days, there is a variation in $\mathrm{CO}_{2}$ levels between horizontal measuring plane sensors and vertical wall sensors. There were periods of a sudden spike in $\mathrm{CO}_{2}$ levels in sensors that were closer to occupants. For example, in Figure 82 and during spring in case study three, when central horizontal measuring plane sensor A2 recorded about 2300 ppm, vertical wall sensor (North) B3 recorded $<1300 \mathrm{pm}$. Given that the rapid increase of $\mathrm{CO}_{2}$ concentration was due to $\mathrm{CO}_{2}$ generation which is caused by people and the rapid decreases are removal of those sources and probably opening windows, these patterns indicate that under the influence of $\mathrm{CO}_{2}$ sources there is a wider variation in $\mathrm{CO}_{2}$ levels. Hence, a one-point sensor may not provide accurate data to represent the $\mathrm{CO}_{2}$ concentration in an entire space. 


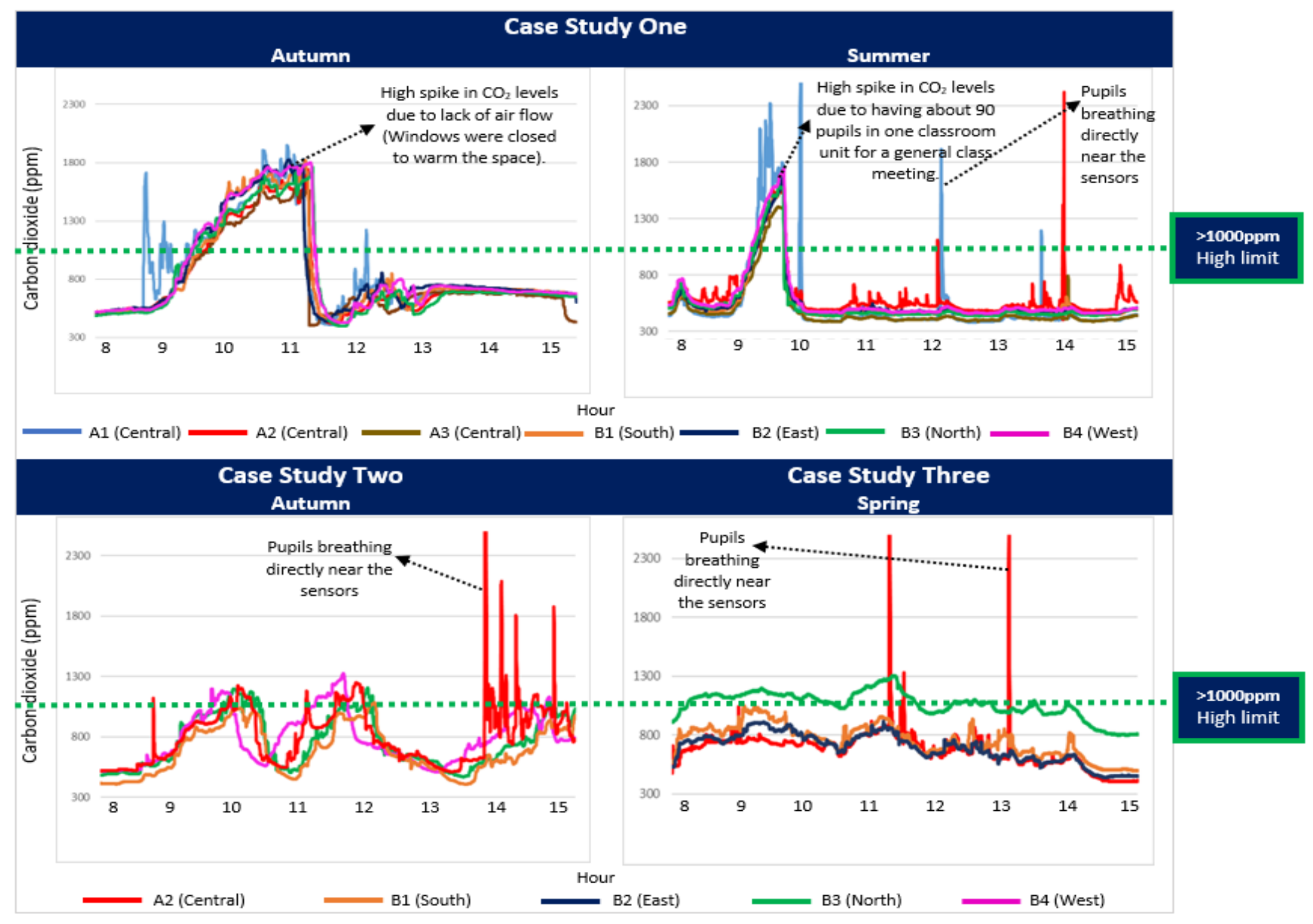

Figure 82: Line graphs showing $\mathrm{CO}_{2}$ trends between $8 \mathrm{am}-3 \mathrm{pm}$ during school days (A sensors horizontal, on the working plane; $B$ sensors vertical, on adjacent wall) 
In Figure 83, the occupied days $\mathrm{CO}_{2}$ sparkline pattern also shows variations in $\mathrm{CO}_{2}$ concentration across sensor points. For example, the horizontal plane sensors (A1-3) showed a spatial variation with the vertical wall sensors (B1-B4). This was more obvious during the summer in case study one and during spring in case study three. This period was a weekday, the spaces were occupied, and there was a movement in and out of the space and across spaces. It was observed that some windows were usually opened during the teaching period and students tend to open and close windows when they feel warm or cold. Hence, it is indicative that the occupancy pattern and airflow within the space resulted in the temporal variance in $\mathrm{CO}_{2}$ concentration across the space.

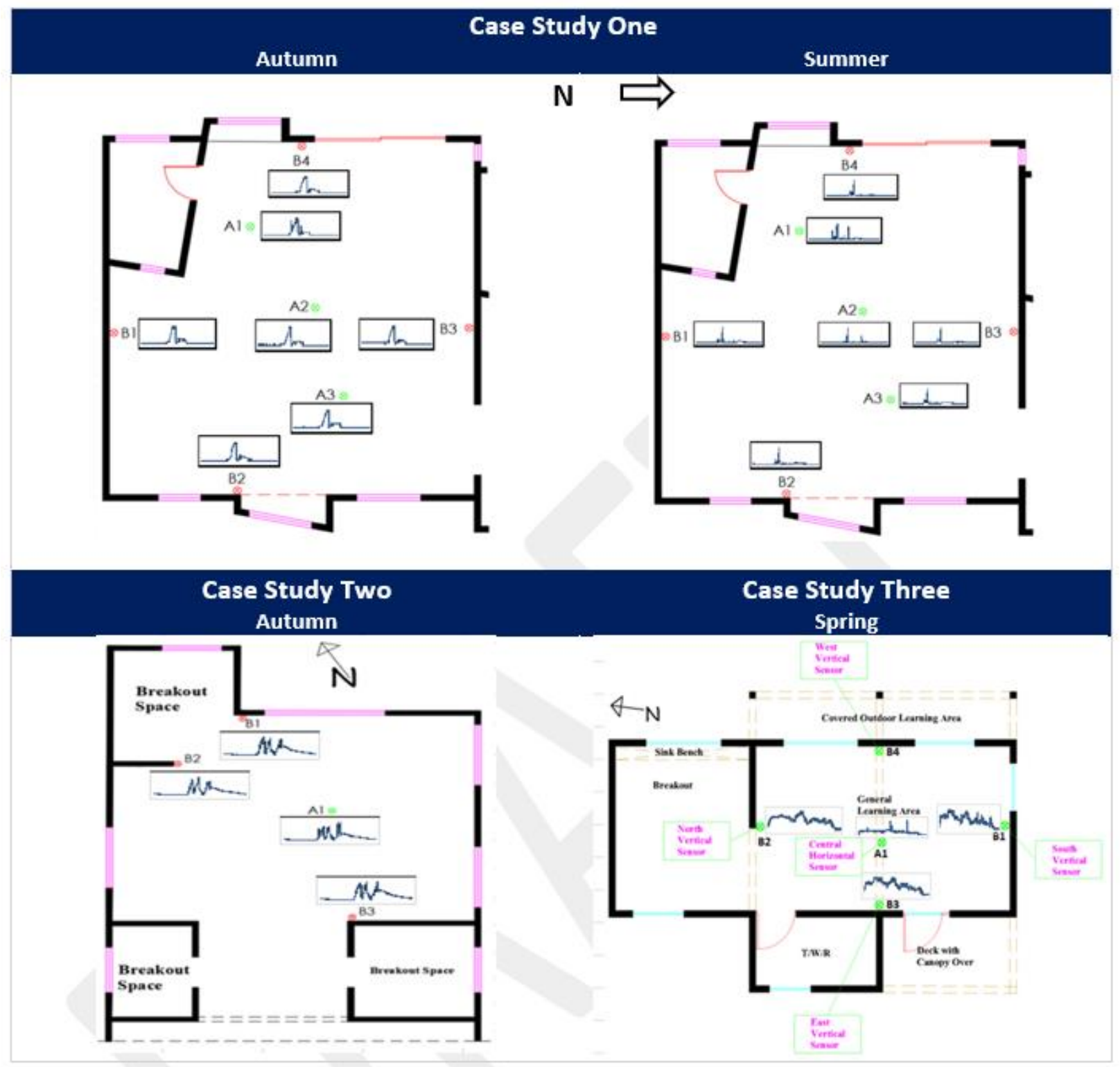

Figure 83: Sparklines showing $\mathrm{CO}_{2}$ visual patterns between 8 am to $3 \mathrm{pm}$ in the school days 


\subsubsection{Carbon dioxide Comparative Ratio Analysis}

As with temperature and sound levels, a ratio analysis was used to compare the relationship between carbon dioxide levels in the central horizontal measuring plane sensor with that of the vertical wall sensor.

In Tables 51 to 53 and Figures, 84 to 86 below, the values recorded on the central horizontal sensor A2 was divided by the values on the vertical wall sensors B1-B4. The frequency of the data was categorised into four bins depending on the ratio of change between the two compared variables and percentages were used to describe the fold change.

In Tables 51 to 53 and Figures 84 to 86 the relationship between the horizontal plane and vertical wall sensors was for $80 \%$ of the time largely consistent around a ratio of $1.0-1.5$, which indicated that a vertical wall sensor can reliably predict the $\mathrm{CO}_{2}$ levels at the centre of a classroom. However, as reported in Section 8.1.2, during instances of higher $\mathrm{CO}_{2}$ levels like in the spikes in Figures 81 to 83 , the ratio increased to 1.5 and could be higher at a point in time, which indicates a variation in $\mathrm{CO}_{2}$ at higher levels, compared to lower levels.

$\mathrm{CO}_{2}$ and sound levels, unlike temperature showed spikes at some point in time, which is most likely due to occupancy and usage, but the overall trends didn't compromise the large consistency in the ratio between the vertical and horizontal plane sensors. These trends suggest that provided the factors of $\mathrm{CO}_{2}$ variability ( $\underline{\text { Section 8.2) }}$ ) are taken into account, a vertical wall sensor can predict sound levels at the centre of a space and can assist with the diagnosis of patterns when measuring $\mathrm{CO} 2$ levels in many school buildings. The application of these findings to identify good and poor acoustic conditions is discussed in detail in Sections 8.1.6 below. 
CASE STUDY ONE - SUMMER

Table 51: Ratio Analysis comparing the relationship between $\mathrm{CO}_{2}$ levels at the central horizontal sensor $\mathrm{A} 2$ with vertical wall sensors $\mathrm{B1}-4$ respectively

\begin{tabular}{|c|c|c|c|c|c|c|c|c|}
\hline \multirow[b]{2}{*}{ Bin } & \multicolumn{2}{|c|}{ A2(Central)/B1(South) } & \multicolumn{2}{|c|}{ A2(Central) /B2(East) } & \multicolumn{2}{|c|}{ A2(Central) /B3(North) } & \multicolumn{2}{|c|}{ A2(Central)/B4(West) } \\
\hline & Frequency & Percentages & Frequency & Percentages & Frequency & Percentages & Frequency & Percentages \\
\hline $0.5-0.99$ & 6 & $0 \%$ & 0 & $0 \%$ & 0 & $0 \%$ & 50 & $2 \%$ \\
\hline $1.0-1.19$ & 130 & $5 \%$ & 87 & $3 \%$ & 188 & $7 \%$ & 319 & $13 \%$ \\
\hline $1.2-1.5$ & 2334 & $93 \%$ & 2399 & $95 \%$ & 2278 & $90 \%$ & 2121 & $84 \%$ \\
\hline$>1.5$ & 53 & $2 \%$ & 37 & $1 \%$ & 57 & $2 \%$ & 33 & $1 \%$ \\
\hline
\end{tabular}

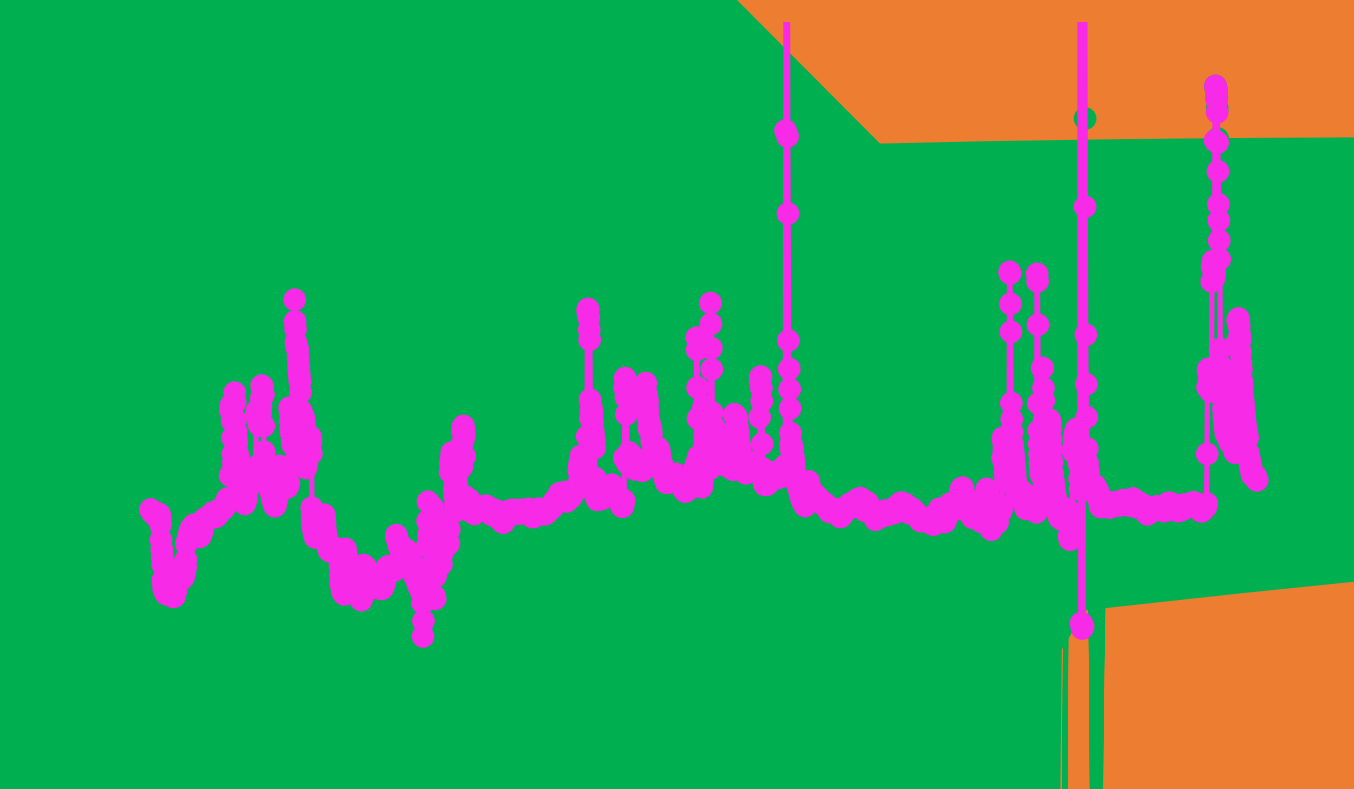

Figure 84: Comparison of ratio between horizontal and vertical sensors 


\section{CASE STUDY TWO - AUTUMN}

Table 52: Ratio Analysis comparing the relationship between $\mathrm{CO}_{2}$ levels at the central horizontal sensor A2 with vertical wall sensors B1-4 respectively

\begin{tabular}{|c|c|c|c|c|c|c|c|c|}
\hline \multirow[b]{2}{*}{ Bin } & \multicolumn{2}{|c|}{ A2(Central)/B1(South) } & \multicolumn{2}{|c|}{ A2(Central) /B2(East) } & \multicolumn{2}{|c|}{ A2(Central) /B3(North) } & \multicolumn{2}{|c|}{ A2(Central)/B4(West) } \\
\hline & Frequency & Percentages & Frequency & Percentages & Frequency & Percentages & Frequency & Percentages \\
\hline $0.5-0.99$ & 1743 & $74 \%$ & 1959 & $83 \%$ & 905 & $38 \%$ & 1899 & $80 \%$ \\
\hline $1.2-1.5$ & 0 & $0 \%$ & 27 & $1 \%$ & 0 & $0 \%$ & 0 & $0 \%$ \\
\hline$>1.5$ & 0 & $0 \%$ & 9 & $0 \%$ & 0 & $0 \%$ & 0 & $0 \%$ \\
\hline
\end{tabular}
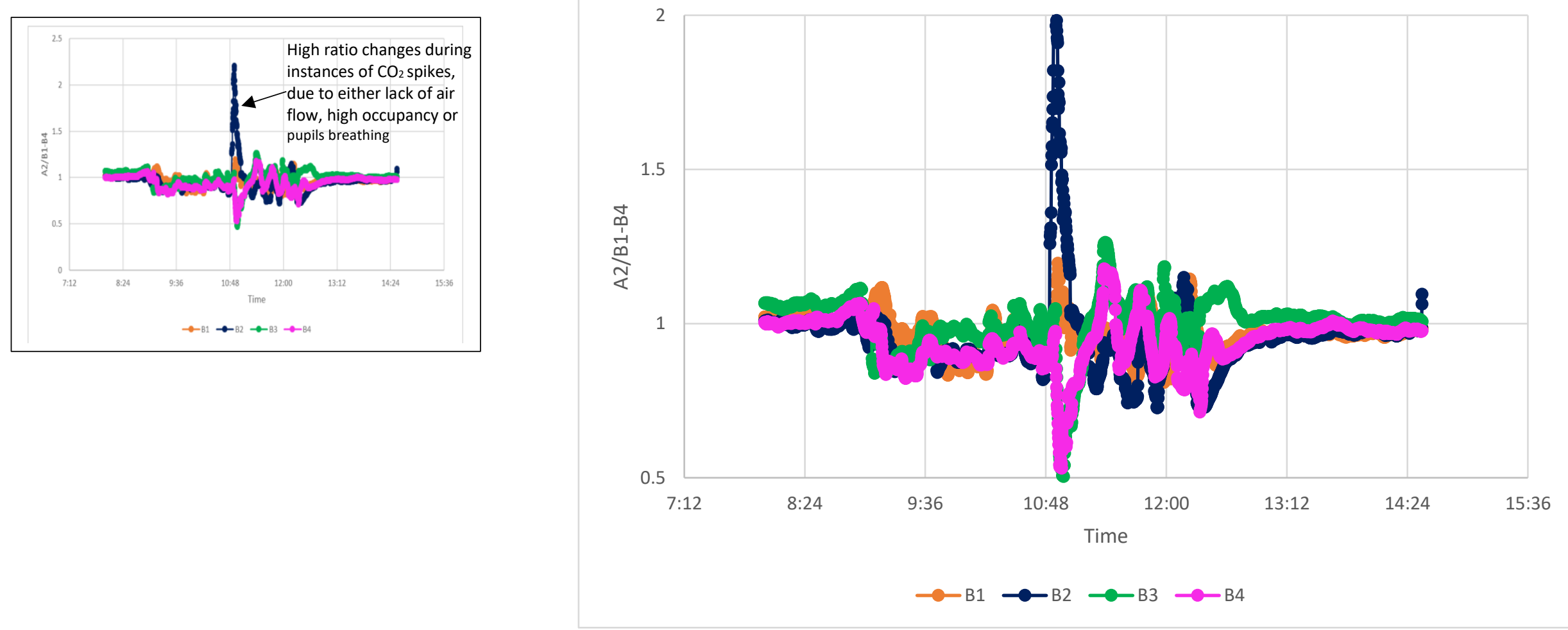

Figure 85: Comparison of ratio between horizontal and vertical sensors 


\section{CASE STUDY THREE - SPRING}

Table 53: Ratio Analysis comparing the relationship between $\mathrm{CO}_{2}$ levels at the central horizontal sensor A2 with vertical wall sensors B1-4 respectively

\begin{tabular}{|c|c|c|c|c|c|c|}
\hline \multirow[b]{2}{*}{ Bin } & \multicolumn{2}{|c|}{ A2(Central)/B1(South) } & \multicolumn{2}{|c|}{ A2(Central) /B2(East) } & \multicolumn{2}{|c|}{ A2(Central) /B3(North) } \\
\hline & Frequency & Percentages & Frequency & Percentages & Frequency & Percentages \\
\hline $0.5-0.99$ & 1812 & $72 \%$ & 1 & $0 \%$ & 2490 & $99 \%$ \\
\hline $1.0-1.19$ & 436 & $17 \%$ & 1863 & $74 \%$ & 13 & $1 \%$ \\
\hline $1.2-1.5$ & 263 & $10 \%$ & 645 & $26 \%$ & 10 & $0 \%$ \\
\hline$>1.5$ & 7 & $0 \%$ & 7 & $0 \%$ & 8 & $0 \%$ \\
\hline More & 3 & $0 \%$ & 5 & $0 \%$ & 0 & $0 \%$ \\
\hline
\end{tabular}
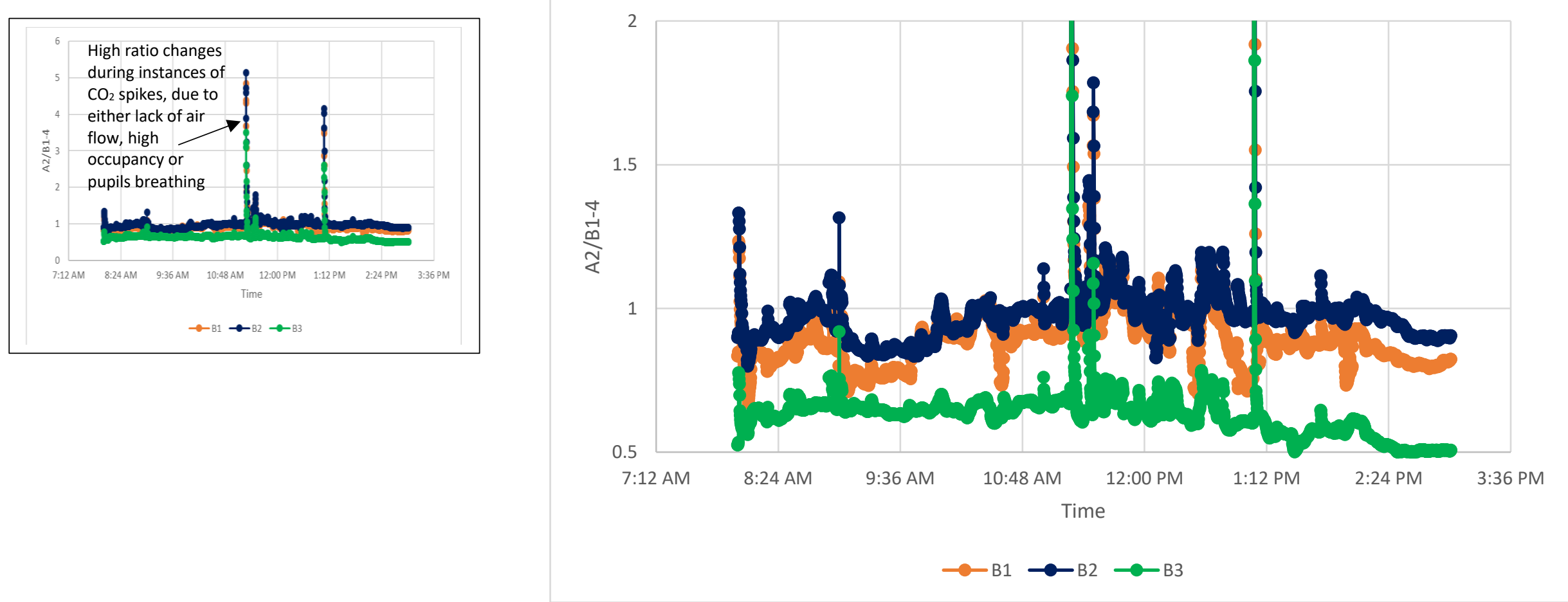

Figure 86: Comparison of ratio between horizontal and vertical sensors 


\subsubsection{Comparison between Horizontal and Vertical Sensors Average $\mathrm{CO}_{2}$ Levels}

In Table 54 to 59, the average of all the sensor points including the external $\mathrm{CO}_{2}$ levels was analysed for the school hours of 8 am to $3 \mathrm{pm}$ in both non-school and school days in all three case studies. The goal of analysing the averages was to identify the possible range of variation between $\mathrm{CO}_{2}$ across the various sensor points. Sensors A1-3 where the spatial horizontal measuring plane sensors while sensors B1-4 where the vertical wall sensors respectively while sensor C1 was the external sensor located outside the building for case study one. For case study two and three, no external $\mathrm{CO}_{2}$ sensor was located outside the building due to security reasons. The column annotated as "Diff" represented the calculation of the difference between sensor A2 (Central) and the vertical wall sensor that showed the least relationship in the ratio analysis above to ascertain the level of variation between the sensor points.

\section{Average $\mathrm{CO}_{2}$ levels}

In Tables 54 to 59, average $\mathrm{CO}_{2}$ levels between 8 am to $3 \mathrm{pm}$ in all three case studies for both horizontal and vertical sensors are presented. As shown in the column annotated with "Diff": the average $\mathrm{CO}_{2}$ level in the central horizontal measuring plane sensor (A2) was subtracted from the vertical wall sensor B2 in case study one and three and sensor B1 in case study two because these sensors had a higher ratio change Section 8.1.3 above. While the "diff" column was annotated with a grey fill, the two sensor points used to calculate the difference between vertical and horizontal sensors is annotated with a green fill. For example, in case study one, around 8 am in the autumn, sensor A2 recorded 412 ppm while sensor B2 (East) recorded 451 ppm and the difference between these two $\mathrm{CO}_{2}$ values was $39 \mathrm{ppm}$.

In Tables 54 to 59 and in all three case studies, the $\mathrm{CO}_{2}$ variation between the horizontal measuring plane sensors and the vertical wall sensors were largely $<100$ ppm. However, during the school days, the $\mathrm{CO}_{2}$ variations went up to $\pm 300 \mathrm{ppm}$ at some point in time. This was observed to be due to $\mathrm{CO}_{2}$ generation by occupants. During the cold autumn season, there are significant variations in the levels of $\mathrm{CO}_{2}$ when the classroom windows are closed to warm up the space and keep the temperature within acceptable levels for teaching. However, the difference becomes less pronounced during the summer which is a warmer season with the windows and doors in the classrooms opened for cross ventilation. This illustrates that under the influence of $\mathrm{CO}_{2}$ 
sources and actions of occupants to close and open their windows, there is a wider variation of $\mathrm{CO}_{2}$ concentration from one part of a space to another, and hence a one-point sensor may not provide reliable data that is representative of an entire space.

\section{Non-School Days}

Table 54: Average $\mathrm{CO}_{2}$ levels in the non-school days from 8 am-3 pm

\begin{tabular}{|c|c|c|c|c|c|c|c|c|}
\hline \multicolumn{9}{|c|}{ Case Study One Autumn } \\
\hline The grey colt & In is the diff & ence betwe & sensor (A2) & Id the vertic & sensor with & le least rela & nship in the & atio ana \\
\hline Hour & $\begin{array}{c}\text { Central } \\
\text { A1 (ppm) }\end{array}$ & $\begin{array}{c}\text { Central } \\
\text { A2 (ppm) }\end{array}$ & $\begin{array}{c}\text { Central } \\
\text { A3 (ppm) }\end{array}$ & $\begin{array}{c}\text { South } \\
\text { B1 (ppm) }\end{array}$ & $\begin{array}{c}\text { East } \\
\text { B2 (ppm) }\end{array}$ & $\begin{array}{c}\text { North } \\
\text { B3 (ppm) }\end{array}$ & $\begin{array}{c}\text { West } \\
\text { B4 (ppm) }\end{array}$ & $\begin{array}{c}\text { Diff } \\
\text { (ppm) }\end{array}$ \\
\hline $8 \mathrm{am}$ & 400 & 412 & 402 & 436 & 451 & 495 & 415 & -39 \\
\hline $9 \mathrm{am}$ & 400 & 409 & 404 & 435 & 451 & 490 & 417 & -42 \\
\hline $10 \mathrm{am}$ & 401 & 411 & 402 & 440 & 453 & 492 & 419 & -42 \\
\hline 11 am & 401 & 412 & 400 & 440 & 453 & 497 & 427 & -41 \\
\hline $12 \mathrm{pm}$ & 404 & 410 & 403 & 441 & 449 & 491 & 429 & -39 \\
\hline $1 \mathrm{pm}$ & 400 & 411 & 402 & 444 & 449 & 490 & 426 & -38 \\
\hline $2 \mathrm{pm}$ & 404 & 408 & 404 & 440 & 453 & 496 & 423 & -45 \\
\hline $3 \mathrm{pm}$ & 408 & 413 & 401 & 442 & 453 & 498 & 423 & -40 \\
\hline
\end{tabular}

Table 55: Average $\mathrm{CO}_{2}$ levels in the non-school days from $8 \mathrm{am}-3 \mathrm{pm}$

Case Study One- Summer

The grey column is the difference between sensor (A2) and the vertical sensor with the least relationship in the ratio analysis

\begin{tabular}{|c|c|c|c|c|c|c|c|c|}
\hline Hour & $\begin{array}{c}\text { Central } \\
\text { A1 (ppm) }\end{array}$ & $\begin{array}{c}\text { Central } \\
\text { A2 (ppm) }\end{array}$ & $\begin{array}{c}\text { Central } \\
\text { A3 (ppm) }\end{array}$ & $\begin{array}{c}\text { South } \\
\text { B1 (ppm) }\end{array}$ & $\begin{array}{c}\text { East } \\
\text { B2 (ppm) }\end{array}$ & $\begin{array}{c}\text { North } \\
\text { B3 (ppm) }\end{array}$ & $\begin{array}{c}\text { West } \\
\text { B4 (ppm) }\end{array}$ & $\begin{array}{c}\text { Diff } \\
\text { (ppm) }\end{array}$ \\
\hline $\mathbf{8 ~ a m ~}$ & 412 & 431 & 408 & 445 & 476 & 450 & 478 & -45 \\
\hline $\mathbf{9} \mathbf{~ a m}$ & 414 & 438 & 413 & 445 & 469 & 453 & 476 & -31 \\
\hline $\mathbf{1 0} \mathbf{~ a m}$ & 410 & 447 & 412 & 447 & 472 & 455 & 472 & -25 \\
\hline $\mathbf{1 1} \mathbf{~ a m}$ & 410 & 447 & 409 & 445 & 469 & 455 & 470 & -22 \\
\hline $\mathbf{1 2} \mathbf{~ p m}$ & 407 & 461 & 405 & 447 & 469 & 453 & 472 & -8 \\
\hline $\mathbf{1} \mathbf{~ p m}$ & 404 & 464 & 410 & 448 & 464 & 449 & 471 & 0 \\
\hline $\mathbf{2} \mathbf{~ p m}$ & 407 & 456 & 410 & 447 & 465 & 449 & 464 & -9 \\
\hline $\mathbf{3} \mathbf{~ p m}$ & 405 & 450 & 408 & 448 & 463 & 449 & 462 & -13 \\
\hline
\end{tabular}

Table 56: Average $\mathrm{CO}_{2}$ levels in the non-school days from $8 \mathrm{am}-3 \mathrm{pm}$

\begin{tabular}{|c|c|c|c|c|c|}
\hline \multicolumn{7}{|c|}{ Case Study Two - Autumn } \\
\hline The grey column is the difference between sensor (A2) and th \\
\hline Hour & $\begin{array}{c}\text { Central } \\
\text { A2 (ppm) }\end{array}$ & $\begin{array}{c}\text { South } \\
\text { B1 (ppm) }\end{array}$ & $\begin{array}{c}\text { West } \\
\text { B4 (ppm) }\end{array}$ & $\begin{array}{c}\text { North } \\
\text { B3 (ppm) }\end{array}$ & $\begin{array}{c}\text { Diff } \\
\text { (ppm) }\end{array}$ \\
\hline $\mathbf{8}$ am & 456 & 512 & 400 & 442 & -56 \\
\hline $\mathbf{9}$ am & 455 & 509 & 406 & 446 & -54 \\
\hline $\mathbf{1 0}$ am & 454 & 505 & 404 & 449 & -51 \\
\hline $\mathbf{1 1}$ am & 450 & 509 & 409 & 445 & -59 \\
\hline $\mathbf{1 2}$ pm & 451 & 508 & 412 & 447 & -57 \\
\hline $\mathbf{1}$ pm & 466 & 519 & 423 & 456 & -53 \\
\hline $\mathbf{2}$ pm & 457 & 514 & 415 & 451 & -57 \\
\hline $\mathbf{3}$ pm & 456 & 508 & 410 & 444 & -52 \\
\hline
\end{tabular}

Case Study Three - Spring

\begin{tabular}{|c|c|c|c|c|c|}
\hline Hour & $\begin{array}{c}\text { Central } \\
\text { A2 (ppm) }\end{array}$ & $\begin{array}{c}\text { South } \\
\text { B1 (ppm) }\end{array}$ & $\begin{array}{c}\text { East } \\
\text { B2 (ppm) }\end{array}$ & $\begin{array}{c}\text { North } \\
\text { B3 (ppm) })\end{array}$ & $\begin{array}{c}\text { Diff } \\
\text { (ppm) }\end{array}$ \\
\hline 8 am & 409 & 472 & 425 & 419 & -16 \\
\hline 9 am & 419 & 469 & 424 & 417 & -5 \\
\hline $\mathbf{1 0}$ am & 431 & 472 & 423 & 416 & 8 \\
\hline $\mathbf{1 1}$ am & 445 & 471 & 412 & 412 & 33 \\
\hline $\mathbf{1 2}$ pm & 454 & 478 & 414 & 415 & 40 \\
\hline $\mathbf{1}$ pm & 426 & 502 & 411 & 408 & 15 \\
\hline $\mathbf{2}$ pm & 469 & 558 & 438 & 438 & 31 \\
\hline $\mathbf{3 ~ p m}$ & 519 & 608 & 441 & 447 & 78 \\
\hline
\end{tabular}




\section{School Days}

Table 57: Average $\mathrm{CO}_{2}$ levels in the school days from 8 am-3 pm

\begin{tabular}{|c|c|c|c|c|c|c|c|c|}
\hline \multicolumn{9}{|c|}{ Case Study One - Autumn } \\
\hline Hour & $\begin{array}{c}\text { Central } \\
\text { A1 (ppm) }\end{array}$ & $\begin{array}{c}\text { Central } \\
\text { A2 (ppm) }\end{array}$ & $\begin{array}{c}\text { Central } \\
\text { A3 (ppm) }\end{array}$ & $\begin{array}{c}\text { South } \\
\text { B1 (ppm) }\end{array}$ & $\begin{array}{c}\text { East } \\
\text { B2 (ppm) }\end{array}$ & $\begin{array}{c}\text { North } \\
\text { B3 (ppm) }\end{array}$ & $\begin{array}{c}\text { West } \\
\text { B4 (ppm) }\end{array}$ & $\begin{array}{c}\text { Diff } \\
(\mathrm{ppm})\end{array}$ \\
\hline $8 \mathrm{am}$ & 682 & 554 & 533 & 542 & 555 & 520 & 546 & -1 \\
\hline $9 \mathrm{am}$ & 1140 & 1025 & 1011 & 1064 & 1133 & 1107 & 1148 & -108 \\
\hline $10 \mathrm{am}$ & 1634 & 1520 & 1452 & 1633 & 1674 & 1549 & 1682 & -154 \\
\hline $11 \mathrm{am}$ & 673 & 722 & 704 & 755 & 666 & 825 & 849 & 56 \\
\hline $12 \mathrm{pm}$ & 680 & 605 & 614 & 646 & 693 & 588 & 669 & -88 \\
\hline $1 \mathrm{pm}$ & 692 & 693 & 682 & 722 & 738 & 672 & 725 & -45 \\
\hline $2 \mathrm{pm}$ & 676 & 677 & 630 & 700 & 696 & 672 & 690 & -19 \\
\hline $3 \mathrm{pm}$ & 452 & 478 & 423 & 478 & 508 & 480 & 516 & -30 \\
\hline
\end{tabular}

Table 58: Average $\mathrm{CO}_{2}$ levels in the school days from $8 \mathrm{am}-3 \mathrm{pm}$

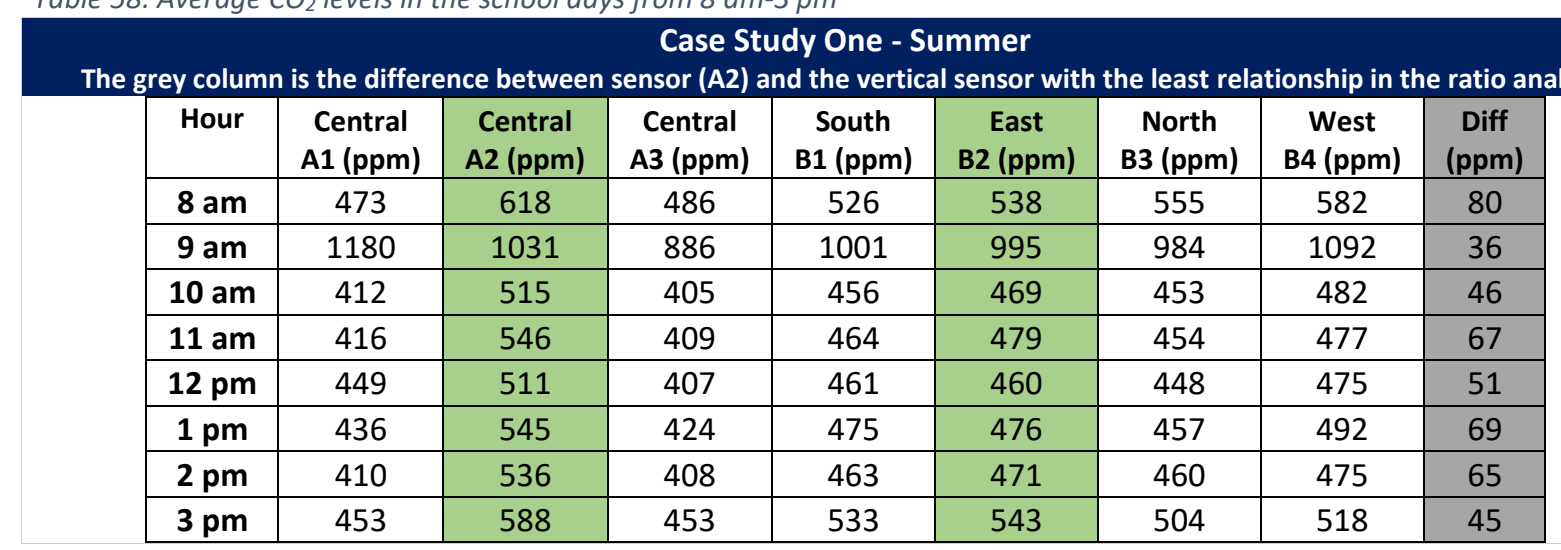

Table 59: Average $\mathrm{CO}_{2}$ levels in the school days from $8 \mathrm{am}-3 \mathrm{pm}$

Case Study Two - Autumn

Case Study Three - Spring

The grey column is the difference between sensor (A2) and the vertical sensor with the least relationship in the ratio analysis

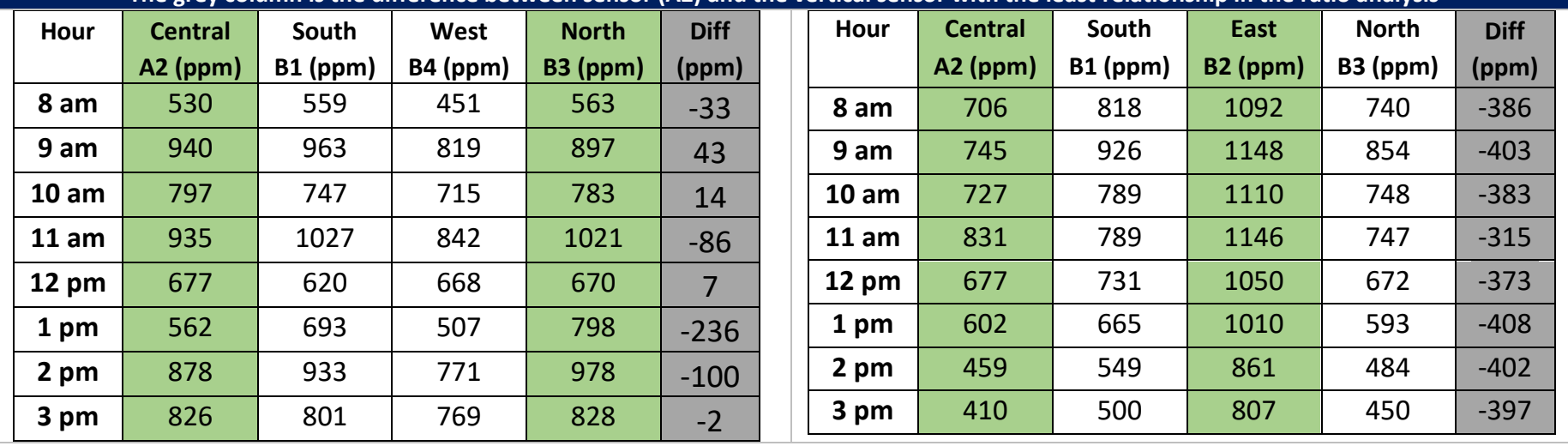




\subsubsection{Carbon Dioxide Measurement Discussion}

There is evidence in the literature that measuring $\mathrm{CO}_{2}$ concentration in spaces is a useful indicator of IAQ and often assist to understand ventilation effectiveness. Hence, the importance of reliably predicting $\mathrm{CO}_{2}$ levels using physical measurements. The results of all three case studies and across all seasons indicated that there is non-uniformity of $\mathrm{CO}_{2}$ concentration between horizontal measuring plane sensors and the vertical wall sensors. The line graphs, sparklines and hourly average analysis showed that in both non-school days (unoccupied) and in school days (occupied) there is the variability of $\mathrm{CO}_{2}$ concentration which was largely $\pm 100 \mathrm{ppm}$. This equates to a variation of about $20 \%$ of the average $\mathrm{CO}_{2}$ concentration within the space. This variation was largely due to the proximity of groups of $\mathrm{CO}_{2}$ sources (such as students) and lack of air movement in relation to the sensors' position. These findings are consistent with a study by Mahyuddin \& Awbi, (2010) which found that "in the spatial distribution of $\mathrm{CO}_{2}$, the difference between the maximum and the minimum concentration was in the range of 76-123ppm". ASTM, (2009) suggested that when measuring multiple $\mathrm{CO}_{2}$ points, the monitored points should differ by less than $10 \%$ of the average $\mathrm{CO}_{2}$ concentration in the building. Given that a $20 \%$ variation was identified in this experiment, it can, therefore, be inferred that it is difficult to use a one-point sensor measurement to estimate the spatial distribution of $\mathrm{CO}_{2}$ across a space.

Occupancy ratio significantly impacted on the variability of $\mathrm{CO}_{2}$ concentrations during occupied school days. About 30 students usually occupy the case study classrooms, but given that it is a flexible learning space, the occupancy may vary depending on the type of activity as students move across the 3 units (90 students in total) of the classroom for case study one and two. In schools, occupants are a major source of $\mathrm{CO}_{2}$ exhalation, the study results and observation indicated that factors such as; the occupancy density, the floor area per person, and the teaching styles largely impact on $\mathrm{CO}_{2}$ levels. Naturally, $\mathrm{CO}_{2}$ concentrations within buildings will fluctuate depending on the number of occupants, activities being performed and time of the year. The results of the experiment and observations revealed that when students arrived in the morning, the line graphs showed a sharp increase in $\mathrm{CO}_{2}$ levels, when they go outside for lunch break, the $\mathrm{CO}_{2}$ levels significantly decrease and increase again after the lunch break. Also, when the students finish for the day, the $\mathrm{CO}_{2}$ levels significantly decreases and seems to be within a 400 to 
500 ppm range throughout the night. This affirmed that when the occupancy in a classroom is transient, there will be a significant effect on the variation of $\mathrm{CO}_{2}$ concentrations

There was an association between airflow (ventilation levels) and $\mathrm{CO}_{2}$ levels in the classrooms. The case study analysis revealed the importance of airflow in maintaining carbon dioxide $\left(\mathrm{CO}_{2}\right)$ levels below $1000 \mathrm{ppm}$. As shown in the analysis above when students arrived the classroom, there was a high spike in $\mathrm{CO}_{2}$ levels, but as the space warms up within the course of the day and they begin to open the windows especially when the classroom doors are open for a lunch break, there was a significant drop in $\mathrm{CO}_{2}$ levels. This indicated that if operated properly the buildings natural ventilation system is fit for purpose. In Figure 66 below and given that it is possible to estimate ventilation rate in a building from the difference between $\mathrm{CO}_{2}$ indoors and outdoors, the air exchange rate in case study one classroom (summer and autumn) was estimated according to the tracer gas $\left(\mathrm{CO}_{2}\right)$ mass balance. To validate the model, the following assumptions were made:

- the classroom was taken as a single zone model when the net rate is pollutant generation and ventilation rate are constant;

- the $\mathrm{CO}_{2}$ was well mixed;

- ventilation effectiveness was 0.75 (Shendell et al., 2004; Toyinbo et al., 2016).

The ambient $\mathrm{CO}_{2}$ outside concentration level of the external sensor ranged from 390-410ppm, hence $400 p p m$ was used for the calculation of ambient $\mathrm{CO}_{2}$; The ventilation rate $\mathrm{Q}$ (in litres per second) to remove pollutants from the air can be calculated with the formula:

$$
Q=\frac{\text { Emission rate } \times\left(10^{6}-\mathrm{C}_{\mathrm{pi}}\right)}{\mathrm{E}_{v} \times \mathrm{C}_{p i}-C_{p o}}
$$

Where:

- $\quad \mathrm{C}_{\mathrm{pi}}=$ Inside concentration in parts per million (ppm)

- $\mathrm{C}_{\mathrm{po}}=$ Outside concentration

- $E_{\mathrm{v}}=$ Ventilation effectiveness 
- The $\mathrm{CO}_{2}$ generation rates were 0.0052L.s- ${ }^{1}$ and 0.0029L.s- ${ }^{1}$ for each teacher and pupil respectively (Bennett et al., 2019).

Using the above formula on a pre-designed Excel calculator, the average $\mathrm{CO}_{2}$ generated in the classroom per hour plus the $\mathrm{CO}_{2}$ coming into classrooms from outside minus the $\mathrm{CO}_{2}$ expelled from the classroom were calculated to equal to the net change of the $\mathrm{CO}_{2}$ concentration. And to calculate the Air Change per Hour (ACH), the classroom volume of $214.2 \mathrm{~m}^{3}$ was applied using the formula below:

$$
A C H=\frac{3.6 \mathrm{Q}}{\text { Volume of space }}
$$

As shown in Figure 66, the average air exchange rate in the classroom was above the 8Ls-1 minimum recommended ASHRAE standard (Bennett et al., 2019) for both summer and autumn, which indicated the effectiveness of the passive ventilation strategy used in the classroom. Coley \& Beisteiner, (2016); Coley \& Greeves, (2004) state that "the value of 8 I s-1p-1 is used because it implies the concentration of $\mathrm{CO}_{2}$ in a fully occupied classroom can never exceed 1000ppm, however long the room is occupied".

As shown in Figure 87, the average air exchange rate in the classroom was above the 7.4L/s*person minimum recommended ASHRAE standard for both summer and autumn, which indicated the effectiveness of the passive ventilation strategy used in the classroom. The line graphs in chapter four also indicated that three were instances of high $\mathrm{CO}_{2}$ concentration especially when the students arrived the class around 9:30 am and shortly after break by noon and prior to when they begin to open their windows to adjust to their indoor environment. This is evident in the poor air exchange rate recorded between 9 am to 10 am and around noon in Figure 87 below. 


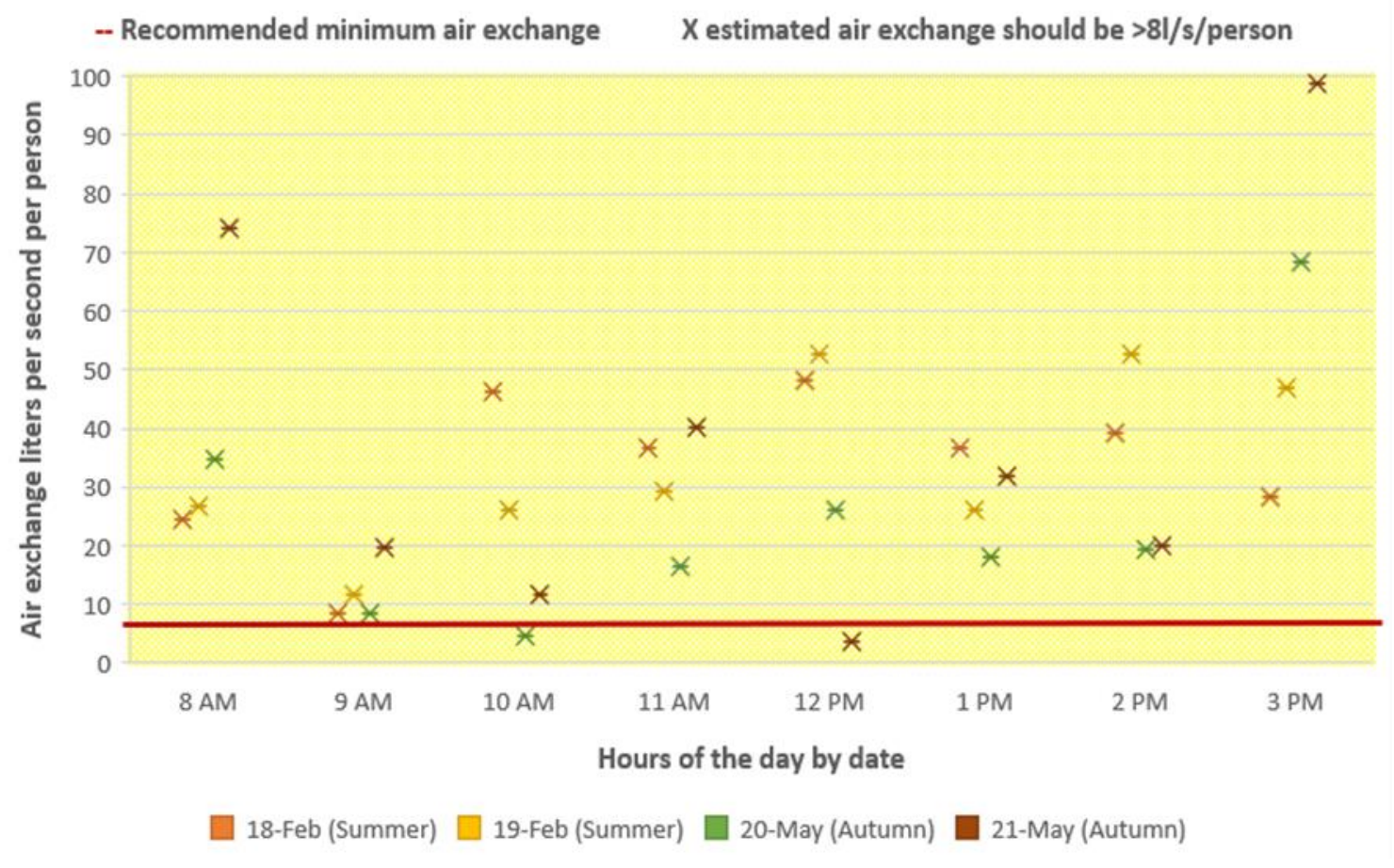

Figure 87: Ventilation rates calculated using measures of $\mathrm{CO}_{2}$

Airflow is achieved through an effective ventilation system, which is needed to remove pollutants such as $\mathrm{CO}_{2}$, moisture and volatile organic compounds from the building's internal environment (Bennett et al., 2019; Mahyuddin \& Awbi, 2010; Mclntosh, 2011). The case study classrooms were naturally ventilated and designed to provide indoor air using openable windows and doors to let in the fresh air, to exhaust stale air and to dilute pollutants in the classroom as well as cool the space in the summer. And this type of ventilation system is typical of a large number New Zealand classrooms (Bassett \& Gibson P, 1999; Boulic et al., 2018; Mclntosh, 2011; Wang et al., 2016).

The pattern of increase and decrease in $\mathrm{CO}_{2}$ levels between non-school and school days and the significant drop in $\mathrm{CO}_{2}$ levels when occupants open the doors indicated that airflow influenced the variation in $\mathrm{CO}_{2}$ levels within the classroom. Mahyuddin \& Awbi, (2010) suggested that "due to gravitational settling and a non-uniform air-flow field, $\mathrm{CO}_{2}$ concentration within a building may vary from location to location". Basset \& Gibson, (1999); Santamouris et al., (2008) concur that steady state conditions of $\mathrm{CO}_{2}$ are rarely achieved in naturally ventilated classrooms due to the forces of wind or buoyancy, resulting in continuous variability and fluctuations in the air-flow through windows and openings which impacts on the variability of $\mathrm{CO}_{2}$ concentrations. In the 
autumn time, the doors and windows were seldom open, and the data trends revealed that in non-ventilated occupied spaces, there is a spatial variation of $\mathrm{CO}_{2}$ concentration across the space. This affirms that airflow in classrooms, which is determined by the type of ventilation strategy and occupant's behaviour has a significant influence on the spatial distribution of $\mathrm{CO}_{2}$ concentrations. This also strengthens the assertion that there is a relationship between reduced air changes (strongly influenced by the available air space per person) and increased $\mathrm{CO}_{2}$ levels. Therefore, to select the correct sampling locations for obtaining average $\mathrm{CO}_{2}$ values in a space, understanding the effect of air movement is a useful factor to take into consideration. Mahyuddin, Awbi, \& Alshitawi, (2014) suggested that "the location and strength of the source of $\mathrm{CO}_{2}$ (mainly occupants), and the type of ventilation systems available and the resulting indoor air movements are factors that affect the spatial distribution of $\mathrm{CO}_{2}$ across a space".

The external $\mathrm{CO}_{2}$ levels were below the internal $\mathrm{CO}_{2}$ levels for both non-school and school days. The commonly referenced guideline value for external $\mathrm{CO}_{2}$ levels is about 410 ppm (NIWA). In case study one, the measured external atmospheric concentrations were around $400 \mathrm{ppm}$ and it is expected that due to normal respiration rates of occupants, $\mathrm{CO}_{2}$ levels in enclosed spaces will naturally increase above atmospheric levels. Therefore, it is vital to measure the outdoor $\mathrm{CO}_{2}$ levels due to the existence of local variations in the outdoor $\mathrm{CO}_{2}$ concentration. The results indicated that irrespective of the season and building orientation, airflow, occupancy ratio, periods and the activity levels, intermittent behaviour of school children and external conditions such as outdoor $\mathrm{CO}_{2}$ levels are the most important parameters that determine the distribution of $\mathrm{CO}_{2}$ in classrooms.

In the literature review, researchers preferred heights between $1.0 \mathrm{~m}$ to $1.5 \mathrm{~m}$ in the middle of a zone as a representative location and preferred having one sampling point in a room at a representative occupied location. However, when $\mathrm{CO}_{2}$ concentration is non-uniform as evident from the analysis above, there will be deviations from the average expected $\mathrm{CO}_{2}$ levels across a space. The results of this study showed that higher levels of $\mathrm{CO}_{2}$ concentration were also found in the wall mounted sensors $(1.5 \mathrm{~m})$, which were not within the students breathing height and the horizontal plane sensors which were within the students breathing height also showed a variance in $\mathrm{CO}_{2}$ concentration. Mahyuddin et al., (2014) experiment on the spatial distribution of 
$\mathrm{CO}_{2}$ levels across different heights indicated that even at higher levels in a room above 1.0m and $1.2 \mathrm{~m}$, there were higher $\mathrm{CO}_{2}$ concentration values. They suggested that deviations from the average measured values could become large when there is a significant variation in $\mathrm{CO}_{2}$ concentration levels. When measuring $\mathrm{CO}_{2}$ concentration at scale in buildings to identify spaces with good or poor air quality, a \pm 100 ppm temporal non-uniform variation of $\mathrm{CO}_{2}$ concentration is not so large, given that it might be within the acceptable $\mathrm{CO}_{2}$ concentration limit and is highly unlikely to constitute a risk to health in the range of values found in this thesis. " $\mathrm{CO}_{2}$ at the concentrations commonly found in buildings (generally found indoors) is not a direct health risk and in most buildings, concentrations rarely rise to very high limits (e.g. greater than 5000 ppm)" (ASHRAE Standard 62.1-2016). Therefore, this thesis concludes that measuring $\mathrm{CO}_{2}$ using a onepoint sensor at a height of $1.5 \mathrm{~m}$ above the floor and not relatively close to people can be useful to estimate the $\mathrm{CO}_{2}$ concentration within a space, in conjunction with the understanding of the sources of $\mathrm{CO}_{2}$ and their distribution. This conclusion is coherent with ASTM, (2009) which recommends that " $\mathrm{CO}_{2}$ concentrations should not be measured close to people and a distance of $2.0 \mathrm{~m}$ away from any occupant is sufficient to avoid the occupant's effects". However, using more than one sensor to monitor $\mathrm{CO}_{2}$ in an occupied space could significantly improve the accuracy of determining the average $\mathrm{CO}_{2}$ concentration that is representative of the space.

\subsubsection{How to use a One-Point Sensor for IAQ Prediction}

The commonly referenced design goal limits for carbon dioxide is $1000 \mathrm{ppm}$, which is based on a 650 ppm concentration difference with the typical outdoor levels of $410 \mathrm{ppm}$. The $\mathrm{CO}_{2}$ concentration limit is intended to serve as a limiting proxy for a range of other airborne pollutants. If measuring $\mathrm{CO}_{2}$ levels at scale in buildings to ascertain indoor air quality conditions, below are insights from the experiment on how a one-point sensor can be used:

- The study results showed that irrespective of the location of the sensors, there was temporal non-uniformity of $\mathrm{CO}_{2}$ concentration across different sensor points, but this variation may not be so great, given that it might be within the acceptable $\mathrm{CO}_{2}$ concentration limit and the ratio change was largely a ratio of one

- While one sensor is not ideal for measuring $\mathrm{CO}_{2}$ concentration across a space, if a sensor is placed at a reasonable distance away from occupants (to avoid the occupant's effects) 
and non-uniform air-flow, a strategically positioned one-point sensor on the vertical wall could be useful to provide indicative data about the $\mathrm{CO}_{2}$ concentration of a space

- This approach can't be used to accurately predict the amount of $\mathrm{CO}_{2}$ concentration in different parts of a space but provides a good indication of spaces with good or poor air quality

- Using more than one sensor to monitor $\mathrm{CO}_{2}$ in an occupied space could significantly improve the accuracy of determining the average $\mathrm{CO}_{2}$ concentration that is representative of the space

- Figure 88 uses a typical simple form classroom typology to illustrate how to use a onepoint sensor to measure $\mathrm{CO}_{2}$ levels at scale in buildings

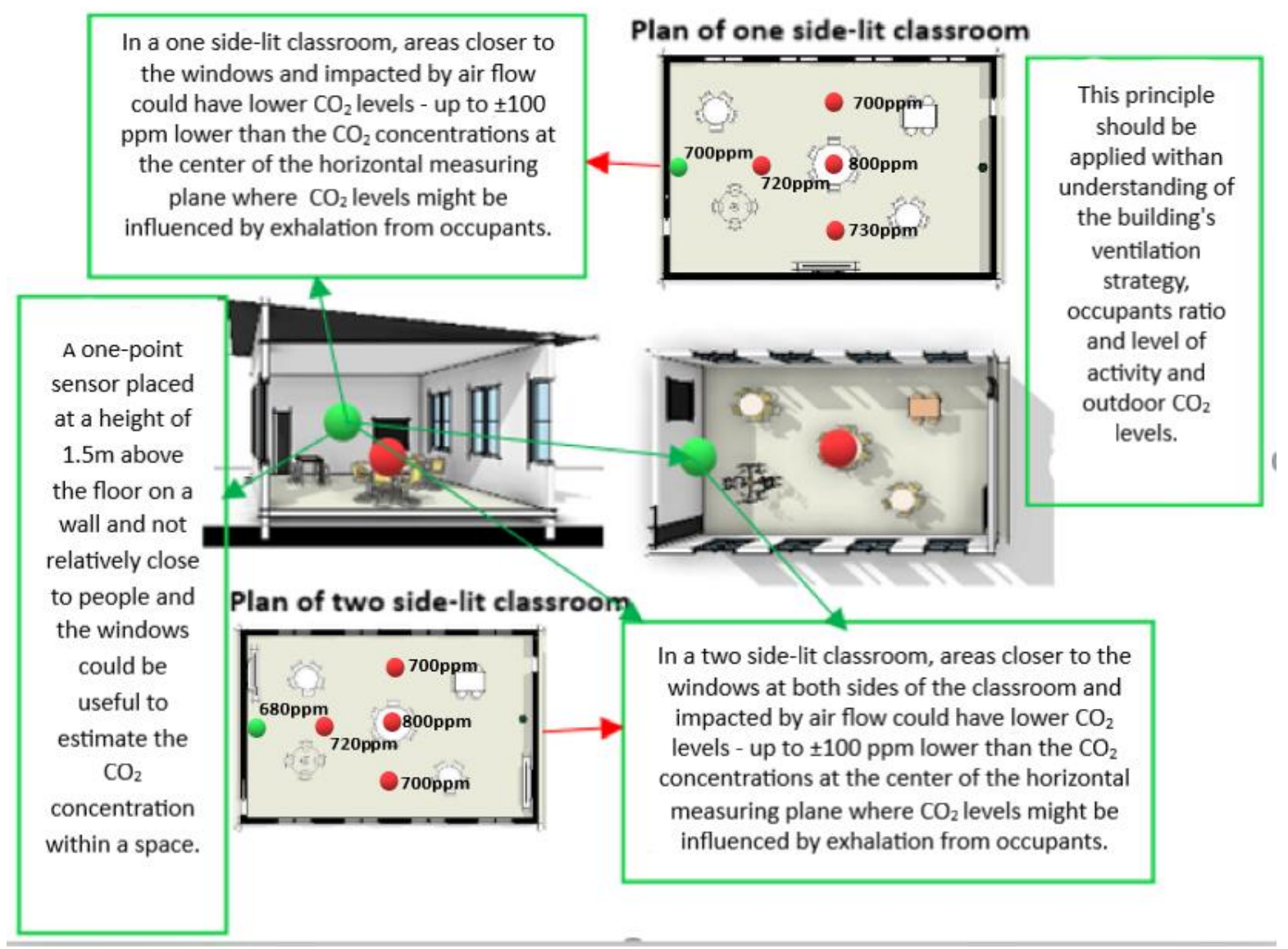

Figure 88: Illustration of how to use a one-point sensor to measure $\mathrm{CO}_{2}$ at scale in many buildings 


\begin{tabular}{|c|c|c|c|c|}
\hline $\begin{array}{c}\text { IEQ } \\
\text { Variable }\end{array}$ & $\begin{array}{l}\text { Factors Influencing } \\
\text { Variability } \\
\text { (What factors impact IEQ) }\end{array}$ & $\begin{array}{c}\text { Key Considerations } \\
\text { (Challenges of using a single multi- } \\
\text { variable sensor) }\end{array}$ & $\begin{array}{c}\text { Solutions } \\
\text { (Prediction of IEQ distribution using a } \\
\text { single multi-variable sensor) }\end{array}$ & $\begin{array}{l}\text { Recommendations } \\
\text { (Suite of simple interventions to } \\
\text { address poor IEQ) }\end{array}$ \\
\hline$\frac{\cos }{\frac{c}{2}}$ & $\begin{array}{l}\text { - The position of the sun at a point } \\
\text { in time } \\
\text { - } \quad \text { Degree of cloudiness } \\
\text { building characteristics (such as } \\
\text { but not limited to building } \\
\text { orientation, form, reflectance's of } \\
\text { the interior surfaces, and window } \\
\text { configuration) } \\
\text { - External site-specific conditions } \\
\text { (such as but not limited to } \\
\text { vegetation, trees, topography) } \\
\text { - Seasonal changes in shading } \\
\text { (reflection from nearby } \\
\text { deciduous vegetation) }\end{array}$ & $\begin{array}{l}\text { The variability of the exterior } \\
\text { illuminance (solar radiation) largely } \\
\text { impacts on the quantity and distribution } \\
\text { of internal illuminance } \\
\text { The position of a sensor relative to the } \\
\text { artificial lighting could also result in } \\
\text { differences in internal illuminance } \\
\text { distribution } \\
\text { - Instances of excessive illuminance } \\
\text { values (glare) revealed that even small } \\
\text { variations in sensor points relative to } \\
\text { the glazed area could produce } \\
\text { significant differences in the illuminance } \\
\text { values } \\
\text { This makes it difficult for a one-point } \\
\text { sensor to predict the illuminance } \\
\text { distribution across a space }\end{array}$ & $\begin{array}{l}\text { The results illustrated that provided any } \\
\text { instances of glare is excluded from the } \\
\text { calculation, a strategically positioned one- } \\
\text { point sensor on the vertical wall could } \\
\text { reliably predict illuminance across the } \\
\text { centre of the horizontal work plane; and } \\
\text { provide a useful benchmark to use the } \\
\text { factors influencing variability to predict the } \\
\text { quantity of lighting distribution within a } \\
\text { space. } \\
\text { The best position for a light sensor is away } \\
\text { from any sources of glare and heat, and a } \\
\text { height of } 1.5 m \text { on the vertical wall could } \\
\text { serve as a proxy for predicting illuminance } \\
\text { across the centre of the horizontal work } \\
\text { plane. } \\
\text { Good lighting prediction requires the } \\
\text { understanding of a building's location, } \\
\text { placement, local climate and use patterns } \\
\text { and the shading of windows and skylights } \\
\text { relative to their solar orientation. }\end{array}$ & $\begin{array}{l}\text { - In more complex and deep open plan } \\
\text { classrooms, it will be ideal to use } \\
\text { more sensors for measurement to } \\
\text { pick up areas impacted by glare or a } \\
\text { Climate Based Daylight Modelling } \\
\text { should be undertaken in conjunction } \\
\text { with the one-point sensor } \\
\text { measurement. } \\
\text { Interventions such as the use of } \\
\text { skylight diffusers, appropriate window } \\
\text { orientation, shading overhangs and } \\
\text { the use of interior blinds are useful } \\
\text { strategies to eliminate glare. } \\
\text { When pleasant daylighting is } \\
\text { available, switching off artificial } \\
\text { lighting when they are not needed, } \\
\text { will save electricity, the life of the } \\
\text { electric lighting system will be } \\
\text { extended and can save much of a } \\
\text { school's maintenance and energy } \\
\text { cost. }\end{array}$ \\
\hline 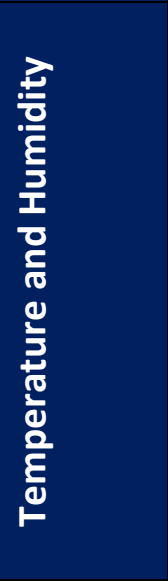 & $\begin{array}{l}\text { - The position of the sun at a point } \\
\text { in time } \\
\text { - Occupancy ratio } \\
\text { - Use of heating systems } \\
\text { - } \quad \text { Activity levels/metabolic rate } \\
\text { building characteristics (such as } \\
\text { shape, fabric, to oriazing, } \\
\text { - fenestration and ventilation) } \\
\text { - Seasonal changes in shading }\end{array}$ & $\begin{array}{l}\text { Sources of heat are primary factors that } \\
\text { determine the variability of } \\
\text { temperature and relative humidity } \\
\text { within a space } \\
\text { Temperature and humidity sensors } \\
\text { should be placed away from glazed } \\
\text { areas, in locations that are not exposed } \\
\text { to direct irradiation from the sun, } \\
\text { avoiding radiators and cooling systems, } \\
\text { lighting sources, and from thermal } \\
\text { sources such as the human body }\end{array}$ & $\begin{array}{l}\text { The results Illustrated that the difference } \\
\text { between the highest and lowest } \\
\text { temperature was largely }<2^{\circ} \mathrm{C} \text { and humidity } \\
\text { was }<7 \% \text {. } \\
\text { The best position for temperature and } \\
\text { relative humidity sensor is near head height } \\
\text { of around } 1.5 \mathrm{~m} \text { away from the floor level } \\
\text { and sources of heat, this will avoid } \\
\text { tampering while not compromising the } \\
\text { collation of reliable data. }\end{array}$ & $\begin{array}{l}\text { - Interventions such as the use of } \\
\text { adjustable shading (blinds and } \\
\text { deciduous plants) can provide } \\
\text { flexibility in variable climatic } \\
\text { situations. } \\
\text { During the summer, night purging } \\
\text { through the opening of windows to } \\
\text { allow for natural airflow or attic fan of } \\
\text { a room during the night before it is } \\
\text { School day could enhance thermal } \\
\text { comfort during the occupied time. } \\
\text { Proper building orientation could } \\
\text { maximize the potentials of solar gain } \\
\text { to cool a space during the hot seasons } \\
\text { and warm it during the cold seasons }\end{array}$ \\
\hline
\end{tabular}


Non-School Days (Unoccupied hours):

- External noise sources such as traffic and wind and birds

\section{School Days (Occupied hours)}

- Noise generated from occupants

- Noise from equipment's (such as but not limited to television, alarm clock)

- $\quad$ External noise sources such as children playing in the nearby school field, which is transferred through open windows and doors

Occupancy leve

- Occupant behaviour

- Location and strength of the source of $\mathrm{CO}_{2}$ (human exhalation)

- Type of ventilation systems

- Air movement (Open or closed doors and windows)

- The existence of local variations in the outdoor $\mathrm{CO}_{2}$ levels

- The amount of time occupants spends in the classroom
- $\quad$ High noise levels generated from either internal or external sources could contribute to a temporal variation of sound levels across a space

- The factors of sound level variability should be taken into consideration when choosing a representative location to measure sound levels

- The influence of these factors on the variability of sound distribution suggested that single sound level figures may not provide a reliable representation of sound level distribution across an occupied classroom

- The variability of $\mathrm{CO}_{2}$ concentration is greater in occupied spaces than in unoccupied spaces

- Due to gravitational settling and a nonuniform air-flow field, $\mathrm{CO}_{2}$ concentration within a building may vary from location to location

- This equates to a variation of about $20 \%$ of the average $\mathrm{CO}_{2}$ concentration within a space

- Hence, the use of a one-point sensor measurement to determine the spatial distribution of $\mathrm{CO}_{2}$ could lead to unreliable predictions of the $\mathrm{CO}_{2}$
- $\quad$ The results showed that the relationship between the highest and lowest hourly average sound level distribution was largely $<3 \mathrm{dBA}$ for both non-school days and Schoo days in both seasons, which equates to a not so great variation of sound leve distribution within the space

- A vertical wall mounted sound level senso at a height of $1.5 \mathrm{~m}$ could provide a benchmark for assessing the sound levels across a space if the various sources of noise are well documented and analysed

- This sensor location assertion should avoid any disruption of the teachers work and should not disturb or distract the children while ensuring that the location of the sensor is not within the direct sound field of the teacher and above the nearest reflecting room surface

- Results illustrated that a $\pm 100 \mathrm{ppm}$ temporal non-uniform variation of $\mathrm{CO}_{2}$ concentration is not so large, given that it might be within the acceptable $\mathrm{CO}_{2}$ concentration limit and is highly unlikely to constitute a risk to health in the range of values found in this thesis

- Hence, $\mathrm{CO}_{2}$ could be measured using a onepoint sensor at a height of $1.5 \mathrm{~m}$ provided occupant's effects and the factors influencing variability are accounted for.

- $\quad$ Such as avoiding low concentration air from windows and air vents
Simple interventions such as:

- $\quad$ The use of acoustic tile ceiling materials with high absorption

- $\quad$ Soft floor finishing (carpets, rugs) with underlay

- $\quad$ Acoustic treatment on walls such as incorporating mass into external walls to block external noise

- $\quad$ Using more than one sensor to measure $\mathrm{CO}_{2}$ could significantly improve the accuracy of the data.

- $\quad$ Simple interventions such as window opening could be useful in reducing high $\mathrm{CO}_{2}$ levels during occupancy periods in naturally ventilated spaces

- And having an internal/external visible $\mathrm{CO}_{2}$ monitor to inform occupants to open windows. 


\section{CHAPTER NINE: DETERMINATION OF IEQ FRAMEWORK FOR}

\section{ANALYSING AND REPORTING IEQ AT SCALE}

The long-term measurements of IEQ in schools will provide big data for the assessment of the performance of school buildings to inform assets management and investment decisions. But how these large quantities of data could easily be processed and how they might be compared to learning performance data has proven challenging. From the intensive experiment on IEQ measurements in real-world classrooms as reported in Chapters 5 to 8 above, this thesis has shown that when monitoring IEQ at scale in classrooms, a one-point sensor located out of the sun, away from doors and windows on a vertical unglazed wall at $1.5 \mathrm{~m}$ height above the ground and in conjunction with the analyses of the factors of variability, could provide indicative IEQ data to identify good and poor classrooms.

If monitoring multiple buildings, the report method for the enormous amount of IEQ measured data is still unclear. Hence, the third objective of this study was to use insights from the case study data analysis to propose an analytical model for reporting IEQ at scale to inform design decisions and policy driven interventions. In the case study experiments, the measurement interval for IEQ was 10 seconds, that is 6 values per IEQ variable, per minute, and when multiplied by 60 minutes equals to 360 IEQ values per hour. When this value is multiplied by seven hours of the school day ( 8 am -3 pm), it translates to 2,520 IEQ values and 8640 IEQ values per variable for a whole day. Therefore, this chapter explores the idea of developing a single index that might be used to rank buildings according to their need for IEQ remedial work. This chapter uses insights from the literature (Chapter two) and case study experiments (Chapter 5 to 8 ) to develop an IEQ weighting scale and code for the systematic extraction and analyses of large quantities of IEQ to reveal patterns, trends and associations especially relating to building design, human behaviour and interactions.

\subsection{IEQ Variables Weighting Factor in Buildings}

In the assessment of IEQ in buildings, four variables are considered paramount. These variables are lighting quality, thermal quality, acoustic quality, and IAQ. These four variables individually contribute to IEQ performance in buildings. However, their relative importance as measures of IEQ may not be equivalent and the literature in Chapter two revealed that their contributory effect on students' learning performance in schools is not yet known. 
As shown in Figure 89 and Table 60 below, different studies have been undertaken towards determining the weight of each IEQ variable by assessing the perception of occupants' satisfaction of the IEQ condition of their building. The IEQ variable weights are either determined through survey responses from occupants or multivariate regression. For example, Chiang \& Lai, (2002) used the "Analytical Hierarchy Process" (AHP - a multi-criteria decision making method to derive ratio scales from paired comparisons) developed by Saaty in 1971 to establish IEQ variable weightings based on responses from professionals in office buildings. They found that IAQ had the highest weighting scheme and was the most important IEQ variable. They suggested that this could be due to the situation which surrounded the physiological and mental sensations of the occupants. Ncube \& Riffat, (2012) used a multiple regression model to derive relative weights for each IEQ variable and this was determined through a mathematical model that explains the relationship between the four variables and office building occupants IEQ perception. Like the study undertaken by Chiang \& Lai, (2002), they found that IAQ was also the most important variable while lighting quality was the least important variable.

In contrast to these two studies, Cao et al., (2012) carried out field studies in Beijing and Shanghai public buildings that included schools, offices and libraries to predict the overall occupant satisfaction with IEQ. They found that thermal quality, followed by acoustic quality and followed by lighting quality were the most important variables, while IAQ had the least weighting. They suggested that given that the model was derived in the environments which are around the comfortable level, thermal comfort was the highest ranked variable because the human body can adapt to the environment through physiological, psychological, and behavioural methods. The satisfaction with the indoor thermal environment was highest when the operative temperature was $22.8^{\circ} \mathrm{C}$ and the acceptable range of operative temperature was $15.8^{\circ} \mathrm{C}-30.0^{\circ} \mathrm{C}$. Catalina \& lordache, (2012) carried out a study on IEQ assessment at the building design stage and proposed a predictive model for IEQ index in schools. The model considered thermal quality as the highest ranked variable, followed by acoustics, IAQ and lighting as the least ranked.

In Hong Kong, Wong, Mui, \& Hui, (2008) carried out a study towards developing a multivariate - logistic model for IEQ acceptance, they sampled occupants' subjective opinion on the IEQ in air-conditioned office buildings, using a multivariate linear regression of occupants' 
responses to determine weighting factors for each IEQ variable in the model. They found that thermal quality was the highest ranked variable, followed by IAQ which ranked next while lighting quality ranked as the least important IEQ variable. They suggested that thermal quality was the highest ranked apparently because occupants were very sensitive to the operative temperature as compared with the other three parameters. In this thesis, the operative temperature was not being measured by the sensor, but a combination of air temperature and radiant temperature were measured. Heinzerling, Schiavon, Webster, \& Arens, (2013) used a multivariate linear regression coefficient established through the relationship between occupant's satisfaction with their office workspaces to propose weighting factors for each IEQ variable. Their weighting scale revealed that lighting and acoustic quality were more important than IAQ and thermal quality in office buildings due to occupant's sensation of these variables. Through the survey of 101 occupants of residential buildings using statistical process, Yoon, (2008) developed weighting factors for IEQ in residential buildings. Based on occupants' responses, they compared the level of importance of one IEQ parameter to another. Their analysis indicated that IAQ was the highest ranked variable while lighting quality ranked the least.

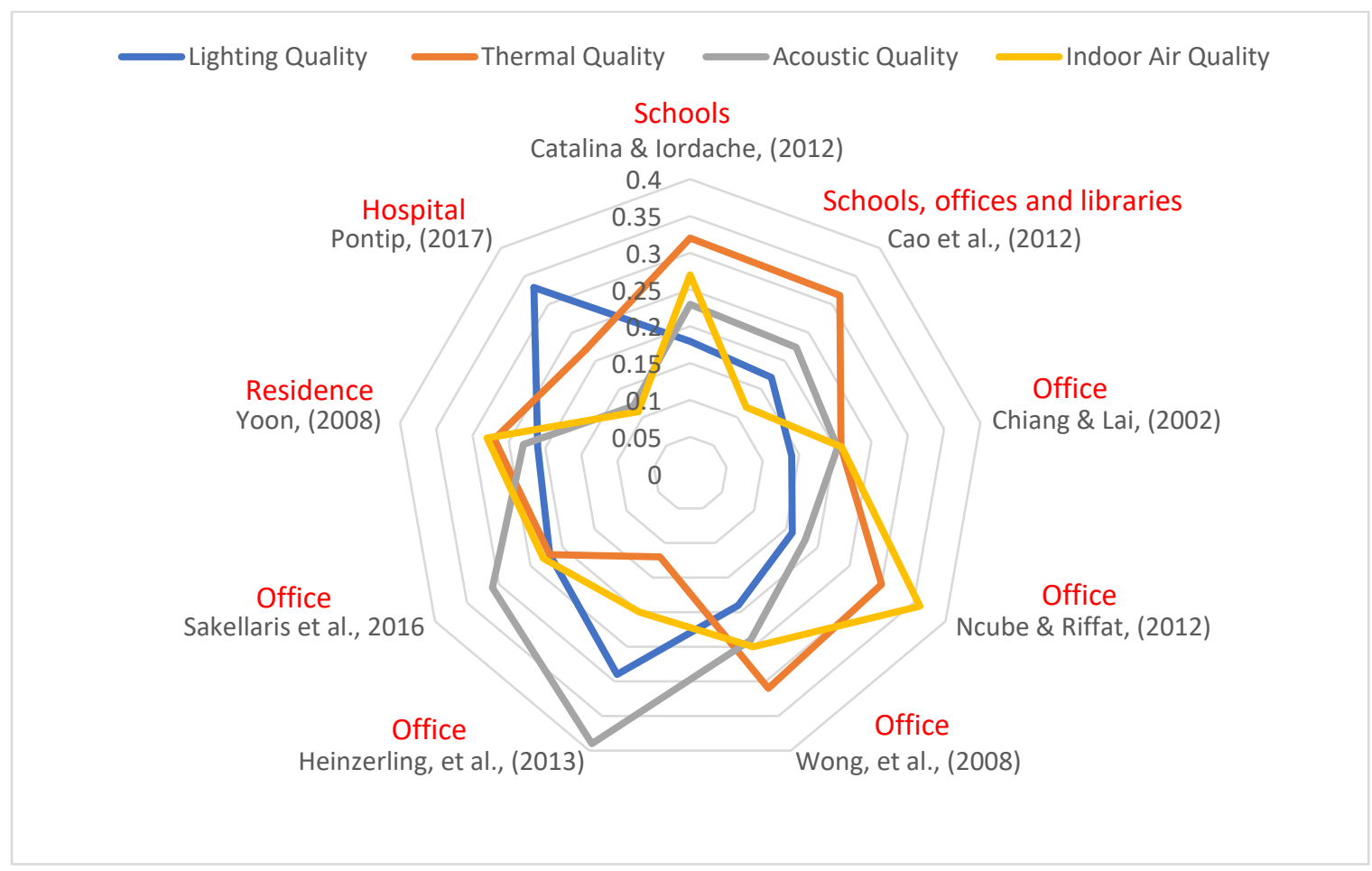

Figure 89: A spider plot summarizing the weighting schemes of the various IEQ studies 
As shown in Figure 89 above and Table 60 below, in Nigeria, Pontip, (2017) used standardized regression to assess the linear relationship between IEQ parameters and patient's overall satisfaction with their hospital ward buildings in a specialist and government hospital. The author found that different hospital ward buildings with different orientation and design configuration had weighting schemes that varied. In the specialist hospital, lighting quality was the highest-ranking variable in evaluating IEQ and patient's overall satisfaction followed by thermal quality, acoustic quality and the least variable was IAQ. Whereas, in the government hospital, the thermal quality was the highest ranking IEQ variable followed by lighting quality, IAQ and acoustic quality was the least variable. The author stated that lighting had a very strong correlation with patient's overall satisfaction due to the orientation of the specialist hospital wards facing the Northeast - Southwest axis, where the windows are exposed only to a short duration of daylight. However, the patient's health outcome had a stronger correlation with IAQ, apparently due to the poor indoor air quality as expressed by the patients in their subjective responses. They concluded that different hospital ward buildings with different orientation and design configuration had weighting schemes that vary.

In eight European countries (Finland, France, Greece, Hungary, Italy, The Netherlands, Portugal, and Spain), Sakellaris et al., (2016) carried out a study on the association between IEQ satisfaction and overall comfort in office buildings. They found that acoustic quality was the highest ranked environmental variable, followed by IAQ, while lighting and thermal quality showed almost the same correlation with overall comfort satisfaction. They suggested that noise was the highest ranked variable due to personal characteristics of occupants (gender and age had a significant association) and office layout. They concluded that perceived IEQ is related to geographical location and building characteristics. 


\begin{tabular}{|c|c|c|c|c|c|c|c|c|c|}
\hline \multirow[b]{2}{*}{$\mathbf{S} / \mathbf{N}$} & \multicolumn{9}{|c|}{ A colour code is used to indicate the IEQ weighting scheme with Green colour as the highest ranked variable, followed by Blue, Orange and Red colour is the least } \\
\hline & Authors & Methodology & Location & Building Type & $\begin{array}{l}\text { Lighting } \\
\text { Quality }\end{array}$ & $\begin{array}{l}\text { Thermal } \\
\text { Quality }\end{array}$ & $\begin{array}{l}\text { Acoustic } \\
\text { Quality }\end{array}$ & IAQ & Others \\
\hline 1. & Chiang \& Lai, (2002) & $\begin{array}{l}\text { Expert Survey } \\
\text { (Analytical Hierarchy Process - AHP) }\end{array}$ & Taiwan & Office & $(0.164)$ & $(0.208)$ & $(0.203)$ & $(0.209)$ & $(0.135)$ \\
\hline 2. & Ncube \& Riffat, (2012) & $\begin{array}{l}\text { Subjective and Objective analysis } \\
\text { (Multivariate Regression) }\end{array}$ & United Kingdom & Office & $(0.16)$ & $(0.30)$ & $(0.18)$ & $(0.36)$ & - \\
\hline 3. & Wong, Mui, \& Hui, (2008) & $\begin{array}{l}\text { Subjective analysis } \\
\text { (Single Variable Regression) }\end{array}$ & Hong Kong & Office & (0.19) & $(0.31)$ & $(0.24)$ & $(0.25)$ & - \\
\hline 4. & Sakellaris et al., 2016 & $\begin{array}{l}\text { Subjective analysis (Spearman } \\
\text { correlation) }\end{array}$ & $\begin{array}{l}\text { Finland, France, } \\
\text { Greece, Hungary, Italy, } \\
\text { The Netherlands, } \\
\text { Portugal, and Spain }\end{array}$ & Office & $(0.22)$ & $(0.22)$ & $(0.31)$ & $(0.23)$ & - \\
\hline 5. & Heinzerling, et al., (2013) & $\begin{array}{l}\text { Subjective analysis } \\
\text { (Multivariate Linear Regression) }\end{array}$ & United States & Office & (0.29) & $(0.12)$ & (0.39) & $(0.20)$ & - \\
\hline 6. & $\begin{array}{l}\text { Catalina \& Lordache, } \\
\text { (2012) }\end{array}$ & Subjective analysis & Romania & Schools & $(0.18)$ & $(0.32)$ & $(0.23)$ & $(0.27)$ & - \\
\hline 7. & Cao et al., (2012) & $\begin{array}{l}\text { Subjective and Objective analysis } \\
\text { (Single and Multivariate Regression) }\end{array}$ & Beijing and Shanghai & $\begin{array}{l}\text { Schools, Offices } \\
\text { and Libraries }\end{array}$ & $(0.171)$ & $(0.316)$ & $(0.224)$ & $(0.118)$ & - \\
\hline 8. & Yoon, (2008) & $\begin{array}{l}\text { Subjective and Objective analysis } \\
\text { (Multivariate Linear Regression) }\end{array}$ & United States & Residential & $(0.21)$ & $(0.27)$ & $(0.23)$ & $(0.28)$ & - \\
\hline 9. & Pontip, (2017) & $\begin{array}{l}\text { Subjective and Objective analysis } \\
\text { (Standardized Regression) }\end{array}$ & Nigeria & Hospital & (0.33) & $(0.22)$ & $(0.12)$ & (0.11) & \\
\hline
\end{tabular}


In Table 61, the weighting scheme of the nine IEQ studies above (Table 60) were further analysed in four different ways by dividing each proportional factor by each of the columns in turn. The goal was to consider how important each variable is relative to the other factors and to ascertain whether there is a consensus amongst the researchers in offices that differs from that for schools. For example, in the lighting quality table below (in the assumption that lighting is the most important variable with a factor of 1), and in the study by Chiang \& Lai, (2002), the thermal factor (0.208) was divided by the lighting factor (0.164) to ascertain how important the resulting factor (1.3) is to light quality. The aim was to ascertain whether there was some consistency in the green/red spectrum where red is less important. The results show that there is no consensus in the importance of each IEQ variable relative to the other factors and there is no consensus amongst the researchers in offices that differs from that for schools and it could easily be argued that there seems to be a very different trend in hospitals.

Table 61: The importance of each IEQ variable relative to the other factors

\begin{tabular}{|c|c|c|c|c|c|}
\hline \multicolumn{6}{|c|}{ Lighting Quality } \\
\hline $\begin{array}{l}\text { Building } \\
\text { Type }\end{array}$ & $\begin{array}{l}\text { Lighting } \\
\text { Quality }\end{array}$ & $\begin{array}{l}\text { Thermal } \\
\text { Quality }\end{array}$ & $\begin{array}{c}\text { Acoustic } \\
\text { Quality }\end{array}$ & IAQ & Others \\
\hline Office & 1.0 & 1.3 & 1.2 & 1.3 & 0.8 \\
\hline Office & 1.0 & 1.9 & 1.1 & 2.3 & \\
\hline Office & 1.0 & 1.6 & 1.3 & 1.3 & \\
\hline Office & 1.0 & 1.0 & 1.4 & 1.0 & \\
\hline Office & 1.0 & 0.4 & 1.3 & 0.7 & \\
\hline Schools & 1.0 & 1.8 & 1.3 & 1.5 & \\
\hline $\begin{array}{l}\text { Schools, } \\
\text { Offices and } \\
\text { Libraries }\end{array}$ & 1.0 & 1.9 & 1.3 & 0.7 & \\
\hline Residential & 1.0 & 1.3 & 1.1 & 1.3 & \\
\hline Hospital & 1.0 & 0.7 & 0.4 & 0.3 & \\
\hline \multicolumn{6}{|c|}{ Thermal Quality } \\
\hline $\begin{array}{l}\text { Building } \\
\text { Type }\end{array}$ & $\begin{array}{l}\text { Lighting } \\
\text { Quality }\end{array}$ & $\begin{array}{l}\text { Thermal } \\
\text { Quality }\end{array}$ & $\begin{array}{c}\text { Acoustic } \\
\text { Quality }\end{array}$ & IAQ & Others \\
\hline Office & 0.8 & 1.0 & 1.0 & 1.0 & 0.6 \\
\hline Office & 0.5 & 1.0 & 0.6 & 1.2 & \\
\hline Office & 0.6 & 1.0 & 0.8 & 0.8 & \\
\hline Office & 1.0 & 1.0 & 1.4 & 1.0 & \\
\hline Office & 2.4 & 1.0 & 3.3 & 1.7 & \\
\hline Schools & 0.6 & 1.0 & 0.7 & 0.8 & \\
\hline $\begin{array}{l}\text { Schools, } \\
\text { Offices and } \\
\text { Libraries }\end{array}$ & 0.5 & 1.0 & 0.7 & 0.4 & \\
\hline Residential & 0.8 & 1.0 & 0.9 & 1.0 & \\
\hline Hospital & 1.5 & 1.0 & 0.5 & 0.5 & \\
\hline
\end{tabular}




\begin{tabular}{|c|c|c|c|c|c|}
\hline \multicolumn{6}{|c|}{ Acoustics Quality } \\
\hline $\begin{array}{l}\text { Building } \\
\text { Type }\end{array}$ & $\begin{array}{l}\text { Lighting } \\
\text { Quality }\end{array}$ & $\begin{array}{l}\text { Thermal } \\
\text { Quality }\end{array}$ & $\begin{array}{l}\text { Acoustic } \\
\text { Quality }\end{array}$ & IAQ & Others \\
\hline Office & 0.8 & 1.0 & 1.00 & 1.0 & 0.7 \\
\hline Office & 0.9 & 1.7 & 1.00 & 2.0 & \\
\hline Office & 0.8 & 1.3 & 1.00 & 1.0 & \\
\hline Office & 0.7 & 0.7 & 1.00 & 0.7 & \\
\hline Office & 0.7 & 0.3 & 1.00 & 0.5 & \\
\hline Schools & 0.8 & 1.4 & 1.00 & 1.2 & \\
\hline $\begin{array}{l}\text { Schools, } \\
\text { Offices and } \\
\text { Libraries }\end{array}$ & 0.8 & 1.4 & 1.00 & 0.5 & \\
\hline Residential & 0.9 & 1.2 & 1.00 & 1.2 & \\
\hline Hospital & 2.8 & 1.8 & 1.00 & 0.9 & \\
\hline \multicolumn{6}{|c|}{ Indoor Air Quality (IAQ) } \\
\hline $\begin{array}{l}\text { Building } \\
\text { Type }\end{array}$ & $\begin{array}{l}\text { Lighting } \\
\text { Quality }\end{array}$ & $\begin{array}{l}\text { Thermal } \\
\text { Quality }\end{array}$ & $\begin{array}{c}\text { Acoustic } \\
\text { Quality }\end{array}$ & IAQ & Others \\
\hline Office & 0.8 & 1.0 & 1.0 & 1.0 & 0.6 \\
\hline Office & 0.4 & 0.8 & 0.5 & 1.0 & \\
\hline Office & 0.8 & 1.2 & 1.0 & 1.0 & \\
\hline Office & 1.0 & 1.0 & 1.3 & 1.0 & \\
\hline Office & 1.5 & 0.6 & 2.0 & 1.0 & \\
\hline Schools & 0.7 & 1.2 & 0.9 & 1.0 & \\
\hline $\begin{array}{l}\text { Schools, } \\
\text { Offices and } \\
\text { Libraries }\end{array}$ & 1.4 & 2.7 & 1.9 & 1.0 & \\
\hline Residential & 0.8 & 1.0 & 0.8 & 1.0 & \\
\hline Hospital & 3.0 & 2.0 & 1.1 & 1.0 & \\
\hline
\end{tabular}

\subsubsection{Summary}

The insights from the above IEQ weighting schemes in buildings suggests that:

- There is no consensus between the highest ranked and least ranked IEQ variable in the different studies.

- The ranking (importance) of the four variables were influenced by the physiological and psychological perception of occupants and the behavioural methods.

- The ranking of the IEQ variables was also influenced by building space type (school, office or hospital building), climate, geographical location and building occupancy This is consistent with the case study analysis in Chapters 5 to 8 , which revealed that these were the factors that influenced the variability of measured IEQ in the classrooms. 
It is clear from the review that the comparative significance of each IEQ variable in a building varies from one type of building to another. Therefore, it is difficult to have an internationally universal weighing scale for each IEQ variable even for the same building types. Humphreys, (2005) states that "the relative importance of the various aspects of IEQ variables differed from country to country, making it impossible to develop an internationally valid index to rate indoor environments by means of a single number". Despite this challenge, further studies in determining the IEQ objective weighting scale especially in school buildings will not be an effort in futility, given that it will provide more insights for the evaluation of quality learning environments.

Given the interconnectivity of IEQ, it is difficult to easily distinguish which IEQ variable had a higher impact or the least impact (weighting). Most IEQ weighting studies are based on building surveys and responses from occupants and some studies state that they used "expert judgement" to analyse some factors to arrive at their weightings. Generally, this approach is usually criticised due to lack of predictive ability. There seems to be little or no weighting scale for measured physical IEQ parameters. This is due to the difficulty in analysing and evaluating the enormous data collected from long term objective IEQ measurements. In the next section, this study develops an IEQ indexing model and code for the analyses and reporting of physical measurements of the four key IEQ variables. 


\subsection{Determination and Distribution of IEQ Code and Index}

In the literature review (Chapter Two), the data considered to represent learning outcomes were: school tasks including mathematical and language-based tasks, psychological tests measuring cognitive abilities and skills to perform schoolwork, midterm and end-of-year grades and exam scores and rating schemes such as aptitude and national and tests used to assess learning performance and studies reporting absence rates. Chapter Two systematically summarized and compared available evidence on the range of IEQ influence on learning performance obtained in different studies using diverse methods to develop a relationship predicting the best and very poor IEQ range that impacts on learning performance in schools. In summary, the appraisal of IEQ variable weightings on learning performance indicates that:

- Most of the studies have reported experiments on single variables, but a few have compared the effects of two or more different variables with no consensus on which IEQ improvements should be prioritized.

- Surprisingly, the weighted impacts ( $14 \%$ to $20 \%$ ) of a combination of two or more IEQ variables on learning performance seemed to be within the same percentage improvement range of the individual variables. Hence, it could be assumed that multiple IEQ variables could have a similar impact of one variable on learning performance.

- This assertion is supported by a study carried out by Yuki, (2020), which assessed the effect of survey scale sizes on how people assess the effect of the built environment on their work performance. The study reviewed many IEQ in offices articles and reported that "there is no obvious evidence that multiple IEQ variables affect people's work performance more than just applying one environmental stressor, with most changes in performance in office occupants being below $10 \%$, with some having around $15 \%$ and a limited number with a change in performance of over $20 \% "$.

Overall, the literature showed that as determined under different building types and settings, each IEQ variable is unique in their weights. Based on the integration of results available from the empirical studies that showed relationships between learning performance and the various IEQ variables in classrooms (Chapter two), this study develops an individual and combined IEQ code and provides a model for determining IEQ objective weighting scale for school buildings. 


\subsection{The IEQ Rating Model (Code and Scale)}

Given the strong relationship between IEQ and learning performance, it is vital to continuously monitor lighting, temperature, sound and $\mathrm{CO}_{2}$ levels in classrooms to use evidence-based data in determining assets management and investment decisions. While it is necessary to collate enormous environmental data, having a logical, simple and insightful method to easily analyse IEQ data to determine the performance of a space is also very important.

In Table 62 below, IEQ model scale is proposed that takes into consideration the differences in physiological and psychological factors between occupants, as a very narrow IEQ range may not cater to those occupants who are very sensitive to environmental variations. An IEQ code of 1-5 is used to categorise the performance threshold to indicate the degree to which the empirical studies predicted the factor in a classroom that would support learning performance with 5 being the acceptable IEQ target (perceived optimum threshold and annotated with colour Green) and 1 being the poor IEQ level (annotated with colour Red). All environmental variables have equal weighting because the results and evaluations of the case study classrooms and previous evidence-based studies (Chapter two) have shown that there is no consensus on the degree to which one factor of the four key indoor environmental factors might be weighted as more important than the others. Also, the analysis of the influence of the outdoor environment on the indoor environment (external noise, climate, solar light) in the case studies showed the importance of considering these factors holistically when making design decisions. Favouring a specific variable independently may impact on another variable due to their interwoven characteristics. Given that the building type and location could influence which weighting is more important, it is necessary to consider an integrated performance scale by giving each value equal weighting when determining a quality indoor environment. Following the collection of objective physical measurements from a school site, the IEQ code and scale is proposed for the data analysis to report the quality of the indoor environment and to determine the comparison of schools with their learning performance data. The rationale of the IEQ code and scale is to provide a systematic process and formulae to convert measured IEQ data against physiological and psychological ranges into a performance rating and classify the various IEQ variables to create a rough index of their potential effects in classrooms. This will enhance the translation of large quantities of 
measured data into useful information that categorises the IEQ of schools into good and poor classrooms, to support decision making. The IEQ code is a simple and holistic measure of the quality of IEQ in the classroom over a year. The IEQ school rating target is designed to provide a simple formula that is consistent, easily applicable to various settings and indicative of which environmental variable requires intervention.

After the assignment of individual IEQ scale (1-5), a combined IEQ Code (rating) was then assigned with consideration to the combined effect of individual variables together. This is the final IEQ code which has a qualitative rating of the building characteristic data and the measured environmental data. The individual and combined IEQ Codes are meant to be simple and crude, but a holistic assessment of the IEQ condition in classrooms over a year. The IEQ code is essentially an index variable, attempting to capture multiple dimensions of the building characteristics and performance in a single scalar to create a stable metric to classify the four IEQ variables to create a rough prediction of their potential combined levels in a classroom. Similar codes, though based on subjective assessments have been applied in other IEQ related studies (Barrett, Zhang, Moffat, \& Kobbacy, 2012; Heschong Mahone Group, 1999) as reported in the literature. Therefore, the relative importance of each IEQ variable is indicated in this study by estimated values known as index factors that are combined in determining a building's overall performance and rating.

The IEQ code is a model for analysing large amounts of IEQ data at scale to support decision making. The code is based on three steps of data analysis.

- Step one: This is the raw data for each IEQ variable that is converted using the acceptable target range of 1-5.

- Step two: A formula that converts measured IEQ data using an equal index on a scale of $1-5$.

- Step three: This is the combined IEQ conversion rating that translates the four variables into a classroom or school graphical rating to triage the IEQ conditions in good or poor classrooms/schools.

As an example of how to apply this model, the spider chart in Table 62 shows the application of the three-step approach in analysing the IEQ data collated from the three case study classrooms. The graphical comparison of the various variables in the spider chat identifies 
which case study classroom had good or poor IEQ and which variable may need further assessment or might require intervention. As shown in the rating table and spider plot, case study two had a lower overall IEQ rating of 14 compared to case study one which had an IEQ rating of 17 . As reported in Chapter 5 to 8 above, this was observed to be due to the usage of the space and not a design issue.

When using a one-point sensor to monitor IEQ at scale, the concept of the IEQ model is to indicate aspects of the indoor environment where intervention is required. This could be simple interventions like providing advice about opening windows for cross ventilation (Section 8.2). However, to make more insightful decisions may require further analysis. For example, the indication of high sound levels during unoccupied periods will typically suggest that the space may have acoustic issues due to external noise, but to determine the intervention to undertake may require further acoustic investigation like reverberation test. But the benefit of the model through using a one-point sensor measurement is that when measuring IEQ at scale, like in 2000 classrooms, the one-point measurement of sound levels analysed using the IEQ rating model could easily triage (bin) the classrooms into good and poor IEQ rating and streamline the spaces that may require further investigation. Therefore, the goal of the IEQ rating model is to provide indicative and not definitive performance data and provide the ability to drill into the performance of IEQ at scale in a property portfolio. However, to make sense of the IEQ rating model will require taking into account the factors of IEQ variability (such as building orientation, window configuration, external micro-climate and occupancy and usage) which are presented in Section 8.2 above. Given that the IEQ code relies on the physiological relationship between IEQ and learning performance, it has the capacity to provide a powerful argument for designers, regulators and policy decision-makers to revise requirements in school related codes and standards. 
Table 62: IEQ Rating Model (Code and Scale)

\begin{tabular}{|c|c|c|c|c|c|c|}
\hline Step One & ur code sc & of $1-5$ with $\mathrm{Gr}$ & $\mathrm{n}$ indicating perce & ed good qualit & threshold, Or: & ge for intermediate and Red for poor threshold \\
\hline Variables & $\begin{array}{c}1 \\
\text { (Poor) }\end{array}$ & $\begin{array}{c}2 \\
\text { (Fair) }\end{array}$ & $\begin{array}{c}3 \\
\text { (Adequate) }\end{array}$ & $\begin{array}{c}4 \\
\text { (Good) }\end{array}$ & $\begin{array}{c}5 \\
\text { (Very Good) }\end{array}$ & Rationale \\
\hline $\begin{array}{l}\text { Lighting Quality } \\
\text { Illuminance }\end{array}$ & $\begin{array}{l}<300 \text { and } \\
>25001 x\end{array}$ & 2001-2500lx & 1501-2000lx & 1001-1500lx & $300-10001 x$ & $\begin{array}{l}\text { From Table } 3 \text { (Chapter two, Section 2.5.1, Page } 53) \text {, empirical studies agree } \\
\text { that the onset of scarce }(<300 \mid x) \text { or excessive }(>25001 x) \text { illuminance } \\
\text { decreases performance due to visual discomfort (Bánhidi et al., 1998; } \\
\text { Winterbottom \& Wilkins, 2009). }\end{array}$ \\
\hline $\begin{array}{l}\text { Thermal Quality } \\
\text { Temperature }\end{array}$ & $\begin{array}{l}<15^{\circ} \mathrm{C} \text { and } \\
>28^{\circ} \mathrm{C}\end{array}$ & $\begin{array}{l}15^{\circ} \mathrm{C}-<17^{\circ} \mathrm{C} \\
\text { and } 26^{\circ} \mathrm{C}-27^{\circ} \mathrm{C}\end{array}$ & $18^{\circ} \mathrm{C}$ and $25^{\circ} \mathrm{C}$ & $\begin{array}{l}19^{\circ} \mathrm{C} \text { and } 23^{\circ} \mathrm{C}- \\
24^{\circ} \mathrm{C}\end{array}$ & $20^{\circ} \mathrm{C}-22^{\circ} \mathrm{C}$ & $\begin{array}{l}\text { From Table } 4 \text { (Chapter two, Section 2.5.2, Page 59), empirical studies have } \\
\text { shown that not too warm and not too cold temperatures enhanced learning } \\
\text { and temperature and humidity above or below the acceptable comfort } \\
\text { threshold for a short period could still be considered tolerable (Balazova, }\end{array}$ \\
\hline Humidity & $\begin{array}{l}<20 \% \text { and } \\
>80 \%\end{array}$ & $\begin{array}{l}20 \%-30 \% \text { and } \\
76 \%-80 \%\end{array}$ & $\begin{array}{l}31 \%-45 \% \text { and } 71 \%- \\
75 \%\end{array}$ & $\begin{array}{l}45 \%-49 \% \text { and } \\
65 \%-70 \%\end{array}$ & $50 \%-65 \%$ & Clausen, \& Wyon, 2007; Park et al., 2016). \\
\hline $\begin{array}{l}\text { Acoustic Quality } \\
\text { Sound Levels } \\
\text { Unoccupied }\end{array}$ & $>55 \mathrm{dBA}$ & $51-55 \mathrm{dBA}$ & $46-50 \mathrm{dBA}$ & $41-45 \mathrm{dBA}$ & $<40 \mathrm{dBA}$ & $\begin{array}{l}\text { From Table } 5 \text { (Chapter two, Section 2.5.3, Page } 68 \text { ), empirical studies agree } \\
\text { that higher noise levels above a normal conversational speech condition } \\
(<70) \text { will impact on performance, while levels below enhance }\end{array}$ \\
\hline Occupied & $>75 \mathrm{dBA}$ & $71-75 \mathrm{dBA}$ & $65-70 \mathrm{dBA}$ & $\overline{61-65 \mathrm{dBA}}$ & $<60 \mathrm{dBA}$ & $\begin{array}{l}\text { performance. In unoccupied classrooms, background noise levels of 40- } \\
\text { 45dBA typically indicate good design (Christie \& Glickman, 1980; Bánhidi et } \\
\text { al., 1998; Vilatarsana, 2004). }\end{array}$ \\
\hline $\begin{array}{l}\text { Indoor Air } \\
\text { Quality (IAQ) } \\
\text { Carbon dioxide }\end{array}$ & $>3000$ ppm & 2001-3000 ppm & $1501-2000$ ppm & $1000-1500$ ppm & $<1000$ ppm & $\begin{array}{l}\text { From Table } 6 \text { (Chapter two, Section 2.5.4, Page 75), empirical studies agree } \\
\text { that lower CO } 2 \text { levels (<1000 ppm) enhance performance (Coley \& Greeves, } \\
\text { 2004; (Bakó-Biró et al., 2012; Petersen et al., 2016). }\end{array}$ \\
\hline
\end{tabular}

\begin{tabular}{|l|c|c|c|}
\hline \multicolumn{5}{|c|}{ Step Two } \\
\hline Individual Variable Rating Table \\
\hline Variable & $\begin{array}{c}\text { Case Study } \\
\text { One }\end{array}$ & $\begin{array}{c}\text { Case Study } \\
\text { Two }\end{array}$ & $\begin{array}{c}\text { Case Study } \\
\text { Three }\end{array}$ \\
\hline Lighting Quality & 5 & 4 & 3 \\
\hline Thermal Quality & 4 & 4 & 3 \\
\hline Acoustic Quality & 5 & 3 & 3 \\
\hline Indoor Air Quality & 3 & 5 & 5 \\
\hline Total Score (TS) & $\mathbf{1 7}$ & $\mathbf{1 6}$ & $\mathbf{1 4}$ \\
\hline
\end{tabular}

IEQ Case Study Rating (CS) Conversion Scale

\section{Step Three}

\section{Combined IEQ Code}

$\mathrm{CS}=\frac{\mathrm{TS}}{4}$

Therefore: Total Case Study 2 rating of all 4 variables is.

$$
S R=\frac{16}{4}=4
$$

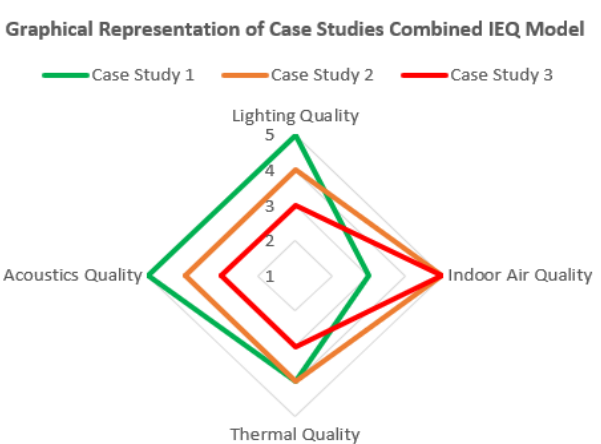

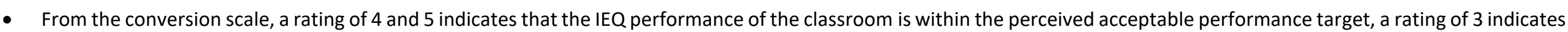
that the classroom meets the minimal (nearly meets) acceptable target and a rating of 1 or 2 indicates that the classroom IEQ is below the acceptable performance target.

- The individual variable rating indicates the IEQ variable that requires intervention in conjunction with the analyses of the factors that influence variability (Section 8.2 ).

- The rationale of this performance model is to use evidence-based data to inform large scale building assets management and investment decisions. 
In Table 62 above, a minimum of 300 lux was selected because it is the typical lighting design goal levels recommended in many national codes and standards. The goal of standards is to ensure that illumination levels are adequate to perform common visual tasks. But light levels less than 300 lux on the reading task and down to 100 lux is more than adequate for most laser print on white paper tasks, and for harder to read tasks 300 lux may not be enough (Cuttle, 2009). For example, Cuttle, (2009) stated that the Lighting Handbook (IES, 1966) reported a measurement programme in schools and offices which found that "for normal-sighted young people reading a 12-point black text on white paper, 6lx was adequate, 10lx was adequate for a 10-point text and 12lx for an 8-point text". Hence, the lighting rating in Table 50 above does not necessarily deal with conditions that might affect the most sensitive to bright or dark light. For relative humidity, the rating has been created taking into account the typical optimum relative humidity levels to provide a process to triage different spaces, but this rating is not meant to be very stringent, given that a wider relative humidity range could be considered tolerable and humidity has a minimal impact on thermal comfort. For sound, the criteria relate to sound levels suited to those of 'normal' hearing ability (those not suffering from hearing loss).

\subsubsection{IEQ Prioritization Category}

A common problem with combined indices is that it is possible for very poor factors to be easily hidden by other factors when aggregated to a single number. Hence, in the IEQ rating model above, the importance of step two is to red flag the individual variable that has a poor rating and may need further assessment or might require intervention. For example, if a school portfolio has about 2000 buildings that have been monitored using a single point sensor, while step three (combined IEQ code) will identify which buildings have good or poor IEQ, step two (individual variable rating) will red flag the IEQ variable that has a poor rating in each of the 2000 monitored buildings. Therefore, as shown in Table 63, the 2000 buildings can be triaged using four IEQ prioritization categories. The rationale is to focus further in-depth monitoring and analyses in a space that will be most useful. Hence, the IEQ prioritization categories can be useful to triage the number of buildings that require a further assessment from the 2000 earlier estimated buildings to about 300 or 200 buildings with high priority. 


\begin{tabular}{|c|c|c|c|}
\hline IEQ Category & Description & Priority & Recommendations \\
\hline One & $\begin{array}{l}\text { A category of buildings with a } \\
\text { fair or poor combined IEQ score. }\end{array}$ & High & $\begin{array}{l}\text { Further assessment using multiple } \\
\text { sensors or building performance } \\
\text { modelling is required to inform } \\
\text { possible interventions. This is } \\
\text { because the spatial variability of IEQ } \\
\text { does not present itself immediately } \\
\text { out of the single IEQ rating score. }\end{array}$ \\
\hline Two & $\begin{array}{l}\text { A category of buildings with a } \\
\text { fair or poor score for one IEQ } \\
\text { variable. }\end{array}$ & Medium & $\begin{array}{l}\text { Conduct on-site IEQ survey to identify } \\
\text { the possible factors of variability for } \\
\text { the red flag variable to inform } \\
\text { possible interventions. }\end{array}$ \\
\hline Three & $\begin{array}{l}\text { A category of buildings with an } \\
\text { adequate score for the } \\
\text { individual or combined IEQ } \\
\text { variables. }\end{array}$ & Low & $\begin{array}{l}\text { No further assessment required. } \\
\text { Consider a strategic plan of works } \\
\text { such as simple interventions to move } \\
\text { the buildings to category four. }\end{array}$ \\
\hline Four & $\begin{array}{l}\text { A category of buildings with a } \\
\text { good or very good score for the } \\
\text { combined IEQ variables and has } \\
\text { no red flag individual IEQ } \\
\text { variable. }\end{array}$ & No action & $\begin{array}{l}\text { No further assessment required. For } \\
\text { example, based on step two in Table } \\
54 \text { above, the } 3 \text { case study } \\
\text { classrooms will fall under this } \\
\text { category. }\end{array}$ \\
\hline
\end{tabular}




\section{CHAPTER TEN: CONCLUSION}

\subsection{Summary}

This study investigated the research question of:

- can a one-point sensor measurement be representative of the environmental condition within a classroom and where will be the best location to position it; and

- can multiple IEQ variables be measured at scale in buildings to identify good and poor IEQ in classrooms?

The results indicated that measuring IEQ at a single location or height may not be an accurate indicator or act as a true representation of the distribution of the environmental conditions across a whole space. This was observed to be due to factors of IEQ variability (such as building orientation, window configuration, movement and intensity of the sun at a point in time, and occupants' activities and space usage).

However, irrespective of building orientation and seasons, the results showed a strong positive relationship (about a ratio of one) between the central horizontal measuring plane sensor (A2) and a one-point sensor positioned at the centre of the vertical wall, out of the sun and away from doors and windows. While one sensor is not ideal for measuring IEQ across a space, provided the factors influencing IEQ variability are taken into account (documenting and analysing) a strategically positioned one-point multi-variable sensor at a height of $1.5 \mathrm{~m}$, at the centre of an unglazed vertical wall relative to the major window areas (where the sun is unlikely to shine), can provide indicative data about the IEQ performance of a space.

This approach can't be used to accurately ascertain the distribution of IEQ for different designs in different locations but can reliably predict the IEQ condition of the most frequently occupied part of a space (centre). It also provides a good indication of the factors of variability to consider and the predicted extent of variability. Accurate IEQ predictions for different designs and specific locations may require conducting building performance modelling. To make sense of the data retrieved from a one-point sensor, to triage the IEQ conditions of school buildings in a large 
property portfolio, this study designed a logical, simple method (IEQ rating code) to easily analyse and report IEQ measured data to identify good and poor IEQ of classrooms.

The main findings for each IEQ variables are:

- For lighting, the findings indicated that even small variations in sensor points relative to the glazed area and artificial light lamps could produce significant differences in the illuminance distribution across a space. But provided any instances of glare are excluded from the calculation, the linear regression analysis showed that approximately $80 \%$ to $90 \%$ (a less that one ratio change) of the variation in the central horizontal measuring plane sensor (A2) can be accounted for by the variation in the vertical wall sensor (B3) (that is, only approximately $10 \%$ to $20 \%$ of the variation is attributed to other factors) (Chapter 5 , Section 5.3.3, Page 182 above).

Therefore, a strategically positioned one-point sensor at a $1.5 \mathrm{~m}$ height on the vertical wall relative to the major window areas (where the sun is unlikely to shine) can reliably predict illuminance across the centre of the horizontal work plane and thus provide a useful benchmark to compare the lighting performance of the most frequently occupied parts of a classroom. This benchmark needs to be analysed in conjunction with the assessment of the building design characteristics, such as orientation, window configuration, sun path and shade diagrams and site-specific conditions. When using a one-point sensor measurement to identify good and poorly lit classrooms, the sensor is unlikely to pick up localised glare issues. But the onset of very high illuminance is an indication of glare issues in the classroom and when the illuminance values are far below the 300lx design goal target, it is an indication of a poorly lit space.

Hence, this study sets an acceptable illuminance range of 300-2000lx and a poor range of $<300$ and $>2500$ as benchmarks to triage good and poorly lit classrooms (Chapter 2, Section 2.5.1, Page 59 above). However, it is recommended that in more complex and deep open plan classrooms, it will be ideal to use more sensors for measurement to pick up areas impacted by glare or a Climate Based Daylight Modelling should be undertaken in conjunction with the one-point sensor measurement. 
- For temperature and humidity, the results revealed that in all three case studies, seasons and orientations, the temperature variation between the vertical wall and horizontal measuring plane sensors were largely $<2^{\circ} \mathrm{C}$ (a less than 1 ratio change) and could vary up to $\pm 4^{\circ} \mathrm{C}$ (a less than 1.5 ratio change) under the factors influencing IEQ variability. The variation in relative humidity was $<7 \%$. Using PPD and PMV comfort models, the effect of this variation on thermal comfort indicated that even when the air temperature is within acceptable limits, occupants may feel discomfort depending on their location within the space, their usage of the space and the time of the day.

This was observed to be due to direct sunlight penetrating the classrooms, internal heat gain, drafts from open windows and doors and in areas next to windows. This indicated that while one sensor is not ideal for measuring thermal performance across a space, if a sensor is placed away from glazed areas, in locations that are not exposed to direct irradiation from the sun, avoiding radiators and cooling systems, lighting sources, and from thermal sources such as the human body, a strategically positioned one-point sensor located at a $1.5 \mathrm{~m}$ height on an unglazed vertical wall can provide indicative data to identify good and poor thermal conditions in classrooms. However, in areas next to windows, the assumption about the variation in temperature could be a bit distorted as airspeed from the windows or high solar gain could impact on the data reading.

When using a one-point sensor measurement to identify good and poor thermal performance in classrooms, the temperature levels above or below the acceptable comfort threshold could lead to discomfort. Hence, an acceptable temperature range of $18-25^{\circ} \mathrm{C}$ and a poor range of $<15^{\circ} \mathrm{C}$ and $>28^{\circ} \mathrm{C}$ was set as benchmarks to triage good and poor thermal performance in classrooms because this range is recognised as adequate in many references (Chapter 2 , Section 2.5.2, Page 64 above).

- For acoustics, factors such as high noise levels generated from either internal or external sources showed an influence in the variation of sound levels across a space. The influence of these factors on the variability of sound distribution suggested that in some instances, single sound level figures may not provide a reliable representation of sound level distribution 
across an occupied classroom. However, the study results largely indicated that the relationship between the highest and lowest hourly average sound level distribution between the vertical wall sensors and the horizontal measuring plane sensors (simultaneous measurements on sensors with different placement in the classroom) was $<3 \mathrm{dBA}$ for both non-school days and school days (a less than 1 ratio change). Given that sound level measurement is a logarithmic scale, a sound level increase of $3 \mathrm{~dB}$ is just noticeable, while an increase of $10 \mathrm{~dB}$ is perceived as twice as loud. Therefore, the subjective variation of $<3 \mathrm{dBA}$ between horizontal measuring plane and vertical wall sensors may not be perceptible (not so great). Hence, a strategically positioned one-point sensor can provide indicative data about the sound levels in unoccupied classrooms to identify spaces that will likely have good (<40 dBA design goal) or poor (>55 dBA) acoustic performance (Table 62, $\underline{\text { Chapter } 9}$, Section 9.3, Page 284 above).

- For $\mathrm{CO}_{2}$, the results indicated that due to non-uniform air-flow, occupancy ratio and exhalation, activity levels (breathing near horizontal sensors placed on tables showed instances of a high spike in $\mathrm{CO}_{2}$ levels) and external conditions such as outdoor $\mathrm{CO}_{2}$ levels, there were varying levels of $\mathrm{CO}_{2}$ concentration from location to location in the case study classrooms. The extent of variation was determined through the daily average results which showed that the difference between the horizontal measuring plane sensor $A 2$ and the highest or lowest vertical wall sensor was largely \pm 100 ppm (a less than 1 ratio change). This could vary up to $\pm 300 \mathrm{ppm}$ from one part of a space to another especially during the cold days/season when the windows are closed to warm the classroom and keep the temperature within acceptable levels for teaching. The variation becomes less pronounced during the warm summer season when occupants in the naturally ventilated classrooms frequently open their windows.

Therefore, it became apparent that $\mathrm{CO}_{2}$ concentration is strongly associated with the status of building occupancy and usage and the status of the ventilation system. But, when measuring $\mathrm{CO}_{2}$ concentration at scale in buildings to identify spaces with good (<1000 ppm) or poor (>3000 ppm) air quality (Table 62, Chapter 9, Section 9.3, Page 284 above), a \pm 100 
ppm temporal non-uniform variation of $\mathrm{CO}_{2}$ concentration is not large, given that it might be within the acceptable $\mathrm{CO}_{2}$ concentration limit and is highly unlikely to constitute a risk to health in the range of values found in this thesis. Therefore, a vertical sensor placed at the centre of the wall at a height of $1.5 \mathrm{~m}$ above the floor and not relatively close to people can be useful to estimate $\mathrm{CO}_{2}$ concentration of a space in conjunction with an understanding of the sources of $\mathrm{CO}_{2}$.

Among the monitored environmental variables, lighting and carbon dioxide are the two variables that showed the largest variation across a space compared to the variation of temperature, humidity and sound levels. The variation in lighting was significantly different from that of $\mathrm{CO}_{2}$, and the two variables do not vary consistently or in parallel to each other, but both variables have some connection, given that they are both influenced by proximity to the windows. Also, indoor climate conditions differ considerably across classrooms, given that there is unique information to obtain from each classroom, thus reinforcing the need to measure each room individually. If there were classrooms with a different orientation at a single school, monitoring these classrooms will be ideal to identify good and poor IEQ in classrooms in the school.

As shown in the calibration results, repeatability and reproducibility of sensors are important to consider (there could be calibration issues due to other factors such as the component of the device and decline in performance during the lifetime of sensors). Placing multiple sensors in a classroom might seem over-elaborate but can have surprisingly beneficial consequences by providing more evidence-based insights. However, the use of a one-point sensor gives a general indication of IEQ trends and patterns. It can suggest that IEQ highs are way too high or the lows way too low, or the range of extremes are too broad. It cannot pinpoint problem causes, or specific local issues, but is useful to triage good and poor classrooms for early discrimination from hundreds or more classrooms of how to direct the maintenance or refurbishment programmes for large groups of school buildings.

This thesis has provided insights on how a one-point multi-variable environmental data logger could be used to measure IEQ performance in classrooms and created a model for the analysis of large IEQ data. This model has the potential to be used as the basis of evidence-based analysis 
of the influence of IEQ on students' learning performance, given that it enables the direct link of measured IEQ data with measured student performance. For example, a study could examine and compare the academic performance in the schools at the extremes of good and poor IEQ and could look at academic performance where lighting is good or poor and determine whether there is a relationship, and then compare this to where temperature or acoustic are good or poor.

From this analysis, one sensor has its pros and cons. It can be useful at scale to determine good and poor IEQ in spaces (classrooms), but may not be very helpful in identifying glare, areas of high solar radiation, draft in windows, levels of fresh air, etc. This level of additional information could be picked up better by using multiple sensors or in combination with other qualitative methods such as surveys of occupants.

Therefore, this thesis concludes that regardless of how representative of a space a one-point measurement is, it is difficult to quantify how well the IEQ variable is distributed over time in a space. But if the various IEQ factors of variability (Section 8.2) are well documented and analysed alongside the measured one-point data, a strategically positioned one-point sensor on the vertical wall (identifying wall and window orientation more carefully) can provide reliable data for predicting the IEQ performance of the most frequently occupied parts of a classroom. The IEQ rating model and prioritization category has shown that if the excursions into poor IEQ scores are fleeting, then the school is categorized into the low or no action priority, but if the poor IEQ scores happen very often, then the school becomes the highest priority (Table 62).

From a methodological perspective, this study has presented a robust design to measure indoor environmental quality at scale in schools, using a multi-variable sensor to objectively measure and analyse the environmental conditions of classrooms. These findings are useful for researchers, designers and policymakers to diagnosis trends and patterns of IEQ performance across many classrooms in a property portfolio and the same process can be used, in any large property portfolio to prioritise remediation works. 


\subsection{Conclusion}

Three typical classrooms with heterogeneous physical characteristics were monitored during autumn, spring and summer in detail to ascertain the variation of IEQ across a space to inform a methodological approach for monitoring IEQ at scale in buildings. The results revealed that for all five environmental variables, the relationship between the horizontal plane and vertical wall sensors were consistent for approximately $80 \%$ of the time. The relationship is stronger for temperature, relative humidity and sound levels than lighting and $\mathrm{CO}_{2}$ levels, which in the other $20 \%$ of the time the deviation for lighting and $\mathrm{CO}_{2}$ is much greater across a space.

Hence, this study concludes that a one-point sensor located on an unglazed vertical wall, where the sun is unlikely to shine and away from any sources of heat can reliably predict IEQ at the most frequently occupied parts of a space (the centre). It provides an indication of what is happening in the space, but not necessarily of the variations (differences) across the room.

It is one thing to use a one-point sensor to monitor IEQ in many buildings, and it is another thing to make sense of the big data retrieved from IEQ monitoring. Therefore, this study went further to develop a logical, simple and insightful framework to easily analyse a large amount of IEQ data. The IEQ scale of 1-5 takes into consideration the differences in physiological and psychological factors between occupants, as a very narrow IEQ range may not cater to those occupants who are very sensitive to environmental variations. The IEQ scale is reliable because it has been developed based on the degree to which previous empirical studies that monitored IEQ in buildings in comparison to student's performance data predicted the factor in a classroom that would support learning performance. The concept of the IEQ framework is to indicate aspects of the indoor environment where intervention is required. This could be simple interventions like providing advice about opening windows for cross ventilation. Hence, the IEQ prioritization categories can be useful to triage the number of buildings that require further assessment from many monitored buildings. The rationale is to focus further in-depth monitoring and analyses in spaces that will be most useful.

The IEQ framework is the first version of an attempt to create a criterion for categorizing a large amount of environmental data to triage good and poor IEQ in classrooms, in a large property 
portfolio. Over time, and with more empirical evidence from the deployment of environmental sensors at scale in school buildings and the observation of space usage, the IEQ criteria will improve. Overall, the IEQ rating index illustrates that the benefit of collating IEQ data at scale is not only to triage good and poor IEQ in classrooms but could provide an improvement to the quality of the IEQ rating model (Table 62 ) by carefully analysing the big data collected. Therefore, the overall findings support the use of data loggers at scale to triage good and poor classrooms and to improve the IEQ framework. This could revise the requirements in school related codes and standards and examine the combined influence of IEQ on learning performance in schools.

The relevance of this study to the Ministry of Education is that it provides scientific evidence that could support the Ministry's school property strategy, 2030 by developing a methodological approach for measuring, analysing, and reporting IEQ in many buildings. The same process can be used in any large property portfolio with some modifications. 


\subsection{Limitation and Areas for Further Study}

Monitoring an occupied classroom using multiple data loggers in multiple locations required planning and preparation and consulting with the school management, teachers, parents and students. To set up the data loggers and ensure all were adequately recording data and reporting to the cloud, time was required before and after the classroom was occupied. The researcher also had to manually check the devices at each location to gather spot measurements for calibration purposes, which meant the researcher had to move through the space while the students were learning. This was an inconvenience for both the researcher, staff and students. The location of data loggers was intrusive of the occupant's space and the occupants were aged between 5-10 years, which meant cooperation was important to avoid the students tampering with the data loggers. Hence, the researcher had to engage with the students and teachers to explain the objective of the study. This was found to help stimulate the right kind of curiosity (rather than the kind that involves tampering with the device and pulling it apart). However, if these data loggers were to be permanently placed in multiple locations in many school classrooms across the country, this may prove difficult.

Measuring IEQ of occupied classrooms at multiple locations is a difficult and time-consuming task requiring set up and pack downtime. There was a likely disruption of teachers and students from having the flexibility to learn or render the space unusable such as when students are sitting on the desk that has a data logger. Careful consideration to the age of the occupants and activities must be applied to determine the appropriate location of data loggers, hence, the use of a single multi-variable sensor for continuous monitoring of IEQ is worth considering to limit the disruption to the occupants and reduce set up and pack downtime. Also, having all four sensors in one device (data logger) could impact the accuracy of the sensors. For example, a typical lighting sensor will typically have a black peripheral which is useful to absorb light. The sensor used in this study had a white peripheral which made it difficult to easily calibrate the lighting variable.

This study is limited to the following:

- the analysis of physical measurements was collected in a few summer and autumn and spring days; 
- the findings primarily relate to the case study classrooms and the conditions which measurements were recorded under, other classrooms may yield different results, hence the need to take into consideration the factors influencing variability on a case by case bases.

However, this research was an intensive study that demonstrated a proof of concept for measuring and reporting IEQ at scale. Future studies should apply the IEQ model proposed in this study to assess the combined influence of lighting, thermal comfort, acoustic, and IAQ on learning performance and health in schools. The holistic measurement protocol of IEQ will be useful in simultaneously investigating the interaction between building design (microenvironment, building characteristics, and meteorological parameters) and students' perception of IEQ. Also, comparing IEQ relationship at other work plane levels such as the floor level of a classroom and the ceiling may be insightful. 


\section{REFERENCES}

ABD. (2008). Perception Vs. Reality: What Our Ears Hear. ABD Engineering and Design Website. https://www.abdengineering.com/blog/perception-vs-reality/

Abdelouahab, B., Mohamed, A., Saad, D., \& Youcef, R. (2013). Evaluation of the acoustic performance of classrooms in public schools. Applied Acoustics, 70(4), 626-635. https://doi.org/10.1016/j.apacoust.2008.06.007

Abo-Hasseba, A., Waaramaa, T., Alku, P., \& Geneid, A. (2016). Difference in Voice Problems and Noise Reports Between Teachers of Public and Private Schools in Upper Egypt. Journal of Voice, 1-6. https://doi.org/10.1016/j.jvoice.2016.10.016

Ackley, A., Donn, M., \& Thomas, G. (2017). The Influence of Indoor Environmental Quality in Schools A Systematic Literature Review. In M. Schnabel (Ed.), The Next 50 Years, (51st International Conference of the Architectural Science Association (ANZAScA)) (pp. 625634). Architectural Science Association.

Ahmed, K., Kurnitski, J., \& Olesen, B. (2017). Data for occupancy internal heat gain calculation in main building categories. Data in Brief, 15, 1030-1034.

https://doi.org/10.1016/j.dib.2017.10.036

Akpan-idiok, P., \& Ackley, A. (2017). Sustainable Therapeutic Environment ; Impacts of the Indoor Environment on Users ' Perception of Well being in Public Healthcare Facilities in Calabar Municipality, Nigeria. World Journal of Pharmaceutical and Medical Research, 3(6), 27-37. www.wjpmr.com/download/article/23062017/1498806625.pdf

Albatayneh, A., Alterman, D., Page, A., \& Moghtaderi, B. (2019). The significance of the adaptive thermal comfort limits on the air-conditioning loads in a temperate climate. Sustainability (Switzerland), 11(2). https://doi.org/10.3390/su11020328

Ali, H., Almomani, H., \& Hindeih, M. (2009). Indoor and Built uilt Environment Evaluating Indoor Environmental Quality of Public School Buildings in Jordan. Indoor Built Environ, 181, 6676. https://doi.org/10.1177/1420326X08100760 
Ali, S. A. A. (2013). Study effects of school noise on learning achievement and annoyance in Assiut city, Egypt. Applied Acoustics, 74(4), 602-606. https://doi.org/10.1016/j.apacoust.2012.10.011

Aliboye, P., White, M., Graves, H., \& Ross, D. (2006). Ventilation and Indoor Air Quality in Schools: Guidance Report 202825. Indoor Air, March.

Allard, F. (1998). Natural Ventilation in Buildings: A design handbook. James \& James Ltd.

Allen, M., \& Fischer, G. (1978). Ambient Temperature Effects on Paired Associate Learning*. Ergonomics, 21(2), 95-101. https://doi.org/10.1080/00140137808931700

Almeida, R. M. S. F., de Freitas, V. P., \& Delgado, J. M. P. Q. (2015). Indoor Environmental Quality; School Buildings Rehabilitation. Springer Briefs in Applied Sciences and Technology, 1(n.a), 83. https://doi.org/10.1007/978-3-319-15359-9

Almeida, R. M. S. F., Ramos, N. M. M., \& De Freitas, V. P. (2016). Thermal comfort models and pupils' perception in free-running school buildings of a mild climate country. Energy and Buildings, 111, 64-75. https://doi.org/10.1016/j.enbuild.2015.09.066

ANSI/ASHRAE55-2004. (2004). ASHRAE standard: thermal environmental conditions for human occupancy. In American Society of Heating, Refrigerating and Air-conditioning Engineers Inc.

Armstrong, S., \& Liaw, J. (2003). The fundamentals of Fungi. British Journal of Healthcare Assistants, 06(06), 285-290.

ASHRAE-55-2010. (2012). Thermal Environment Conditions for Human Occupancy. American Society of Heating, Ventilating and Air-Conditioning Engineers, Inc.

ASTM. (2009). Standard Test Method for Determining Air Change in a Single Zone by Means of a Tracer Gas Dilution (Reapproved 2006), 1-17. https://doi.org/10.1520/E0741-00R06E01.2

Aturupane, H., Glewwe, P., \& Wisniewski, S. (2013). The Impact of School Quality, Socioeconomic Factors, and Child Health on Students' Academic Performance: Evidence from Sri Lankan Primary Schools. Education Economics, 21(1), 2-37. 
https://doi.org/10.1080/09645292.2010.511852

Au, P., \& Donn, M. (2010). HDR luminance measurement: comparing real and simulated data. Master's Thesis, March, 1-8. http://anzasca.net/2012papers/

Bakó-Biró, Z., Clements-Croome, D. J., Kochhar, N., Awbi, H. B., \& Williams, M. J. (2012). Ventilation rates in schools and pupils' performance. Building and Environment, 48(1), 215-223. https://doi.org/10.1016/j.buildenv.2011.08.018

Balazova, I., Clausen, G., \& Wyon, D. P. (2007). The influence of exposure to multiple indoor environmental parameters on human perception, performance and motivation. Clima 2007 WellBeing Indoors.

Bánhidi, L., Száday, E., \& Antalovics, A. (1998). The measuring method for combined effects. Proceedings of the Conference on Mechanical Engineering, GEPESZET, 98(2), 555-559.

Barkmann, C., Wessolowski, N., \& Schulte-Markwort, M. (2012). Applicability and efficacy of variable light in schools. Physiology and Behavior, 105(3), 621-627. https://doi.org/10.1016/j.physbeh.2011.09.020

Barrett, P. P., \& Zhang, Y. (2009). Optimal learning spaces: design implications for primary schools. SCRI Research Report, October, 47. http://usir.salford.ac.uk/18471/

Barrett, P., Zhang, Y., Davies, D. F., \& Barrett, D. L. (2015). Clever Classrooms (Issue February). http://www.salford.ac.uk/cleverclassrooms/1503-Salford-Uni-Report-Digital.pdf

Bartlett, K. H., Martinez, M., \& Bert, J. (2004). Modeling of Occupant-Generated $\mathrm{CO}_{2}$ Dynamics in Naturally Ventilated Classrooms. Journal of Occupational and Environmental Hygiene, 1(3), 139-148. https://doi.org/10.1080/15459620490424393

Basset, M., \& Gibson, P. (1999). Indicators of natural ventilation effectiveness in twelve New Zealand schools. The 8th International Conference on Indoor Air Quality and Climate, 298303.

Bassett, M., \& Gibson P. (1999). Indicators of natural ventilation effectiveness in twelve New Zealand schools. In Proceedings of the 8th International Conference on Indoor Air Quality 
and Climate.

Batterman, S., \& Peng, C. (1995). TVOC and $\mathrm{CO}_{2}$ Concentrations as Indicators in Indoor Air Quality Studies. American Industrial Hygiene Association Journal, 56(1), 55-65. https://doi.org/10.1080/15428119591017321

Bauman, F., Arens, E., Huizenga, C., Xu, T., Zhang, H., Akimoto, T., \& Miura, K. (1996). The Impact of Humidity Standards on Energy Efficient Cooling in california. Center for the Built Environment.

Bellia, L., Musto, M., \& Spada, G. (2011). Illuminance measurements through HDR imaging photometry in scholastic environment. Energy and Buildings, 43(10), 2843-2849. https://doi.org/10.1016/j.enbuild.2011.07.006

Bellia, L., Spada, G., Pedace, A., \& Fragliasso, F. (2015). Methods to evaluate lighting quality in educational environments. Energy Procedia, 78, 3138-3143. https://doi.org/10.1016/j.egypro.2015.11.770

Bennett, J., Davy, P., Trompetter, B., Wang, Y., Pierse, N., Boulic, M., Phipps, R., \& HowdenChapman, P. (2019a). Sources of indoor air pollution at a New Zealand urban primary school; a case study. Atmospheric Pollution Research, 10(2), 435-444. https://doi.org/10.1016/j.apr.2018.09.006

Bennett, J., Davy, P., Trompetter, B., Wang, Y., Pierse, N., Boulic, M., Phipps, R., \& HowdenChapman, P. (2019b). Sources of indoor air pollution at a New Zealand urban primary school; a case study. Atmospheric Pollution Research, 10(2), 435-444. https://doi.org/10.1016/j.apr.2018.09.006

Berglund, L. . (1998). Comfort and Humidity. ASHRAE J, 40(8), 35-41.

Bian, Y., \& Ma, Y. (2017). Analysis of daylight metrics of side-lit room in Canton, south China: A comparison between daylight autonomy and daylight factor. Energy and Buildings, 138, 347-354. https://doi.org/10.1016/j.enbuild.2016.12.059

Bobenhausen, W. (1994). Simplified design of HVAC systems. Wiley-IEEE. 
Boulic, M. (2012). The Indoor Environmental Benefits from Replacing Unflued Gas and Portable Electric Heaters With Higher Capacity Non Indoor Polluting Heaters: An Interventional Field Study. PhD Thesis, Massey University.

Boulic, M., Wang, Y., Phipps, R., Chitty, C., Cunningham, C., Moses, A., Weyers, R., Jaccard, J. J., Olivares, G., Longley, I., Tookey, L., Sutton, A. P., \& Waters, D. (2018). Warmer, drier, healthier buildings Feasibility of using SКОМОВО (Skool Monitoring Box) to explore the indoor environment in New Zealand schools . Final report - December 2018. 1-91.

Bradley, J. S., \& Sato, H. (2008). The intelligibility of speech in elementary school classrooms. The Journal of the Acoustical Society of America, 123(4), 2078-2086. https://doi.org/10.1121/1.2839285

Canning, D., Cogger, N., Greenland, E., Harvie-Clark, J., James, A., Oeters, D., Orlowski, R., Parkin, A., \& Shield, R. R. B. (2015). Acoustics of Schools: a design guide. In Building Bulletin Institute of Acoustics (IOA) and the Association of Noise Consultants (ANC) (Issue November, 2015).

Cao, B., Ouyang, Q., Zhu, Y., Huang, L., Hu, H., \& Deng, G. (2012). Development of a multivariate regression model for overall satisfaction in public buildings based on field studies in Beijing and Shanghai. Building and Environment, 47(1), 394-399.

https://doi.org/10.1016/j.buildenv.2011.06.022

Carlos, J. S. (2016). Sustainability assessment of government school buildings in Portugal Sustainability assessment of government school buildings in Portugal. Architectural Science Review, 59(August), 413-422. https://doi.org/10.1080/00038628.2016.1167666

Cartieaux, E., Rzepka, M. A., \& Cuny, D. (2011). Indoor Air Quality in Schools. Archives de Pediatrie, 18(7), 789-796. https://doi.org/10.1016/j.arcped.2011.04.020

Catalina, T., \& Iordache, V. (2012). IEQ assessment on schools in the design stage. Building and Environment, 49(1), 129-140. https://doi.org/10.1016/j.buildenv.2011.09.014

Chatzidiakou, L., Mumovic, D., \& Summerfield, A. J. (2012). What do we know about indoor air 
quality in school classrooms? A critical review of the literature. Intelligent Buildings International, 4(4), 228-259. https://doi.org/10.1080/17508975.2012.725530

Chatzidiakou, L., Mumovic, D., Summerfield, A. J., Tàubel, M., \& Hyvärinen, A. (2014). Indoor air quality in London schools. Part 2: long-term integrated assessment. Intelligent Buildings International, O(January 2015), 1-17. https://doi.org/10.1080/17508975.2014.918871

Cheryan, S., Ziegler, S. A., Plaut, V. C., \& Meltzoff, A. N. (2014). Designing classrooms to maximize student achievement. Policy Insights from the Behavioral and Brain Sciences, 1(1), 4-12. https://doi.org/10.1177/2372732214548677

Chiang, C.-M., \& Lai, C.-M. (2002). The Study on the Comprehensive Indicators of Indoor Environment Assessment for Occupants' Health. Building and Environment, 37, 387-392.

Chien, Y. C., Chang, C. P., \& Lo, C. P. (2009). Assessment of air change rates in chemical laboratories. Indoor and Built Environment, 18(2), 162-167. https://doi.org/10.1177/1420326X08101725

Choi, J., Aziz, A., \& Loftness, V. (2010). Investigation on the impacts of different genders and ages on satisfaction with thermal environments in office buildings. Building and Environment, 45(6), 1529-1535. https://doi.org/10.1016/j.buildenv.2010.01.004

Christie, D., \& Glickman, C. (1980). The Effects of Classroom Noise on Children: Evidence for Sex Differences. Psychology in Schools, 17, 405-408.

Chung, K. C., \& Hsu, S. P. (2001). Effect of ventilation pattern on room air and contaminant distribution. Building and Environment, 36(9), 989-998. https://doi.org/10.1016/S03601323(00)00051-2

CIBSE. (2006). A CIBSE Guide, Environmental Design. In The Chartered Institution of Building Services Engineers,.

CIBSE. (2010). Lighting Guide 5 : Lighting in Education.

Claude, L. R. (1986). Daylighting : Design And Analysis. Van Nostrand Reinhold Company, 4-13. 
Coakley, D., Raftery, P., Molloy, P., \& White, G. (2011). Calibration of a Detailed Bes Model to Measured Data Using an Evidence-Based Analytical Optimisation Approach. 12th Conference of International Building Performance Simulation Association, 374-381.

Cohen, S., Evans, G. W., Krantz, D. S., \& Stokols, D. (1980). Physiological, motivational, and cognitive effects of aircraft noise on children: Moving from the laboratory to the field. American Psychologist, 35(3), 231-243. https://doi.org/10.1037/0003-066X.35.3.231

Coley, D. A., \& Beisteiner, A. (2002). Carbon Dioxide Levels and Ventilation Rates in Schools. International Journal of Ventilation, 1(1), 45-52. https://doi.org/10.1080/14733315.2002.11683621

Coley, D. A., \& Beisteiner, A. (2016). Carbon Dioxide Levels and Ventilation Rates in Schools. International Journal of Ventilation, 1(1), 45-52. https://doi.org/10.1080/14733315.2002.11683621

Coley, D. A., \& Greeves, R. (2004). The Effect of low ventilation rates on the cognitive function of a primary school class. Education, 01392.

Conceição, E., Lúcio, M., Vicente, V., \& Rosão, V. (2008). Evaluation of Local Thermal Discomfort in a Classroom Equipped with Cross Flow Ventilation. International Journal of Ventilation, 7(3), 267-277.

Costanzo, V., Evola, G., \& Marletta, L. (2017a). A Review of Daylighting Strategies in Schools: State of the Art and Expected Future Trends. Buildings, 7(2), 41. https://doi.org/10.3390/buildings7020041

Costanzo, V., Evola, G., \& Marletta, L. (2017b). Static and dynamic strategies for improving daylight use in side-lit classrooms : a case study. February.

Crampton, F. E. (2009). Spending on school infrastructure: does money matter? Journal of Educational Administration, 47(3), 305-322. https://doi.org/10.1108/09578230910955755

Crandell, C. C., \& Smaldino, J. J. (2000). Classroom Acoustics for Children with Normal and With Hearing Impairment. Language, Speech, and Hearing Services in Schools, 31(October), 
362-370. https://doi.org/0161-1461/00/3104-0362

Crukley, J., Scollie, S., \& Parsa, V. (2011). An Exploration of Non-Quiet Listening at School. Journal of Educational Audiology, 17, 23-35.

Cutiva, L. C., \& Burdorf, A. (2015). Effects of noise and acoustics in schools on vocal health in teachers. Noise and Health, 17(74), 17. https://doi.org/10.4103/1463-1741.149569

Daisey, J. M., Angell, W. J., \& Apte, M. G. (2003). Indoor air quality, ventilation and health symptoms in schools: an analysis of existing information. Indoor Air, 13(1), 53-64. https://doi.org/10.1034/j.1600-0668.2003.00153.x

De Dear, R, Kim, J., Candido, C., \& Deuble, M. (2015). Adaptive thermal comfort in Australian school classrooms. Building Research and Information, 43(3), 383-398. https://doi.org/10.1080/09613218.2015.991627

de Dear, R, Leow, K., \& Ameen, A. (1991). Thermal comfort in the humid tropics. Part II. Climate chamber experiments on thermal acceptability in Singapore. ASHRAE Trans., 97(1), 880886.

Dear, Richard, \& Brager, G. (2002). Thermal comfort in naturally ventilated buildings: revisions to ASHRAE Standard 55. Energy and Buildings, 34, 549-561.

Dias Pereira, L., Raimondo, D., Corgnati, S. P., \& Gameiro da Silva, M. (2014). Assessment of indoor air quality and thermal comfort in Portuguese secondary classrooms: Methodology and results. Building and Environment, 81, 69-80.

https://doi.org/10.1016/j.buildenv.2014.06.008

Djamila, H., Chu, C.-M., \& Kumaresan, S. (2014). Effect of Humidity on Thermal Comfort in the Humid Tropics. Journal of Building Construction and Planning Research, 02(02), 109-117. https://doi.org/10.4236/jbcpr.2014.22010

Dockrell, J., \& Shield, B. (2006). Effects of classroom acoustics on teachers' well-being and perceived disturbance by classroom noise. British Educational Research Journal, Vol. 32, $N($ june), 509-525. https://doi.org/10.1080/01411920600635494 
Dorizas, P. V., Assimakopoulos, M.-N., \& Santamouris, M. (2015). A holistic approach for the assessment of the indoor environmental quality, student productivity, and energy consumption in primary schools. Environmental Monitoring and Assessment, 187(5), 4503. https://doi.org/10.1007/s10661-015-4503-9

DQLS. (2016). Designing Quality Learning Spaces : Acoustics. New Zealand Ministry of Education, September.

Earthman, G. (2004). Prioritization of 31 Criteria for School Building Adequacy. In Manual. https://doi.org/10.1016/S0022-3913(12)00047-9

Edwards, L., \& Torcellini, P. (2002). A Literature Review of the Effects of Natural Light on Building Occupants. Colorado: National Renewable Energy Laboratory - U.S. Department of Energy, July, 58. https://doi.org/10.2172/15000841

Evans, G., \& Maxwell, L. (1997). Chronic noise exposure and reading deficits. In Environment and Behavior. http://eab.sagepub.com/content/29/5/638.short

Fabbri, K. (2013). Thermal comfort evaluation in kindergarten: PMV and PPD measurement through data logger and questionnaire. Building and Environment, 68, 202-214. https://doi.org/10.1016/j.buildenv.2013.07.002

Fabrizio, E., \& Monetti, V. (2015). Methodologies and advancements in the calibration of building energy models. Energies, 8(4), 2548-2574. https://doi.org/10.3390/en8042548

Fang, L., Clausen, G., \& Fanger, P. (1998). Impact of temperature and humidity on perception of indoor air quality during immediate and longer whole-body exposures. Indoor Air, 8(4), 276-284. https://doi.org/10.1111/j.1600-0668.1998.00008.x

Fanger, P. O. (1982). The effect of air humidity in buildings on man's comfort and health. In Proceedings of the CISCO-ITBTP Seminar Humidity in Building, Saint Remy Les Chevreuse,.

Fanger, P. O. (1971). Air Humidity, Comfort and Health T. Technical University of Denmark: Kongens Lyngby, 192-195.

Ferreira, A. M. da C., \& Cardoso, M. (2014). Indoor air quality and health in schools. Jornal 
Brasileiro de Pneumologia : Publicaçâo Oficial Da Sociedade Brasileira de Pneumologia e Tisilogia, 40(3), 259-268. https://doi.org/10.3760/cma.j.issn.0366-6999.2009.17.007

Fidêncio, V. L. D., Moret, A. L. M., \& Jacob, R. T. de S. (2014). Measuring noise in classrooms: a systematic review. CoDAS, 26(2), 155-158. https://doi.org/10.1590/2317-1782/2014029IN

Figueiro, M. G., Rea, M. S., Rea, A. C., \& Stevens, R. G. (2002). Daylight and Productivity - A Field Study. ACEEE Summer Study on Energy Efficiency in Buildings, 69-78.

Fisk, W. J., Satish, U., Mendell, M. J., Hotchi, T., \& Sullivan, D. (2013). Is $\mathrm{CO}_{2}$ an indoor pollutant?: Higher levels of $\mathrm{CO} 2$ may diminish decision making performance. REHVA Journal, October, 63.

Free, S., Howden-Chapman, P., Pierse, N., \& Viggers, H. (2010). More effective home heating reduces school absences for children with asthma. Journal of Epidemiology and Community Health, 64(5), 379-386. https://doi.org/10.1136/jech.2008.086520

Frontczak, M., Andersen, R. V., \& Wargocki, P. (2012). Questionnaire survey on factors influencing comfort with indoor environmental quality in Danish housing. Building and Environment, 50, 56-64. https://doi.org/10.1016/j.buildenv.2011.10.012

Gaihre, S., Semple, S., Miller, J., Fielding, S., \& Turner, S. (2014). Classroom carbon dioxide concentration, school attendance, and educational attainment. Journal of School Health, 84(9), 569-574. https://doi.org/10.1111/josh.12183

Gaitani, N., Lehmann, C., Santamouris, M., Mihalakakou, G., \& Patargias, P. (2010). Using principal component and cluster analysis in the heating evaluation of the school building sector. Applied Energy, 87(6), 2079-2086. https://doi.org/10.1016/j.apenergy.2009.12.007

Gao, J., Wargocki, P., \& Wang, Y. (2014). Ventilation system type, classroom environmental quality and pupils' perceptions and symptoms. Building and Environment, 75, 46-57. https://doi.org/10.1016/j.buildenv.2014.01.015

Geelen, L. M. J., Huijbregts, M. A. J., Ragas, A. M. J., Bretveld, R. W., Jans, H. W. A., Van Doorn, W. J., Evertz, S. J. C. J., \& Van Der Zijden, A. (2008). Comparing the effectiveness of 
interventions to improve ventilation behavior in primary schools. Indoor Air, 18(5), 416424. https://doi.org/10.1111/j.1600-0668.2008.00542.x

Givoni, B. (1969). Man, Climate and Architecture. Elsevier Publishing Company Ltd.

Godwin, C., \& Batterman, S. (2007). Indoor air quality in Michigan schools. Indoor Air, 17(2), 109-121. https://doi.org/10.1111/j.1600-0668.2006.00459.x

Griffiths, M., \& Eftekhari, M. (2008). Control of CO2in a naturally ventilated classroom. Energy and Buildings, 40(4), 556-560. https://doi.org/10.1016/j.enbuild.2007.04.013

Grimsrud, D., Bridges, B., \& Schulte, R. (2006). Continuous measurements of air quality parameters in schools. Building Research and Information, 34(5), 447-458. https://doi.org/10.1080/09613210600808880

Haddad, S., Osmond, P., \& King, S. (2016). Revisiting thermal comfort models in Iranian classrooms during the warm season. Building Research \& Information, 3218(December), 117. https://doi.org/10.1080/09613218.2016.1140950

Haines, M. M., Stansfeld, S. A., Head, J., \& Job, R. F. S. (2002). Multilevel modelling of aircraft noise on performance tests in schools around Heathrow Airport London. Journal of Epidemiology and Community Health, 56(2), 139-144.

https://doi.org/10.1136/jech.56.2.139

Harner, D. (1974). Effects of thermal environment on learning skills. The Educational Facility Planner, 12(2), 4-6.

Hathaway, W., Hargreaves, J., Thompson, G., \& Novitsky, D. (1992). A Study into the Effects of Light on Children of Elementary School-Age--A Case of Daylight Robbery. http://eric.ed.gov/?id=ED343686

Haverinen-Shaughnessy, U., \& Shaughnessy, R. J. (2015). Effects of classroom ventilation rate and temperature on students' test scores. PLOS ONE, 10(8), 1-14. https://doi.org/10.1371/journal.pone.0136165

Hayakawa, K., Isoda, N., \& Yanase, T. (1989). Study of the effects of air temperature and 
humidity on the human body during physical exercise in the summer. J. Archit. Plan. Environ. Eng., 47-55.

Heinzerling, D., Schiavon, S., Webster, T., \& Arens, E. (2013). Indoor Environmental Quality Assessment Models: A Literature Review and a Proposed Weighting and Classification Scheme. Building and Environment, 70, 10-222.

Heschong, L. (2003). Windows and Classrooms: A Study of Student Performance and the Indoor Environment. California Energy Commission, 37(4), 414-435. https://doi.org/10.1175/1520-0450(1998)037<0414:TDFBIM>2.0.CO;2

Heschong, L., Group, H. M., Wright, R. L., \& Analytics, R. L. W. (1999). Daylighting and Human Performance : Latest Findings Background on Previous Study. 91-104.

Heschong Mahone Group. (1999). Daylighting in Schools. In Submitted to George Loisos The Pacific Gas and Electric Company on behalf of the California Board for Energy Efficiency Third Party Program (Vol. 1999, Issue 1). http://www.nrel.gov/docs/fy00osti/28049.pdf

Ho, M. C., Chiang, C. M., Chou, P. C., Chang, K. F., \& Lee, C. Y. (2008). Optimal sun-shading design for enhanced daylight illumination of subtropical classrooms. Energy and Buildings, 40(10), 1844-1855. https://doi.org/10.1016/j.enbuild.2008.04.012

Hodgson, M., Rempel, R., \& Kennedy, S. (1999). Measurement and prediction of typical speech and background-noise levels in university classrooms during lectures. J. Acoust Soc Am, $105,33-226$.

Howard Wall, G. J. (2010). What affects student achievement. PhD Thesis.

Humphreys, M.A. (1977). A study of the thermal comfort of primary school children in summer. Building and Environment, 12(4), 231-239. https://doi.org/10.1016/0360-1323(77)90025-7

Humphreys, M.A., \& Nicol, J. F. (2002). Adaptive thermal comfort and sustainable thermal standards for buildings. Energy and Buildings, 34(6), 563-572. https://doi.org/10.1016/S0378-7788(02)00006-3

Humphreys, Michael A. (2005). Quantifying occupant comfort: Are combined indices of the 
indoor environment practicable? Building Research and Information, 33(4), 317-325. https://doi.org/10.1080/09613210500161950

Hwang, R. L., Lin, T. P., \& Kuo, N. J. (2006). Field experiments on thermal comfort in campus classrooms in Taiwan. Energy and Buildings, 38(1), 53-62. https://doi.org/10.1016/j.enbuild.2005.05.001

Hygge, S. (1993). Classroom experiment on the effects of aircraft, traffic and verbal noise on long term recall and recognition in children aged 11-14 years. Proceedings of 6 International Congress on Noise as a Public Health Problem, 531-534.

Hygge, Staffan. (2003). Classroom experiments on the effects of different noise sources and sound levels on long-term recall and recognition in children. Applied Cognitive Psychology, 17(8), 895-914. https://doi.org/10.1002/acp.926

Hygge, Staffan, \& Knez, I. (2001). Effects of noise, heat and indoor lighting on cognitive performance and self-reported affect. Journal of Environmental Psychology, 21(3), 291299. https://doi.org/10.1006/jevp.2001.0222

ISO. (1998). Ergonomics of the Thermal Environment-Instruments for Measuring Physical Quantities: ISO Standard 7726.

ISO. (2004). Ergonomics of the Thermal Environment e Determination of Metabolic Rate; ISO Standard 8996.

ISO. (2005). Ergonomics of the Thermal Environment: Analytical Determination and Interpretation of Thermal Comfort Using Calculation of the PMV and PPD Indices and Local Thermal Comfort Criteria.

ISO. (2007). Ergonomics of the Thermal Environment and Estimation of the Thermal Insulation and Evaporative Resistance of a Clothing Ensemble; ISO Standard 9920.

ISO 3382-2. (2008). Acoustics - Measurement of room acoustic parameters - Part 2:

Reverberation time in ordinary rooms. In International Organization for Standardization. Jackson, Q. (2006). Daylighting in Schools: A New Zealand Perspective [Victoria University of 
Wellington, New Zealand].

http://restrictedarchive.vuw.ac.nz.helicon.vuw.ac.nz/handle/123456789/6390

Jin, L, Zhang, Y., \& Zhang, Z. (2017). Human responses to high humidity in elevated temperatures for people in hot-humid climates. Build. Environ, 114, 257-266.

Jin, Ling, Zhang, Y., \& Zhang, Z. (2017). Human responses to high humidity in elevated temperatures for people in hot-humid climates. Building and Environment, 114, 257-266. https://doi.org/10.1016/j.buildenv.2016.12.028

Jing, S., Li, B., Tan, M., \& Liu, H. (2013). Impact of relative humidity on thermal comfort in a warm environment. Indoor and Built Environment, 22(4), 598-607. https://doi.org/10.1177/1420326X12447614

Jones, B. M., \& Kirby, R. (2012). Indoor air quality in U.K. school classrooms ventilated by natural ventilation wind catchers. International Journal of Ventilation, 10(4), 323-338. https://doi.org/10.1080/14733315.2012.11683959

Kajtár, L., \& Herczeg, L. (2012). Influence of carbon-dioxide concentration on human well-being and intensity of mental work. Idojaras, 116(2), 145-169.

Karami, M., McMorrow, G. V., \& Wang, L. (2018). Continuous monitoring of indoor environmental quality using an Arduino-based data acquisition system. Journal of Building Engineering, 19(May), 412-419. https://doi.org/10.1016/j.jobe.2018.05.014

Katafygiotou, M.C., \& Serghides, D. K. (2014). Indoor comfort and energy performance of buildings in relation to occupants' satisfaction: investigation in secondary schools of Cyprus. Advances in Building Energy Research, 8(2), 216-240. https://doi.org/10.1080/17512549.2013.865554

Katafygiotou, Martha C., \& Serghides, D. K. (2014). Thermal comfort of a typical secondary school building in Cyprus. Sustainable Cities and Society, 13, 303-312. https://doi.org/10.1016/j.scs.2014.03.004

Katsoulas, M. (2002). Monitoring and Modelling Indoor Air Quality Purpose-Designed Naturally 
Ventilated School. Inoor Built Environment, 316-326.

Kiri, M. (2016). Classroom acoustic conditions: Understanding what is suitable through a review of national and international standards, recommendations, and live classroom measurements. Proceedings of Acoustics The Second Australasian Acoustical Societies Conference.

Kleindienst, S., Bodart, M., \& Andersen, M. (2008). Graphical Representation of Climate-Based Daylight Performance to Support Architectural Design,. LEUKOS, 5(1), 39-61. doi: $10.1080 / 15502724.2008 .10747628)$

Knecht, H. A., Nelson, P. B., Whitelaw, G. M., \& Feth, L. L. (2002). Background Noise Levels and Reverberation Times in Unoccupied ClassroomsPredictions and Measurements. American Journal of Audiology, 11(2), 65-71. https://doi.org/10.1044/1059-0889(2002/009)

Knecht, H., Nelson, P., \& Whitelaw, G. (2002). Background Noise Levels and Reverberation Times in Unoccupied Classrooms: Predictions and Measurements. American Journal of Audiology, 11, 65-71.

Koch-Nielsen, H. (2002). Stay Cool a Design Guide for the Built environment in Hot climates. James \& James (Science Publishers) Ltd.

Koenigsberger, O., Ingersoll, T., Mayhew, A., \& Szokolay, S. (1980). Manual of Tropical Housing and Building (4th ed.). Longman Inc.

Kong, D., Liu, H., Wu, Y., Li, B., Wei, S., \& Yuan, M. (2019). Effects of indoor humidity on building occupants' thermal comfort and evidence in terms of climate adaptation. Building and Environment, 155(March), 298-307. https://doi.org/10.1016/j.buildenv.2019.02.039

Korsavi, S. S., Zomorodian, Z. S., \& Tahsildoost, M. (2016). Visual comfort assessment of daylit and sunlit areas: A longitudinal field survey in classrooms in Kashan, Iran. Energy and Buildings, 128, 305-318. https://doi.org/10.1016/j.enbuild.2016.06.091

Krigger, J., \& Dorsi, C. (2004). Residential Energy: cost savings and comfort for existing buildings (4th ed.). Saturn Resource Management. 
Kristiansen, J., Persson, R., Lund, S. P., Shibuya, H., \& Nielsen, P. M. (2015). Effects of Classroom Acoustics and Self- Reported Noise Exposure on Teachers' Well-Being. Environment and Behavior, 45(2), 283-300. https://doi.org/10.1177/0013916511429700

Krüger, E. L., \& Dorigo, A. L. (2008). Daylighting analysis in a public school in Curitiba, Brazil. Renewable Energy, 33(7), 1695-1702. https://doi.org/10.1016/j.renene.2007.09.002

Kruger, E. L., \& Zannin, P. H. T. (2004). Acoustic, thermal and luminous comfort in classrooms. Building and Environment, 39(9), 1055-1063.

https://doi.org/10.1016/j.buildenv.2004.01.030

Kruisselbrink, T., Tang, J., Bruggema, H., \& Zeiler, W. (2016). The indoor environmental quality in a Dutch day care centres : the effects of ventilation on the conditions within the baby cots.

Küller, R., \& Lindsten, C. (1992). Health and behavior of children in classrooms with and without windows. Journal of Environmental Psychology, 12(4), 305-317. https://doi.org/10.1016/S0272-4944(05)80079-9

Kwok, A. G., \& Chun, C. (2003). Thermal comfort in Japanese schools. Solar Energy, 74(3), 245252. https://doi.org/10.1016/S0038-092X(03)00147-6

Lackney, J. A. (1999). Assessing school facilities for learning / assessing the impact of the physical environment on the educational process: Integrating theoretical issues with practical concerns. UEF21 New Jersey Institute of Technology Conference.

Lawrence, T., \& Braun, J. (2007). A methodology for estimating occupant CO2 source generation rates from measurements in small commercial buildings. Building and Environment, 42(2), 623-639. https://doi.org/10.1016/j.buildenv.2004.10.021

Lee, S., \& Chang, M. (2000). Indoor and outdoor air quality investigation at schools in Hong Kong. Chemosphere, 41(1-2), 109-113. https://doi.org/10.1016/S0045-6535(99)00396-3

Lee, T., Biasio, D. De, \& Santini, A. (1996). Health and the built environment: Indoor air quality. ... , Health and the Built Environment, .... http://www.mtpinnacle.com/pdfs/iaq.pdf

Leigh, R. M. (2012). School Facility Conditions and the Relationship Between Teacher Attitudes 
[Faculty of Virginia Polytechnic Institute and State University].

http://www.efc.gwu.edu/wp-content/uploads/2014/11/Leigh_dissertation.pdf

Lercher, P. (2003). Annoyance, disturbance and severances in children exposed to transportation noise. Proceedings of the 8th International Congress on Noise as a Public Health Problem, 6, 241-248.

Li, C., Liu, H., Li, B., Cheng, Y., Du, C., \& Sheng, A. (2017). Human responses to the air relative humidity ramps: a chamber study. Build. Environ., 123, 458-468.

Li, D. H. W., \& Wong, S. L. (2007). Daylighting and energy implications due to shading effects from nearby buildings. Applied Energy, 84(12), 1199-1209. https://doi.org/10.1016/j.apenergy.2007.04.005

Lîfberg, H. A., Lîfstedt, B., Nilsson, I., \& Wyon, D. P. (1975). Combined temperature and lighting ejects on the performance of repetitive tasks with different visual content. Proceedings of the 18th CIE Session.

Loe, D., Watson, N., Rowlands, E., Mansfield, K., \& Baker, J. (1999). Lighting Design for Schools. Building Bulletin, 90, 81pages.

Luther, M. B., Horan, P., \& Tokede, O. (2018). Investigating CO2 concentration and occupancy in school classrooms at different stages in their life cycle. Architectural Science Review, 61(12), 83-95. https://doi.org/10.1080/00038628.2017.1416576

Mahyuddin, N, Awbi, H., \& Alshitawi, M. (2014). The spatial distribution of carbon dioxide in rooms with particular application to classrooms. Indoor and Built Environment, 23(3), 433448. https://doi.org/10.1177/1420326X13512142

Mahyuddin, Norhayati, \& Awbi, H. (2010). The spatial distribution of carbon dioxide in an environmental test chamber. Building and Environment, 45(9), 1993-2001. https://doi.org/10.1016/j.buildenv.2010.02.001

Mahyuddin, Norhayati, \& Awbi, H. (2012). A review of CO2 measurement procedures in ventilation research. International Journal of Ventilation, 10(4), 353-370. 
https://doi.org/10.1080/14733315.2012.11683961

Mallick, F. H. (1996). Thermal comfort and building design in the tropical climates. Energy and Buildings, 23(3), 161-167. https://doi.org/10.1016/0378-7788(95)00940-X

Mardaljevic, J. (2001). The BRE-IDMP data set: a new benchmark for the validation of illuminance prediction techniques. Institute of Energy and Sustainable Development, 33, 117-134.

Mardaljevic, J. (2000). Simulation of annual daylighting profiles for internal illuminance. CIBSE Daylight Group/Society of Light and Lighting Conference on Daylight Design and Research, 2, 111-118.

Mardaljevic, J, \& Nabil, A. (2005). The Useful Daylight Illuminance Paradigm: A Replacement for Daylight Factors. Lux Europa, Berlin, 169-174.

Mardaljevic, John, Brembilla, E., \& Drosou, N. (2016). Real-World Validation of Climate-Based Daylight Metrics: Mission Impossible? CIBSe Technical Symposium, 1-12.

McColl, S. L., \& Veitch, J. A. (2001). Full-spectrum fluorescent lighting: a review of its effects on physiology and health. Psychological Medicine, 6, 949-964.

https://doi.org/10.1017/\$003329170105425

McIntyre, D. . (1980). Indoor Climate. Applied Science Publishers LTD.

McIntosh, J. (2011). The Indoor Air Quality in 35 Wellington Primary Schools During the School Day. Master's Thesis.

http://restrictedarchive.vuw.ac.nz.helicon.vuw.ac.nz/handle/123456789/6390

Mendell, M. J., Eliseeva, E. A., Davies, M. M., Spears, M., Lobscheid, A., Fisk, W. J., \& Apte, M. G. (2013). Association of classroom ventilation with reduced illness absence: A prospective study in California elementary schools. Indoor Air, 23(6), 515-528.

https://doi.org/10.1111/ina.12042

MetService. (2018). Wellington Metrological Data. www.Metservice.Com/TownsCities/Wellington/Wellington-City\#!/Ten-Day. http://www.metservice.com/towns- 
cities/wellington/wellington-city\#!/ten-day

Mi, Y. H., Norbäck, D., Tao, J., Mi, Y. L., \& Ferm, M. (2006). Current asthma and respiratory symptoms among pupils in Shanghai, China: Influence of building ventilation, nitrogen dioxide, ozone, and formaldehyde in classrooms. Indoor Air, 16(6), 454-464. https://doi.org/10.1111/j.1600-0668.2006.00439.x

Mikulski, W., \& Radosz, J. (2011). Acoustics of classrooms in primary Schools - Results of the reverberation time and the speech transmission index assessments in selected buildings. Archives of Acoustics, 36(4), 777-793. https://doi.org/10.2478/V10168-011-0052-6

Ministry of Education. (2011). The New Zealand School Property Strategy 2011-2021.

Ministry of Education. (2016). New Zealand Education System Overview.

Ministry of Education. (2020). Te rautaki rawa kura = The school property strategy 2030. https://www.education.govt.nz/assets/Documents/Ministry/Strategies-and-policies/MOETe-Rautaki-Rawa-Kura-The-School-Property-Strategy-2030.pdf

Mirrahimi, S., Ibrahim, N. L. N., \& Surat, M. (2012). Effect of daylighting on student health and performance. Computational Methods in Science and Engineering, 5(4), 127-132.

Mistrick, R., \& Thongtipaya, J. (1997). Analysis of daylight photocell placement and view in a small office. Journal of the Illuminating Engineering Society, 26(2), 150-160. https://doi.org/10.1080/00994480.1997.10748199

Montgomery, D. A. (1987). Landscaping as a passive solar strategy. Passive Solar Journal, 4(1), 78-108.

Mumovic, D., Palmer, J., Davies, M., Orme, M., Ridley, I., Oreszczyn, T., Judd, C., Critchlow, R., Medina, H. A., Pilmoor, G., Pearson, C., \& Way, P. (2009). Winter indoor air quality, thermal comfort and acoustic performance of newly built secondary schools in England. Building and Environment, 44(7), 1466-1477. https://doi.org/10.1016/j.buildenv.2008.06.014

Murray, V., O’Flynn, C. J., \& Beattie, K. (2001). Advanced Building Services Simulation Software 
Providing Design Solutions In Dublin And Boston. Seventh International IBPSA Conference, 499-504. http://www.ibpsa.org/proceedings/BS2001/BS01_0499_504.pdf

Myhrvold, A., Olsen, E., \& Lauridsen, O. (1996). Indoor environment in schools-pupils health and performance in regard to $\mathrm{CO}_{2}$ concentrations. In Indoor Air (Vol. 94, Issue 4, pp. 369371).

http://gammelweb.iris.no/internet/student.nsf/199f312efd2a0cacc125680e00635b85/56 20dc0e13696990c1257b2b002c6991/\$FILE/1996-353.pdf

Mysen, M., Schild, P. G., Hellstrand, V., \& Thunshelle, K. (2005). Evaluation of simplified ventilation system with direct air supply through the facade in a school in a cold climate. Energy and Buildings, 37(2), 157-166. https://doi.org/10.1016/j.enbuild.2004.05.010

Nathaniel, M. (2008). Benefits of Sunlight. Environmental Health Perspectives, 116(1), 161-167. https://doi.org/10.1289/ehp.116-a160

Ncube, M., \& Riffat, S. (2012). Developing an indoor environment quality tool for assessment of mechanically ventilated office buildings in the UK - A preliminary study. Building and Environment, 53, 26-33. https://doi.org/10.1016/j.buildenv.2012.01.003

Neufert, E. (2000). Neufert Architects Data. Malden, MA : Blackwell Science Publishers.

Nevins, R., Rohles, F., Springer, W., \& Feyerherm, A. (1966). A temperature-humidity chart for thermal comfort of seated persons. ASHRAE Transact, 72, 283-29.

Nicklas, M. H., \& Bailey, G. B. (1997). Student Performance in Daylit Schools.

Noh, K.-C., Jang, J.-S., \& Oh, M.-D. (2007). Thermal comfort and indoor air quality in the lecture room with 4-way cassette air-conditioner and mixing ventilation system. Building and Environment, 42(2), 689-698. https://doi.org/10.1016/j.buildenv.2005.10.033

Noisehelp. (2018). The Decibel Scale. www.Noisehelp.Com/Decibel-Scale. https://www.noisehelp.com/decibel-scale.html

Norbäck, D., \& Nordström, K. (2008). An experimental study on effects of increased ventilation flow on students' perception of indoor environment in computer classrooms. Indoor Air, 
18(4), 293-300. https://doi.org/10.1111/j.1600-0668.2008.00530.x

Olgyay, V. (1963). Design with Climate Bioclimatic Approach to Architectural Regionalism. Princeton University Press.

Oughton, D., \& Hodkinson, S. (2002). Faber and Kell's Heating and Air-conditioning of Buildings (9th ed.). Butterworth Heinemann.

Park, J., Katz, L., Stavins, R., Shleifer, A., Heal, G., Chetty, R., Aldy, J., Goldin, C., Glaeser, E., Stock, J., Feldstein, M., Miron, J., Liebman, J., Mankiw, G., Keith, D., Goodman, J., Cutler, D., Auffhammer, M., Hsiang, S., \& Reardon, S. (2016). Temperature, Test Scores, and Educational Attainment. Harvard Economics Job Market Paper, 166.

Parkinson, T., \& de Dear, R. J. (2016). Thermal pleasure in built environments: spatial alliesthesia from air movement. Building Research \& Information, 00(June), 1-16. https://doi.org/10.1080/09613218.2016.1140932

Parsons, K. (1993). Human Thermal Environment, the Principles and the Practice. Taylor \& Francis.

Pellegrino, A., Cammarano, S., \& Savio, V. (2015). Daylighting for Green schools: A resource for indoor quality and energy efficiency in educational environments. Energy Procedia, 78, 3162-3167. https://doi.org/10.1016/j.egypro.2015.11.774

Penna, P., Gasparella, A., Cappelletti, F., Tahmasebi, F., Mahdavi, A. (2015). Optimization-based calibration of a school building based on short-term monitoring data. Proceedings of the 10th European Conference on Product and Process Modelling, ECPPM 2014, December, 259-264. https://doi.org/10.1201/b17396-46

Perez, J., Montano, J., \& Perez, J. (2005). Room temperature and its impact on student test scores. In Council of Educational Facilities Planner International.

Perez, Y. V., \& Capeluto, I. G. (2009). Climatic considerations in school building design in the hot-humid climate for reducing energy consumption. Applied Energy, 86(3), 340-348. https://doi.org/10.1016/j.apenergy.2008.05.007 
Persily, A. K. (1997). Evaluating building IAQ and ventilation with indoor carbon dioxide. ASHRAE Transactions, 103(pt 2), 193-204.

Petersen, S., Jensen, K. L., Pedersen, A. L. S., \& Rasmussen, H. S. (2016). The effect of increased classroom ventilation rate indicated by reduced $\mathrm{CO} 2$ concentration on the performance of schoolwork by children. Indoor Air, 26(3), 366-379. https://doi.org/10.1111/ina.12210

Pizzo, J. (1981). An investigation of the relationship between selected acoustic environments and sound, an element of learning style, as they affect sixth-grade students' reading achievement and attitudes. John's University.

Pontip, S. N. (2017). Patient's Satisfaction of Indoor Environmental Quality in Hospitals [Universiti Teknologi Malaysia]. In PhD Thesis. https://doi.org/10.13140/RG.2.2.27114.93126

Pugh, K. C., Miura, C. a, \& Asahara, L. L. Y. (2006). Noise levels among first, second, and third grade elementry school classrooms in hawaii. Journal of Educational Audiology, 13, 32-38.

Puteh, M., Adnan, M., Ibrahim, M. H., Noh, N. M., \& Che'Ahmad, C. N. (2014). An Analysis of Comfortable Teaching and Learning Environment: Community Response to Climate Change in School. Procedia - Social and Behavioral Sciences, 116, 285-290.

https://doi.org/10.1016/j.sbspro.2014.01.209

Ranasinghe, S., \& Mistrick, R. (2003). A study of photosensor configuration and performance in a daylighted classroom space. Journal of the Illuminating Engineering Society, 32(2), 3-20. https://doi.org/10.1080/00994480.2003.10748412

Rashid, M., \& Zimring, C. (2008). A Review of the Empirical Literature on the Relationships Between Indoor Environment and Stress in Health Care and Office Settings: Problems and Prospects of Sharing Evidence. Environment and Behavior, 40(2), 151-190. https://doi.org/10.1177/0013916507311550

Reddy, T. A. (2006). Literature Review on Calibration of Building Energy Simulation ProgramsUses,Problems, Procedures, Uncertainty, and Tools. ASHRAE Transactions, 112, 226-240. 
https://doi.org/Article

Reinhart, C. F., \& Walkenhorst, O. (2001). Validation of dynamic RADIANCE-based daylight simulations for a test office with external blinds. Energy and Buildings, 33(7), 683-697. https://doi.org/10.1016/S0378-7788(01)00058-5

Richard, M. W. (1970). Elimination of Biases in Loudness Judgments for Tones. Journal of the Acoustic Society, 48(6B), 1397-1403.

Rosbach, J. T. M., Vonk, M., Duijm, F., van Ginkel, J. T., Gehring, U., \& Brunekreef, B. (2013). A ventilation intervention study in classrooms to improve indoor air quality: the FRESH study. Environmental Health : A Global Access Science Source, 12, 110. https://doi.org/10.1186/1476-069X-12-110

Rosén, K. G., \& Richardson, G. (1999). Would removing indoor air particulates in children's environments reduce rate of absenteeism - A hypothesis. Science of the Total Environment, 234(1-3), 87-93. https://doi.org/10.1016/S0048-9697(99)00266-1

Roudsari, M., \& Pak, M. (2013). Ladybug: a Parametric Environmental Plugin for Grasshopper To Help Designers Create an Environmentally-Conscious Design. 13th Conference of International Building Performance Simulation Association, 3129-3135. http://www.ibpsa.org/proceedings/bs2013/p_2499.pdf

Sakellaris, I. A., Saraga, D. E., Mandin, C., Roda, C., Fossati, S., De Kluizenaar, Y., Carrer, P., Dimitroulopoulou, S., Mihucz, V. G., Szigeti, T., Hänninen, O., De Oliveira Fernandes, E., Bartzis, J. G., \& Bluyssen, P. M. (2016). Perceived indoor environment and occupants' comfort in European "Modern" office buildings: The OFFICAIR Study. International Journal of Environmental Research and Public Health, 13(5). https://doi.org/10.3390/ijerph13050444

Salmon, C. (1999). Architectural Design for Tropical Regions. John Wileys \& Sons, Inc.

Salthammer, T., Uhde, E., Schripp, T., Schieweck, A., Morawska, L., Mazaheri, M., Clifford, S., He, C., Buonanno, G., Querol, X., Viana, M., \& Kumar, P. (2016). Children's well-being at 
schools: Impact of climatic conditions and air pollution. Environment International, 94, 196-210. https://doi.org/10.1016/j.envint.2016.05.009

Santamouris, M., Synnefa, A., Asssimakopoulos, M., Livada, I., Pavlou, K., Papaglastra, M., Gaitani, N., Kolokotsa, D., \& Assimakopoulos, V. (2008). Experimental investigation of the air flow and indoor carbon dioxide concentration in classrooms with intermittent natural ventilation. Energy and Buildings, 40(10), 1833-1843.

https://doi.org/10.1016/j.enbuild.2008.04.002

Sanz, S. A., García, A. M., \& García, A. (1993). Road traffic noise around schools: a risk for pupil’s performance? International Archives of Occupational and Environmental Health, 65(3), 205-207. https://doi.org/10.1007/BF00381157

Satish, U., Mendell, M. J., Shekhar, K., Hotchi, T., Sullivan, D., Streufert, S., \& Fisk, W. J. (2012). Is $\mathrm{CO}_{2}$ an indoor pollutant? Direct effects of low-to-moderate $\mathrm{CO}_{2}$ concentrations on human decision-making performance. Environmental Health Perspectives, 120(12), 1671-1677. https://doi.org/10.1289/ehp.1104789

Sato, H., \& Bradley, J. (2008). Evaluation of acoustical conditions for speech communication in working elementary school classrooms. Journal of Acoustical Society of America, 123(4), 2064-2077.

Schibuola, L., Scarpa, M., \& Tambani, C. (2016). Natural Ventilation Level Assessment in a School Building by CO2 Concentration Measures. Energy Procedia, 101(September), 257264. https://doi.org/10.1016/j.egypro.2016.11.033

Schneider, M. (2002). Do School Facilities Affect Academic Outcomes? National Clearinghouse for Educational Facilities; Building, 75(October), 2-19.

Schoer, L., \& Shaffran, J. (1973). A combined evaluation of three separate research projects on the effects of thermal environment on learning and performance. ASHRAE Trans, 79(97), 108.

Sekhar, S. C., Tham, K. W., \& Cheong, K. W. (2003). Indoor air quality and energy performance 
of air-conditioned office buildings in Singapore. Indoor Air, 13(4), 315-331.

https://doi.org/10.1111/j.1600-0668.2003.00191.x

Sengpielaudio. (2018). Subjectively perceived loudness (volume), objectively measured sound pressure (voltage), and theoretically calculated sound intensity (acoustic power). Www.Sengpielaudio.Com. http://www.sengpielaudio.com/calculator-levelchange.htm

Shendell, D. G., Prill, R., Fisk, W. J., Apte, M. G., Blake, D., \& Faulkner, D. (2004). Associations between classroom $\mathrm{CO} 2$ concentrations and student attendance in Washington and Idaho. Indoor Air, 14(5), 333-341. https://doi.org/10.1111/j.1600-0668.2004.00251.x

Shield, B., Greenland, E., \& Dockrell, J. (2010). Noise in open plan classrooms in primary schools: A review. Noise and Health, 12(49), 225-234. https://doi.org/10.4103/1463-1741.70501

Shield, B. M., \& Dockrell, J. E. (2003). The effect of noise on children at school: A review. J. Building Acoustics, 10(2), 97-106. https://doi.org/10.1260/135101003768965960

Shrestha, S. S. (2009). Performance evaluation of carbon-dioxide sensors used in building HVAC applications. http://lib.dr.iastate.edu/etd

Singh, P., \& Arora, R. (2014). Classroom Illuminance: Its impact on Students' Health Exposure \& Concentration Performance. International Ergonomics Conference HWWE 2014 Classroom, December 2014, 1-5.

Smedje, G., \& Norbäck, D. (2001). Irritants and allergens at school in relation to furnishings and cleaning. Indoor Air, 11(2), 127-133. https://doi.org/10.1034/j.1600-0668.2001.110207.x

Soebarto, V., \& Bennetts, H. (2014). Thermal comfort and occupant responses during summer in a low to middle income housing development in South Australia. Building and Environment, 75, 19-29. https://doi.org/10.1016/j.buildenv.2014.01.013

Standard IES LM-83-1. (2012). Approved Method: IES SpatialDaylight Autonomy (sDA) andAnnual Sunlight Exposure (ASE). In Illuminating Engeneering Society:

Stevens, S. S. (1973). Hearing : its psychology and physiology. New York : Wiley. 
Sundell, J. (1999). Indoor Air Sciences: A Defined Area of Study or a Field to be Defined. Education and Training in Indoor Air Sciences, 9-18.

Sundell, J., Levin, H., Nazaroff, W. W., Cain, W. S., Fisk, W. J., Grimsrud, D. T., Gyntelberg, F., Li, Y., Persily, A. K., Pickering, A. C., Samet, J. M., Spengler, J. D., Taylor, S. T., \& Weschler, C. J. (2011). Ventilation rates and health: Multidisciplinary review of the scientific literature. Indoor Air, 21(3), 191-204. https://doi.org/10.1111/j.1600-0668.2010.00703.x

Szokolay, V. S. (2008). Architectural Science, the Basics of Sustainable Design. Architectural Press.

Tanner, C. K. (2008). Effects of school design on student outcomes. Journal of Educational Administration, 47(3), 381-399. https://doi.org/10.1108/09578230910955809

Teli, D., Jentsch, M. F., \& James, P. A. B. (2014). The role of a building's thermal properties on pupils' thermal comfort in junior school classrooms as determined in field studies. Building and Environment, 82, 640-654. https://doi.org/10.1016/j.buildenv.2014.10.005

Tham, K. W., \& Willem, H. C. (2010). Room air temperature affects occupants' physiology, perceptions and mental alertness. Building and Environment, 45(1), 40-44. https://doi.org/10.1016/j.buildenv.2009.04.002

Theodosiou, T. G., \& Ordoumpozanis, K. T. (2008). Energy, comfort and indoor air quality in nursery and elementary school buildings in the cold climatic zone of Greece. Energy and Buildings, 40(12), 2207-2214. https://doi.org/10.1016/j.enbuild.2008.06.011

Toyinbo, O., Shaughnessy, R., Turunen, M., Putus, T., Metsämuuronen, J., Kurnitski, J., \& Haverinen-Shaughnessy, U. (2016). Building characteristics, indoor environmental quality, and mathematics achievement in Finnish elementary schools. Building and Environment, 104, 114-121. https://doi.org/10.1016/j.buildenv.2016.04.030

Trombetta, Z., \& Paulo, H. (2012). Assessment of Acoustic Quality in Classrooms Based on Measurements, Perception and Noise Control. Noise Control, Reduction and Cancellation Solutions in Engineering, 2(1), 298. https://doi.org/10.5772/26429 
Turunen, M., Toyinbo, O., Putus, T., Nevalainen, A., Shaughnessy, R., \& Haverinen-Shaughnessy, U. (2014). Indoor environmental quality in school buildings, and the health and wellbeing of students. International Journal of Hygiene and Environmental Health, 217(7), 733-739. https://doi.org/10.1016/j.ijheh.2014.03.002

Tzempelikos, A., Athienitis, A. K., Neill, B. O., Kapsis, K., Drive, S. M., \& Lafayette, W. (2006). Lighting and Shading Control Studies at P. E. Trudeau Airport, School of Civil Engineering, Purdue University, Department of Building, Civil and Environmental Engineering, Concordia University, 1455 de Maisonneuve W. EV . 6-139, Montréal , QC , Ca.

USGBC. (2014). LEED v 4.

Valentine, J. (1993). Classroom Acoustics - A New Zealand Perspective Principal Authors : Abstract : The Oticon Foundation in New Zealand, 1-16.

Van Hoof, J. (2008). Forty years of Fanger's model of thermal comfort: Comfort for all? Indoor Air, 18(3), 182-201. https://doi.org/10.1111/j.1600-0668.2007.00516.x

Vilatarsana, G. (2004). The environmental noise exposure of schools around Heathrow. South Bank University.

Walinder, R., Norback, D., Wieslander, G., Smedje, G., \& Erwall, C. (1997). Nasal Mucosal Swelling in Relation to Low Air Exchange Rate in Schools. Indoor Air, 7(3), 198-205. https://doi.org/10.1111/j.1600-0668.1997.t01-1-00005.x

Wall, G. (2016). The impact of physical design on student outcomes. In Report. Ministry of Education, New Zealand. www.educationcounts.edcentre.govt.nz

Walsh D. (1975). Noise levels and annoyance in open plan educational facilities. Journal of Architectural Research, 4, 5-16.

Wang, Y., Boulic, M., \& Phipps, R. (2016). Increasing the ventilation rate and temperature in New Zealand classrooms using a solar ventilation unit. Central Europe Sustainable Building Conference, 22-24.

Wargocki, P., Porras-Salazar, J., \& Bahnfleth, W. (2017). Quantitative relationships between 
classroom CO 2 concentration and learning in elementary schools. Aivc.

Wargocki, P., \& Wyon, D. (2007). The Effects of Moderately Raised Classroom Temperatures and Classroom Ventilation Rate on the Performance of Schoolwork by Children. HVAC\&R Research, 13(2), 193-220. https://doi.org/10.1080/10789669.2007.10390951

Wargocki, P., \& Wyon, D. P. (2013). Providing better thermal and air quality conditions in school classrooms would be cost-effective. Building and Environment, 59, 581-589. https://doi.org/10.1016/j.buildenv.2012.10.007

Wargocki, P., \& Wyon, D. P. (2017). Ten questions concerning thermal and indoor air quality effects on the performance of office work and schoolwork. Building and Environment, 112, 359-366. https://doi.org/10.1016/j.buildenv.2016.11.020

Watson, A. (2015). Use of Whirling Hygrometers. AWE Internaytional. https://www.aweimagazine.com/article/use-of-whirling-hygrometers-1137

Wilson, O., Valentine, J., Halstead, M., McGunnigle, K., Dodd, G., Hellier, A., Wood, J., \& Simpson, R. (2002). Classroom_Acoustics_11.Pdf. The Oticon Foundation in New Zealand Donations.

Winterbottom, M., \& Wilkins, A. (2009). Lighting and discomfort in the classroom. Journal of Environmental Psychology, 29(1), 63-75. https://doi.org/10.1016/j.jenvp.2008.11.007

Wong, L., \& Mui, K. (2007). Evaluation on four sampling schemes for assessing indoor air quality. Building and Environment, 42(3), 1119-1125. https://doi.org/10.1016/j.buildenv.2005.11.014

Wong, L. T., Mui, K. W., \& Hui, P. S. (2008). A multivariate-logistic model for acceptance of indoor environmental quality (IEQ) in offices. Building and Environment, 43(1), 1-6. https://doi.org/10.1016/j.buildenv.2007.01.001

Wong, N. H., \& Khoo, S. S. (2003). Thermal comfort in classrooms in the tropics. Energy and Buildings, 35(4), 337-351. https://doi.org/10.1016/S0378-7788(02)00109-3

Wu, T., Cao, B., \& Zhu, Y. (2018). A field study on thermal comfort and air-conditioning energy 
use in an office building in Guangzhou. Energy and Buildings.

https://doi.org/10.1016/j.enbuild.2018.03.030

Wyon, D. . (1970). Studies of children under imposed noise and heat stress. Ergonomics, 13(5), 598-612.

Wyon, D. P., Andersen, I. B., \& Lundqvist, G. R. (1979). The effects of moderate heat stress on mental performance. Scandinavian Journal of Work, Environment \& Health, 5(4), 352-361. https://doi.org/10.1016/S0166-1116(08)71093-8

Yin, R. (2014). Case Study Research Design and Methods (5th ed.). Sage Publications Ltd.

Yoon, S. (2008). An Integrative Approach: Environmental Quality (EQ) Evaluation in Residential Buildings. PhD Thesis. The University of Michigan. Zagreus.

Yun, G. Y. (2018). Influences of perceived control on thermal comfort and energy use in buildings. Energy and Buildings, 158, 822-830.

https://doi.org/10.1016/j.enbuild.2017.10.044

Zannin, P. H. T., \& Zwirtes, D. P. Z. (2009). Evaluation of the acoustic performance of classrooms in public schools. Applied Acoustics, 70(4), 626-635.

https://doi.org/10.1016/j.apacoust.2008.06.007

Zeiler, W., \& Boxem, G. (2009). Effects of thermal activated building systems in schools on thermal comfort in winter. Building and Environment, 44(11), 2308-2317. https://doi.org/10.1016/j.buildenv.2009.05.005

Zeitzer, J. M., Dijk, D. J., Kronauer, R., Brown, E., \& Czeisler, C. (2000). Sensitivity of the human circadian pacemaker to nocturnal light: melatonin phase resetting and suppression. The Journal of Physiology, 526 Pt 3(Pt 3), 695-702. https://doi.org/10.1111/j.14697793.2000.00695.x

Zomorodian, Z. S., Korsavi, S. S., \& Tahsildoost, M. (2016). The effect of window configuration on daylight performance in classrooms : A field and simulation study. Int. J. Architect. Eng. Urban Plan, 26(June), 15-24. 


\section{APPENDIXES}

\section{Appendix 1: The Systematic Appraisal of 150 Articles that met the Inclusion Criteria of the Study}

Table 64 shows the systematic appraisal of the 150 articles that met the inclusion criteria of the study. This Table should be read alongside the data extraction process (Section 2.1) for clearer understanding.

\begin{tabular}{|c|c|c|c|c|c|c|c|c|c|c|c|c|c|c|}
\hline \multicolumn{2}{|c|}{ DESCRIPTION } & \multicolumn{2}{|c|}{ DEPENDENT VARIABLES } & \multicolumn{6}{|c|}{ INDEPENDENT VARIABLES } & \multicolumn{5}{|c|}{ OTHERS } \\
\hline $\mathbf{S} / \mathbf{N}$ & STUDIES & $\begin{array}{l}\text { LEARNING } \\
\text { PERFORMANCE }\end{array}$ & HEALTH & D & $\mathbf{T}$ & A & IAQ & SEC & ENV & $\begin{array}{l}\text { Rank } \\
\left({ }^{3}\right)\end{array}$ & METHOD & Country & $\begin{array}{l}\text { School } \\
\text { Type }\end{array}$ & $\begin{array}{l}\text { No of } \\
\text { Students }\end{array}$ \\
\hline 1. & $\begin{array}{l}\text { Nicklas \& Bailey, } \\
(1997)\end{array}$ & $*$ & & $S$ & & & & & & 4 & Measured & USA & TPS & $24 \mathrm{SCH}$ \\
\hline 2. & $\begin{array}{l}\text { Cheryan et al., } \\
(2014)\end{array}$ & * & & & & & & & $\mathrm{R}$ & 3 & Lit Rev & - & - & - \\
\hline 3. & $\begin{array}{l}\text { Heschong Mahone } \\
\text { Group (1999) }\end{array}$ & * & & $S$ & & & & $S$ & & 5 & Measured & USA & TPS & $\begin{array}{l}21000 \\
\text { Students } \\
3 \mathrm{SCH} \\
2000 \mathrm{CR}\end{array}$ \\
\hline 4. & $\begin{array}{l}\text { Edwards \& } \\
\text { Torcellini, (2002) }\end{array}$ & $*$ & $*$ & $\mathrm{R}$ & & & & & $R$ & 3 & Lit Rev & - & - & - \\
\hline 5. & $\begin{array}{l}\text { Issa, Rankin, Attalla, } \\
\text { \& Christian, (2011) }\end{array}$ & $*$ & & & & & & & NS & 1 & Survey & Canada & TPS & $\begin{array}{l}30 \mathrm{SCH} \\
150 \\
\text { Teachers }\end{array}$ \\
\hline 6. & $\begin{array}{l}\text { Loe, Watson, } \\
\text { Rowlands, }\end{array}$ & $*$ & & $\mathrm{R}$ & & & & & $\mathrm{R}$ & & $\begin{array}{l}\text { Policy } \\
\text { Document }\end{array}$ & - & - & - \\
\hline
\end{tabular}

\section{(3) Note: In the ranking column}

5 - Articles that showed a significant (S) association between the dependent and independent variable and considered socio-economics

4 - Articles that showed a significant $(S)$ association between the dependent and independent variable and did not consider socio-economic

3 - Literature reviews and reports that showed a relationship of an independent variable

2 - Articles that suggested there is a relationship

1 - Articles that had a non-significant association 


\begin{tabular}{|c|c|c|c|c|c|c|c|c|c|c|c|c|c|c|}
\hline & $\begin{array}{l}\text { Mansfield, \& Baker, } \\
\text { (1999) }\end{array}$ & & & & & & & & & & & & & \\
\hline 7. & $\begin{array}{l}\text { Bakó-Biró, } \\
\text { Clements-Croome, } \\
\text { Kochhar, Awbi, \& } \\
\text { Williams, (2012) }\end{array}$ & $*$ & & & & & $\mathrm{~S}$ & & & 4 & Measured & UK & TPS & $\begin{array}{l}200 \text { Pupils } \\
8 \mathrm{SCH} \\
16 \mathrm{CR}\end{array}$ \\
\hline 8. & $\begin{array}{l}\text { Mendell \& Heath, } \\
(2002)\end{array}$ & $*$ & $*$ & & & & & & $\mathrm{R}$ & 3 & Lit Rev & - & - & - \\
\hline 9. & $\begin{array}{l}\text { Wargocki \& Wyon, } \\
(2007)\end{array}$ & $*$ & & & $\mathrm{~S}$ & & & & & 4 & Measured & Denmark & TSS & $2 \mathrm{CR}$ \\
\hline 10. & $\begin{array}{l}\text { Andersen, \& } \\
\text { Lundqvist, (1979) }\end{array}$ & $*$ & & & $\mathrm{~S}$ & & & & & 4 & Measured & Denmark & $\begin{array}{l}\text { Climate } \\
\text { Chamber }\end{array}$ & $\begin{array}{l}72,17- \\
\text { year-old } \\
\text { students }\end{array}$ \\
\hline 11. & $\begin{array}{l}\text { De Dear et al., } \\
(2015)\end{array}$ & $*$ & & & $\mathrm{~S}$ & & & & & 4 & Measured & Australia & $\begin{array}{l}\text { TPS and } \\
\text { TSS }\end{array}$ & $\begin{array}{l}2850 \\
\text { Students }\end{array}$ \\
\hline 12. & $\begin{array}{l}\text { Zeiler \& Boxem, } \\
(2009)\end{array}$ & $*$ & & & $\mathrm{~S}$ & & $\mathrm{~S}$ & & & 4 & Measured & Denmark & TPS & $14 \mathrm{SCH}$ \\
\hline 13. & $\begin{array}{l}\text { Mirrahimi, Ibrahim, } \\
\& \text { Surat, (2012) }\end{array}$ & $*$ & $*$ & $R$ & & & & & & 3 & Lit Rev & - & - & - \\
\hline 14. & Lee et al., (2012) & $*$ & & & & & $\mathrm{~S}$ & & & 4 & Measured & China & $\begin{array}{l}\text { University } \\
\text { rooms }\end{array}$ & - \\
\hline 15. & $\begin{array}{l}\text { Katafygiotou \& } \\
\text { Serghides, (2014a) }\end{array}$ & $*$ & $*$ & & & & & & $\mathrm{R}$ & 3 & Survey & Cyprus & Gym & - \\
\hline 16. & Schneider, (2002) & $*$ & & & $\mathrm{R}$ & $\mathrm{R}$ & $\mathrm{R}$ & & & 3 & Lit Rev & - & - & - \\
\hline 17. & Fabbri, (2013) & $*$ & & & $S$ & & & & & 4 & Measured & Italy & TPS & - \\
\hline 18. & Earthman, (2004) & $*$ & & & & & & & $\mathrm{R}$ & 3 & Lit Rev & - & - & - \\
\hline 19. & $\begin{array}{l}\text { Allen \& Fischer, } \\
\text { (1978) }\end{array}$ & $*$ & & & & & & & & & - & - & - & - \\
\hline 20. & $\begin{array}{l}\text { Shield \& Dockrell, } \\
(2003)\end{array}$ & $*$ & & & & $R$ & & & & & Lit Rev & - & - & - \\
\hline 21. & $\begin{array}{l}\text { Evans \& Maxwell, } \\
\text { (1997) }\end{array}$ & $*$ & & & & $\mathrm{~S}$ & & $S$ & & 5 & Measured & USA & TPS & $\begin{array}{l}160 \text { Pupils } \\
2 \mathrm{SCH}\end{array}$ \\
\hline 22. & Hygge, (2003) & $*$ & & & & $\mathrm{~S}$ & & & & 4 & Measured & Sweden & TSS & $\begin{array}{l}1358 \\
\text { children }\end{array}$ \\
\hline 23. & $\begin{array}{l}\text { Dockrell \& Shield, } \\
(2006)\end{array}$ & $*$ & & & & $S$ & & & & 4 & Measured & UK & TPS & $\begin{array}{l}158 \\
\text { Children }\end{array}$ \\
\hline
\end{tabular}




\begin{tabular}{|c|c|c|c|c|c|c|c|c|c|c|c|c|c|c|}
\hline & & & & & & & & & & & & & & $3 \mathrm{CR}$ \\
\hline 24. & Lackney, (1999) & $*$ & & & & & & & $\mathrm{R}$ & 3 & Lit Rev & - & - & - \\
\hline 25. & Valentine, (1993) & $*$ & & & & $S$ & & & & 4 & Survey & $\begin{array}{l}\text { New } \\
\text { Zealand }\end{array}$ & TPS & $\begin{array}{l}120 \\
\text { teachers in } \\
7 \text { schools }\end{array}$ \\
\hline 26. & $\begin{array}{l}\text { Dorizas et al., } \\
\text { (2015) }\end{array}$ & $*$ & $*$ & & $S$ & & $S$ & & & 4 & Measured & Greece & $\mathrm{T}$ & - \\
\hline 27. & $\begin{array}{l}\text { Haverinen- } \\
\text { Shaughnessy \& } \\
\text { Shaughnessy, } \\
(2015)\end{array}$ & $*$ & & & & & $S$ & & & 4 & Measured & USA & TPS & $\begin{array}{l}3109 \text { Pupils } \\
70 \text { SCH } 140 \\
\text { CR }\end{array}$ \\
\hline 28. & $\begin{array}{l}\text { Myhrvold, Olsen, \& } \\
\text { Lauridsen, 1996) }\end{array}$ & $*$ & $*$ & & & & $S$ & & & 4 & Measured & Norway & $\mathrm{T}$ & $\begin{array}{l}550 \text { Pupils } \\
5 \mathrm{SCH} \\
22 \mathrm{CR}\end{array}$ \\
\hline 29. & $\begin{array}{l}\text { El Asmar, Chokor, \& } \\
\text { Srour, (2014) }\end{array}$ & & $*$ & & $\mathrm{R}$ & $\mathrm{R}$ & $\mathrm{R}$ & & & 3 & Survey & $\begin{array}{l}\text { USA \& } \\
\text { Lebanon/ }\end{array}$ & $\begin{array}{l}\text { University } \\
\text { Classroom }\end{array}$ & $\begin{array}{l}320 \\
\text { Students }\end{array}$ \\
\hline 30. & Puteh et al., (2014) & & $*$ & & $S$ & & & $S$ & $S$ & 5 & Survey & $\begin{array}{l}\text { Malaysia } \\
\text { Tropical }\end{array}$ & $\mathrm{T}$ & - \\
\hline 31. & $\begin{array}{l}\text { Cartieaux, Rzepka, } \\
\text { \& Cuny, (2011) }\end{array}$ & & $*$ & & & & $\mathrm{R}$ & & & 3 & Survey & France & $\mathrm{T}$ & - \\
\hline 32. & $\begin{array}{l}\text { Ferreira \& Cardoso, } \\
(2014)\end{array}$ & & $*$ & & & & $S$ & $S$ & & 5 & Survey & Portugal & TPS & $\begin{array}{l}1,019 \\
\text { students } \\
51 \mathrm{SCH}\end{array}$ \\
\hline 33. & $\begin{array}{l}\text { Mendell et al., } \\
(2013)\end{array}$ & & $*$ & & & & $S$ & $S$ & & 5 & Measured & USA & TPS & $\begin{array}{l}162 \mathrm{CR} \\
28 \mathrm{SCH}\end{array}$ \\
\hline 34. & Satish et al., (2012) & $*$ & $*$ & & & & $S$ & & & 4 & Measured & USA & $\begin{array}{l}\text { Office } \\
\text { Building }\end{array}$ & - \\
\hline 35. & $\begin{array}{l}\text { Sundell et al., } \\
(2011)\end{array}$ & & $*$ & & & & $\mathrm{R}$ & & & 3 & Lit Rev & - & - & - \\
\hline 36. & $\begin{array}{l}\text { Turunen et al., } \\
\text { (2014) }\end{array}$ & & $*$ & & & & $S$ & $S$ & & 5 & Survey & Finland & TPS & $\begin{array}{l}4248 \\
\text { Students } \\
355 \mathrm{SCH}\end{array}$ \\
\hline 37. & Loe et al., (1999) & & $*$ & $\mathrm{R}$ & & & & & $\mathrm{R}$ & 3 & Policy Doc & - & - & - \\
\hline
\end{tabular}




\begin{tabular}{|c|c|c|c|c|c|c|c|c|c|c|c|c|c|}
\hline 38. & $\begin{array}{l}\text { Clements-Croome, } \\
\text { (2015) }\end{array}$ & & $*$ & & & & & $\mathrm{R}$ & 3 & Lit Rev & - & - & - \\
\hline 39. & Bommel, (2003) & & $*$ & $\mathrm{R}$ & & & & $\mathrm{R}$ & 3 & Lit Rev & - & - & - \\
\hline 40. & Fisk, (2000) & & * & & & & & $\mathrm{R}$ & 3 & Lit Rev & - & - & - \\
\hline 41. & $\begin{array}{l}\text { Rashid \& Zimring, } \\
(2008)\end{array}$ & & $*$ & & & & & $\mathrm{R}$ & 3 & Lit Rev & - & - & - \\
\hline 42. & Mead et al., (2012) & & $*$ & $\mathrm{R}$ & & & & $\mathrm{R}$ & 3 & Lit Rev & - & - & - \\
\hline 43. & $\begin{array}{l}\text { Zeitzer, et al., } \\
(2000)\end{array}$ & & $*$ & $S$ & & & & & 4 & Measured & USA & - & - \\
\hline 44. & Claude, (1986) & & $*$ & $R$ & & & & & 3 & - & - & - & - \\
\hline 45. & $\begin{array}{l}\text { Edwards \& } \\
\text { Torcellini, (2002) }\end{array}$ & & * & $R$ & & & & & 3 & Lit Rev & - & - & - \\
\hline 46. & $\begin{array}{l}\text { Hathaway, et al., } \\
\text { (1992) }\end{array}$ & & $*$ & $S$ & & & $\mathrm{~S}$ & & 5 & Measured & Canada & TPS & - \\
\hline 47. & Nathaniel, (2008) & & $*$ & $\mathrm{R}$ & & & & $\mathrm{R}$ & 3 & Lit Rev & - & - & - \\
\hline 48. & $\begin{array}{l}\text { Küller \& Lindsten, } \\
\text { (1992) }\end{array}$ & & $*$ & $S$ & & & & & 4 & Measured & Sweden & TSS & $\begin{array}{l}90 \\
\text { Students } \\
3 \mathrm{SCH}\end{array}$ \\
\hline 49. & Wang et al., (2008) & & $*$ & $S$ & & & & & 4 & Measured & - & - & - \\
\hline 50. & $\begin{array}{l}\text { Abo-Hasseba, } \\
\text { Waaramaa, Alku, \& } \\
\text { Geneid, (2016) }\end{array}$ & & $*$ & & $S$ & & & & 4 & Survey & Egypt & - & $\begin{array}{l}140 \\
\text { Teachers } \\
4 \mathrm{SCH}\end{array}$ \\
\hline 51. & $\begin{array}{l}\text { (Kristiansen, } \\
\text { Persson, Lund, } \\
\text { Shibuya, \& Nielsen, } \\
\text { 2015) }\end{array}$ & & $*$ & & NS & & & & 1 & Measured & Denmark & $T$ & $\begin{array}{l}283 \\
\text { Teachers } \\
10 \mathrm{SCH}\end{array}$ \\
\hline 52. & $\begin{array}{l}\text { Salthammer et al., } \\
(2016)\end{array}$ & & $*$ & & & $\mathrm{R}$ & & & 2 & - & - & - & - \\
\hline 53. & $\begin{array}{l}\text { Cartieaux et al., } \\
\text { (2011) }\end{array}$ & $*$ & & & & $\mathrm{R}$ & & & 2 & - & - & - & - \\
\hline 54. & $\begin{array}{l}\text { Heschong, Group, } \\
\text { Wright, \& Analytics, } \\
\text { (2003) }\end{array}$ & $*$ & & $S$ & & & $S$ & & 5 & Survey & USA & TPS & $\begin{array}{l}7,000 \text { to } \\
9,000 \\
\text { students } \\
27 \mathrm{SCH} \\
\end{array}$ \\
\hline 55. & $\begin{array}{l}\text { Miller, Pogue, } \\
\text { Gough, \& Davis, } \\
(2009)\end{array}$ & $*$ & & & & & & $\mathrm{R}$ & 2 & Survey & - & - & - \\
\hline
\end{tabular}




\begin{tabular}{|c|c|c|c|c|c|c|c|c|c|c|c|c|c|}
\hline 56. & $\begin{array}{l}\text { Tham \& Willem, } \\
\text { (2010) }\end{array}$ & $*$ & & $S$ & & & & & 4 & Measured & Tropics & $\begin{array}{l}\text { Office } \\
\text { buildings }\end{array}$ & - \\
\hline 57. & $\begin{array}{l}\text { Ngarmpornprasert } \\
\text { \& Koetsinchai, } \\
\text { (2010). }\end{array}$ & $*$ & & $S$ & & & & & 4 & Measured & Thailand & $\begin{array}{l}\text { Office } \\
\text { Buildings }\end{array}$ & \\
\hline 58. & $\begin{array}{l}\text { Kekalainen et al., } \\
(2010)\end{array}$ & $*$ & & $\mathrm{~S}$ & & & & & 4 & Measured & - & $\begin{array}{l}\text { Office } \\
\text { Buildings }\end{array}$ & - \\
\hline 59. & $\begin{array}{l}\text { Niemelä, Hannula, } \\
\text { Rautio, Reijula, \& } \\
\text { Railio, (2002) }\end{array}$ & $*$ & & $S$ & & & & & 4 & Measured & - & $\begin{array}{l}\text { Office } \\
\text { Buildings }\end{array}$ & \\
\hline 60. & $\begin{array}{l}\text { Tanabe, Kobayashi, } \\
\text { Kiyota, Nishihara, \& } \\
\text { Haneda, (2009) }\end{array}$ & $*$ & & $\mathrm{~S}$ & & & & & 4 & Measured & - & $\begin{array}{l}\text { Office } \\
\text { Buildings }\end{array}$ & - \\
\hline 61. & $\begin{array}{l}\text { Seppanen, Fisk, \& } \\
\text { Lei, (2006) }\end{array}$ & $*$ & $*$ & $S$ & & & & $S$ & 4 & Measured & - & $\begin{array}{l}\text { Office } \\
\text { Buildings }\end{array}$ & - \\
\hline 62. & $\begin{array}{l}\text { Gabrielle Wall } \\
(2010)\end{array}$ & $*$ & & & & & $S$ & $\mathrm{~S}$ & 5 & Survey & $\begin{array}{c}\text { New } \\
\text { Zealand }\end{array}$ & TSS & $\begin{array}{c}700 \\
\text { Students }\end{array}$ \\
\hline 63. & $\begin{array}{l}\text { Al-Bustami, Hadil } \\
(2014)\end{array}$ & * & & $\mathrm{S}$ & & $\mathrm{S}$ & & & 4 & - & - & - & - \\
\hline 64. & Allcock, J. (1997) & & & & $\mathrm{R}$ & & & & 3 & Lit Rev & - & - & - \\
\hline 65. & $\begin{array}{l}\text { American Speech- } \\
\text { Language Hearing } \\
\text { Association (ASHA) } \\
(2005)\end{array}$ & & & & $\mathrm{R}$ & & & & 2 & Policy Doc & - & - & - \\
\hline 66. & $\begin{array}{l}\text { Arnot, M., \& Reay, } \\
\text { D. (2007) }\end{array}$ & & & & $\mathrm{R}$ & & & & 2 & Lit Rev & - & - & - \\
\hline 67. & $\begin{array}{l}\text { Barrett, P., Zhang, } \\
\text { Y., Moffat, J., \& } \\
\text { Kobbacy, K. (2013) }\end{array}$ & $*$ & & & & & & $\mathrm{~S}$ & 4 & Measured & UK & TPS & $\begin{array}{c}751 \\
\text { pupils } 34 \\
\text { CR }\end{array}$ \\
\hline 68. & $\begin{array}{l}\text { Barrett, P., Davies, } \\
\text { F., Zhang, Y., \& } \\
\text { Barrett, L. (2015) }\end{array}$ & $*$ & & $\mathrm{~S}$ & & $\mathrm{~S}$ & & $\mathrm{~S}$ & 4 & surveys & UK & TPS & $\begin{array}{l}153 \mathrm{CR} \text { in } \\
27 \mathrm{SCH}\end{array}$ \\
\hline 69. & $\begin{array}{l}\text { Barrett, P. S., } \\
\text { Zhang, Y., Davies, } \\
\text { F., \& Barrett, L. C. } \\
\text { (2015) }\end{array}$ & $*$ & & $S$ & & $\mathrm{~S}$ & & $\mathrm{~S}$ & 4 & Surveys & UK & TPS & $\begin{array}{c}3766 \text { pupils } \\
153 \mathrm{CR} \text { in } \\
27 \mathrm{SCH}\end{array}$ \\
\hline
\end{tabular}




\begin{tabular}{|c|c|c|c|c|c|c|c|c|c|c|c|c|c|}
\hline 70. & $\begin{array}{l}\text { Bennetts, L. K., \& } \\
\text { Flynn, M. C. (2002) }\end{array}$ & $*$ & & & $S$ & & & & 4 & Measured & $\begin{array}{c}\text { New } \\
\text { Zealand }\end{array}$ & & 4 children \\
\hline 71. & Benya, J. R. (2001) & & & & & & & $\mathrm{R}$ & 2 & Policy Doc & - & - & - \\
\hline 72. & Bisset, J. A. (2014) & & & & & & & $R$ & 2 & Survey & $\begin{array}{c}\text { New } \\
\text { Zealand }\end{array}$ & $\begin{array}{l}\text { MLE } \\
\text { And } \\
\text { TSS }\end{array}$ & $3 \mathrm{SCH}$ \\
\hline 73. & $\begin{array}{l}\text { Blackmore, J., } \\
\text { Bateman, D., } \\
\text { Loughlin, J., } \\
\text { O'Mara, J., \& } \\
\text { Aranda, G. (2011) }\end{array}$ & & & & & & & $\mathrm{R}$ & 2 & Lit Rev & - & - & - \\
\hline 74. & $\begin{array}{l}\text { BRANZ Ltd } \\
\text { Acoustics } \\
(2007) \\
\end{array}$ & & & & $\mathrm{R}$ & & & & 4 & Policy Doc & - & - & - \\
\hline 75. & $\begin{array}{l}\text { BRANZ Ltd } \\
\text { Lighting (2007) }\end{array}$ & & & $\mathrm{R}$ & & & & & 4 & Policy Doc & - & - & - \\
\hline 76. & $\begin{array}{l}\text { BRANZ Ltd } \\
\text { Ventilation (2007) }\end{array}$ & & & & & $\mathrm{R}$ & & & 4 & Policy Doc & - & - & - \\
\hline 77. & $\begin{array}{l}\text { BRANZ Ltd } \\
\text { Interior design } \\
(2007) \\
\end{array}$ & & & & & & & $\mathrm{R}$ & 4 & Policy Doc & - & - & - \\
\hline 78. & $\begin{array}{l}\text { Breithecker, D. } \\
(2005)\end{array}$ & & & & & & & $\mathrm{S}$ & 4 & Measured & Germany & TPS & 89 students \\
\hline 79. & $\begin{array}{l}\text { Bullock, A. A., \& } \\
\text { Foster-Harrison, E. } \\
(1997)\end{array}$ & & & & & & & NS & 1 & - & - & - & - \\
\hline 80. & $\begin{array}{l}\text { Burchett, M., Torpy, } \\
\text { F., Brennan, J., \& } \\
\text { Craig, A. (2010) }\end{array}$ & & $*$ & & & & & & 4 & Measured & - & $\begin{array}{l}\text { Office } \\
\text { Building }\end{array}$ & - \\
\hline 81. & $\begin{array}{l}\text { Byers, T., Imms, W., } \\
\text { \& Hartnell-Young, } \\
\text { E. (2014) }\end{array}$ & $*$ & & & & & & $S$ & 4 & Measured & Australia & $\begin{array}{l}\text { TSS } \\
\text { And } \\
\text { MLE }\end{array}$ & $7 \mathrm{SCH}$ \\
\hline 82. & Cash, C. (1993) & $*$ & & & & & $\mathrm{~S}$ & $\mathrm{~S}$ & 5 & Survey & USA & TSS & $205 \mathrm{SCH}$ \\
\hline 83. & $\begin{array}{l}\text { Cash, C., \& Twiford, } \\
\text { T. (2009) }\end{array}$ & $*$ & & & & & & $\mathrm{R}$ & 3 & Lit Rev & - & - & - \\
\hline
\end{tabular}




\begin{tabular}{|c|c|c|c|c|c|c|c|c|c|c|c|c|c|}
\hline 84. & Chan, T. C. (1996) & $*$ & & & & & & $\mathrm{R}$ & 3 & Lit Rev & - & & - \\
\hline 85. & Clark, H. (2002) & $*$ & & & & & & $\mathrm{R}$ & 3 & Lit Rev & - & & - \\
\hline 86. & $\begin{array}{l}\text { Cleveland, B., \& } \\
\text { Fisher, K. (2014) }\end{array}$ & & & & & & & $\mathrm{R}$ & 2 & Lit Rev & - & & - \\
\hline 87. & $\begin{array}{l}\text { Cole, T., Visser, J., \& } \\
\text { Upton, G. (1998) }\end{array}$ & & & & & & & $\mathrm{R}$ & 2 & Book & - & & - \\
\hline 88. & Cornell, P. (2002) & & & & & & & $\mathrm{R}$ & 2 & Lit Rev & - & & - \\
\hline 89. & $\begin{array}{l}\text { Grocoff, P. N. } \\
(1995)\end{array}$ & & & $\mathrm{R}$ & & & & $\mathrm{R}$ & 2 & Lit Rev & - & & - \\
\hline 90. & $\begin{array}{l}\text { Earthman, G. I., \& } \\
\text { Lemasters, L. (1998) }\end{array}$ & & & & $\mathrm{R}$ & & & $\mathrm{R}$ & 3 & Lit Rev & - & & - \\
\hline \multirow[t]{2}{*}{91.} & $\begin{array}{l}\text { Earthman, G. I., \& } \\
\text { Lemasters, L. (1996) }\end{array}$ & & & & & & & $\mathrm{R}$ & 3 & Lit Rev & - & & - \\
\hline & $\begin{array}{l}\text { Ryan Hannah } \\
(2013)\end{array}$ & & & & & & & $\mathrm{R}$ & 2 & Lit Rev & - & & - \\
\hline 92. & $\begin{array}{l}\text { M. Klatte and J. } \\
\text { Hellbrück (2010) }\end{array}$ & $*$ & & & & $S$ & & & 4 & Measured & Germany & $\mathrm{T}$ & $\begin{array}{c}398 \\
\text { children } \\
\text { from } 17 \\
\text { classrooms }\end{array}$ \\
\hline 93. & Lucas, J. (1981) & $*$ & & & & $\mathrm{~S}$ & & & 4 & Measured & USA & TPS & $15 \mathrm{SCH}$ \\
\hline 94. & $\begin{array}{l}\text { Siebein, G. W., } \\
\text { Gold, M. A., } \\
\text { Siebein, G. W., \& } \\
\text { Ermann, M. G. } \\
(2000)\end{array}$ & & & & & $\mathrm{R}$ & & $\mathrm{R}$ & 3 & Measured & USA & TPS & $10 \mathrm{CR}$ \\
\hline 95. & $\begin{array}{l}\text { Daisey, J. M., } \\
\text { Angell, W. J., \& } \\
\text { Apte, M. G. (2003) }\end{array}$ & & $*$ & & & & $\mathrm{R}$ & $\mathrm{R}$ & 3 & Lit Rev & - & & - \\
\hline 96. & $\begin{array}{l}\text { Daly, J., Burchett, } \\
\text { M., \& Torpy, F. } \\
\text { (2010) }\end{array}$ & $*$ & & & & & $\mathrm{~S}$ & & 4 & Measured & Australia & TPS & $\begin{array}{c}360 \\
\text { students } 13 \\
\text { CR }\end{array}$ \\
\hline 97. & Han, K.-T. (2008) & & $*$ & & & & $S$ & & 4 & Measured & Taiwan & TSS & $2 \mathrm{CR}$ \\
\hline 98. & $\begin{array}{l}\text { Higgins, S. E., Hall, } \\
\text { E., Wall, K., } \\
\text { Woolner, P., \& }\end{array}$ & $*$ & & & $\mathrm{R}$ & $\mathrm{R}$ & $\mathrm{R}$ & & 3 & Lit Rev & - & & - \\
\hline
\end{tabular}




\begin{tabular}{|c|c|c|c|c|c|c|c|c|c|c|c|}
\hline & $\begin{array}{l}\text { McCaughey, C. } \\
\text { (2005) }\end{array}$ & & & & & & & & & & \\
\hline 99. & $\begin{array}{l}\text { Lohr, V. I., Pearson- } \\
\text { Mims, C. H., \& } \\
\text { Goodwin, G. K. } \\
\text { (1996) }\end{array}$ & $*$ & & $\mathrm{~S}$ & $\mathrm{~S}$ & & 5 & Measured & USA & University & $\begin{array}{c}96 \\
\text { participants }\end{array}$ \\
\hline 100. & $\begin{array}{l}\text { Rosen, K.G., \& } \\
\text { Richardson, G. } \\
(2010)\end{array}$ & & & $S$ & & $S$ & 4 & Measured & Sweden & TPS & $2 \mathrm{SCH}$ \\
\hline 101. & $\begin{array}{l}\text { Schneider, M. } \\
(2002)\end{array}$ & $*$ & & & & $\mathrm{R}$ & 3 & Policy Doc & - & - & - \\
\hline 102. & $\begin{array}{l}\text { Shibata, S., \& } \\
\text { Suzuki, N. (2004) }\end{array}$ & $*$ & & $\mathrm{~S}$ & & & 4 & Measured & Japan & University & - \\
\hline 103. & $\begin{array}{l}\text { Smedje, G., \& } \\
\text { Norback, D. (2001) }\end{array}$ & & $*$ & $S$ & & $S$ & 4 & Measured & Sweden & TPS & $181 \mathrm{CR}$ \\
\hline 104. & $\begin{array}{l}\text { Department for } \\
\text { Children, Schools } \\
\text { and Families. (2008) }\end{array}$ & & $*$ & & & $\mathrm{R}$ & 3 & Policy Doc & - & - & - \\
\hline 105. & $\begin{array}{l}\text { Department for } \\
\text { Education and } \\
\text { Employment: } \\
\text { School Buildings } \\
\text { and Design Unit } \\
\text { (2001) }\end{array}$ & & & & & $\mathrm{R}$ & 3 & Policy Doc & - & - & - \\
\hline 106. & $\begin{array}{l}\text { Doxey, J. S., } \\
\text { Waliezek, T. M. \& } \\
\text { Zajicek, J.M. (2009) }\end{array}$ & $*$ & & $S$ & & & 4 & Measured & USA & University CR & $\begin{array}{c}385 \\
\text { students }\end{array}$ \\
\hline 107 & $\begin{array}{l}\text { Eric Wayne .H } \\
(1996)\end{array}$ & $*$ & & & $\mathrm{~S}$ & $S$ & 5 & Measured & USA & TSS & - \\
\hline 108. & $\begin{array}{l}\text { Edwards, M.M } \\
\text { (1992) }\end{array}$ & $*$ & & & & $S$ & 4 & Measured & USA & $\mathrm{T}$ & $52 \mathrm{SCH}$ \\
\hline 109. & $\begin{array}{l}\text { Ellis, R. A., \& } \\
\text { Goodyear, P. } \\
\text { (2016) }\end{array}$ & & & & & $\mathrm{R}$ & 2 & Lit Rev & - & - & - \\
\hline 110. & $\begin{array}{l}\text { Erkilic, M., \& Durak, } \\
\text { S. (2013) }\end{array}$ & & & & & NS & 1 & Rev Doc & Turkey & - & - \\
\hline
\end{tabular}




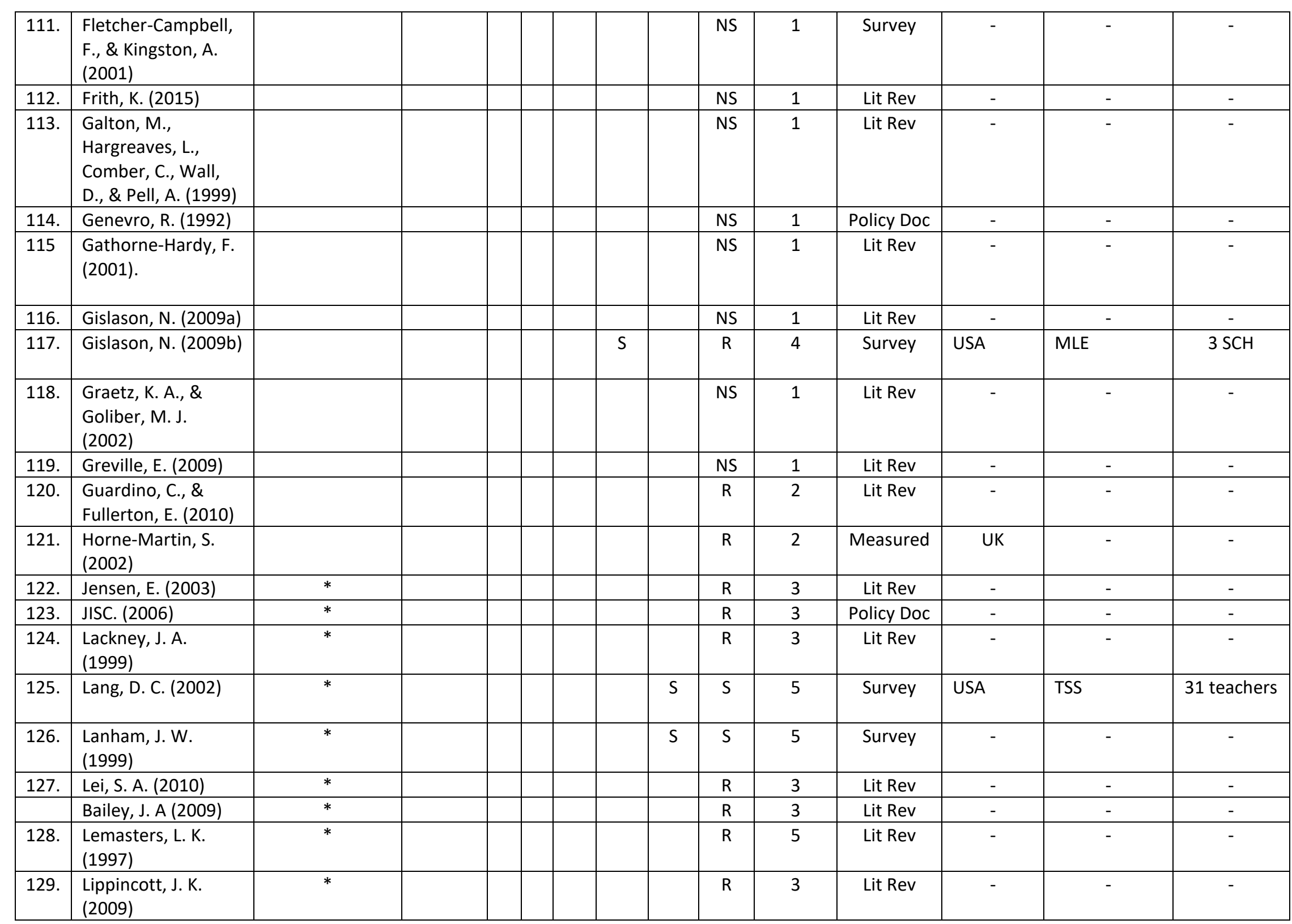




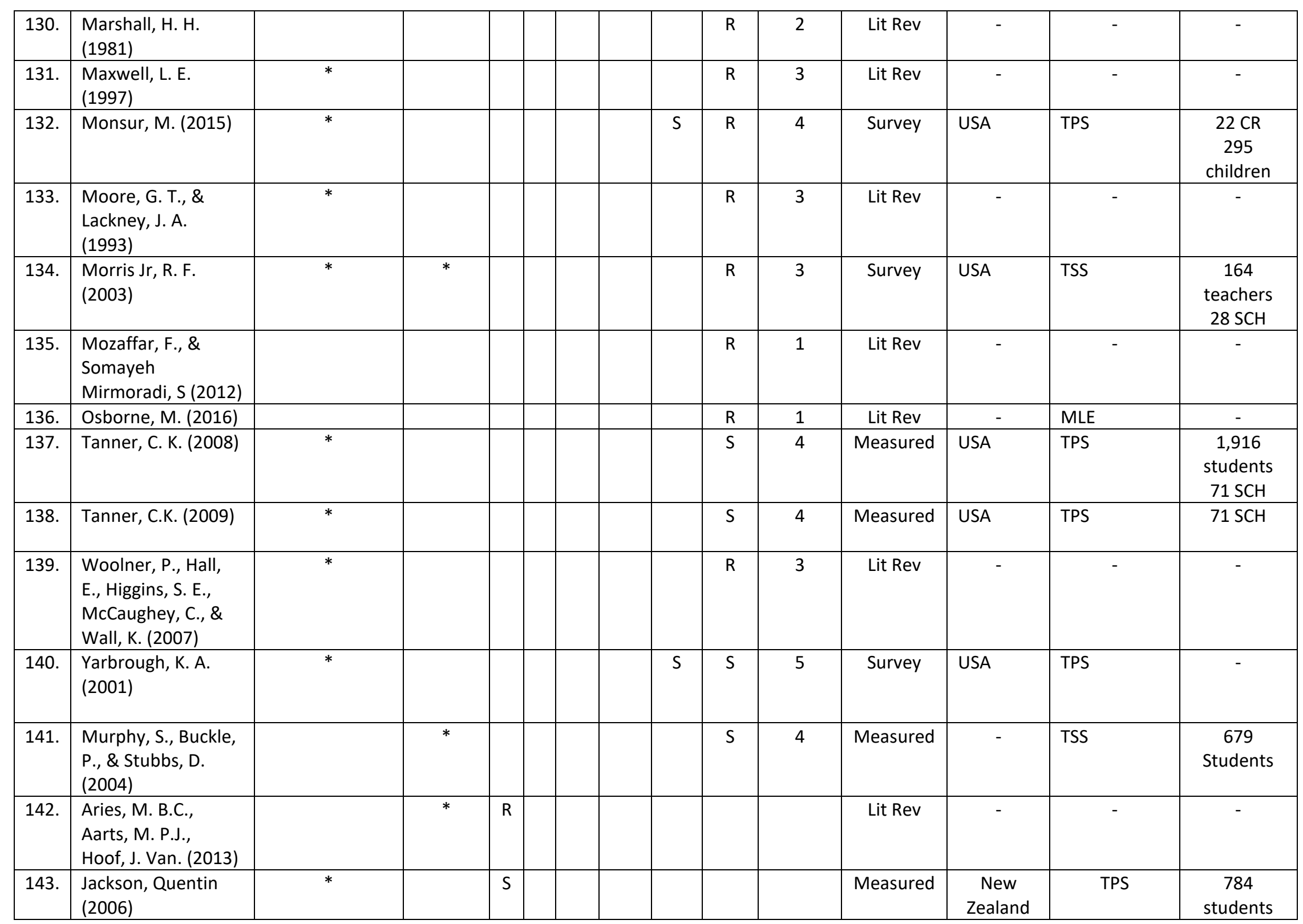




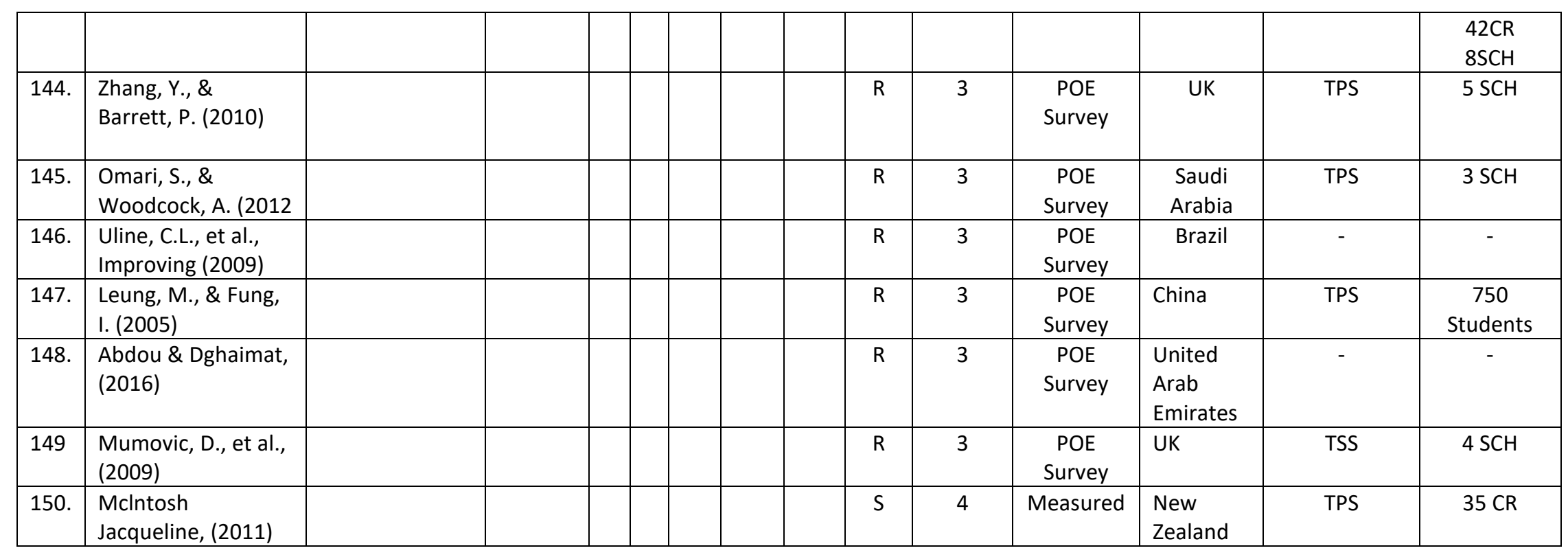


Appendix 2: Building Survey Templates

The templates below were used to collate space usage environmental observations.

Table 65: IEQ On-site Observation Check list

\section{IEQ On-site Observation Check list}

IEQ Variable

Observation

\section{Lighting}

Note building orientation in relation to glazed area

East - West

Note any areas of glare

Glare at west facing area and through the skylight

Sensor 182, big overhang in the west side to shade glare and the south west orientation has a

Note sensors that appear to be exposed to glare retaining wall

Note sensors that appear to be in dark areas

Sensors on Eastern wall

Note if the usage of the space covers any sensor

None

Note if the windows have blinds and if it is being used

No blinds

Note if students prefer daylight areas of the space

Students preferred the daylight areas

Note the work plane height

$600 \mathrm{~mm}$ and $800 \mathrm{~mm}$ and floor level

Note weather conditions (bright, sunny, overcast, etc)

Clear sky

\section{Temperature}

Note the usage of HVAC

Observe if the space is too hot or cold

Note the layers of cloth worn by the occupants

Note the external weather temperature

Natural ventilation and heating during autumn days

Moderate temperature

Some kids wearing jumper, some on light clothing Monday 16 degrees Celsius

Confirm what insulation is in the roof spaces

\section{Acoustics}

Observe if windows are closed or open

Note sources of external noise (Cars, Wind, etc)

Note sources of internal noise (Movement, people talking, HVAC)

Observe noise transfer between rooms

Observe if students can hear the teacher clearly

Three high rise windows open in each room

Wind

People, clock, bells, noise transfer from one room to another

Noise transfer because of door opening

Yes - when quite 


\begin{tabular}{|l|l|} 
Note any sensor within the sound field of the teacher & Northern wall facing sensors and central sensors \\
\hline Note the activity level and occupancy & $\begin{array}{l}90 \text { children, } 5 \text { staff, } 4 \text { researchers- } 30 \text { children in } \\
\text { one unit }\end{array}$ \\
\hline $\begin{array}{l}\text { Note any occurrences of high noise levels and identify the } \\
\text { sources }\end{array}$ & Conversation between occupants \\
\hline $\begin{array}{l}\text { Note if floor, ceiling and wall materials have acoustic } \\
\text { properties }\end{array}$ & Floor and ceilings have acoustic materials \\
\hline $\mathrm{CO}_{2}$ & \\
\hline Note information on prevailing wind -air flow movement & Cross ventilation \\
\hline $\begin{array}{l}\text { Note air-flow movement in relation to open and closed } \\
\text { windows }\end{array}$ & Cross ventilation \\
\hline Note sensors close to area of prevailing air flow & West and East facing sensors \\
\hline Record each teaching periods, break and lunchtime & $11: 30$ am-12pm break \\
\hline Note occupancy around sensors & About 5 pupils around horizontal sensors \\
\hline
\end{tabular}




\section{Appendix 3: IEQ On-Site Measurement Information Collation Templates}

The templates below were used to collate building characteristics data. The collated data have been reported within the thesis chapters.

\begin{tabular}{|l|l|l|l|l|l|l|}
\hline \multicolumn{2}{|l|}{ Basic School Characteristics Information } & \multicolumn{3}{l|}{ Age } \\
\hline School & Decile & Location & Year Built & School Type & Roll & \\
\hline School 1 & & Wellington & & & & \\
\hline School 2 & & Wellington & & & & \\
\hline
\end{tabular}

\begin{tabular}{|c|c|c|c|}
\hline Form & Orientation & Classroom Area $\mathbf{m}^{2}$ & No of Classrooms \\
\hline Square & East West & & \\
\hline Square & North South & & \\
\hline
\end{tabular}

\begin{tabular}{|c|c|c|c|}
\hline \multicolumn{4}{|c|}{ Classroom Internal Dimensions } \\
\hline Description & Room 1 & Room 2 & Room 3 \\
\hline \multicolumn{4}{|l|}{ Length } \\
\hline \multicolumn{4}{|l|}{ Width } \\
\hline \multicolumn{4}{|l|}{ Height } \\
\hline \multicolumn{4}{|l|}{ GFA } \\
\hline Combined GFA & & & \\
\hline
\end{tabular}

\begin{tabular}{|c|c|c|c|c|c|c|c|c|c|c|c|c|}
\hline \multicolumn{13}{|l|}{ Glazed area data } \\
\hline \multirow{2}{*}{$\begin{array}{l}\text { North-Wall } \\
\text { Description }\end{array}$} & \multicolumn{3}{|c|}{ Length } & \multicolumn{3}{|c|}{ Width } & \multicolumn{3}{|c|}{ Number } & \multicolumn{3}{|c|}{ Total } \\
\hline & R1 & $\mathbf{R 2}$ & R3 & $\mathbf{R} 1$ & $\mathbf{R 2}$ & R3 & R1 & $\mathbf{R 2}$ & R3 & R1 & $\mathbf{R 2}$ & $\mathbf{R 3}$ \\
\hline \multicolumn{13}{|l|}{ Windows } \\
\hline \multicolumn{13}{|c|}{ Clerestory Windows } \\
\hline \multicolumn{13}{|l|}{ Doors } \\
\hline \multicolumn{13}{|l|}{ Top Window } \\
\hline Bottom window & & & & & & & & & & & & \\
\hline
\end{tabular}

\begin{tabular}{|c|c|c|c|c|c|c|c|c|c|c|c|c|}
\hline \multicolumn{13}{|l|}{ Glazed area data } \\
\hline \multirow{2}{*}{$\begin{array}{l}\text { South-Wall } \\
\text { Description }\end{array}$} & \multicolumn{3}{|c|}{ Length } & \multicolumn{3}{|c|}{ Width } & \multicolumn{3}{|c|}{ Number } & \multicolumn{3}{|c|}{ Total } \\
\hline & R1 & $\mathbf{R 2}$ & $\mathbf{R 3}$ & $\mathbf{R} 1$ & $\mathbf{R 2}$ & R3 & $\mathbf{R} 1$ & $\mathbf{R 2}$ & $\mathbf{R 3}$ & R1 & $\mathbf{R 2}$ & R3 \\
\hline \multicolumn{13}{|l|}{ Windows } \\
\hline Clerestory Windows & & & & & & & & & & & & \\
\hline
\end{tabular}




\begin{tabular}{|l|l|l|l|l|l|l|l|l|l|l|l|l|} 
Doors & & & & & & & & & & & & \\
\hline Top Window & & & & & & & & & & & & \\
\hline Bottom window & & & & & & & & & & & & \\
\hline
\end{tabular}

\begin{tabular}{|l|l|}
\hline \multicolumn{2}{|l|}{ General Observations (Exterior) } \\
\hline Foundations & \\
\hline Roof Cladding & \\
\hline Spouting & \\
\hline Exterior Wall Cladding & \\
\hline Exterior Window & \\
\hline Exterior Door & \\
\hline
\end{tabular}




\section{Appendix 4: Sensors' Calibration Template}

\section{The templates below were used to collate environmental sensors spot calibration data}

\begin{tabular}{|c|c|c|c|c|c|c|c|c|c|c|c|c|c|c|c|c|}
\hline \multicolumn{2}{|c|}{ CO2 Data } & \multicolumn{7}{|c|}{ Multiple Sensors } & \multicolumn{8}{|c|}{ Wall Sensors } \\
\hline Date & Time Round & 168 (Cen) & 176 (Cen) & 162 (Nx Cen) 1 & 164 (Nex Cen) & 1) 183 (R2) & 171 (R3) & Ext & $161(\mathrm{SW})$ & $174(S W)$ & 1) 167 (EW) & 166 (EW) & 158 (NW) & 165 (NW) & 169 (WW) & 184 (WW) \\
\hline 23/11/2018 & 8:00pm & & & & & & & & & & & & & & & \\
\hline $23 / 11 / 2018$ & $4: 30 \mathrm{pm}$ & & & & & & & & & & & & & & & \\
\hline $23 / 11 / 2018$ & 5:00pm & & & & & & & & & & & & & & & \\
\hline $23 / 11 / 2018$ & $5: 45 \mathrm{pm}$ & 1043 & 1043 & 1110 & 1110 & 729 & 686 & & 920 & 920 & 897 & 820 & 782 & 782 & 782 & 782 \\
\hline $23 / 11 / 2018$ & 6:00pm & & & & & & & & & & & & & & & \\
\hline $26 / 11 / 2018$ & 9:00am & 2281 & 2281 & 2303 & 2303 & 2020 & 2040 & & 2130 & 2130 & 1936 & 2027 & 2058 & 2058 & 2267 & 2267 \\
\hline $26 / 11 / 2018$ & 10:00am & & & & & & & & & & & & & & & \\
\hline $26 / 11 / 2018$ & 11:00am & 2489 & 2489 & 2609 & 2609 & 2500 & 2500 & & 2490 & 2490 & 2500 & 2500 & 2600 & 2600 & 2550 & 2550 \\
\hline $26 / 11 / 2018$ & 12:00pm & & & & & & & & & & & & & & & \\
\hline
\end{tabular}

\begin{tabular}{|c|c|c|c|c|c|c|c|c|c|c|c|c|c|c|c|c|}
\hline \multicolumn{2}{|c|}{ Sound Data } & \multicolumn{7}{|c|}{ Multiple Sensors } & \multicolumn{8}{|c|}{ Wall Sensors } \\
\hline Date & Time Round & 168 (Cen) & 176 (Cen) & 162 (Nx Cen) & 164 (Nex Cen) & 183 (R2) & 171 (R3) & Ext & $161(S W)$ & 174 (SW) & 1) 167 (EW) & 166 (EW) & ) 158 (NW) & 165 (NW) & 1) 169 (WW) & 184 (WW) \\
\hline $23 / 11 / 2018$ & 8:00pm & & & & & & & & & & & & & & & \\
\hline $23 / 11 / 2018$ & 8:30pm & & & & & & & & & & & & & & & \\
\hline $23 / 11 / 2018$ & 8:00pm & & & & & & & & & & & & & & & \\
\hline $23 / 11 / 2018$ & 8:30pm & 43 & 43 & 43 & 43 & 43 & 43 & & 43 & 43 & 43 & 43 & 43 & 43 & 43 & 43 \\
\hline $23 / 11 / 2018$ & 8:00pm & & & & & & & & & & & & & & & \\
\hline $26 / 11 / 2018$ & 9:31am & 63 & 63 & 51 & 51 & 50 & 50 & & 60 & 60 & 62 & 60 & 54 & 54 & 60 & 60 \\
\hline $26 / 11 / 2018$ & 8:00am & & & & & & & & & & & & & & & \\
\hline $26 / 11 / 2018$ & 81:05am & 65 & 65 & 62 & 63 & 72 & 72 & & 69 & 69 & 65 & 65 & 64 & 64 & 58 & 58 \\
\hline $26 / 11 / 2018$ & 812:00pm & & & & & & & & & & & & & & & \\
\hline
\end{tabular}




\section{Appendix 4.1 Calibration Instruments - Reference Sensors}

The following are the reference instruments used for calibration procedure one and two:

\section{Lighting}

A Lutron LX-102 Electronic Light Meter was used for lighting calibration. According to the manufacture's specifications, the meter's calibrated details are:

Table 66: Light meter specifications

\begin{tabular}{|l|l|}
\hline Description & Calibrated details \\
\hline Lux Range & 0 to 50000 Lux \\
\hline Resolution & 1 Lux for 2000 Lux, 10 Lux for 20000 Lux, 100 Lux for 50000 Lux \\
\hline Accuracy & $\pm(5 \%+2 \mathrm{~d})$ \\
\hline Display & $13 \mathrm{~mm}\left(0.5^{\prime \prime}\right)$ LCD \\
\hline Zero adjustment & Internal adjustment \\
\hline Sampling time & Approx. 0.4 second \\
\hline Operating Temperature & $0^{\circ}$ Cto $50^{\circ} \mathrm{C}$ \\
\hline Operating Humidity & $<80 \%$ R.H
\end{tabular}

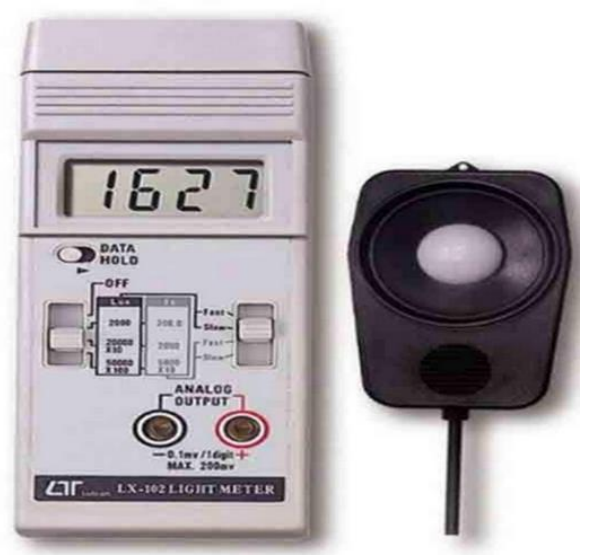

Figure 90: Image of the Lutron LX-102 Electronic Light Meter

\section{Correction Factor for Different Types of Lighting}

The specification guide suggested that the meter is calibrated under a precision "Standard light tungsten incandescent source of $2856^{\circ} \mathrm{K}^{\prime \prime}$. The guide states that when making measurements 
under different light sources, the measurement value can be corrected by multiplying it using the following tested values of the incandescent source:

Table 67: Light values correction factor
\begin{tabular}{|l|c|}
\hline Description & Values \\
\hline Mercury Lamp & $* 1.05$ \\
\hline Fluorescent Lamp & $* 0.98$ \\
\hline Sodium Lamp & $* 1.11$ \\
\hline Daylight & $* 0.95$ \\
\hline
\end{tabular}

\section{Temperature and Humidity}

Whirling Hygrometer was the reference instrument used for temperature and humidity calibration. This instrument is hand-held, and it is approximately $5 \mathrm{~cm}$ wide and $23 \mathrm{~cm}$ long, excluding the handle. The mainframe was made of steel and consists of two thermometers mounted on the frame that can be whirled in the air by hand. A handle passes through the frame at the top, supported by bearings which when spun, allowing the frame to revolve freely. Both thermometers are cushioned and firmly fixed within the frame. The wet bulb helps to determine the relative humidity, while the dry bulb indicates the temperature of the air. The wet bulb is covered by a fine muslin sleeve and kept moist with distilled water. In direct proportion to the dryness of the surroundings, the temperature of the wet bulb thermometer is reduced by the evaporation of the water from the wet muslin into the surrounding atmosphere. The dry bulb is open to the atmosphere and measures the temperature of the surrounding atmosphere. On one end of the reservoir is a screwed cap which is fitted to prevent loss of water when the hygrometer is rotated. The thermometer is calibrated in degrees Celsius to include a range of -5 to 50 으.

Table 68: Whirling Hygrometer specifications

\section{Key Specification}

Measurement range (Dry/wet bulb -5 to $+50{ }^{\circ} \mathrm{C}$ temperature)

Measurement range (Relative humidity): 10 to 100\%, for dry bulb temperature between -1 and $38{ }^{\circ} \mathrm{C}$

Accuracy:

$\pm 0.5^{\circ} \mathrm{C}$ 


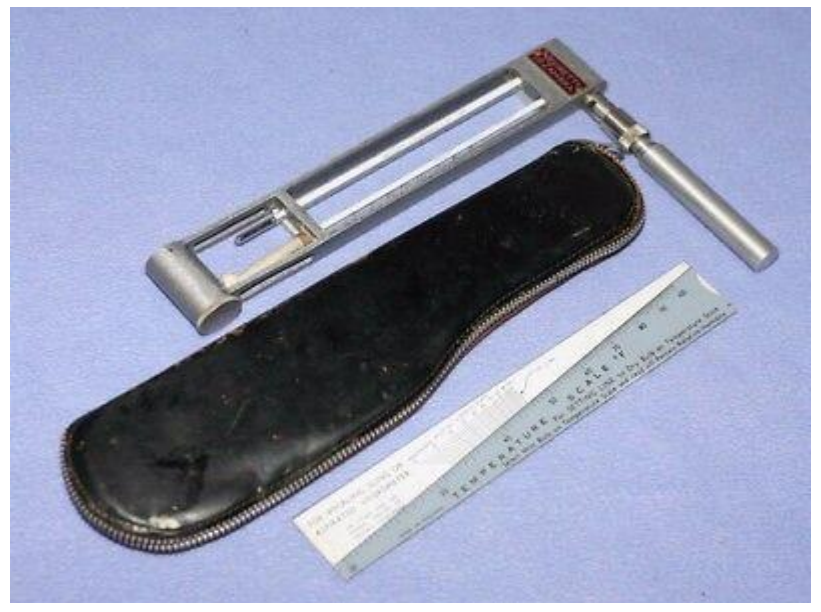

Figure 91 Image of the Whirling Hygrometer

\section{Operation of the thermometer on-site}

After checking to ensure that the thermometers were in a readable position, the hygrometer was spun at arm's length at many revolutions per minute. Watson, (2015) suggest that "the spinning would produce a simulated airspeed of 3.5 metres per second and this rapid airflow is fundamental to the operation of the instrument and the speed at which the wet bulb is influenced". The time of the spinning was noted, and care was taken to ensure that the instrument was clear of any obstructions while being spun. Watson, (2015) states that when the spun hygrometer comes to rest, the reading indicated on the wet bulb may have been slightly altered because the air surrounding the wet bulb will pick up moisture from the wet muslin and the humidity of that small pocket of air will be artificially increased. They suggested that the wet bulb should be read before the dry bulb at the precise moment the rotation ceases. This was adhered to in documenting the data. When reading the temperatures obtained, it was important to avoid contact with the thermometers because sources of heat such as the operator's hands or cap lamp could influence the thermometer's reading. Watson, (2015) suggested that "the wet bulb reading should never be more than the dry bulb reading". This is because as the moisture dries from the surface (adiabatic evaporation of water from the thermometer bulb), the wet bulb thermometer records the extent of cooling and except when there is $100 \%$ relative humidity, it 
is always lower than the dry bulb temperature, thereby making it a more accurate measurement of temperature.

\section{Sound}

A 3M Sound Detector SD-200 Sound Level Meter was the reference instrument used to carry out sound level spot measurement. It is a handheld compact, lightweight meter used for testing noise levels. According to the manufacture's specifications, the meter's calibrated details are:

\section{Table 69: Sound meter specifications}

\section{Key Specifications}

45 to $140 \mathrm{~dB}$ dynamic range, with 3 or $5 \mathrm{~dB}$ exchange rate

LED alert levels: Flashing green at 80 to $85 \mathrm{~dB}$, flashing yellow at 85 to $105 \mathrm{~dB}$, flashing red $>105 \mathrm{~dB}$

Measures SPL, Max, Min, Leq, Lavg, runtime overload and under-range

Bright display has $3 / 4$ " digits, $0.1 \mathrm{~dB}$ resolution, 0.5 second update rate

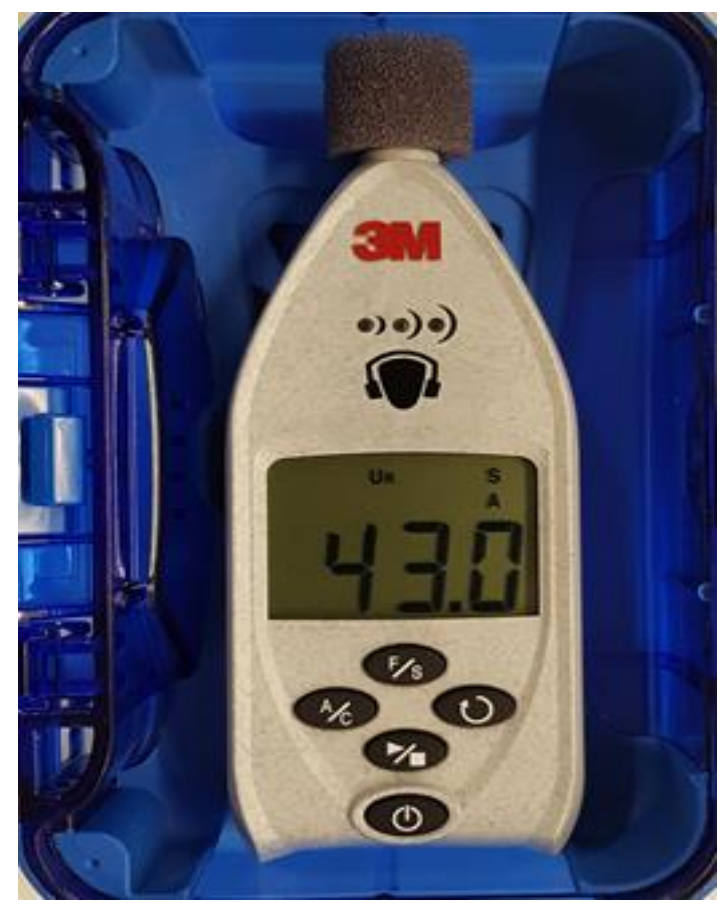

Figure 92: Image of the 3M Sound Detector SD-200 Sound Level Meter 


\section{Carbon dioxide}

A TSI Alnor CF910 CompuFlow $\mathrm{CO}_{2}$ Monitor was the reference instrument used to carry out sound level spot measurement. It is a handheld diagnostic instrument ideally used for investigating indoor air quality and evaluating ventilation systems in schools, offices, factories and hospitals. It measures and monitors carbon dioxide levels, temperature, humidity, and calculates dew point, wet bulb temperature, and \% outside air. The Model CF930 adds a measurement of carbon monoxide (CO). According to the manufacture's specifications, the meter's calibrated details are:

Table 70: $\mathrm{CO}_{2}$ monitor instrument specification

\section{Key Specification}

\begin{tabular}{l|l} 
Sensor Type & Dual-wavelength NDIR (non-dispersive infrared) \\
\hline Range & 0 to $5000 \mathrm{ppm}$ \\
\hline Accuracy & $\pm 3.0 \%$ of reading or $\pm 50 \mathrm{ppm}$ (whichever is greater) \\
\hline Resolution & $1 \mathrm{ppm}$ \\
\hline Response Time & 20 seconds \\
\hline Statistics & average, maximum and minimum values
\end{tabular}

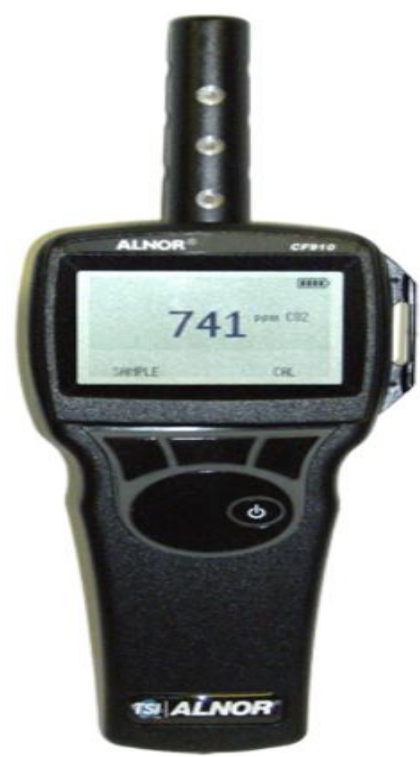

Figure 93: Image of the TSI Alnor CF910 CompuFlow CO2 Monitor 


\section{Appendix 4.2 Sensors Calibration}

This section presents the results of a pilot study calibration and spot measurement calibrations carried out at case study one classroom. The results of these calibrations are explained below.

\subsubsection{Pilot Study Calibration One}

The first pilot study calibration was carried out in a design studio at the Faculty of Architecture and Design, School of Architecture, Victoria University of Wellington. The space could usually contain up to 40 students but given that students were on holiday during the time of carrying out the measurements, only very few students from a minimum of 2 students to a maximum of 12 students were observed to use the space at different times of the day.

As reported in Section 4.11 above, fourteen sensors were paired and placed at the centre of the four walls respectively, two paired sensors were placed at the measuring plane height of $0.8 \mathrm{~m}$ in the centre of the space and another set of two paired sensors at strategic locations on the measuring plane. Data was collected per minute for 7 days. The classroom had a mix-mode ventilation system and was about $10 \mathrm{~m}$ length by $7 \mathrm{~m}$ width. It was a North facing one-side lit classroom as shown in Figure 91 below.
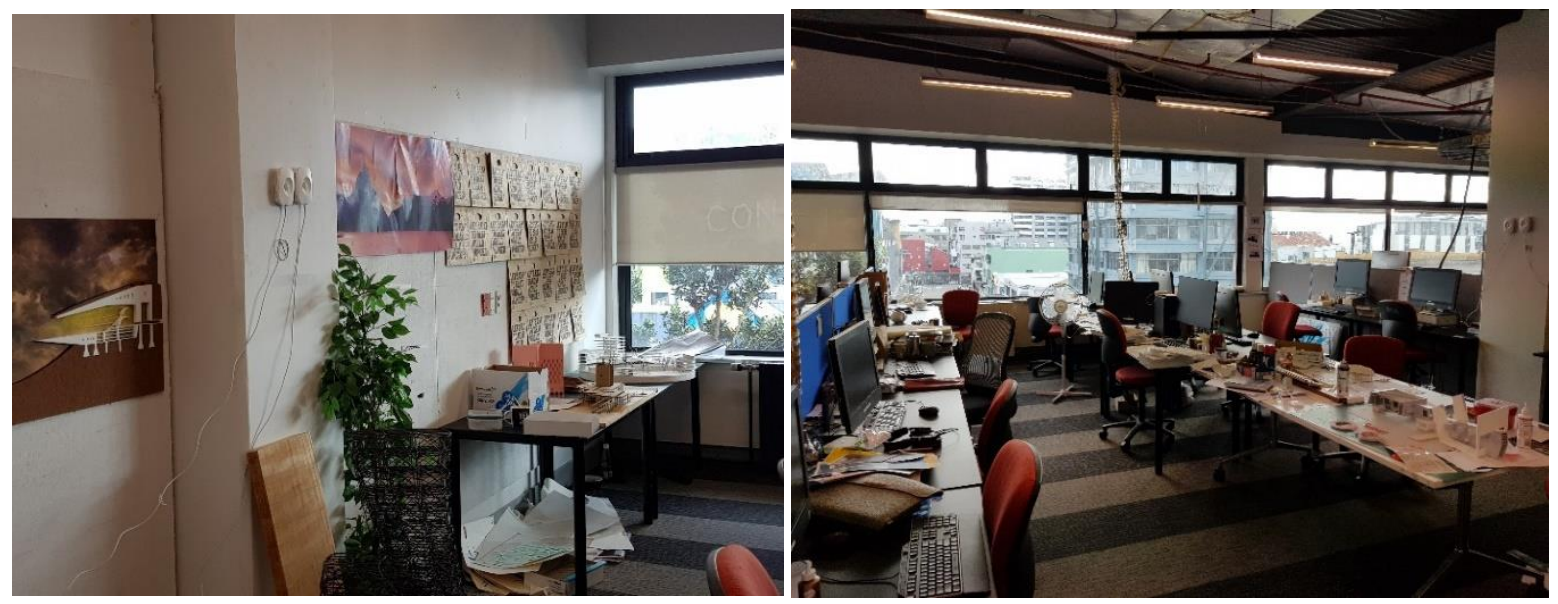

Figure 94: Images showing sensors on the wall of an occupied design classroom

Following the deployment of the sensors, reference lighting, sound, temperature and $\mathrm{CO}_{2}$ devices as described in Section 4.1 of the Appendix above were used to carry out spot environmental measurements for different days and time within the measurement period. Table 71 shows a calibration template used to collate the spot measurements. 
Table 71: Spot measurement calibration recording

\begin{tabular}{|c|c|c|c|c|c|c|c|}
\hline \multicolumn{8}{|c|}{ Spot Measurement Data Collection } \\
\hline Date & Time & Sensors & Light (Lux) & Temp (Celsius) & Sound (dBA) & $\mathrm{CO}_{2}$ (PPM) & Occupancy \\
\hline $05 / 10 / 2018$ & 7.00pm & $\mathrm{A} 3 / \mathrm{A} 2$ & 200 & 23.0 & 46.3 & 495 & 8 to 12 Students \\
\hline $05 / 10 / 2018$ & $7.05 \mathrm{pm}$ & A4/A5 & 383 & 22.5 & 46.3 & 604 & 8 to 12 Students \\
\hline $05 / 10 / 2018$ & 7.07pm & A6/A7 & 162 & 22.5 & 47.8 & 596 & 8 to 12 Students \\
\hline $05 / 10 / 2018$ & 7.09pm & A8/A9 & 350 & 22.5 & 48.5 & 604 & 8 to 12 Students \\
\hline $05 / 10 / 2018$ & $7.11 \mathrm{pm}$ & A10/A1 & 150 & 23.0 & 47.6 & 502 & 8 to 12 Students \\
\hline $05 / 10 / 2018$ & 7.14pm & $\mathrm{A} 11 / \mathrm{A} 12$ & 143 & 22.5 & 47.9 & 605 & 8 to 12 Students \\
\hline $05 / 10 / 2018$ & $7.17 \mathrm{pm}$ & A13/A14 & 172 & 22.5 & 48.4 & 601 & 8 to 12 Students \\
\hline
\end{tabular}

The reason for paring the sensors together was in case one sensor fails; data could be gotten from the second sensor and values from both sensors could be compared to establish their accuracy. This was also to test whether one sensor could be reliable for data monitoring. The occupancy was recorded within a range of 8 to 12 students because there was a frequent movement of occupants in an out of the space.

Following the spot measurements, data were collated from the sensors and a comparison between the sensors data with that of the trusted reference instrument was carried out as shown in Table 72 below. Due to data retrieval challenges as described in Chapter 4, section 4.8 above, continuous data were retrieved for only two sensors. These two sensors were compared with that of the reference instrument in this pilot calibration. While sensor A2 in Table 59 was a vertical wall sensor on a dead wall, sensor A1 was a horizontal working plane sensor centrally located within the classroom. This made the analyses of these two sensor points to be useful. 
Table 72: Pilot Study One Spot Measurement Calibration Table

\section{DATA LOGGERS SPOT MEASUREMENT CALIBRATION TABLE}

\begin{tabular}{l|l|l} 
Description & Data from Reference Instrument & Data from Sensors
\end{tabular}

\begin{tabular}{|c|c|c|c|c|c|c|c|c|c|c|c|c|c|c|}
\hline & & & & & & \multirow[b]{2}{*}{$\begin{array}{c}\text { Sound - Diff } \\
\text { (dBA) }\end{array}$} & \multirow[b]{2}{*}{$\begin{array}{l}\text { CO2 - Diff } \\
\text { (PPM) }\end{array}$} \\
\hline Date & Time & Sensor & $\begin{array}{l}\text { Light } \\
\text { (Lux) }\end{array}$ & $\begin{array}{c}\text { Temp } \\
\text { (Celsius) }\end{array}$ & $\begin{array}{l}\text { Sound } \\
\text { (dBA) }\end{array}$ & $\begin{array}{c}\mathrm{CO2} \\
\text { (PPM) }\end{array}$ & $\begin{array}{l}\text { Light } \\
\text { (Lux) }\end{array}$ & $\begin{array}{c}\text { Temp } \\
\text { (Celsius) }\end{array}$ & $\begin{array}{l}\text { Sound } \\
\text { (dBA) }\end{array}$ & $\begin{array}{c}\mathrm{CO2} \\
\text { (PPM) }\end{array}$ & $\begin{array}{c}\text { Light - } \\
\text { Factor (\%) }\end{array}$ & $\begin{array}{l}\text { Temp - Diff } \\
\text { (Celsius) }\end{array}$ & & \\
\hline $05 / 10 / 2018$ & 7:00pm & $\mathrm{A} 1$ & 150 & 23.00 & 47.6 & 502 & 46.30 & 21.00 & 49.90 & 481.97 & 119 & 2.00 & -2.30 & 20.03 \\
\hline 05/10/2018 & $8.30 \mathrm{pm}$ & $\mathrm{A} 1$ & 166 & 23.00 & 45.2 & 481 & 45.90 & 21.00 & 48.63 & 460.50 & 138 & 2.00 & -3.43 & 20.50 \\
\hline $06 / 10 / 2018$ & $12: 34 \mathrm{pm}$ & $\mathrm{A} 1$ & 429 & 23.00 & 47.8 & 469 & 131.14 & 21.00 & 50.68 & 444.54 & 398 & 2.00 & -2.88 & 24.46 \\
\hline $06 / 10 / 2018$ & $1: 44 \mathrm{pm}$ & $\mathrm{A} 1$ & 402 & 24.00 & 48.2 & 452 & 118.37 & 22.00 & 51.03 & 432.70 & 373 & 2.00 & -2.83 & 19.30 \\
\hline $06 / 10 / 2018$ & 3:18pm & $\mathrm{A} 1$ & 364 & 24.00 & 47.8 & 458 & 104.07 & 22.00 & 50.10 & 440.79 & 335 & 2.00 & -2.30 & 17.21 \\
\hline $06 / 10 / 2018$ & $4: 45 p m$ & $\mathrm{~A} 1$ & 312 & 24.00 & 47.5 & 452 & 76.60 & 22.00 & 50.10 & 438.43 & 287 & 2.00 & -2.60 & 13.57 \\
\hline $07 / 10 / 2018$ & 9:00am & $\mathrm{A} 1$ & 385 & 23.00 & 46.5 & 538 & 132.66 & 21.00 & 49.79 & 522.31 & 351 & 2.00 & -3.29 & 15.69 \\
\hline $07 / 10 / 2018$ & 9:45am & $\mathrm{A} 1$ & 325 & 23.00 & 47.1 & 548 & 138.10 & 21.00 & 49.97 & 535.17 & 283 & 2.00 & -2.87 & 12.83 \\
\hline $07 / 10 / 2018$ & $12: 10 \mathrm{pm}$ & $\mathrm{A} 2$ & 323 & 23.00 & 47.2 & 563 & 105.71 & 21.00 & 51.14 & 540.43 & 290 & 2.00 & -3.94 & 22.57 \\
\hline $05 / 10 / 2018$ & 7:00pm & $\mathrm{A} 2$ & 200 & 23.00 & 46.3 & 495 & 51.97 & 21.00 & 49.87 & 472.53 & 174 & 2.00 & -3.57 & 22.47 \\
\hline $05 / 10 / 2018$ & $8.30 \mathrm{pm}$ & $\mathrm{A} 2$ & 190 & 23.00 & 47.4 & 483 & 50.77 & 21.00 & 49.40 & 461.33 & 163 & 2.00 & -2.00 & 21.67 \\
\hline $06 / 10 / 2018$ & $12: 34 \mathrm{pm}$ & $\mathrm{A} 2$ & 345 & 24.00 & 47.7 & 468 & 124.77 & 22.00 & 50.63 & 445.50 & 309 & 2.00 & -2.93 & 22.50 \\
\hline $06 / 10 / 2018$ & 1:44pm & $\mathrm{A} 2$ & 410 & 24.00 & 46.7 & 459 & 149.70 & 22.00 & 50.53 & 437.63 & 373 & 2.00 & -3.83 & 21.37 \\
\hline $06 / 10 / 2018$ & 3:18pm & $\mathrm{A} 2$ & 375 & 24.00 & 47.7 & 460 & 105.34 & 22.00 & 51.03 & 446.76 & 347 & 2.00 & -3.33 & 13.24 \\
\hline $06 / 10 / 2018$ & $4: 45 p m$ & $\mathrm{~A} 2$ & 330 & 24.00 & 48.2 & 463 & 104.67 & 22.00 & 50.23 & 446.50 & 298 & 2.00 & -2.03 & 16.50 \\
\hline $07 / 10 / 2018$ & 9:00am & $\mathrm{A} 2$ & 406 & 23.00 & 47.6 & 583 & 147.67 & 21.00 & 50.57 & 556.80 & 370 & 2.00 & -2.97 & 26.20 \\
\hline $07 / 10 / 2018$ & 9:45am & $\mathrm{A} 2$ & 426 & 23.00 & 47.2 & 580 & 139.31 & 21.00 & 51.07 & 569.38 & 393 & 2.00 & -3.87 & 10.62 \\
\hline $07 / 10 / 2018$ & 12:10pm & $\mathrm{A} 2$ & 344 & 24.00 & 47.4 & 581 & 100.41 & 22.00 & 51.31 & 566.54 & 315 & 2.00 & -3.91 & 14.50 \\
\hline
\end{tabular}


In Table 72 , the offset errors for lighting appears to vary between $+100 \%$, to nearly $+300 \%$ respectively. These give concerns about the accuracy of the light sensors. However, the differences imply that each sensor may have to be calibrated differently. Given that this was only two sensors, the accuracy of the light sensor was further explored in the subsequent calibration experiments. Temperature ranges were consistent at $+2{ }^{\circ} \mathrm{C}$, sound indicated by these calibration checks ranged from $-2 \mathrm{dBA}$ to nearly $-3 \mathrm{dBA} . \mathrm{CO}_{2}$ indicated by these calibration checks was $<30$ ppm. Further analyses of the implication of these results are reported in the section below.

\section{Appendix 4.3. Sensors Unit Connection Capability Experiment}

Following the missing data challenges identified in the first phase case study data collection experiment, a series of operational connection capability test were carried out to ascertain the sensors connection capability. Also, another sequence of calibration was undertaken to evaluate the accuracy and consistency of data readings. Below are the findings of the sensors' connection capability test.

\section{Methodology}

A qualitative observation method was used to assess the connection capability of the sensors. This involved the use of a predesigned checklist to systematically document random time and situation sampling of each deployed sensors connection capability. Six sensors identified as 1036, 1006, 1041, 1057, 1075 and 1117 were randomly selected and deployed in a test environment. As shown in Figure 92, the two phases of test were carried out in an open plan office at the Victoria University of Wellington was used to carry out this test. The space is north-south facing and about $10 \mathrm{~m}$ in length by $10 \mathrm{~m}$ in width excluding the kitchen area and breakout offices. The glazed area is a one-side lit south facing. It is a mechanically ventilated space with an occupancy number of about 50 people and occupied by Doctoral students in the School of Architecture. Figure 95 is a sketch plan indicating the location of the sensors to provide some information about the test environment and the positioning of the devices relative to the Wi-Fi AP. 


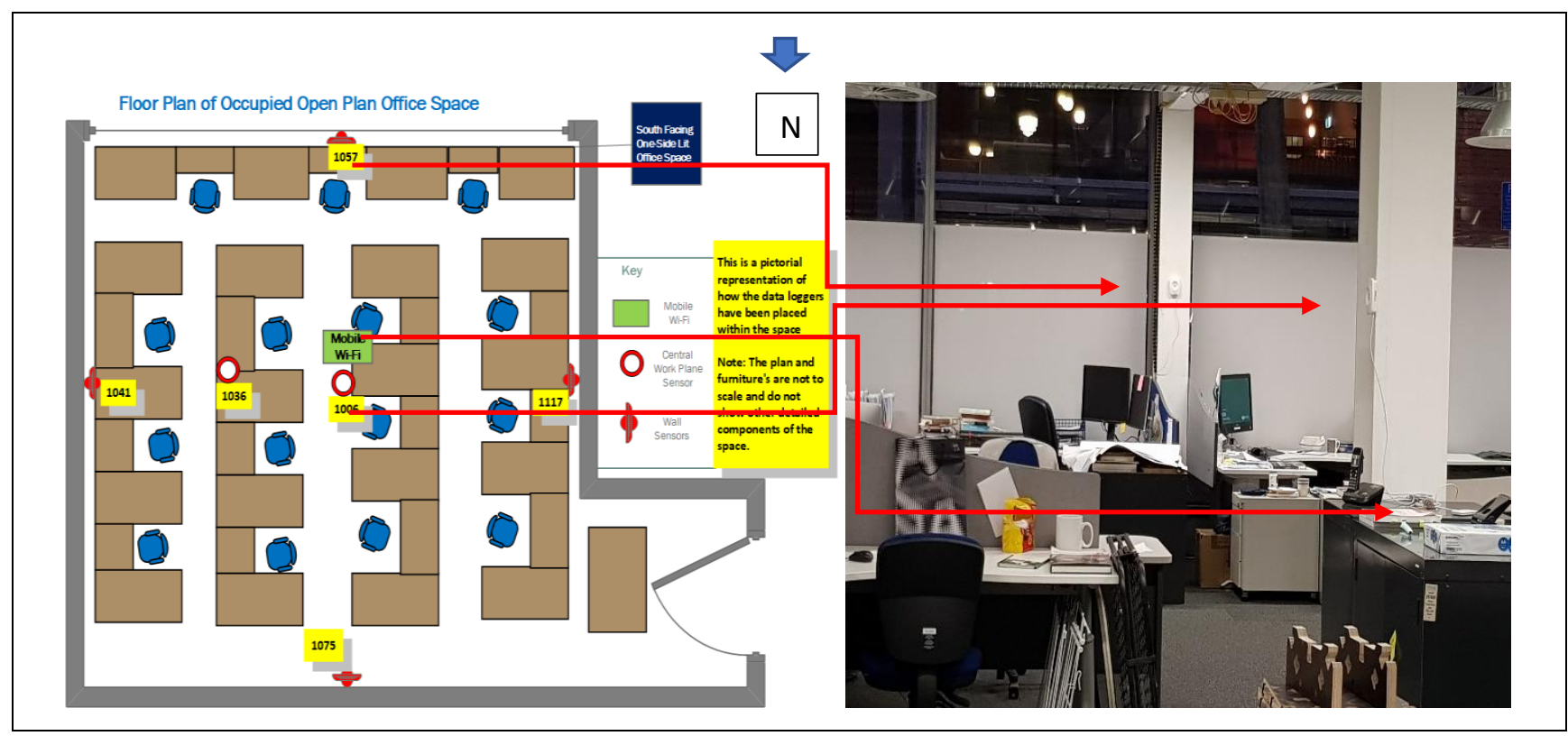

Figure 95: Plan and the interior picture showing the location of sensors within the test environment

In Figure 95, four sensors annotated as 1041, 1057, 1075 and 1117 were located on the four walls at about $1.8 \mathrm{~m}$ height above the ground, while two sensors annotated as 1006 and 1036 and a Huawei Wi-Fi are located around the centre of the space in such a way that the Wi-Fi was relatively the same distance away from all four wall sensors. These sensors transmitted the measured IEQ data wirelessly to the MoE online IEQ database.

In Table 73, it was observed from the random time sampling that while sensors 1057 and 1075 were resetting intermittently, sensors 1036, 1006, 1117 and 1041 were not resetting very frequently. Resetting refers to the sensor blinking a green light to indicate that it is trying to establish a connection to the wireless network. The observed resetting issue informed the need to check a Wi-Fi analyser application to determine the signal strength of the sensors.

Table 73: Summary of Test Results - Performance Analysis

\begin{tabular}{|c|c|c|c|c|c|c|c|c|}
\hline \multicolumn{9}{|c|}{ Sensor Units } \\
\hline Name & Description & 1057 & 1075 & 1041 & 1006 & 1117 & 1036 & Overall \\
\hline $\begin{array}{l}\text { APP Search } \\
\text { Wi-Fi }\end{array}$ & $\begin{array}{l}\text { Ensure that the app will } \\
\text { search for all available Wi- } \\
\mathrm{Fi} \text { - and the user is able to } \\
\text { choose one. }\end{array}$ & Pass & Pass & Pass & Pass & Pass & Pass & Pass \\
\hline
\end{tabular}




\begin{tabular}{|c|c|c|c|c|c|c|c|c|}
\hline $\begin{array}{l}\text { Unit } \\
\text { Connected }\end{array}$ & Did the unit connect? & Pass & Pass & Pass & Pass & Pass & Pass & Pass \\
\hline $\begin{array}{l}\text { Unit Stay } \\
\text { Connected }\end{array}$ & $\begin{array}{l}\text { Does the unit stay } \\
\text { connected for at least } 1 \\
\text { hour }\end{array}$ & Fail & Fail & Pass & Pass & Pass & Pass & Fail \\
\hline Unit Reconnect & $\begin{array}{l}\text { If applicable - did the unit } \\
\text { reconnect }\end{array}$ & Fail & Pass & Pass & Pass & Pass & Pass & Fail \\
\hline $\begin{array}{l}\text { Connection } \\
\text { Capability }\end{array}$ & $\begin{array}{l}\text { Which units required a } \\
\text { hard restart (switching off } \\
\text { and on of power source to } \\
\text { reconnect) }\end{array}$ & Fail & Fail & Pass & Pass & Pass & Pass & Fail \\
\hline
\end{tabular}

\section{Wi-Fi Analyzer Results}

In Figure 96, the Wi-Fi analyser indicated that sensor 1006 had a signal strength of about $30 \mathrm{dBM}$. This sensor was located close to the Wi-Fi AP and didn't have any resetting issue throughout the observation period as indicated in Table 73.

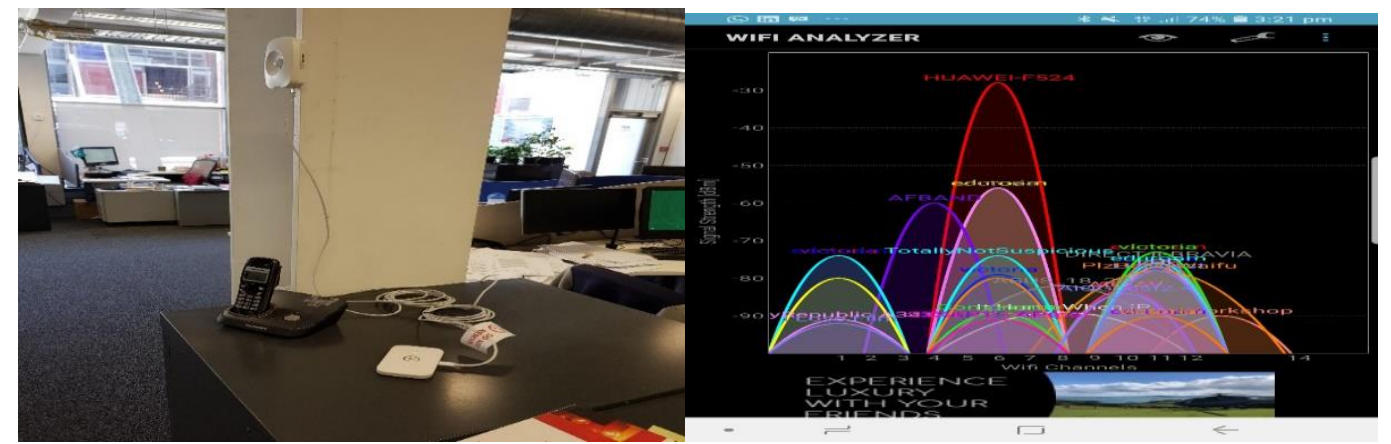

Figure 96: Pictures showing the location of the Wi-Fi AP and Sensor 1006 located at the centre of the space

In Figure 97, sensor 1117 was located on the east facing wall and had a signal strength of around $60 \mathrm{dBm}$ while sensor 1041 was located on the west facing wall and had a signal strength of about $55 \mathrm{dBm}$. These two sensors passed the connection acceptance test as well, thereby indicating that a signal strength of around $-60 \mathrm{dBm}$ was suitable for a good connection. 


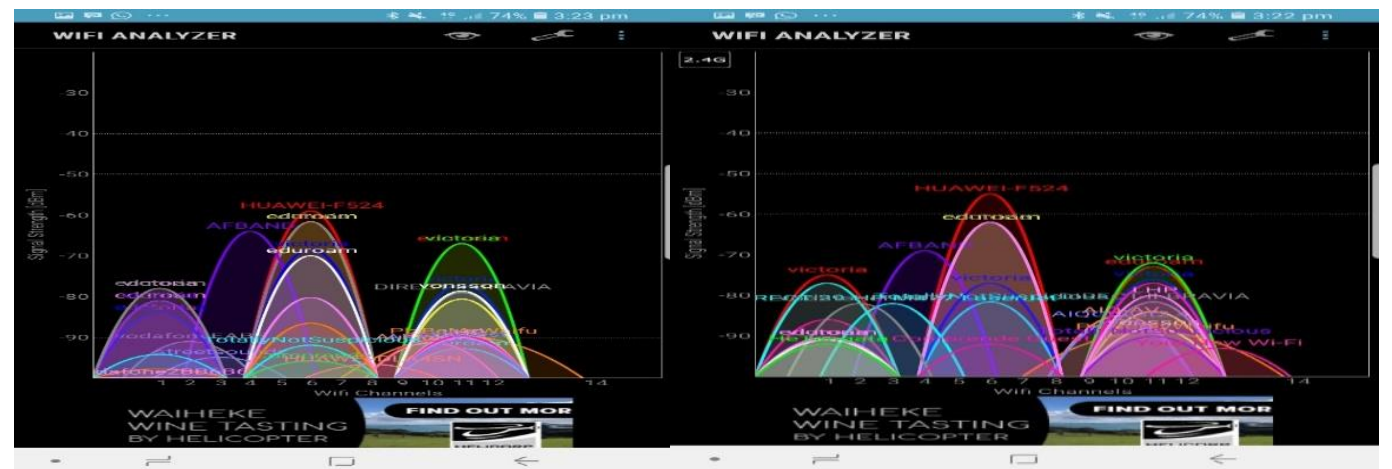

Figure 97: Pictures showing the Wi-Fi Analyzer image for Sensors 1117 and 1041 respectively

In Figure 98, sensor 1075 was located on the north facing wall and had a signal strength of around $60 \mathrm{dBm}$ while sensor 1057 was on the south facing wall and had a signal strength of about $65 \mathrm{dBm}$. These two sensors failed the connection acceptance test given that they frequently had resetting issues which appeared worst in sensor 1057.

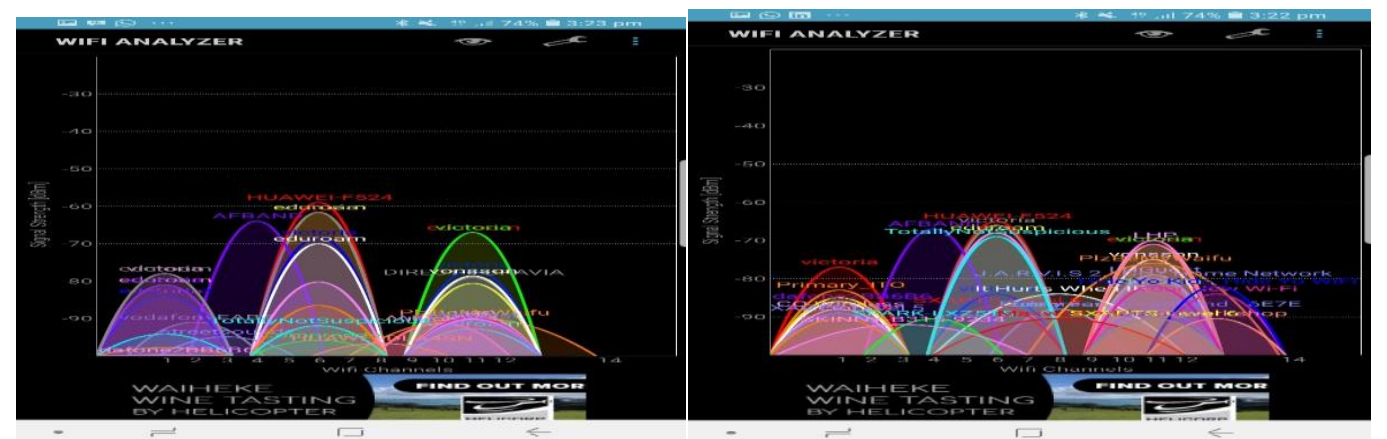

Figure 98: Pictures showing the Wi-Fi Analyzer image for sensors 1075 and 1057 respectively

\section{Observation Result}

Though the sensors were placed in such a way that the Wi-Fi was relatively the same distance away from all four wall sensors, the Wi-Fi analyzer indicated that sensors 1075 and 1057 may have been located a bit further away from the Wi-Fi AP than the other two wall sensors, which made it more susceptible to resetting. As shown in Table 73 above, no resetting issue was observed for devices 1006 1041, 1117 and 1036 which were located relatively close to the Wi-Fi. This suggested that there is a correlation between any resetting issue and the positioning of the sensors relative to the Wi-Fi AP, which led to missing data in the earlier case study classroom deployment. 


\section{Summary}

- From a total of 6 sensors observed between in 11days, 4 sensors (1041, 1006, 1117, and 1036) passed the unit connection capability test, while 2 sensors $(1057,1075)$ which required a hard reset failed the test.

- Possible reasons for the failure was observed to be the strength of the Wi-Fi connection and the distance of the sensor from the Wi-Fi AP.

- The Wi-Fi Analyser (sensor 1041 \& 1117) indicated that the positioning of the devices relative to the Wi-Fi AP should be better than $-60 \mathrm{dBm}$ for optimum performance.

- In relation to the spatial dimension of a space, $-47 \mathrm{dbm}$ is about $1 \mathrm{~m}$, hence, $-60 \mathrm{dBm}$ to $75 \mathrm{dBm}$ should be around $1.5 \mathrm{~m}$ to $1.8 \mathrm{~m}$.

- The finding of this experiment suggested that on the deployment of the sensors in a school site, a Wi-Fi analyzer test should be carried out to ensure that the signal connection strength is within the required $\mathrm{dBm}$. This was adhered to in the repeated deployment of the sensors in the case study classroom. 


\section{Appendix 5. Case Study One Pilot Study Calibration}

The same process of calibration in pilot study one was used for the case study one pilot calibration. Spot measurements using the reference instruments described in Section 4.1 of the Appendix above were used to measure the environmental variables at different times of the.

Table 74 below presents the calibration results. The offset errors for lighting appear to vary between $\pm 100 \%$, to nearly $+300 \%$ respectively. However, vertical wall sensors 1075 (C4) and 1117 (C5), which were further away from the glazed area had an offset error of $\pm 100 \%$, vertical wall sensor 1041 (C1) and 1057 (C3), which were more exposed to the glazed area had an offset error of $\pm 200 \%$, while horizontal measuring plane sensors 1006 (C2) and 1036 (C6) also had an offset error of $\pm 200 \%$. Given that these measurements took into consideration both natural and artificial lighting, these results indicate that the placement of the sensors (vertical or horizontal) relative to the lighting source influences the percentage of accuracy of the sensor. This assertion was further explored in the calibration analysis reported in Chapter 4 above. Temperature ranges were consistent with the findings the previous pilot study calibrations as was $+2^{\circ} \mathrm{C}$, Sound also indicated by these calibration checks ranged from - $2 \mathrm{dBA}$ to nearly - $3 \mathrm{dBA} . \mathrm{CO}_{2}$ indicated by these calibration checks was $<50 \mathrm{ppm}$.

The outcome of these calibration experiments were presented to the MoE and they decommission the old sensors following lessons learned in the rapid prototyping phase which informed a significant improvement in the new production version, such as the sensors capability to provide accurate and consistent readings. Hence, another pilot study calibration exercise in case study one was carried out to determine the accuracy of the new sensors. The findings of the calibration experiment are reported in Section 4.9.3 in Chapter 4 above. 
Table 74: Case Study One Pilot Study Spot Measurement Calibration Table

\begin{tabular}{|c|c|c|c|c|c|c|c|c|c|c|c|c|c|c|}
\hline \multicolumn{3}{|l|}{ Description } & \multicolumn{4}{|c|}{ Data from Reference Instrument } & \multicolumn{4}{|c|}{ Data from Sensors } & \multicolumn{4}{|c|}{ Calibration Variation } \\
\hline Date & Time & Sensor & $\begin{array}{l}\text { Light } \\
\text { (Lux) }\end{array}$ & $\begin{array}{l}\text { Temp } \\
\text { (Celsius) }\end{array}$ & $\begin{array}{l}\text { Sound } \\
\text { (dBA) }\end{array}$ & $\begin{array}{l}\mathrm{CO} 2 \\
\text { (PPM) }\end{array}$ & $\begin{array}{l}\text { Light } \\
\text { (Lux) }\end{array}$ & $\begin{array}{l}\text { Temp } \\
\text { (Celsius) }\end{array}$ & $\begin{array}{l}\text { Sound } \\
\text { (dBA) }\end{array}$ & $\begin{array}{l}\mathrm{CO2} \\
\text { (PPM) }\end{array}$ & $\begin{array}{c}\text { Light - } \\
\text { Factor (\%) }\end{array}$ & $\begin{array}{l}\text { Temp - Diff } \\
\text { (Celsius) }\end{array}$ & $\begin{array}{l}\text { Sound - Diff } \\
\text { (dBA) }\end{array}$ & $\begin{array}{c}\text { CO2 - Diff } \\
\text { (PPM) }\end{array}$ \\
\hline $22 / 01 / 2019$ & $5: 11 \mathrm{pm}$ & C1 & 238 & 25 & 47 & 710 & 103.00 & 23.00 & 50.00 & 662.00 & 195 & 2.00 & -3.00 & 48.00 \\
\hline $23 / 01 / 2019$ & $5: 30 \mathrm{pm}$ & $\mathrm{C} 1$ & 245 & 24 & 50 & 671 & 99.00 & 22.00 & 53.00 & 627.00 & 205 & 2.00 & -3.00 & 44.00 \\
\hline $24 / 01 / 2019$ & 3:30:pm & C1 & 269 & 24 & 49 & 664 & 92.00 & 22.00 & 52.00 & 626.00 & 235 & 2.00 & -3.00 & 38.00 \\
\hline $27 / 01 / 2019$ & 9:34am & C1 & 220 & 23 & 47 & 489 & 65.00 & 21.00 & 51.00 & 450.00 & 190 & 2.00 & -4.00 & 39.00 \\
\hline $27 / 01 / 2019$ & $12: 51 \mathrm{pm}$ & C1 & 265 & 24 & 48 & 550 & 86.00 & 22.00 & 51.00 & 510.00 & 233 & 2.00 & -3.00 & 40.00 \\
\hline $22 / 01 / 2019$ & $5: 15 p m$ & $\mathrm{C} 2$ & 201 & 24 & 47 & 801 & 95.00 & 22.00 & 50.00 & 754.00 & 154 & 2.00 & -3.00 & 47.00 \\
\hline $23 / 01 / 2019$ & $5: 46 \mathrm{pm}$ & $\mathrm{C} 2$ & 204 & 23 & 47 & 734 & 102.00 & 21.00 & 50.00 & 689.00 & 154 & 2.00 & -3.00 & 45.00 \\
\hline $24 / 01 / 2019$ & 3:50pm & $\mathrm{C} 2$ & 201 & 23 & 47 & 675 & 78.00 & 21.00 & 49.00 & 628.00 & 162 & 2.00 & -2.00 & 47.00 \\
\hline $27 / 01 / 2019$ & 9:41am & $\mathrm{C} 2$ & 214 & 22 & 47 & 566 & 60.00 & 20.00 & 50.00 & 539.00 & 186 & 2.00 & -3.00 & 27.00 \\
\hline $27 / 01 / 2019$ & $1: 00 \mathrm{pm}$ & $\mathrm{C} 2$ & 230 & 23 & 47 & 606 & 91.00 & 21.00 & 50.00 & 565.00 & 190 & 2.00 & -3.00 & 41.00 \\
\hline $22 / 01 / 2019$ & $5: 20 \mathrm{pm}$ & $\mathrm{C} 3$ & 318 & 25 & 48 & 700 & 175.00 & 23.00 & 51.00 & 652.00 & 263 & 2.00 & -3.00 & 48.00 \\
\hline $23 / 01 / 2019$ & 5:30pm & $\mathrm{C} 3$ & 334 & 28 & 48 & 669 & 179.00 & 26.00 & 51.00 & 620.00 & 280 & 2.00 & -3.00 & 49.00 \\
\hline $24 / 01 / 2019$ & 3:43pm & C3 & 341 & 27 & 48 & 701 & 152.00 & 25.00 & 50.00 & 653.00 & 296 & 2.00 & -2.00 & 48.00 \\
\hline $27 / 01 / 2019$ & 9:37am & $\mathrm{C} 3$ & 320 & 22 & 52 & 462 & 94.00 & 20.00 & 55.00 & 429.00 & 291 & 2.00 & -3.00 & 33.00 \\
\hline $27 / 01 / 2019$ & $12: 54 \mathrm{pm}$ & $\mathrm{C} 3$ & 332 & 23 & 47 & 537 & 156.00 & 21.00 & 50.00 & 491.00 & 285 & 2.00 & -3.00 & 46.00 \\
\hline $22 / 01 / 2019$ & $5: 23 \mathrm{pm}$ & $\mathrm{C} 4$ & 175 & 24 & 47 & 709 & 134.00 & 22.00 & 50.00 & 669.00 & 98 & 2.00 & -3.00 & 40.00 \\
\hline $23 / 01 / 2019$ & $5: 49 \mathrm{pm}$ & $\mathrm{C} 4$ & 189 & 23 & 47 & 589 & 140.00 & 21.00 & 49.00 & 546.00 & 115 & 2.00 & -2.00 & 43.00 \\
\hline $24 / 01 / 2019$ & 4:07pm & $\mathrm{C} 4$ & 171 & 22 & 47 & 691 & 123.00 & 20.00 & 50.00 & 645.00 & 99 & 2.00 & -3.00 & 46.00 \\
\hline $27 / 01 / 2019$ & 9:44am & $\mathrm{C4}$ & 134 & 22 & 47 & 504 & 67.00 & 20.00 & 49.00 & 463.00 & 84 & 2.00 & -2.00 & 41.00 \\
\hline $27 / 01 / 2019$ & $12: 57 \mathrm{pm}$ & C5 & 256 & 22 & 47 & 563 & 215.00 & 20.00 & 49.00 & 518.00 & 172 & 2.00 & -2.00 & 45.00 \\
\hline $22 / 01 / 2019$ & 5:36pm & $\mathrm{C5}$ & 167 & 30 & 49 & 830 & 116.00 & 28.00 & 52.00 & 787.00 & 98 & 2.00 & -3.00 & 43.00 \\
\hline $23 / 01 / 2019$ & $5: 44 \mathrm{pm}$ & C5 & 173 & 25 & 49 & 777 & 117.00 & 23.00 & 52.00 & 735.00 & 105 & 2.00 & -3.00 & 42.00 \\
\hline $24 / 01 / 2019$ & $3: 45 \mathrm{pm}$ & C5 & 160 & 25 & 49 & 815 & 87.00 & 23.00 & 52.00 & 777.00 & 106 & 2.00 & -3.00 & 38.00 \\
\hline $27 / 01 / 2019$ & 9:39am & C5 & 155 & 24 & 49 & 635 & 55.00 & 22.00 & 52.00 & 623.00 & 120 & 2.00 & -3.00 & 12.00 \\
\hline $27 / 01 / 2019$ & $12: 56 \mathrm{pm}$ & C5 & 167 & 25 & 49 & 656 & 78.00 & 23.00 & 52.00 & 622.00 & 120 & 2.00 & -3.00 & 34.00 \\
\hline $24 / 01 / 2019$ & 4:04pm & C6 & 318 & 24 & 47 & 778 & 252.00 & 22.00 & 50.00 & 740.00 & 239 & 2.00 & -3.00 & 38.00 \\
\hline $27 / 01 / 2019$ & 9:42am & C6 & 321 & 23 & 49 & 503 & 241.00 & 21.00 & 52.00 & 457.00 & 246 & 2.00 & -3.00 & 46.00 \\
\hline $27 / 01 / 2019$ & 01:01pm & C6 & 333 & 23 & 47 & 551 & 298.00 & 21.00 & 50.00 & 508.00 & 244 & 2.00 & -3.00 & 43.00 \\
\hline
\end{tabular}


Appendix 6: Lighting Measurement Results

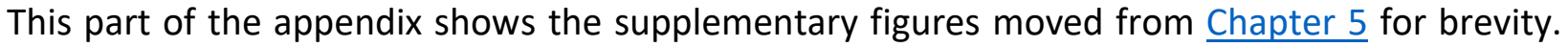
Non-School Days

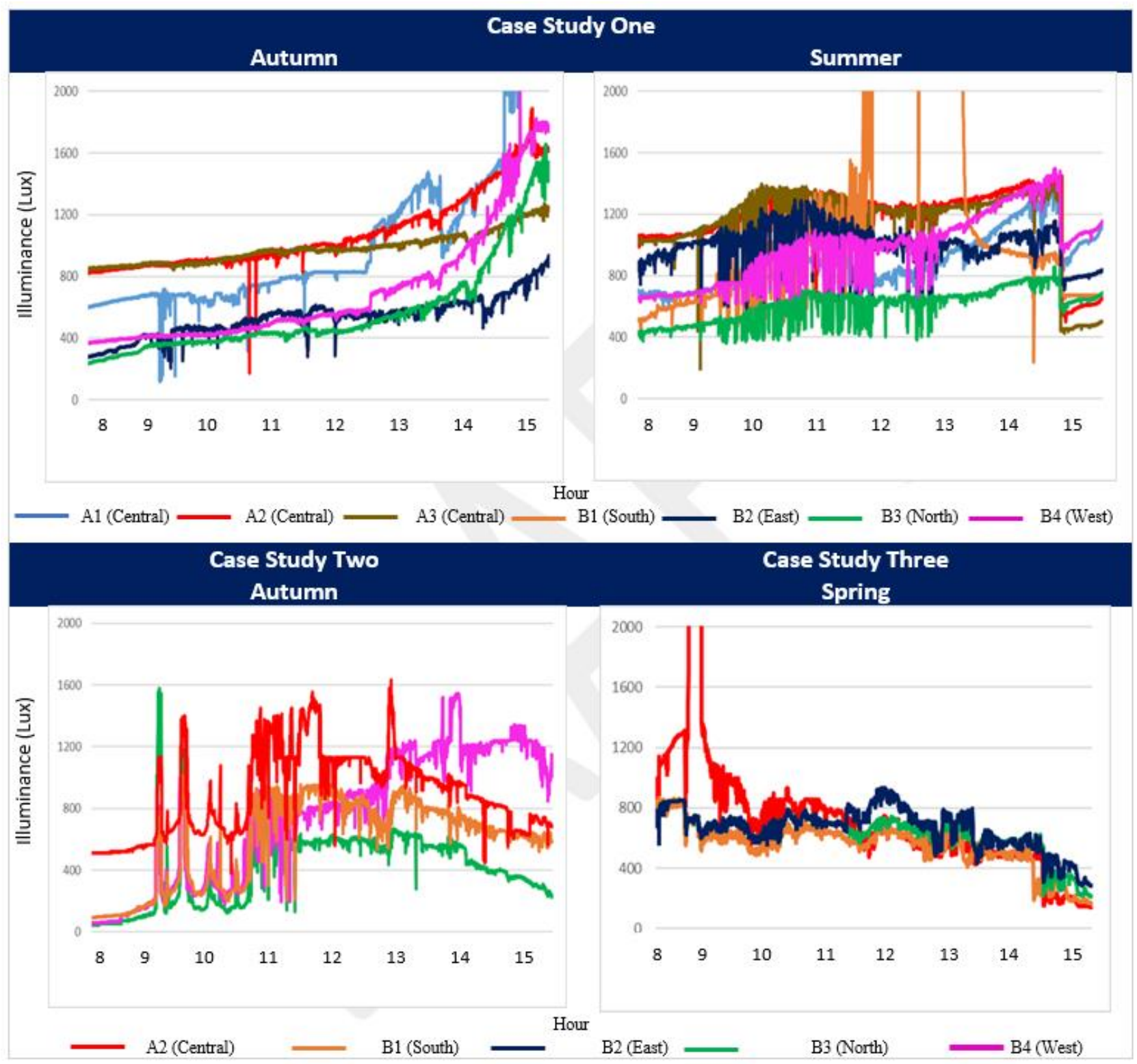

Figure 99: Line graphs showing illuminance trends between 8 am-3 pm during non-school days in all three case studies 


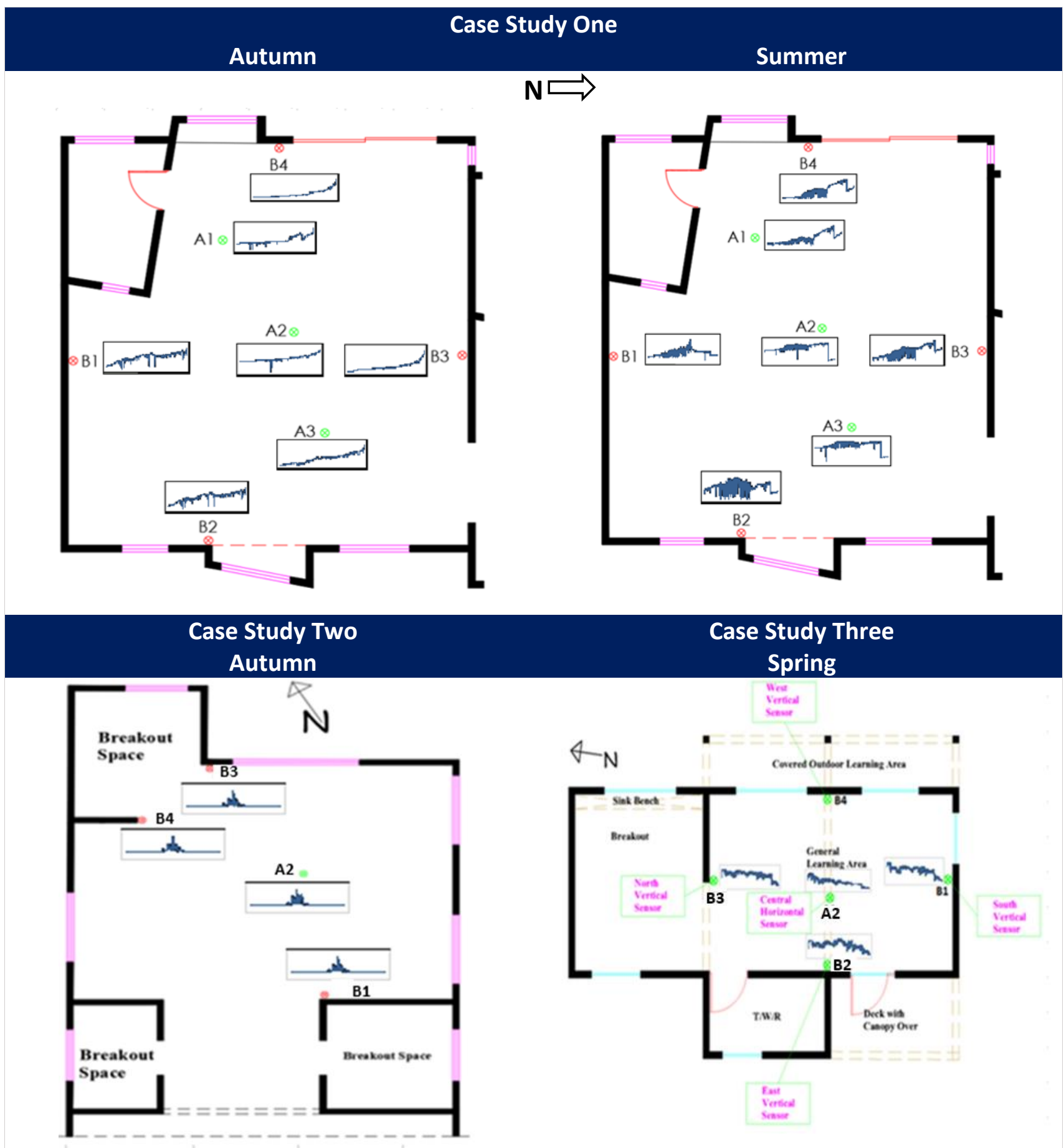

Figure 100: Sparklines showing illuminance visual patterns $<=2000 l u x$ between 8 am to 3 pm in the non-school days 


\section{School Days}

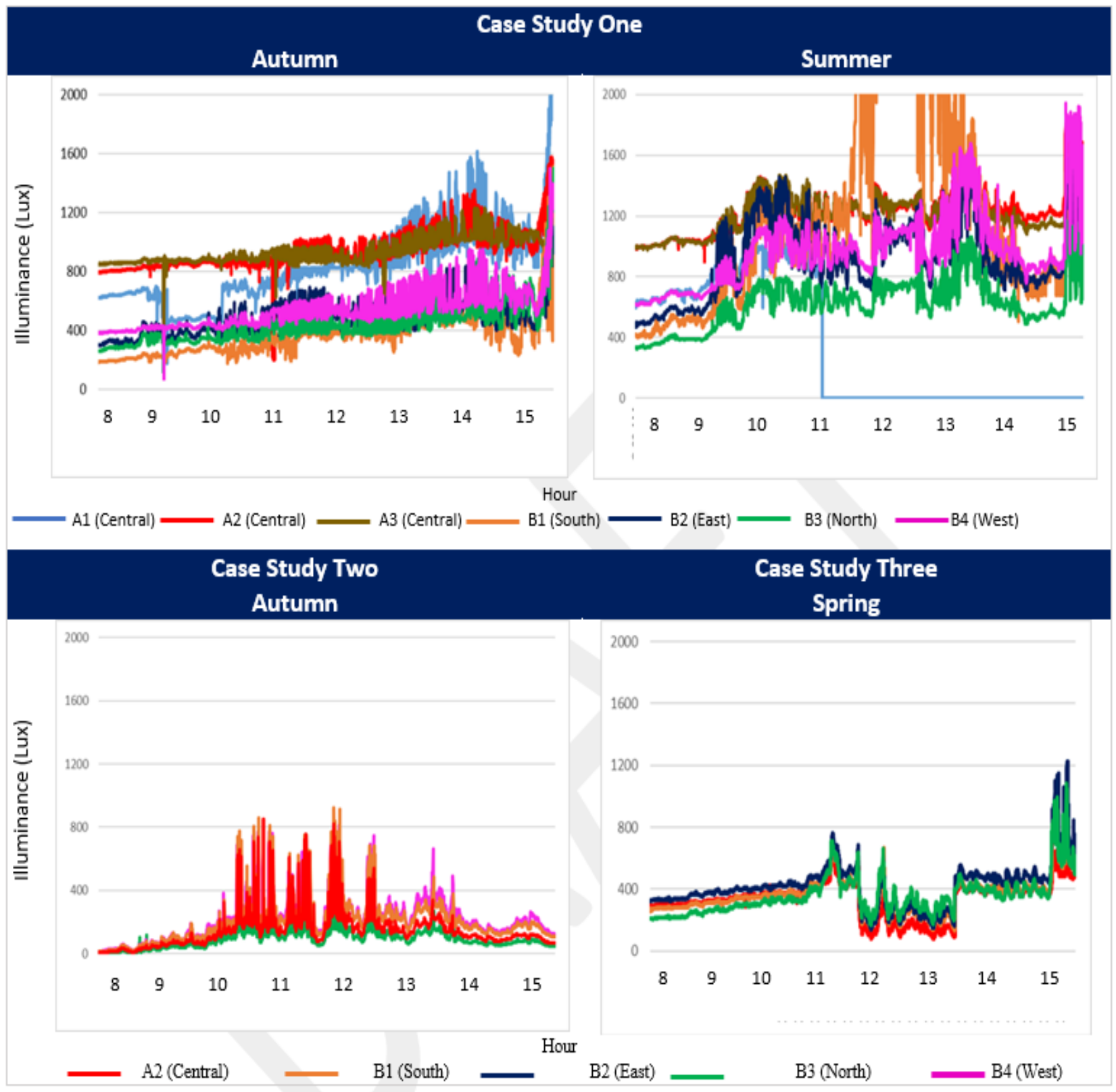

Figure 101: Line graphs showing illuminance trends between 8 am - 3 pm during school days in all three case studies 


\section{School Days}

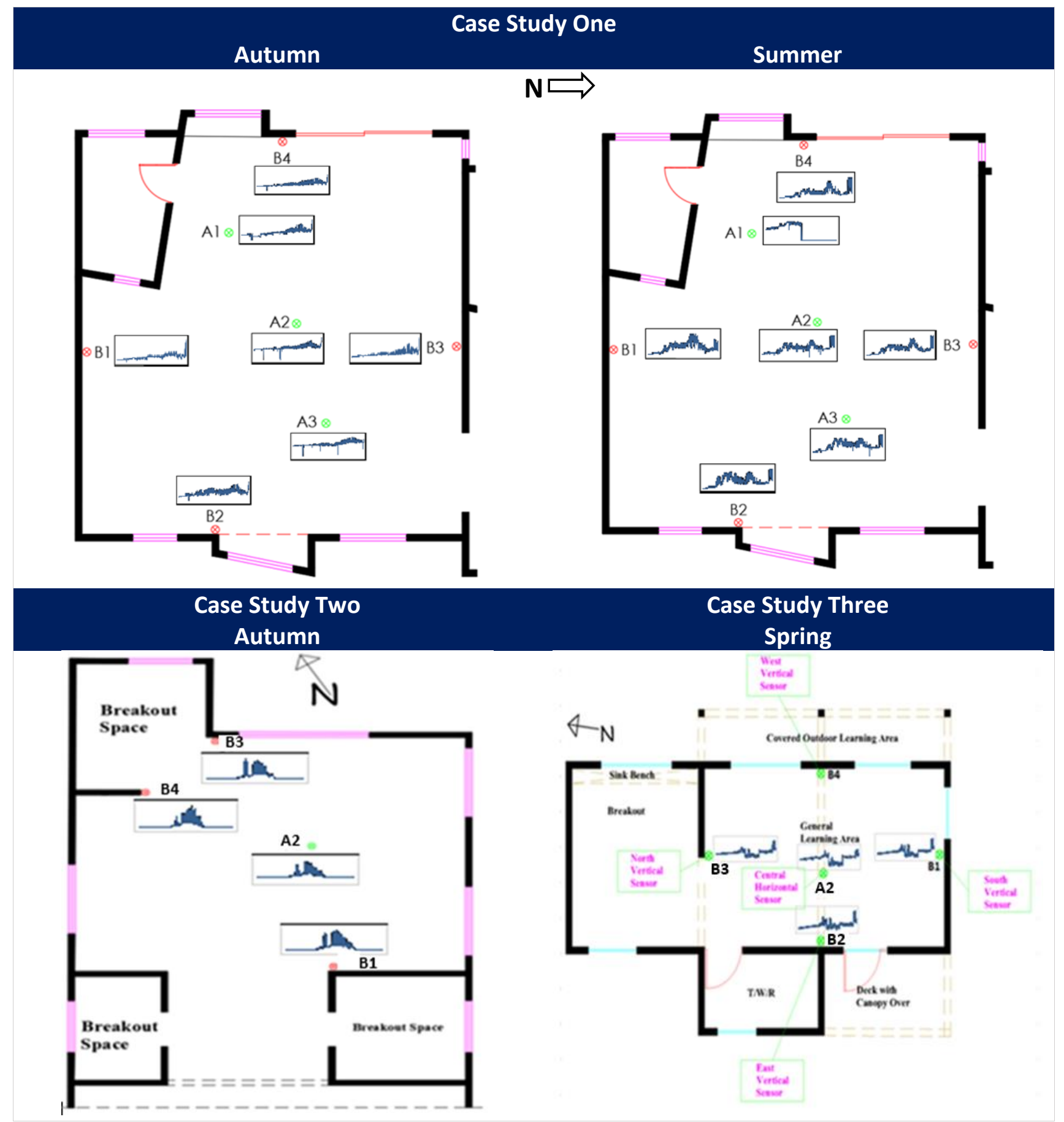

Figure 102: Sparklines showing illuminance visual patterns $<=2000 l u x$ between 8 am to $3 \mathrm{pm}$ in the non-school days 
Appendix 7: Thermal Measurement Results

This part of the appendix shows the supplementary figures moved from Chapter 6 for brevity

Non-School Day - Temperature

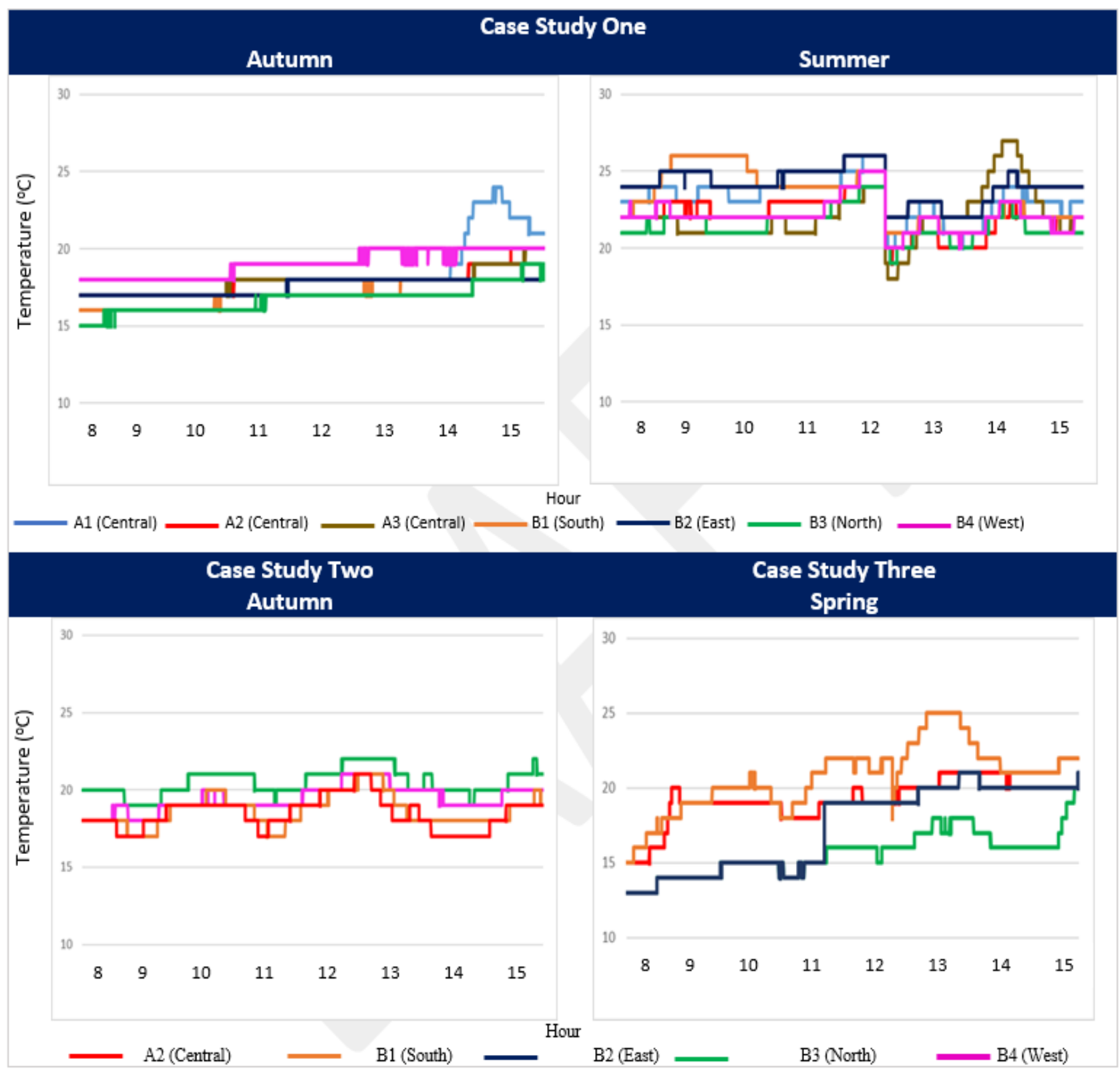

Figure 103: Line graphs showing temperature trends between 8 am - 3 pm during school days 


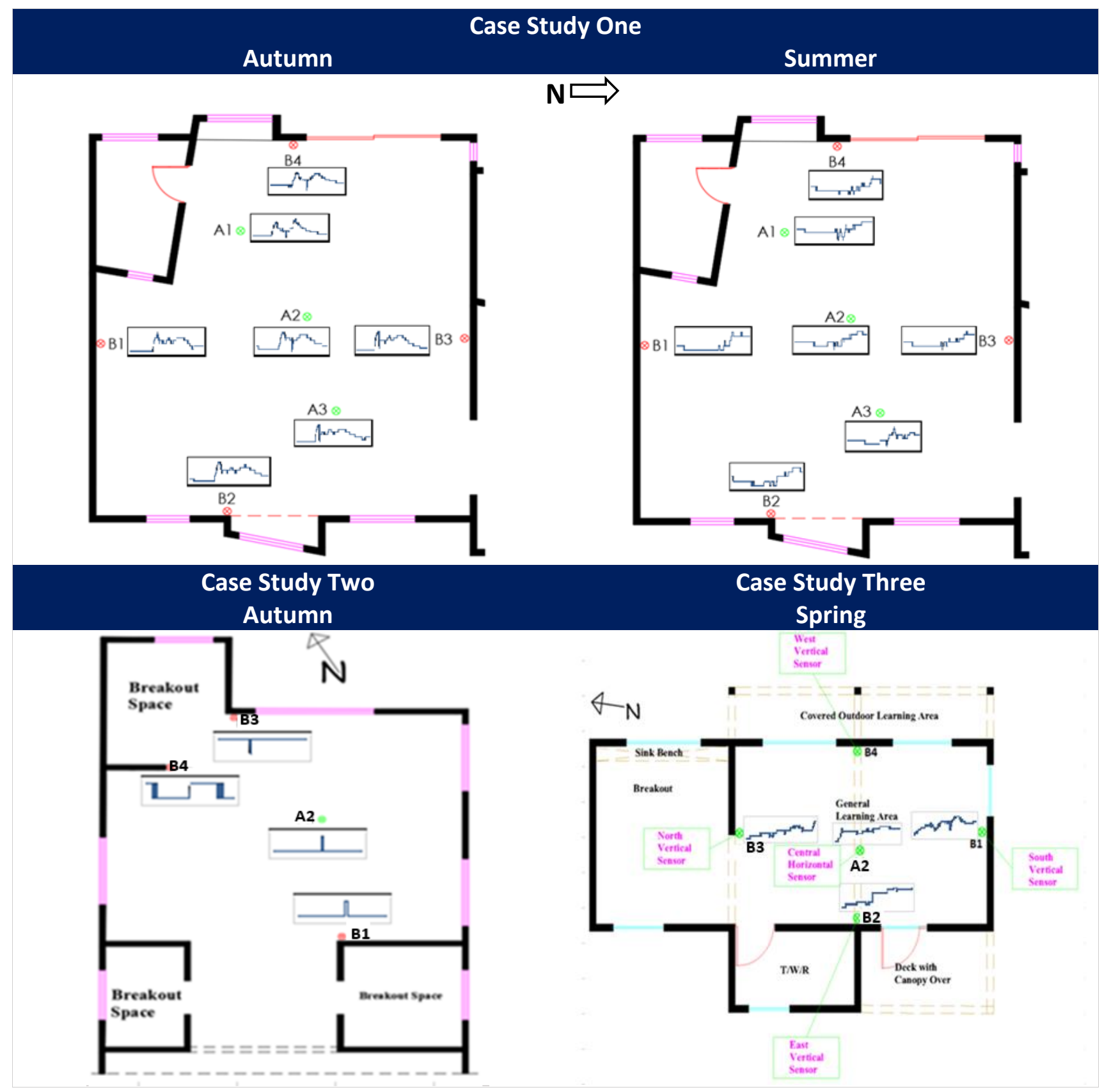

Figure 104: Sparklines showing temperature visual patterns between 8 am to 3 pm in the non-school days 


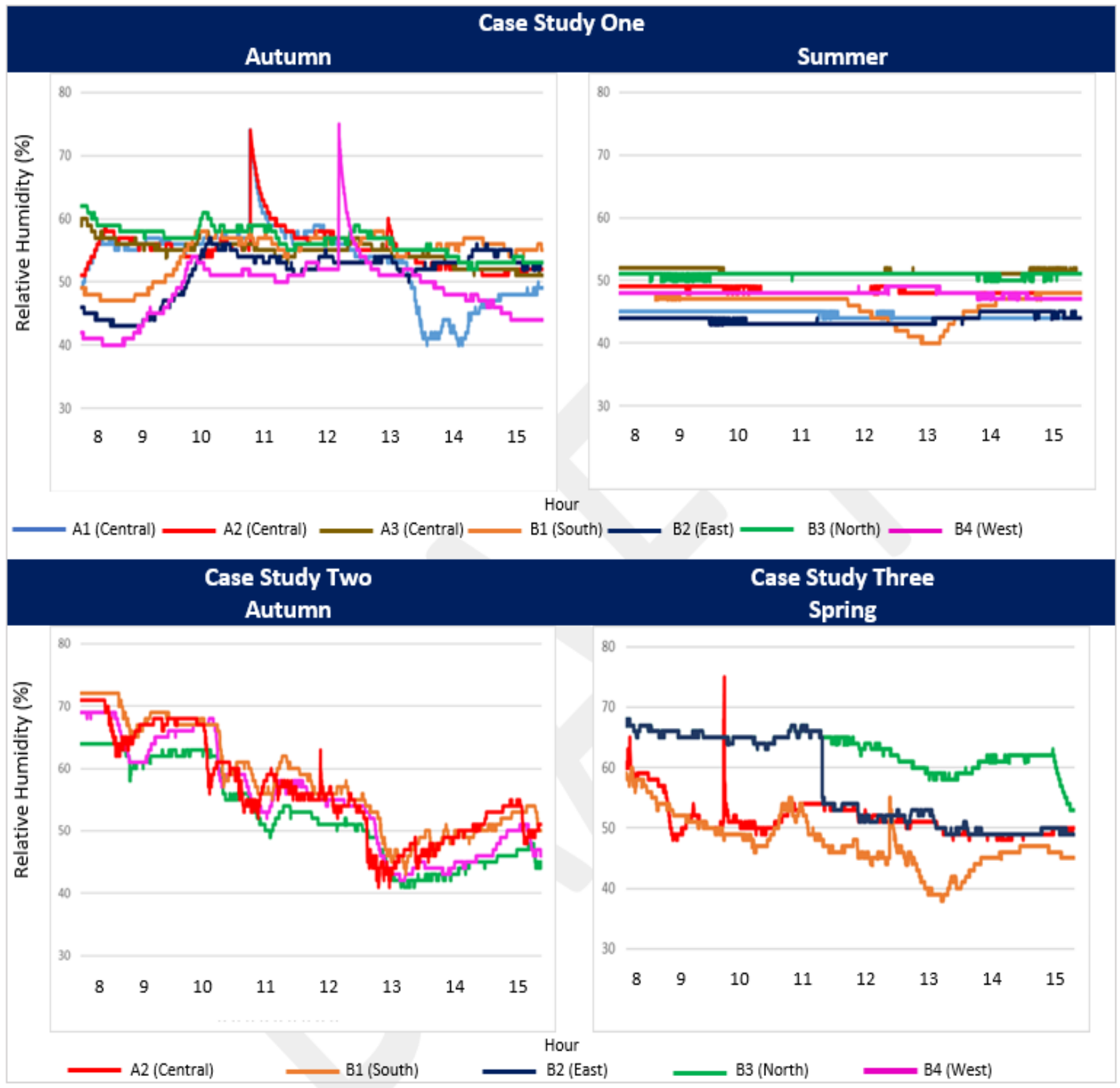

Figure 105: Line graphs showing relative humidity trends between 8 am - 3 pm during non-school days 


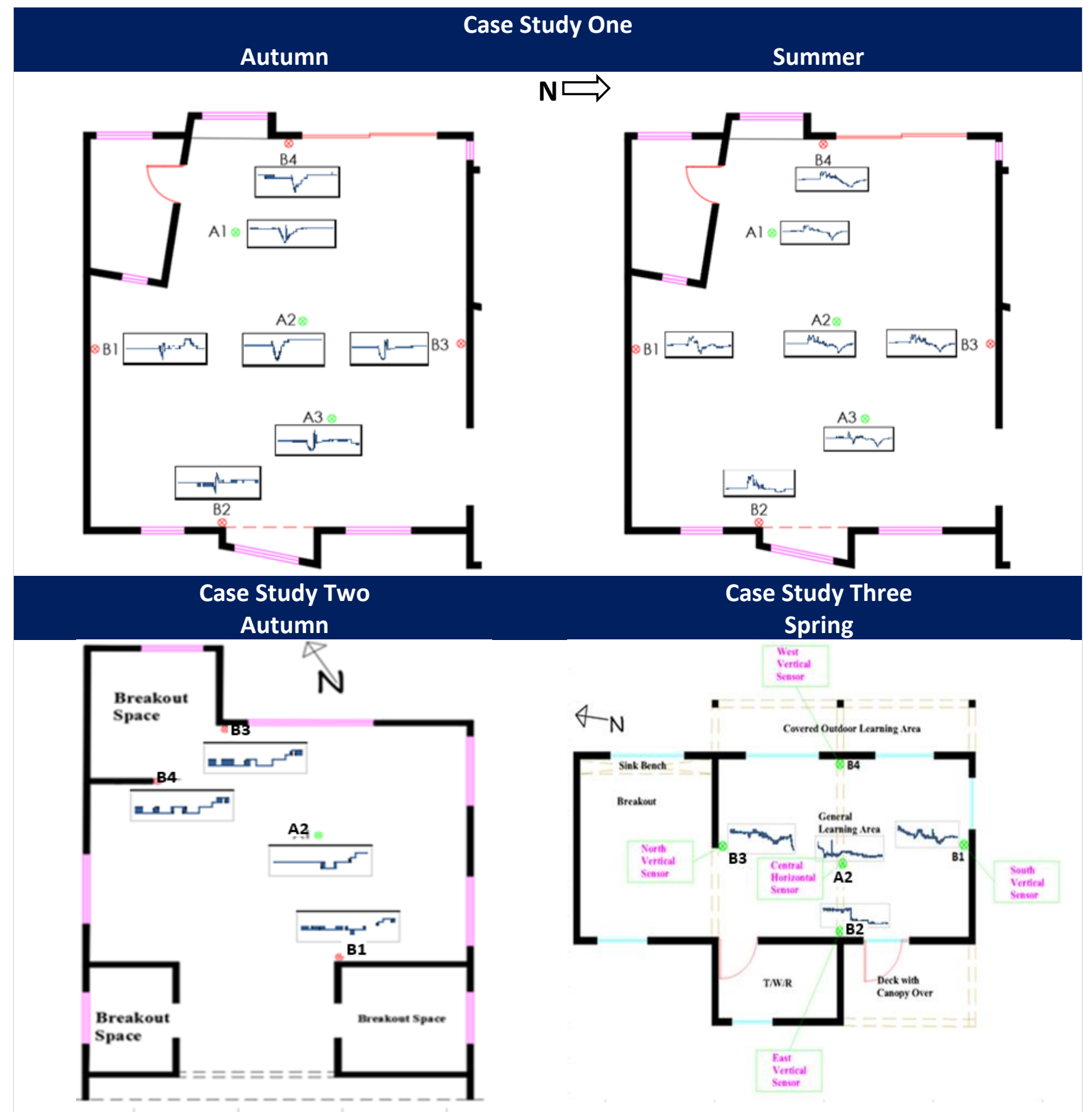

Figure 106: Sparklines showing relative humidity visual patterns between 8 am to $3 \mathrm{pm}$ in the non-school days 


\section{School Day - Temperature}

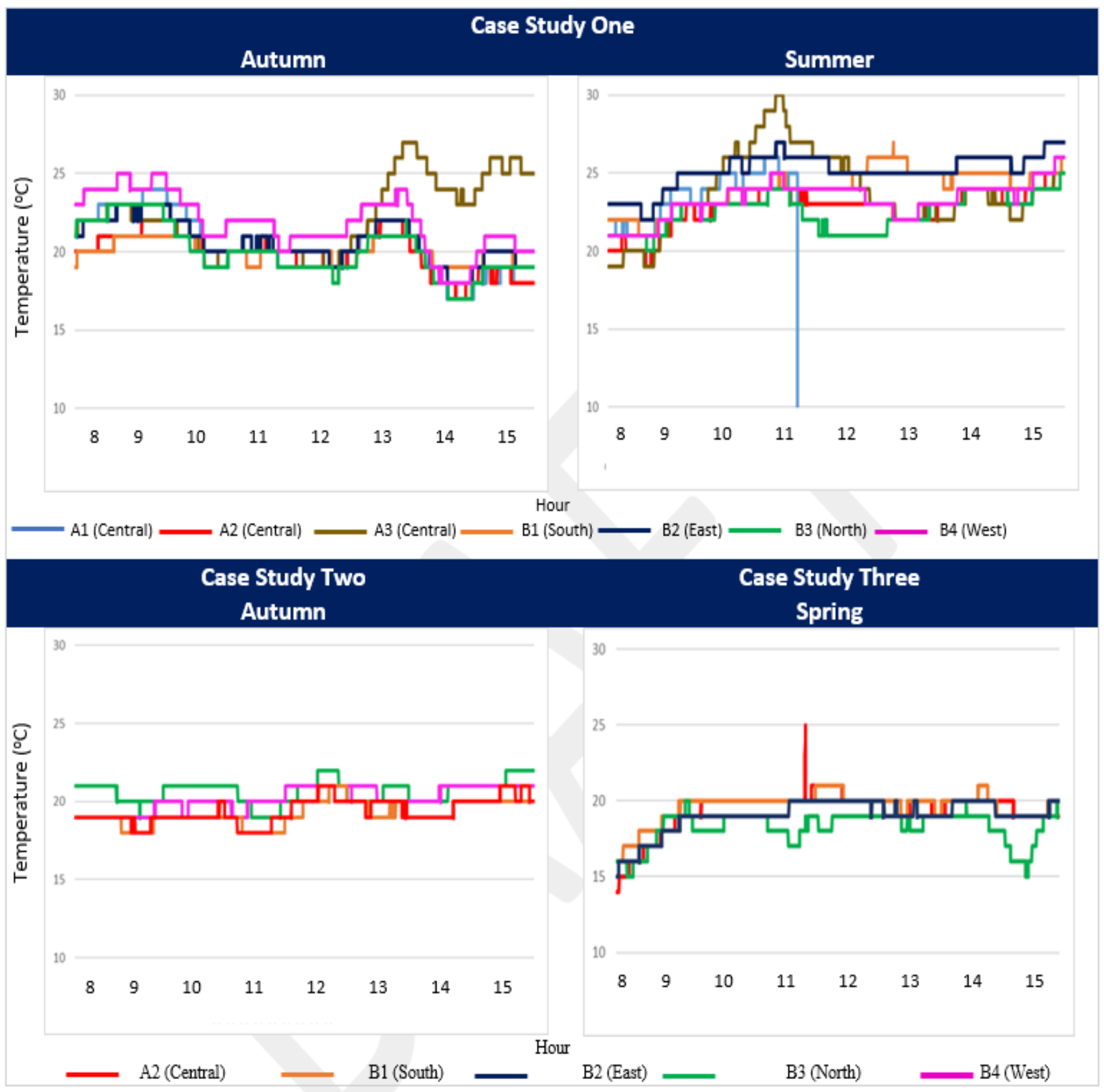

Figure 107: Line graphs showing temperature trends between 8 am - 3 pm during school days 


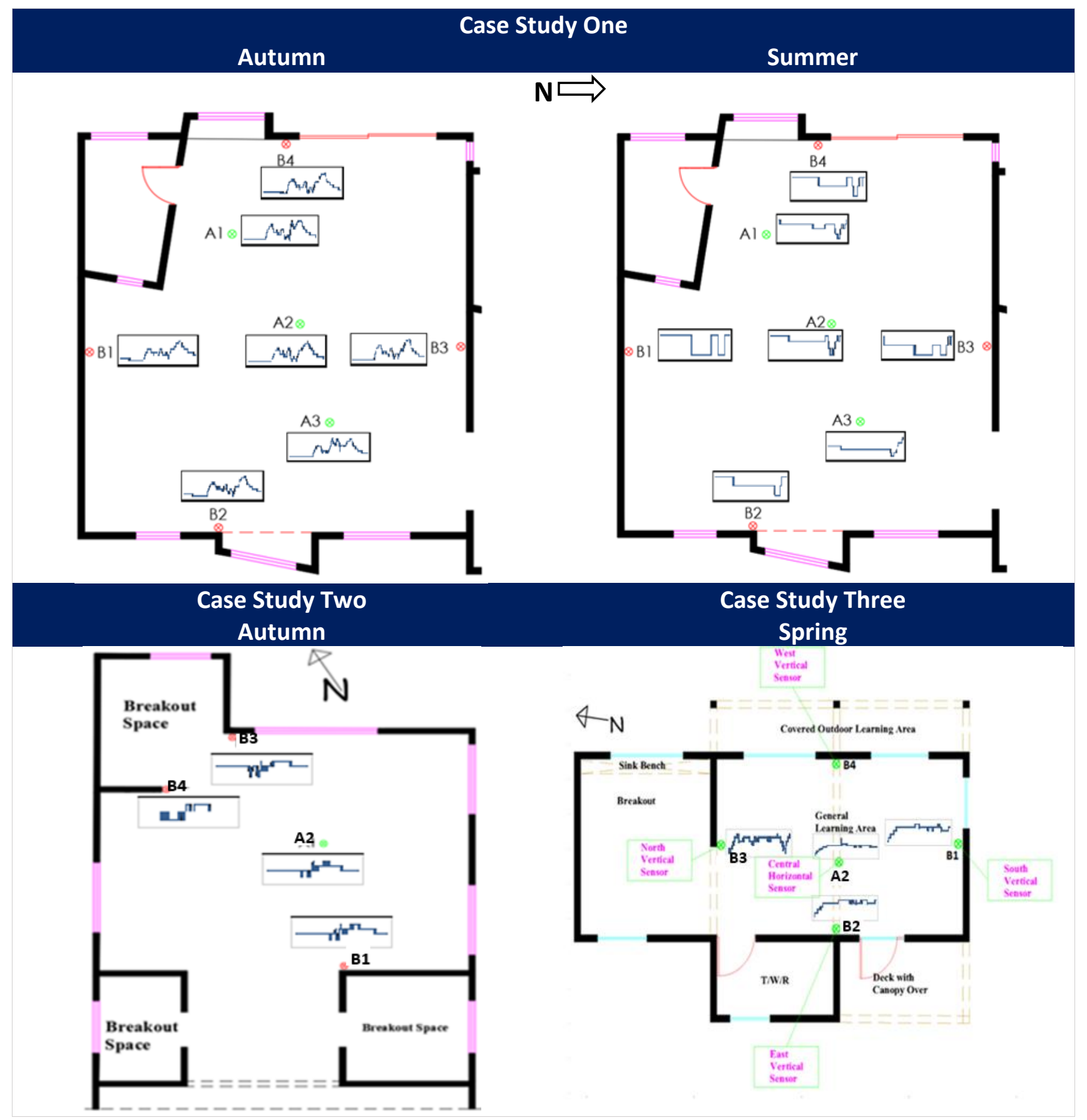

Figure 108: Sparklines showing temperature visual patterns between 8 am to 3 pm in the school days 


\section{School Day - Humidity}

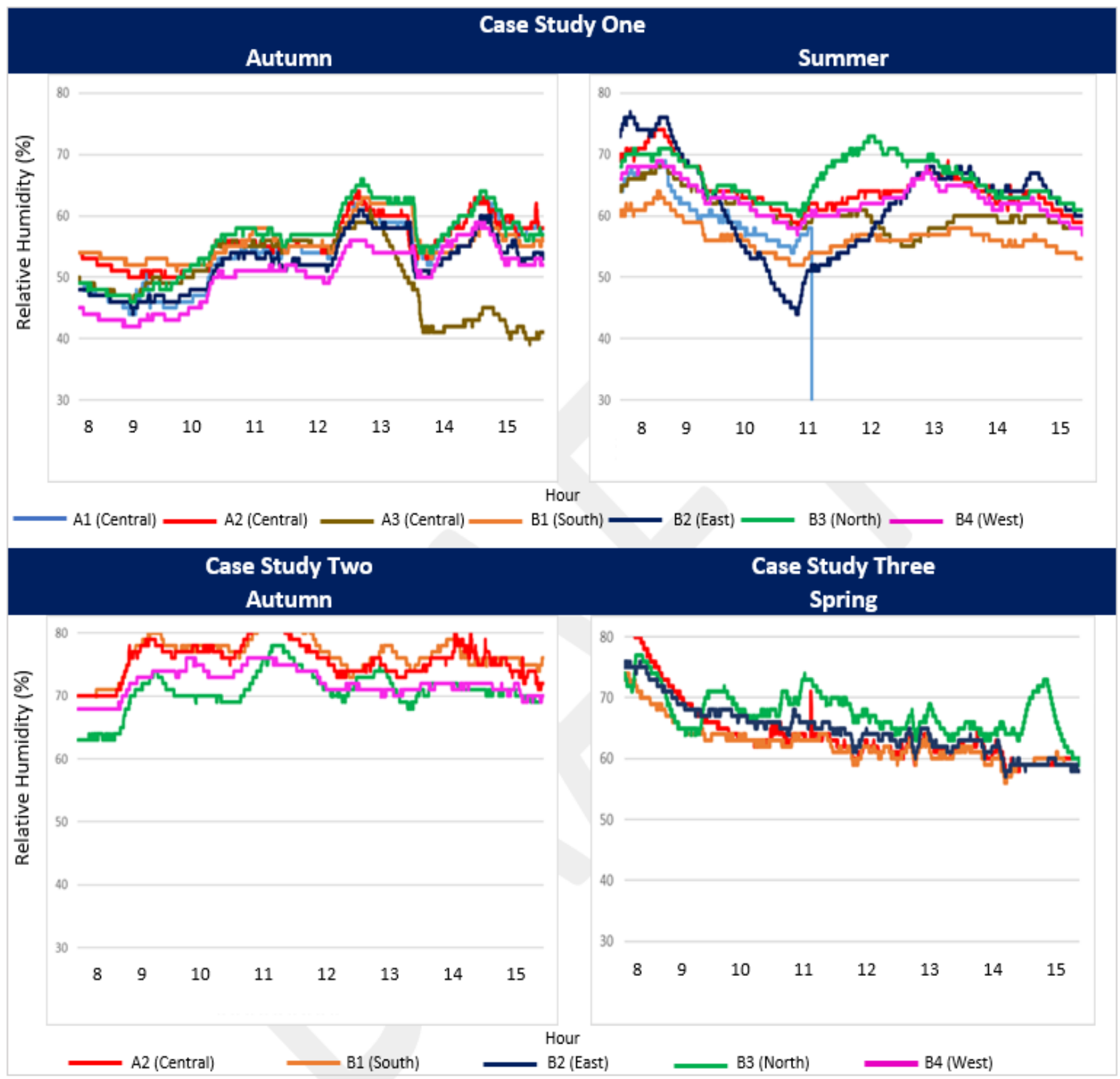

Figure 109: Line graphs showing relative humidity trends between 8 am - 3 pm during school days 


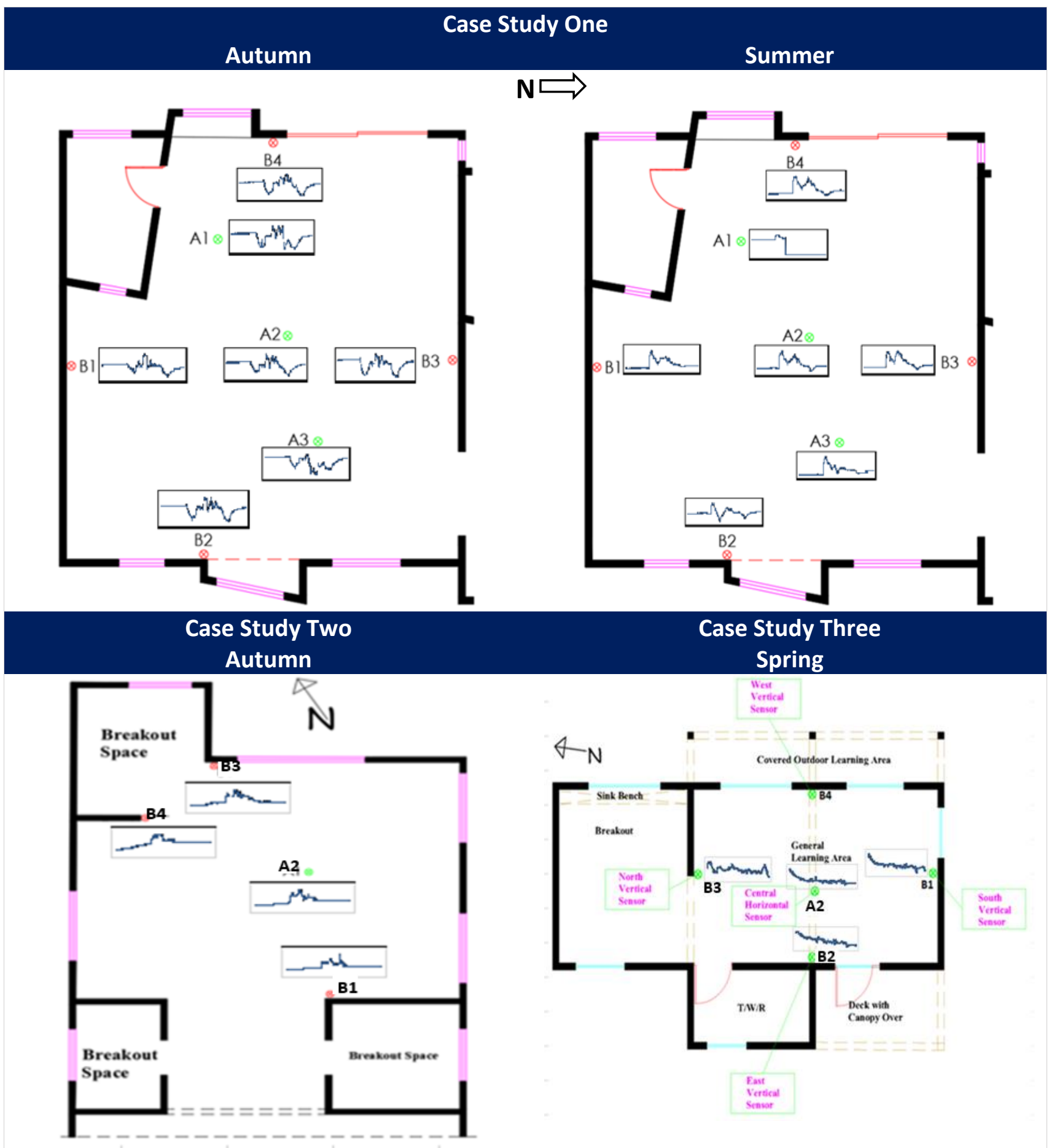

Figure 110: Sparklines showing relative humidity visual patterns between 8 am to $3 \mathrm{pm}$ in the school days 


\section{Non-School Days: Average Temperature}

Table 75: Average temperature in the non-school days from 8 am-3 pm

Non-School Days: Case Study One - Summer

The grey column is the difference between sensor (A2) and the vertical sensor with the least relationship in the ratio analysis

\begin{tabular}{|c|c|c|c|c|c|c|c|c|c|}
\hline Hour & $\begin{array}{c}\text { Central } \\
\mathbf{A} 1\left({ }^{\circ} \mathbf{C}\right)\end{array}$ & $\begin{array}{c}\text { Central } \\
\mathbf{A} 2\left({ }^{\circ} \mathbf{C}\right)\end{array}$ & $\begin{array}{c}\text { Central } \\
\mathrm{A} 3\left({ }^{\circ} \mathbf{C}\right)\end{array}$ & $\begin{array}{c}\text { South } \\
\mathrm{B} 1\left({ }^{\circ} \mathbf{C}\right)\end{array}$ & $\begin{array}{c}\text { East } \\
\mathrm{B} 2\left({ }^{\circ} \mathbf{C}\right)\end{array}$ & $\begin{array}{c}\text { North } \\
\mathrm{B} 3\left({ }^{\circ} \mathbf{C}\right)\end{array}$ & $\begin{array}{c}\text { West } \\
\mathrm{B} 4\left({ }^{\circ} \mathbf{C}\right)\end{array}$ & $\begin{array}{c}\text { Diff } \\
\left({ }^{\circ} \mathbf{C}\right)\end{array}$ & $\begin{array}{c}\text { External } \\
\mathbf{C} 1\left({ }^{\circ} \mathbf{C}\right)\end{array}$ \\
\hline $\mathbf{8} \mathbf{~ a m}$ & 22 & 20 & 20 & 21 & 22 & 20 & 21 & -1 & 16 \\
\hline $\mathbf{9} \mathbf{~ a m}$ & 22 & 21 & 23 & 22 & 23 & 21 & 22 & -1 & 17 \\
\hline $\mathbf{1 0} \mathbf{~ a m}$ & 23 & 22 & 23 & 22 & 23 & 22 & 22 & 0 & 19 \\
\hline $\mathbf{1 1} \mathbf{~ a m}$ & 23 & 22 & 22 & 24 & 24 & 22 & 22 & -2 & 20 \\
\hline $\mathbf{1 2} \mathbf{~ p m}$ & 23 & 22 & 22 & 24 & 24 & 22 & 22 & -2 & 21 \\
\hline $\mathbf{1} \mathbf{~ p m}$ & 24 & 23 & 22 & 24 & 24 & 22 & 22 & -1 & 21 \\
\hline $\mathbf{2} \mathbf{~ p m}$ & 25 & 24 & 23 & 24 & 25 & 23 & 24 & 0 & 23 \\
\hline $\mathbf{3} \mathbf{~ p m}$ & 25 & 25 & 24 & 25 & 25 & 24 & 25 & 0 & 23 \\
\hline
\end{tabular}

Table 76: Average temperature in the non-school days from $8 \mathrm{am}-3 \mathrm{pm}$

Non-School Days: Case Study One - Autumn

The grey column is the difference between sensor (A2) and the vertical sensor with the least relationship in the ratio analysis

\begin{tabular}{|c|c|c|c|c|c|c|c|c|c|}
\hline Hour & $\begin{array}{c}\text { Central } \\
\mathbf{A} \mathbf{(}\left({ }^{\circ} \mathbf{C}\right)\end{array}$ & $\begin{array}{c}\text { Central } \\
\mathbf{A} \mathbf{2}\left({ }^{\circ} \mathbf{C}\right)\end{array}$ & $\begin{array}{c}\text { Central } \\
\mathbf{A} \mathbf{3}\left({ }^{\circ} \mathbf{C}\right)\end{array}$ & $\begin{array}{c}\text { South } \\
\mathbf{B} 1\left({ }^{\circ} \mathbf{C}\right)\end{array}$ & $\begin{array}{c}\text { East } \\
\mathbf{B} 2\left({ }^{\circ} \mathbf{C}\right)\end{array}$ & $\begin{array}{c}\text { North } \\
\mathbf{B} 3\left({ }^{\circ} \mathbf{C}\right)\end{array}$ & $\begin{array}{c}\text { West } \\
\mathbf{B} 4\left({ }^{\circ} \mathbf{C}\right)\end{array}$ & $\begin{array}{c}\text { Diff } \\
\left({ }^{\circ} \mathbf{C}\right)\end{array}$ & $\begin{array}{c}\text { External } \\
\mathbf{C} \mathbf{1}\left({ }^{\circ} \mathbf{C}\right)\end{array}$ \\
\hline $\mathbf{8} \mathbf{~ a m}$ & 19 & 20 & 19 & 20 & 21 & 18 & 23 & 0 & 12 \\
\hline $\mathbf{9} \mathbf{~ a m}$ & 18 & 20 & 18 & 19 & 20 & 18 & 21 & 1 & 13 \\
\hline $\mathbf{1 0} \mathbf{~ a m}$ & 18 & 19 & 19 & 19 & 19 & 19 & 20 & 0 & 14 \\
\hline $\mathbf{1 1} \mathbf{~ a m}$ & 18 & 18 & 19 & 18 & 19 & 19 & 19 & 0 & 15 \\
\hline $\mathbf{1 2} \mathbf{~ p m}$ & 19 & 18 & 19 & 19 & 20 & 19 & 20 & -1 & 16 \\
\hline $\mathbf{1} \mathbf{~ p m}$ & 22 & 18 & 20 & 19 & 19 & 19 & 21 & -1 & 18 \\
\hline $\mathbf{2} \mathbf{~ p m}$ & 22 & 19 & 20 & 19 & 19 & 20 & 21 & 0 & 24 \\
\hline $\mathbf{3} \mathbf{~ p m}$ & 20 & 20 & 20 & 20 & 20 & 19 & 21 & 0 & 17 \\
\hline
\end{tabular}

Table 77: Average temperature in the non-school days from $8 \mathrm{am}-3 \mathrm{pm}$

Non-School Days: Case Study Three - Spring

The grey column is the difference between sensor (A2) and the vertical sensor with the least relationship in the ratio analysis

\begin{tabular}{|l|c|c|c|c|c|c|}
\hline Hour & $\begin{array}{c}\text { Central } \\
\mathrm{A} 2\left({ }^{\circ} \mathrm{C}\right)\end{array}$ & $\begin{array}{c}\text { South } \\
\mathrm{B} 1\left({ }^{\circ} \mathbf{C}\right)\end{array}$ & $\begin{array}{c}\text { East } \\
\mathrm{B} 2\left({ }^{\circ} \mathbf{C}\right)\end{array}$ & $\begin{array}{c}\text { North } \\
\mathrm{B} 3\left({ }^{\circ} \mathbf{C}\right)\end{array}$ & $\begin{array}{c}\text { Diff } \\
\left({ }^{\circ} \mathbf{C}\right)\end{array}$ & $\begin{array}{c}\text { External } \\
\mathbf{C} 1\left({ }^{\circ} \mathbf{C}\right)\end{array}$ \\
\hline $\mathbf{8} \mathbf{~ a m}$ & 17 & 17 & 14 & 14 & 0 & 7 \\
\hline $\mathbf{9} \mathbf{~ a m}$ & 19 & 20 & 15 & 15 & -1 & 9 \\
\hline $\mathbf{1 0} \mathbf{~ a m}$ & 18 & 19 & 15 & 15 & -1 & 12 \\
\hline $\mathbf{1 1} \mathbf{~ a m}$ & 19 & 22 & 16 & 19 & -3 & 15 \\
\hline $\mathbf{1 2} \mathbf{~ p m}$ & 20 & 23 & 17 & 19 & -3 & 16 \\
\hline $\mathbf{1} \mathbf{~ p m}$ & 21 & 23 & 17 & 20 & -2 & 17 \\
\hline $\mathbf{2} \mathbf{~ p m}$ & 20 & 21 & 17 & 20 & -1 & 18 \\
\hline $\mathbf{3} \mathbf{~ p m}$ & 20 & 22 & 21 & 21 & -2 & 18 \\
\hline
\end{tabular}




\section{Non-School Days: Average Relative Humidity}

Table 78: Average relative humidity in the non-school days from $8 \mathrm{am}-3 \mathrm{pm}$

Non-School Days: Case Study One - Summer

The grey column is the difference between sensor (A2) and the vertical sensor with the least relationship in the ratio analysis

\begin{tabular}{|c|c|c|c|c|c|c|c|c|c|}
\hline Hour & $\begin{array}{c}\text { Central } \\
\text { A1 (\%) }\end{array}$ & $\begin{array}{c}\text { Central } \\
\text { A2 (\%) }\end{array}$ & $\begin{array}{c}\text { Central } \\
\text { A3 (\%) }\end{array}$ & $\begin{array}{c}\text { South } \\
\text { B1 (\%) }\end{array}$ & $\begin{array}{c}\text { East } \\
\text { B2 (\%) }\end{array}$ & $\begin{array}{c}\text { North } \\
\text { B3 (\%) }\end{array}$ & $\begin{array}{c}\text { West } \\
\text { B4 (\%) }\end{array}$ & $\begin{array}{c}\text { Diff } \\
\text { (\%) }\end{array}$ & $\begin{array}{c}\text { External } \\
\text { C1 (\%) }\end{array}$ \\
\hline $\mathbf{8}$ am & 55 & 59 & 60 & 56 & 52 & 60 & 58 & 3 & 74 \\
\hline $\mathbf{9}$ am & 57 & 60 & 51 & 58 & 54 & 60 & 58 & 2 & 71 \\
\hline $\mathbf{1 0}$ am & 51 & 55 & 52 & 54 & 49 & 57 & 55 & 1 & 65 \\
\hline $\mathbf{1 1}$ am & 50 & 54 & 55 & 50 & 48 & 56 & 54 & 4 & 60 \\
\hline $\mathbf{1 2} \mathbf{~ p m}$ & 49 & 52 & 56 & 47 & 47 & 55 & 53 & 5 & 58 \\
\hline $\mathbf{1} \mathbf{~ p m}$ & 48 & 51 & 55 & 47 & 46 & 54 & 53 & 4 & 54 \\
\hline $\mathbf{2} \mathbf{~ p m}$ & 46 & 49 & 52 & 48 & 45 & 52 & 50 & 1 & 49 \\
\hline $\mathbf{3} \mathbf{~ p m}$ & 45 & 50 & 52 & 50 & 45 & 52 & 48 & 0 & 48 \\
\hline
\end{tabular}

Table 79: Average relative humidity in the non-school days from $8 \mathrm{am}-3 \mathrm{pm}$

Non-School Days: Case Study One - Autumn

The grey column is the difference between sensor (A2) and the vertical sensor with the least relationship in the ratio analysis

\begin{tabular}{|c|c|c|c|c|c|c|c|c|c|}
\hline Hour & $\begin{array}{c}\text { Central } \\
\text { A1 (\%) }\end{array}$ & $\begin{array}{c}\text { Central } \\
\text { A2 (\%) }\end{array}$ & $\begin{array}{c}\text { Central } \\
\text { A3 (\%) }\end{array}$ & $\begin{array}{c}\text { South } \\
\text { B1 (\%) }\end{array}$ & $\begin{array}{c}\text { East } \\
\text { B2 (\%) }\end{array}$ & $\begin{array}{c}\text { North } \\
\text { B3 (\%) }\end{array}$ & $\begin{array}{c}\text { West } \\
\text { B4 (\%) }\end{array}$ & $\begin{array}{c}\text { Diff } \\
\text { (\%) }\end{array}$ & $\begin{array}{c}\text { External } \\
\text { C1 (\%) }\end{array}$ \\
\hline $\mathbf{8} \mathbf{~ a m}$ & 55 & 56 & 57 & 49 & 49 & 58 & 49 & 7 & 81 \\
\hline $\mathbf{9} \mathbf{~ a m}$ & 56 & 55 & 56 & 54 & 49 & 58 & 49 & 1 & 74 \\
\hline $\mathbf{1 0} \mathbf{~ a m}$ & 60 & 59 & 56 & 57 & 54 & 58 & 51 & 2 & 68 \\
\hline $\mathbf{1 1} \mathbf{~ a m}$ & 58 & 58 & 55 & 56 & 53 & 56 & 53 & 2 & 66 \\
\hline $\mathbf{1 2} \mathbf{~ p m}$ & 54 & 56 & 55 & 56 & 53 & 57 & 53 & 0 & 63 \\
\hline $\mathbf{1} \mathbf{~ p m}$ & 45 & 53 & 53 & 56 & 53 & 54 & 49 & -3 & 55 \\
\hline $\mathbf{2} \mathbf{~ p m}$ & 48 & 52 & 52 & 55 & 54 & 53 & 46 & -3 & 41 \\
\hline $\mathbf{3} \mathbf{~ p m}$ & 50 & 52 & 52 & 54 & 51 & 53 & 44 & -2 & 60 \\
\hline
\end{tabular}

Table 80: Average relative humidity in the non-school days from $8 \mathrm{am}-3 \mathrm{pm}$

Non-School Days: Case Study Three - Spring

The grey column is the difference between sensor (A2) and the vertical sensor with the least relationship in the ratio analysis

\begin{tabular}{|l|c|c|c|c|c|c|}
\hline Hour & $\begin{array}{c}\text { Central } \\
\text { A2 (\%) }\end{array}$ & $\begin{array}{c}\text { South } \\
\text { B1 (\%) }\end{array}$ & $\begin{array}{c}\text { East } \\
\text { B2 (\%) }\end{array}$ & $\begin{array}{c}\text { North } \\
\text { B3 (\%) }\end{array}$ & Diff & $\begin{array}{c}\text { External } \\
\text { C1 (\%) }\end{array}$ \\
\hline $\mathbf{8}$ am & 55 & 55 & 66 & 66 & 0 & 94 \\
\hline $\mathbf{9}$ am & 51 & 49 & 65 & 65 & 2 & 88 \\
\hline $\mathbf{1 0}$ am & 52 & 50 & 65 & 65 & 2 & 77 \\
\hline $\mathbf{1 1}$ am & 53 & 46 & 64 & 53 & 7 & 59 \\
\hline $\mathbf{1 2}$ pm & 51 & 44 & 60 & 52 & 7 & 52 \\
\hline $\mathbf{1}$ pm & 49 & 43 & 60 & 49 & 6 & 52 \\
\hline $\mathbf{2}$ pm & 49 & 46 & 60 & 49 & 3 & 49 \\
\hline $\mathbf{3}$ pm & 50 & 46 & 50 & 49 & 4 & 48 \\
\hline
\end{tabular}




\section{School Days: Average Temperature}

Table 81: Average temperature in the school days from $8 \mathrm{am}-3 \mathrm{pm}$

School Days: Case Study One - Summer

The grey column is the difference between sensor (A2) and the vertical sensor with the least relationship in the ratio analysis

\begin{tabular}{|c|c|c|c|c|c|c|c|c|c|}
\hline Hour & $\begin{array}{l}\text { Central } \\
\text { A1 }\left({ }^{\circ} \mathrm{C}\right)\end{array}$ & $\begin{array}{l}\text { Central } \\
\text { A2 }\left({ }^{\circ} \mathrm{C}\right)\end{array}$ & $\begin{array}{l}\text { Central } \\
\text { A3 }\left({ }^{\circ} \mathrm{C}\right)\end{array}$ & $\begin{array}{l}\text { South } \\
\text { B1 }\left({ }^{\circ} \mathrm{C}\right)\end{array}$ & $\begin{array}{c}\text { East } \\
\text { B2 }\left({ }^{\circ} \mathrm{C}\right)\end{array}$ & $\begin{array}{l}\text { North } \\
\text { B3 }\left({ }^{\circ} \mathrm{C}\right)\end{array}$ & $\begin{array}{l}\text { West } \\
\text { B4 }\left({ }^{\circ} \mathrm{C}\right)\end{array}$ & $\begin{array}{l}\text { Diff } \\
\left({ }^{\circ} \mathrm{C}\right) \\
\end{array}$ & $\begin{array}{c}\text { External } \\
\mathrm{C} 1\left({ }^{\circ} \mathrm{C}\right)\end{array}$ \\
\hline $8 \mathrm{am}$ & 22 & 20 & 20 & 22 & 22 & 21 & 21 & -2 & 17 \\
\hline 9 am & 24 & 22 & 24 & 23 & 24 & 23 & 23 & -1 & 18 \\
\hline $10 \mathrm{am}$ & 23 & 24 & 25 & 24 & 25 & 23 & 24 & 0 & 20 \\
\hline $11 \mathrm{am}$ & 0 & 23 & 25 & 24 & 25 & 23 & 24 & -1 & 20 \\
\hline $12 \mathrm{pm}$ & 0 & 23 & 23 & 25 & 25 & 23 & 23 & -2 & 21 \\
\hline $1 \mathrm{pm}$ & 0 & 23 & 23 & 25 & 26 & 24 & 24 & -2 & 22 \\
\hline $2 \mathrm{pm}$ & 0 & 24 & 23 & 25 & 25 & 24 & 25 & -1 & 21 \\
\hline $3 \mathrm{pm}$ & 0 & 26 & 25 & 26 & 26 & 25 & 26 & 0 & 22 \\
\hline
\end{tabular}

Table 82: Average temperature in the school days from $8 \mathrm{am}-3 \mathrm{pm}$

\section{School Days: Case Study One - Autumn}

The grey column is the difference between sensor (A2) and the vertical sensor with the least relationship in the ratio analysis

\begin{tabular}{|c|c|c|c|c|c|c|c|c|c|}
\hline Hour & $\begin{array}{c}\text { Central } \\
\mathbf{A} 1\left(^{\circ} \mathbf{C}\right)\end{array}$ & $\begin{array}{c}\text { Central } \\
\mathbf{A} 2\left({ }^{\circ} \mathbf{C}\right)\end{array}$ & $\begin{array}{c}\text { Central } \\
\mathbf{A} 3\left({ }^{\circ} \mathbf{C}\right)\end{array}$ & $\begin{array}{c}\text { South } \\
\mathbf{B} 1\left({ }^{\circ} \mathbf{C}\right)\end{array}$ & $\begin{array}{c}\text { East } \\
\mathbf{B} 2\left({ }^{\circ} \mathbf{C}\right)\end{array}$ & $\begin{array}{c}\text { North } \\
\mathbf{B} 3\left({ }^{\circ} \mathbf{C}\right)\end{array}$ & $\begin{array}{c}\text { West } \\
\mathbf{B} 4\left({ }^{\circ} \mathbf{C}\right)\end{array}$ & $\begin{array}{c}\text { Diff } \\
\left({ }^{\circ} \mathbf{C}\right)\end{array}$ & $\begin{array}{c}\text { External } \\
\mathbf{C} 1\left({ }^{\circ} \mathbf{C}\right)\end{array}$ \\
\hline $\mathbf{8} \mathbf{~ a m}$ & 23 & 21 & 22 & 20 & 22 & 22 & 24 & 1 & 11 \\
\hline $\mathbf{9} \mathbf{~ a m}$ & 23 & 21 & 21 & 21 & 22 & 21 & 24 & 0 & 11 \\
\hline $\mathbf{1 0} \mathbf{~ a m}$ & 20 & 20 & 20 & 20 & 20 & 20 & 22 & 0 & 12 \\
\hline $\mathbf{1 1} \mathbf{~ a m}$ & 20 & 19 & 19 & 20 & 20 & 19 & 21 & -1 & 13 \\
\hline $\mathbf{1 2} \mathbf{~ p m}$ & 21 & 21 & 22 & 20 & 21 & 20 & 22 & 1 & 12 \\
\hline $\mathbf{1} \mathbf{~ p m}$ & 19 & 19 & 20 & 20 & 20 & 19 & 20 & -1 & 13 \\
\hline $\mathbf{2} \mathbf{~ p m}$ & 18 & 18 & 19 & 19 & 19 & 19 & 20 & -1 & 13 \\
\hline $\mathbf{3} \mathbf{~ p m}$ & 21 & 19 & 22 & 19 & 19 & 19 & 21 & 0 & 16 \\
\hline
\end{tabular}

Table 83: Average temperature in the school days from 8 am-3 pm

\begin{tabular}{|c|c|c|c|c|c|c|c|c|c|c|c|c|c|}
\hline \multicolumn{14}{|c|}{ School Days } \\
\hline \multicolumn{7}{|c|}{ Case Study Two - Autumn } & \multicolumn{7}{|c|}{ Case Study Three - Spring } \\
\hline \multicolumn{14}{|c|}{ The grey column is the difference between sensor (A2) and the vertical sensor with the least relationship in the ratio analysis } \\
\hline $8 \mathrm{am}$ & 20 & 19 & 18 & 19 & 1 & 16 & 8 am & 17 & 18 & 17 & 17 & -1 & 9 \\
\hline $9 \mathrm{am}$ & 20 & 19 & 18 & 19 & 1 & 17 & $9 \mathrm{am}$ & 20 & 20 & 19 & 19 & 0 & 12 \\
\hline 11 am & 21 & 19 & 19 & 19 & 2 & 18 & $11 \mathrm{am}$ & 20 & 20 & 20 & 19 & 0 & 15 \\
\hline $12 \mathrm{pm}$ & 21 & 19 & 19 & 19 & 2 & 18 & $12 \mathrm{pm}$ & 20 & 20 & 19 & 19 & 0 & 16 \\
\hline $1 \mathrm{pm}$ & 21 & 19 & 19 & 19 & 2 & 18 & $1 \mathrm{pm}$ & 20 & 20 & 20 & 19 & 0 & 18 \\
\hline 2 pm & 21 & 19 & 19 & 19 & 2 & 18 & 2 pm & 19 & 19 & 19 & 17 & 0 & 19 \\
\hline
\end{tabular}




\section{School Days: Average Relative Humidity}

Table 84: Average relative humidity in the school days from 8 am-3 pm

School Days: Case Study One - Summer

The grey column is the difference between sensor (A2) and the vertical sensor with the least relationship in the ratio analysis

\begin{tabular}{|c|c|c|c|c|c|c|c|c|c|}
\hline Hour & $\begin{array}{c}\text { Central } \\
\text { A1 (\%) }\end{array}$ & $\begin{array}{c}\text { Central } \\
\text { A2 (\%) }\end{array}$ & $\begin{array}{c}\text { Central } \\
\text { A3 (\%) }\end{array}$ & $\begin{array}{c}\text { South } \\
\text { B1 (\%) }\end{array}$ & $\begin{array}{c}\text { East } \\
\text { B2 (\%) }\end{array}$ & $\begin{array}{c}\text { North } \\
\text { B3 (\%) }\end{array}$ & $\begin{array}{c}\text { West } \\
\text { B4 (\%) }\end{array}$ & $\begin{array}{c}\text { Diff } \\
\text { (\%) }\end{array}$ & $\begin{array}{c}\text { External } \\
\text { C1 (\%) }\end{array}$ \\
\hline $\mathbf{8} \mathbf{~ a m}$ & 66 & 71 & 66 & 61 & 71 & 70 & 68 & 10 & 89 \\
\hline $\mathbf{9} \mathbf{~ a m}$ & 60 & 65 & 63 & 57 & 62 & 65 & 63 & 8 & 83 \\
\hline $\mathbf{1 0} \mathbf{~ a m}$ & 52 & 61 & 59 & 53 & 49 & 62 & 59 & 8 & 75 \\
\hline $\mathbf{1 1} \mathbf{~ a m}$ & 0 & 63 & 60 & 56 & 55 & 65 & 61 & 7 & 76 \\
\hline $\mathbf{1 2} \mathbf{~ p m}$ & 0 & 66 & 57 & 57 & 65 & 65 & 65 & 9 & 73 \\
\hline $\mathbf{1} \mathbf{~ p m}$ & 0 & 64 & 60 & 57 & 65 & 65 & 63 & 7 & 68 \\
\hline $\mathbf{2} \mathbf{~ p m}$ & 0 & 62 & 59 & 55 & 64 & 63 & 60 & 7 & 71 \\
\hline $\mathbf{3} \mathbf{~ p m}$ & 0 & 58 & 58 & 53 & 60 & 61 & 57 & 5 & 70 \\
\hline
\end{tabular}

Table 85: Average relative humidity in the school days from $8 \mathrm{am}-3 \mathrm{pm}$

\section{School Days: Case Study One - Autumn}

The grey column is the difference between sensor (A2) and the vertical sensor with the least relationship in the ratio analysis

\begin{tabular}{|c|c|c|c|c|c|c|c|c|c|}
\hline Hour & $\begin{array}{c}\text { Central } \\
\text { A1 (\%) }\end{array}$ & $\begin{array}{c}\text { Central } \\
\text { A2 (\%) }\end{array}$ & $\begin{array}{c}\text { Central } \\
\text { A3 (\%) }\end{array}$ & $\begin{array}{c}\text { South } \\
\text { B1 (\%) }\end{array}$ & $\begin{array}{c}\text { East } \\
\text { B2 (\%) }\end{array}$ & $\begin{array}{c}\text { North } \\
\text { B3 (\%) }\end{array}$ & $\begin{array}{c}\text { West } \\
\text { B4 (\%) }\end{array}$ & $\begin{array}{c}\text { Diff } \\
\text { (\%) }\end{array}$ & $\begin{array}{c}\text { External } \\
\text { C1 (\%) }\end{array}$ \\
\hline $\mathbf{8}$ am & 47 & 52 & 48 & 53 & 47 & 48 & 44 & -1 & 87 \\
\hline $\mathbf{9} \mathbf{~ a m}$ & 47 & 51 & 50 & 52 & 47 & 50 & 45 & -1 & 86 \\
\hline $\mathbf{1 0} \mathbf{~ a m}$ & 54 & 55 & 55 & 56 & 53 & 57 & 51 & -1 & 85 \\
\hline $\mathbf{1 1} \mathbf{~ a m}$ & 55 & 55 & 56 & 55 & 53 & 57 & 51 & 0 & 82 \\
\hline $\mathbf{1 2} \mathbf{~ p m}$ & 60 & 61 & 57 & 62 & 59 & 63 & 55 & -1 & 82 \\
\hline $\mathbf{1} \mathbf{~ p m}$ & 57 & 57 & 47 & 55 & 53 & 56 & 54 & 2 & 78 \\
\hline $\mathbf{2} \mathbf{~ p m}$ & 60 & 60 & 51 & 57 & 55 & 60 & 54 & 3 & 77 \\
\hline $\mathbf{3} \mathbf{~ p m}$ & 53 & 58 & 49 & 56 & 55 & 58 & 52 & 2 & 65 \\
\hline
\end{tabular}

Table 86: Average relative humidity in the school days from $8 \mathrm{am}-3 \mathrm{pm}$

\begin{tabular}{|c|c|c|c|c|c|c|c|c|c|c|c|c|c|}
\hline \multicolumn{14}{|c|}{ School Days - Tuesday } \\
\hline \multicolumn{7}{|c|}{ Case Study Two - Autumn } & \multicolumn{7}{|c|}{ Case Study Three - Spring } \\
\hline \multicolumn{14}{|c|}{ The grey column is the difference between sensor (A2) and the vertical sensor with the least relationship in the ratio analysis } \\
\hline Hour & $\begin{array}{l}\text { Central } \\
\text { A2 (\%) }\end{array}$ & $\begin{array}{l}\text { South } \\
\text { B1 (\%) }\end{array}$ & $\begin{array}{c}\text { West } \\
\text { B4 (\%) }\end{array}$ & $\begin{array}{l}\text { North } \\
\text { B3 (\%) }\end{array}$ & $\begin{array}{l}\text { Diff } \\
(\%)\end{array}$ & $\begin{array}{c}\text { External } \\
\text { C1 (\%) }\end{array}$ & Hour & $\begin{array}{l}\text { Central } \\
\text { A2 (\%) }\end{array}$ & $\begin{array}{l}\text { South } \\
\text { B1 (\%) }\end{array}$ & $\begin{array}{c}\text { East } \\
\text { B2 (\%) }\end{array}$ & $\begin{array}{l}\text { North } \\
\text { B3 (\%) }\end{array}$ & $\begin{array}{l}\text { Diff } \\
(\%)\end{array}$ & $\begin{array}{l}\text { External } \\
\text { C1 (\%) }\end{array}$ \\
\hline 8 am & 64 & 69 & 72 & 72 & -5 & 83 & $8 \mathrm{am}$ & 76 & 69 & 71 & 72 & 7 & 82 \\
\hline 9 am & 64 & 69 & 72 & 72 & -5 & 83 & $9 \mathrm{am}$ & 65 & 64 & 68 & 67 & 1 & 70 \\
\hline $10 \mathrm{am}$ & 64 & 69 & 72 & 71 & -5 & 78 & $10 \mathrm{am}$ & 64 & 63 & 70 & 66 & 1 & 61 \\
\hline $11 \mathrm{am}$ & 64 & 69 & 72 & 71 & -5 & 72 & $11 \mathrm{am}$ & 62 & 61 & 68 & 64 & 1 & 60 \\
\hline $12 \mathrm{pm}$ & 64 & 69 & 71 & 71 & -5 & 73 & $12 \mathrm{pm}$ & 62 & 61 & 66 & 63 & 1 & 53 \\
\hline $1 \mathrm{pm}$ & 64 & 69 & 71 & 71 & -5 & 71 & $1 \mathrm{pm}$ & 61 & 60 & 65 & 62 & 1 & 40 \\
\hline 2 pm & 64 & 69 & 71 & 71 & -5 & 71 & $2 \mathrm{pm}$ & 59 & 59 & 66 & 59 & 0 & 35 \\
\hline 3 pm & 64 & 69 & 71 & 71 & -5 & 70 & 3 pm & 60 & 57 & 58 & 58 & 3 & 35 \\
\hline
\end{tabular}


Appendix 8: Sound Level Measurement Results

This part of the appendix shows the supplementary figures moved from Chapter 7 for brevity

School Days

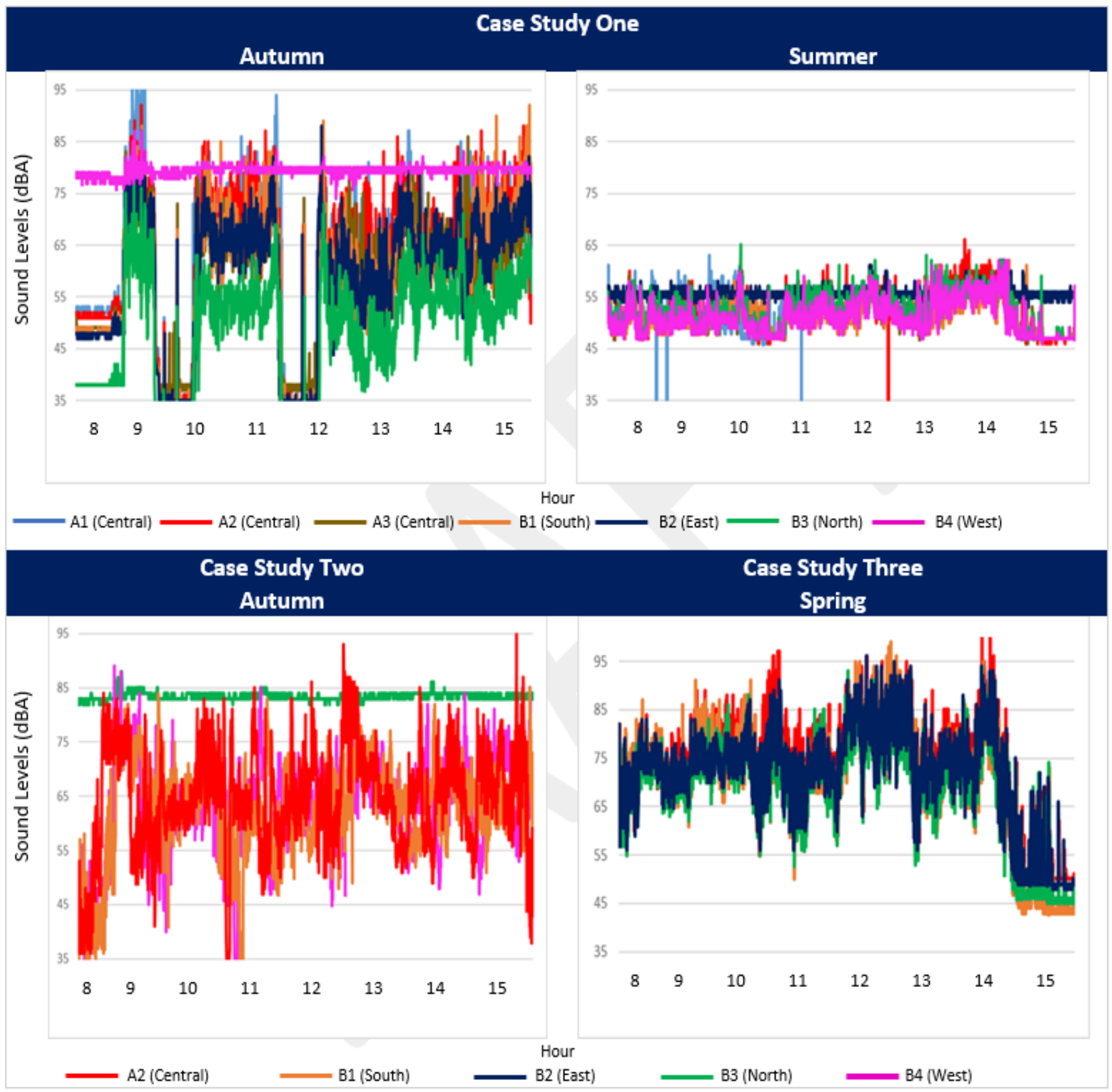

Figure 111: Line graphs showing sound levels between 8 am -3 pm during school days 


\section{School Days}
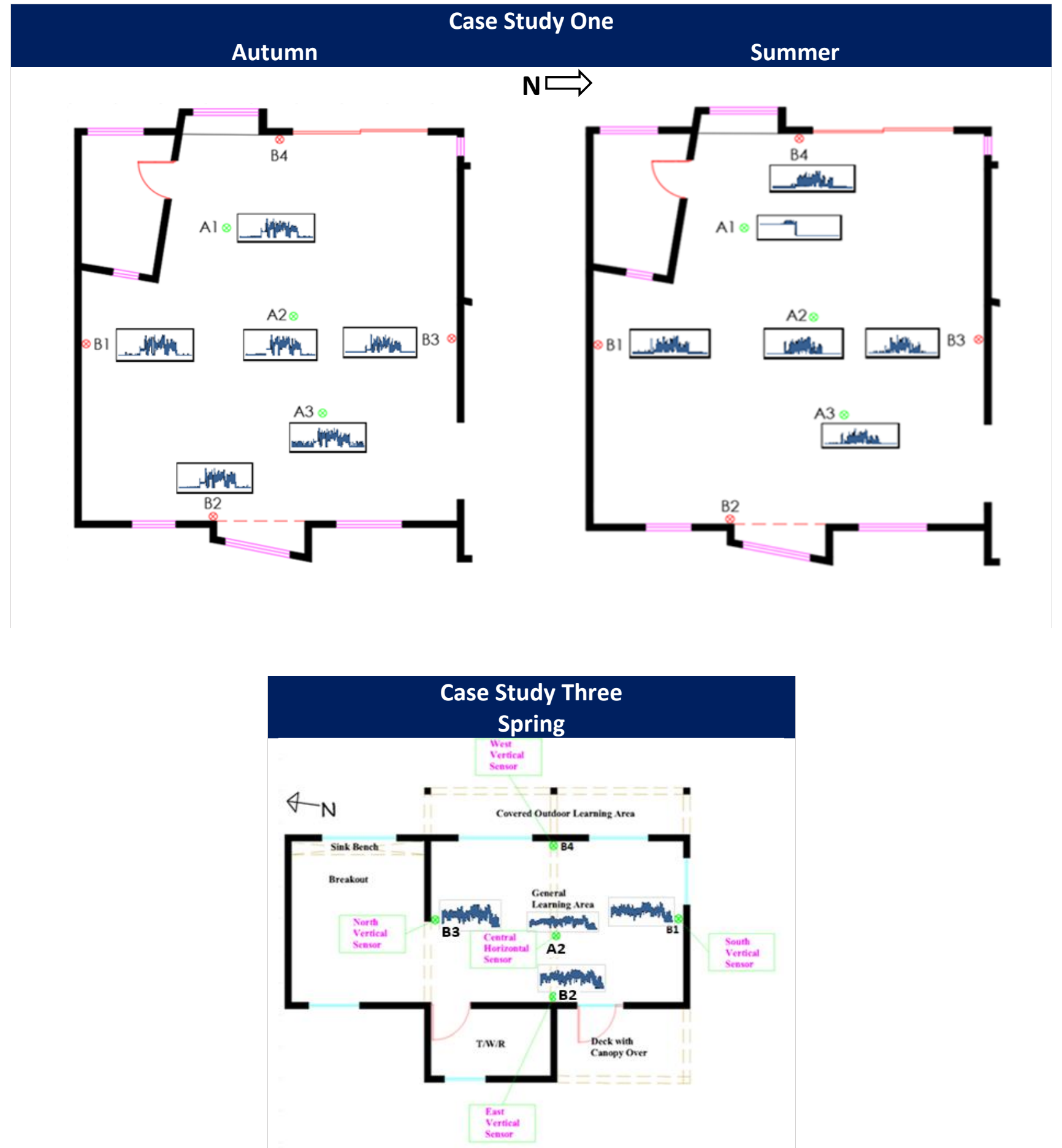

Figure 112: Sparklines showing sound level visual patterns between 8 am to $3 \mathrm{pm}$ in the school days 


\section{School Days}

Table 87: Average sound levels in the school days from 8 am-3 pm

Case Study One Autumn

The grey column is the difference between sensor (A2) and the vertical sensor with the least relationship in the ratio analysis

\begin{tabular}{|c|c|c|c|c|c|c|c|c|}
\hline Hour & $\begin{array}{c}\text { Central } \\
\text { A1 (dBA) }\end{array}$ & $\begin{array}{c}\text { Central } \\
\text { A2 (dBA) }\end{array}$ & $\begin{array}{c}\text { Central } \\
\text { A3 (dBA) }\end{array}$ & $\begin{array}{c}\text { South } \\
\text { B1 (dBA) }\end{array}$ & $\begin{array}{c}\text { East } \\
\text { B2 (dBA) }\end{array}$ & $\begin{array}{c}\text { North } \\
\text { B3 (dBA) }\end{array}$ & $\begin{array}{c}\text { Diff } \\
\text { (dBA) }\end{array}$ & $\begin{array}{c}\text { External } \\
\text { C1 (dBA) }\end{array}$ \\
\hline $\mathbf{8} \mathbf{~ a m}$ & 59 & 59 & 57 & 57 & 56 & 56 & 2 & 59 \\
\hline $\mathbf{9} \mathbf{~ a m}$ & 51 & 50 & 50 & 49 & 49 & 49 & 1 & 51 \\
\hline $\mathbf{1 0} \mathbf{~ a m}$ & 70 & 70 & 68 & 69 & 68 & 67 & 1 & 70 \\
\hline $\mathbf{1 1} \mathbf{~ a m}$ & 49 & 48 & 49 & 47 & 47 & 47 & 1 & 49 \\
\hline $\mathbf{1 2} \mathbf{~ p m}$ & 60 & 61 & 60 & 59 & 59 & 58 & 2 & 60 \\
\hline $\mathbf{1} \mathbf{~ p m}$ & 67 & 67 & 65 & 65 & 65 & 65 & 2 & 67 \\
\hline $\mathbf{2} \mathbf{~ p m}$ & 69 & 71 & 69 & 70 & 68 & 68 & 1 & 69 \\
\hline $\mathbf{3} \mathbf{~ p m}$ & 49 & 48 & 50 & 48 & 48 & 48 & 0 & 49 \\
\hline
\end{tabular}

Table 88: Average sound levels in the school days from $8 \mathrm{am}-3 \mathrm{pm}$

Case Study One- Summer

The grey column is the difference between sensor (A2) and the vertical sensor with the least relationship in the ratio analysis

\begin{tabular}{|c|c|c|c|c|c|c|c|c|}
\hline Hour & $\begin{array}{c}\text { Central } \\
\text { A1 (dBA) }\end{array}$ & $\begin{array}{c}\text { Central } \\
\text { A2 (dBA) }\end{array}$ & $\begin{array}{c}\text { Central } \\
\text { A3 (dBA) }\end{array}$ & $\begin{array}{c}\text { South } \\
\text { B1 (dBA) }\end{array}$ & $\begin{array}{c}\text { North } \\
\text { B3 (dBA) }\end{array}$ & $\begin{array}{c}\text { West } \\
\text { B4 (dBA) }\end{array}$ & $\begin{array}{c}\text { Diff } \\
\text { (dBA) }\end{array}$ & $\begin{array}{c}\text { External } \\
\text { C1 (dBA) }\end{array}$ \\
\hline $\mathbf{8} \mathbf{~ a m}$ & 58 & 57 & 56 & 56 & 56 & 57 & 1 & 52 \\
\hline $\mathbf{9} \mathbf{~ a m}$ & 58 & 58 & 57 & 57 & 56 & 59 & 1 & 52 \\
\hline $\mathbf{1 0} \mathbf{~ a m}$ & 56 & 57 & 57 & 57 & 56 & 58 & 0 & 50 \\
\hline $\mathbf{1 1} \mathbf{~ a m}$ & 0 & 59 & 58 & 58 & 58 & 58 & 1 & 0 \\
\hline $\mathbf{1 2} \mathbf{~ p m}$ & 0 & 58 & 58 & 58 & 57 & 61 & 0 & 0 \\
\hline $\mathbf{1} \mathbf{~ p m}$ & 0 & 63 & 61 & 61 & 61 & 58 & 2 & 0 \\
\hline $\mathbf{2} \mathbf{~ p m}$ & 0 & 55 & 54 & 54 & 54 & 57 & 1 & 0 \\
\hline $\mathbf{3} \mathbf{~ p m}$ & 0 & 55 & 55 & 56 & 54 & 58 & -1 & 0 \\
\hline
\end{tabular}

Table 89: Average sound levels in the school days from $8 \mathrm{am}-3 \mathrm{pm}$

\begin{tabular}{|c|c|c|c|c|c|}
\hline \multicolumn{7}{|c|}{ Case Study Three - Spring } \\
\hline Hour & $\begin{array}{c}\text { South } \\
\text { B1 (dBA) }\end{array}$ & $\begin{array}{c}\text { East } \\
\text { B2 (dBA) }\end{array}$ & $\begin{array}{c}\text { North } \\
\text { B3 (dBA) }\end{array}$ & $\begin{array}{c}\text { Diff } \\
\text { (dBA) }\end{array}$ \\
\hline $\mathbf{8}$ am & 73 & 73 & 70 & - \\
\hline $\mathbf{9}$ am & 79 & 76 & 74 & - \\
\hline $\mathbf{1 0}$ am & 76 & 71 & 69 & - \\
\hline $\mathbf{1 1}$ am & 80 & 77 & 76 & - \\
\hline $\mathbf{1 2} \mathbf{~ p m}$ & 79 & 77 & 74 & - \\
\hline $\mathbf{1} \mathbf{~ p m}$ & 78 & 74 & 73 & - \\
\hline $\mathbf{2} \mathbf{~ p m}$ & 53 & 48 & 50 & - \\
\hline $\mathbf{3} \mathbf{~ p m}$ & 51 & 44 & 47 & - \\
\hline
\end{tabular}


Appendix 9: Carbon dioxide Measurement Results

This part of the appendix shows the supplementary figures moved from Chapter 8 for brevity School Days

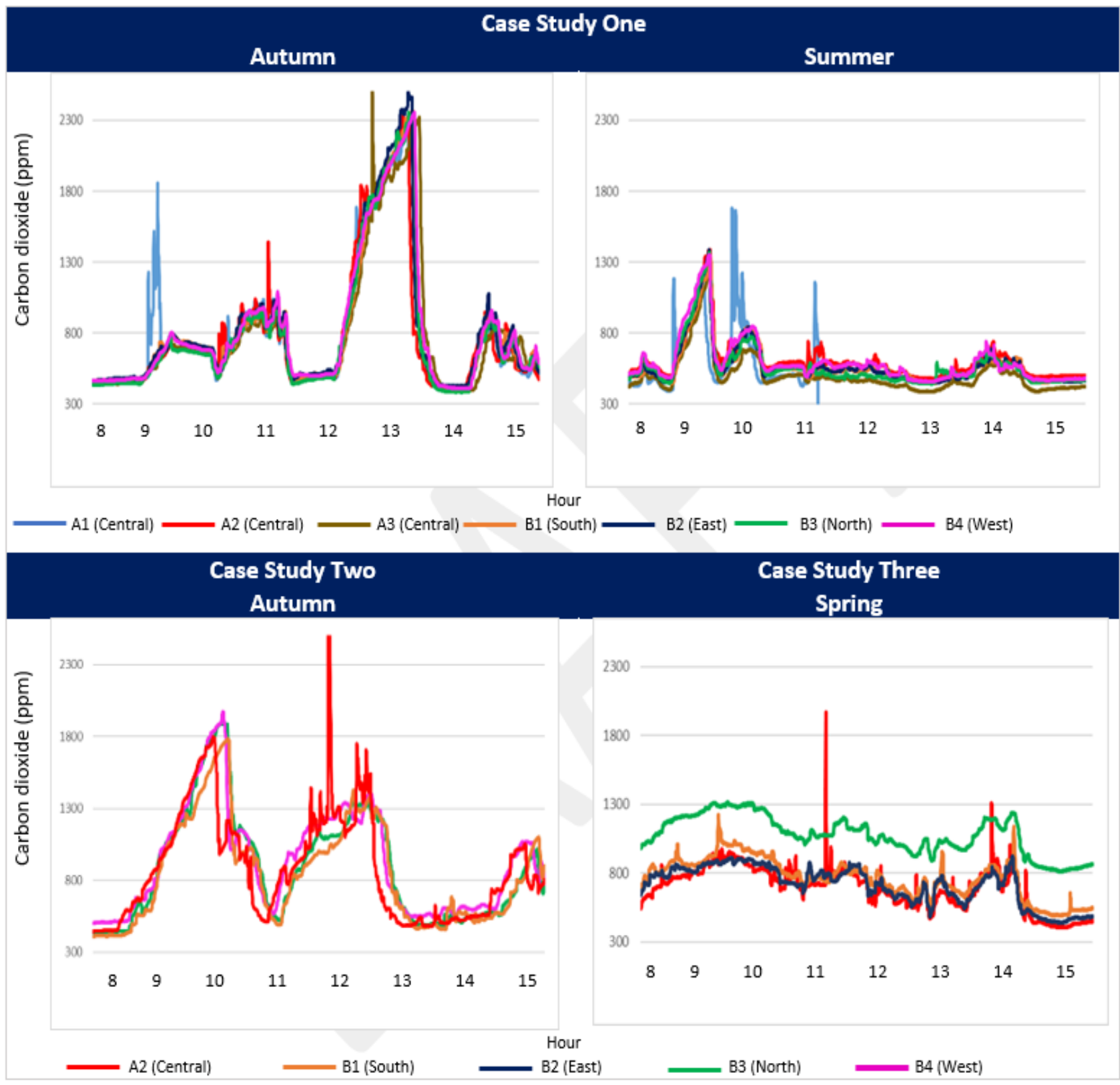

Figure 113: Line graphs showing $\mathrm{CO} 2$ trends between 8 am - 3 pm during school days 


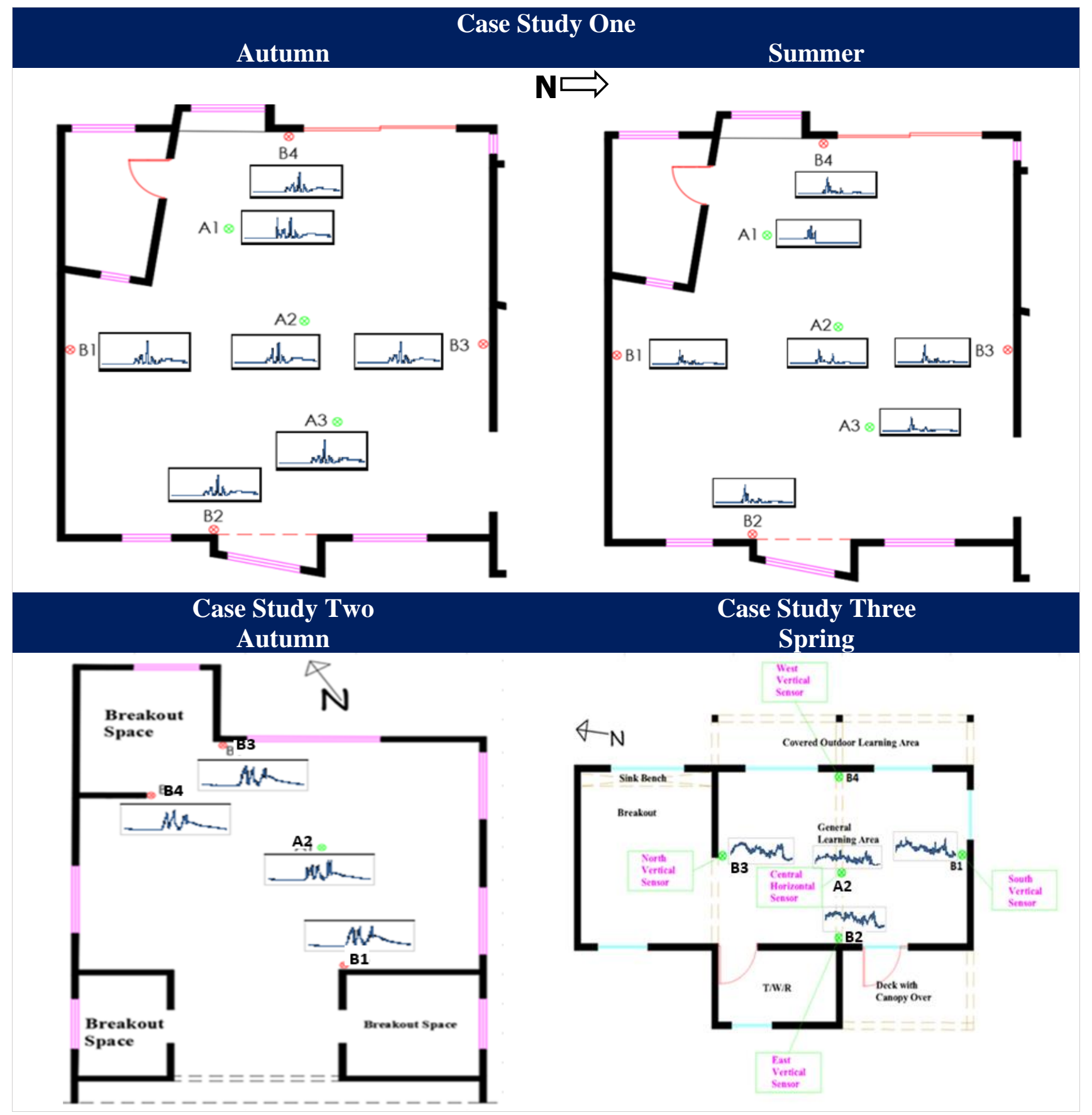

Figure 114: Sparklines showing $\mathrm{CO}_{2}$ visual patterns between 8 am to $3 \mathrm{pm}$ in the school days 


\section{School Days}

Table 90: Average $\mathrm{CO}_{2}$ levels in the school days from $8 \mathrm{am}-3 \mathrm{pm}$

Case Study One Autumn

The grey column is the difference between sensor (A2) and the vertical sensor with the least relationship in the ratio analysis

\begin{tabular}{|c|c|c|c|c|c|c|c|c|}
\hline Hour & $\begin{array}{c}\text { Central } \\
\text { A1 (ppm) }\end{array}$ & $\begin{array}{c}\text { Central } \\
\text { A2 (ppm) }\end{array}$ & $\begin{array}{c}\text { Central } \\
\text { A3 (ppm) }\end{array}$ & $\begin{array}{c}\text { South } \\
\text { B1 (ppm) }\end{array}$ & $\begin{array}{c}\text { East } \\
\text { B2 (ppm) }\end{array}$ & $\begin{array}{c}\text { North } \\
\text { B3 (ppm) }\end{array}$ & $\begin{array}{c}\text { West } \\
\text { B4 (ppm) }\end{array}$ & $\begin{array}{c}\text { Diff } \\
\text { (ppm) }\end{array}$ \\
\hline $\mathbf{8} \mathbf{~ a m}$ & 549 & 472 & 466 & 492 & 497 & 462 & 486 & -25 \\
\hline $\mathbf{9} \mathbf{~ a m}$ & 681 & 669 & 656 & 695 & 694 & 646 & 686 & -25 \\
\hline $\mathbf{1 0} \mathbf{~ a m}$ & 841 & 863 & 793 & 837 & 872 & 827 & 866 & -9 \\
\hline $\mathbf{1 1} \mathbf{~ a m}$ & 525 & 533 & 523 & 543 & 555 & 525 & 567 & -22 \\
\hline $\mathbf{1 2} \mathbf{~ p m}$ & 1717 & 1816 & 1633 & 1731 & 1810 & 1744 & 1737 & 6 \\
\hline $\mathbf{1} \mathbf{~ p m}$ & 676 & 567 & 850 & 687 & 680 & 703 & 761 & -113 \\
\hline $\mathbf{2} \mathbf{~ p m}$ & 647 & 668 & 661 & 709 & 710 & 689 & 704 & -42 \\
\hline $\mathbf{3} \mathbf{~ p m}$ & 445 & 454 & 461 & 468 & 471 & 442 & 467 & -17 \\
\hline
\end{tabular}

Table 91: Average $\mathrm{CO}_{2}$ levels in the school days from $8 \mathrm{am}-3 \mathrm{pm}$

Case Study One- Summer

The grey column is the difference between sensor (A2) and the vertical sensor with the least relationship in the ratio analysis

\begin{tabular}{|c|c|c|c|c|c|c|c|c|}
\hline Hour & $\begin{array}{c}\text { Central } \\
\text { A1 (ppm) }\end{array}$ & $\begin{array}{c}\text { Central } \\
\text { A2 (ppm) }\end{array}$ & $\begin{array}{c}\text { Central } \\
\text { A3 (ppm) }\end{array}$ & $\begin{array}{c}\text { South } \\
\text { B1 (ppm) }\end{array}$ & $\begin{array}{c}\text { East } \\
\text { B2 (ppm) }\end{array}$ & $\begin{array}{c}\text { North } \\
\text { B3 (ppm) }\end{array}$ & $\begin{array}{c}\text { West } \\
\text { B4 (ppm) }\end{array}$ & $\begin{array}{c}\text { Diff } \\
\text { (ppm) }\end{array}$ \\
\hline $\mathbf{8} \mathbf{~ a m}$ & 557 & 600 & 522 & 561 & 581 & 598 & 636 & 19 \\
\hline $\mathbf{9} \mathbf{~ a m}$ & 806 & 860 & 711 & 813 & 812 & 808 & 863 & 48 \\
\hline $\mathbf{1 0} \mathbf{~ a m}$ & 470 & 604 & 490 & 550 & 549 & 543 & 564 & 55 \\
\hline $\mathbf{1 1} \mathbf{~ a m}$ & 0 & 582 & 465 & 534 & 541 & 494 & 573 & 41 \\
\hline $\mathbf{1 2} \mathbf{~ p m}$ & 0 & 501 & 410 & 469 & 468 & 476 & 485 & 33 \\
\hline $\mathbf{1} \mathbf{~ p m}$ & 0 & 604 & 506 & 555 & 559 & 568 & 577 & 45 \\
\hline $\mathbf{2} \mathbf{~ p m}$ & 0 & 501 & 412 & 472 & 467 & 468 & 479 & 34 \\
\hline $\mathbf{3} \mathbf{~ p m}$ & 0 & 514 & 433 & 480 & 485 & 485 & 493 & 29 \\
\hline
\end{tabular}

Table 92: Average $\mathrm{CO}_{2}$ levels in the school days from $8 \mathrm{am}-3 \mathrm{pm}$

\begin{tabular}{|l} 
Case Study Three - Spring \\
\hline \\
The grey column is the difference between sensor (A2) and the vertical sensor with the least relationship in the ratio analysis \\
$\qquad$\begin{tabular}{|c|c|c|c|c|c|}
\hline Hour & $\begin{array}{c}\text { Central } \\
\text { A2 (ppm) }\end{array}$ & $\begin{array}{c}\text { South } \\
\text { B1 (ppm) }\end{array}$ & $\begin{array}{c}\text { East } \\
\text { B2 (ppm) }\end{array}$ & $\begin{array}{c}\text { North } \\
\text { B3 (ppm) }\end{array}$ & $\begin{array}{c}\text { Diff } \\
\text { (ppm) }\end{array}$ \\
\hline $\mathbf{8}$ am & 735 & 842 & 1151 & 798 & -416 \\
\hline $\mathbf{9}$ am & 880 & 973 & 1284 & 881 & -404 \\
\hline $\mathbf{1 0}$ am & 755 & 785 & 1087 & 765 & -332 \\
\hline $\mathbf{1 1}$ am & 722 & 775 & 1094 & 742 & -372 \\
\hline $\mathbf{1 2} \mathbf{~ p m}$ & 599 & 684 & 984 & 638 & -385 \\
\hline $\mathbf{1 ~ p m}$ & 725 & 764 & 1105 & 704 & -380 \\
\hline $\mathbf{2 ~} \mathbf{~ p m}$ & 432 & 521 & 840 & 468 & -408 \\
\hline $\mathbf{3 ~ p m}$ & 454 & 549 & 865 & 486 & -411 \\
\hline
\end{tabular}
\end{tabular}




\section{Appendix 10: Policy Output at the New Zealand Ministry of Education (MoE)}

The data loggers used for physical measurement in this study were provided by the Ministry of Education (MoE) and are the same data loggers the MoE used for their pilot study in 90 selected schools at the Bay of Plenty. Following the large amount of missing data identified during the pilot study experiments of this thesis as reported in Section 4.8 (data collection challenges), a range of experimental test were carried out to ascertain the sensors connectivity capability, uptime test capability and tolerance level. The outcome of these experiments provided insights that led to:

1. The development of a Fitness for Purpose performance standard for assessing IEQ in the Ministry's Te Haratau programme.

2. The development of internal environmental monitoring device technical specifications for the Ministry of Education (MoE). Other calibration related findings that informed policy decisions at the MoE were:

- The connectivity capability test result led to the sensors' provider resolving the frequent resetting issues of the sensors

O It also established that the Wi-Fi connection signal strength should be better than -60 $\mathrm{dBM}$ for optimum performance of the data loggers and a Wi-Fi application should be included in a sensor's dashboard interface to ease deployment setup

- The tolerance level test for lighting indicated that depending on the source of light, there was a varying light factor offset error

- Hence, it was suggested that the characteristics of the device that makes it necessary to calibrate each device separately even though they were identical models could hinder the use of the light component of the device as an accurate measurement tool due to the need to perform the calibration on each device separately

$\circ$ The sound level measurement (SLM) calibration experiment indicated that the highest cut-off level for sound was $65 \mathrm{dBA}$. This led to an increase in the highest SLM cut-off level to $100 \mathrm{dBA}$ by the data logger provider 
3. Provided scientific evidence to guide the deployment of data loggers at scale for IEQ monitoring.

4. Informed updates to the MoE's Designing Quality Learning Spaces (DQLS) suite of documents (Lighting, Acoustics and IAQ and Thermal Comfort design requirements).

5. Informed the development of data logger deployment manual and register for the MoE's Te Haratau programme. 


\begin{tabular}{|c|c|c|c|}
\hline $\mathbf{S} / \mathbf{N}$ & Article Title & Journal/Conference & Comments \\
\hline 1. & $\begin{array}{l}\text { The Influence of Indoor Environmental Quality in Schools A Systematic } \\
\text { Literature Review }\end{array}$ & ASA Conference & $\begin{array}{l}\text { Published Nov } \\
\qquad 2017\end{array}$ \\
\hline 2. & $\begin{array}{l}\text { Measuring the Daylight Performance of Classrooms: Can a One-Point } \\
\text { Sensor Measurement Predict the Daylight Distribution within a Space? }\end{array}$ & ASA Conference & $\begin{array}{l}\text { Published Nov } \\
2018\end{array}$ \\
\hline 3. & $\begin{array}{l}\text { Measuring Lighting Performance in a National School Property } \\
\underline{\text { Portfolio }}\end{array}$ & Architectural Science Review & $\begin{array}{l}\text { Published } 21^{\text {st }} \\
\text { August } 2020\end{array}$ \\
\hline 4. & $\begin{array}{l}\text { Assessing Indoor Thermal Performance in a National School Property } \\
\text { Portfolio }\end{array}$ & $\begin{array}{l}\text { Intelligent Buildings } \\
\text { International }\end{array}$ & Under review \\
\hline 5. & $\begin{array}{l}\text { Measuring Indoor Air Quality (IAQ) in a National School Property } \\
\text { Portfolio }\end{array}$ & $\begin{array}{l}\text { Intelligent Buildings } \\
\text { International }\end{array}$ & To be submitted \\
\hline 6. & $\begin{array}{l}\text { Determining the Acoustics Performance in in a National School } \\
\text { Property Portfolio }\end{array}$ & Applied Acoustics & To be submitted \\
\hline 7. & $\begin{array}{l}\text { Holistic Measurement of Indoor Environmental Quality (IEQ) in a } \\
\text { National School Building Portfolio }\end{array}$ & $\begin{array}{l}\text { International Journal of } \\
\text { Architecture }\end{array}$ & To be submitted \\
\hline 8. & $\begin{array}{l}\text { Determination of Indoor Environmental Quality and Learning } \\
\text { Performance Ranges and Indexing }\end{array}$ & Sustainability & To be submitted \\
\hline 9. & $\begin{array}{l}\text { The Relationship between Building Design and Measured IEQ in } \\
\text { Learning Environments }\end{array}$ & Buildings & To be submitted \\
\hline 10. & $\begin{array}{l}\text { Students' and Teachers' Experience of Indoor Environmental Quality } \\
\text { (IEQ) in a Flexible Learning Environment }\end{array}$ & $\begin{array}{l}\text { International Journal of } \\
\text { Architecture }\end{array}$ & To be submitted \\
\hline
\end{tabular}


